\title{
System Simulation Results
}

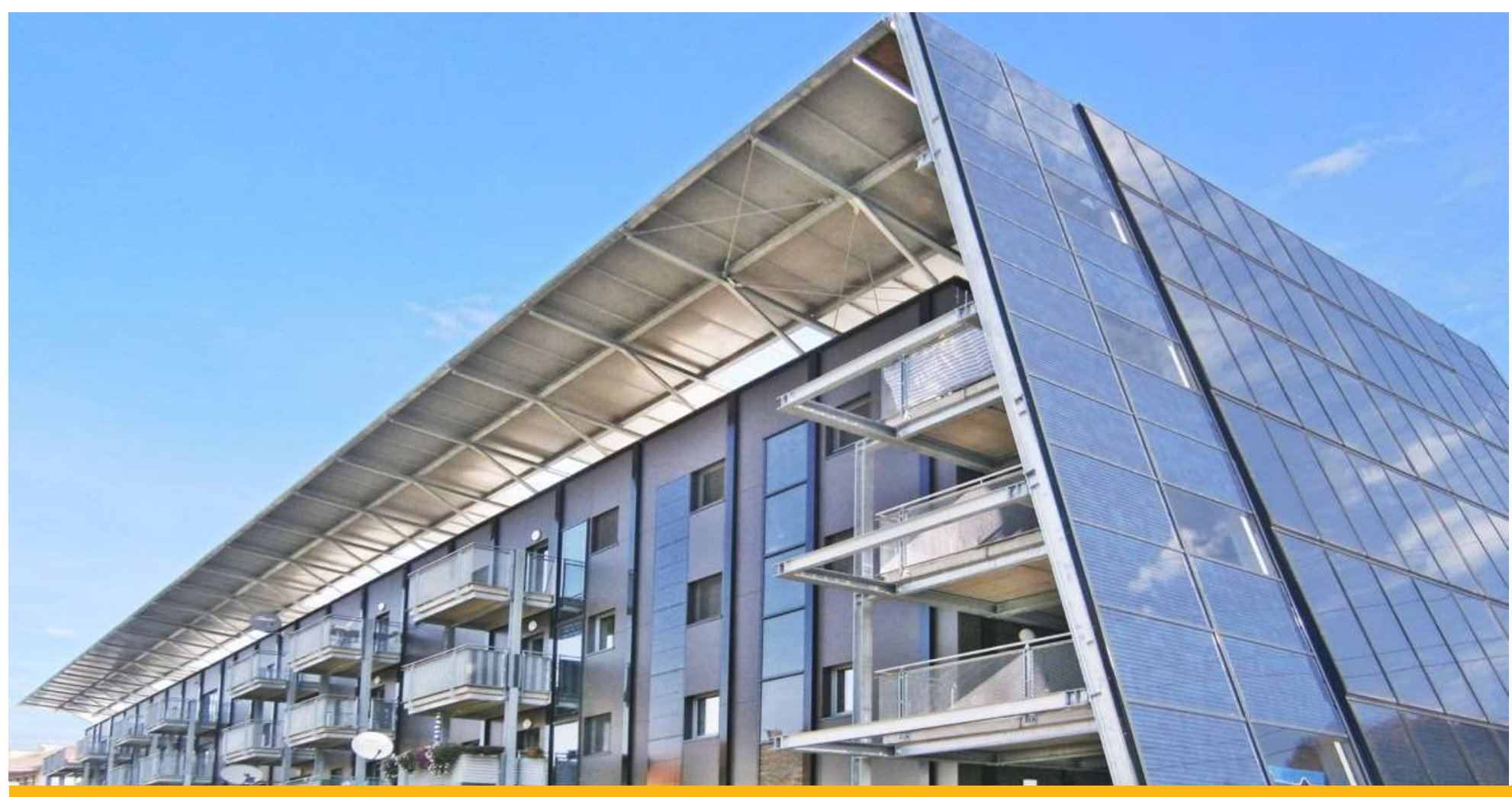

IEA SHC TASK 56 | Building Integrated Solar Envelope Systems for HVAC and Lighting 


\section{System Simulation Results}

Deliverable DC.2

Authors: Ochs Fabian, Magni Mara, Hauer Martin, Geisler-Moroder David, Bonato Paolo, de Vries Samuel, Loonen Roel, Venus David, Abdelnour Nermeen, Calabrese Toni, Venturi Elisa, Maccarini Alessandro, Häringer Simon, Bueno Bruno, loannidis Zissis, Rounis Efstratios

April, 2020

DC.2, DOI: 10.18777/ieashc-task56-2020-0005

The contents of this report do not necessarily reflect the viewpoints or policies of the International Energy Agency (IEA) or its member countries, the IEA Solar Heating and Cooling Technology Collaboration Programme (SHC TCP) members or the participating researchers. 


\section{IEA Solar Heating and Cooling Technology Collaboration Programme (IEA SHC)}

The Solar Heating and Cooling Technology Collaboration Programme was founded in 1977 as one of the first multilateral technology initiatives ("Implementing Agreements") of the International Energy Agency. Its mission is "To enhance collective knowledge and application of solar heating and cooling through international collaboration to reach the goal set in the vision of solar thermal energy meeting $50 \%$ of low temperature heating and cooling demand by 2050."

The members of the IEA SHC collaborate on projects (referred to as Tasks) in the field of research, development, demonstration (RD\&D), and test methods for solar thermal energy and solar buildings.

Research topics and the associated Tasks in parenthesis include:

- Solar Space Heating and Water Heating (Tasks 14, 19, 26, 44, 54)

- Solar Cooling (Tasks 25, 38, 48, 53)

- Solar Heat for Industrial or Agricultural Processes (Tasks 29, 33, 49, 62, 64)

- Solar District Heating (Tasks 7, 45, 55)

- Solar Buildings/Architecture/Urban Planning (Tasks 8, 11, 12, 13, 20, 22, 23, 28, 37, 40, 41, 47, 51, 52, 56, $59,63)$

- $\quad$ Solar Thermal \& PV (Tasks 16, 35, 60)

- Daylighting/Lighting (Tasks 21, 31, 50,61)

- Materials/Components for Solar Heating and Cooling (Tasks 2, 3, 6, 10, 18, 27, 39)

- $\quad$ Standards, Certification, and Test Methods (Tasks 14, 24, 34, 43, 57)

- $\quad$ Resource Assessment (Tasks 1, 4, 5, 9, 17, 36, 46)

- Storage of Solar Heat (Tasks 7, 32, 42, 58)

In addition to our Task work, other activities of the IEA SHC include our:

$>$ International Conference on Solar Heating and Cooling for Buildings and Industry

$>$ SHC Solar Academy

$>$ Solar Heat Worldwide annual statics report

$>$ Collaboration with solar thermal trade associations

\section{Country Members}

\section{Australia}

Austria

Belgium

Canada

China

Denmark

European Commission

\section{Sponsor Members}

European Copper Institute International Solar Energy Society EACREEE

$\begin{array}{ll}\text { France } & \text { South Africa } \\ \text { Germany } & \text { Spain } \\ \text { Italy } & \text { Sweden } \\ \text { Netherlands } & \text { Switzerland } \\ \text { Norway } & \text { Turkey } \\ \text { Portugal } & \text { United Kingdom } \\ \text { Slovakia } & \end{array}$

ECREEE

RCREEE

SACREEE

For more information on the IEA SHC work, including many free publications, please visit www.iea-shc.org 


\section{Contents}

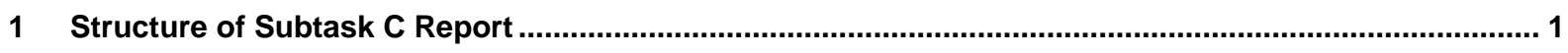

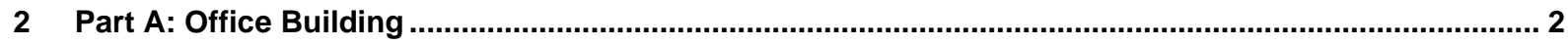

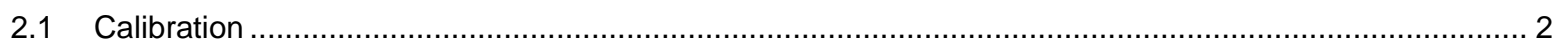

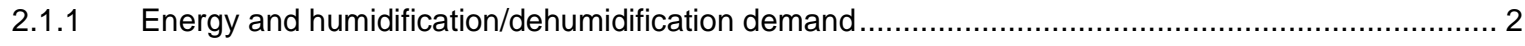

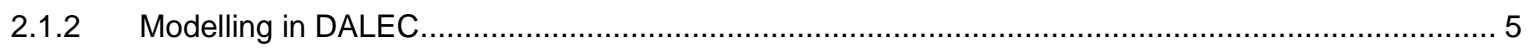

2.1.3 Comparison of simulation results between different Building Energy Simulation (BES) tools ........... 9

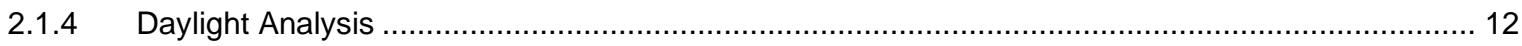

2.1.5 Comparison of the results of the office building simulated together with air to air Heat Pump and

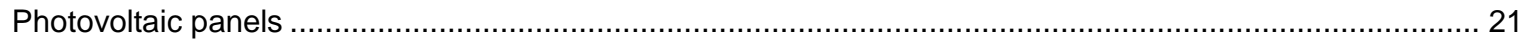

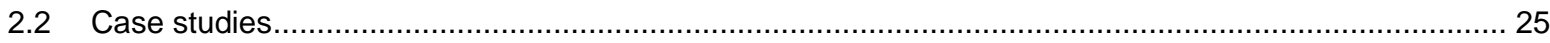

2.2.1 Cost-optimality - variation of the envelope and HVAC quality and BIPV................................... 25

2.2.2 Analysis of the impact of different HVAC configurations and control strategies on primary energy and

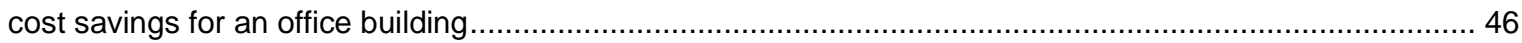

2.2.3 Integration of the PV-Modules into the Building Skin (BIPV/T Concept) ................................... 51

2.2.4 Integration of a solar thermal collectors in curtain walls in tertiary office building: simulation-based evaluation of the energy performance

2.2.5 Solar thermal venetian blind as synergetic and adaptive sun protection device in double skin façades 79

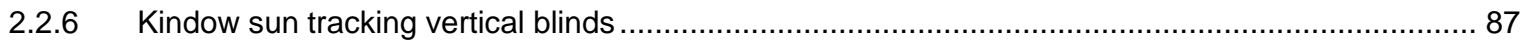

2.2.7 Impact of Integral Day- and Artificial Lighting Solutions on Energy Demand and User Comfort......95

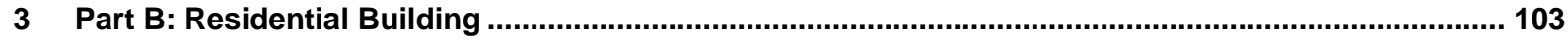

3.1 Renovation case study of a multi-family house (project SaLüH!) ................................................ 103

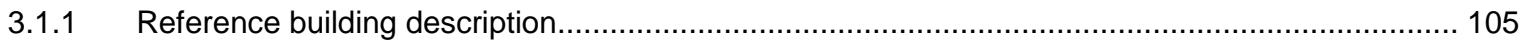

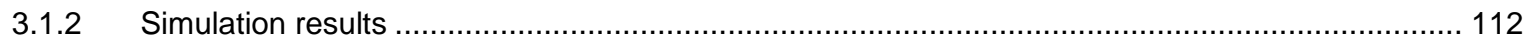

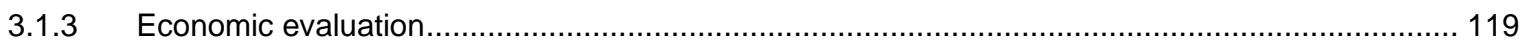

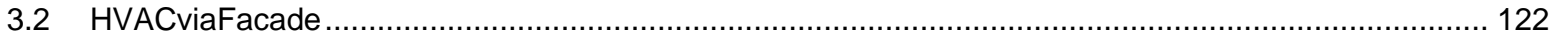

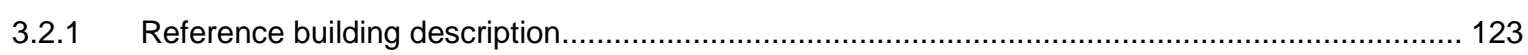

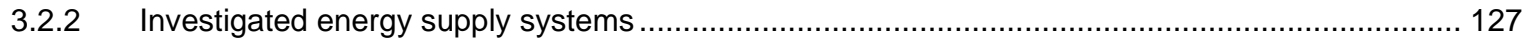

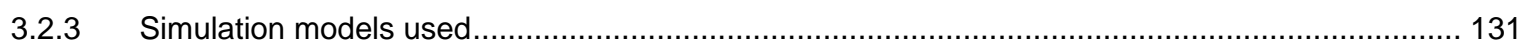

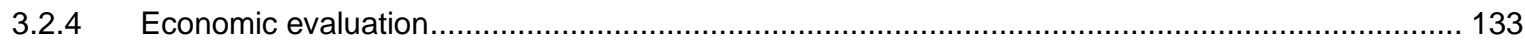

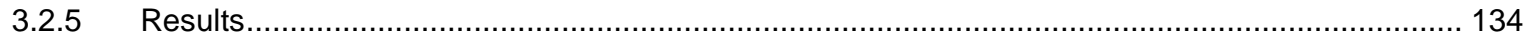

3.3 Variation of the envelope and HVAC quality and cost-optimality for a SFH.................................. 142

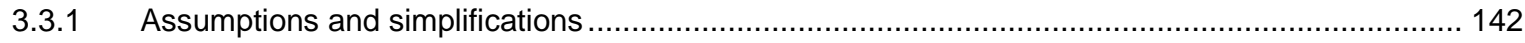

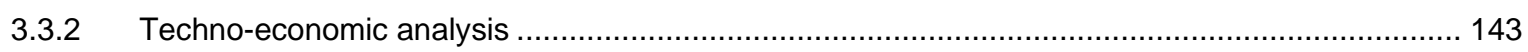

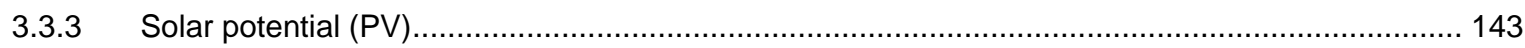

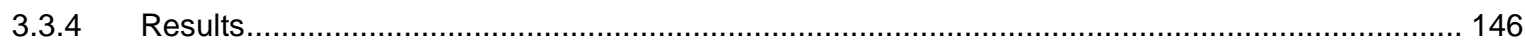

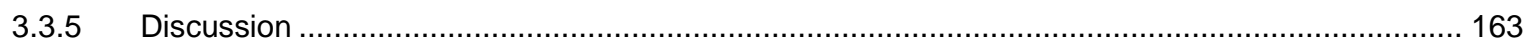

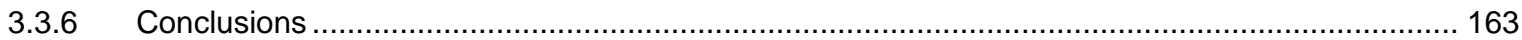

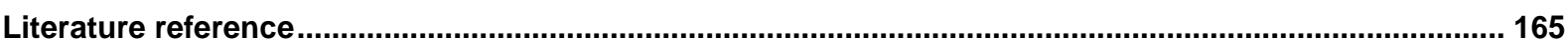

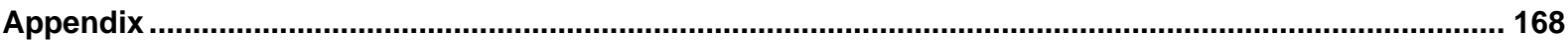




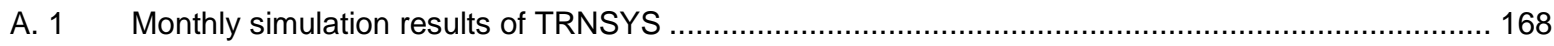

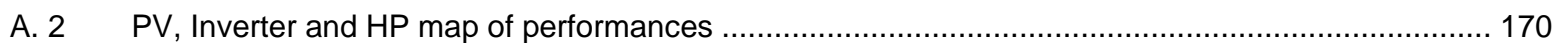

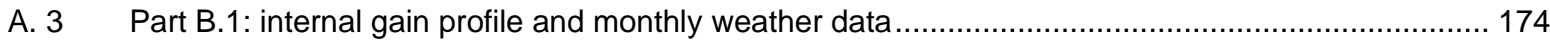

A. 4 Part B.2: internal gain profile, monthly weather data and surfaces included in the flat model.......... 176 


\section{Structure of Subtask C Report}

Different approaches for investigating Solar Envelope Systems are required for residential and office buildings. This report has the goal to describe the different methods used for non-residential (i.e. office) and residential buildings and to give comprehensive information about the reference buildings and HVAC systems used in IEA SHC Task 56.

In report DC.1 gives general information about benchmarks, simulation models of the reference buildings as well as, reference locations and climate analysis and finally Key Performance Indicators (KPIs). Additionally, an overview on the features of different simulation platforms is given.

Based on this, the Report DC.2 documents the simulation results and consists of two parts:

- $\quad$ Part A presents the simulation results of the office reference building;

- $\quad$ Part B describes the approach for residential buildings. Two examples are described in detail following different approaches.

In Deliverable DC.3, guidelines are provided based on the simulation results.

Deliverable DC.4 will provide monitoring results of demonstration buildings. 


\section{Part A: Office Building}

\subsection{Calibration}

The model of the reference office building, described in report DC.1, is implemented by different experts in building simulations, with different tools (i.e. dynamics simulation tools such as EnergyPlus, TRNSYS, CarnotUIBK, ALMAbuild, DALEC, Modelica and quasi steady state calculation tool such as PHPP) considering three different locations (Rome, Stuttgart and Stockholm). The properties of the wall and windows are varied with the climate (see DC.1). The results of this study are reported in section 2.1.2 while some preliminary results are published in [1]. The next section will give an overview on the yearly energy demands of the studied office cell.

\subsubsection{Energy and humidification/dehumidification demand}

\section{Energy Demand}

The simulation results for the reference climates of Stockholm, Stuttgart and Rome performed with TRNSYS are shown in Figure 2-1. The results are plotted in terms of specific energy balance, where solar gains $\left(Q_{\text {sol }}\right)$, internal gains $\left(Q_{\text {gint }}\right)$ and space heating demand $\left(Q_{\text {heat }}\right)$ are denoted with a positive sign, whereas ventilation losses $\left(Q_{\text {vent }}\right)$, infiltration losses ( $\left.Q_{\text {inf }}\right)$, transmission ( $\left.Q_{\text {trans }}\right)$ losses and space cooling $\left(Q_{\text {cool }}\right)$ demand are negative terms. The space heating energy demands amount to $17.8 \mathrm{kWh} /\left(\mathrm{m}^{2} \mathrm{y}\right), 13.9 \mathrm{kWh} /\left(\mathrm{m}^{2} \mathrm{y}\right)$ and $3.3 \mathrm{kWh} /\left(\mathrm{m}^{2} \mathrm{y}\right)$ in Stockholm, Stuttgart and Rome, respectively. The space cooling energy demands for the three reference locations are equal to 25.1 $\mathrm{kWh} /\left(\mathrm{m}^{2} \mathrm{y}\right), 25.3 \mathrm{kWh} /\left(\mathrm{m}^{2} \mathrm{y}\right)$ and $32.1 \mathrm{kWh} /\left(\mathrm{m}^{2} \mathrm{y}\right)$. Monthly values of the energy balances for the three locations are reported in chapter 2.1.2.

Figure 2-1 shows humidification (Qhum) and dehumidification (Qdehum) energy loads, which are in general quite low if compared to the space heating and cooling energy demands.

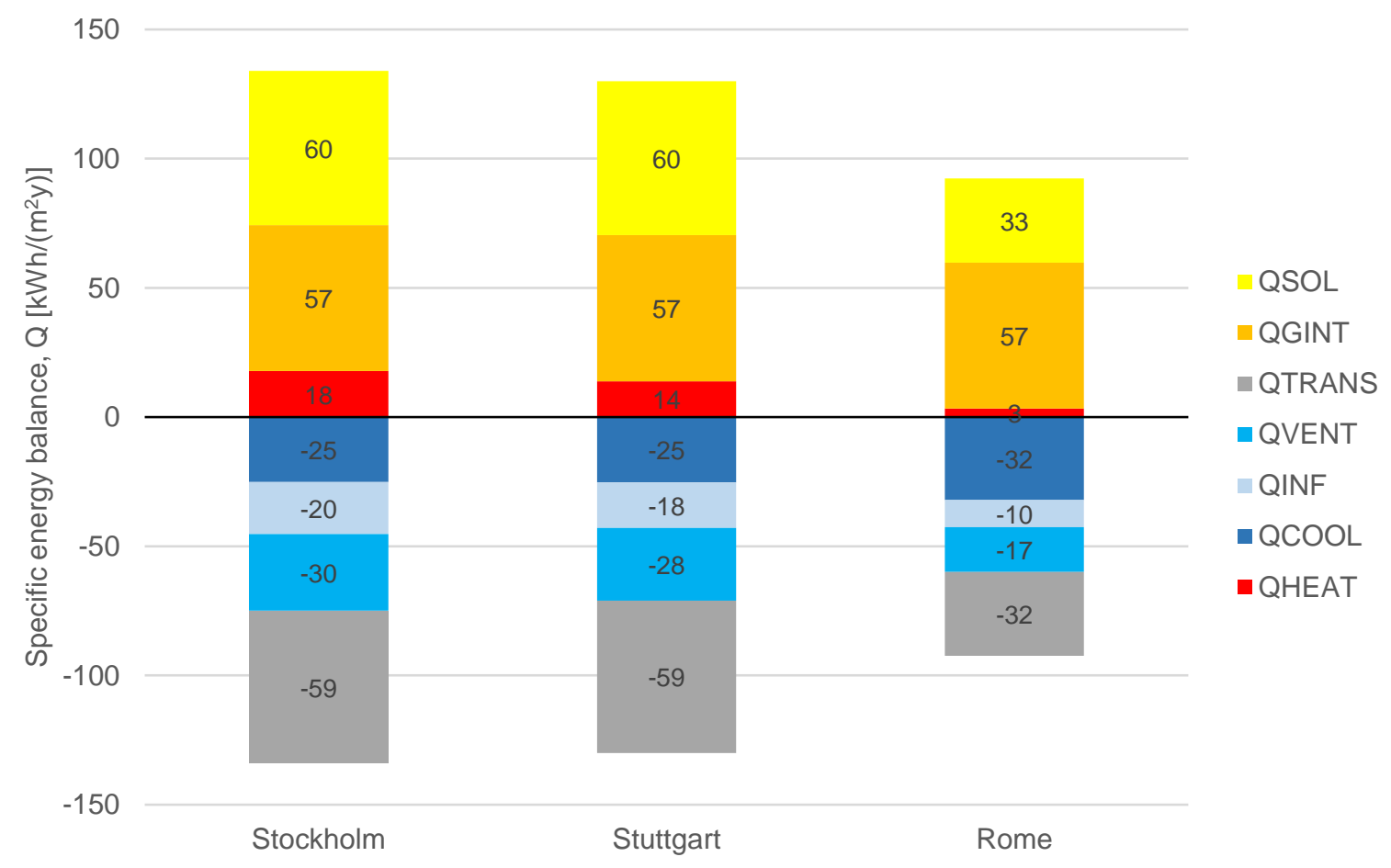

Figure 2-1: Specific energy balance of the reference office space for the locations of Stockholm, Stuttgart and Rome

The specific electrical demand of the zone for appliances, lights, fans and antifreeze protection is plotted in Figure 2-2. Appliances, lights and fans operation are responsible for $13.5 \mathrm{kWh} /\left(\mathrm{m}^{2} \mathrm{y}\right), 31.3 \mathrm{kWh} /\left(\mathrm{m}^{2} \mathrm{y}\right)$ and $7.0 \mathrm{kWh} /\left(\mathrm{m}^{2} \mathrm{y}\right)$, respectively. The electrical consumption for frost protection is dependent on the climate and vary from 2.6 $\mathrm{kWh} /\left(\mathrm{m}^{2} \mathrm{y}\right)$ in Stockholm to $0 \mathrm{kWh} /\left(\mathrm{m}^{2} \mathrm{y}\right)$ in Rome, where the frost protection is not activated. 


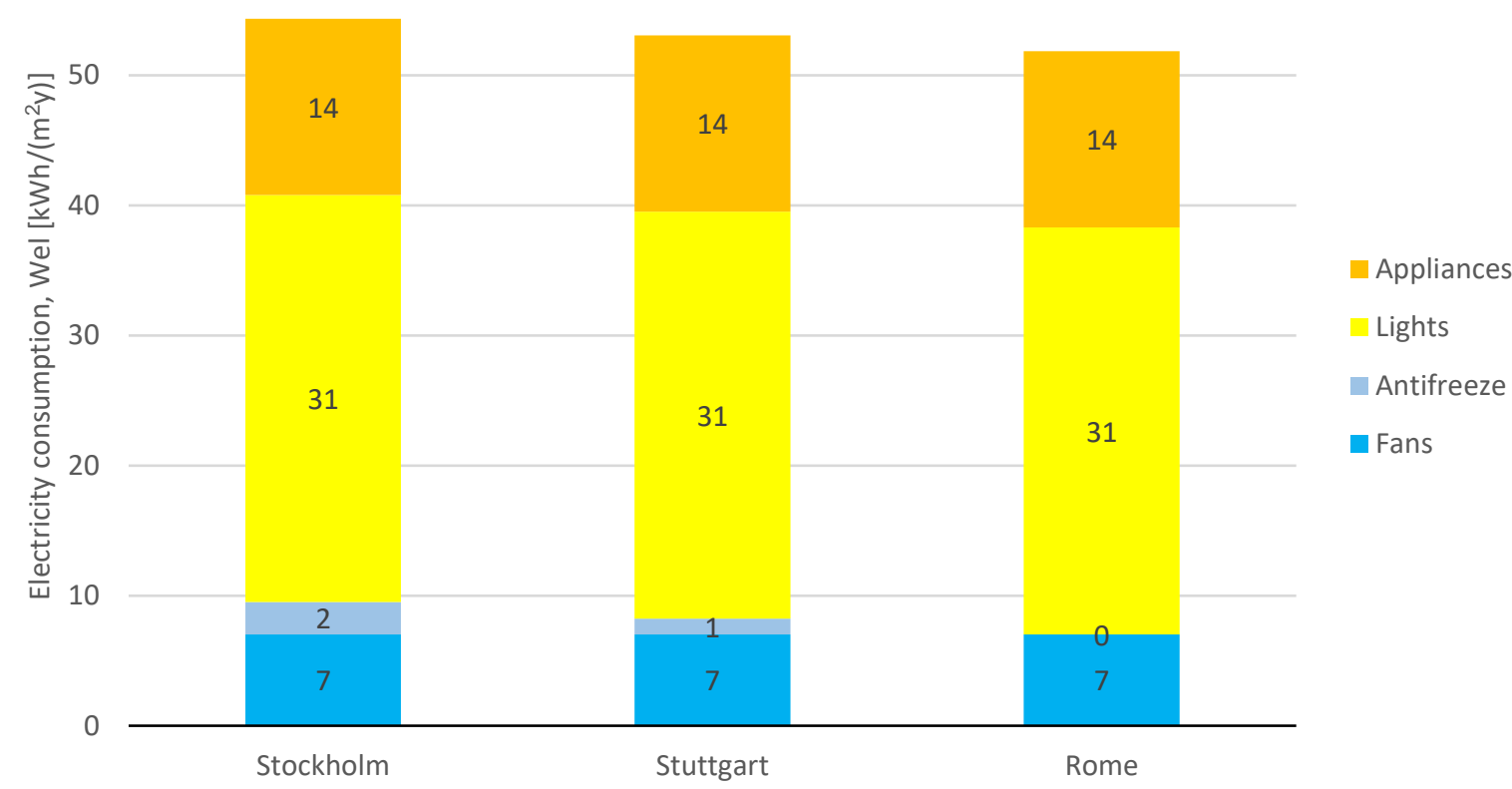

Figure 2-2: Electricity consumption for appliances, lights, frost protection and fans for the three reference locations

\section{Domestic Hot Water Demand}

As described in report DC.1 the reference hot water demand for offices amounts to $3.0 \mathrm{l} /$ person/day (weekdays only) produced at $60{ }^{\circ} \mathrm{C}$ [2]. The temperature of cold tap water is assumed to be constant at $10^{\circ} \mathrm{C}$. The default DHW system is an electric boiler with 5 I water content and ErP class $A(U A=0.37 \mathrm{~W} / \mathrm{K})$ serving 8 offices. The useful energy demand for DHW in the considered office cell amount to $5.04 \mathrm{kWh} /\left(\mathrm{m}^{2} \mathrm{a}\right)$. Considering the thermal losses of the default DHW storage, the final energy for DHW preparation is $5.56 \mathrm{kWh} /\left(\mathrm{m}^{2} \mathrm{a}\right)$. The thermal losses of the DHW storage are considered to be included in the internal gains.

\section{Humidification and Dehumidification Demand}

The specific humidification and dehumidification demands of the reference office space have been simulated with Simulink taking into consideration also the humidity buffer of the walls and floor. In order to show the influence of the presence of a moisture buffer on the eventual need of a dehumidification/humidification system, different simulations have been performed:

- Without moisture buffer;

- With moisture buffer only in the floor structure;

- With moisture buffer in the floor and internal walls structures.

Figure 2-3 shows the specific Humidification (a) and dehumidification (b) demand for the climates of Rome, Stuttgart and Stockholm. It can be noticed that in Stuttgart and Stockholm we would need a Humidification system in any case while in Rome the Humidification system seems to be necessary from the simulations only when no humidity buffer is considered. Looking at the graphs for the dehumidification demand (b) it is possible to notice that a dehumidification system is necessary in Rome, while might not be the case for Stockholm and Stuttgart.

Figure 2-4 reports the sorted plot of the absolute humidity for all the climates considering the different humidity buffer and taking into account (continuous lines) or not (dashed lines) the humidification/dehumidification system. The green dotted lines represent the absolute humidity limits $(4.5-13.6 \mathrm{~g} / \mathrm{kg})$ within which the comfort is guaranteed. In Stockholm and Stuttgart there is the need for dehumidification only for a few hours during the year, therefore it can be avoided without affecting the comfort of the ambient. The need for humidification in Rome is relevant only when no humidity buffer is simulated. 


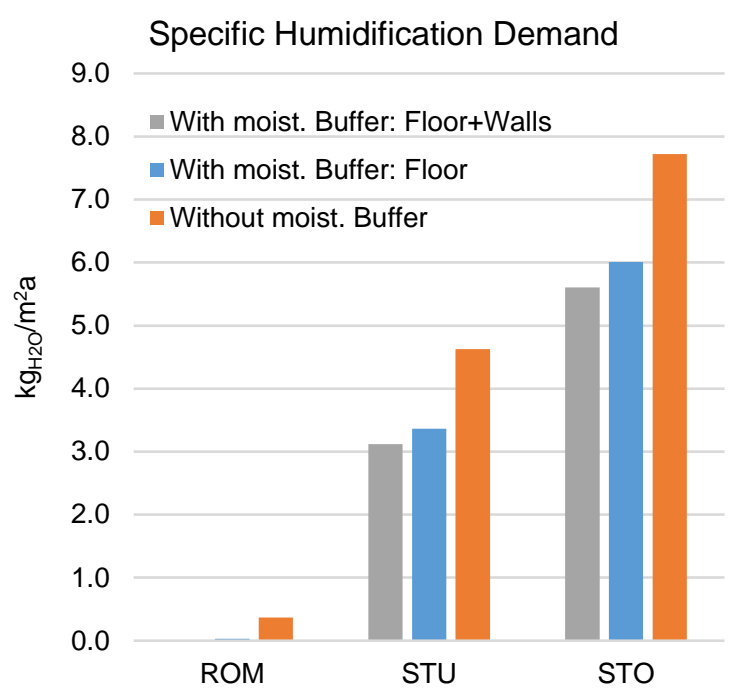

(a)

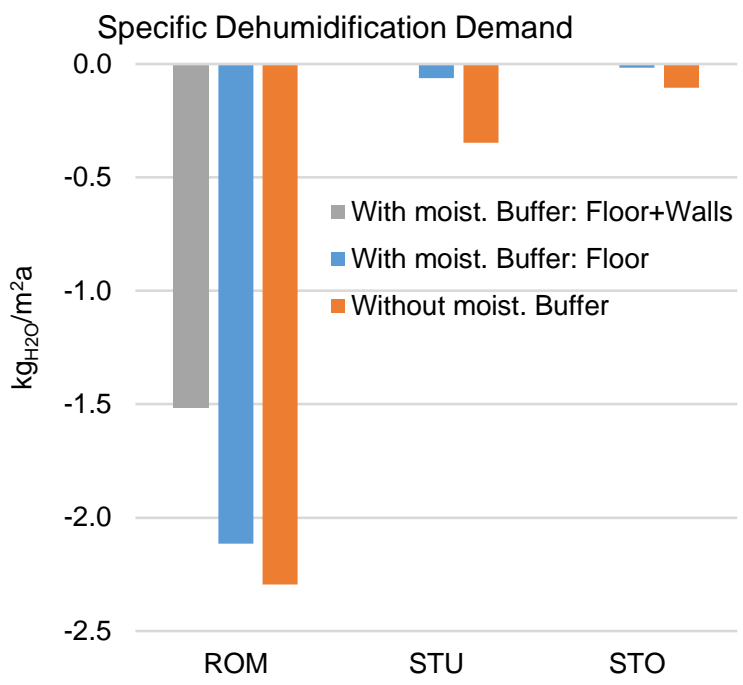

(b)

Figure 2-3: Specific Humidification (a) and dehumidification (b) demand for the climates of Rome, Stuttgart and Stockholm considering no humidity buffer, with moisture buffer only in the floor structure and with moisture buffer in the floor and internal walls structures
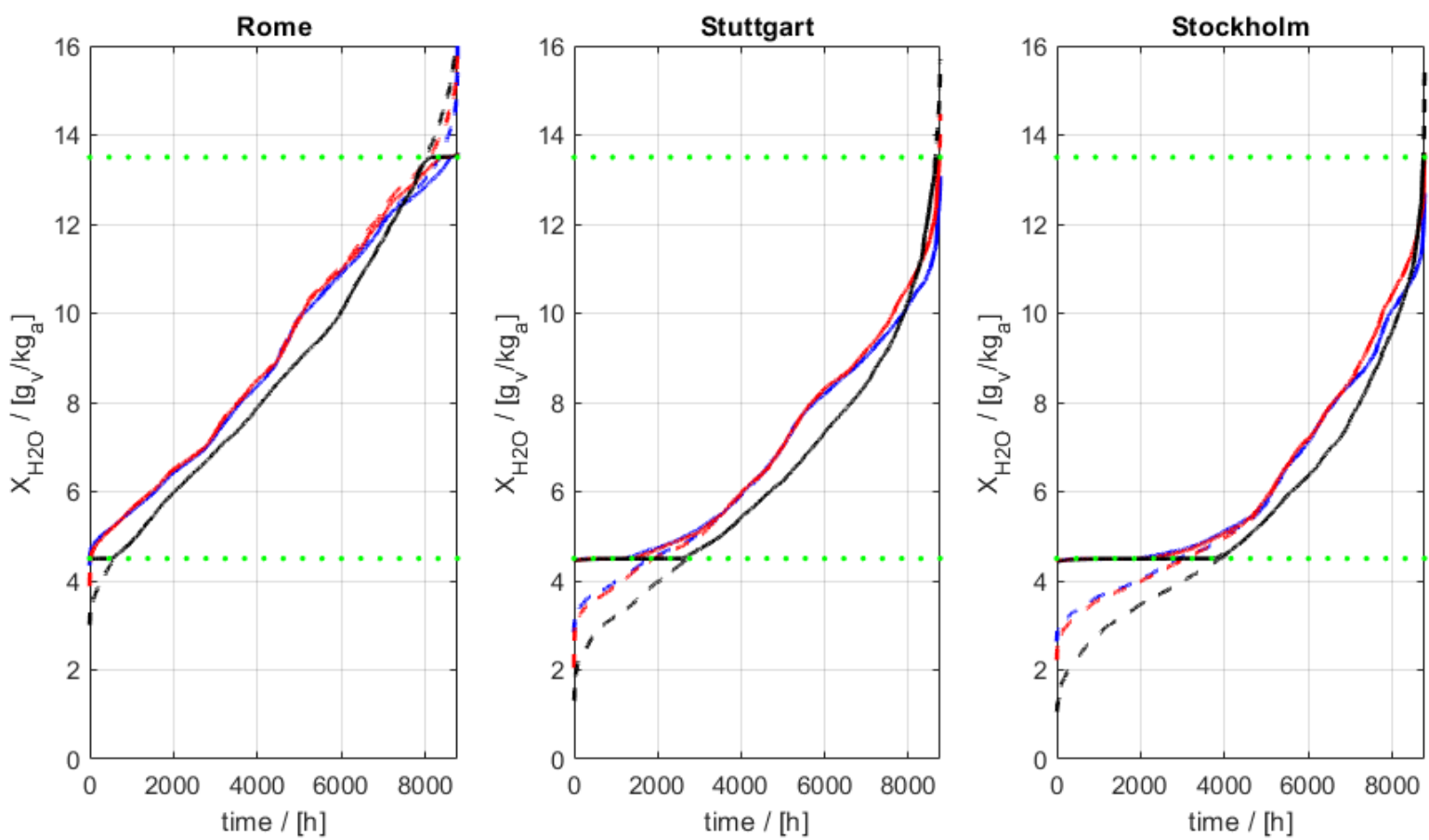

... With moist. Buffer: Floor+Walls w/o de/hum

With moist. Buffer. Floor+Walls w de/hum

...-With moist. Buffer. Walls w/o de/hum

With moist. Buffer: Walls w de/hum

-..-With moist. Buffer w/o de/hum

With moist. Buffer $w$ de/hum

Figure 2-4: Absolute humidity for all the climates and analysed humidity buffer, with and without humidification and dehumidification system 


\subsubsection{Modelling in DALEC}

DALEC (Day- and Artificial Light with Energy Calculation) is an online concept evaluation tool, freely accessible at [3], for architects, building engineers, lighting designers and building. Although easy to use and short calculation times are required, the software accounts for the complex thermal and light processes in buildings and allows a simple evaluation of heating, cooling and electric lighting loads. This allows optimisations of the façade settings, the artificial lighting installation and the thermal parameters of a building in an early design phase.

The following inputs/assumptions need to be derived from the specified boundary conditions in order to implement the reference office cell (see DC.1) in DALEC online:

\section{- Internal Gains}

Occupancy and appliances need to be summarized as internal gains. Calculating the gains according to the schedules given in DC. 1 results in total $8.79 \mathrm{~W} / \mathrm{m}^{2}$ of internal gains over the 11 hours of overall occupancy time from 08:00 to 19:00 are used;

\section{- $\quad$ Active Window Area}

In DALEC, the transparent area of the façade is defined as relative fraction of the overall façade in three areas. In the lower area FA1 (below $1 \mathrm{~m}$ ) no transparent structure is present. For the middle façade area FA2 $(1 \mathrm{~m}-2 \mathrm{~m}$ height) the window size is set as defined in DC. 1 starting at $1.20 \mathrm{~m}$ height and with $11 \mathrm{~cm}$ frame, which results in 0.59 active window area. For the upper façade area FA3, an active area of 0.76 is obtained;

\section{- Ventilation}

Two air exchange rates are considered in DALEC. The general energy-equivalent air exchange rate is the sum of infiltration and energy-effective air exchange rate in terms of ventilation losses. This rate is applied 24/7. The window / night ventilation air exchange rate assumes an additional passive ventilation whenever the indoor temperature exceeds a given threshold and is higher than the outdoor temperature. This strategy also operates the whole day (and not only during occupancy times). For DALEC, the specified infiltration $(0.15 / \mathrm{h}, \mathrm{DC} .1)$ and the fresh air supply - converted to an equivalent all-day rate of $0.13 / \mathrm{h}$ are put together as the general energy-equivalent air exchange rate of $0.28 / \mathrm{h}$. The additional energy-equivalent air exchange due to bypassing the heat recovery unit when the indoor temperature is higher than $23^{\circ} \mathrm{C}$ is calculated over the occupancy time of 11 hours (where overheating is most critical and thus the ventilation rate should match) as $0.81 / \mathrm{h}$ and is applied as window / night ventilation;

- $\quad$ Shading Control

According to DC.1, the shading device is activated whenever the direct solar radiation incident on the façade exceeds $120 \mathrm{~W} / \mathrm{m}^{2}$. However, in the standard DALEC implementation the total radiation incident at the façade is used for the solar shading control;

- Glare Control

DALEC evaluates the resulting luminance level observed at the inner side of the façade in order to account for glare protection. In case of activated glare control by a user-defined threshold in [cd/ $/ \mathrm{m}^{2}$ ], the façade configuration changes according to the given setting for glare protection. To be able to compare the results from DALEC and TRNSYS, the glare control is deactivated. However, to evaluate also the glare situation in the case study, the evaluation of exceeding luminance levels is provided.

\section{- Thermal Capacity of the Building}

In DC. 1 the thermal characteristics of the opaque assemblies and building materials are given. The setup matches with a typical medium construction. Thus, the value of $165000 \mathrm{~J} /\left(\mathrm{m}^{2} \mathrm{~K}\right)$ is assumed.

A slightly modified version of DALEC called original has been used in the comparison reported in chapter 1.1.3, daylight analysis reported in chapter 1.1.4.1 and 1.1.4.3 and the DALEC case study reported in chapter 1.2.5. The only difference between the online and original version is the adapted shading control; in the online version the shading system is controlled according to the total irradiation impinging the south façade while in the original version the control is based on the direct radiation (as described in DC.1).

A third version of the DALEC code called calibrated has been analysed in order to reach a good match with the dynamic simulation tool such as Simulink and Trnsys. The main differences of the calibrated version from the original version are the following:

- The mechanical ventilation is modelled using the profile described in the report DC.1 instead using a constant average air exchange rate;

- The shading model is represented by a fixed reduction of the solar radiation entering the thermal zone; 
- The threshold for the shading control is calibrated in order to obtain the same solar gain as in Simulink, reducing the differences given by a different sky model between DALEC and the other tools;

- The thermal transmittance of the window has been corrected in order to match the average $U$ value obtained with the dynamic simulation.

Table 2-1: Main differences between Online and Matlab versions of DALEC

\begin{tabular}{|c|c|c|c|c|}
\hline DALEC Version & Ventilation rate & Shading control & Shading model & Windows $U$ value \\
\hline Online & constant & Itot,south & g-value & report \\
\hline Original & constant & $I_{\text {dir,south }}$ & $g$-value & report \\
\hline Calibrated & profile & Idir,south & Constant reduction & Average simulation \\
\hline
\end{tabular}

Figure 2-5 shows the monthly heating and cooling demand, ventilation and transmission losses, solar gain and average convective temperature simulated with DAL online, original and calibrated and Simulink (denoted with SIM BO see chapter 2.1.3), for the climate of Stockholm. It can be noticed that the main difference between the online and original versions is represented by the solar gain because of the different control strategy. The original and calibrated versions differ for the ventilation and transmission losses and solar gain resulting in a better match with Simulink also in terms of heating and cooling demand and air temperature.

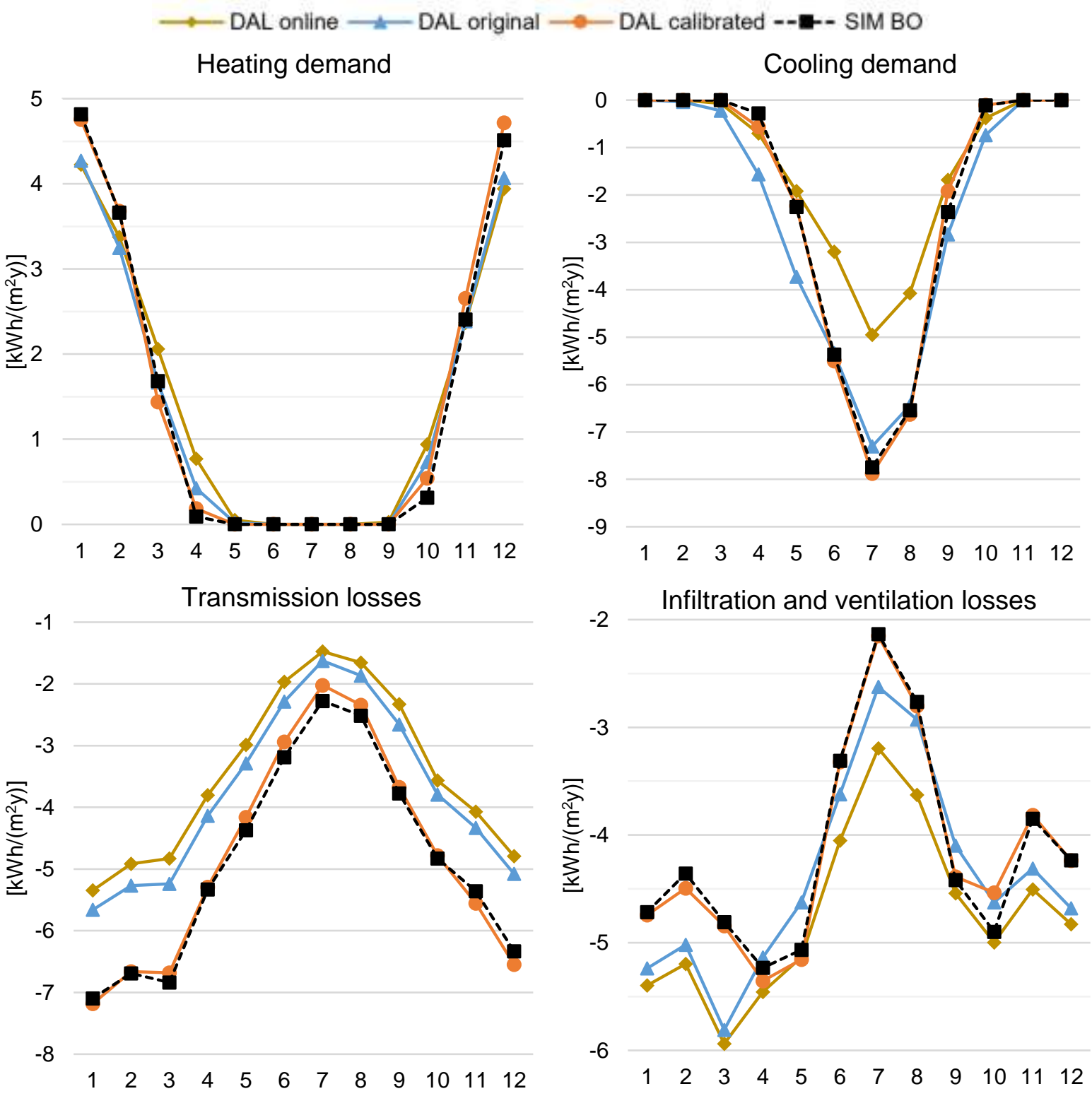



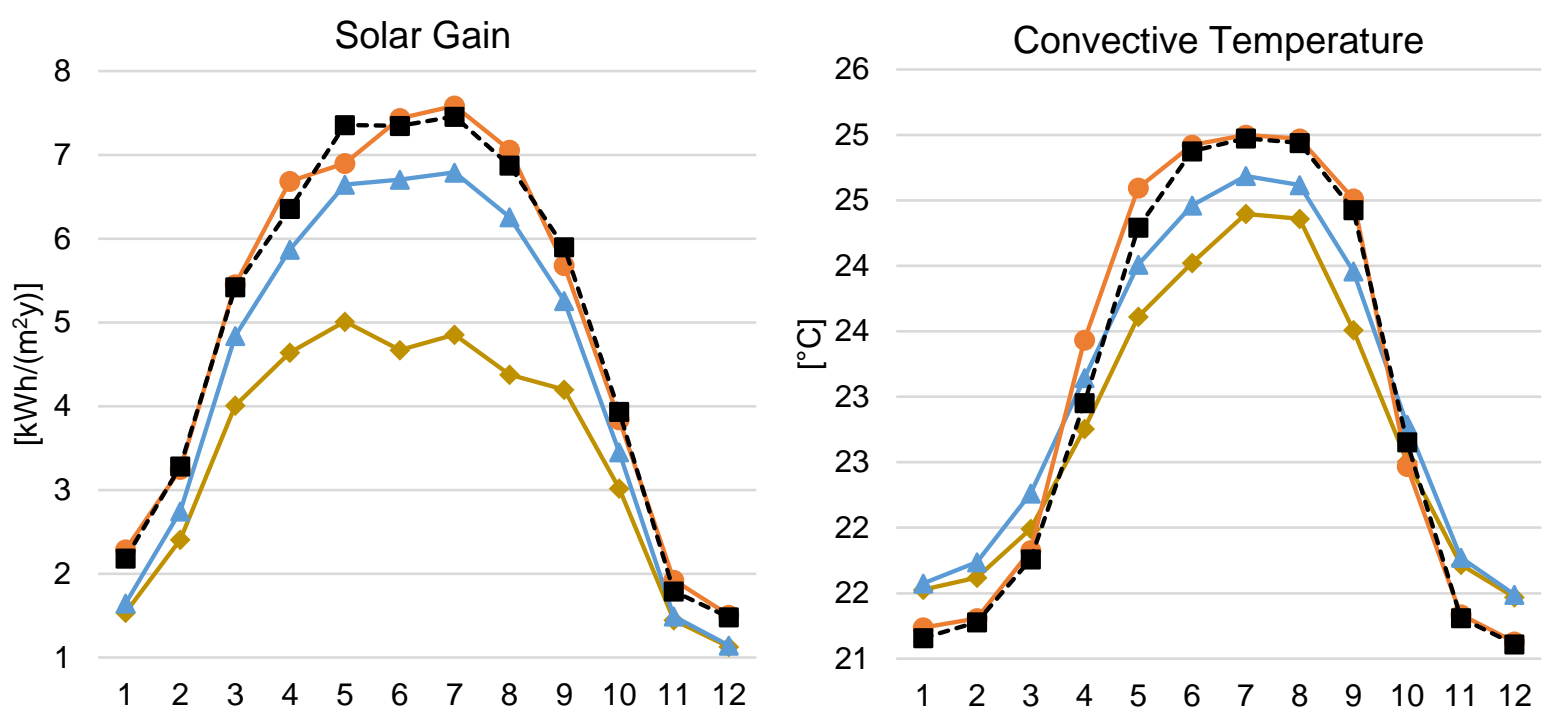

Figure 2-5: Monthly heating and cooling demand, Ventilation and transmission losses, solar gain and convective temperature simulated with DAL online, original and calibrated and SIM BO, for the climate of STOCKHOLM

\subsubsection{DALEC simulation results}

The monthly simulation results for heating, cooling and lighting, obtained with DALEC original, are summarized in Table 2-2 and displayed in the following three figures for the locations of Stockholm, Stuttgart and Rome.

Table 2-2: Monthly results from DALEC simulations.

\begin{tabular}{l|ccc|ccc|ccc|}
\multirow{2}{*}{ Month } & \multicolumn{7}{|c|}{ Monthly useful energy demand [kWh/(m²mo)] } \\
\cline { 2 - 10 } & \multicolumn{3}{|c}{ Stockholm } & \multicolumn{3}{c|}{ Stuttgart } & \multicolumn{3}{c|}{ Rome } \\
\cline { 2 - 10 } & Heating & Cooling & Lighting & Heating & Cooling & Lighting & Heating & Cooling & Lighting \\
\hline January & 4.29 & 0.00 & 2.76 & 4.71 & -0.16 & 2.76 & 1.77 & -0.33 & 2.76 \\
February & 3.26 & -0.04 & 2.40 & 3.11 & -0.13 & 2.40 & 1.54 & -0.47 & 2.40 \\
March & 1.68 & -0.22 & 2.64 & 1.89 & -0.58 & 2.64 & 0.47 & -0.86 & 2.64 \\
April & 0.43 & -1.56 & 2.52 & 0.52 & -1.52 & 2.52 & 0.21 & -1.40 & 2.52 \\
May & 0.02 & -3.73 & 2.76 & 0.06 & -4.28 & 2.76 & 0.01 & -3.50 & 2.76 \\
June & 0.00 & -5.34 & 2.52 & 0.00 & -5.54 & 2.52 & 0.00 & -5.16 & 2.52 \\
July & 0.00 & -7.30 & 2.64 & 0.00 & -5.83 & 2.64 & 0.00 & -6.66 & 2.64 \\
August & 0.00 & -6.44 & 2.76 & 0.01 & -6.08 & 2.76 & 0.00 & -7.57 & 2.76 \\
September & 0.00 & -2.83 & 2.40 & 0.03 & -2.78 & 2.40 & 0.00 & -4.68 & 2.40 \\
October & 0.73 & -0.74 & 2.76 & 0.61 & -1.15 & 2.76 & 0.06 & -3.61 & 2.76 \\
November & 2.40 & 0.00 & 2.64 & 2.53 & -0.31 & 2.64 & 0.48 & -1.38 & 2.64 \\
December & 4.07 & 0.00 & 2.52 & 4.72 & -0.02 & 2.52 & 1.36 & -0.30 & 2.52 \\
\hline Total & $\mathbf{1 6 . 8 7}$ & $\mathbf{- 2 8 . 2 0}$ & $\mathbf{3 1 . 2 9}$ & $\mathbf{1 8 . 1 9}$ & $\mathbf{- 2 8 . 3 8}$ & $\mathbf{3 1 . 2 9}$ & $\mathbf{5 . 9 0}$ & $\mathbf{- 3 5 . 9 4}$ & $\mathbf{3 1 . 2 9}$
\end{tabular}




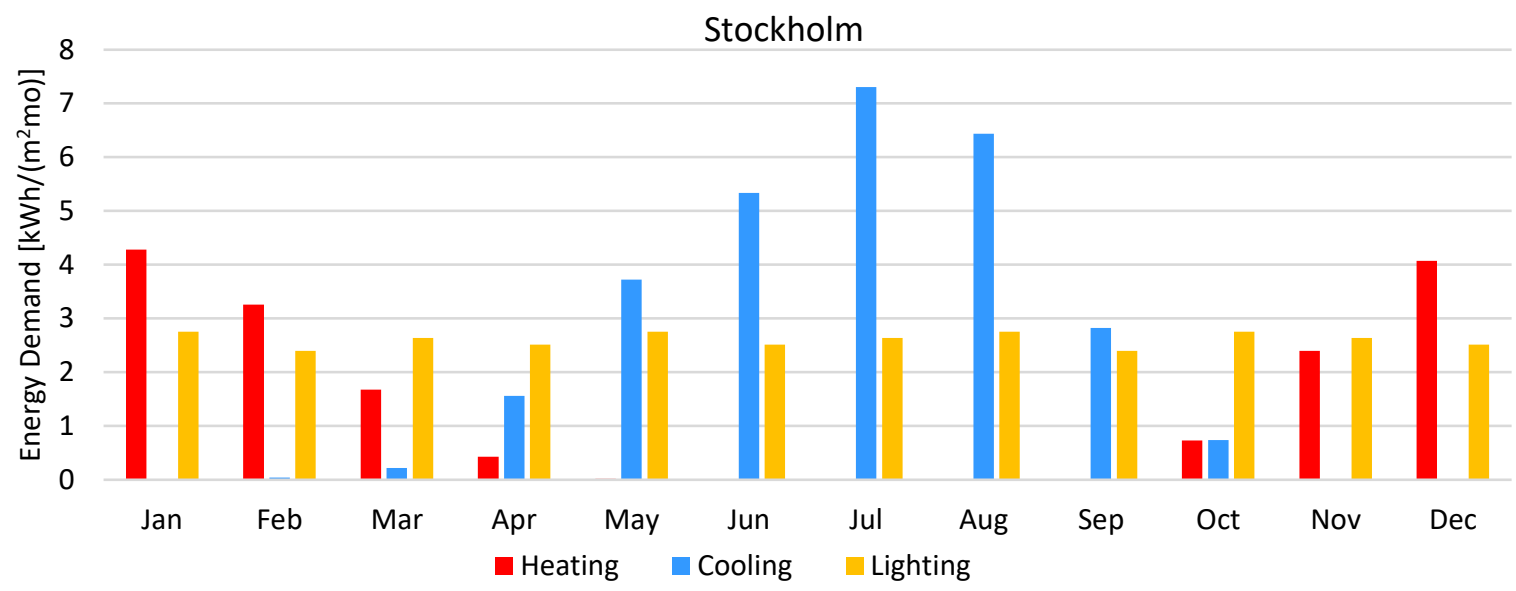

Figure 2-6: Monthly useful energy demands from DALEC simulations for location Stockholm

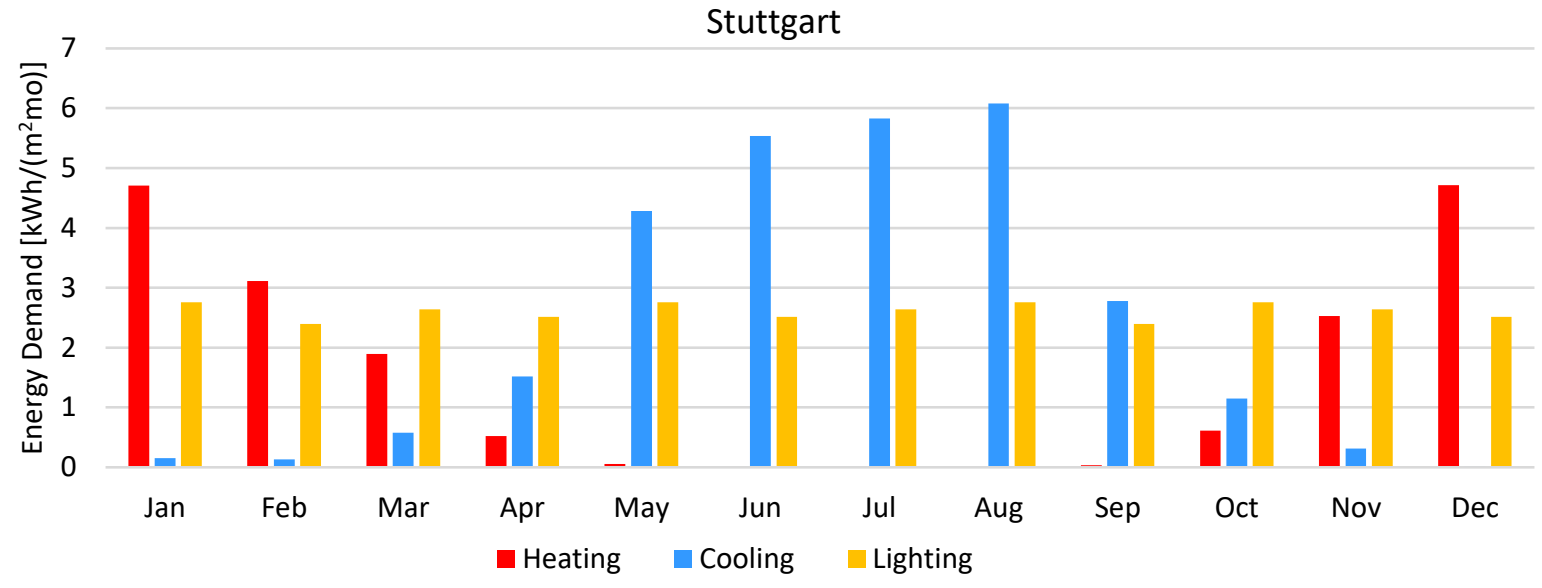

Figure 2-7: Monthly useful energy demands from DALEC simulations for location Stuttgart

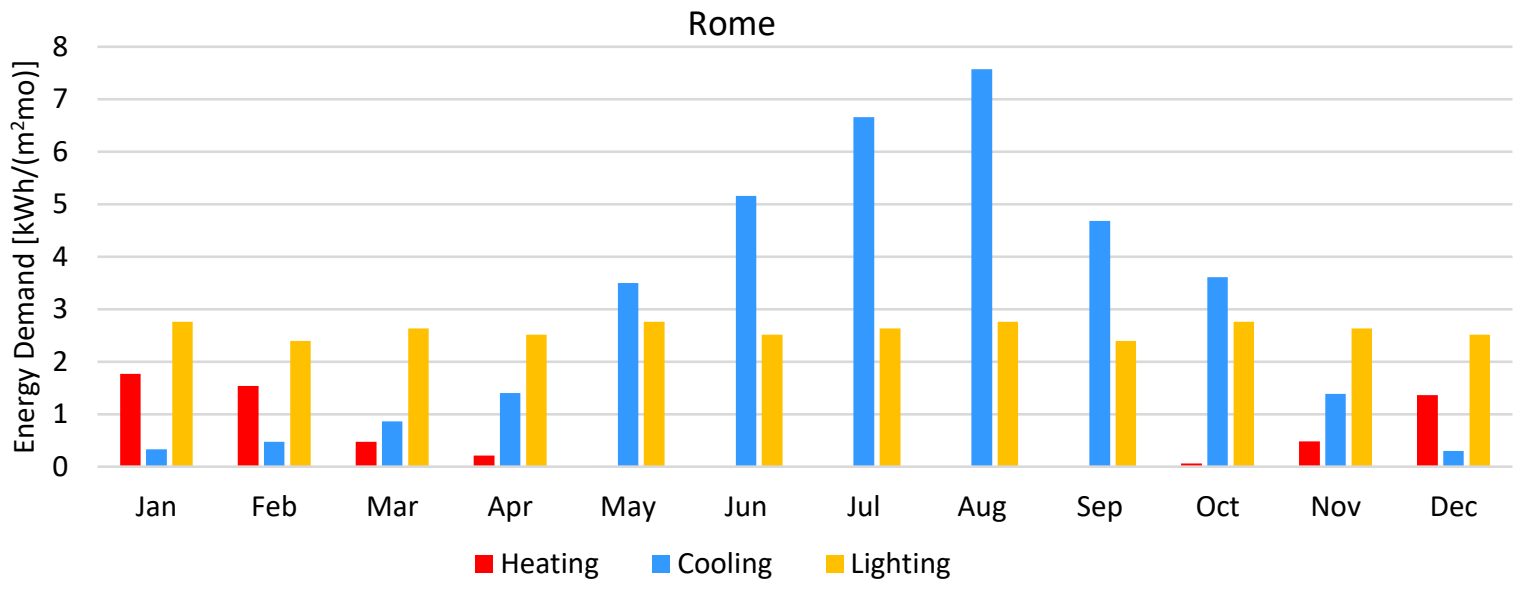

Figure 2-8: Monthly useful energy demands from DALEC simulations for location Rome 


\subsubsection{Comparison of simulation results between different Building Energy Simulation (BES) tools}

The tools analysed in this comparison have different focus:

- $\quad$ EnergyPlus ${ }^{\mathrm{TM}}(\mathrm{EP})$ is a whole building energy simulation program that engineers, architects, and researchers use to model both energy consumption for heating, cooling, ventilation, lighting and plug and process loads and water use in buildings [4];

- $\quad$ TRNSYS (TRN) is a transient system simulation program based on a component approach with modular structure. The TRNSYS library includes a detailed multizone building model and components for HVAC systems, renewable energy systems, etc. [5];

- $\quad$ Simulink UIBK (SIM_IBK) is a Matlab/Simulink library, compatible with CARNOT Toolbox, developed by the University of Innsbruck, based on object-oriented programming of a parameterized building model [6];

- $\quad$ ALMAbuild (SIM_BO) is a Matlab/Simulink library, compatible with CARNOT Toolbox, developed by the University of Bologna where a user develops a building model by means of a series of Graphical User Interfaces [7];

- $\quad$ DALEC (DAL) is a free web tool developed by Bartenbach, University of Innsbruck and Zumtobel. The main focus is on combined thermal and lighting building simulations in early design phases [8]. Different modified versions of DALEC have been compared in chapter 2.1.2, in this section the results obtained with DALEC original are shown;

- $\quad$ MODELICA (MOD) is a non-proprietary, object-oriented, equation-based language to conveniently model complex physical systems, with a wide open source library (in this case the LBNL Buildings library is used) [9];

- $\quad$ PHPP Passive House Planning Package is a quasi-steady state calculation tool, developed as spread sheet, for the use of architects and planning experts [10].

IDA ICE will be added in this comparison with a later publication.

After several feedback loops, agreement between the experts was achieved to have comparable simulation models implemented. The results, proved to be particularly sensitive to user interpretation of overall glazing system properties.

Table 2-3 shows the yearly simulation results, for each scenario, reporting yearly heating and cooling demand. The heating demand increases with the colder climates in spite of the higher insulation level of the envelope. On the right side of Table 2-3, the relative deviations of the heating and cooling demands with respect to the median value are reported, except for the heating demand in Rome where the relative deviation would not be a realistic indicator since absolute values are quite low. For the cooling demand, which contributes most to the energy demand in all the climates, the deviation between the different tools reaches the maximum value of $15 \%$ in Rome.

DALEC models the ventilation losses with a constant average air exchange rate instead of modelling the profile described in report DC.1. This is the reason for the deviations in terms of ventilation losses. Moreover, the solar gain in DALEC deviates from the other tools because a different sky and shading model is applied. Further investigations regarding DALEC are reported in chapter 2.1.2 and 2.1.4.

In EP is not possible to model the control system of the ventilation bypass as it is described in the report, for this reason the ventilation losses are higher.

PHPP presents in general a good agreement since the average air exchange rate and the effective shading value used in the PHPP calculation were "calibrated" taking as a reference SIM_IBK.

Figure 2-9 reports the monthly heating and cooling demand for each tool for the climates of Rome, Stuttgart and Stockholm. From March to November in Rome, from April to October in Stuttgart and from April to September in Stockholm, the cooling demand is higher than the heating demand.

Figure 2-10 shows the monthly average convective temperature. The internal and solar gains cannot be easily dissipated through the well-insulated envelope and therefore, high indoor temperatures also occur during midseasons. This can be clearly seen in Figure 2-10, where all the tools have an average temperature higher than the heating set point also during the coldest month of the coldest climates. In Rome, the heating demand is nearly zero and the convective temperature is higher than the heating set point. Longer periods in which the convective and mean radiant temperatures are not controlled by either the heating system or the cooling system occur during the transition months. The deviation with respect to the median value for each month (excluding the temperature from PHPP) are within $-3 \%$ and $+3 \%$. 
Table 2-3: Yearly simulation results and relative deviation with respect to the median value for all the cases

\begin{tabular}{|c|c|c|c|c|c|c|c|c|c|c|c|}
\hline Loc. & Tools & Qh & Qc & $\begin{array}{l}\text { Qvv } \\
W h /\left(m^{2}\right)\end{array}$ & Qtr & Qsol & Qh & Qc & $\begin{array}{l}\text { Qvv } \\
\text { [\%] }\end{array}$ & Qtr & Qsol \\
\hline \multirow{8}{*}{ 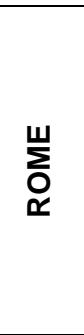 } & EP & 3.0 & -37.0 & -34.3 & -21.2 & 33.0 & - & $14 \%$ & $23 \%$ & $-38 \%$ & $-4 \%$ \\
\hline & TRN & 3.5 & -31.7 & -27.0 & -35.0 & 33.7 & - & $-3 \%$ & $-3 \%$ & $2 \%$ & $-2 \%$ \\
\hline & SIM_UIBK & 3.0 & -32.7 & -27.6 & -33.2 & 28.0 & - & $1 \%$ & $-1 \%$ & $-4 \%$ & $-19 \%$ \\
\hline & SIM_BO & 3.5 & -31.7 & -27.8 & -34.5 & 34.5 & - & $-2 \%$ & $0 \%$ & $0 \%$ & $0 \%$ \\
\hline & DAL & 5.9 & -35.9 & -31.7 & -37.5 & 42.7 & - & $11 \%$ & $14 \%$ & $9 \%$ & $24 \%$ \\
\hline & MOD & 3.2 & -32.5 & -27.9 & -33.8 & 34.4 & - & $0 \%$ & $0 \%$ & $-2 \%$ & $0 \%$ \\
\hline & PHPP & 2.8 & -32.0 & -27.1 & -35.3 & 34.91 & - & $-1 \%$ & $-3 \%$ & $2 \%$ & $1 \%$ \\
\hline & MEDIAN & 3.2 & -32.5 & -27.8 & -34.5 & 34.4 & & & & & \\
\hline \multirow{8}{*}{ 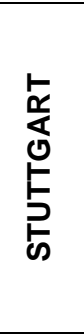 } & EP & 13.3 & -27.9 & -51.0 & -53.8 & 62.7 & $0 \%$ & $6 \%$ & $12 \%$ & $-11 \%$ & $0 \%$ \\
\hline & TRN & 13.6 & -24.9 & -45.2 & -60.6 & 60.6 & $2 \%$ & $-5 \%$ & $0 \%$ & $0 \%$ & $-3 \%$ \\
\hline & SIM_UIBK & 13.5 & -25.6 & -45.0 & -61.3 & 61.9 & $1 \%$ & $-2 \%$ & $-1 \%$ & $2 \%$ & $-1 \%$ \\
\hline & SIM_BO & 13.2 & -26.5 & -45.9 & -60.1 & 63.2 & $-1 \%$ & $1 \%$ & $1 \%$ & $0 \%$ & $1 \%$ \\
\hline & DAL & 18.2 & -28.4 & -45.9 & -57.2 & 56.8 & $37 \%$ & $8 \%$ & $1 \%$ & $-5 \%$ & $-9 \%$ \\
\hline & MOD & 13.0 & -25.2 & -45.3 & -62.1 & 63.1 & $-2 \%$ & $-4 \%$ & $0 \%$ & $3 \%$ & $1 \%$ \\
\hline & PHPP & 13.0 & -26.2 & $-45.0^{1}$ & $-60.3^{1}$ & $62.7^{1}$ & $-3 \%$ & $0 \%$ & $-1 \%$ & $0 \%$ & $0 \%$ \\
\hline & MEDIAN & 13.3 & -26.2 & -45.3 & -60.3 & 62.7 & & & & & \\
\hline \multirow{8}{*}{ 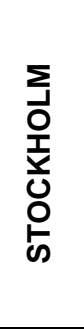 } & EP & 17.7 & -26.7 & -55.6 & -51.4 & 59.5 & $1 \%$ & $7 \%$ & $12 \%$ & $-10 \%$ & $2 \%$ \\
\hline & TRN & 18.4 & -24.6 & -49.2 & -59.3 & 58.3 & $5 \%$ & $-1 \%$ & $-1 \%$ & $4 \%$ & $0 \%$ \\
\hline & SIM_UIBK & 17.0 & -24.9 & -49.5 & -57.7 & 58.6 & $-2 \%$ & $0 \%$ & $-1 \%$ & $1 \%$ & $1 \%$ \\
\hline & SIM_BO & 17.5 & -24.9 & -49.8 & -58.6 & 59.6 & $0 \%$ & $0 \%$ & $0 \%$ & $2 \%$ & $2 \%$ \\
\hline & DAL & 16.8 & -28.2 & -52.7 & -45.2 & 52.8 & $-4 \%$ & $13 \%$ & $6 \%$ & $-21 \%$ & $-9 \%$ \\
\hline & MOD & 16.6 & -23.7 & -49.1 & -57.3 & 56.9 & $-5 \%$ & $-5 \%$ & $-2 \%$ & $0 \%$ & $-3 \%$ \\
\hline & PHPP & 17.6 & -25.3 & $-50.8^{1}$ & $-56.5^{1}$ & 58.01 & $1 \%$ & $1 \%$ & $2 \%$ & $-1 \%$ & $-1 \%$ \\
\hline & MEDIAN & 17.5 & -24.9 & -49.8 & -57.3 & 58.3 & & & & & \\
\hline
\end{tabular}

\footnotetext{
1 PHPP is a quasi-steady state tool that calculates losses and gains considering a fixed set point temperature. It performs two different balances by using the two set point temperatures for winter and summer. The ventilation, transmission losses and solar gains are estimated using the winter balance for the heating season and the summer balance for the cooling season.
} 

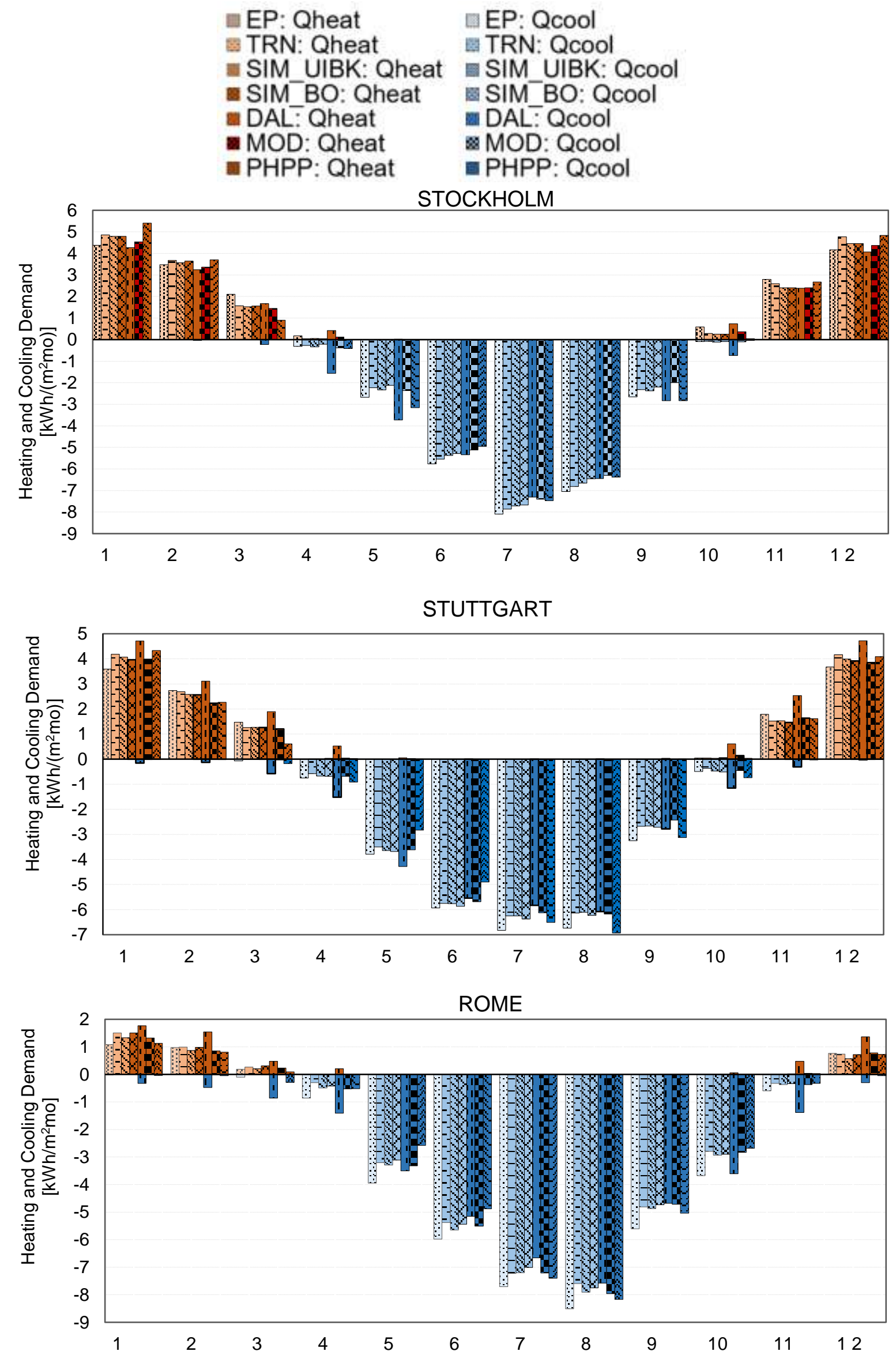

Figure 2-9: Comparison of monthly heating and cooling demands simulated with all the considered tools and climates 


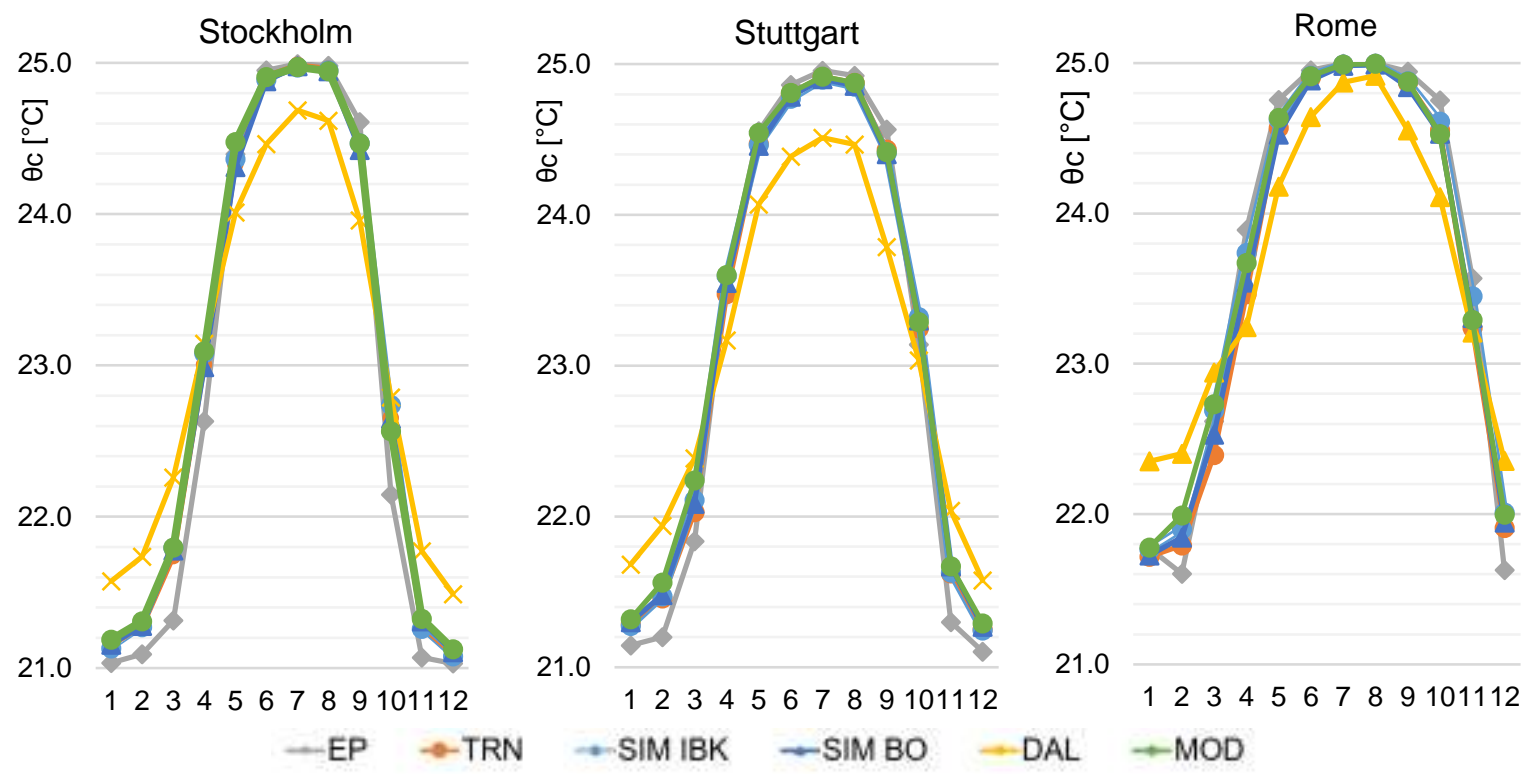

Figure 2-10: Average monthly convective temperature for the climates of Stockholm, Stuttgart and Rome

\subsubsection{Daylight Analysis}

In this section, the daylight analysis of the office described in report DC.1 is reported. This analysis is carried out by means of two different tools: DALEC and a co-simulation model developed by Eindhoven University of Technology (TUe co-sim) [11]. Chapter 2.1.4.1 reports the results obtained with DALEC, chapter 2.1.4.2 reports the comparison between DALEC and TUe co-sim, and chapter 2.1.4.3 shows possible ways to increase daylight comfort with respect to the reference office cell described in DC.1, and shows the performance effects of conventional approaches for mitigating daylight glare discomfort with respect to the reference office cell described in DC.1.

The position of the sensors in DALEC (see Figure 2-11) and TUe co-sim (see Figure 1-2-12) are the same as can be seen in the figures below. MP3 and MP4 describe the position of the eyes of a sitting occupant, looking towards the façade in different directions. Table 2-4 reports the coordinates of these sensors where the luminance level on the façade is measured in order to evaluate the glare.

MA1 and MA2 measure the horizontal illuminance level on work plane, this parameter is used for the evaluation of smart control of the lights.

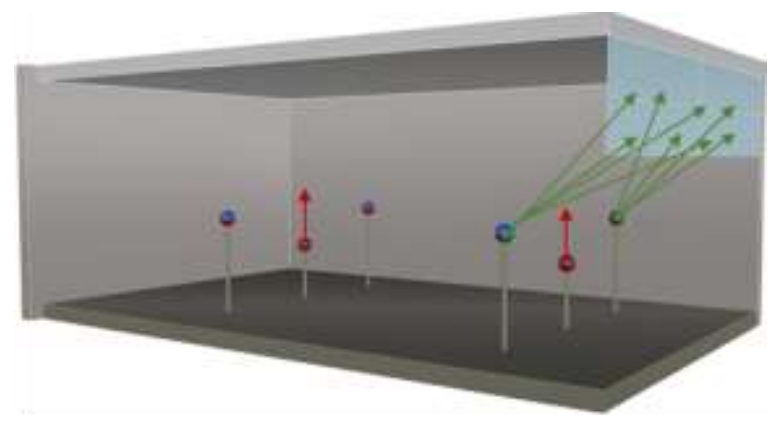

(a)

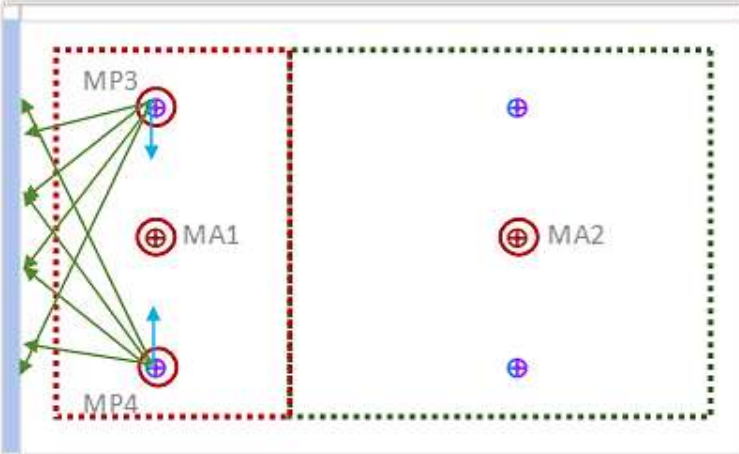

(b)

Figure 2-11: (a) 3D sketch of the office cell in DALEC with the position of the sensors, (b) plan of the office cell showing the measurement areas MA1 and MA2 and the measurement points MP1-2-3-4 


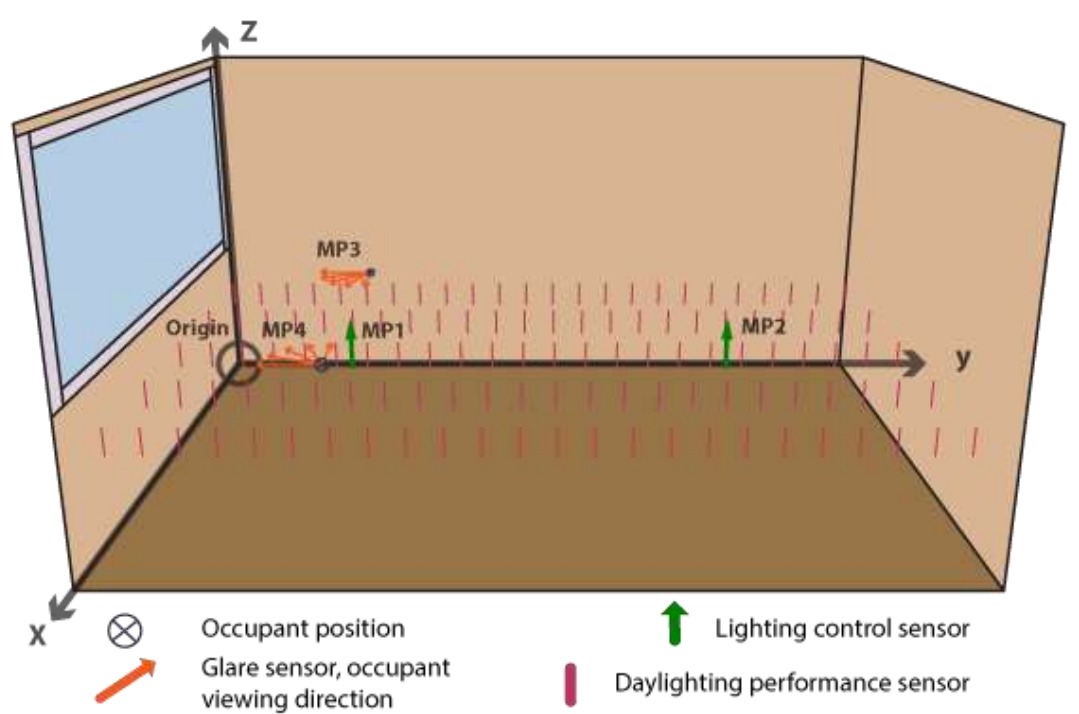

Figure 1-2-12 Overview of sensor positions and directions used in the TU/e co-sim daylighting model

Table 2-4: Coordinates used of measurement points relative to the origin shown in Figure 1-2-12

\begin{tabular}{c|ccc} 
MEASUREMENT POINT & X COORD [M] & Y COORD [M] & Z COORD [M] \\
\hline MP1 & 2.25 & 1.50 & 0.75 \\
MP2 & 2.25 & 4.50 & 0.75 \\
MP3 & 3.50 & 1.50 & 1.20 \\
MP4 & 1.00 & 1.50 & 1.20 \\
\hline
\end{tabular}

\subsubsection{DALEC}

The monthly results for continuous daylight autonomy give a qualitative measure to evaluate the daylight supply in the room throughout the year. It describes the illuminance level on working plane height $(0,75 \mathrm{~m}$ above floor) in measurement area 1 (MA1, near the façade) and measurement area 2 (MA2, back of the room) (see section 2.1.4).

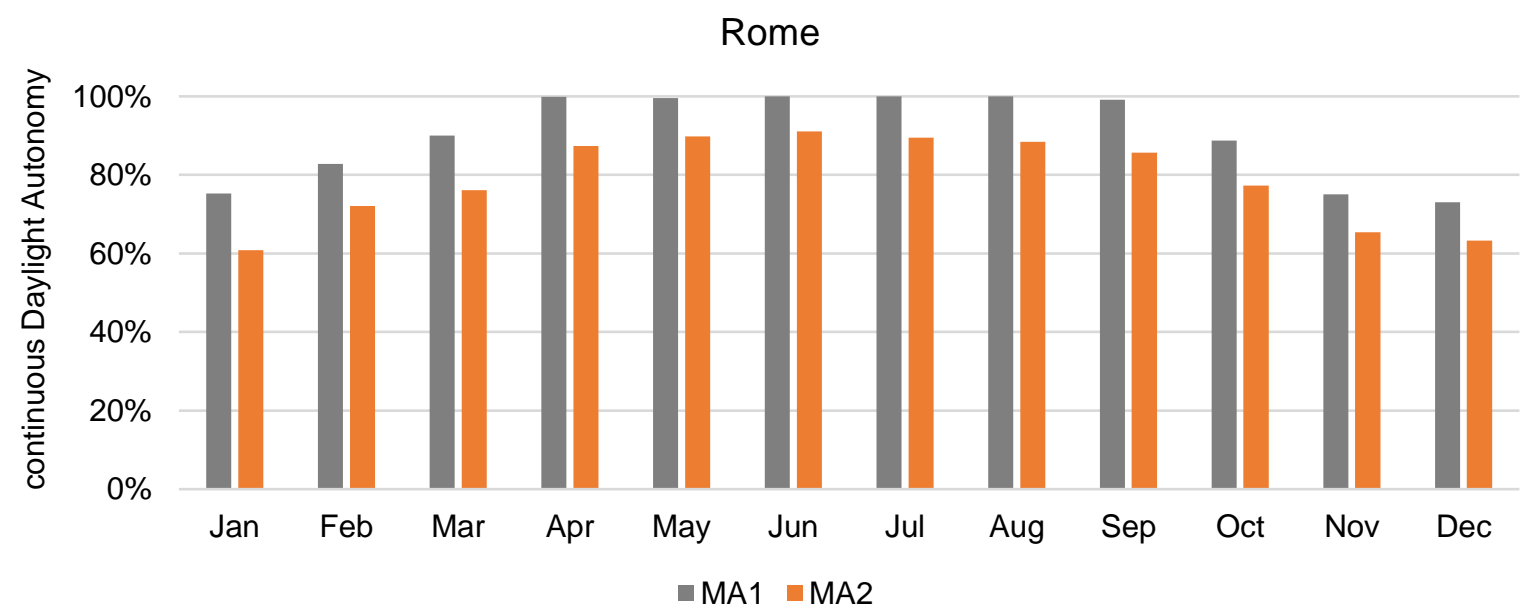

Figure 2-13: Monthly continuous daylight autonomy from DALEC simulations for location Rome 


\section{Stuttgart}

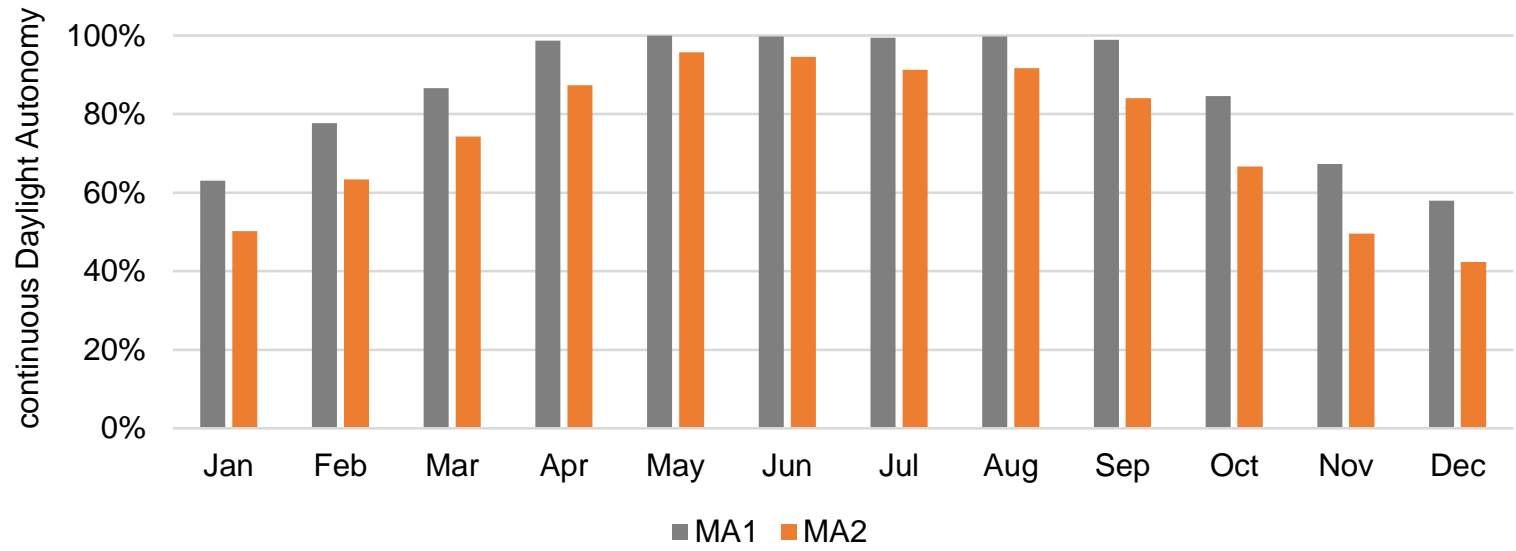

Figure 2-14: Monthly continuous daylight autonomy from DALEC simulations for location Stuttgart

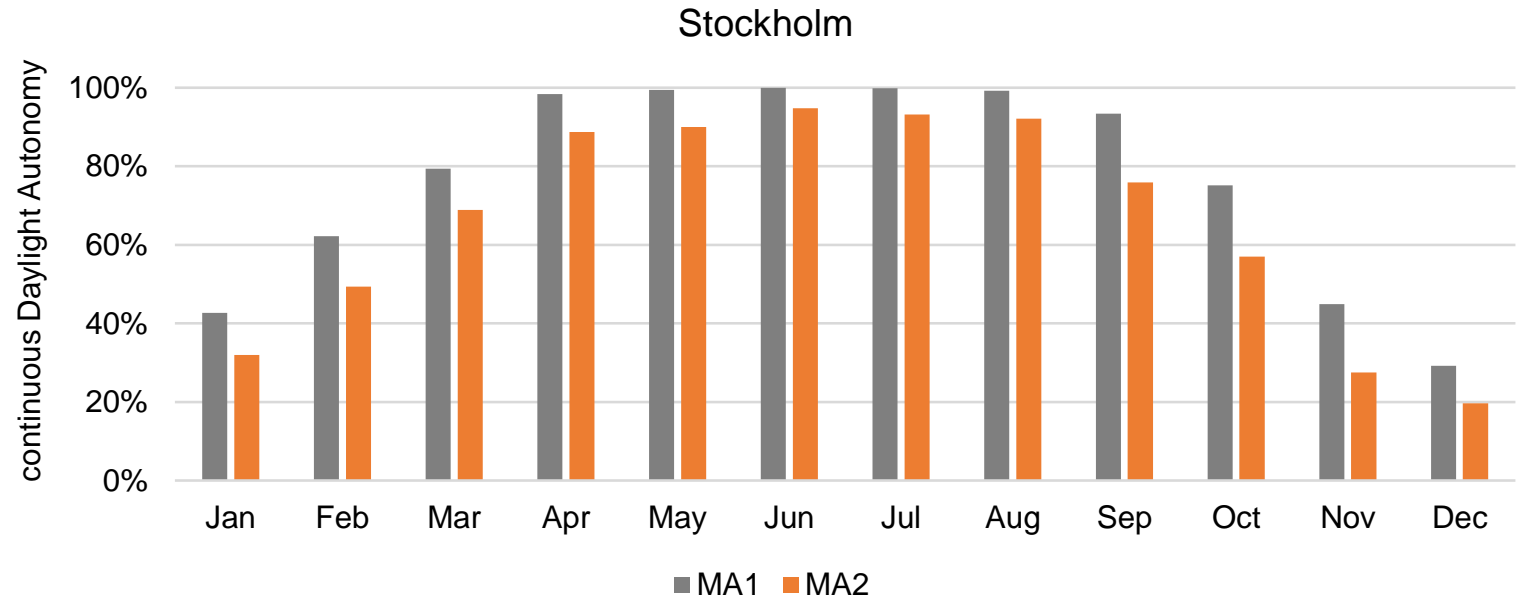

Figure 2-15: Monthly continuous daylight autonomy from DALEC simulations for location Stockholm

The monthly figures for the continuous daylight autonomy show good daylighting provision (>55\%) throughout the year for Rome (Figure 2-13). Especially for the positions next to the façade a very high level on daylight availability can be expected. In Stockholm (Figure 2-15) and Stuttgart (Figure 2-14), for the winter months November to January a low daylight autonomy results due to the low exterior daylight availability. Nevertheless, the overall daylight autonomy (Figure 2-16) for all locations Rome, Stuttgart and Stockholm are above $66 \%$ in the depth of the room and above $77 \%$ near the façade. 
All locations

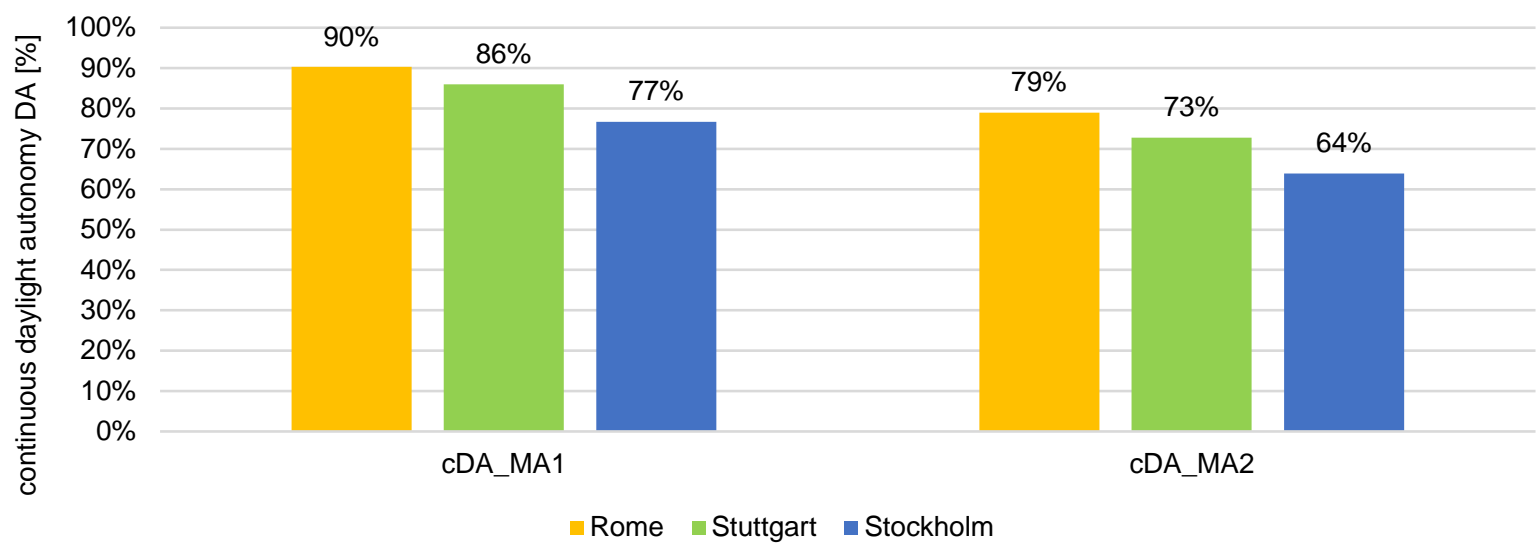

Figure 2-16: Yearly continuous daylight autonomy from DALEC simulations for all locations

The results for the glare risk evaluation are based on the measure luminance threshold Lmax observed from the interior at the façade. With a user-defined luminance threshold of $3000 \mathrm{~cd} / \mathrm{m} 2$, the resulting percentage of annual occupied hours above this value show the potential risk of glare (Figure 2-17). The evaluation is done for both viewpoints (M3/M4), representing the occupants.

The results show clearly a significant risk of glare for the given situation, which is due to two reasons:

- The control based on an incident direct solar radiation threshold is useful to block excessive solar gains but is not appropriate to avoid glare issues;

- $\quad$ On sunny days with high incident solar radiation, the generic external solar shading with a high visual transmittance of 0,3 does not provide sufficient glare protection even in closed position.

Differences between the locations are due to the lower amount of incident radiation for northern locations. By an additional daylighting case study provided in Chapter 2.2.7 of this document, further investigations in glare evaluations are made and reported.

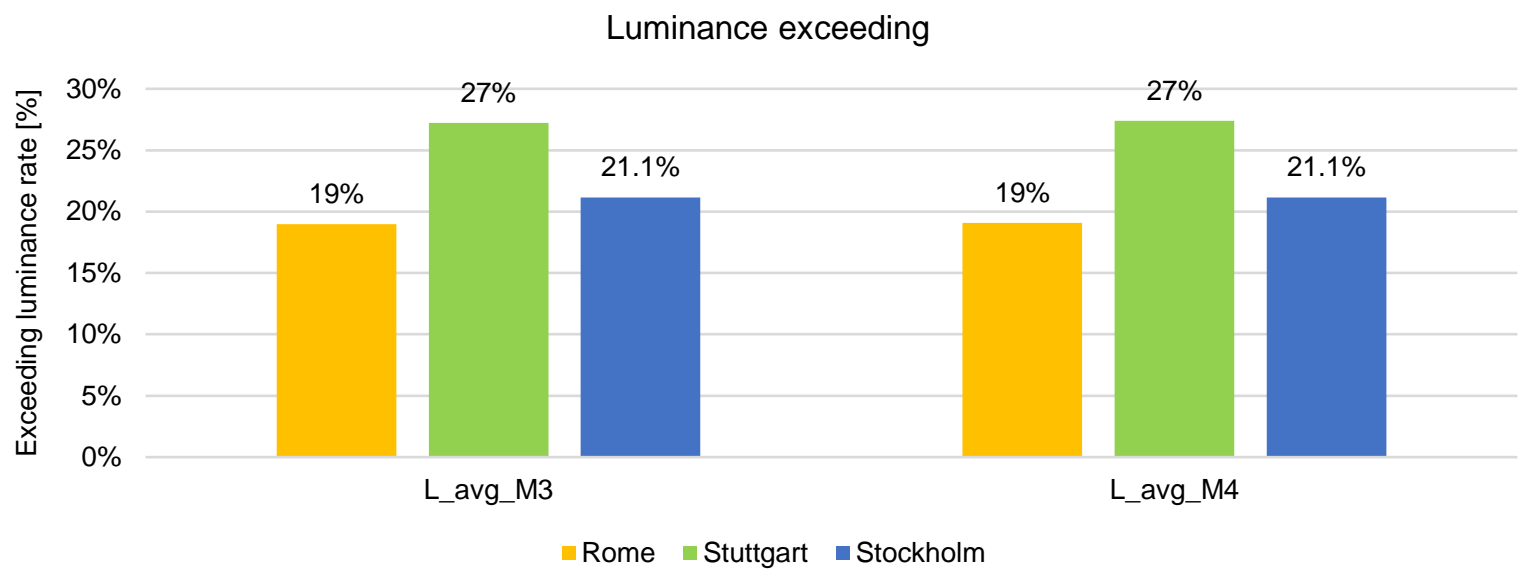

Figure 2-17: Yearly exceeding luminance rate from DALEC simulations for all locations 


\subsubsection{Comparison of simulation results between different daylighting tools}

Figure 2-18 shows a comparison of predicted daylight glare discomfort from two different daylighting simulation tools: DALEC and a co-simulation model developed by Eindhoven University of Technology (TUe co-sim). The TUe cosim model [11] utilises a co-simulation approach which couples the Radiance three-phase method to EnergyPlus and Matlab. The model was developed for providing and integral assessment of daylighting, glare and energy performance of advanced solar shading concepts.

Although the daylighting simulation techniques which are employed in DALEC and the TUe co-sim model are similar, the performance indicators which they can provide to assess glare discomfort are different. Both simulation tools report glare discomfort for the two occupant positions described in section 2.1.4. DALEC uses the share of occupied hours that an average window luminance of $3000 \mathrm{~cd} / \mathrm{m}^{2}$ is exceeded (see section 2.1.4) whereas TUe cosim uses the share of occupied hours that a DGPs of 0.4 (disturbing glare) is exceeded. DGPs is based on vertical illuminance rather than luminance. For the TUe co-sim model DGPs 0.4 exceedance is shown using two approaches (Figure 1-2-12). In the first a viewing direction facing the window at 45 degrees is assumed. In the second approach a series of viewing directions are assumed, ranging from the occupant facing a side wall to the occupant facing the window directly with the view normal pointing perpendicular into the window. Three intermediate viewing directions are considered which are positioned at 22.5 degree rotation intervals (orange arrows). At each time step the average DGPs value of all viewing angles is considered.

Figure 2-18 shows a comparison of the glare performance that is predicted by the two tools. From left to right, the first three bars show glare performance for the MP4 occupant position based on:

- $\quad$ annual DGPs 0.4 exceedance for the 45 degree viewing direction using TU/e co-sim

- annual average DGPs 0.4 exceedance for the full range of viewing directions using TU/e co-sim

- $\quad$ average window luminance $3000 \mathrm{~cd} / \mathrm{m}^{2}$ exceedance using DALEC.

The next three bars show the same indicators for the MP3 occupant position. Regardless of the difference in the applied approaches that are used, the agreement between the two tools is quite good. The average luminance exceedance approach used in DALEC gives nearly identical results as the average view direction DGPs exceedance approach used in the TU/e co-sim tool. From the results for all climates it can be concluded that the office does not guarantee visually comfortable indoor conditions. CEN-EN 14501 [12] classifies a 5\% exceedance of DGPs 0.4 as medium glare protection and anything above that as offering minimal glare protection. It can be seen that all climates and all viewing directions would fall in this minimal glare protection class. 

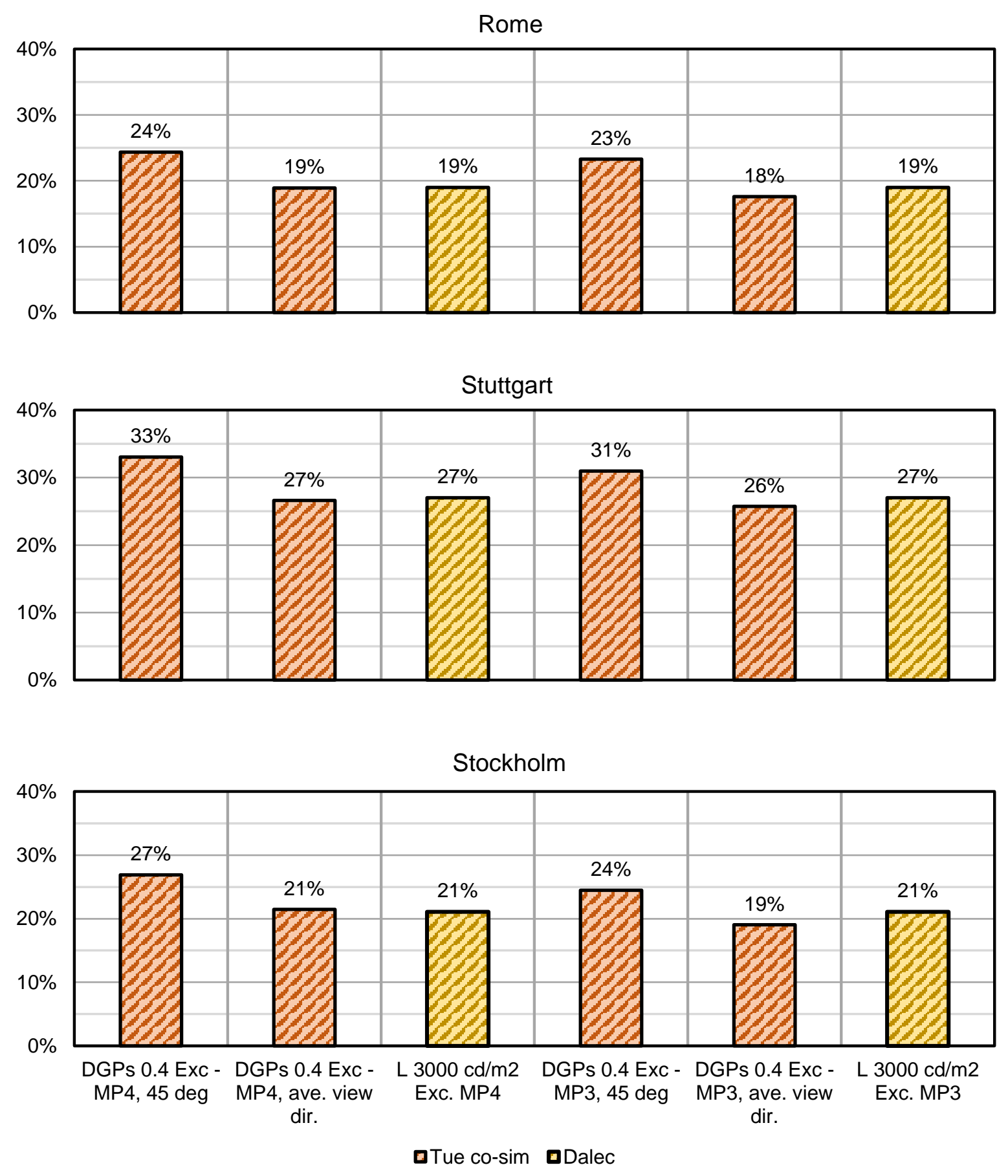

Figure 2-18 Comparison of predicted daylight glare discomfort from DALEC and the TUe-cosimulation model

Figure 2-19 shows the daylighting performance that is predicted using the two tools. Here for both tools cDA $\mathrm{A}_{300 \mathrm{x}}$ is reported for the two sensor points (MP1 and MP2 in Figure 1-2-12). Additionally, TUe co-sim also reports sDA $5001 \times 50 \%$, a metric which cannot easily be reported by DALEC. For computing $\mathrm{sDA}_{5001 \times 50 \%}$ a grid of sensor points is used (purple sensors in Figure 1-2-12) Here too, the agreement between the two tools is good. Only for the climate of Rome there is some disagreement between the two tools for the sensor point deeper into the space. Overall the predicted degree of daylighting performance predicted in all climates is very good. For both performance indicators, values above $70-75 \%$ can be considered to indicate good daylighting performance.

It can be concluded that the reference office performs good in terms of daylighting but less good in terms of visual comfort (glare). This performance can be explained by the high visual transmittance of the shading fabric (30\%) as well as the simple control approach. It should be noted that in utilizing this reference office description to assess 
daylighting and glare protection technologies the goal should be to maintain the beneficial daylighting performance whilst improving the degree of visual comfort. In chapters 2.2.6 and 2.2.7two case studies are presented which provide an example of how this reference office description can be used to assess daylighting technologies. Additionally, the influence of the assumptions regarding glare protection made in this reference description are explored in 2.1.4.3.
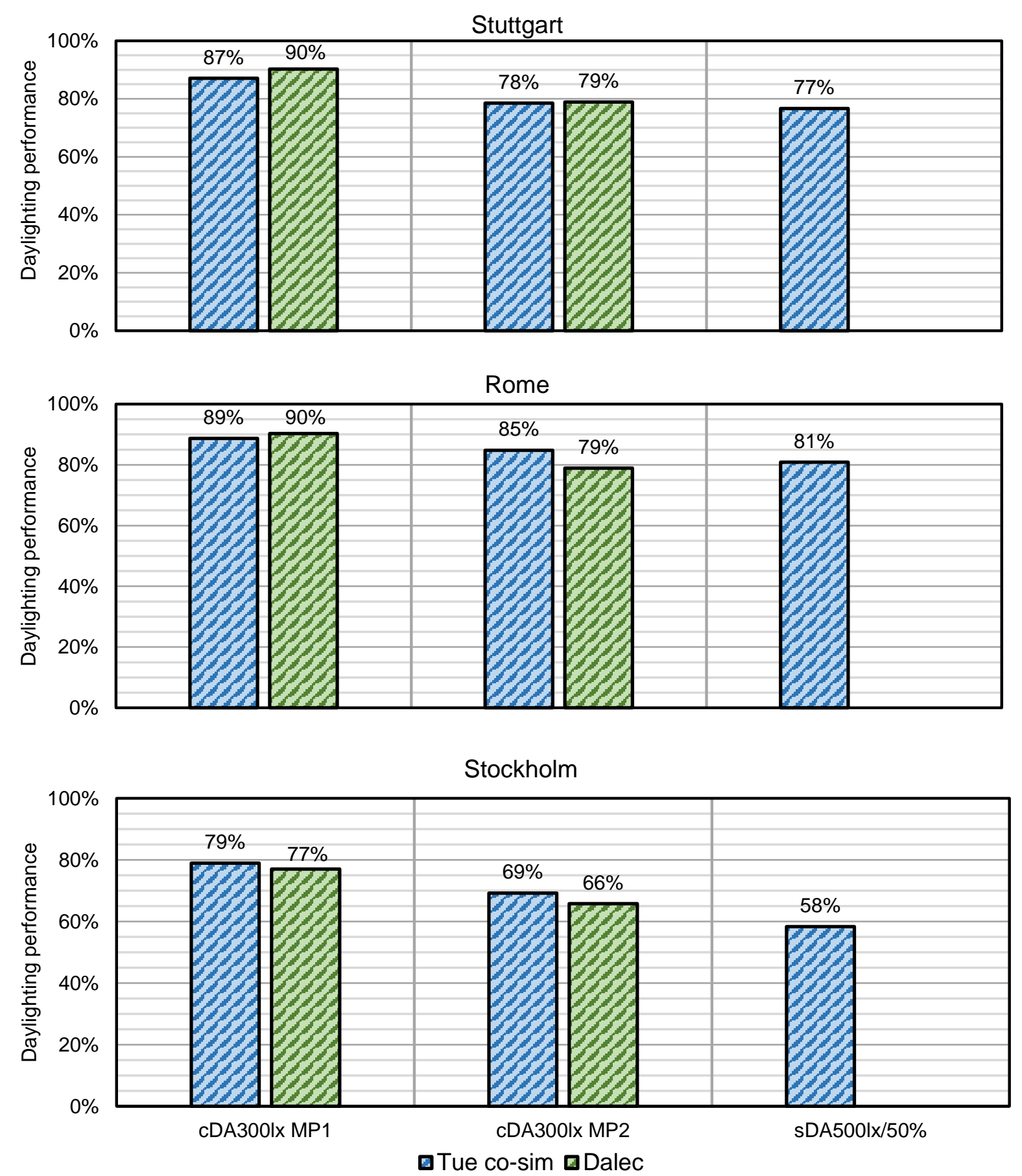

Figure 2-19 Comparison of predicted daylighting performance from DALEC and the TUe-cosimulation model 


\subsubsection{Energy Plus - Improving visual comfort: a case study into daylight dimming using TUe co-sim}

This case-study focusses on the same daylight dimming strategy as discussed in DC.1. Here the influence is explored of the occurrence of daylight glare discomfort, and the mitigation thereof, on the predicted daylighting performance and energy reduction from a dimming system. Three alternatives will be compared:

- No dimming, shade $T_{v}{ }^{2} 30 \%$ : The reference office with the glare protection strategy described in DC.1;

- Dimming, shade $T_{v}{ }^{2} 30 \%$ : The reference office with the glare protection strategy described in DC.1, and with daylight dimming of artificial lighting.

- Dimming, shade $T_{v}{ }^{2} 1.3 \%$, glare free control: The reference office, daylight dimming of artificial lighting, and a shading strategy which prevents glare (glare free).

In the glare free scenario a shading fabric with a visual transmittance of $1.3 \%$ is used. The shading system is now controlled according to an up/down open-loop control approach using a vertical illuminance sensor directly behind the window, but in front of the shading system. Here a control threshold, of $6400 \mathrm{~lx}$, is used. This control threshold has been chosen such that the shade is lowered whenever there would be a risk of 'disturbing' glare at one of the sensor points, using the method presented in [11]. This approach to glare mitigation is deliberately chosen to be unrefined. It can be considered to be indicative of a conventional automated control approach where the control threshold is chosen very conservatively in order to prevent glare. Additionally, the approach gives an idea of the performance that could result from occupants interacting with the shading control strategy described in 2.1.2.

For this study the TUe co-sim environment, which is described in section 2.1.4.2, is used. For assessing daylighting, glare and artificial lighting performance, this study uses the same measurement sensors as in the assessment using DALEC in section 2.1.4 Figure 2-11 and Figure 1-2-12 give an overview of the position and viewing direction of these sensors. The coordinates shown in Table 2-4 are relative to the origin marked in Figure 1-2-12. The (Continuous Daylight Autonomy) $\mathrm{CDA}_{3001 \times}$ and $\mathrm{sDA} \mathrm{A}_{5001 \times 50 \%}$ metrics are used to assess daylighting performance (see $\mathrm{DC}$. 1 chapter 5.4). $\mathrm{CDA}_{3000 \times}$ is assessed at MP1 and MP2. For $\mathrm{SDA}_{5001 \times 50 \%}$ the entire grid of sensor points is used. For assessing glare, the maximum (Daylight Glare Probability) DGPs value of both occupant positions (MP3 and MP4) is taken at each time step for two viewing directions, one facing the window at 45 degrees and one facing a side wall. As a performance indicator DGPs 0.4 exceedance is used. Additionally, the occupied hours where the shade is in the raised position is given as a measure for the degree of view to the outdoors. For assessing energy performance both energy demand and primary energy consumption are given. For computing primary energy consumption the efficiency ratios, shown in Table 2-5, are used. In this case study the climate of Stuttgart is used.

Figure 2-20 shows that, compared to the reference situation where the lights are always on during occupied hours, the linear daylight dimming strategy offers significant reductions in lighting and cooling energy consumption. Such reduction, however, would be much smaller with the 'glare free' scenario. The way in which glare is mitigated in this scenario has a detrimental influence on daylighting and view performance. This comparison gives an idea of the uncertainty associated to the energy performance predictions of the daylight dimming strategy, evaluated in the second scenario, where a glare free situation cannot be assured.

Table 2-5 Assumed energy ratios in this case-study

\begin{tabular}{l|l}
\multicolumn{2}{c}{ Efficiency ratio } \\
\hline EER $_{\text {COOLING }}$ & 3.0 \\
COP $_{\text {HEATING }}$ & 2.5 \\
PEER $_{\text {TOTAL ELECTRICITY-SITE-TO-SOURCE }}{ }^{3}$ & 2.41 \\
\hline
\end{tabular}

\footnotetext{
2 The Visible light transmittance (Tv) is the proportion of incident visible light, integrated over all hemispherical incidence directions, that is transmitted through the shading fabric.

3 Total site-to-source primary energy ratio for electricity that is prescribed by the Dutch EPBD standard [34]
} 

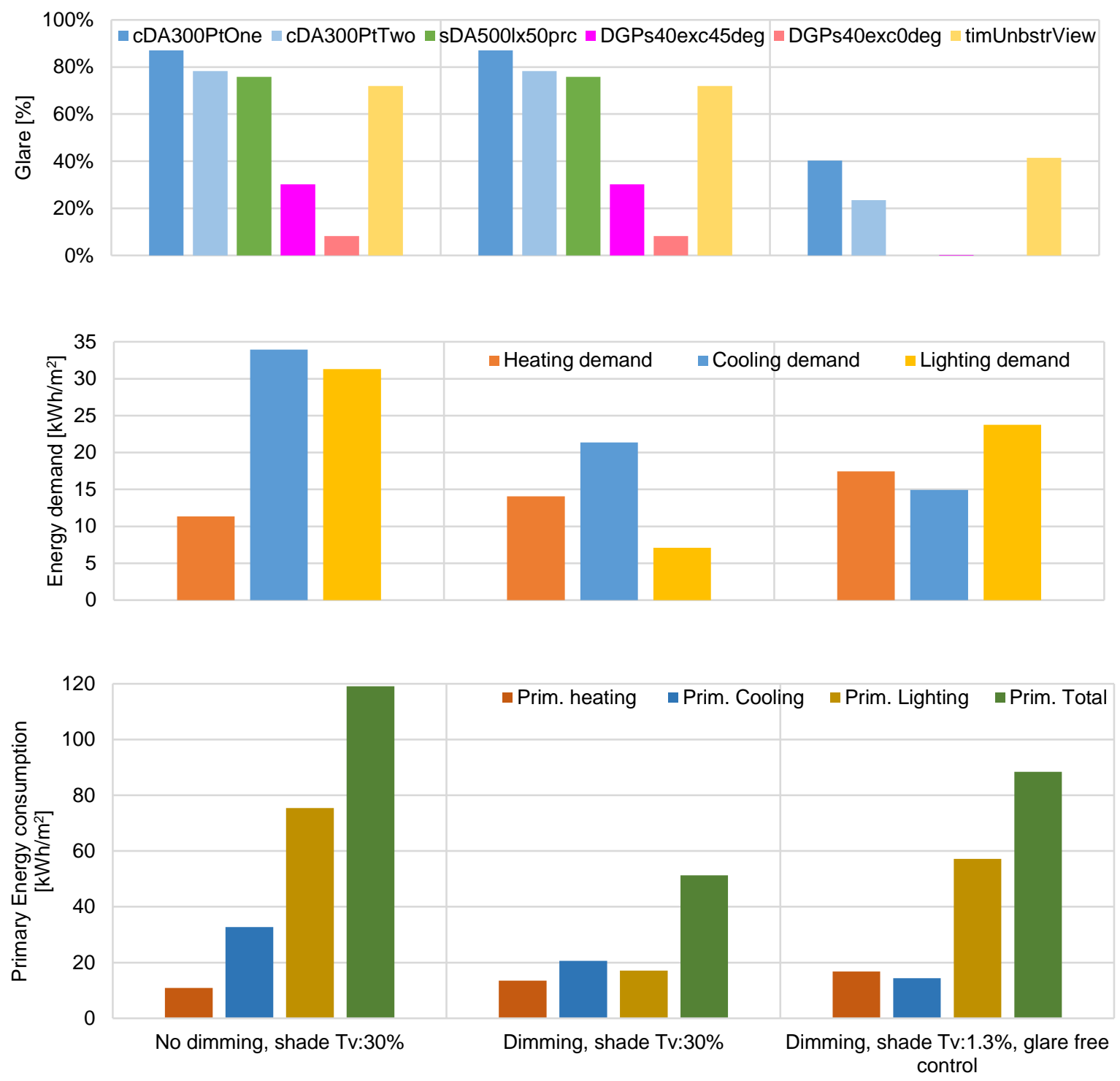

Figure 2-20 Summary of glare, daylighting, energy demand and primary energy consumption. 


\subsubsection{Comparison of the results of the office building simulated together with air to air Heat Pump and Photovoltaic panels}

The office cell equipped with a heat pump and photovoltaic panels with inverter has been simulated with Simulink, TRNSYS and Energy Plus and the results compared. The technical characteristics of PV, inverter and Heat pumps are reported in the appendix 0 . The building model used in this comparison is the same presented in the previous chapter, therefore are here presented only the results related to the PV and HP.

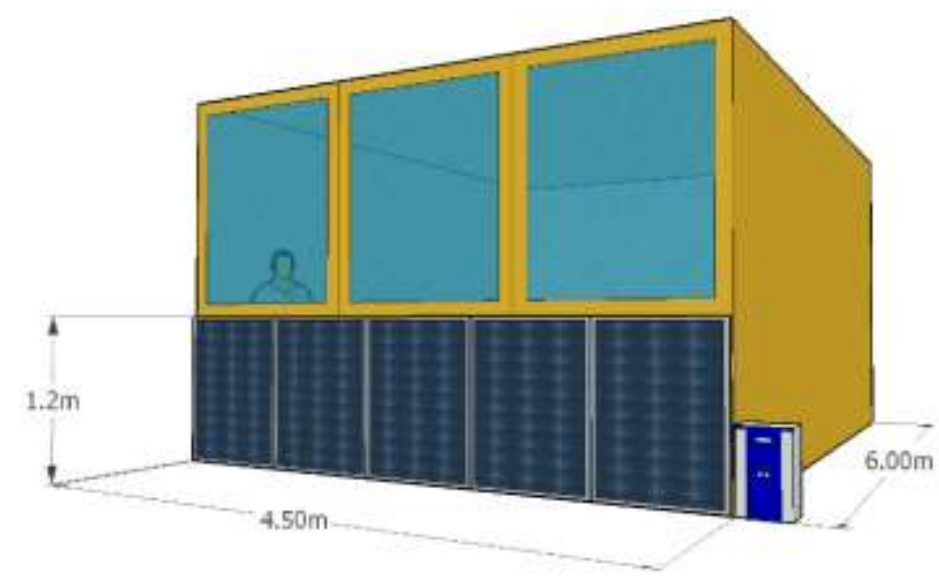

Figure 2-21: Office cell equipped with PV on the available façade

\section{Comparison (TRNSYS) TRN and (Simulink ALMAbuild) SIM BO}

The modulating HP providing heating and cooling to the office cell (see annex 0 ) has been modelled in TRNSYS and Simulink together with the PV panels and the results in terms of monthly electric energy demand of the HP, PV production and PV self-consumption are reported in Figure 2-22. The match between SIM and TRN is quite good except for some deviation in the PV production and self consumption in Rome. 

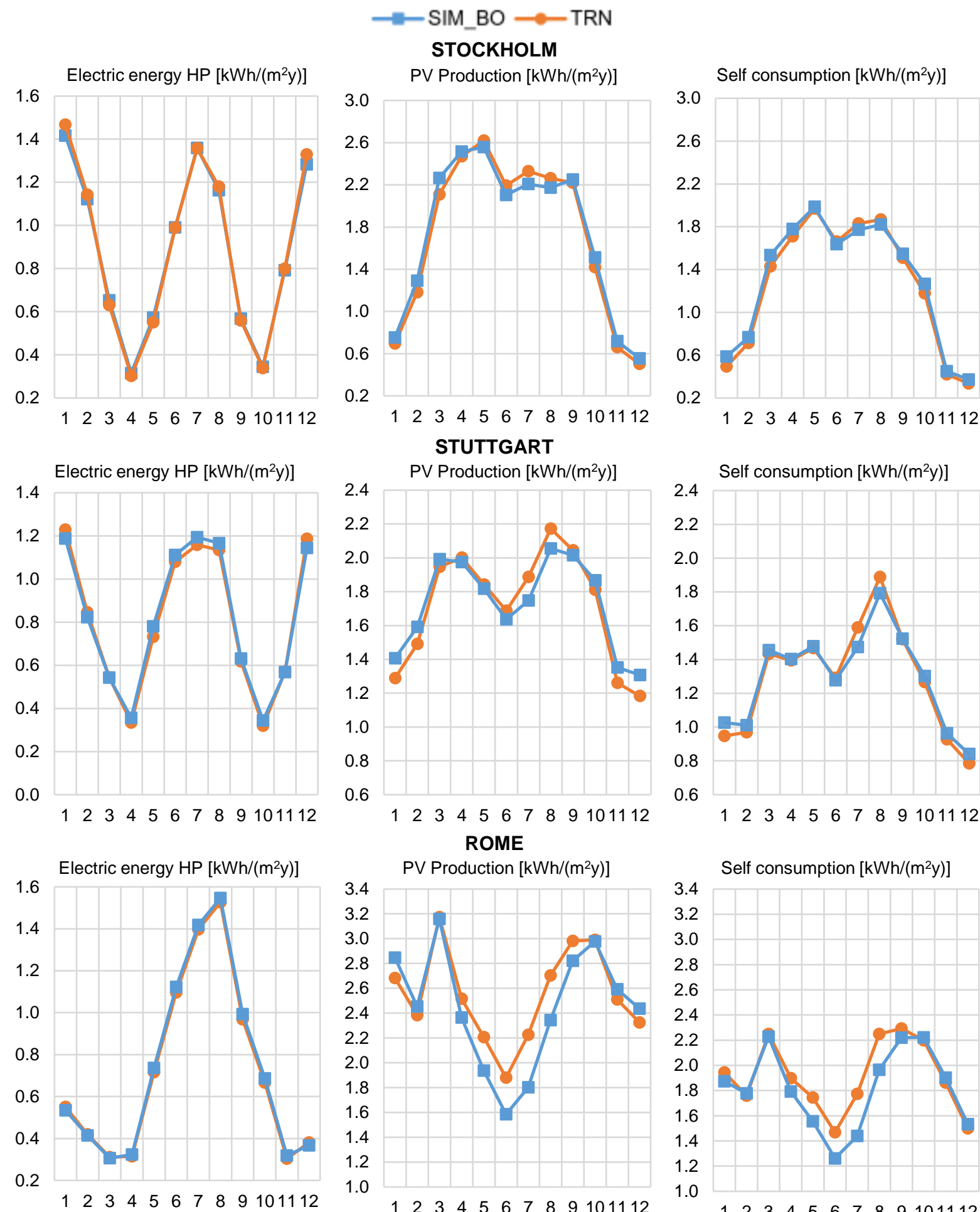

Figure 2-22: Monthly electric energy demand for heating and cooling, PV production and self-consumption simulated with TRN and SIM_BO for the climates of Stockholm, Stuttgart and Rome 


\section{Comparison (EnergyPlus) EP and (Simulink ALMAbuild) SIM BO}

In this case study the On/Off mode of the HP is activated when the people are in the office and outside this timeframe the HP is used in modulating mode. When the HP works in On/Off mode the air flow is reduced and also the noise produced by the split, for this reason it is preferable to use this working mode during the working hours in order to guarantee higher acoustic comfort. The results (i.e. Monthly electric energy demand for heating and cooling, PV production and self-consumption) of SIM BO and EP are reported in Figure 2-23 for the climates of Stockholm, Stuttgart and Rome. The match between SIM and EP is quite good except for some deviation in the PV production and self consumption in Rome. 

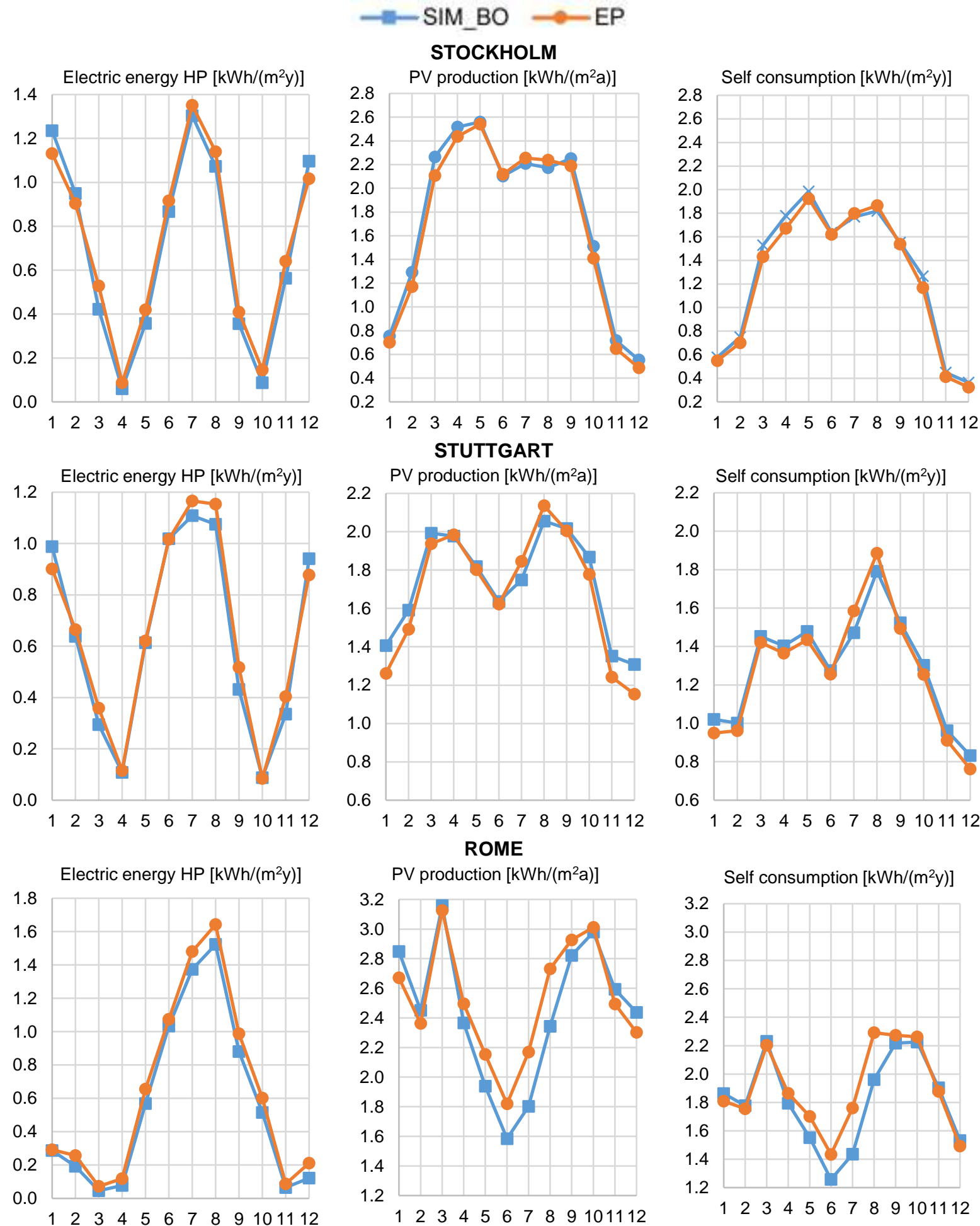

ROME

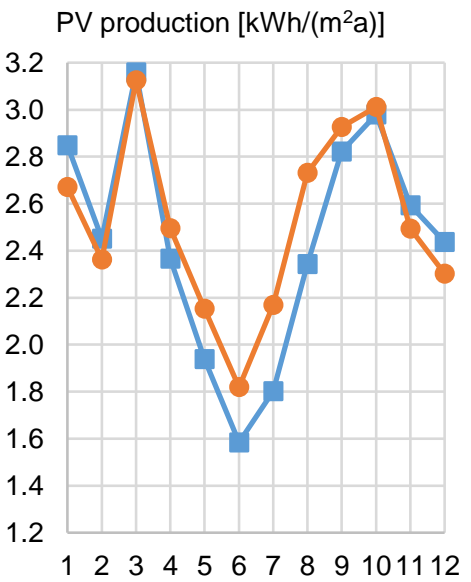

Self consumption $\left[\mathrm{kWh} /\left(\mathrm{m}^{2} \mathrm{y}\right)\right]$

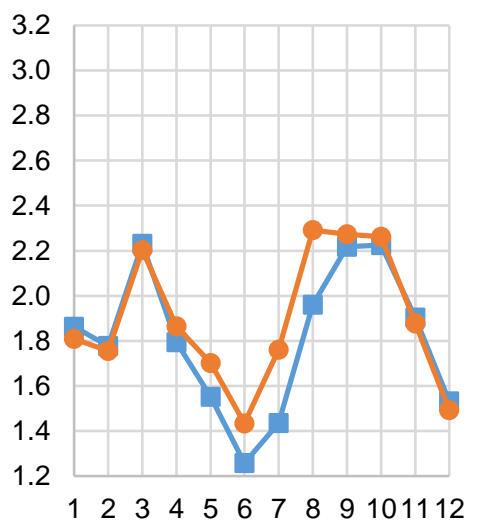

Figure 2-23: Monthly electric energy demand for heating and cooling, PV production and self-consumption simulated with EP and SIM_BO for the climates of Stockholm, Stuttgart and Rome 


\subsection{Case studies}

\subsubsection{Cost-optimality - variation of the envelope and HVAC quality and BIPV}

Fabian Ochs ${ }^{a}$, Mara Magnia, Elisa Venturia

aUniversity of Innsbruck, Technikerstraße 13, Innsbruck 6020, Austria

\section{Scope of the Study}

The reference office cell is implemented as a simplified lumped capacity model in Matlab and various cases are simulated. The cost-optimality study includes:

1) Envelope quality (best, very good, good, moderate, poor, very poor)

2) MVHR (no, HRV, ERV)

3) Direct Electric (DE) or Heat pump (Heating)

4) With or without PV (façade integrated)

5) LED (instead of fluorescent lights)

\section{Simplifications and Adaptions}

Following simplifications and adaptions with respect to the reference office description in DC.1 are introduced.

- Lumped heat capacity building model (with $c=204 \mathrm{Wh} /\left(\mathrm{m}^{2} \mathrm{~K}\right)$ ) and with constant conductance UA

- Effective moisture buffer $V_{\text {eff }}=10 \mathrm{~V}$

- Average occupation between 7:00h and 19:00h

- Corresponding ventilation control between 7:00h and 19:00h with ventilation rate acc. to DC.1

- Average load profile for appliances with total internal gains acc. to DC.1

- Carnot based efficiency for heating heat pump with $\eta_{\text {carnot }}=0.4$

- Constant EER of 4 for cooling

- Auxiliary includes fans and defrosting of MVHR and constant $20 \mathrm{~W}$ standby.

- PV self-consumption of const. $70 \%$.

- Constant primary energy factor of $f_{P E, t o t}=2.5, f_{P E, n o n R E}=2.3$

\section{Envelope Quality, Heating and Cooling Demand}

Table 2-3 summarizes the overall heat transfer coefficient of the reference office cell for the three investigated climates and Table 2-7 gives an overview about the varied envelope qualities.

Additionally, all cases are simulated:

- $\quad$ without MVHR;

- $\quad$ with HRV ( $\eta \mathrm{T}=0.7)$;

- $\quad$ with ERV $(\eta T=0.7, \eta x=0.6)$.

further

- $\quad$ Direct electric heating

- Split type heat pump $(\eta c=0.4)$

and

- with fluorescent light

- LED

Table 2-6: Overall heat transfer coefficient of reference office cell and summary of investigated variants

\begin{tabular}{c|cccc}
\multicolumn{4}{c}{} & \multicolumn{3}{c}{$\begin{array}{c}\text { Overall heat transfer coefficient } \\
\mathbf{U} /\left[\mathbf{W} /\left(\mathbf{m}^{\mathbf{2}} \mathbf{K}\right)\right]\end{array}$} & SHGC / [-] \\
Climate & opaque & transparent & façade & \\
\hline Stockholm & 0.3 & 0.9 & 0.66 & 0.632 \\
Stuttgart & 0.39 & 1.35 & 0.97 & 0.598 \\
Rome & 0.82 & 1.26 & 1.08 & 0.333 \\
\hline
\end{tabular}

Table 2-7: Overall heat transfer coefficient of reference office cell and summary of investigated variants. Remark: for cooling dominated climates, lower SHGC might be preferable 


\begin{tabular}{|c|c|c|c|c|c|}
\hline \multirow[b]{2}{*}{ NR } & \multirow[b]{2}{*}{ Name } & \multicolumn{3}{|c|}{$\begin{array}{l}\text { Overall Heat Transfer Coefficient } \\
\qquad U /\left[W /\left(m^{2} K\right)\right]\end{array}$} & \multirow[t]{2}{*}{ SHGC / [-] } \\
\hline & & opaque & transparent & façade & \\
\hline 1 & Very poor & 0.375 & 1.6 & 1.11 & 0.45 \\
\hline 2 & Poor & 0.255 & 1.2 & 0.82 & 0.45 \\
\hline 3 & moderate & 0.193 & 1.2 & 0.80 & 0.4 \\
\hline 4 & Good & 0.156 & 0.8 & 0.54 & 0.3 \\
\hline 5 & Very good & 0.13 & 0.6 & 0.41 & 0.3 \\
\hline 6 & Best & 0.098 & 0.6 & 0.40 & 0.3 \\
\hline
\end{tabular}

Figure 2-1 shows the heating demand (HD) vs. the overall heat transfer coefficient with and without MVHR for the three different climates. The heating load is displayed as a function of the heating demand in Figure 2-25 with and without MVHR. In Stockholm, with MVHR the heating demand can be reduced by approximately $30 \mathrm{kWh} /\left(\mathrm{m}^{2} \mathrm{a}\right)$ and the heating load is reduced by $12 \mathrm{~W} / \mathrm{m}^{2}$. In Rome, the heating demand can be reduced to zero with MVHR and good envelope quality. Without MVHR the heating demand is maximum $10 \mathrm{kWh} /\left(\mathrm{m}^{2} \mathrm{a}\right)$ with a heating load of 14 $\mathrm{W} / \mathrm{m}^{2}$. A slight increase of cooling demand with increasing envelope quality (lower U-value and lower SHGC) can be recognised. There is no significant influence of MVHR on the cooling demand and cooling as can be seen in Figure 2-26. Remark: In all cases free cooling and MVHR bypass is considered as described in DC.1. Because of the shading control, the cooling load is dominated by the internal gains.

For the case without MVHR an exhaust ventilation is considered with an SFP of $0.2 \mathrm{Wh} / \mathrm{m}^{3}$. It is noteworthy that in particular in the cold climates (Stockholm and Stuttgart) such a ventilation would lead to some discomfort hours (cold air downdraught). For all cases a const. auxiliary electric load (control) of $20 \mathrm{~W}$ is assumed. Electric energy for auxiliary devices and lighting are summarized together with the appliances, here.

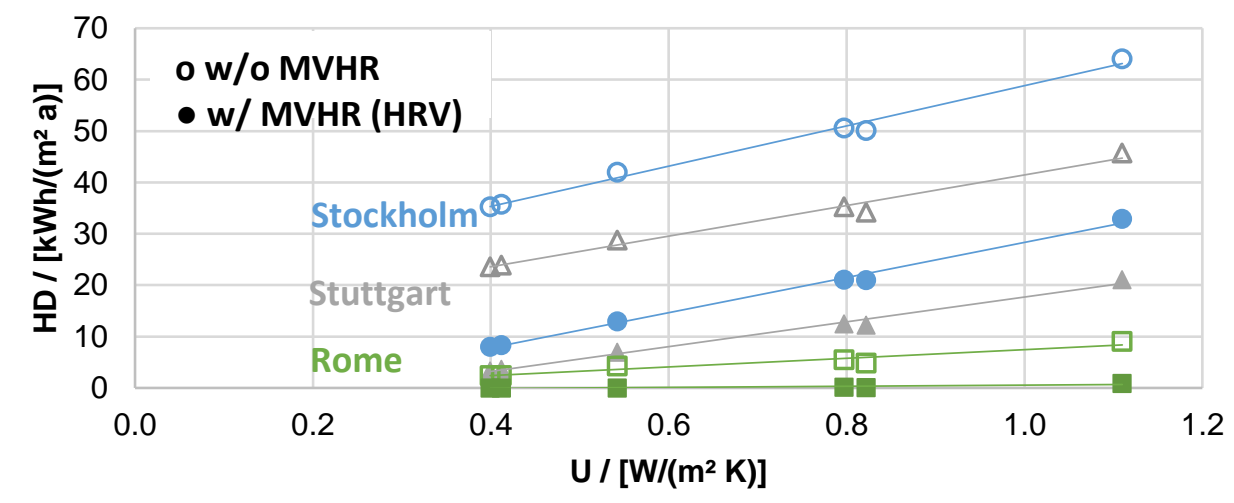

Figure 2-24: Heating demand (HD) vs. overall heat transfer coefficient (U) for the three climates, with and without mechanical ventilation with heat recovery (MVHR), fluorescent lights

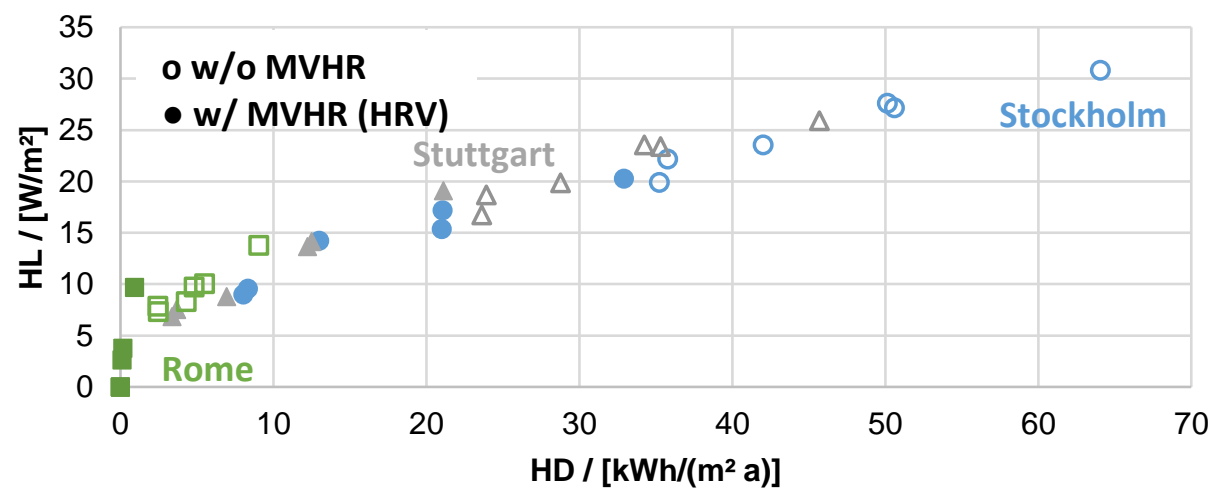

Figure 2-25: Heating Load (HL) vs. Heating Demand (HD) for Rome, Stuttgart and Stockholm with and without MVHR, fluorescent lights 


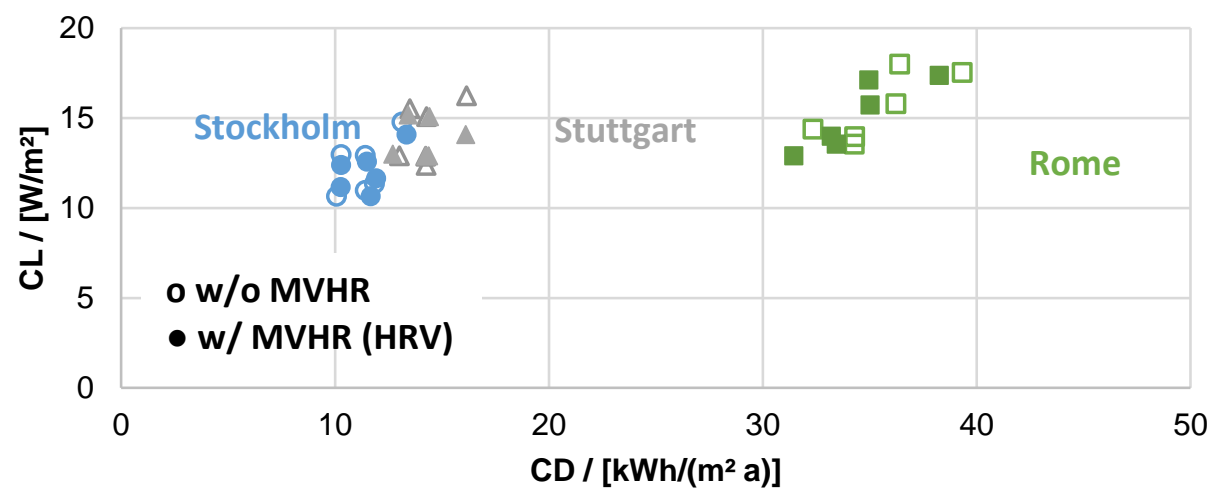

Figure 2-26: Cooling Load (HL) vs. Cooling Demand (HD) for Rome, Stuttgart and Stockholm with and without MVHR, fluorescent lights

The useful energy (heating and DHW) is summarized in Figure 2-27 for the three different climates, with and without MVHR (HRV/ERV). Figure 2-28 reports the cooling demand (useful energy). The cooling demand decreases by approx. $4 \mathrm{kWh} /\left(\mathrm{m}^{2}\right.$ a) in case of LED in Stockholm and Stuttgart and by approx. $8 \mathrm{kWh} /\left(\mathrm{m}^{2}\right.$ a) in Rome. The corresponding electric energy demand is presented in Figure 2-29 for fluorescent lights and in Figure 2-30 for LED lights and each with and without heat pump.

With LED instead of fluorescent lights, the internal gains reduce, influencing the heating and the cooling demand. However, the main effect is obviously the reduced electricity required for lighting. 

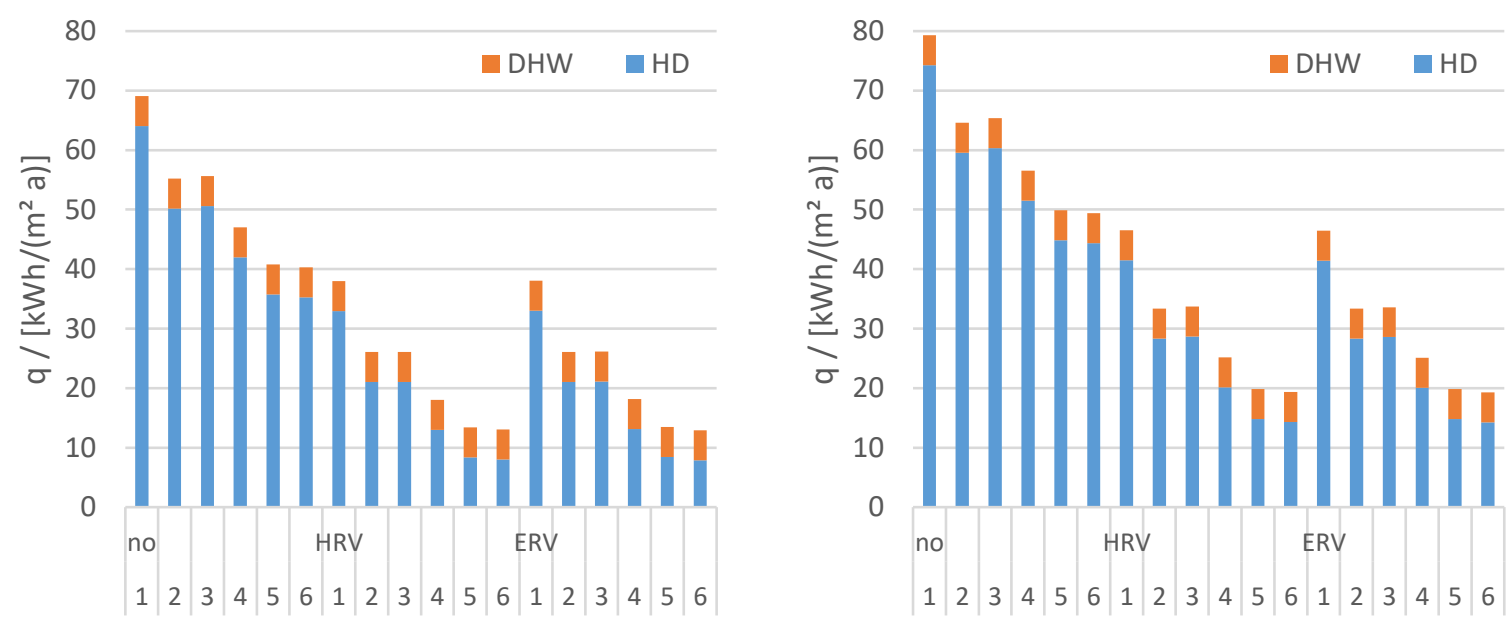

( a )
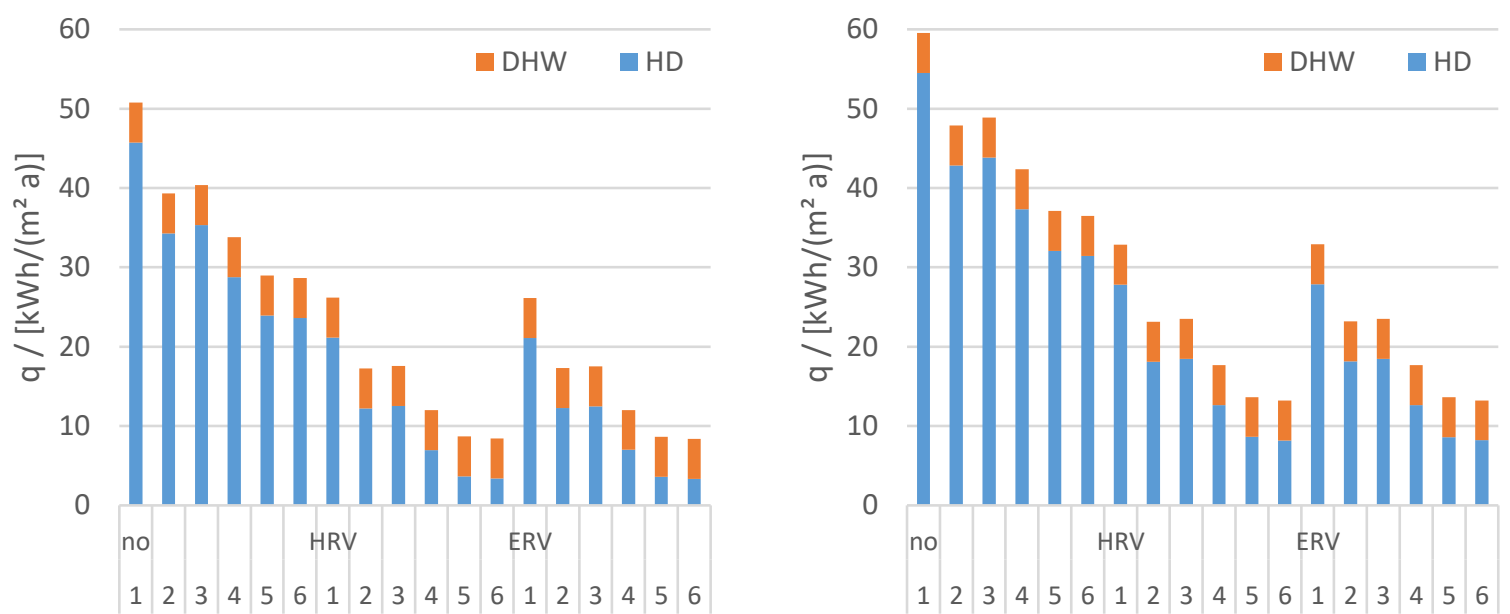

(b)
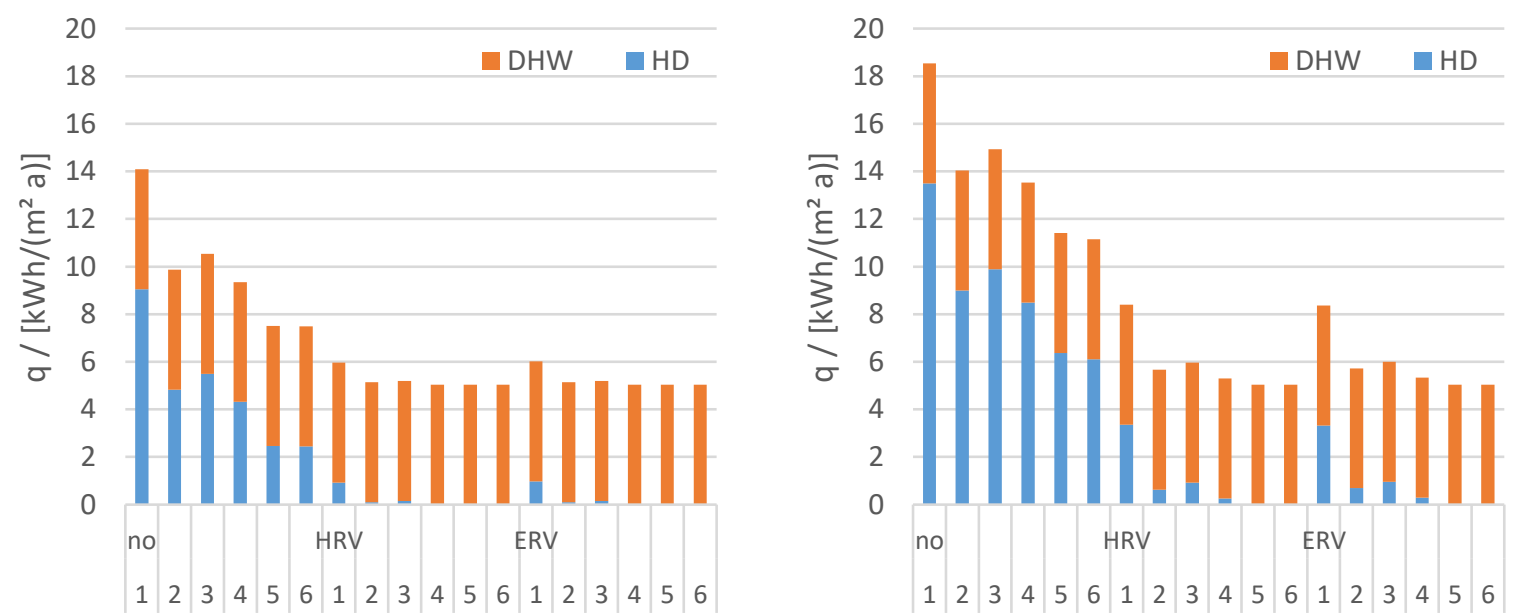

(c)

Figure 2-27: Annual Useful Energy (UE) for Heating (HD) and Domestic Hot Water (DHW) for the investigated cases in the three climates (Stockholm (a), Stuttgart (b), Rome(c)), fluorescent lights (left) LED lights (right); no: no MVHR, envelope quality 1 to 6 according to Table 2-7 

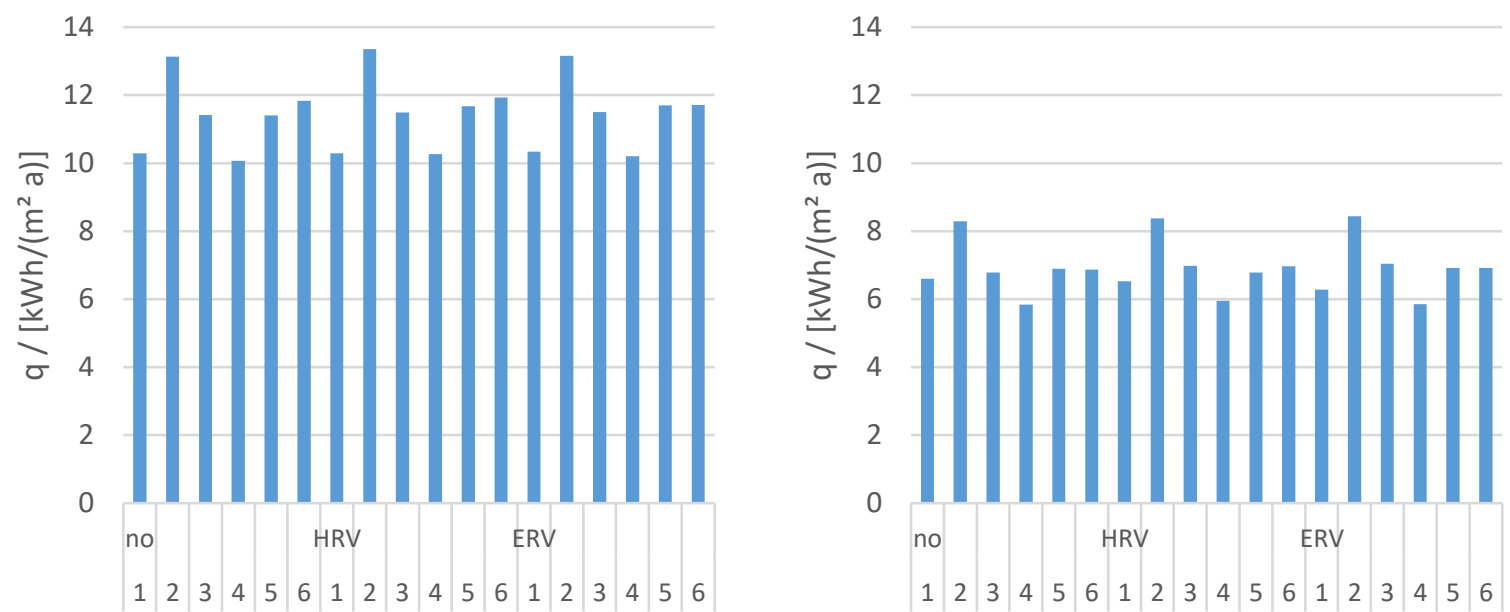

( a )
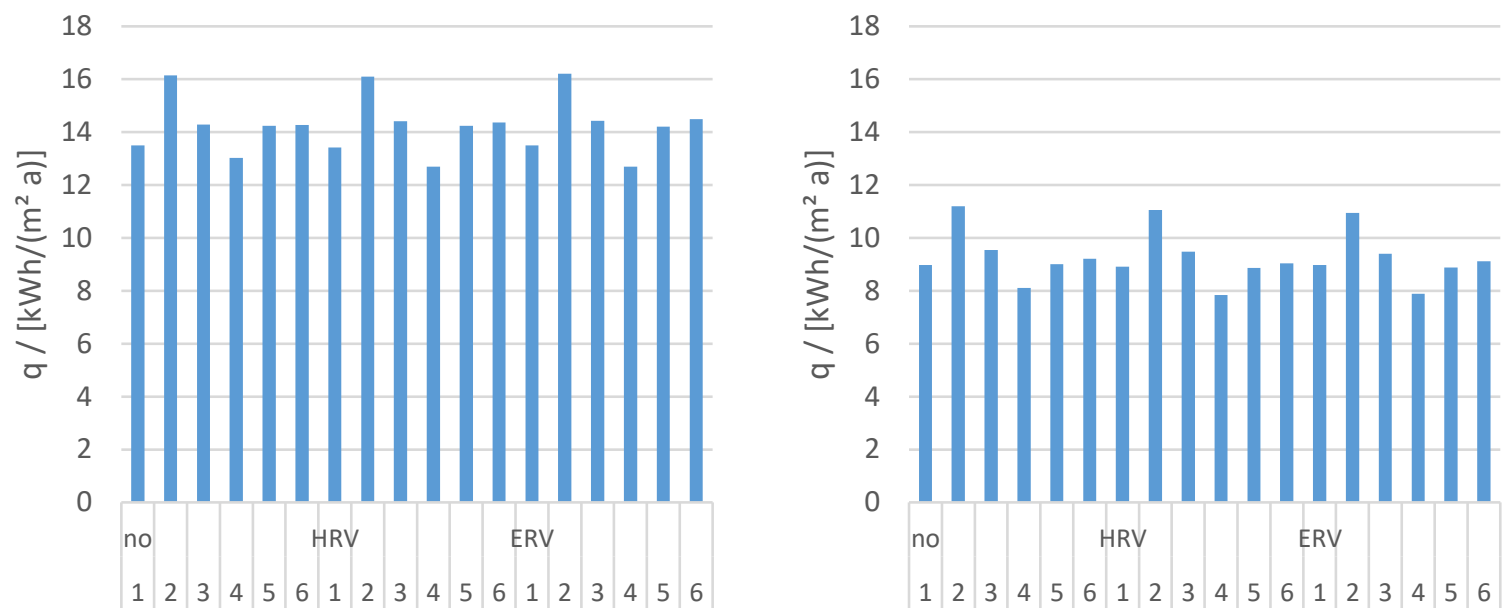

(b)
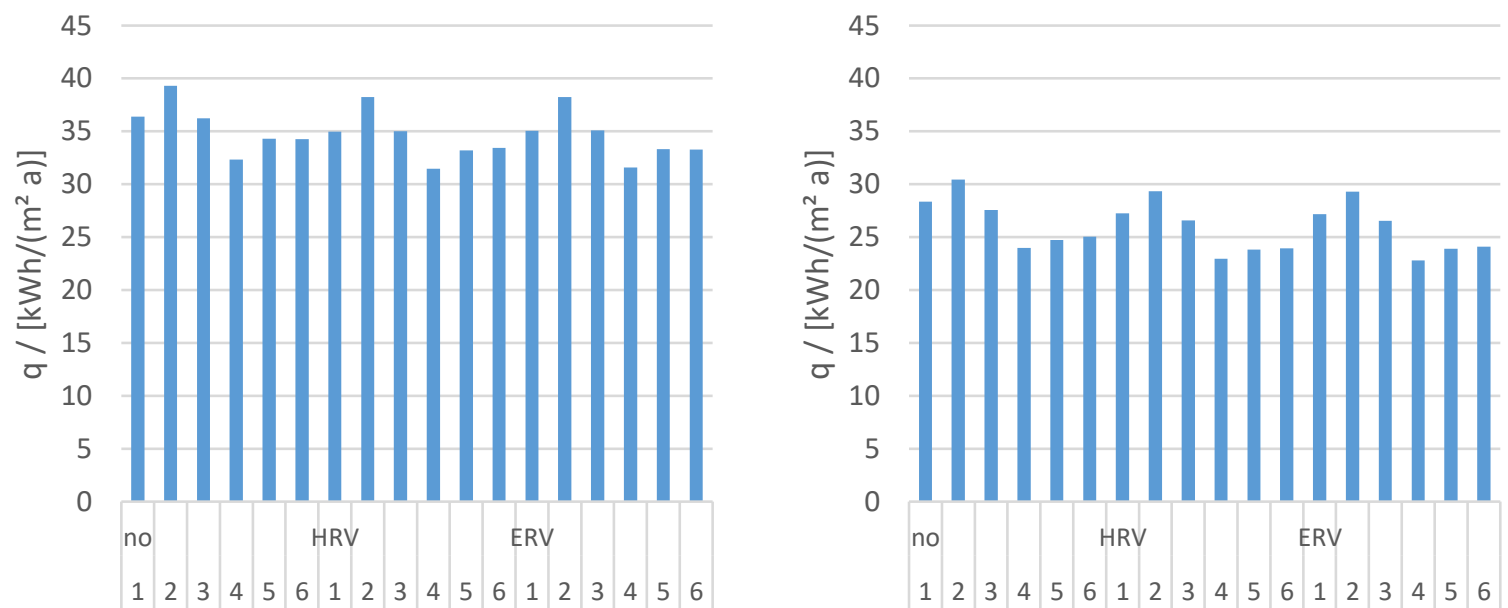

(c)

Figure 2-28: Annual Useful Energy (UE) for cooling for the investigated cases in the three climates (Stockholm (a), Stuttgart (b), Rome(c)), fluorescent lights (left), LED lights (right); no: no MVHR, envelope quality 1 to 6 according to Table 2-7 


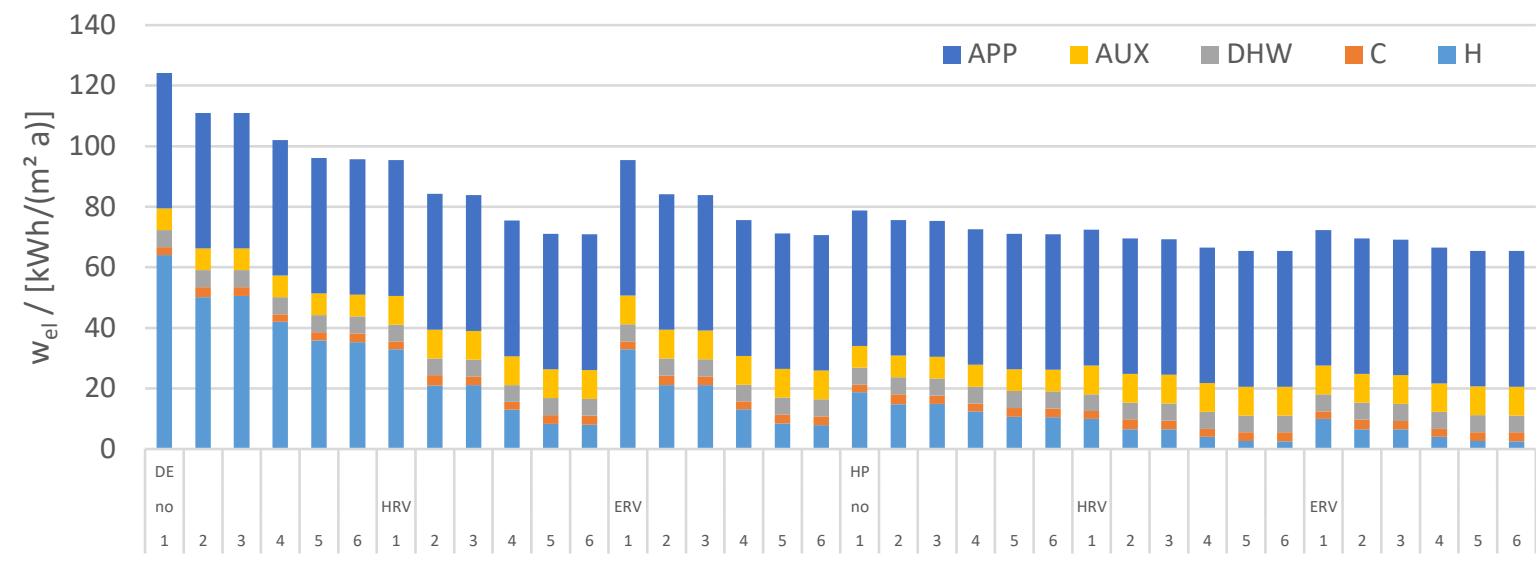

( a )

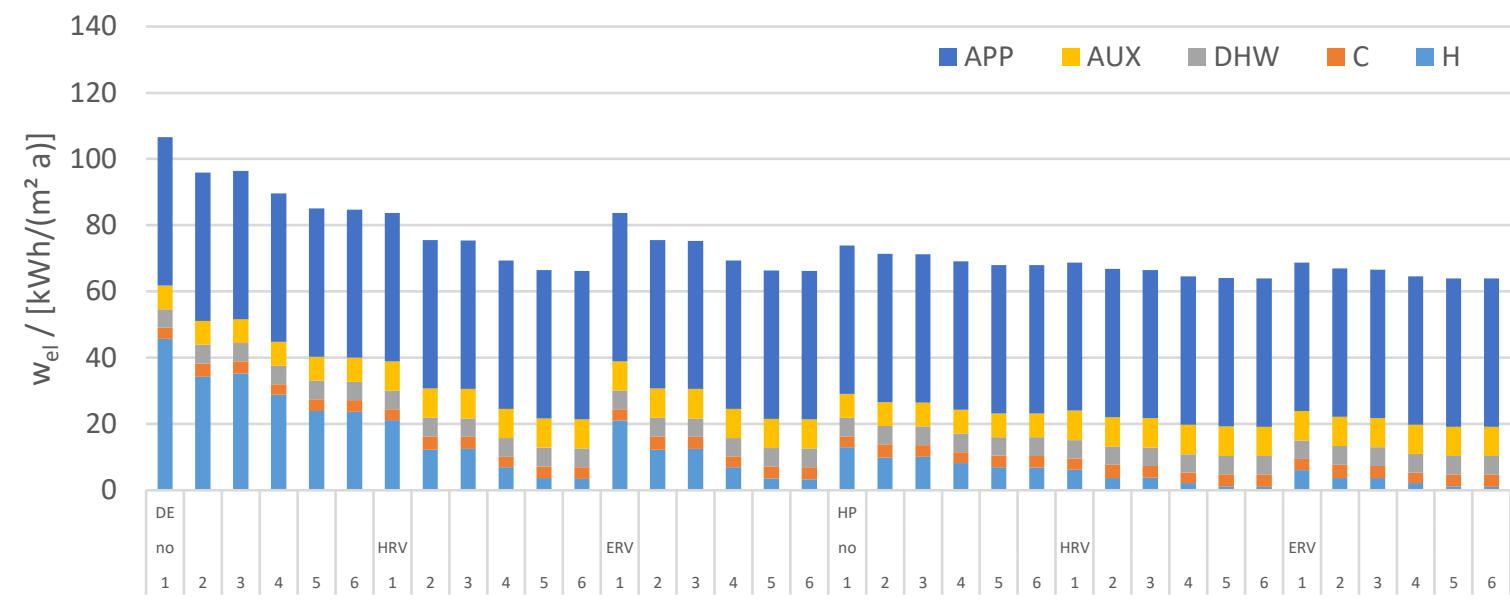

(b)

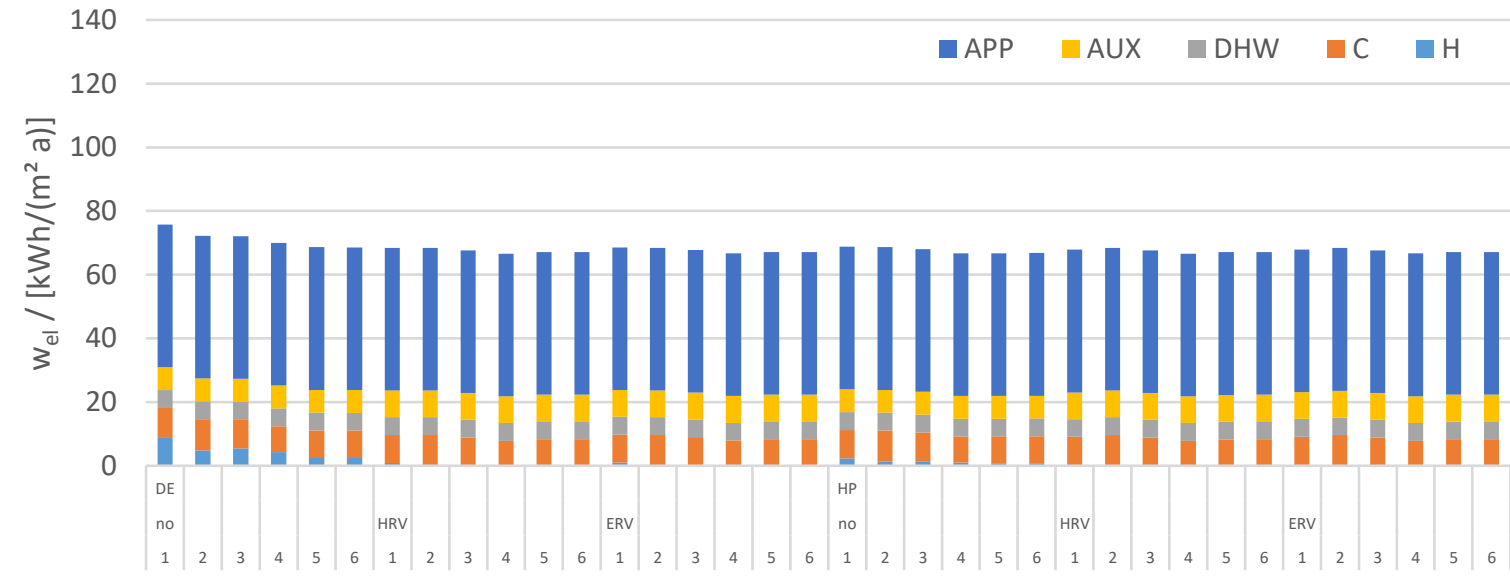

(c)

Figure 2-29: Annual Delivered (electric) Energy (DE) for the investigated cases in the three climates (Stockholm (a), Stuttgart (b), Rome(c)); appliances include lighting (fluorescent lights); no: no MVHR, envelope quality 1 to 6 according to Table 2-7 (H: Heating, DHW: domestic hot water, C: Cooling, APP: Appliances including lighting, AUX: auxiliary, HRV: heat recovery ventilaton, ERV: energy recoveryventilation, DE: direcrt electric, HP: heat pump) 


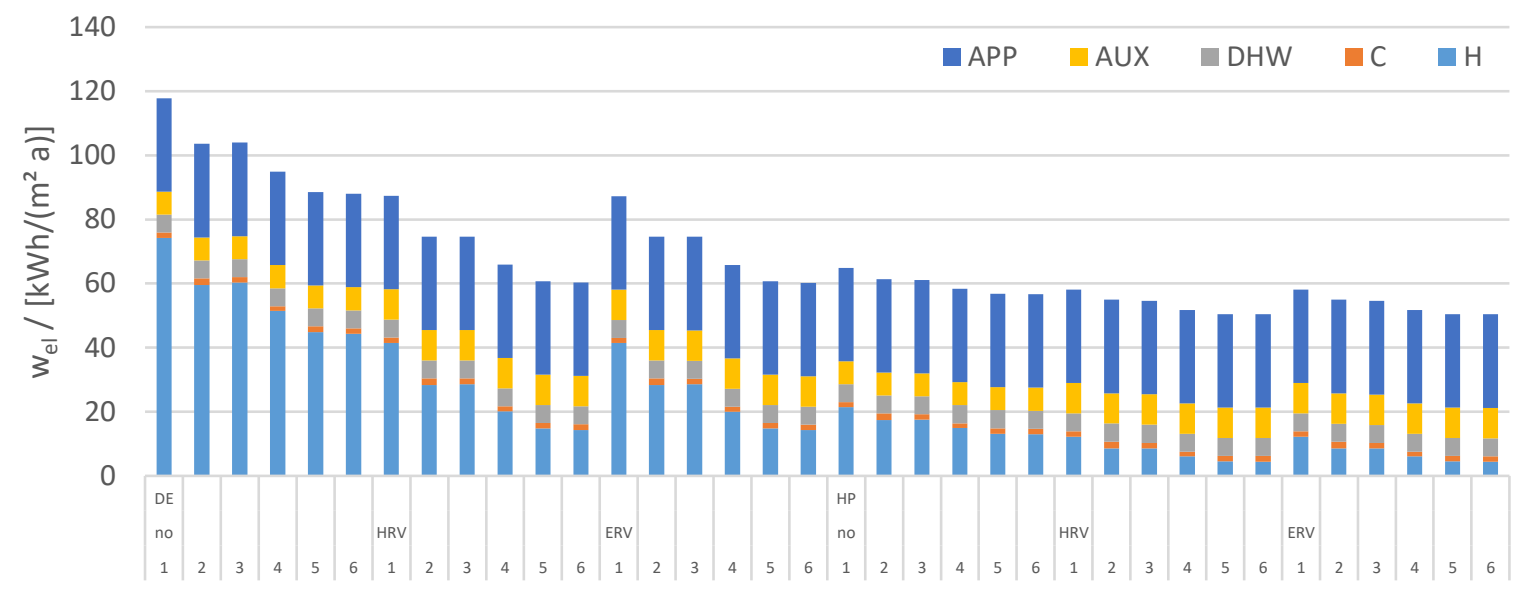

( a )

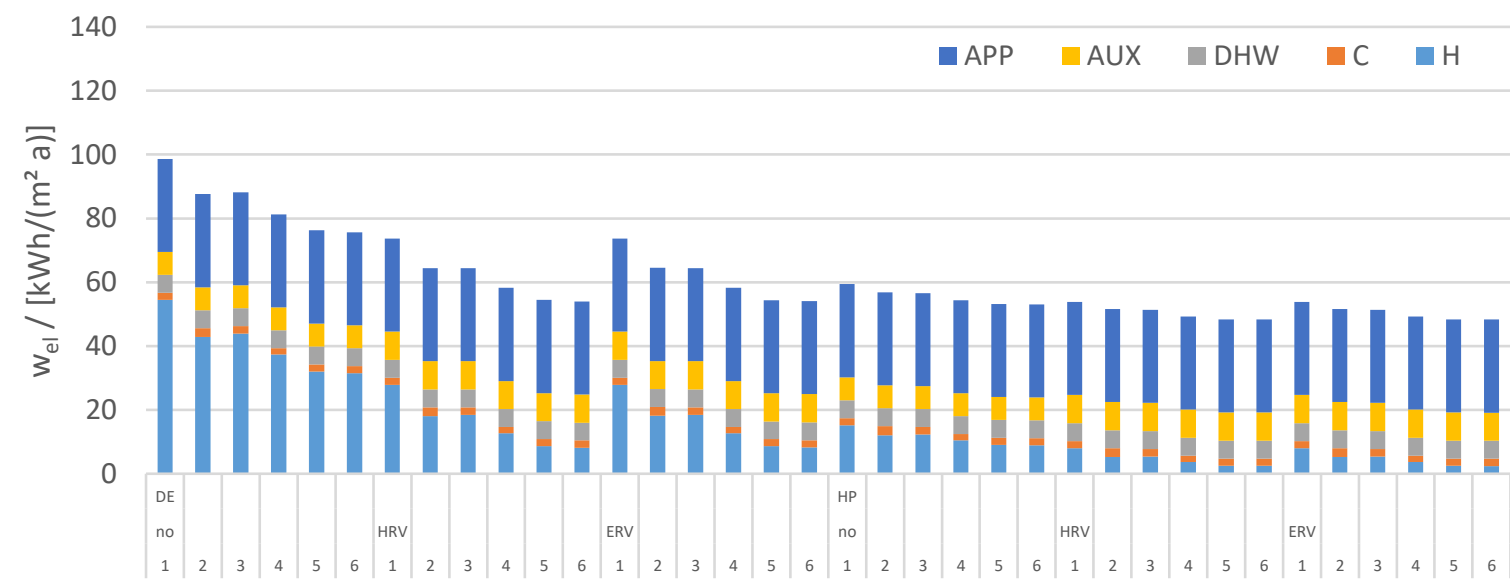

(b)

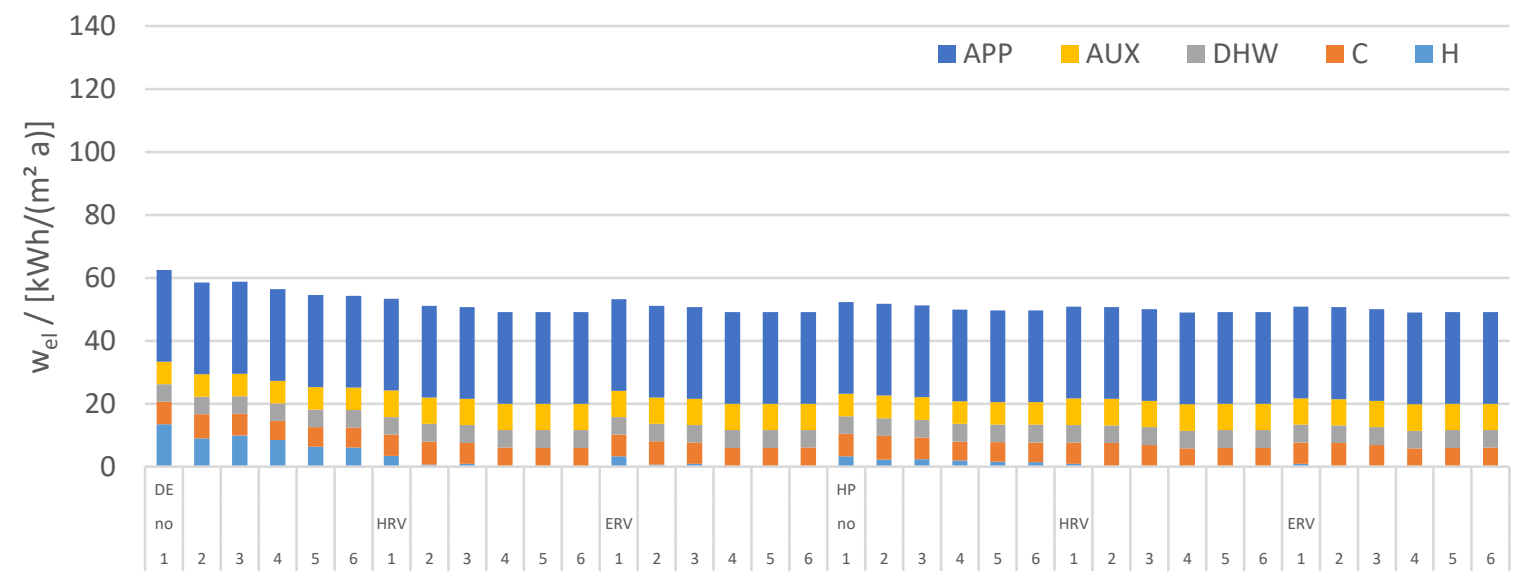

(c)

Figure 2-30: Annual Delivered (electric) Energy (DE) for the investigated cases in the three climates (Stockholm (a), Stuttgart (b), Rome(c)) for the case with LED, i.e. reduced electricity demand and internal gains; appliances include lighting; no: no MVHR, envelope quality 1 to 6 according to Table 2-7 


\section{Active Solar Façade (BIPV)}

For the office cell with the given share of opaque structures, the maximum available façade area is $5.4 \mathrm{~m}^{2}$ or approximately $0.89 \mathrm{~kW}_{\mathrm{p}}$. The maximum annual yield in Stockholm and Stuttgart is comparable and is $23.0 \mathrm{kWh} /\left(\mathrm{m}^{2} \mathrm{AT}\right.$ a) and $22.7 \mathrm{kWh} /\left(\mathrm{m}^{2} \mathrm{AT}\right.$ a), while in Rome $31.6 \mathrm{kWh} /\left(\mathrm{m}^{2} \mathrm{AT}\right.$ a) can be harvested from the sun. This applies for a treaded area of $A T=27 \mathrm{~m}^{2}$. Having a closer look on the monthly distribution, it can be seen in Figure 2-32, that there is a clear seasonal trend in Stockholm, while in Rome the peak PV electricity yield is in March and October. It can be concluded that the potential of the BIPV to contribute to heating is very limited in Stockholm, instead a significant share can be expected Rome. Overall, due to the small available façade surface $5.4 \mathrm{~m}^{2}$ with respect to the treated area $\left(27 \mathrm{~m}^{2}\right)$ the potential contribution of solar to the total energy demand is limited. Nevertheless, this means that there is a high potential for share of PV own-consumption.

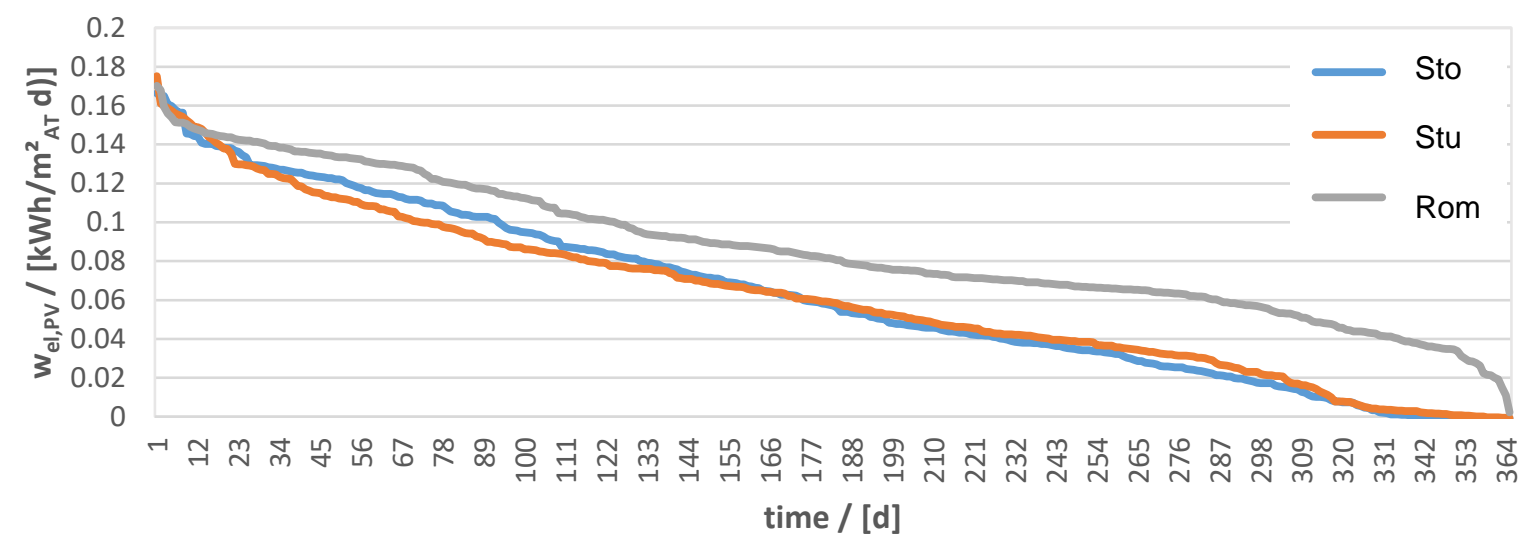

Figure 2-31: Sorted daily specific electricity yield from façade integrated PV in the office reference cell (5.4 $\mathrm{m}^{2}$ of PV) for the three climates (Sto: Stockholm, Stu: Stuttgart, Rom: Rome)

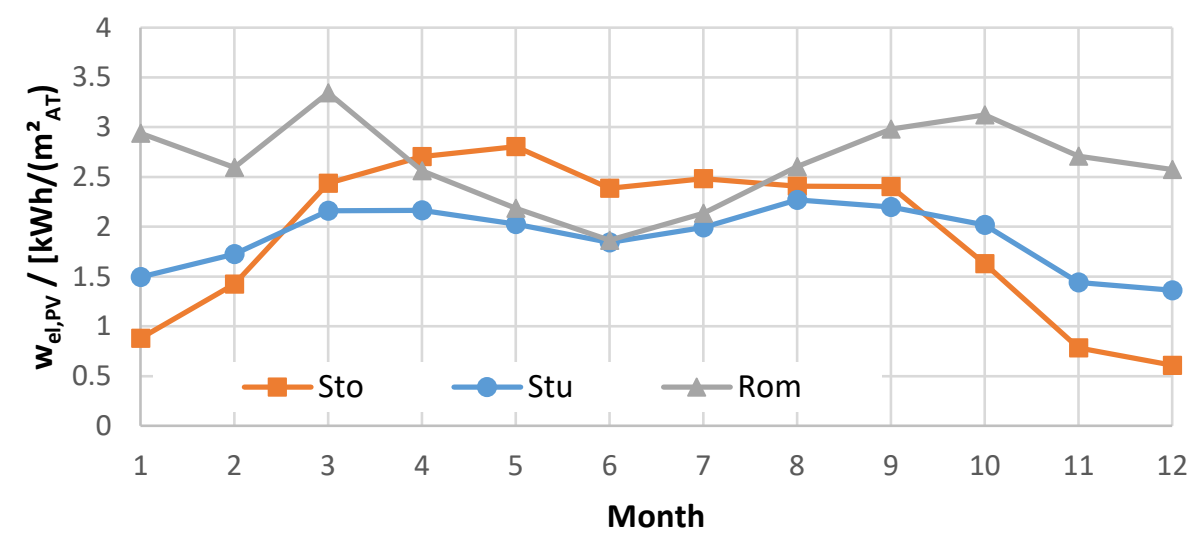

Figure 2-32: Monthly specific electricity yield from façade integrated PV in the office reference cell (5.4 $\mathrm{m}^{2}$ of PV)

The supply cover factor is in the range of SCF $=70 \%$ for all cases and all climates with little variation. The load cover factor varies widely with climate and building electricity demand and ranges from $15 \%$ (Stockholm, poor performance building) to $50 \%$ in Rome (high performance building). 


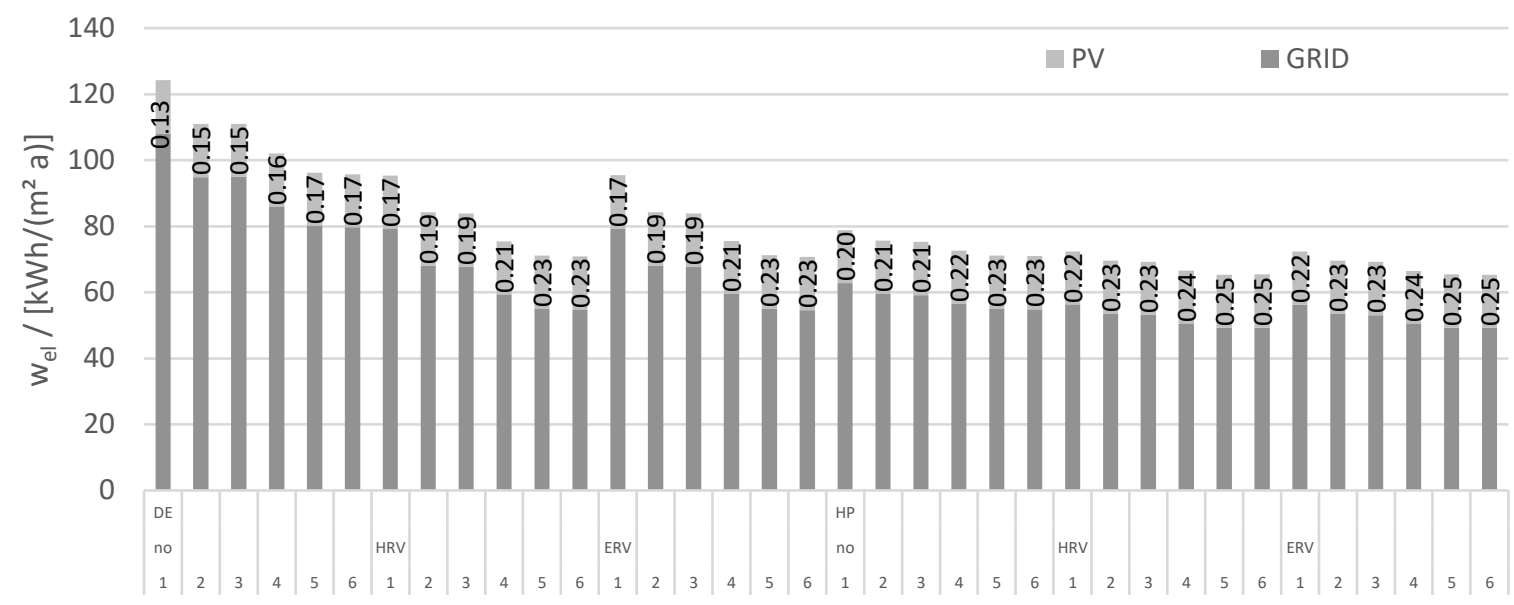

(a)

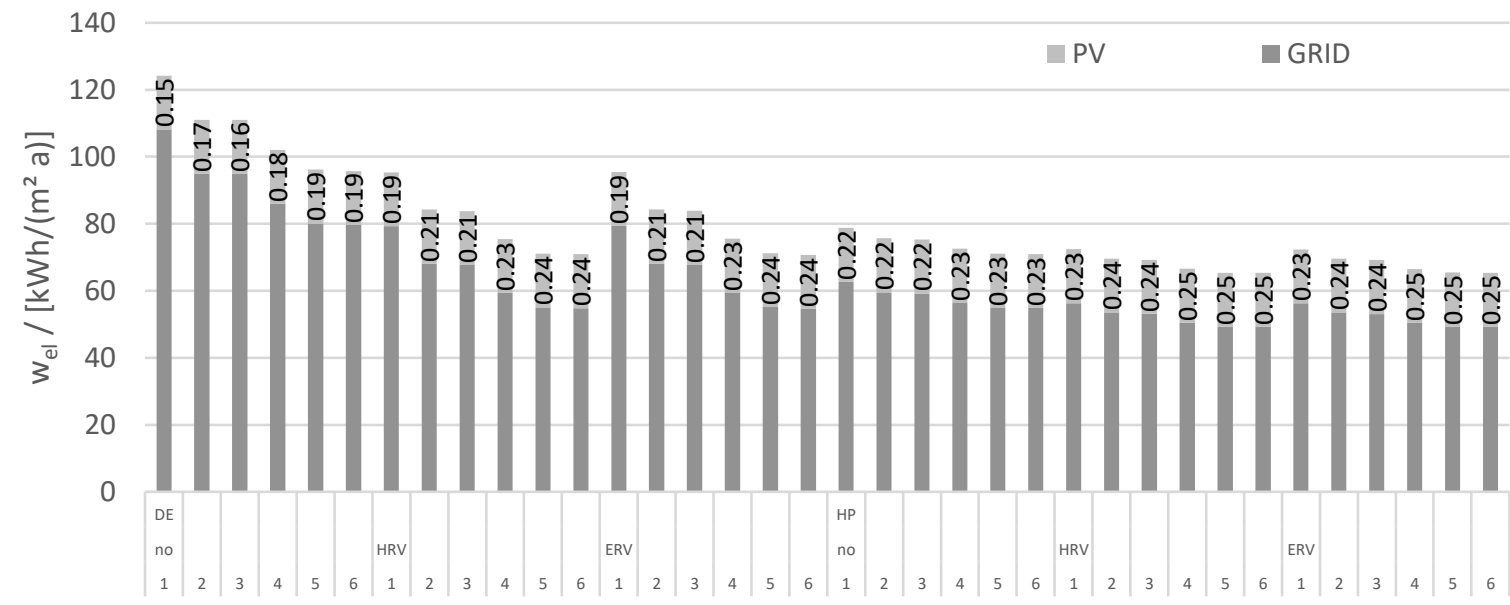

(b)

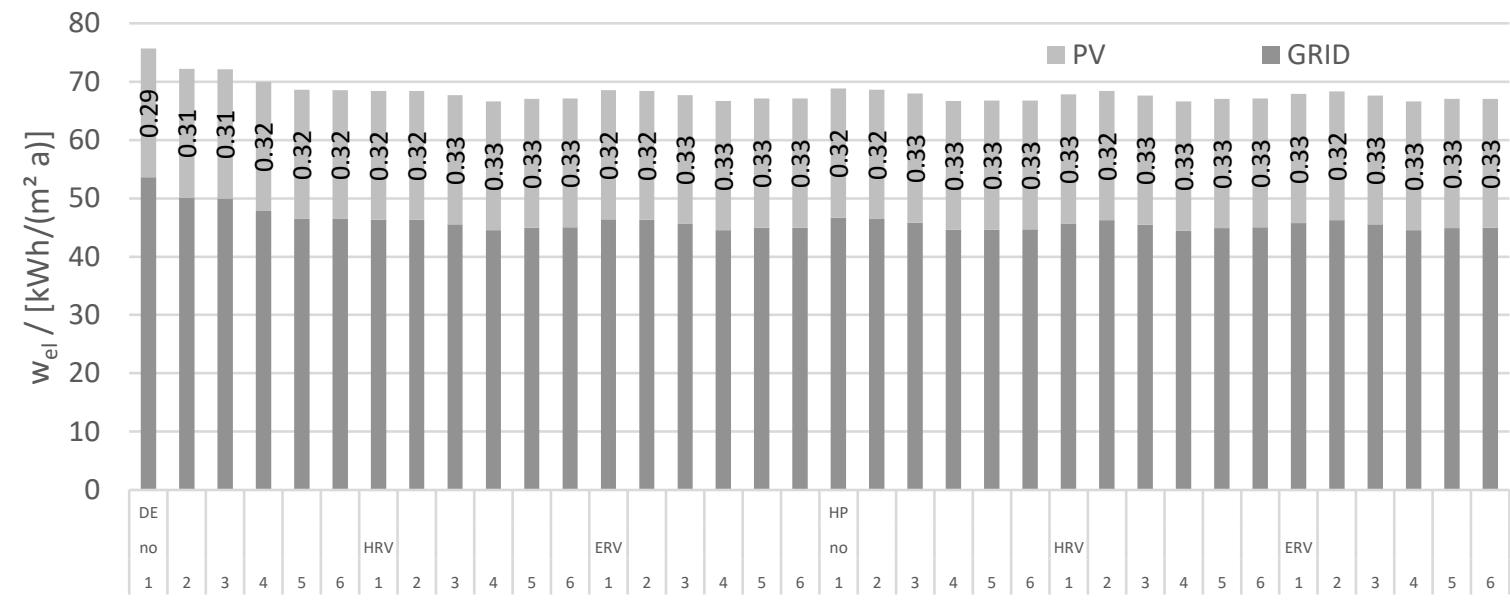

(c)

Figure 2-33: Annual grid electricity (i.e. total electricity - PV own consumption) for the investigated cases in the three climates (Stockholm (a), Stuttgart (b), Rome(c)) (fluorescent lighting); no: no MVHR, envelope quality 1 to 6 according to Table 2-7 


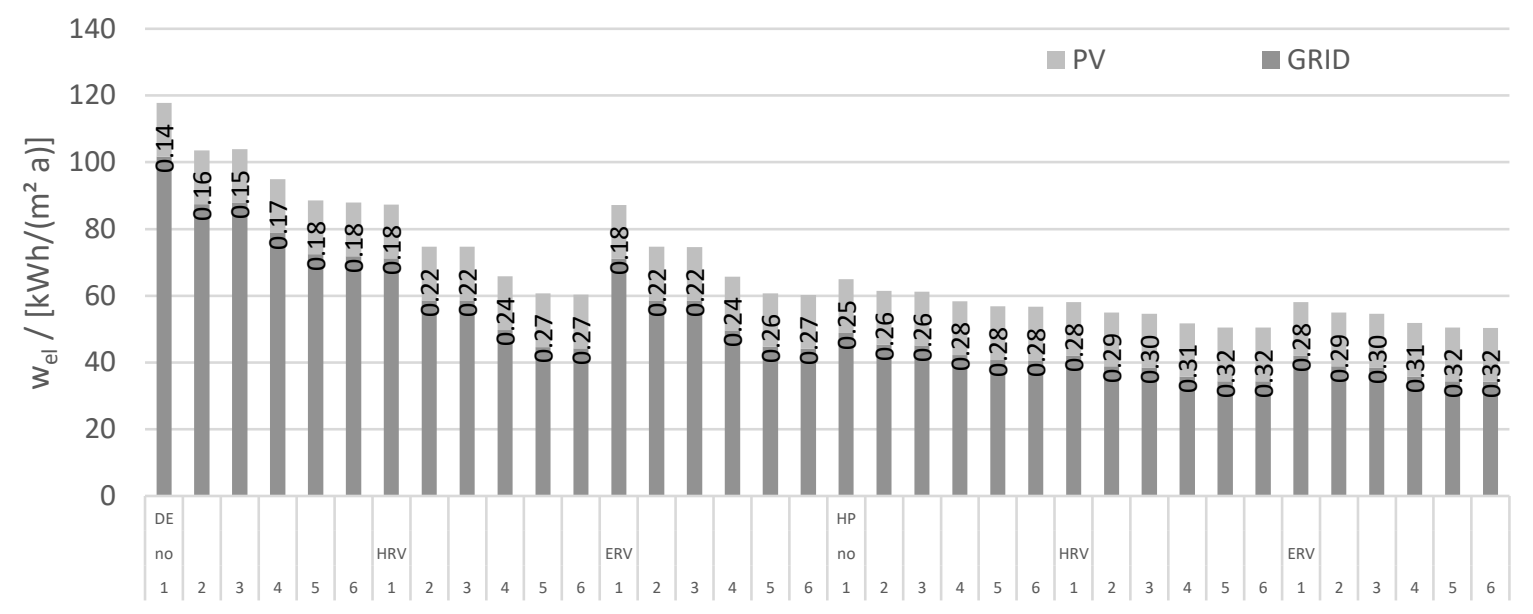

(a)

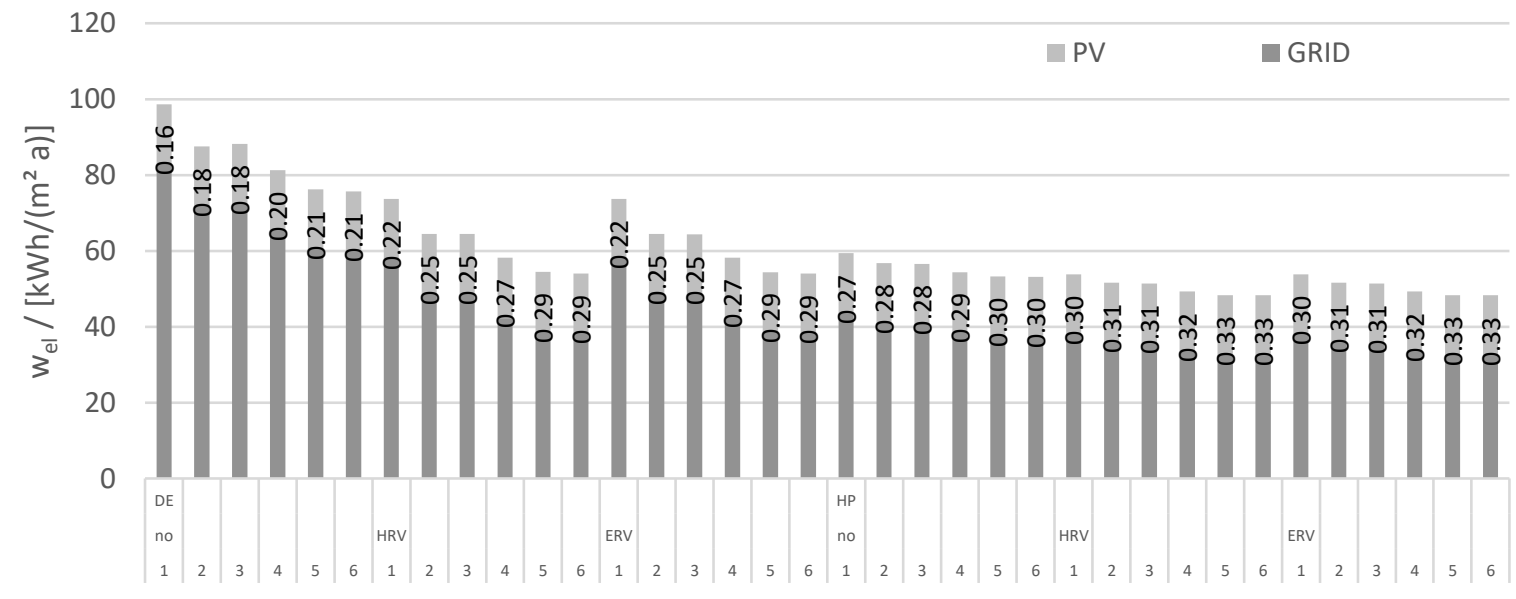

(b)

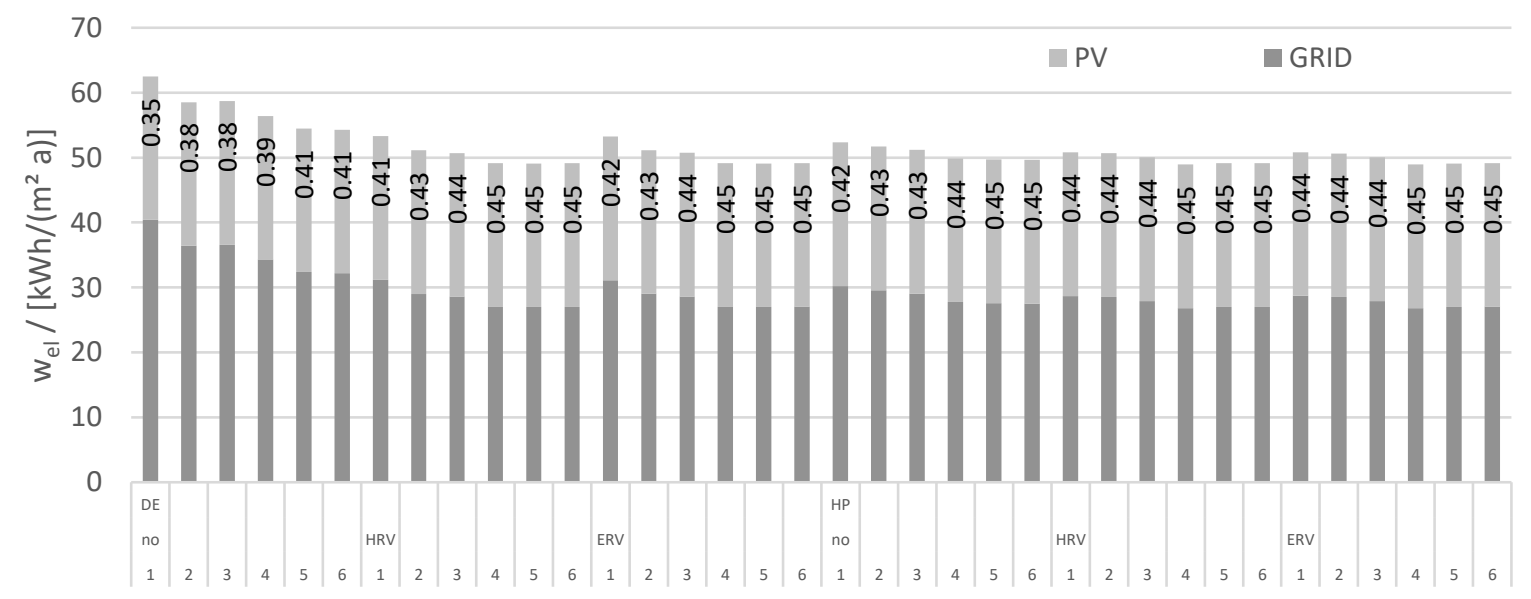

(c)

Figure 2-34: Annual grid electricity (i.e. total electricity - PV own consumption) for the investigated cases in the three climates (Stockholm (a), Stuttgart (b), Rome(c)) (LED lighting); no: no MVHR, envelope quality 1 to 6 according to Table 2-7 


\section{Peak Power}

Because of the relative small PV area $\left(5.4 \mathrm{~m}^{2}\right)$ with respect to the treated area $\left(27 \mathrm{~m}^{2}\right)$ and the relative high loads of the office cell, the PV does not introduce stress to the grid (as shown previously, the SCF is in the range of 70 $\%$ ). However, load peak powers are relevant and can be significantly reduced with improving the building quality. The introduction of (BI)PV does not have relevant influence of the peak power. Peak powers can be derived from the following diagrams.

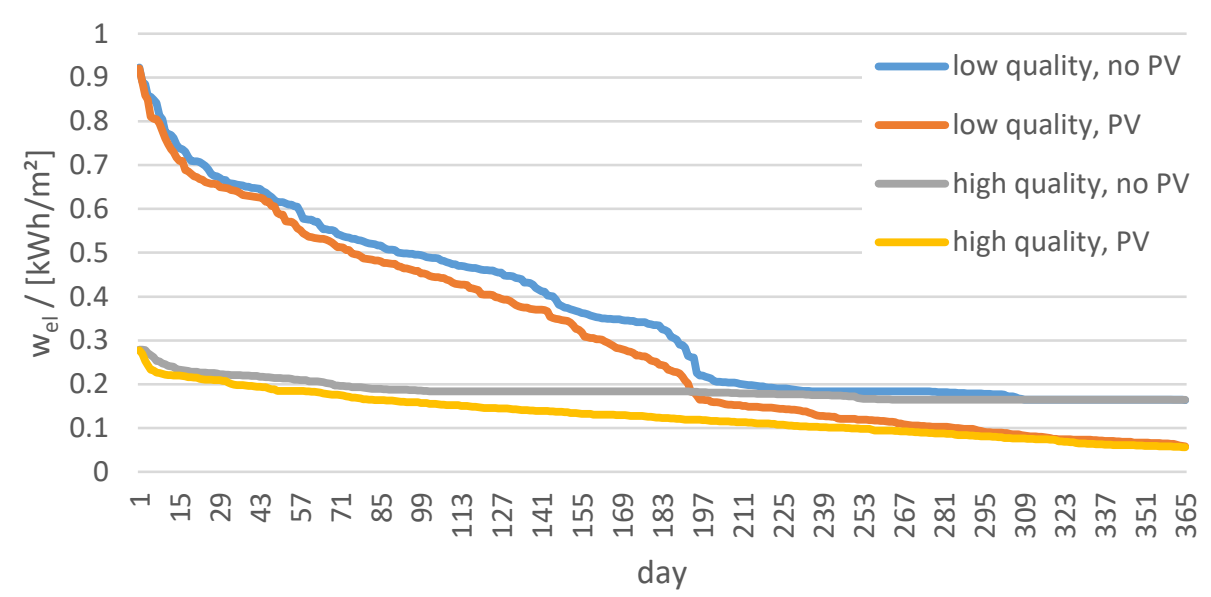

( a )

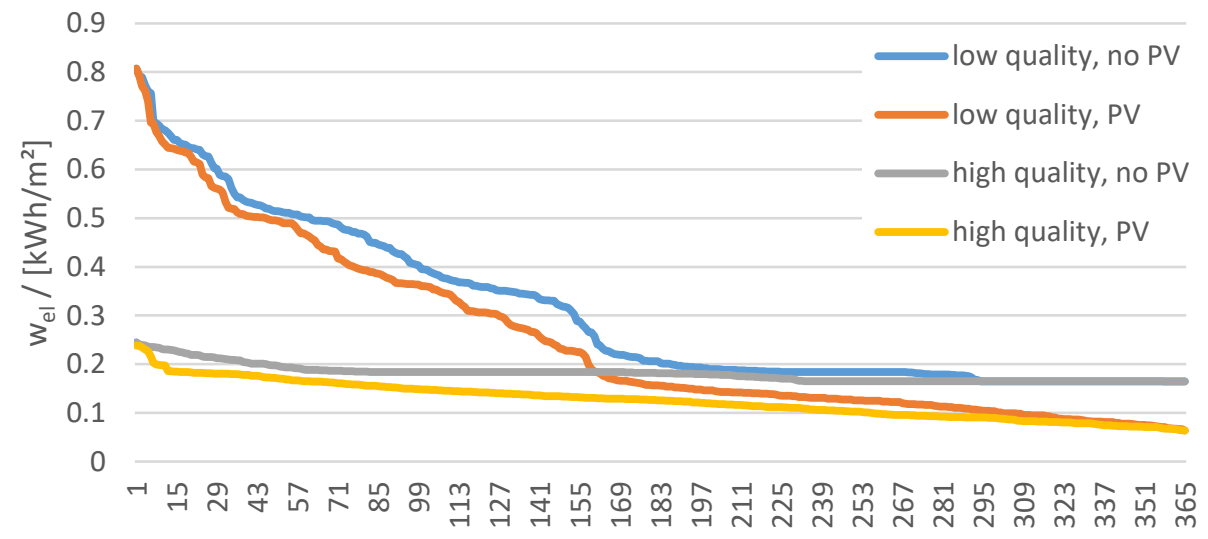

day

( b )

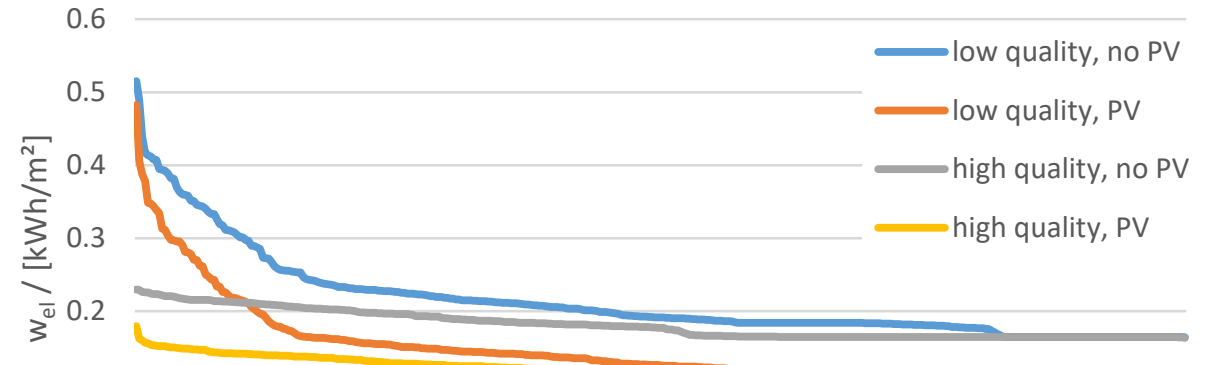

0.1

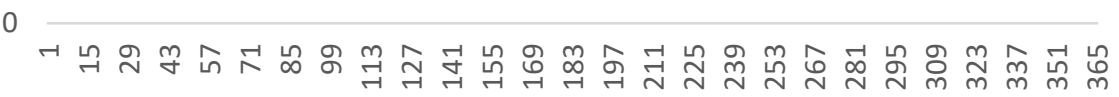
day

(c)

Figure 2-35: Load duration curves of grid electric energy (daily average) for the three climates (Stockholm (a), Stuttgart (b), Rome(c)) (fluorescent lighting) 


\section{Economic Parameters}

For the techno-economic analysis (annuity method, see D.C1), the following parameters are used.

Economic Parameter

- Period of Consideration

$\mathrm{N}=20$ yrs.

- Interest Rate (nominal)

$i=3 \%$

$» \quad$ Investment

- Envelope (Insulation)

$125 € / \mathrm{m}^{3}$

$\mathrm{L}=40 \mathrm{yrs}$.

- Envelope (Window) $75 € / \mathrm{m}^{2}$

$\mathrm{L}=50$ yrs.

- MVHR (HRV)

$3000 €$

$\mathrm{L}=15 \mathrm{yrs}$.

- MVHR (ERV)

$4500 €$

$\mathrm{L}=15$ yrs.

- A-HP

$2000 €$

$L=15$ yrs.

- BIPV

$3000 € / \mathrm{kW}_{\mathrm{p}}$

$L=15 \mathrm{yrs}$.

- LED

$940 €$

$L=15$ yrs.

- No incentives

»Operation

- Electricity

$\mathrm{Cel}_{\mathrm{el}}=0.25 € / \mathrm{kWh}$ (average over the period of consideration)

- Maintenance/Repair

$5 \%$ of investment

The capitalized annual costs (investment, operation, i.e. energy and maintenance) are plotted in the following figures for the investigated cases and the three climates. In Figure 2-36 is the case with fluorescent light without $\mathrm{PV}$, in Figure 2-37 with fluorescent light with PV and in Figure 2-38 with LED light without PV. 


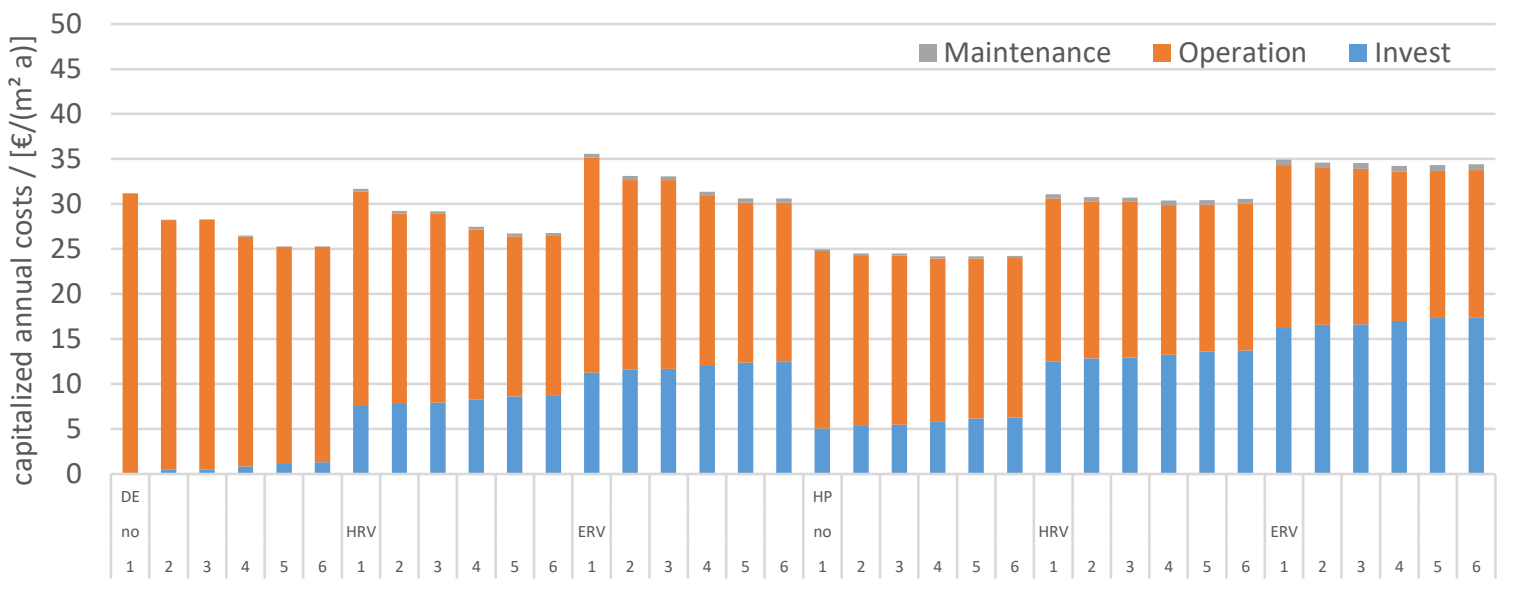

(a)

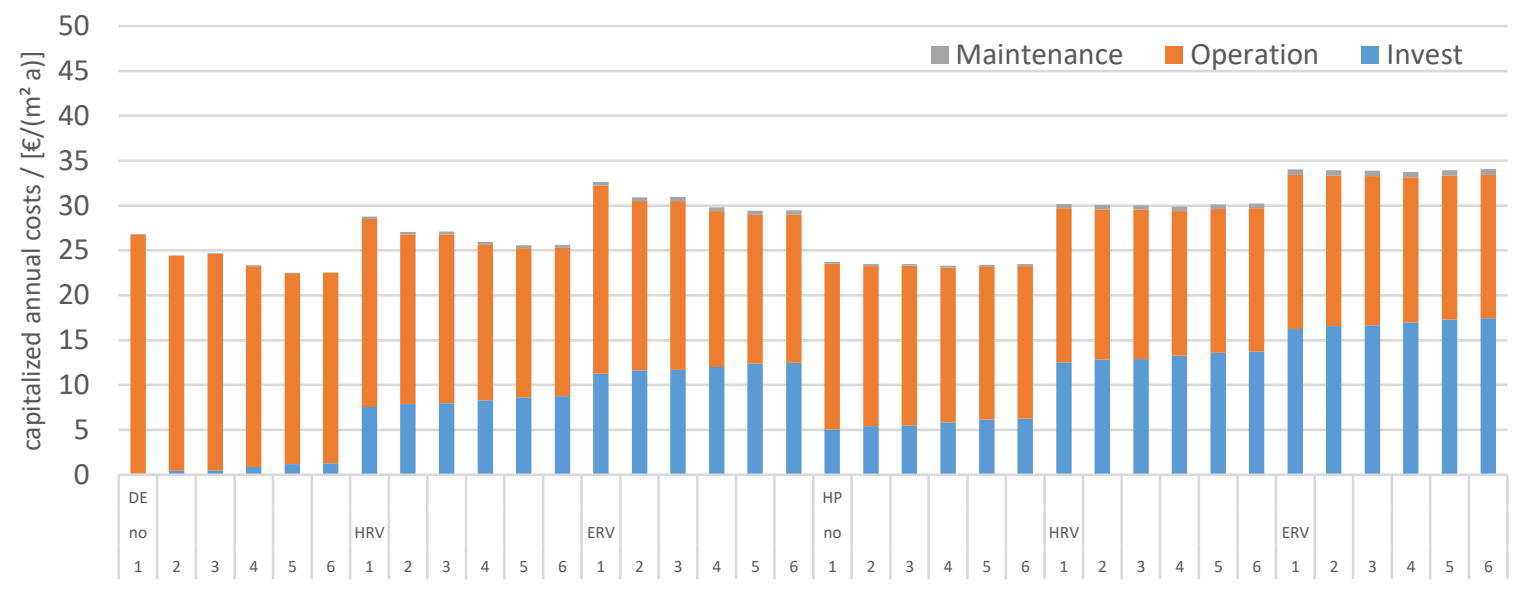

( b )

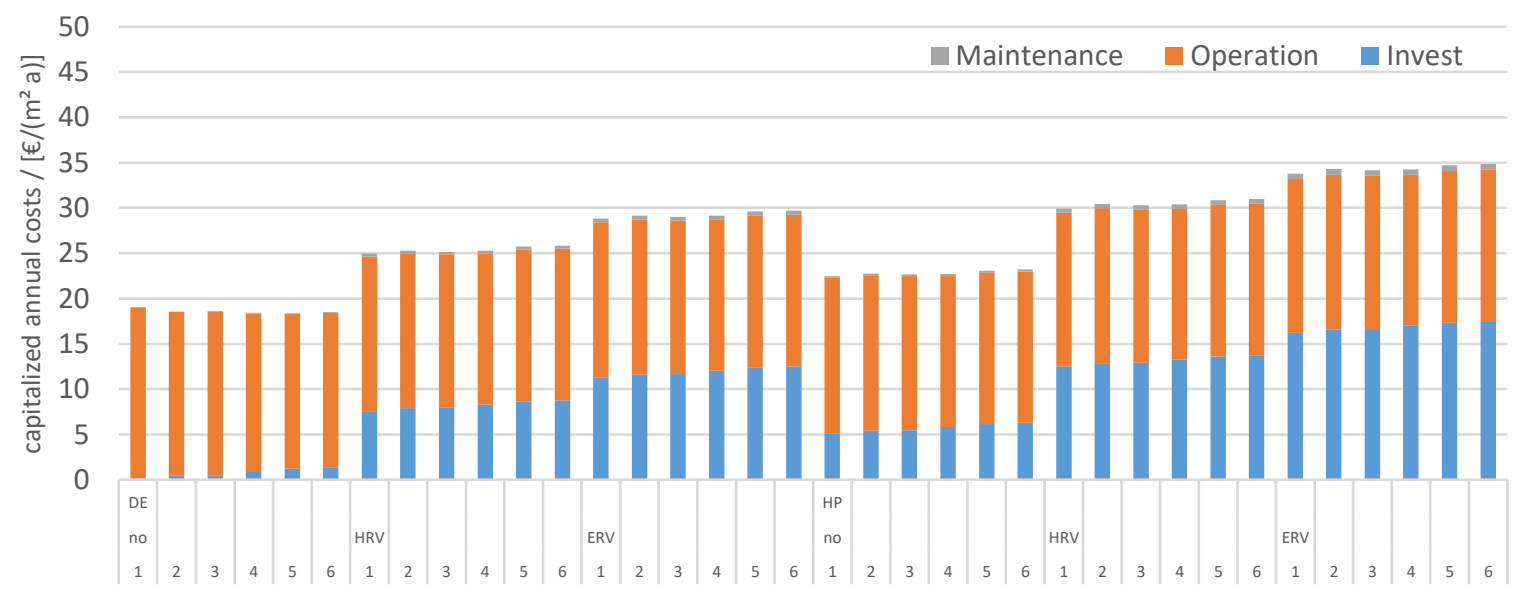

(c)

Figure 2-36: Capitalized annual costs (investment, operation and maintenance) for the investigated cases in the three climates (Stockholm (a), Stuttgart (b), Rome(c)); (fluorescent lighting); costs are given as difference costs to reference, i.e. low envelope quality, no MHVR, electric heating, no PV; no: no MVHR, envelope quality 1 to 6 according to Table 2-7 


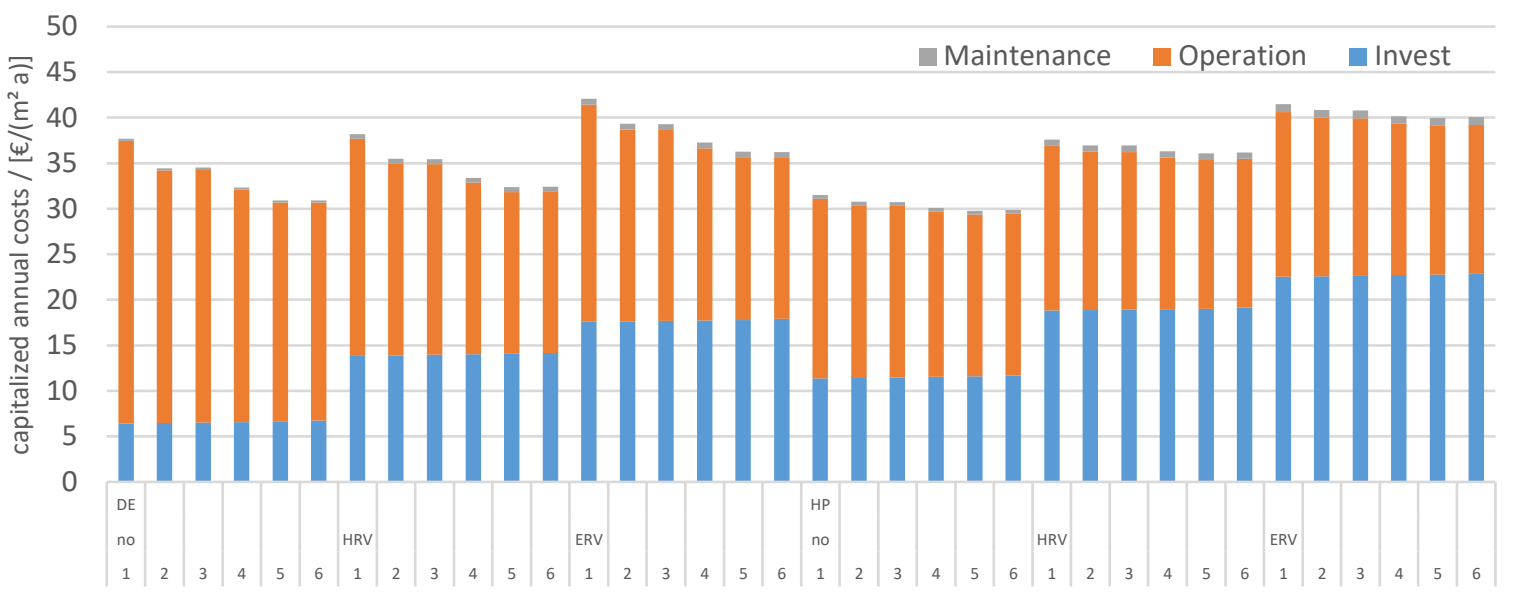

( a )

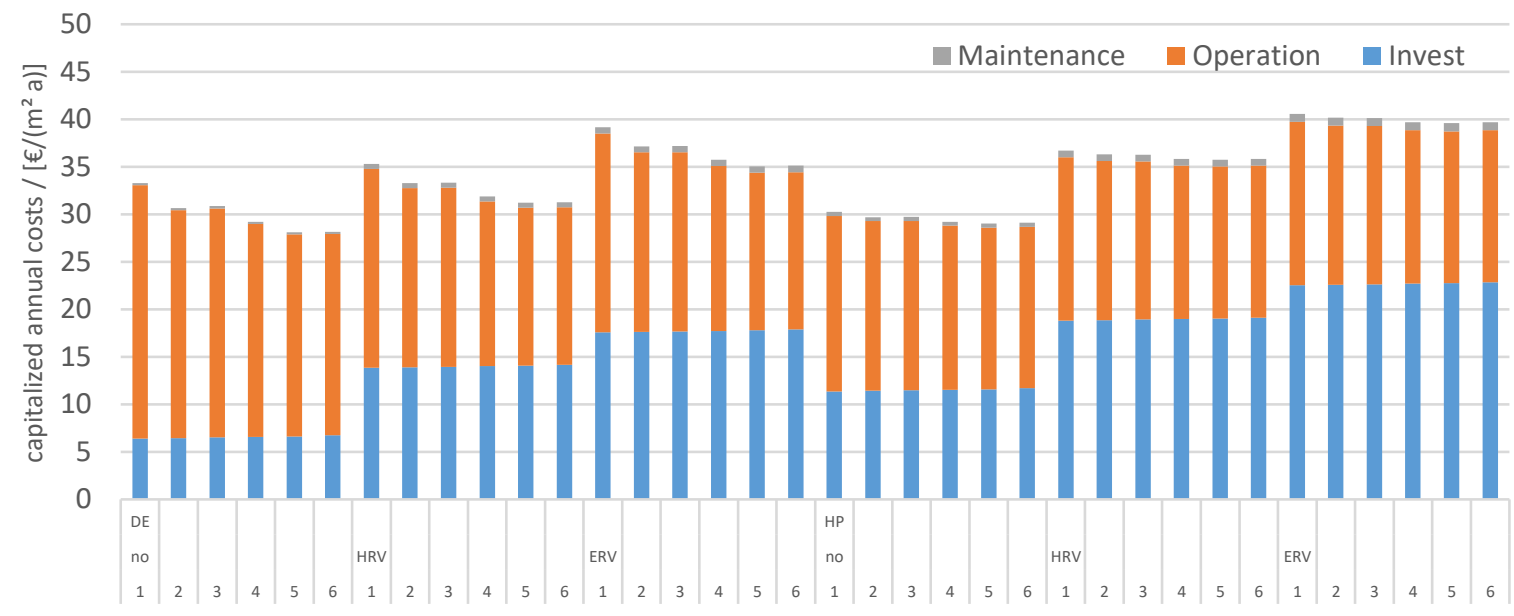

(b)

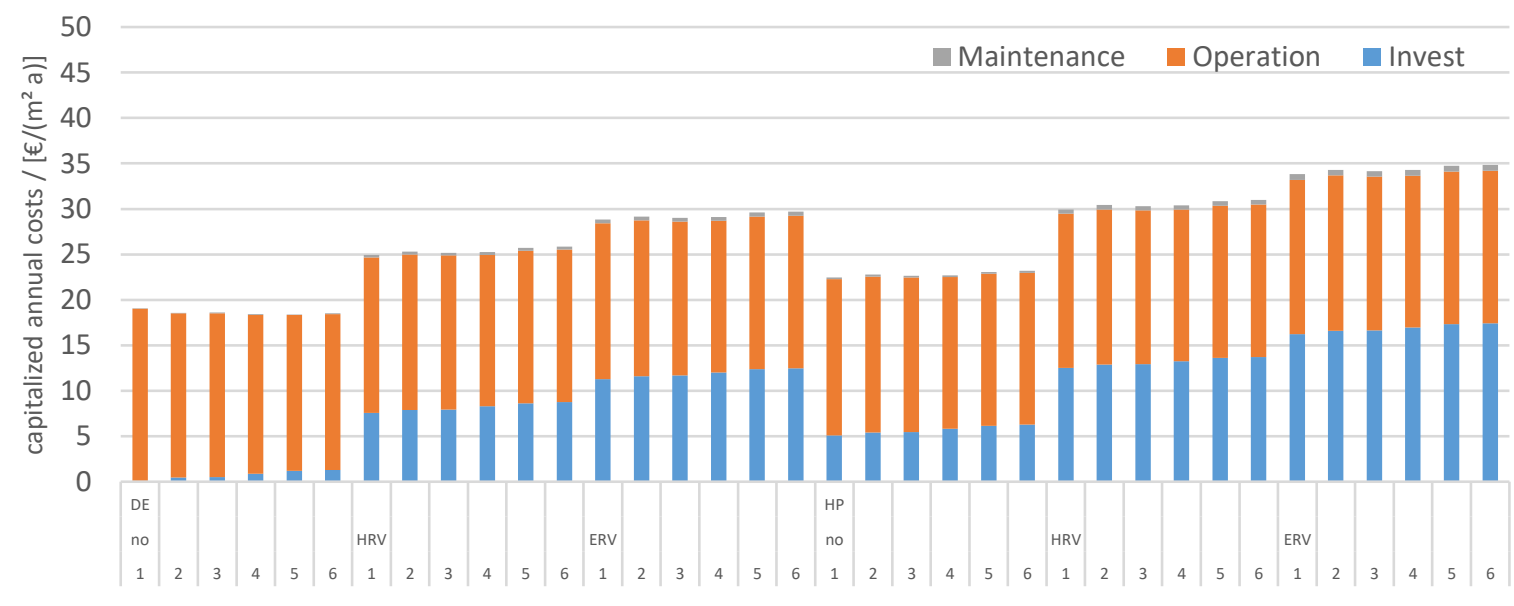

(c)

Figure 2-37: Capitalized annual costs (investment, operation and maintenance) for the investigated cases in the three climates (Stockholm (a), Stuttgart (b), Rome(c)); (fluorescent lighting); costs are given as difference costs to reference, i.e. low envelope quality, no MHVR, electric heating, with PV; ; no: no MVHR, envelope quality 1 to 6 according to Table 


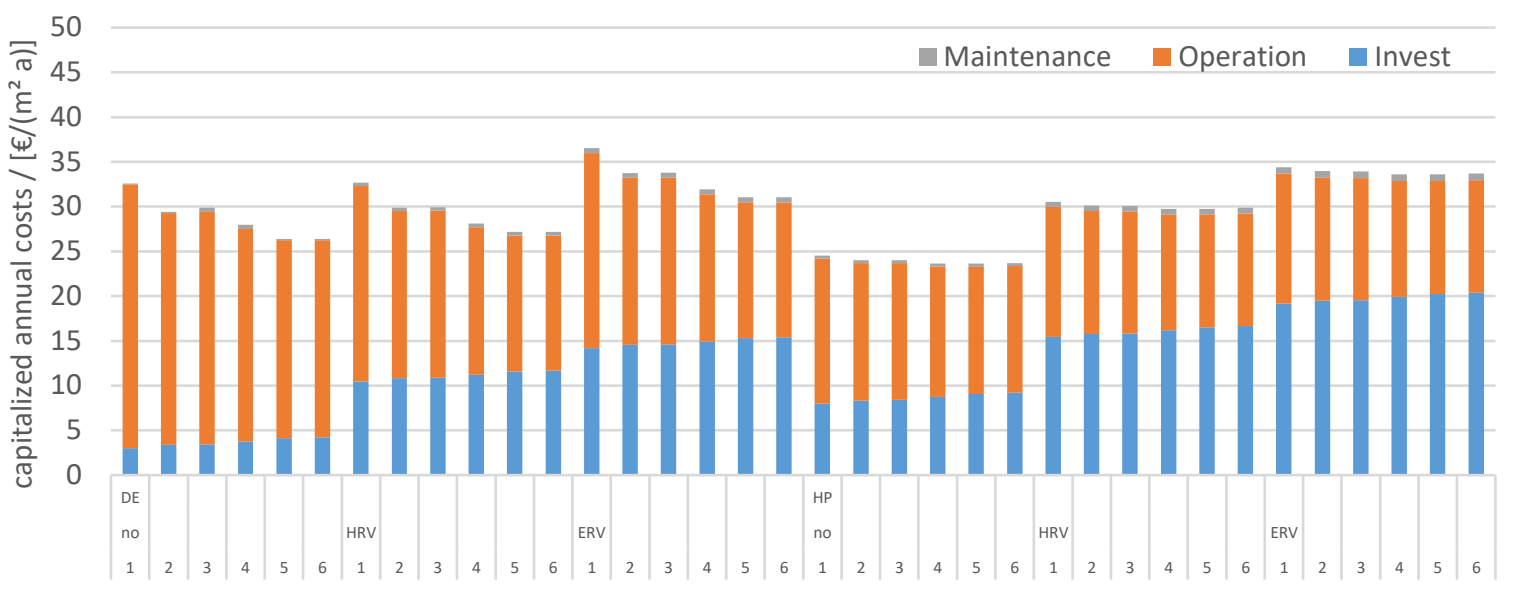

( a )

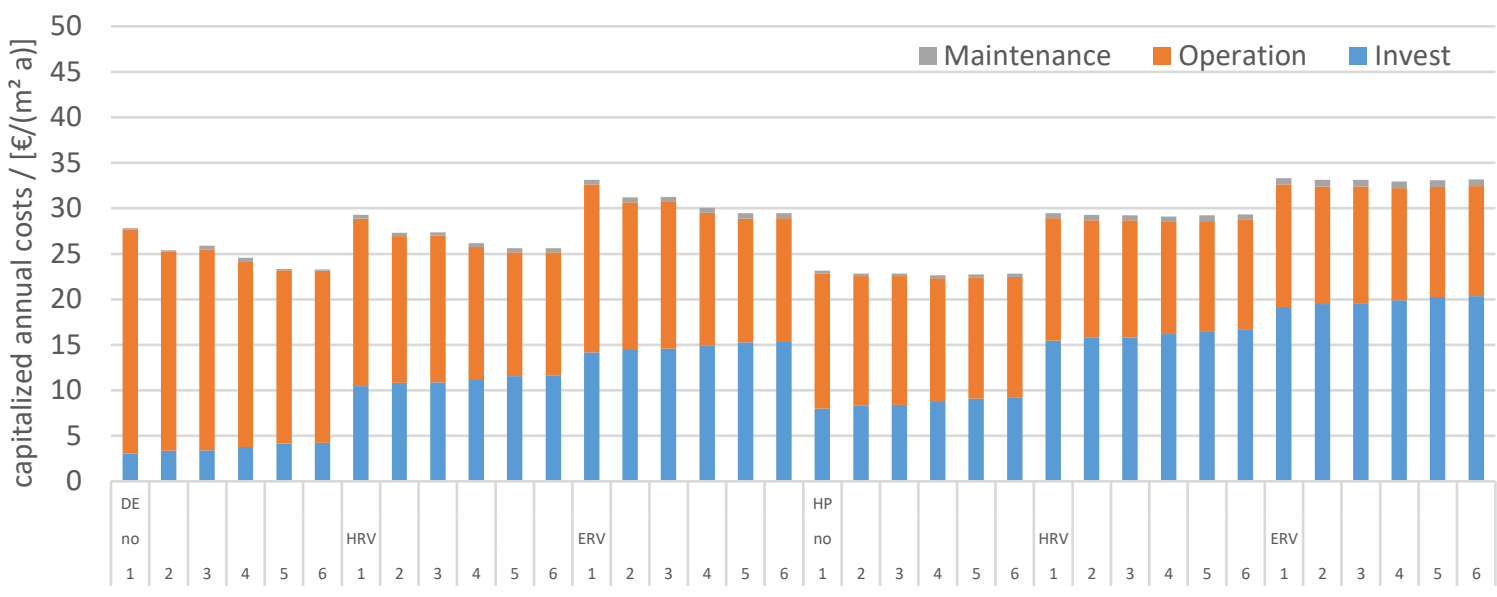

(b)

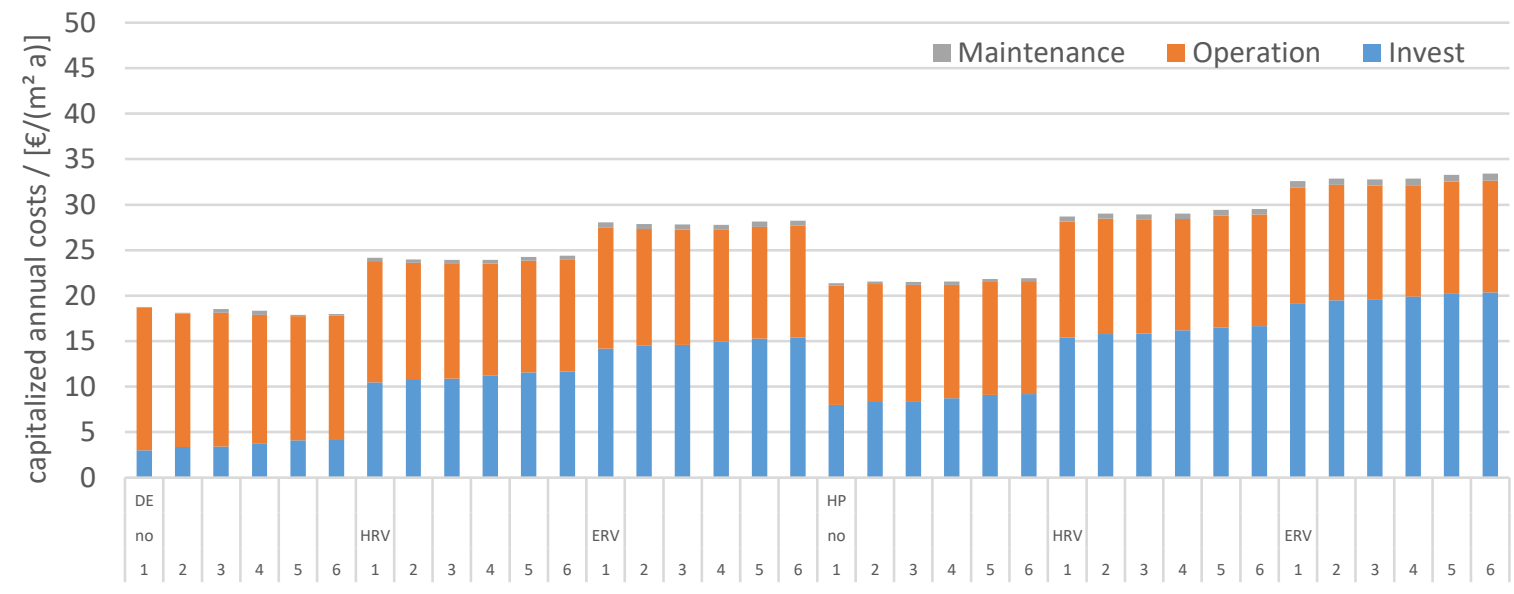

(c)

Figure 2-38: Capitalized annual costs (investment, operation and maintenance) for the investigated cases in the three climates (Stockholm (a), Stuttgart (b), Rome(c)); (LED lighting); costs are given as difference costs to reference, i.e. low envelope quality, no MHVR, electric heating, fluorescent lighting, no PV; ; no: no MVHR, envelope quality 1 to 6 according to Table 2-7 


\section{Cost-optimality}

With a non-renewable primary energy conversion factor of $f_{P E n R E}$ of 2.5 the primary energy ranges from more than $300 \mathrm{kWh}$ PEtot $/\left(\mathrm{m}^{2} \mathrm{a}\right)$ for the poor performing building in Stockholm down to $67 \mathrm{kWh}$ PEtot $/\left(\mathrm{m}^{2} \mathrm{a}\right)$ for the best performing building in Rome, see Table 2-8. The annual capitalized costs depend on the climate with lowest costs for Rome and highest for Stockholm. However, the maximum costs (for the max. PE savings) are in all climates around 40 $€ /\left(\mathrm{m}^{2}\right.$ a) as can be seen in Table 2-9.

In the following figures Figure 2-39, Figure 2-40 and Figure 2-41) for the three climates the annual capitalized specific costs vs. primary energy, the cost difference vs. primary energy savings as well as the costs per saved $\mathrm{KWh}$ of primary energy vs. the primary energy savings are shown. This is shown for both cases, with fluorescent and with LED lights. The reference is for each climate the case with poor envelope quality, no MVHR, with direct electric heating, no PV and fluorescent light. The (mathematical) cost-optimum case is summarized in Table 2-10 and Table 2-11.

Table 2-8: minimum annual specific primary energy demand in $\mathrm{kWhPEtot} /\left(\mathrm{m}^{2} \mathrm{a}\right)$ for the three climates and for comparison the PE demand of the reference case

\begin{tabular}{l|cccc}
\multicolumn{1}{c}{} & $\begin{array}{c}\operatorname{minPE} \\
\text { w/o PV }\end{array}$ & $\begin{array}{c}\text { minPE } \\
\text { w/ PV }\end{array}$ & $\begin{array}{c}\text { minPE } \\
\text { w/ PV + LED }\end{array}$ & Ref \\
\hline Sto & 163 & 123 & 86 & 311 \\
Stu & 160 & 120 & 81 & 267 \\
Rom & 167 & 111 & 67 & 189 \\
\hline
\end{tabular}

Table 2-9: minimum and maximum annual capitalized costs in $€ /\left(m^{2}\right.$ a) for the three climates

\begin{tabular}{|c|c|c|c|c|}
\hline & $\max C$ & $\min C$ & $\begin{array}{c}\operatorname{minC} \\
w / \text { LED }\end{array}$ & Ref \\
\hline Sto & 42.3 & 24.2 & 23.6 & 31.2 \\
\hline Stu & 40.8 & 22.5 & 22.6 & 26.8 \\
\hline Rom & 40.8 & 18.4 & 17.8 & 19.0 \\
\hline
\end{tabular}

Table 2-10: (tot) PE, PE savings and cost per saved kWh of PE at cost minimum (fluorescent light)

\begin{tabular}{|c|c|c|c|c|}
\hline & $\begin{array}{c}P E \\
k W h /\left(m^{2} a\right)\end{array}$ & $\begin{array}{c}\Delta P E \\
k W h /\left(m^{2} a\right)\end{array}$ & $\begin{array}{l}\Delta \mathrm{c} / \Delta \mathrm{PE} \\
\epsilon / \mathrm{kWh}\end{array}$ & \\
\hline Sto & 177.8 & 132.8 & -0.052 & v. good, no MVHR, HP, no PV \\
\hline Stu & 212.6 & 54.0 & -0.079 & v. good, no MVHR, DE, no PV \\
\hline Rom & 174.9 & 14.4 & -0.045 & good, no MVHR, DE, no PV \\
\hline
\end{tabular}

Table 2-11: (tot) PE, PE savings and cost per saved kWh of PE at cost minimum (fluorescent light)

\begin{tabular}{|c|c|c|c|c|}
\hline & $\begin{array}{c}P E \\
k W h /\left(m^{2} a\right)\end{array}$ & $\begin{array}{c}\Delta P E \\
k W h /\left(m^{2} a\right)\end{array}$ & $\begin{array}{l}\Delta \mathrm{c} / \Delta \mathrm{PE} \\
\epsilon / \mathrm{kWh}\end{array}$ & \\
\hline Sto & 142.0 & 168.5 & -0.045 & v. good, no MVHR, HP, no PV \\
\hline Stu & 136.0 & 130.6 & -0.032 & good, no MVHR, HP no PV \\
\hline Rom & 136.2 & 53.1 & -0.023 & v. good no MVHR, no PV \\
\hline
\end{tabular}

There is for all climates a relative flat cost minimum. This means that with no or very little extra costs solutions are feasible that feature low(er) primary energy consumption (and low $\mathrm{CO}_{2}$-emissions). The (mathematical) optimum and thus the cost-optimal solution is however depending on the climate. 
For Rome, as an example of a cooling dominated climate, neither the improved envelope quality nor MVHR, nor the use of a HP for heating is economic, whereas in the cooling dominated climates good envelope quality and the use of a HP is recommended.

In Stockholm good envelope quality and use of a heat pump delivers a cost-optimal solution, with LED primary energy can be reduced from $180 \mathrm{kWh} /\left(\mathrm{m}^{2}\right.$ a) to $143 \mathrm{kWh} /\left(\mathrm{m}^{2} \mathrm{a}\right)$. With (BI)PV primary energy can be reduced down to $90 \mathrm{kWh} /\left(\mathrm{m}^{2}\right.$ a) but annual cost increase significantly.

In Stuttgart with fluorescent light, the cost-optimum is a good to very good envelope with electric heating, whereas with LED, the solution with HP outperforms the other solutions.

In Rome, the envelope quality is not very sensitive to the PE savings and thus the primary energy savings are limited, instead, application of PV is close to be economic and the primary energy can be reduced significantly, down to $120 \mathrm{kWh} /\left(\mathrm{m}^{2}\right.$ a) with fluorescent light and $75 \mathrm{kWh} /\left(\mathrm{m}^{2}\right.$ a) with LED lights.

MHVR (HRV or ERV) is not economic in any of the considered cases, however, it is recommended anyway because of comfort constraints and air quality aspects. Furthermore, the results also depend on the additional investment costs for MVHR, which can vary depending on the type of installation and reference. The possible PE savings with MVHR depend on the use of HP and or PV.

The black dashed line in the figures represents the lowest cost at each level of primary energy demand. The Pareto front is the part from the minimum costs towards the minimum primary energy, or maximum primary energy savings, respectively. 

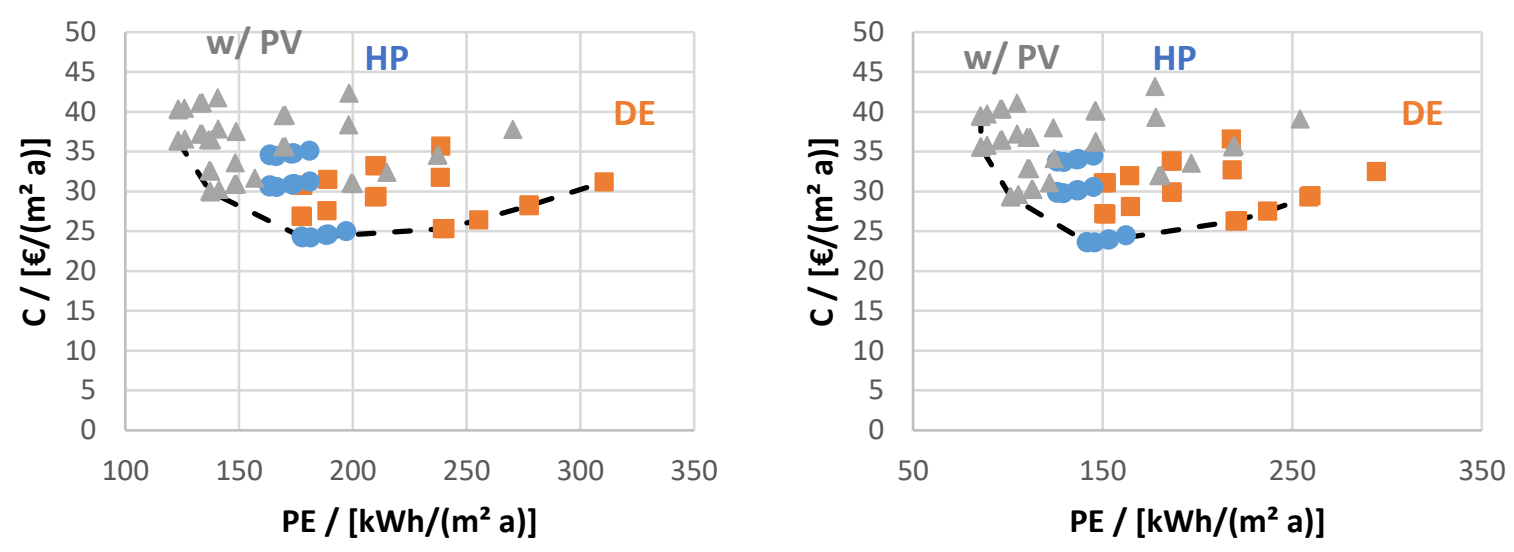

( a )
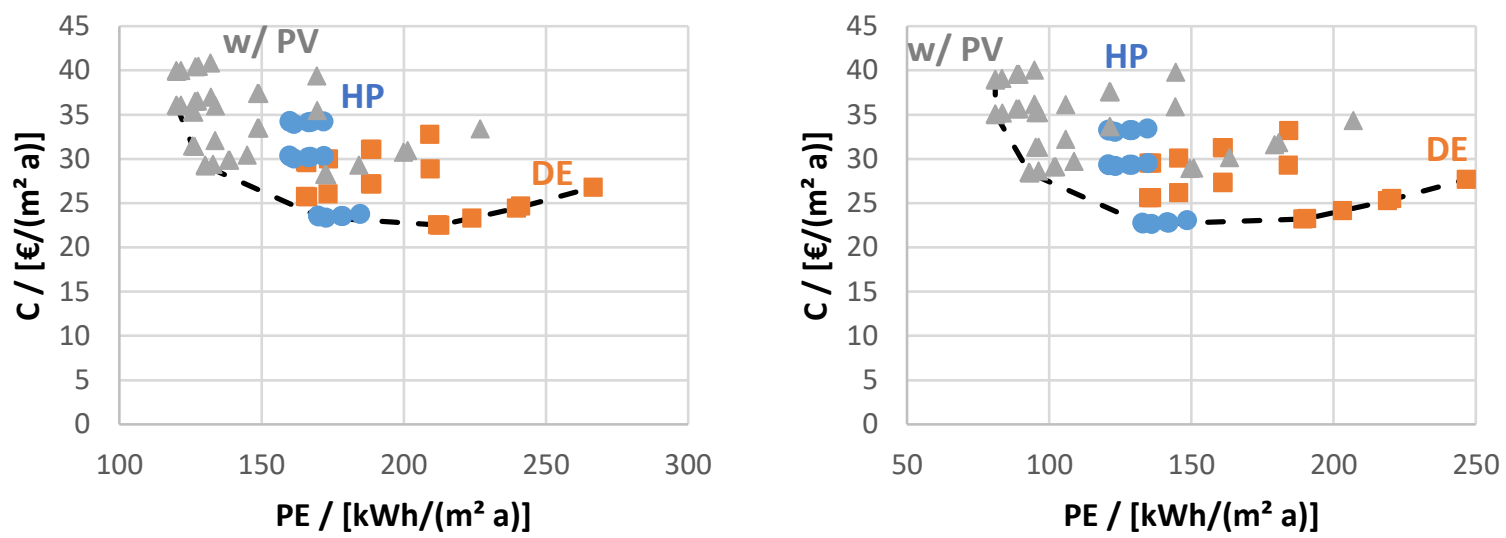

(b)
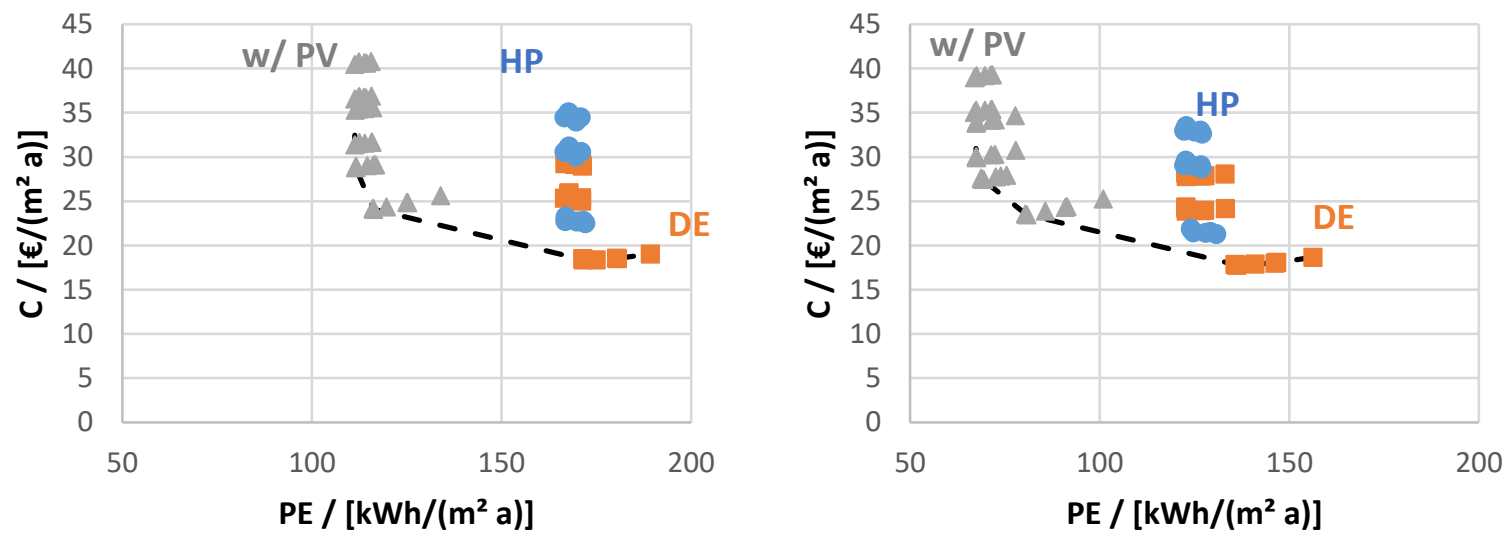

(c)

Figure 2-39: Specific annual capitalized costs vs. specific primary energy PE for the investigated cases in the three climates (Stockholm (a), Stuttgart (b), Rome(c)); for fluorescent lighting (left) and LED lighting (right); 

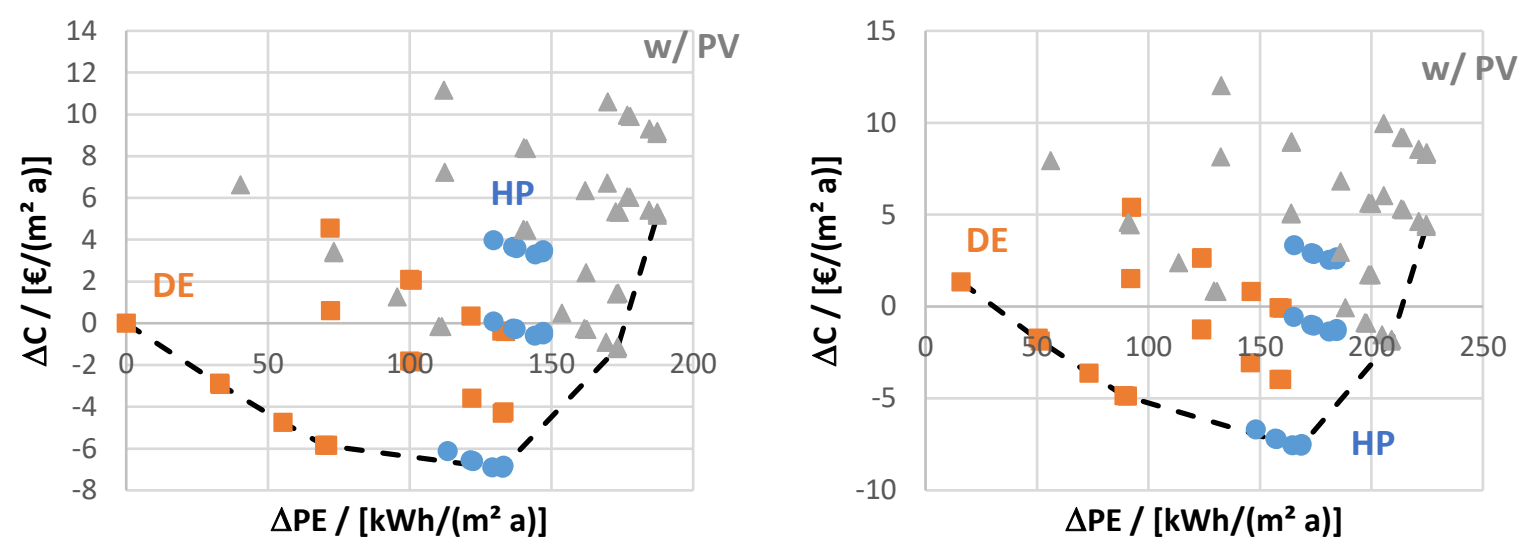

( a )
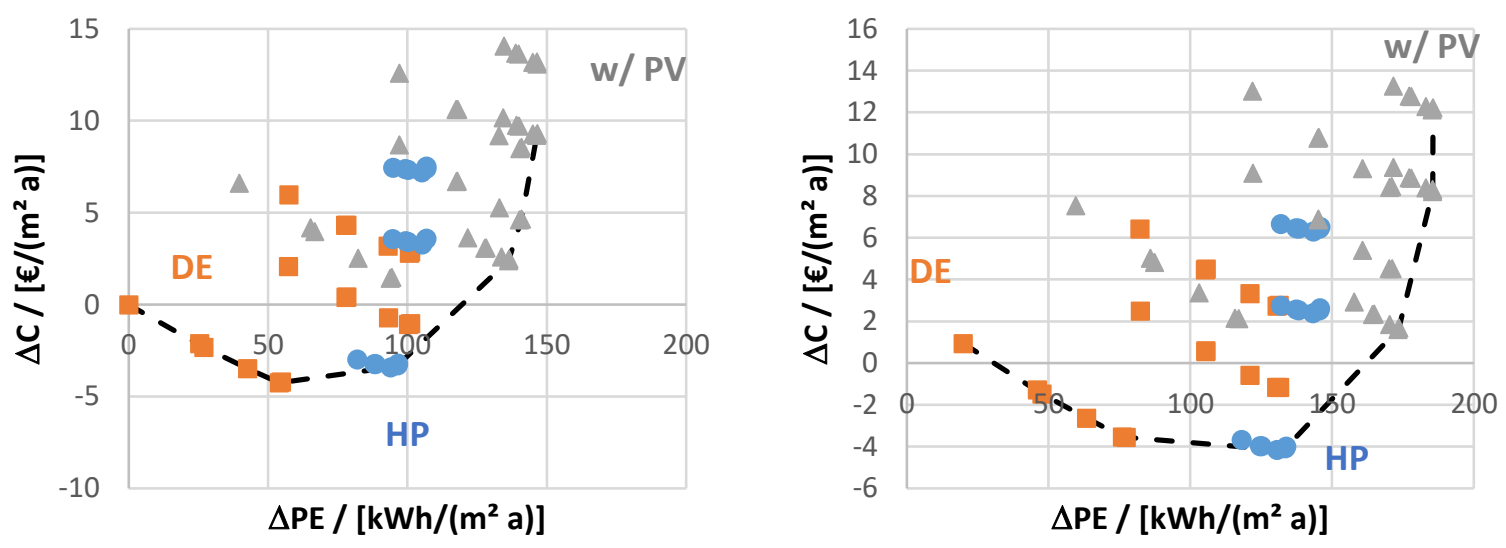

(b)
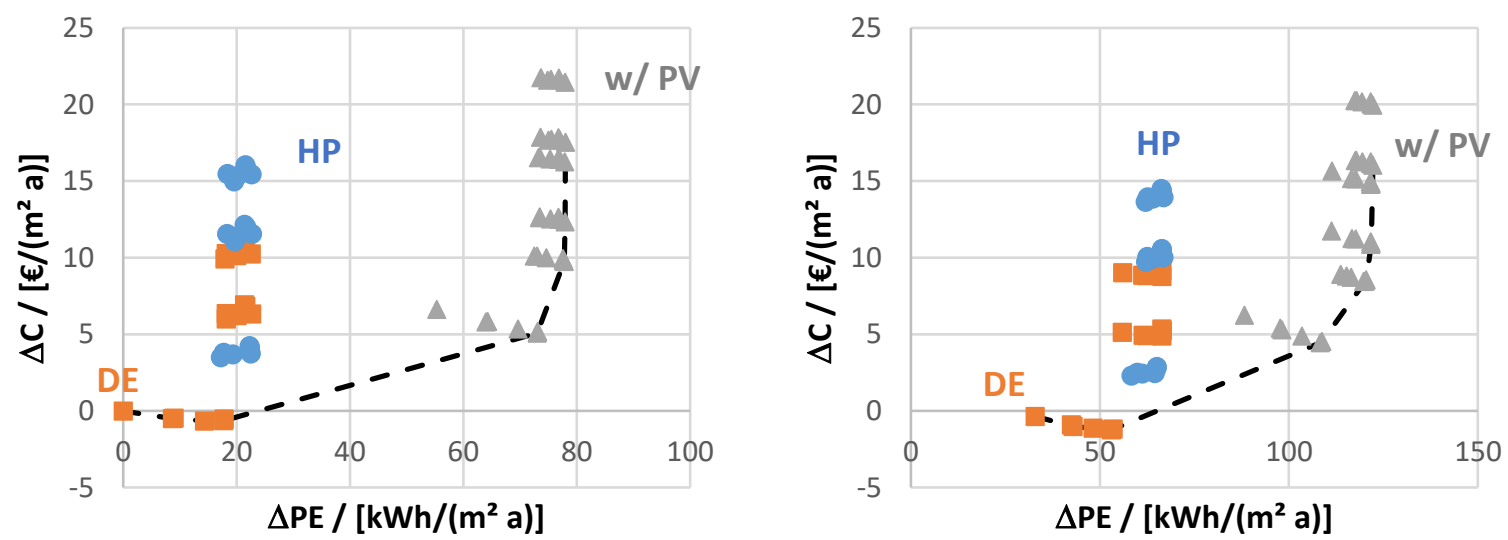

(c)

Figure 2-40: Specific annual capitalized cost difference vs. specific primary energy savings with respect to the reference case for the investigated cases in the three climates (Stockholm (a), Stuttgart (b), Rome(c)); for fluorescent lighting (left) and LED lighting (right); 

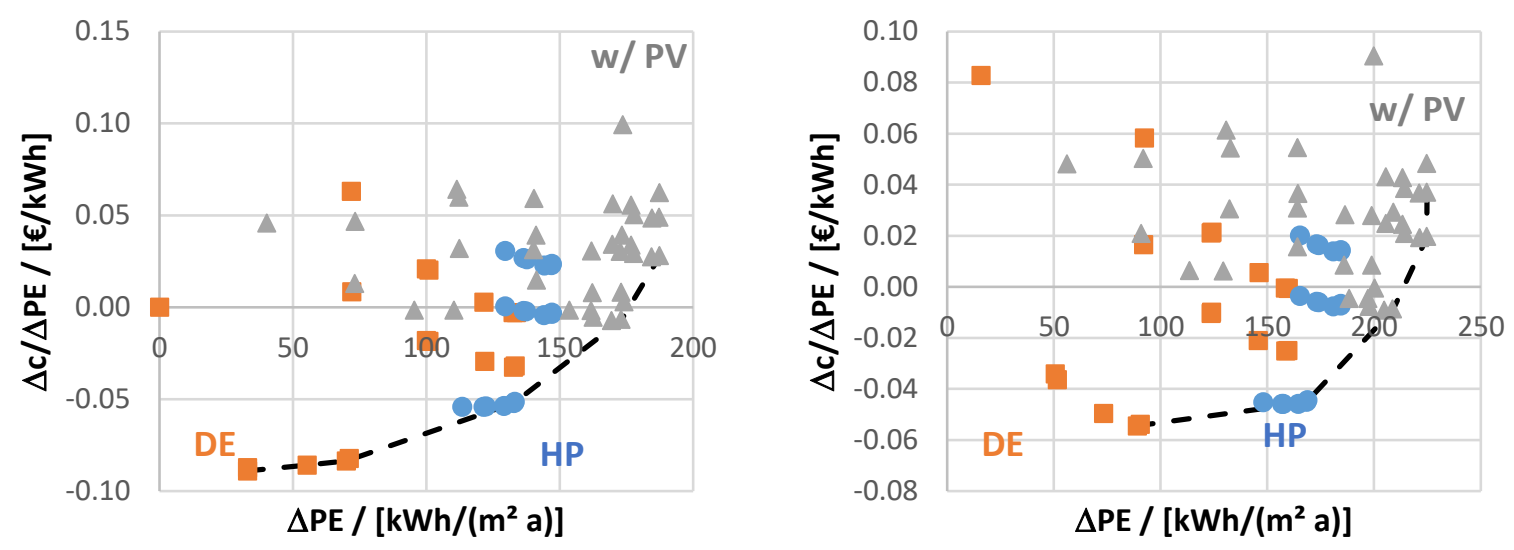

(a)
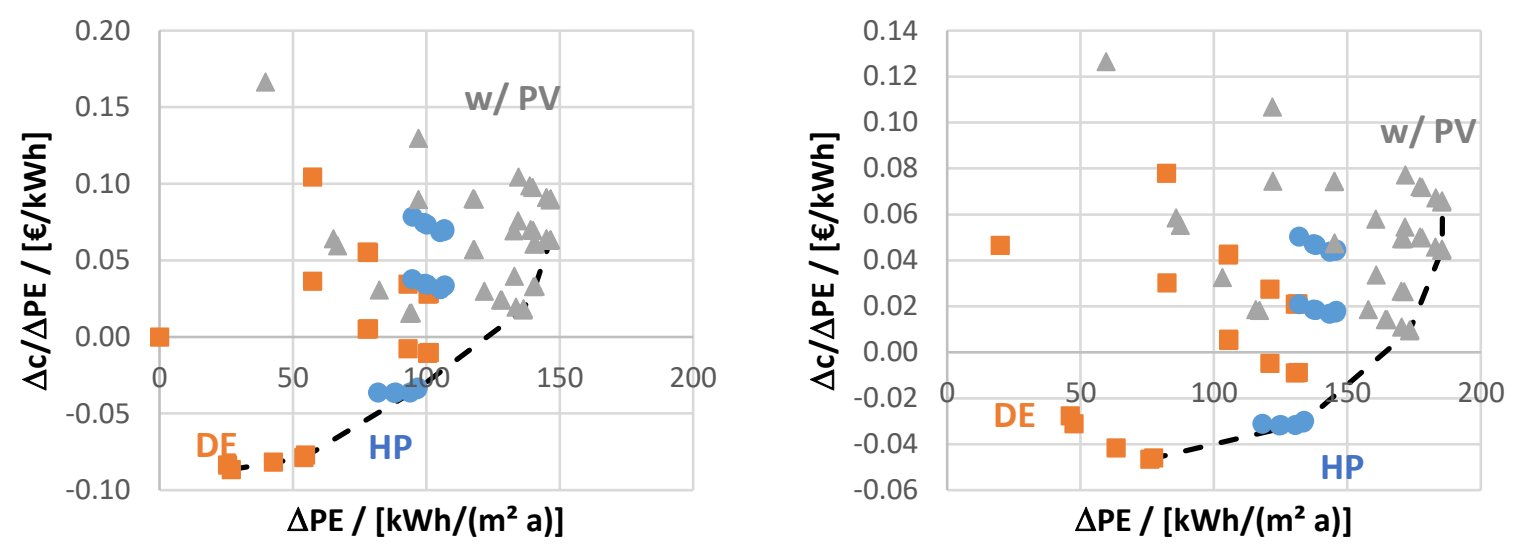

(b)
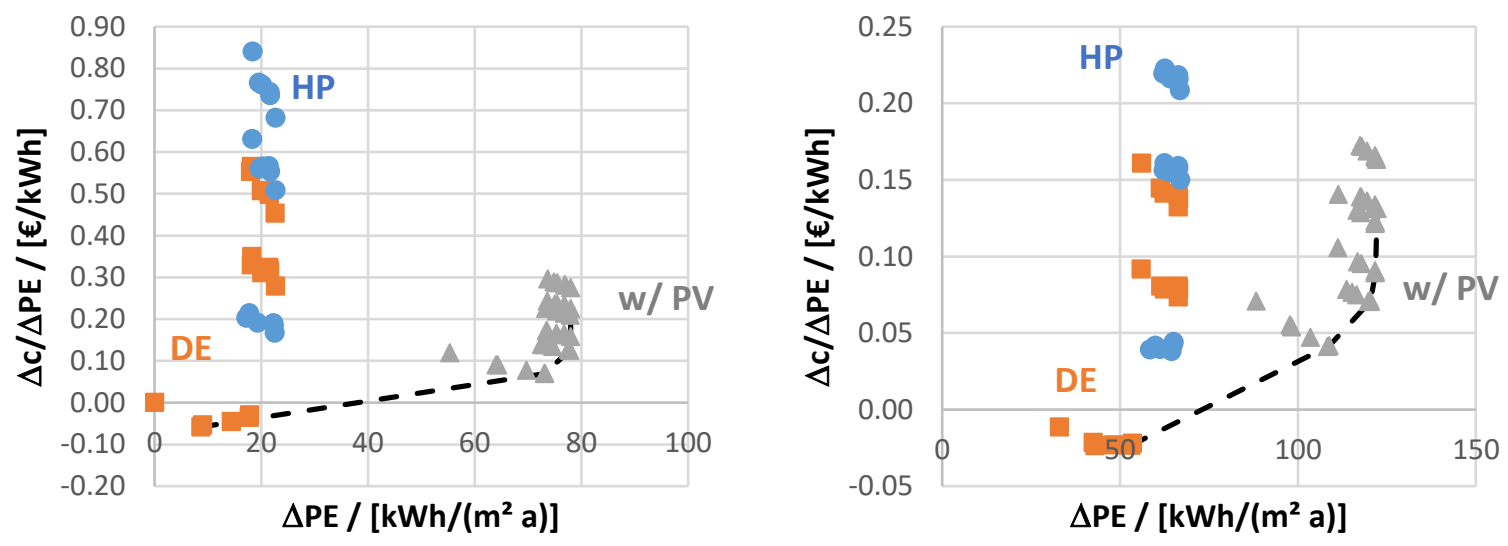

(c)

Figure 2-41: Specific cost per saved kWh of primary energy vs. specific primary energy savings with respect to the reference case for the investigated cases in the three climates (Stockholm (a), Stuttgart (b), Rome(c)); for fluorescent lighting (left) and LED lighting (right); 


\section{Discussion}

This study compares the performance (in terms of cost vs. primary energy or cost difference vs. primary energy savings) and cost-optimality (in terms of cost per saved kWh of primary energy vs. primary energy savings) for the office cell in three climates by varying the envelope as well as HVAC quality and considering or not the PV. The situation is completely different between the heating and cooling dominated climates. While in Rome the envelope quality is not very sensitive on the overall building performance, but with (BI)PV the grid electricity demand can be reduced to approx. $67 \%$ with fluorescent light and to approx. $50 \%$ with LED, in the cold climates, a good envelope is key and the use of a heat pump is beneficial. Use of LED instead of fluorescent light is recommended in all climates and with all combinations.

It must be concluded that under the given boundary conditions, (BI)PV is not economic, neither in the cooling nor in the heating dominated climates. Contrariwise, PV is required to reduce the primary energy demand to acceptable values. From this study it can be concluded that on European level, it is recommended to foster the improvement of the envelope and the use of heat pumps in central/northern climates and to subsidise the use of PV in southern climates. 


\title{
2.2.2 Analysis of the impact of different HVAC configurations and control strategies on primary energy and cost savings for an office building
}

\author{
Mara Magnia, Fabian Ochs ${ }^{a}$ \\ aUniversity of Innsbruck, Technikerstraße 13, Innsbruck 6020, Austria
}

In this work different HVAC retrofit solutions (i.e. HP, PV, Batteries, LED etc..) are compared against a reference case involving an electric heating system with an On/Off split unit for cooling and fluorescent lamps combining both economic and environmental analysis. A sensitivity analysis is carried out in order to evaluate the influence of input parameter (i.e. interest rate, investment cost and electricity price) on the results of the economic analysis. The environmental analysis is performed using different share of renewables in the electricity mix showing the impact of the development of increasingly share of RE on the ranking of the different retrofit solutions [13].

The office building described in report DC. 1 is used as a basis for this analysis. The renovation packages discussed in this study are listed in Table 2-12 where the reference system is highlighted in bold (i.e. electric heating and On/Off HP for cooling with a standby consumption running for the entire year, fluorescent lighting and the reference control system for the ventilation and free-cooling). The main characteristics of the HP and PV are reported in annex 0

Table 2-12. Characterization of the investigated renovation components

\begin{tabular}{|c|c|c|}
\hline & Options & Description \\
\hline \multirow{3}{*}{ Heating } & Direct electric & Electric resistance, efficiency equal to 1 . \\
\hline & On/Off (Split type) HP & See appendix 0. Two different On/Off HP sizes are considered. \\
\hline & Modulating (Split type) HP & See appendix 0. \\
\hline \multirow{2}{*}{ Cooling } & On/Off (Split type) Air-Con. & See appendix 0. Two different On/Off HP sizes are considered. \\
\hline & Modulating (Split type) Air-Con. & See appendix 0. \\
\hline PV & Mono-crystalline silicon & $\begin{array}{l}\text { PV installed in the available wall area }\left(5.4 \mathrm{~m}^{2}\right) \text { in the south façade with an } \\
\text { efficiency of } 17.7 \% \text { and a peak power of } 877 \mathrm{Wp} \text {. }\end{array}$ \\
\hline Battery & Ideal battery & Efficiency of $90 \%$ (4kWh capacity). \\
\hline \multirow{4}{*}{ Control } & HP and mechanical ventilation & $\begin{array}{l}\text { On/Off HP and PI for the modulating HP, for the mechanical ventilation } \\
\text { see the building description. }\end{array}$ \\
\hline & Free cooling $7 / 7$ & $\begin{array}{l}\text { Free cooling can be activated every time the internal and external } \\
\text { conditions makes it effective. }\end{array}$ \\
\hline & Improved standby consumption & $\begin{array}{l}\text { Standby consumption of } 10 \mathrm{~W} \text { accounted only during the working season } \\
\text { of the considered technology (instead of the whole year). }\end{array}$ \\
\hline & Night set back & $\begin{array}{l}\text { The heating and cooling systems are switched off during non-occupied } \\
\text { periods and restarted } 4 \mathrm{~h} \text { before the working time. }\end{array}$ \\
\hline \multirow{2}{*}{ Lighting } & Fluorescent & $10.9 \mathrm{~W} / \mathrm{m}^{2}$ (500 lux on the working desk, 8 luminaire). \\
\hline & LED & $5.45 \mathrm{~W} / \mathrm{m}^{2}$ (500 lux on the working desk, 8 luminaire). \\
\hline
\end{tabular}

\section{Economic analysis}

The economic analysis adopted in this work is based on the Equivalent Annual Cost (EAC) as described in report DC.1. A real interest rate of $3 \%$ is considered and an electricity price of $0.2 € / \mathrm{kWh}$ with an escalation rate of the energy price of $2 \%$ is considered. A sensitivity analysis is carried out varying the interest rate, the investment cost and the electricity price in order to assess the sensitivity of the economic results to the input data. The annual interest rate is varied $\pm 1 \%$ point from the default value (3\%), the electricity price and the investment costs are varied $\pm 20 \%$. In Table 2-13 the investment, installation, maintenance costs, the technical lifetime and the resulting EAC for each technology are reported. The data for HP and PV are all taken from [14] except the investment cost of PV which is taken from [15] where mono-crystalline silicon PV are considered.

The PV self-consumption contributes to the reduction of the electricity demand of the building system. When the battery is considered, the PV surplus energy is stored and later used by the building, otherwise the benefit of selling the surplus to the main grid is disregarded. 
Table 2-13. Investment costs, installation costs, maintenance costs and EAC of the studied renovation measures

\begin{tabular}{l|ccccc}
\multicolumn{1}{l|}{ Renovation measure } & $\begin{array}{c}\text { Investment } \\
\text { costs [€] }\end{array}$ & $\begin{array}{c}\text { Installation } \\
\text { costs }[\boldsymbol{\epsilon}]\end{array}$ & $\begin{array}{c}\text { Maintenance } \\
\text { costs [€/y] }\end{array}$ & $\begin{array}{c}\text { Technical } \\
\text { lifetime [y] }\end{array}$ & $\begin{array}{c}\text { EAC } \\
\text { [€] }\end{array}$ \\
\hline On/Off HP low power & $500[14]$ & $100[14]$ & $16[14]$ & $12[14]$ & 76.3 \\
On/Off HP high power & $1400[14]$ & $290[14]$ & $50[14]$ & $12[14]$ & 219.8 \\
Modulating HP & $1400[14]$ & $290[14]$ & $50[14]$ & $12[14]$ & 219.8 \\
PV (877 Wp) & $2322[15]$ & $380[14]$ & $34.2[14]$ & $20[14]$ & 215.8 \\
Battery (4.8 kWh) with Inverter & 4000 & 1400 & 0 & 10 & 663.1 \\
LED light (8 luminaire) & 640 & 300 & 0 & 15 & 78.7 \\
\hline
\end{tabular}

\section{Environmental analysis}

In this case study all the analysed solutions are using electricity as input, therefore they can be compared considering the savings in terms of electricity demand. In order to compare the savings in terms of primary energy, different scenarios for the PE conversion factor are taken into account [16] (see appendix DC.1).

\section{Results}

The results of the dynamic simulations investigating different HVAC and lighting solutions are compared to the base case considering the additional capitalized cost and energy savings. The latter are expressed in terms of electric energy $\left(E_{E L}\right)$ and of total PE calculated with the constant conversion factor $\left(P E_{E U}\right)$, with the 10-10-10 scenario $\left(P E_{10}\right.$ -

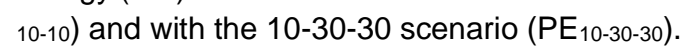

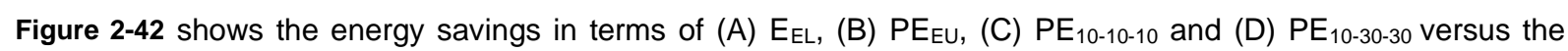
additional total annual cost of each technology for the climate of Stockholm. Figure 2-43 shows the energy savings

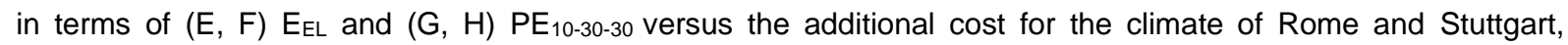
respectively. In both figures, the square markers represent the results of the different technologies together with the PV panels, while the asterisk markers represent the solutions including battery and PV. The error bars show the results of the economic sensitivity analysis, indicating the impact on the additional total annual cost by varying the investment cost, energy price and interest rate. The investment cost has the highest impact on the economic evaluation.

The two objects of this optimization are the minimization of the cost and the maximization of the energy savings under the constraint of maintaining thermal comfort. In such a case, typically a feasible solution that minimizes all objective functions simultaneously does not exist. The optimal cases lay on the Pareto front composed by solutions that cannot be improved in any of the objectives without degrading the second object. In Figure 2-42 and Figure 2-43, the Pareto front, for the set of solutions considered in this work, is highlighted with a light green underlay. The red underlay highlights solutions that are not optimal since enable lower savings and same cost of at least one solution of the Pareto front. The differences in terms of energy savings between the On/Off low or high power and modulating HP are not significant in all the considered climates but the modulating HP and high power On/Off HP are more expansive than the On/Off low power HP.

The night set back slightly reduces the heating demand, therefore it has a small effect in Stockholm and Stuttgart but no effect in Rome where the heating demand is almost zero.

Switching off the air conditioner, when not in operation, i.e. the during the winter season for the case when the electric heating is active), reduces the standby consumption and comes without any additional costs.

The free-cooling active seven days per week on the one hand reduces the cooling demand while on the other hand increases the energy consumption of the fans, increasing also the overall energy consumption. When the $P E_{10-30-}$ 30 instead of $E_{E L}$ is considered, the results of the cases with free cooling (see violet and dark green markers) are overlapped to the respective cases without free cooling (see yellow and light blue markers).

Since in the reference case almost half of the electricity demand is required for lighting, changing the illumination system from fluorescent to LED has a great benefit at low cost. In fact, the solution with electric heating, HP and LED (see light grey circle marker) is close to the Pareto front in all the climates for both $\mathrm{E}_{\mathrm{EL}}$ and PE savings plots. The same technology with PV (square light grey marker) is close to the Pareto front only for Rome. Since here, the heating demand is almost zero, the HP technology appears between the cost optimal solutions only when it is combined with PV and LED or PV, LED and battery. The reversible On/Off HP (for heating and cooling) either combined or not with LED, is always between the best solutions for the climate of Stockholm and Stuttgart. When the renovation package involving electric heating, On/Off cooling HP and LED (see light grey circle marker) is 
compared with On/Off HP H/C (see yellow circle marker), in Stuttgart and Stockholm, it is noteworthy that the scenario for evaluation of the energy savings (i.e. $\mathrm{E}_{\mathrm{EL}}$ or $\mathrm{PE}_{10-30-30}$ ) might change the ranking of the solutions. In Figure 2-42 A and Figure 2-43 F, it can be seen that the renovation package with electric heating, On/Off cooling HP and LED (light grey marker) gives the same or even more $\mathrm{E}_{\mathrm{EL}}$ savings than the On/Off HP H/C, but the situation is

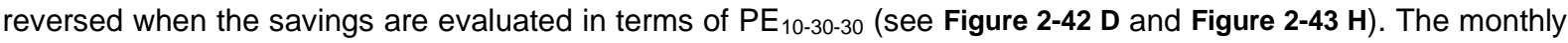
conversion factors of the 10-30-30 scenario are almost zero during summer therefore the savings during the wintertime have higher impact on the calculated yearly energy savings. When the PV is considered together with the HP and LED with or without battery (see square and asterisk light blue markers) these solutions are cost optimal in all the climates.

The Pareto front highlights a set of cost optimal solutions from which one renovation package has to be selected based on economic restrictions and other parameters (e.g. thermal and visual comfort, quickness of the retrofitting, personal preferences, etc.). But there are some clear and remarkable trends that can be noted: in Stockholm and Stuttgart the solution with reversible On/Off HPlp H/C + LED have the same cost but guarantee higher energy savings with respect to other solutions such as reversible On/Off HPIp H/C and El. Heating + On/Off HPIp + LED. Adding PV increases the energy savings but also the cost therefore the selection of this solution depends on the economic restriction. Adding battery only slightly increases the energy savings while the cost substantially increases. In Rome El. Heating + On/Off HPIp + LED with or without PV allows to keep the additional cost near to zero enabling high-energy savings. 


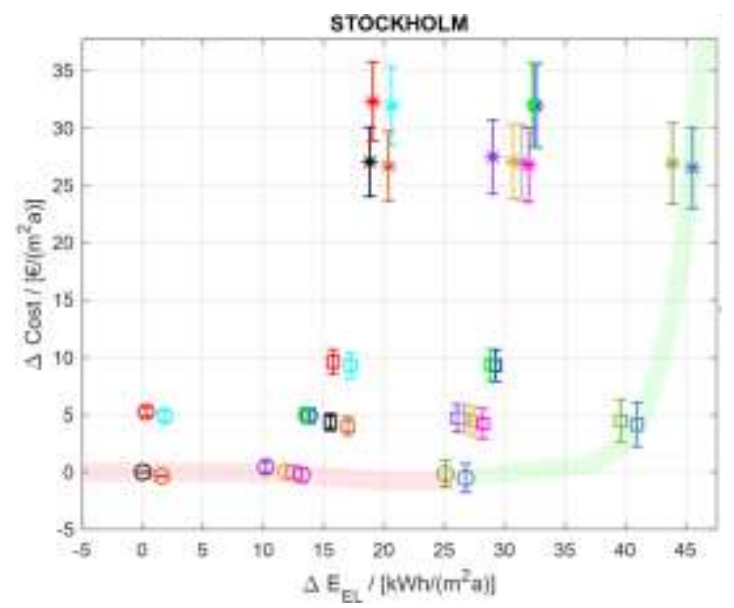

(A)

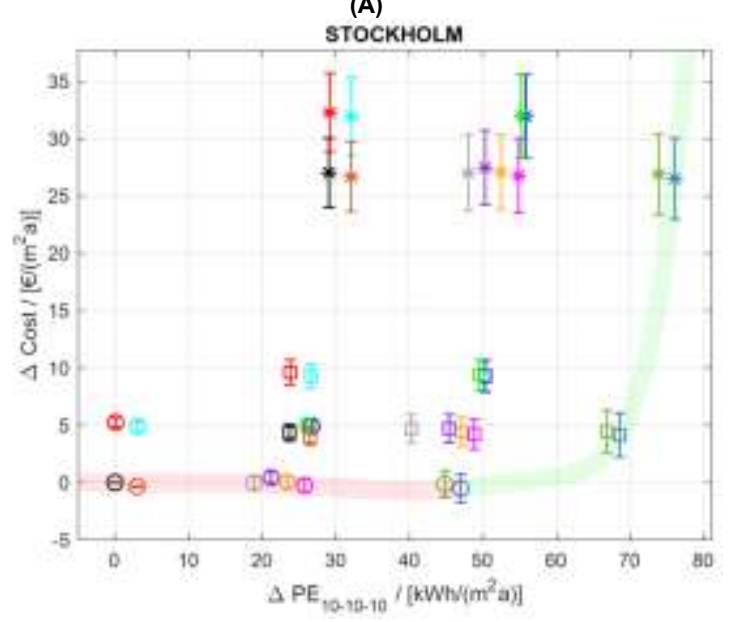

(C)

ФEL. Heating + On/Off $\mathrm{HP}_{\mathrm{b}}$ (standby all year)

El. Heating + Modul. HP (standby only summer)

El. Heating + Modul. HP (standby all year)

El. Heating + On/Off $\mathrm{HP}_{\mathrm{b}}$ (standby only summer)

El. Heating $+\mathrm{On} / \mathrm{Off}_{\mathrm{HP}}$ (standby only summer) +1

$\Phi$ Modul. $\mathrm{HP}(\mathrm{H} / \mathrm{C})$

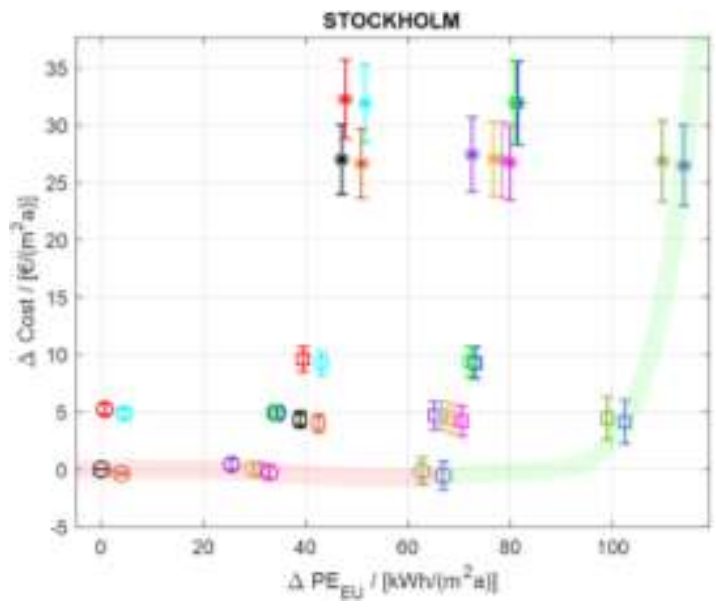

(B)

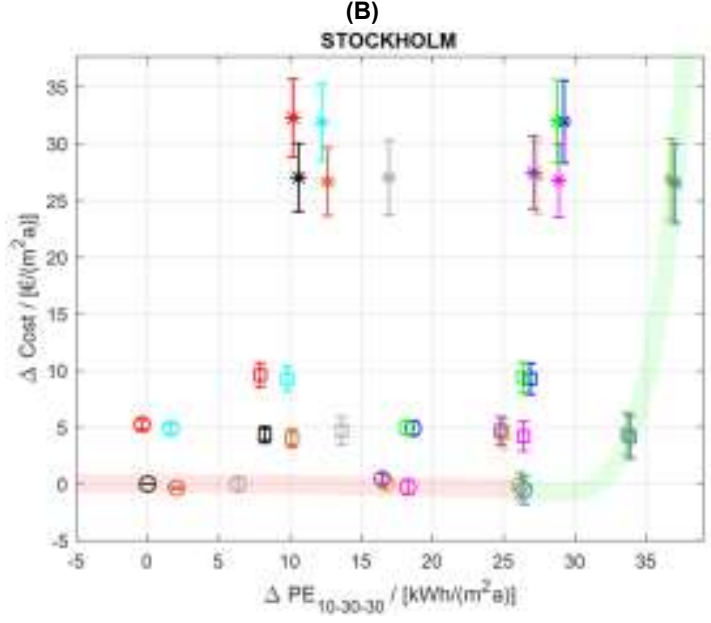

(D)

Figure 2-42: Savings in terms of (A) Electric energy, (B) Primary energy according to EU (total) conversion factor, (C) Primary energy according to 10-10-10 (non-ren.) scenario conversion factors,(D) Primary energy according to 10-30-30 (non-ren.) scenario conversion factors vs additional cost of the analysed technologies for the climate of Stockholm 


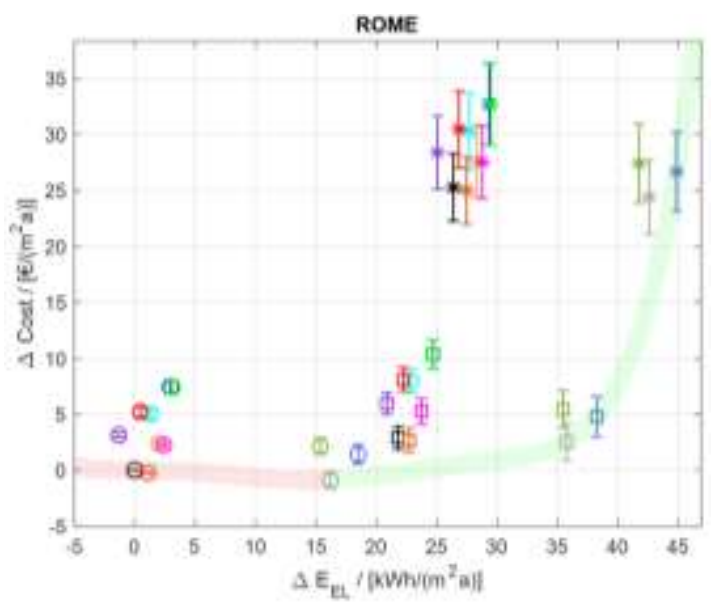

(E)

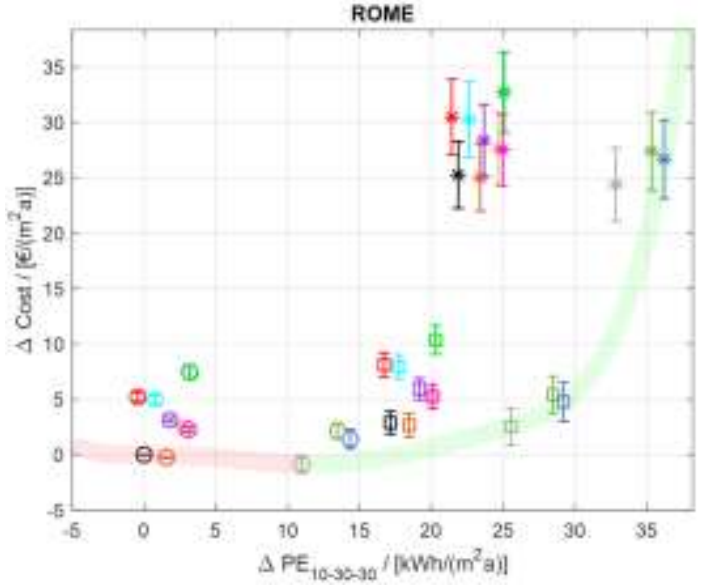

(G)

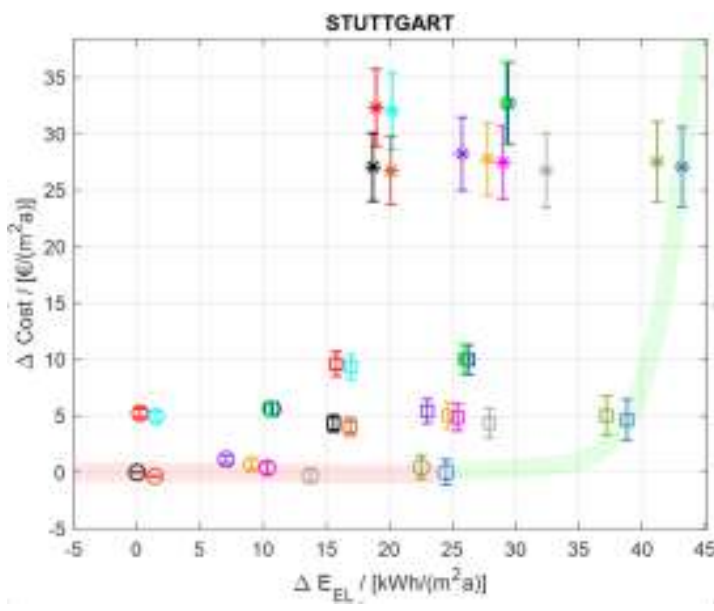

(F)

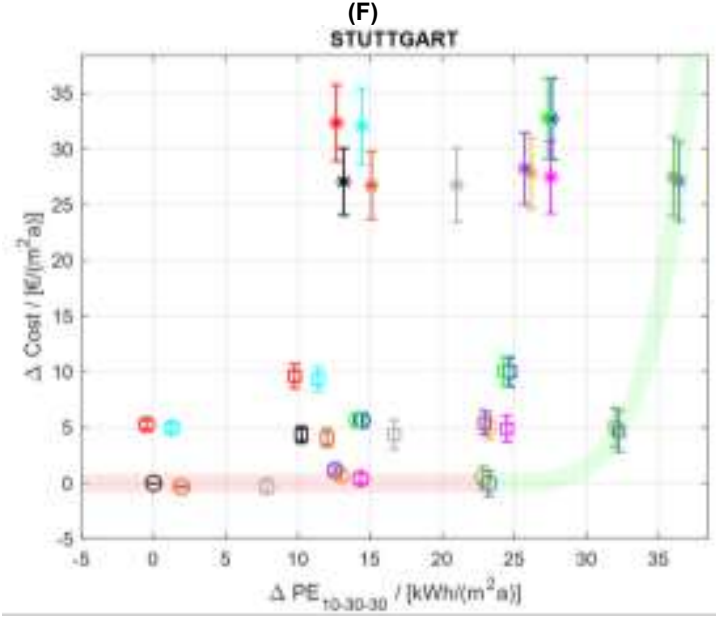

(H)

\footnotetext{
$\Phi$ EL. Heating + On/Off $\mathrm{HP}_{\mathrm{b}}$ (standby all year)

El. Heating + Modul. HP' (standby only summer)

El. Heating + Modul. HP (standby all year)

El Heating $+\mathrm{On} / \mathrm{Off} \mathrm{HP}_{\mathrm{b}}$ (standby only summer)

El. Heating $+\mathrm{On} / \mathrm{Off} \mathrm{HP}_{\mathrm{b}}$ (standby only summer) + LED

$\Phi$ Modul. HP $(\mathrm{H} / \mathrm{C})$

5on/Off HP $(\mathrm{H} / \mathrm{C})$

On/Otf HPP $(\mathrm{H} / \mathrm{C})$

On/Off $\mathrm{HP}_{\mathrm{h}}(\mathrm{H} / \mathrm{C})+$ LED

\$On/Off HP $(\mathrm{H} / \mathrm{C})+$ FreeCool.

LED $\mathrm{On} / \mathrm{Off} \mathrm{HP}_{p}(\mathrm{H} / \mathrm{C})+\mathrm{LED}+$ FreeCool

$\Phi$ On/Off $\mathrm{HP}_{t p}(\mathrm{H} / \mathrm{C})+$ night set-back
}

Figure 2-43: Savings in terms of (E,F) Electric energy and (G,H) Primary energy according to 10-30-30 scenario

The renovation packages allowing high-energy savings with low additional cost are represented, in Stockholm and Stuttgart, by HP in combination or not with LED and PV and in Rome, by LED and PV in combination with electric heating. Battery in combination with PV, HP and LED brings, in all the climates, additional energy savings with high additional cost. Technologies, which will lead to higher savings in winter with lower availability of renewables and generally higher loads, will be more valuable and this can be quantified by the proposed method. 


\subsubsection{Integration of the PV-Modules into the Building Skin (BIPV/T Concept)}

Nermeen Abdelnoura ${ }^{a}$ Efstratios Dimitrios Rounis ${ }^{b}$, Paolo Bonato $^{c}$

aHochschule für Technik Stuttgart, Centre of Applied Research Sustainable Energy Technologies (zafh.net), Stuttgart, Germany

${ }^{b}$ Concordia University, Montreal, Canada

${ }^{c}$ EURAC research, Institute for renewable energy, Via A.Volta 13/A, 39100 Bolzano, Italy

The thermal coupling between the PV-Modules and the building envelope was further investigated in the dynamic simulation environment of TRNSYS. There are quite a wide range of components offered within TRNSYS18Package that could be used for this purpose. All available TRNSYS types that could represent a PV/T were carefully reviewed, in order to find a component (Type) that best simulates the thermal coupling between all layers. A comprehensive summary for such a review is presented in Figure 2-44. As shown on figure, TESS Electrical Library already offers PVT as well as BIPV models, which outperform the standard PV-Panels from TRNSYS standard electrical library (Type190 and Type103) by including a dynamic thermal model for the ventilated façade. On the other hand, the PVT collectors from the standard TRNSYS library (Type50) basically adds a PV module on top to the standard flat-plate solar thermal collector, which is not the real configuration in this case-study.

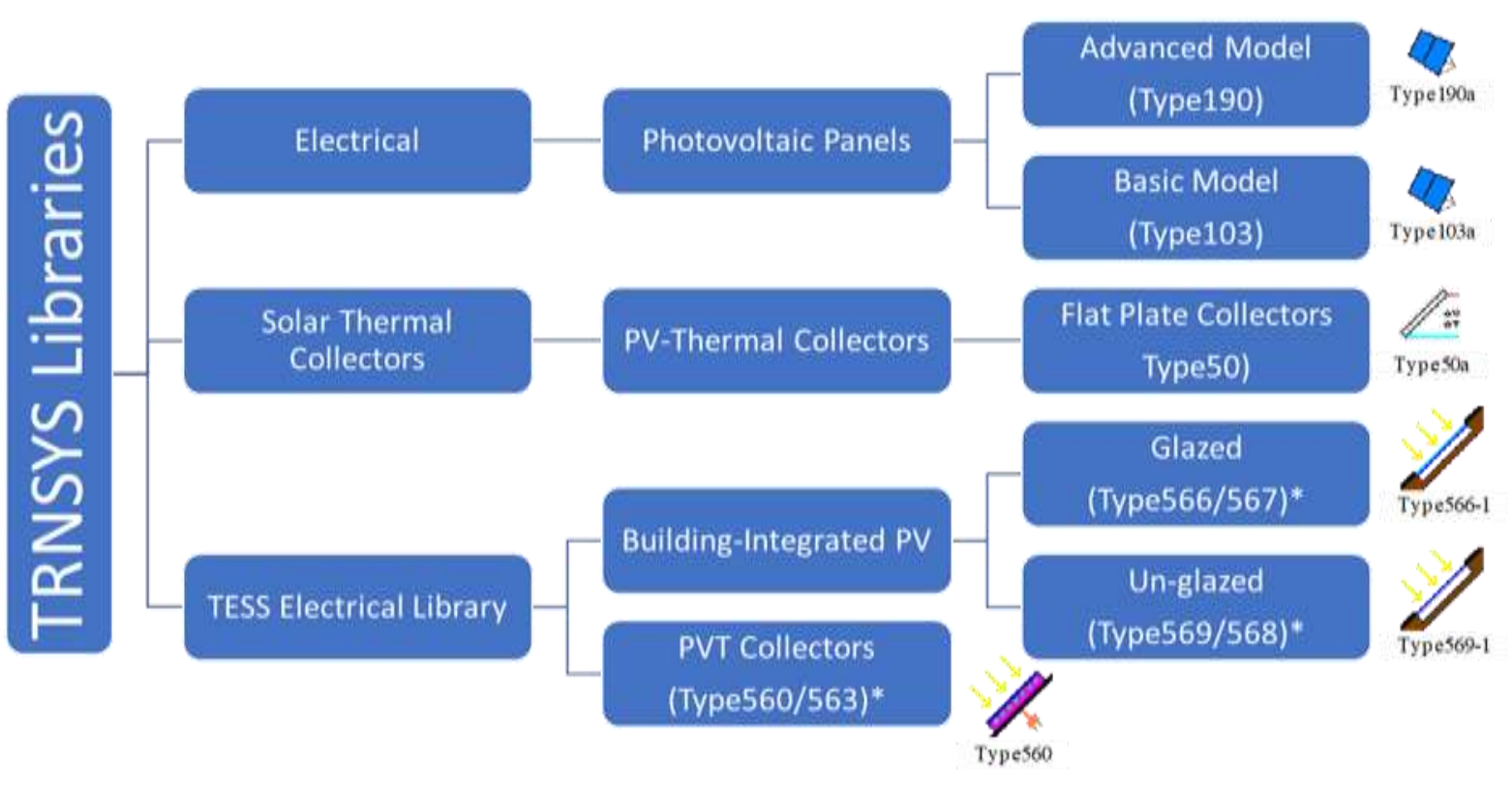

* (Interacting with Simple Building Models (Zone Air Temperature) / Interfaces with Detailed Building Models "Type65")

Figure 2-44: A summary for all available TRNSYS Types that could serve in modelling a BIPV/T Component [17]

Three dual types from the two main categories of the TESS Library represented possible options to simulate the resulting BIPV/T configuration. The three dual types are namely: Type560/563, Type566/567, and Type569/568. The duality results from the possibility of the PV/T module to interact with a simple or a detailed building model. From the components' definition and considering the assumptions adopted in Task56, Type567 was selected to represent the BIPV/T component in this new scenario. The PV-Modules used in this part of the study have the same technical specification of the PV-Panels presented in section 2.1.5. The technical characteristics of PV, inverter and Heat pumps are reported in the appendix 0 . The building model (Type56) used in the simulation of this BIPV/T study models the office reference building defined within Task56 (report DC.1). The energy system is also the same as introduced so far. The full description of the office reference building as well as the building data, weather and occupancy profiles are documented in the report DC.1.

\section{BIPV/T System Description}

Three BIPV/T modules are integrated into the three opaque external surfaces at the bottom of the south external wall of the building model (Figure 2-45). In TRNBuild those three surfaces correspond to S5, S7 and S8, each is $1.5 \mathrm{~m}$ length and $1 \mathrm{~m}$ high. Accordingly, the dimensions of the PV-Panel defined in the Task (appendix 0) was 
slightly modified, so that it covers the gross area of each surface $\left(1.5 \mathrm{~m}^{2}\right)$. It was also assumed to have a glass/glass PV-Panel, where the glass thickness at both sides is $3 \mathrm{~mm}$ and has a thermal conductivity of $1.1 \mathrm{~W} /(\mathrm{m} . \mathrm{K})$. The three PV-Modules were assumed to be horizontally integrated to the three surfaces of the external wall at a separation distance of $5 \mathrm{~cm}$, and connected in series. Such a configuration forms a horizontal air-channel of $4.5 \mathrm{~m}$ length (along the direction of the air flow through the channel) and $0.05 \mathrm{~m}^{2}$ cross-sectional area (perpendicular to the direction of the air flow through the channel).

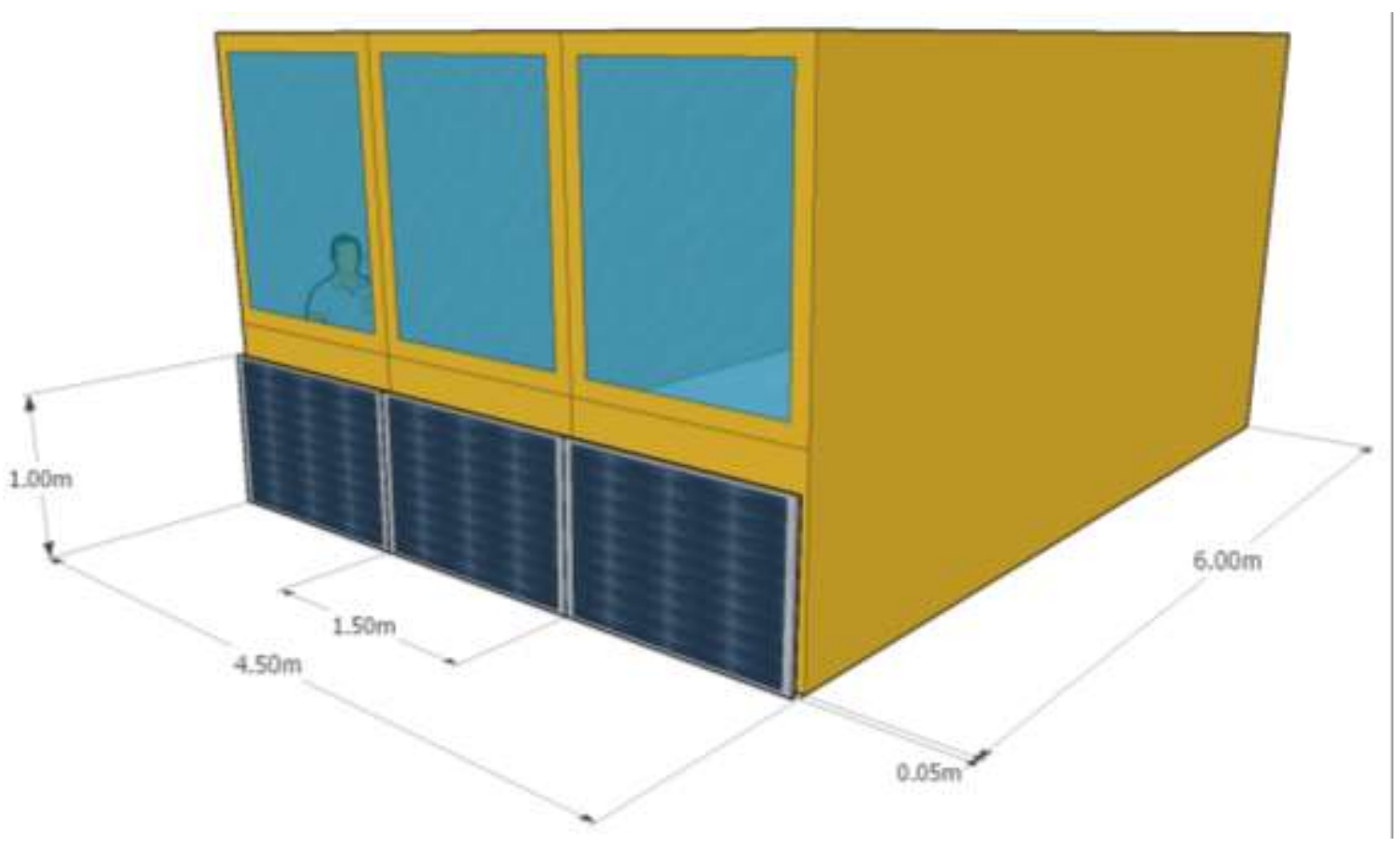

Figure 2-45: The BIPV/T Concept implemented to the office reference building of T56

\section{BIPV/T System Simulation in TRNSYS18}

The resulting BIPV/T system could be thermally (and electrically) simulated by a single 4 glazed BIPVT component from TESS electrical library in TRNSYS18 (Type567). To account for the integration process to the building, the category of the three corresponding external walls in the building model were manually adjusted from the default setting (EXTERNAL) into (BOUNDARY), where the boundary conditions were defined by user (instead of "identical") and were assigned to the lower channel temperature of the BIPVT-model. The back-surface temperature of the resulting air-collector in Type 567 is the average of the inside surface temperature of S5, S7 and S8.

\section{Thermal Utilization of the BIPV/T System}

Based on the proposed configuration, a couple of implementation scenarios could be considered for the possible thermal utilization of the BIPV/T concept. E.g. Connection to a heat pump (HP) during the heating season, thermal storage, preheating the ventilation air during the heating season, and/or cooling the PV-Modules during the cooling season. In this study, the latter two scenarios were investigated. Figure 2-46 presents a schematic diagram for those two operations.

\footnotetext{
${ }^{4}$ A single BIPVT component that considers the combined physical properties of $n$-components connected in series
} 


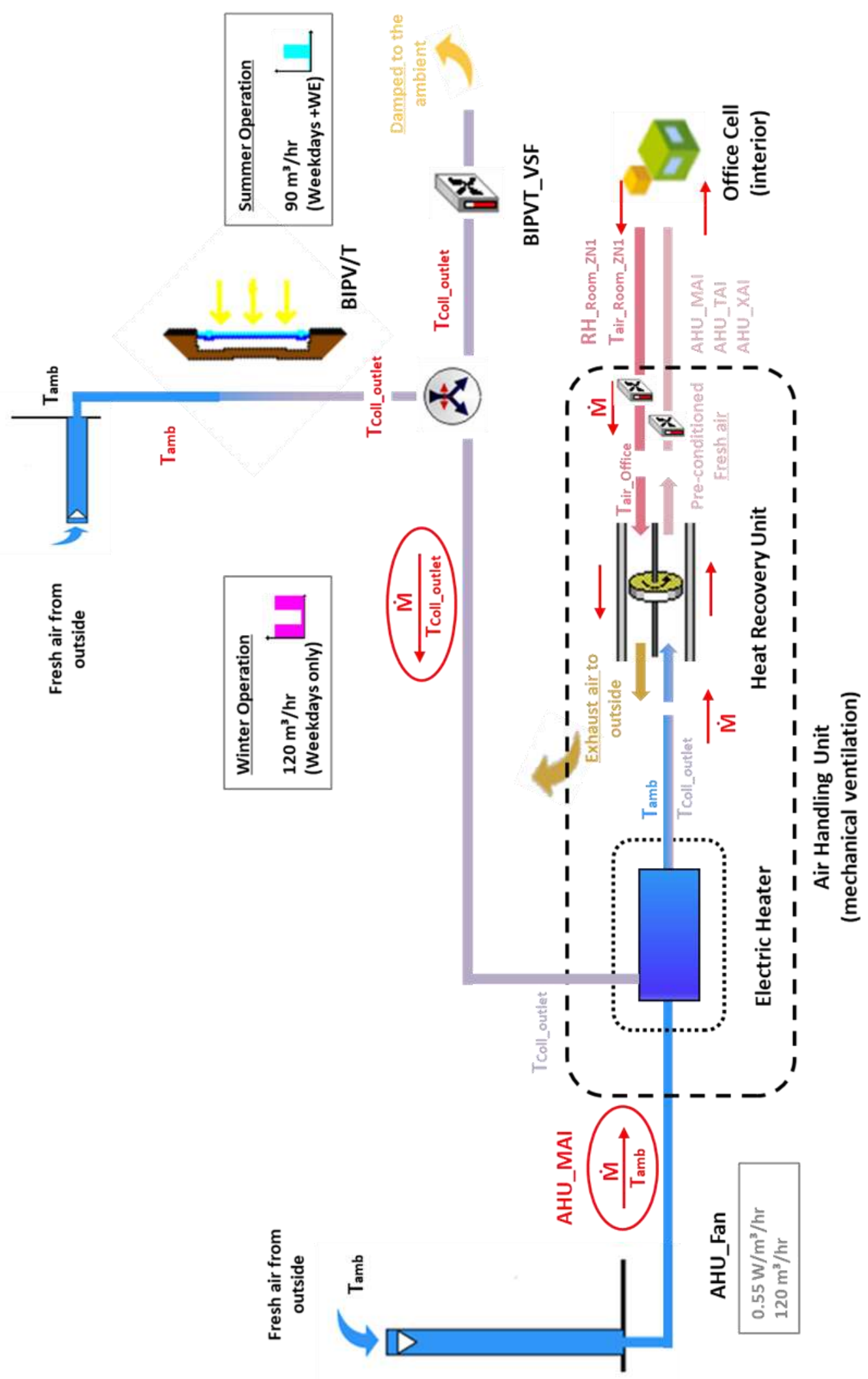

Figure 2-46: A schematic representing the thermal utilization of the BIPV/T System 


\section{Control Strategy of the BIPVT- Mechanical System}

The BIPV/T system as previously described is an air-based open-loop system, where ambient air is drawn by a variable speed Fan (BIPVT_VSF) and used as the heat transfer fluid. The specs of the fan were inspired from a previous BIPV/T case-study [18]. The fan rated power is $50 \mathrm{~W}$ sized for a $209 \mathrm{~m} 3 / \mathrm{hr}$ maximum air-flow (this corresponds to a velocity of the air in the gap (u_gap) of $1.16 \mathrm{~m} / \mathrm{s}$ in the case here). In the used VSF-Model (TRNSYS Type 926), the volumetric flow rate of air moved by the fan is linearly related to the control signal. Moreover, typically in Type926, the power drawn by the fan at a given flow rate can be any polynomial expression of the control signal. However, since the main power consumption of the BIPVT-VSF (the kinetic pressure drop) can be considered within the power consumption of the existing mechanical ventilation system $\left(0.55 \mathrm{~W} / \mathrm{m}^{3} / \mathrm{h}\right.$ was assumed as a lumpsum in the report DC.1), the calculation method of the BIPVT-Fan power consumption in this part of the study considers the frictional pressure drop, and namely only the major component of the friction pressure drop as presented in [19].

$$
\Delta P_{M}=\sum_{i=1}^{n} f_{i} \frac{L_{i}}{D_{H_{i}}} \frac{\rho v_{i_{a v g}}^{2}}{2}
$$

$\triangle \mathrm{PM}$ is the major pressure drop which includes the pressure loss of collector duct and air distribution ductwork [19].

where $\mathrm{L}$ is the length of duct, $\mathrm{DH}$ is the hydraulic diameter of duct, $\mathrm{f}$ is the friction factor and Vavg is the average velocity of the air in duct.

The friction factor is calculated with the following equation by [20]:

$$
\frac{1}{\sqrt{f}}=1.8 \log \left[\frac{6.9}{R e}+\left(\frac{\frac{\varepsilon}{D_{H}}}{3.7}\right)^{1.11}\right]
$$

where $\varepsilon$ is the absolute roughness of ducts (assumed $0.3 \mathrm{~mm}$ in this work) and Re is the Reynolds number. During the analysis of this case-study, the value of $\triangle \mathrm{PM}$ was negligible.

The operation of the BIPV/T mechanical system is mainly to cool-down the PV-Panels in Summer and hence provide a cooler boundary for the building. Accordingly, the fan is controlled during the cooling season so that a minimum flow rate of $90 \mathrm{~m}^{3} / \mathrm{hr}(25 \mathrm{l} / \mathrm{s})$ is adopted. This corresponds to a u_gap of $0.5 \mathrm{~m} / \mathrm{s}$. At the moment, a constant air-flow is assumed throughout the cooling season and specifically at the minimum value (as a first assumption). The outlet flow of the air-channel is damped to the ambient as indicated in Figure 2-46.

For the BIPVT/T fan control, the cooling season is defined in this work from April until September, in the three cities for the sake of simplicity.

Figure 2-47 illustrates the control strategy that was implemented to use the thermal part of the BIPV/T System as explained previously in section "Thermal Utilization of the BIPV/T System".

In the heating season, the BIPVT-fan operation is mainly to supply ventilation air to the AHU (i.e. during occupancy hours "Sch_Occ") provided that the outdoor temperature "Tamb" is below the heating set-point "THEAT" and is colder than BIPVT air stream "T_coll_m", during the day time "Pelec,BIPVT >0". Worthy to mention is that in Winter this forced flow operation for the BIPVT system should also be activated at any time the PV-Cells temperature exceeds a certain threshold in order to avoid lower efficiencies. This latter condition is less likely to occur in winter and was not considered in the current control strategy. At the moment, the control signal triggers also a constant flow rate that corresponds to the ventilation requirements $\left(120 \mathrm{~m}^{3} / \mathrm{hr}\right)$ as explained in the report DC.1. In fact, to get a significantly warmer outlet air from the BIPVT air-channel, smaller flow rates should be adopted, but in this case mixing with the ambient air in the AHU would be necessary; so as to comply with the ventilation requirements of fresh air $40 \mathrm{~m}^{3} / \mathrm{hr} /$ person as already defined in DC.1. In general, to have variable flow rates between 0 and the rated value, the control strategy gets more complicated. 


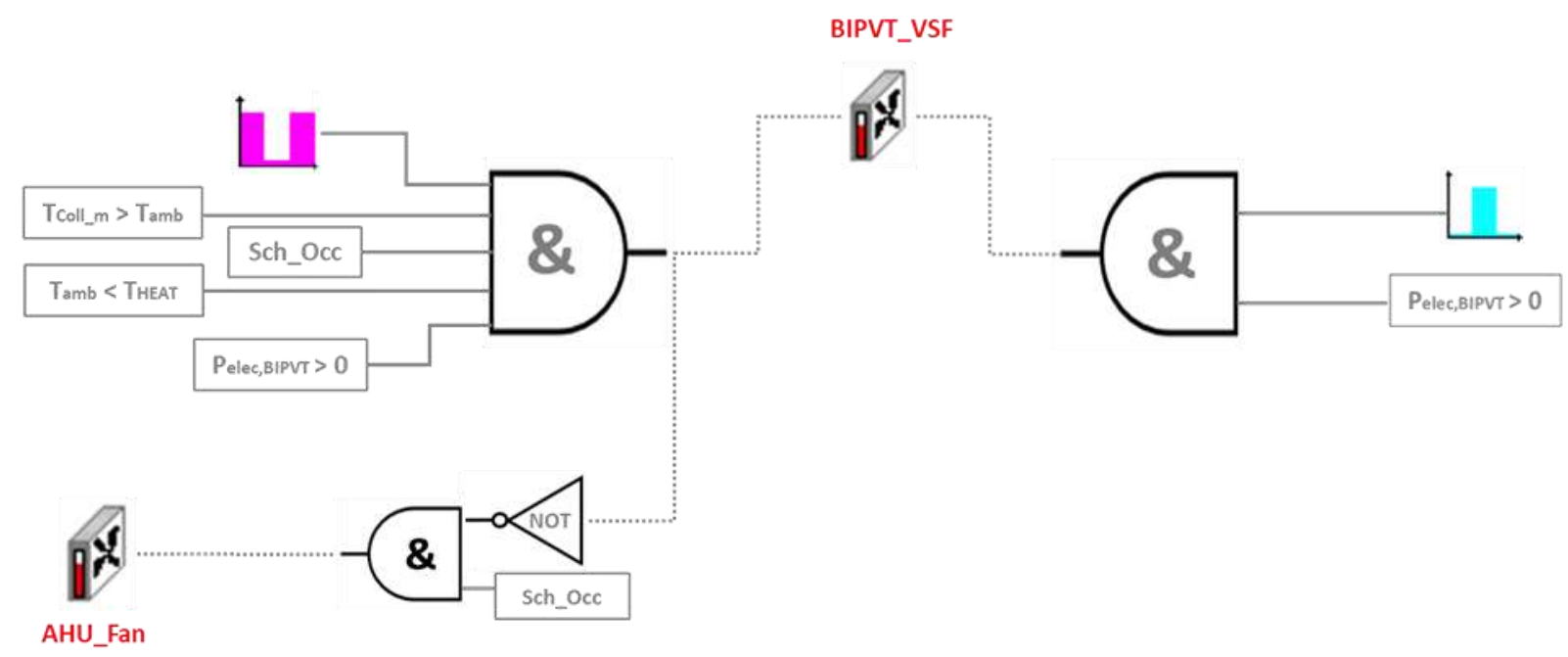

Figure 2-47: The control signals of the BIPV/T System for the thermal utilization

The operation conditions of the heat recovery unit were slightly modified to that described in the DC. 1 report. The new control includes now a free heating mode when the ventilation fresh air-stream comes from behind the BIPVT (i.e. In addition to the previously defined by-pass condition, the HR-Unit is by-passed also now if the preheated fresh air is warmer than the indoor unit, to avoid any loss of useful thermal energy in the supply stream).

\section{Simulation Cases of the BIPV/T Concept}

Three cases were considered to investigate the proposed BIPV/T system. The first case adopts the operation of the fan of the BIPV/T system as explained in the previous section. The second case implies a forced shut-off of the BIPV/T mechanical system, i.e. no forced air flow in the ducts of the BIPV/T system. This case is to represent the scenario of having a PV-System installed onto the building envelope without a prior planning for the thermal utilization of the resulting PV/T concept. Finally, the third simulation case doesn't include a BIPV/T component. Instead, only PV-Modules are implemented in the simulation model without really being integrated to the building skin (Type103 was used instead of Type567). This latter is considered as the reference case where no thermal coupling between the PV-Modules and the building external walls is taken into account. Table 2-14 summarizes the three simulation cases.

Table 2-14: The three cases which were considered in the simulation of the BIPV/T case study

\begin{tabular}{ccc} 
Case (1) & Case (2) & Case (3) \\
\hline BIPVT - operation & BIPV/T - No Flow & No BIPV (Only PV) \\
Control strategy & $\dot{\mathbf{m}}=\mathbf{0}$ & Reference Case \\
\hline
\end{tabular}

\section{Results \& Analysis of the BIPV/T Concept}

For each climate, the simulation was run for the three cases mentioned above. Firstly, the temperature of the PVModules was monitored as well as the PV electrical efficiency which directly affects the electrical power production of the PV-System. For this part of the analysis, the third simulation case was not considered, since a different TRNSYS component was used5. As shown in Figure 2-48, forcing an air-stream to flow in the air-gap between the PV-panels and the external wall of the building (Case 1 - represented by the blue line) has a positive impact on the PV-Temperatures. In the three cities, the operation times at which the PV-Modules experience high temperatures (e.g. $>30^{\circ} \mathrm{C}$ ) are reduced. On the other hand, it can be noticed from the graph-lines of both cases that the PVmodules in Rome suffer longer times at high temperatures than in Stuttgart than in Stockholm. This can be explained

\footnotetext{
5 Type567 and 103 use quite different methods to come up with their electrical outputs (array/cell temperature, efficiency, power estimate) [TRNSYS Technical Support]
} 
by the more intense solar irradiance incident on the vertical PV-Modules in the three cities respectively, as presented in Figure 2-49.

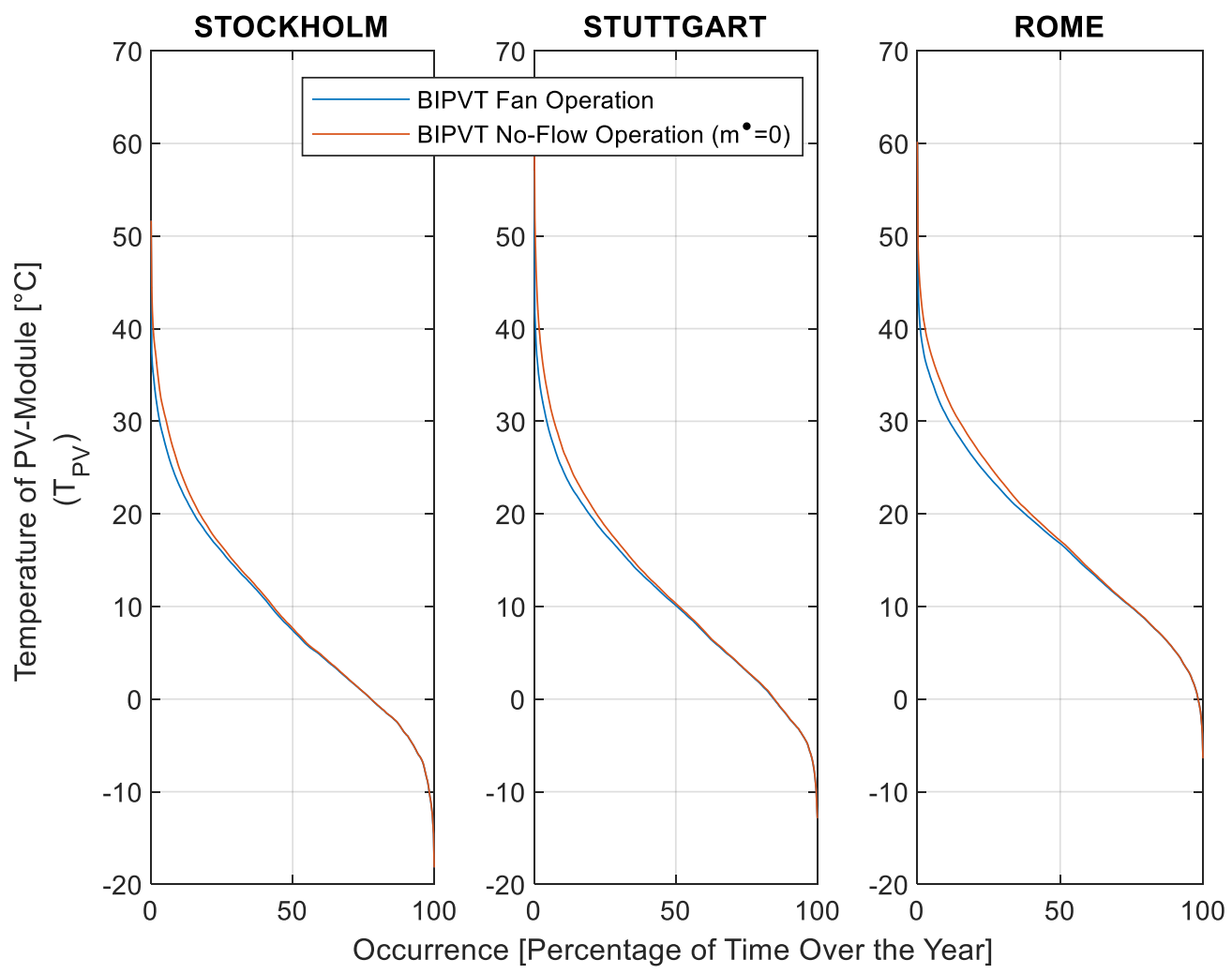

Figure 2-48: An accumulative graph of the PV-Modules temperatures all over the year in the three climates considering two simulation cases of the BIPV/T concept -1) Fan operation according to the control strategy and 2) No flow operation $(\dot{m}=0)$

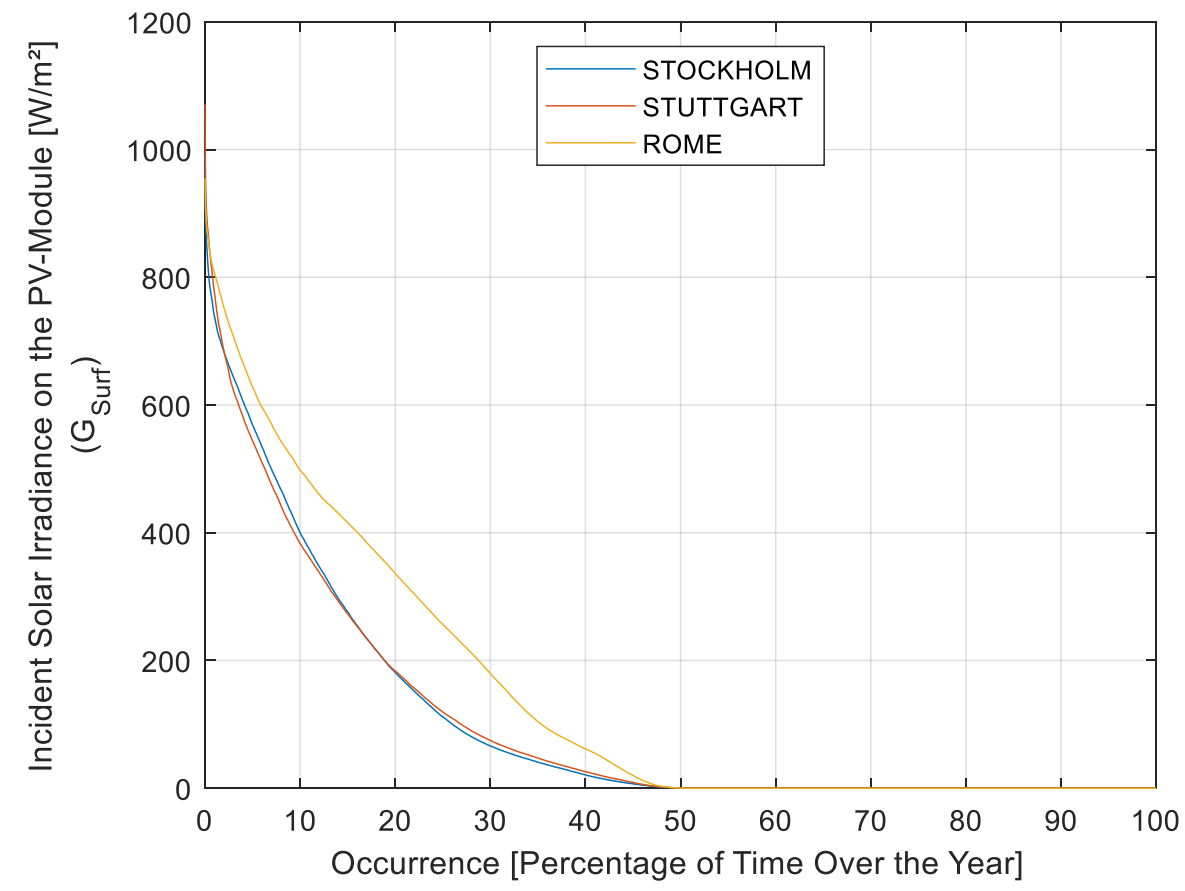

Figure 2-49: An accumulative graph shows the amount and duration of the incident solar irradiance on the vertical PVModules in the three cities under study over the whole year 
The direct impact of the PV-Temperature is on the electrical efficiency of the PV-Modules. The three plots on ROME Figure 2-50 show the inverse relationship between the temperature of the PV-Module (the solid lines) and its electrical efficiency (the dotted lines). The graphs also show the benefit of cooling the PV-modules in the three cities. The blue lines of the BIPV/T fan operation (Case 1) indicate lower monthly mean PV-Temperatures and hence higher monthly mean efficiencies. In Figure 2-51, this effect can be noticed all over the year in the shift between the two lines in each city. The blue line represents the accumulative values of the PV-Efficiency in case 1 , while the red line is of case 2. The shift towards the left indicates less occurrence at lower efficiencies. This difference is compensated by higher occurrence at higher efficiencies. As a general note when comparing the PVEfficiency range among the three cities, the simulation results match well the data reported from experiments and real life measurements. As the climate gets colder, the range of the electrical efficiency of the same installed PVModules improves. In Stockholm (in Case 1), for $53 \%$ of the operation time the electrical efficiency goes below $17.7 \%$, while this percentage reaches $89 \%$ of the time in Rome. This value lies in-between in the moderate weather of Stuttgart, and specifically at $63.8 \%$ of the time. In case (2), this pattern applies but those values increase as a drawback of the warmer PV-Modules at the no-flow case. The values in case (2) are namely: $54.5 \%$ in Stockholm, $65 \%$ in Stuttgart, and $90 \%$ in Rome. The nominal efficiency of the PV-Modules used in the simulation is $17.7 \%$. 

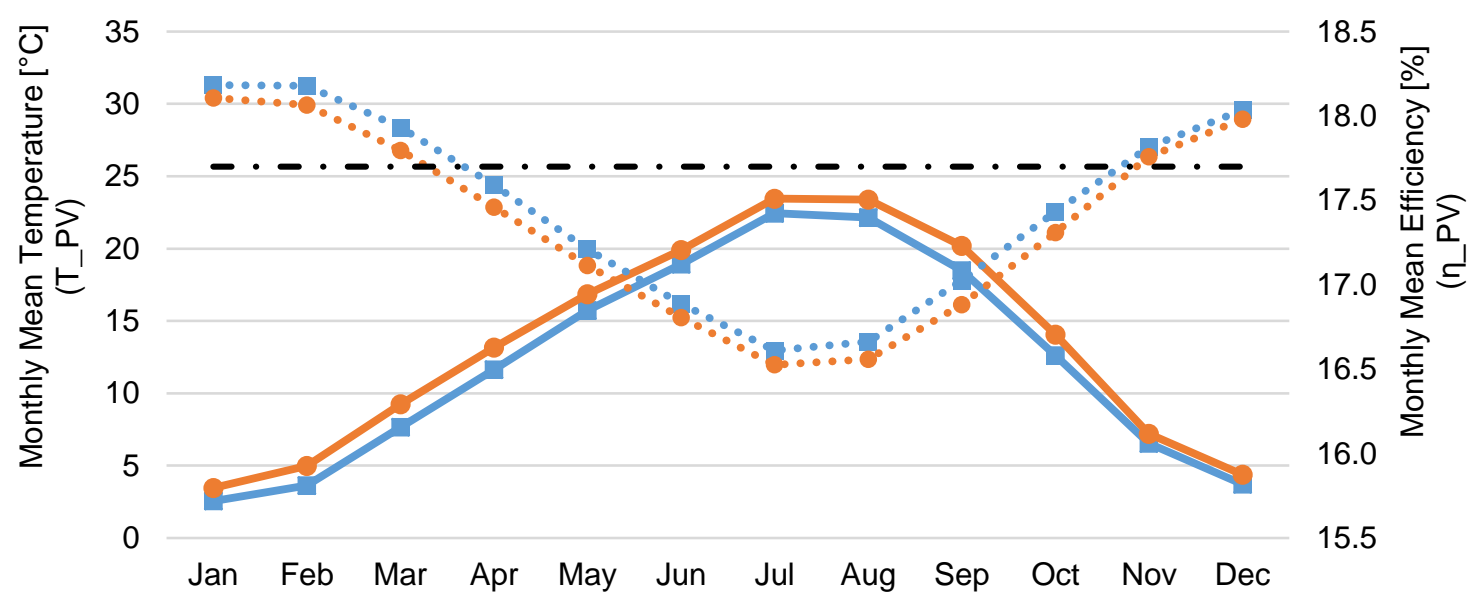

a) STOCKHOLM
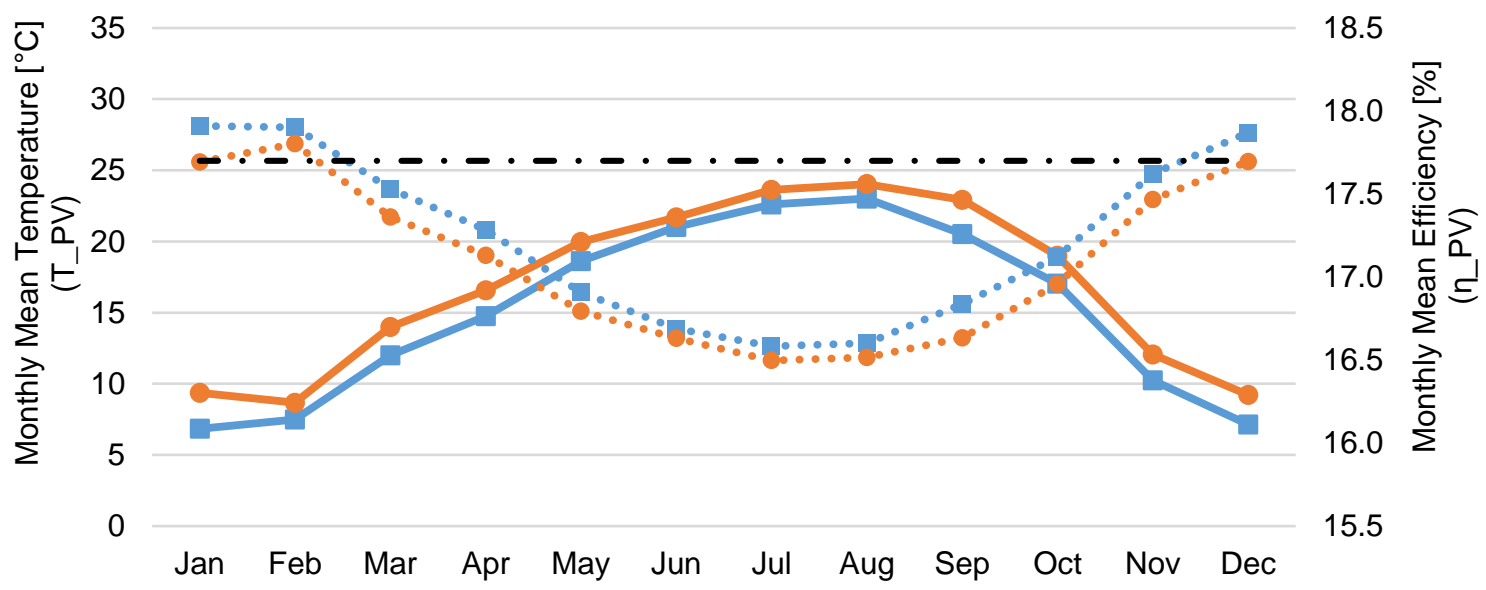

\section{b) STUTTGART}

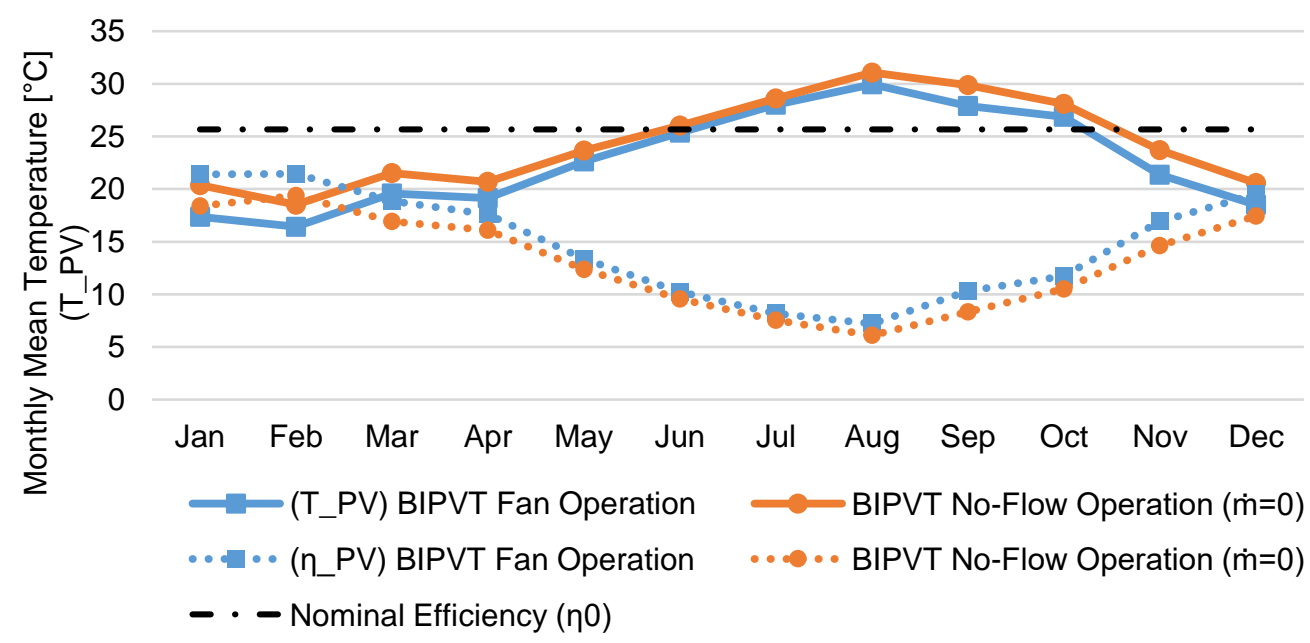

18.5

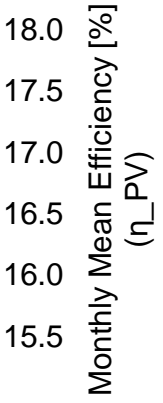

c) ROME

Figure 2-50: The effect of cooling the PV-Modules on the PV-Temperature and PV-Efficiency. 


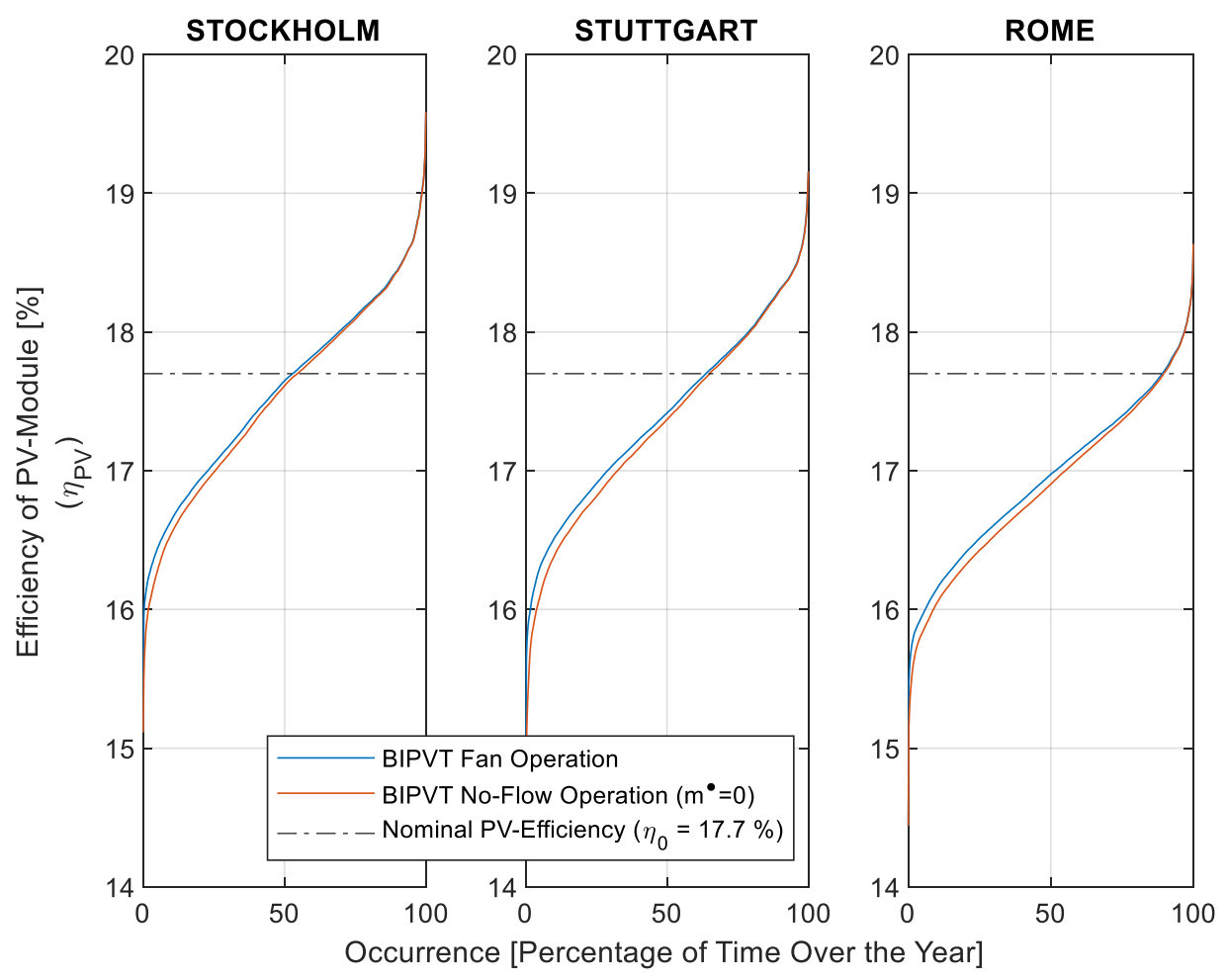

Figure 2-51: An accumulative graph of the PV-Efficiency all over the year in the three cities, indicating the positive effect of the BIPV/T mechanical fan operation compared to the no-flow case

The reduction in the electrical efficiency due to the heating-up of the PV-Modules in case (2) in comparison to case (1) can be also noticed when calculating the electrical power produced by the PV-Panels. Figure 2-52 plots the specific monthly electrical energy that can be generated by the PV-System of both cases in each city. The forced air-flow behind the PV-Modules (Case 1) helps cooling the PV-Panels and hence improve their performance in terms of producing higher electrical power. The percentage increase of the monthly and annual generated energy is calculated in Table 1-2-15. Cooling down the PV-Panels is most beneficial in moderate climates, represented by Stuttgart. The annual increase in the PV-Power generation is $2.31 \%$, compared to $1.74 \%$ in Stockholm and $1.62 \%$ in Rome. 
Table 1-2-15: The net PV-Electricity producible in the simulation cases (1) and (2) in the three cities under study and the percentage increase is calculated for each city.

\begin{tabular}{|c|c|c|c|c|c|c|c|c|c|}
\hline \multirow[b]{3}{*}{ Month } & \multicolumn{9}{|c|}{ PV_WEI_NetProd [kWh/m².month] } \\
\hline & \multicolumn{3}{|c|}{ STOCKHOLM } & \multicolumn{3}{|c|}{ STUTTGART } & \multicolumn{3}{|c|}{ ROM } \\
\hline & $\begin{array}{c}\text { Case (1) } \\
\text { BIPVT- } \\
\text { Operatio } \\
n\end{array}$ & $\begin{array}{c}\text { Case (2) } \\
\dot{\mathrm{m}}=0\end{array}$ & $\begin{array}{c}\% \\
\text { increase } \\
\text { due to } \\
\text { cooling }\end{array}$ & $\begin{array}{c}\text { Case (1) } \\
\text { BIPVT- } \\
\text { Operatio } \\
n\end{array}$ & $\begin{array}{c}\text { Case (2) } \\
\dot{\mathrm{m}}=0\end{array}$ & $\begin{array}{c}\% \\
\text { increase } \\
\text { due to } \\
\text { cooling }\end{array}$ & $\begin{array}{c}\text { Case (1) } \\
\text { BIPVT- } \\
\text { Operatio } \\
n\end{array}$ & $\begin{array}{c}\text { Case (2) } \\
\dot{\mathrm{m}}=0\end{array}$ & $\begin{array}{c}\% \\
\text { increase } \\
\text { due to } \\
\text { cooling }\end{array}$ \\
\hline Jan & 3.93 & 3.89 & 1.14 & 6.87 & 6.60 & 4.11 & 13.97 & 13.60 & 2.69 \\
\hline Feb & 6.47 & 6.38 & 1.46 & 7.89 & 7.79 & 1.39 & 12.12 & 11.90 & 1.81 \\
\hline Mar & 11.09 & 10.88 & 1.92 & 9.50 & 9.25 & 2.78 & 15.27 & 15.03 & 1.60 \\
\hline Apr & 12.11 & 11.90 & 1.77 & 9.18 & 8.97 & 2.34 & 11.11 & 10.95 & 1.46 \\
\hline May & 12.03 & 11.81 & 1.80 & 7.78 & 7.64 & 1.86 & 8.98 & 8.87 & 1.19 \\
\hline Jun & 9.66 & 9.51 & 1.61 & 7.06 & 6.99 & 0.95 & 7.33 & 7.26 & 0.92 \\
\hline Jul & 10.10 & 9.93 & 1.65 & 7.81 & 7.69 & 1.54 & 8.51 & 8.44 & 0.84 \\
\hline Aug & 10.11 & 9.94 & 1.67 & 9.32 & 9.20 & 1.34 & 10.93 & 10.80 & 1.23 \\
\hline Sep & 10.69 & 10.47 & 2.14 & 9.25 & 8.97 & 3.17 & 13.14 & 12.90 & 1.90 \\
\hline Oct & 7.31 & 7.15 & 2.21 & 8.88 & 8.67 & 2.49 & 14.15 & 14.00 & 1.07 \\
\hline Nov & 3.58 & 3.54 & 1.12 & 6.62 & 6.43 & 2.97 & 12.64 & 12.37 & 2.13 \\
\hline Dec & 2.83 & 2.79 & 1.23 & 6.34 & 6.15 & 3.16 & 11.95 & 11.74 & 1.82 \\
\hline Total & 99.91 & 98.20 & 1.74 & 96.53 & 94.34 & 2.31 & 140.10 & 137.87 & 1.62 \\
\hline
\end{tabular}


a) STOCKHOLM

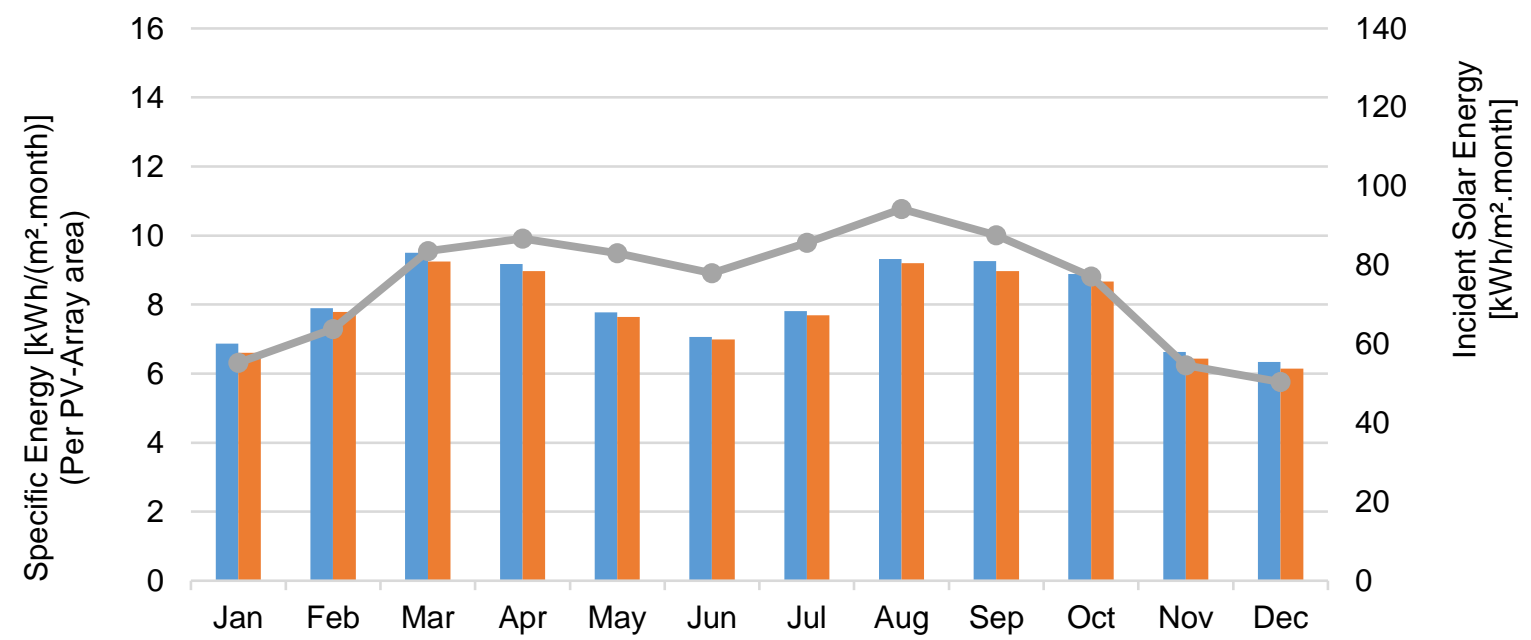

b) STUTTGART

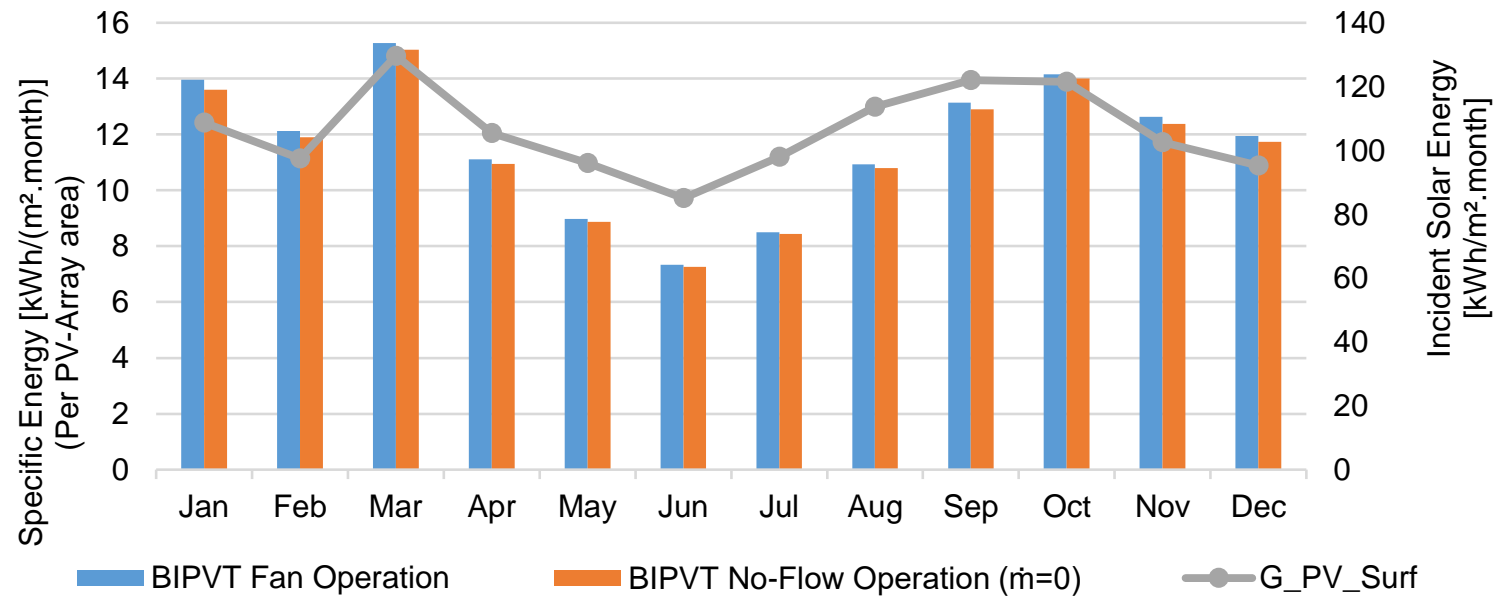

c) ROME

Figure 2-52: The monthly electrical energy producible by the PV-System according to the simulation cases (1) and (2) showing the effect of cooling the PV-Modules - The monthly incident solar radiation on the PV-plane is indicated on the right-axis 
Worthy to mention is that the values of the electrical power output from Type567 are underestimated. The calculation of the PV-Power includes the optical losses of the PV/T model further to the PV-Efficiency (see Eq. 2-3) [21]. As a result, comparing the electrical power produced by a BIPV/T model in TRNSYS to that produced by only a PV model is an inaccurate method and should not be done. To be able to do so, advanced conditioning to Type567 is needed.

$$
\operatorname{Power}_{P V}=\operatorname{Area}(\tau \alpha)_{n} I A M G_{T} \eta_{P V}
$$

Where Power_PV is the PV power production $(\mathrm{kJ} / \mathrm{hr})$, Area is the PV-Module area $\left(\mathrm{m}^{2}\right)$, (Tau-Alpha)n is the transmittance-absorptance product at normal incidence, IAM is the incidence angle modifier, G_T is the total incident solar radiation on the collector surface $\left(\mathrm{kJ} / \mathrm{hr} \cdot \mathrm{m}^{2}\right)$, and Eta_PV is the PV-Efficiency output from Type567 (according to the calculation mode chosen during the Type-Configuration).

The second part of the analysis focused on the effect of the different integration concepts, represented by the three simulation cases, on the thermal behaviour of the building as a thermal zone. Such a behaviour could be analysed by monitoring the consumption of the energy system provided in the office cell to keep the thermal comfort conditions as defined in the DC.1 report. The energy system that was implemented in the three simulation cases was based on the silent mode heat-pump model. The technical specifications of the HP can be found in appendix 0 . The monthly heating demand of the thermal zone in the three simulation cases is plotted on Figure 2-53 for the three cities. 


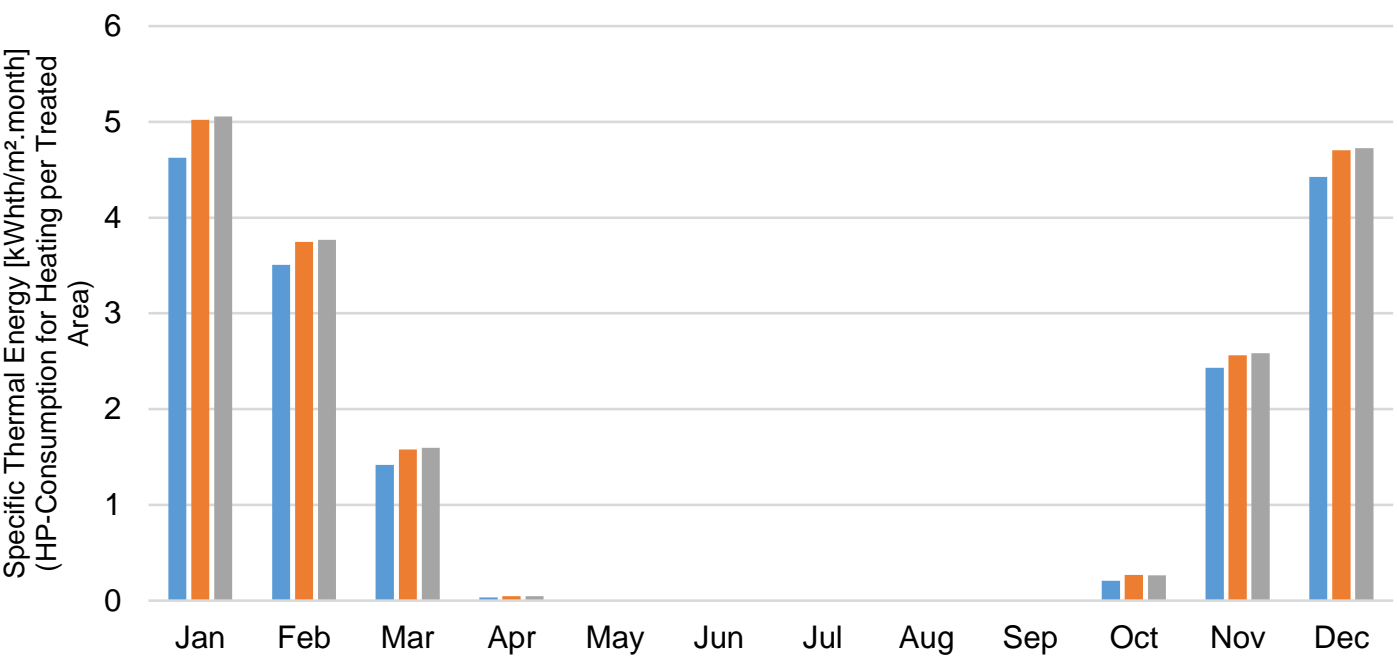

a) STOCKHOLM

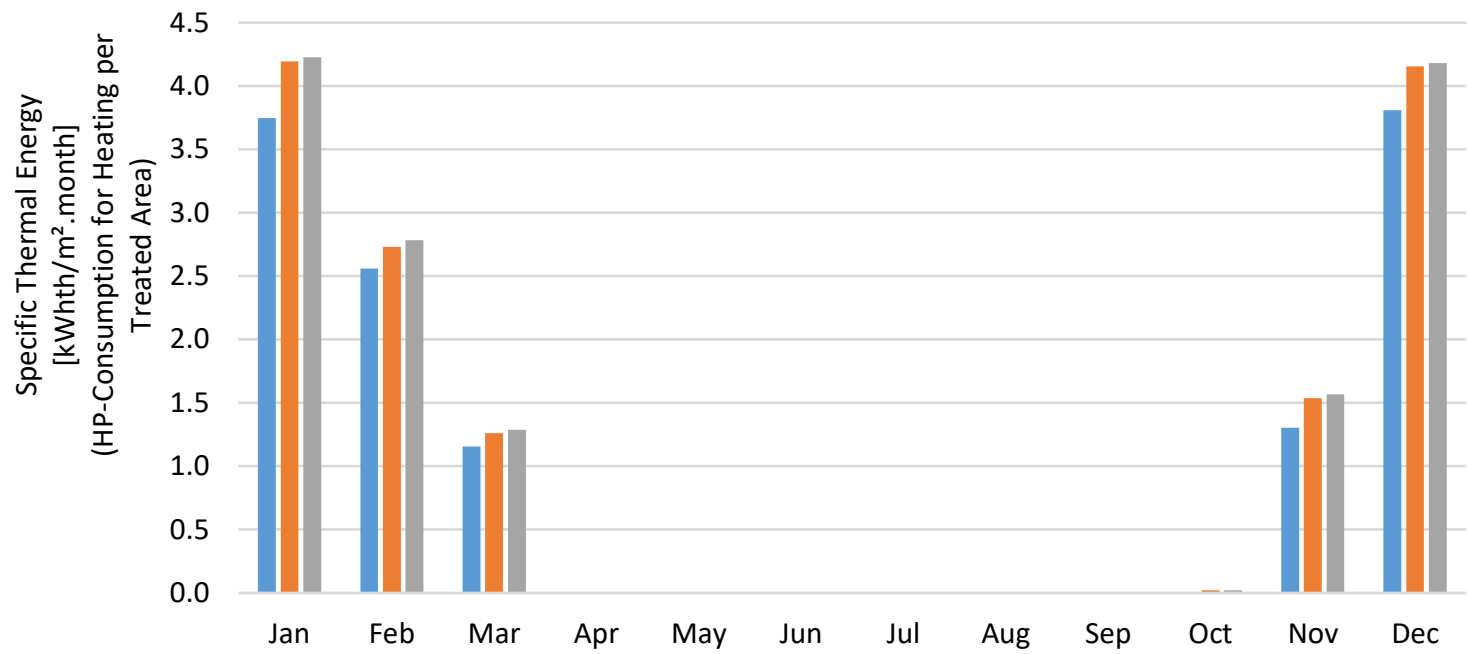

b) STUTTGART

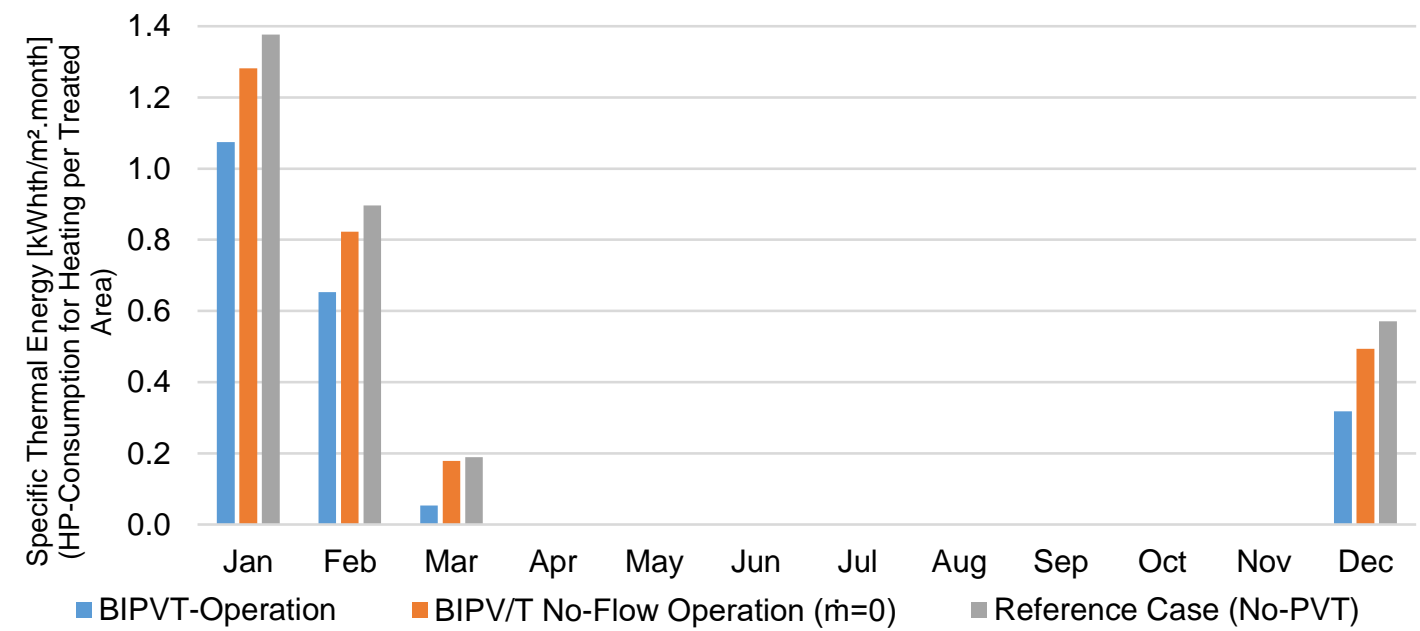

c) ROME

Figure 2-53: The monthly thermal heating demand of the thermal zone (supplied by the HP) in the three simulation cases of the BIPV/T concept in the three cities under study 
Generally, integrating the PV-Modules to the building's envelope (Case 2) reduces the heating demand in winter in the three cities compared to the reference case (the orange bars on Figure 2-53). The PV-Panels represent an extra thermally-insulating layer to the building's skin. This effect is more noticeable in Rome since the building construction is characterized by poor thermal insulation. Conversely, this effect is hardly recognized in Stockholm, where the building is thermally very well insulated, so no significant benefit of the PV-integration concept. On the other hand, having an air-flow through the gap between the PV-Panels and the building's envelope (Case 1) should actually increase the heating demand, since it increases the transmission losses of the thermal zone as indicated in the below Figure 2-54. But as noticed from the blue bars in Figure 2-53, Case 1 shows the lowest heating demand in the three cities. This deviation in the behavior of case 1 is due to using the preheated air from the BIPVT system for ventilation. Such an operation has a positive impact as it helps in reducing the heating demand of the thermal zone furthermore. Figure 2-55 depicts the ventilation losses of the three cases all over the year in each city, and will be further discussed in the following part. 


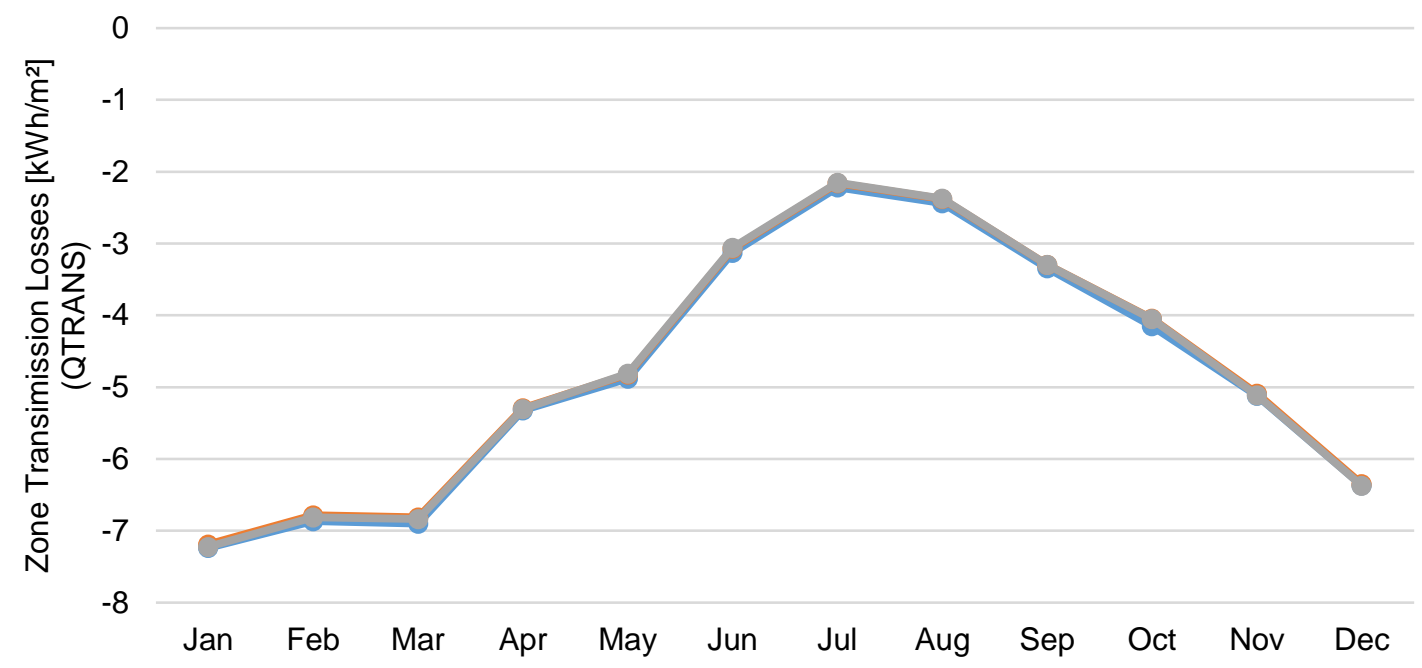

a) STOCKHOLM

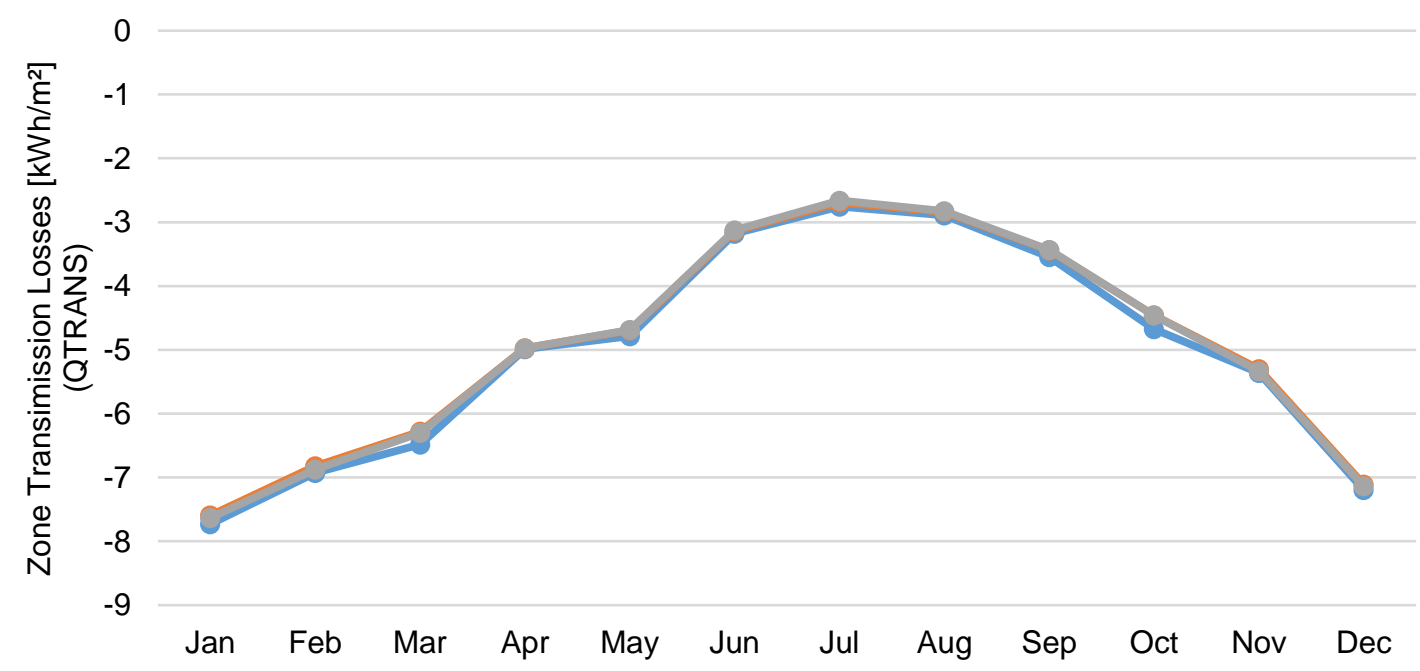

b) STUTTGART

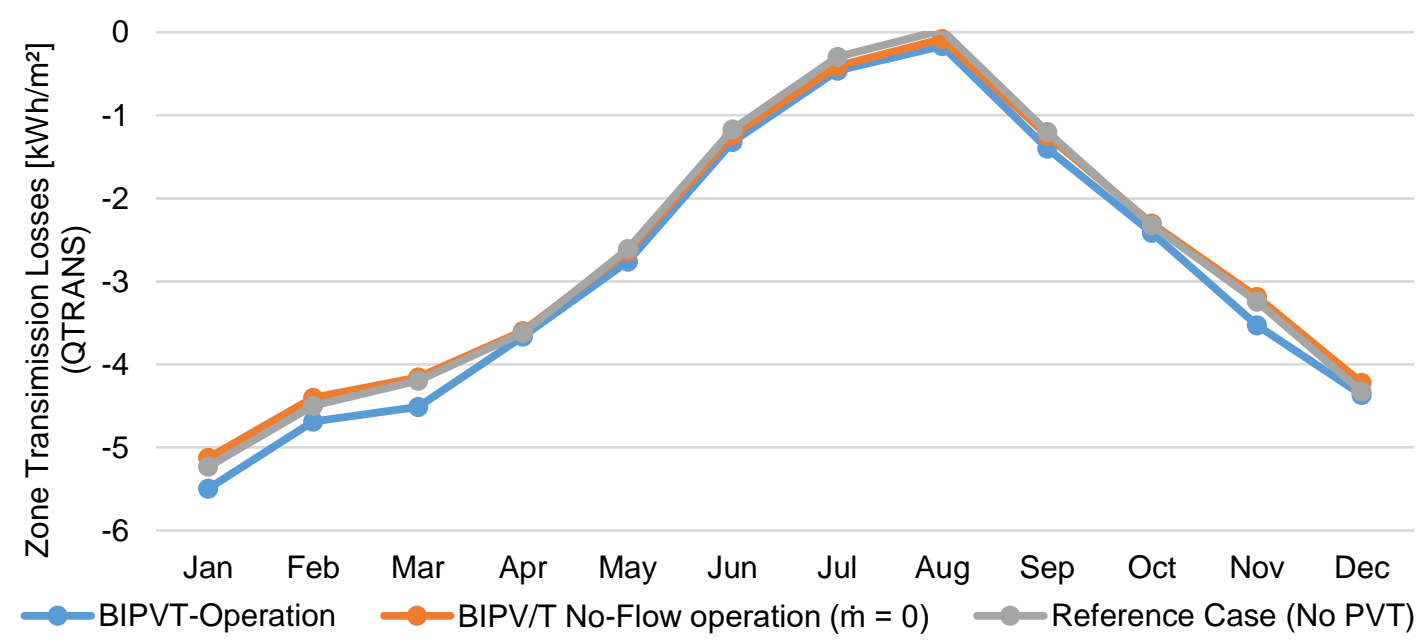

a) ROME

Figure 2-54: The monthly balance transmission losses of the thermal zone under simulation for the three cases of the BIPV/T integration concept 
In the following figure the ventilation losses of the three cases are presented. Case (1) is the only case that shows a noticeable difference. However, this effect of reducing the ventilation losses occurs during the heating season only. This is because in case (1) the preheated air of the BIPV/T operation is activated to support the ventilation cycle of the AHU during the heating season only (Oct - Mar) according to the control strategy adopted in this study. On the other hand, case (2) has almost the same ventilation losses as the reference case all over the year, since both cases use the ambient air for ventilation. Accordingly, it's obvious that during the cooling season (Apr - Sep) the ventilation losses/gains in the three cases are almost the same. 
$-1.0$

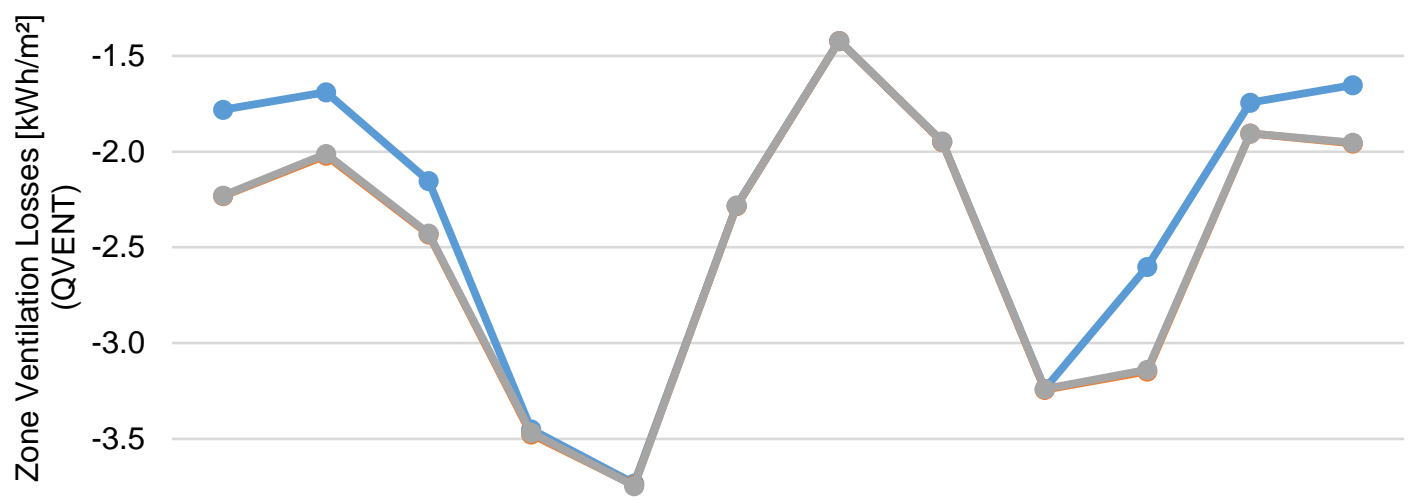

$-4.0$

Jan Feb Mar Apr May Jun Jul Aug Sep Oct Nov Dec

a) STOCKHOLM

$-1.0$

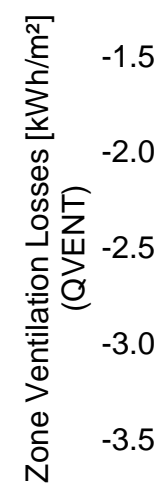

$-4.0$

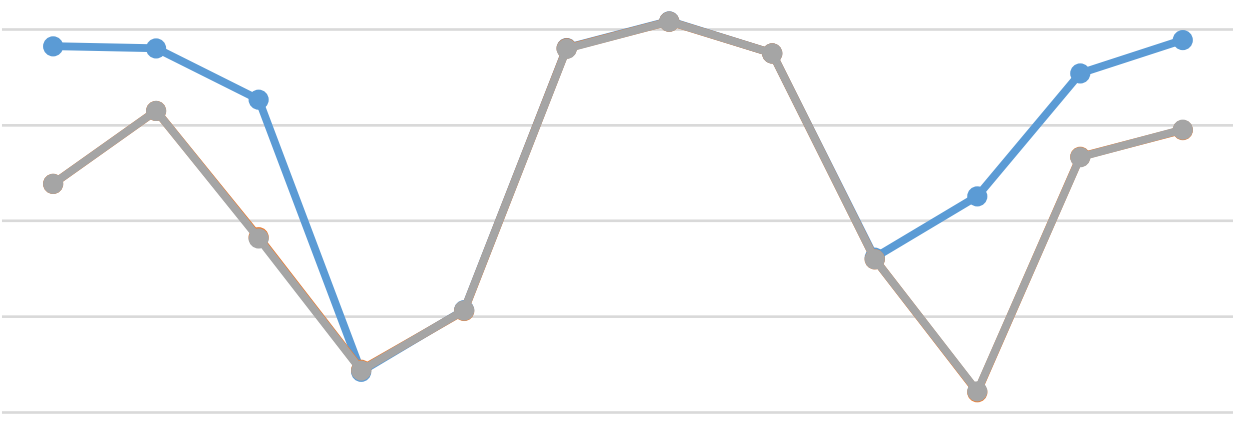

Jan Feb Mar Apr May Jun Jul Aug Sep Oct Nov Dec

b) STUTTGART

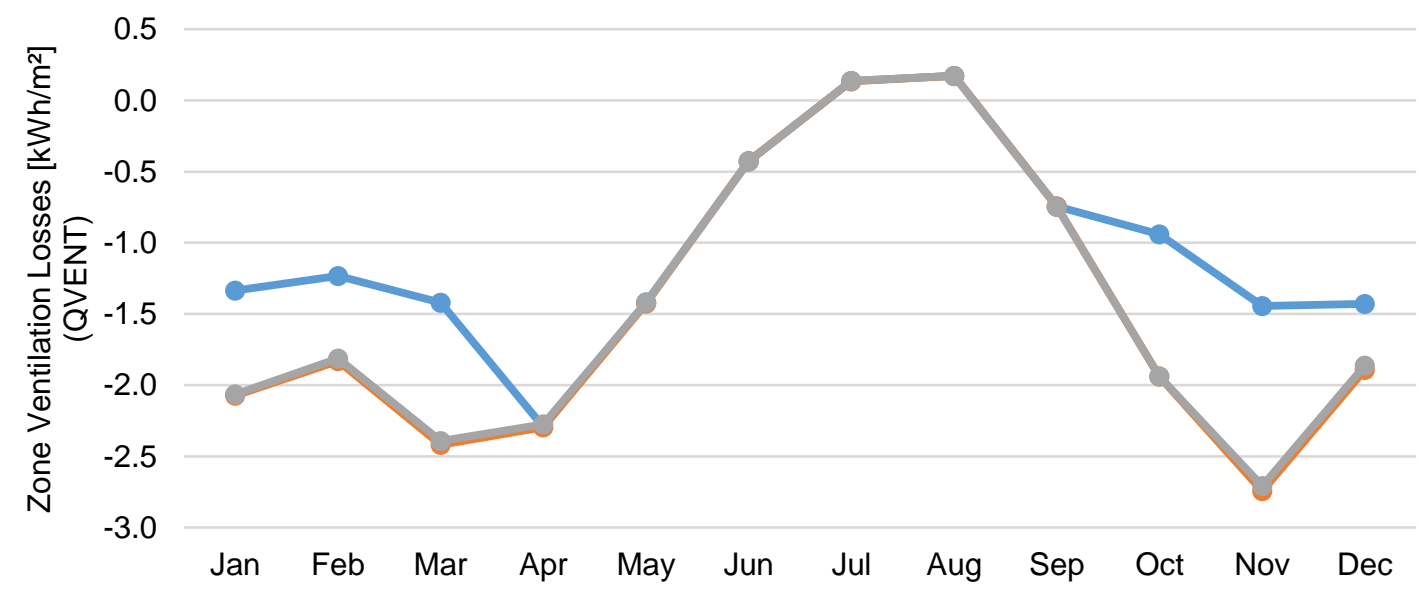

$\longrightarrow$ BIPVT-Operation $\longrightarrow$ BIPV/T No-Flow operation $(\dot{m}=0) \quad$ Reference Case (No PVT)

c) ROME

Figure 2-55: The monthly balance ventilation losses of the thermal zone under simulation for the three cases of the $\mathrm{BIPV} / \mathrm{T}$ integration concept 
Table 2-16 summarizes the heating demand of the thermal zone supplied by the HP all over the year of the three simulation cases for each of the three cities. The total (annual) values of the reference case (Case 3) matches to a good extent the calibration values of TRNSYS as presented in section 2.1.3. Because of the previously explained effect of preheating the ventilation air, the percentage reduction of the heating demand is more significant in case (1) compared to case (2) although it has a stand-still air-layer. This preheating effect is most obvious in Rome, since the ambient air temperature levels (and hence the outlet collector temperature) are already high during the occupancy hours when ventilation takes place (day-time). Worthy to mention is that the monthly values of the percentage reduction during the transitional months of April and October should not be considered, especially in case (1). There is a change in the control strategy in case (1) at the beginning of those two months. The ventilation air is supplied to the AHU from the ambient during the cooling season (Apr - Sep). This supply switches between the ambient and the pre-heated collector air-stream during the heating season (Oct - Mar) according to the control signals as explained previously in section "Control Strategy of the BIPVT- Mechanical System". This can be noticed in the highlighted monthly values in Stockholm (and partially in Stuttgart), where there is a need for heating in those transitional months. When those months are excluded from the analysis, the annual percentage reduction in Stockholm is corrected to $0.65 \%$ in case (2) and to $7.45 \%$ in case (1). This correction is not needed in Stuttgart nor in Rome, since the heating demand in those two transitional months is almost zero.

Table 2-16: The heating demand of the thermal zone supplied by the energy system (HP) in the three simulation cases

\begin{tabular}{|c|c|c|c|c|c|c|}
\hline & \multirow[b]{3}{*}{ Month } & \multicolumn{3}{|c|}{ HP_Q_Heat $\left[k W h t h / m^{2}\right.$.month] } & \multicolumn{2}{|c|}{$\begin{array}{c}\text { Benefit (\%) compared to the } \\
\text { Ref.Case }\end{array}$} \\
\hline & & Case (1) & Case (2) & Case (3) & Case (1) & Case (2) \\
\hline & & $\begin{array}{l}\text { BIPVT- } \\
\text { Operation }\end{array}$ & $\begin{array}{l}\mathrm{BIPV} / \mathrm{T} \\
(\dot{\mathrm{m}}=0)\end{array}$ & No-PVT & $\begin{array}{l}\text { BIPVT- } \\
\text { Operation }\end{array}$ & $\mathrm{BIPV} / \mathrm{T}(\dot{\mathrm{m}}=0)$ \\
\hline \multirow{13}{*}{ 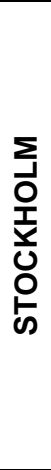 } & Jan & 4.6 & 5.0 & 5.1 & -8.5 & -0.6 \\
\hline & Feb & 3.5 & 3.8 & 3.8 & -7.0 & -0.6 \\
\hline & Mar & 1.4 & 1.6 & 1.6 & -11.1 & -1.1 \\
\hline & Apr & 0.0 & 0.1 & 0.1 & -24.6 & 0.1 \\
\hline & Mai & 0 & 0 & 0 & & \\
\hline & Jun & 0 & 0 & 0 & & \\
\hline & Jul & 0 & 0 & 0 & & \\
\hline & Aug & 0 & 0 & 0 & & \\
\hline & Sep & 0 & 0 & 0 & & \\
\hline & Okt & 0.2 & 0.3 & 0.3 & -21.8 & 1.3 \\
\hline & Nov & 2.4 & 2.6 & 2.6 & -5.8 & -0.9 \\
\hline & Dez & 4.4 & 4.7 & 4.7 & -6.3 & -0.4 \\
\hline & Total & 16.7 & 17.9 & 18.0 & -7.7 & -0.6 \\
\hline \multirow{13}{*}{ 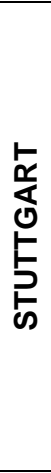 } & Jan & 3.8 & 4.2 & 4.2 & -11.4 & -0.8 \\
\hline & Feb & 2.6 & 2.7 & 2.8 & -8.0 & -1.9 \\
\hline & Mar & 1.2 & 1.3 & 1.3 & -10.5 & -2.0 \\
\hline & Apr & 0 & 0 & 0 & & \\
\hline & Mai & 0 & 0 & 0 & & \\
\hline & Jun & 0 & 0 & 0 & & \\
\hline & Jul & 0 & 0 & 0 & & \\
\hline & Aug & 0 & 0 & 0 & & \\
\hline & Sep & 0 & 0 & 0 & & \\
\hline & Okt & 0.0 & 0.0 & 0.0 & -100.0 & 0.4 \\
\hline & Nov & 1.3 & 1.5 & 1.6 & -16.8 & -2.0 \\
\hline & Dez & 3.8 & 4.2 & 4.2 & -8.9 & -0.6 \\
\hline & Total & 12.6 & 13.9 & 14.1 & -10.6 & -1.2 \\
\hline \multirow{13}{*}{ 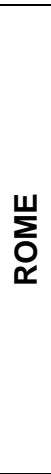 } & Jan & 1.1 & 1.3 & 1.4 & -22.0 & -7.0 \\
\hline & Feb & 0.7 & 0.8 & 0.9 & -27.2 & -8.2 \\
\hline & Mar & 0.1 & 0.2 & 0.2 & -71.7 & -5.7 \\
\hline & Apr & 0 & 0 & 0 & & \\
\hline & Mai & 0 & 0 & 0 & & \\
\hline & Jun & 0 & 0 & 0 & & \\
\hline & Jul & 0 & 0 & 0 & & \\
\hline & Aug & 0 & 0 & 0 & & \\
\hline & Sep & 0 & 0 & 0 & & \\
\hline & Okt & 0 & 0 & 0 & & \\
\hline & Nov & 0 & 0 & 0 & & \\
\hline & Dez & 0.3 & 0.5 & 0.6 & -44.3 & -13.6 \\
\hline & Total & 2.1 & 2.8 & 3.0 & -30.8 & -8.5 \\
\hline
\end{tabular}


The other part of the thermal consumption of the building under study is the cooling demand supplied also by the HP energy system. Table 2-17 presents the specific monthly cooling demand of the thermal zone in the three simulation cases. Unlike the heating case, the total (annual) values of the reference case (Case 3 ) of the cooling energy demand does not match well the calibration values of TRNSYS as presented in section 2.1.3. This is mainly because the energy system used in TRNSYS simulation at that early phase of Task56 was the ideal heating \& cooling energy system provided by TRNBuild, while in this part of the study (the BIPV/T case-study) the energy system was based on a HP-model.

Table 2-17: The cooling demand of the thermal zone supplied by the energy system (HP) in the three simulation cases

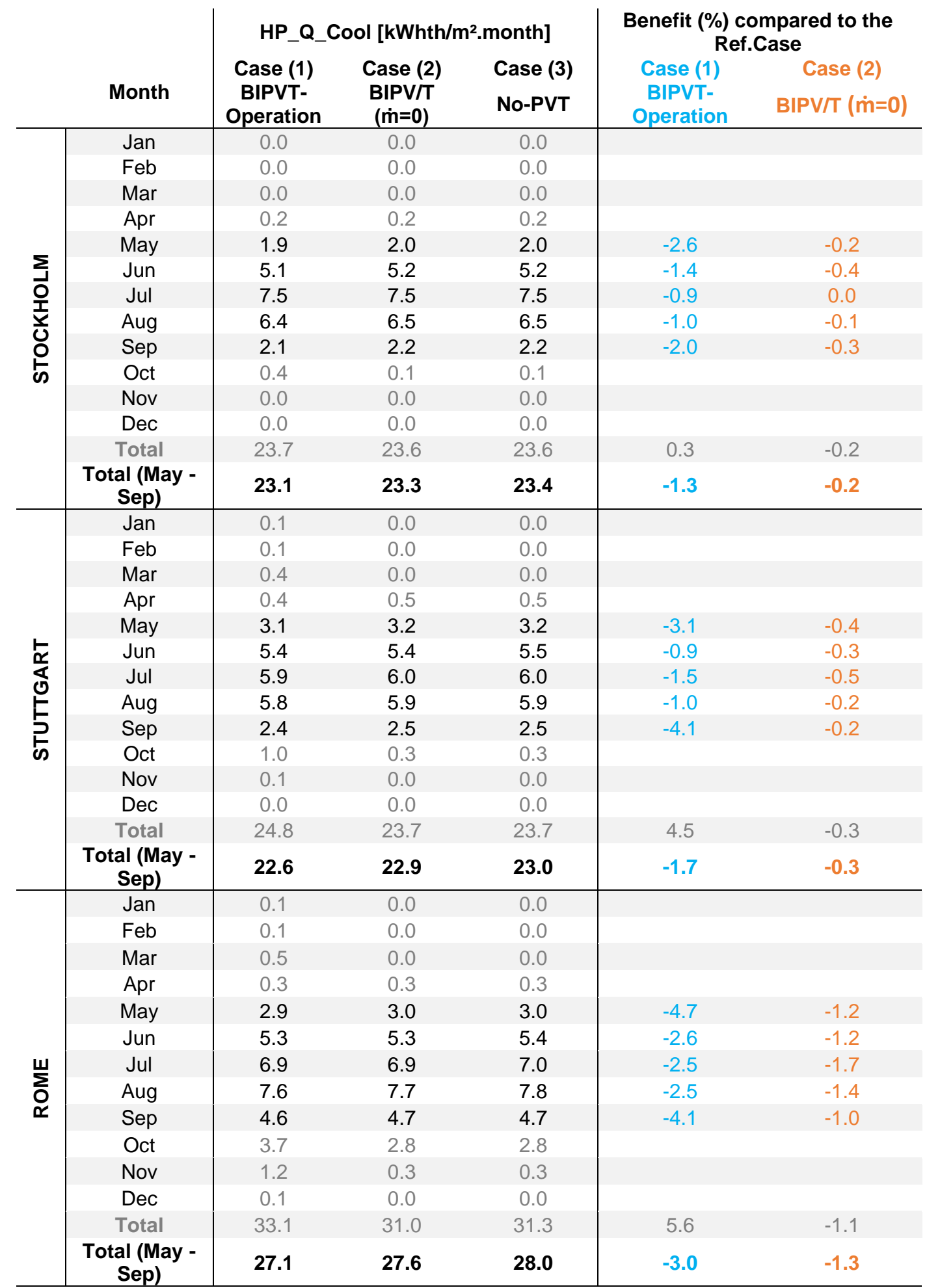


The monthly as well as the annual cooling consumption values of the BIPV/T cases (Case 1 and Case 2) in Table 2-17 shows also a positive effect of the BIPV/T concept. There is a reduction in the cooling demand of cases (1) and (2) in comparison to the reference case, although it is a humble reduction especially in case (2). The forced airflow of case (1) in summer helps to cool-down the building during the day-time (occupancy hours). The convective heat losses from the building's skin accordingly increases compared to the reference case (case 3 ) where the building skin is exposed to the ambient. This can still be seen in the relatively higher overall transmission losses of the thermal zone in case (1) as indicated in the Figure 2-54. This explains the reduction in the cooling demand by $1.29 \%$ in Stockholm and by $1.74 \%$ in Stuttgart and $3.02 \%$ in Rome. So, the BIPVT operation is beneficial in summer as it reduces the cooling demand of the thermal zone. Worthy to mention is that those annual values result from considering the demand in the cooling season only, i.e. from May till September. This is to avoid any uncertainty in the results that might be led to, because of the control strategy of case (1) that uses the pre-heated collector air for ventilation in winter, which can cause overheating during the period from October till March, as can be noticed from the highlighted lines in Table 2-17. In case (2), the overall zone's transmission losses as indicated on Figure 2-54 are also slightly higher in summer than the reference case. This explains the humble reduction in the cooling demand of case (2). Figure 2-56 shows the specific monthly cooling (thermal) demand of the thermal zone supplied by the HP in the three cities. 


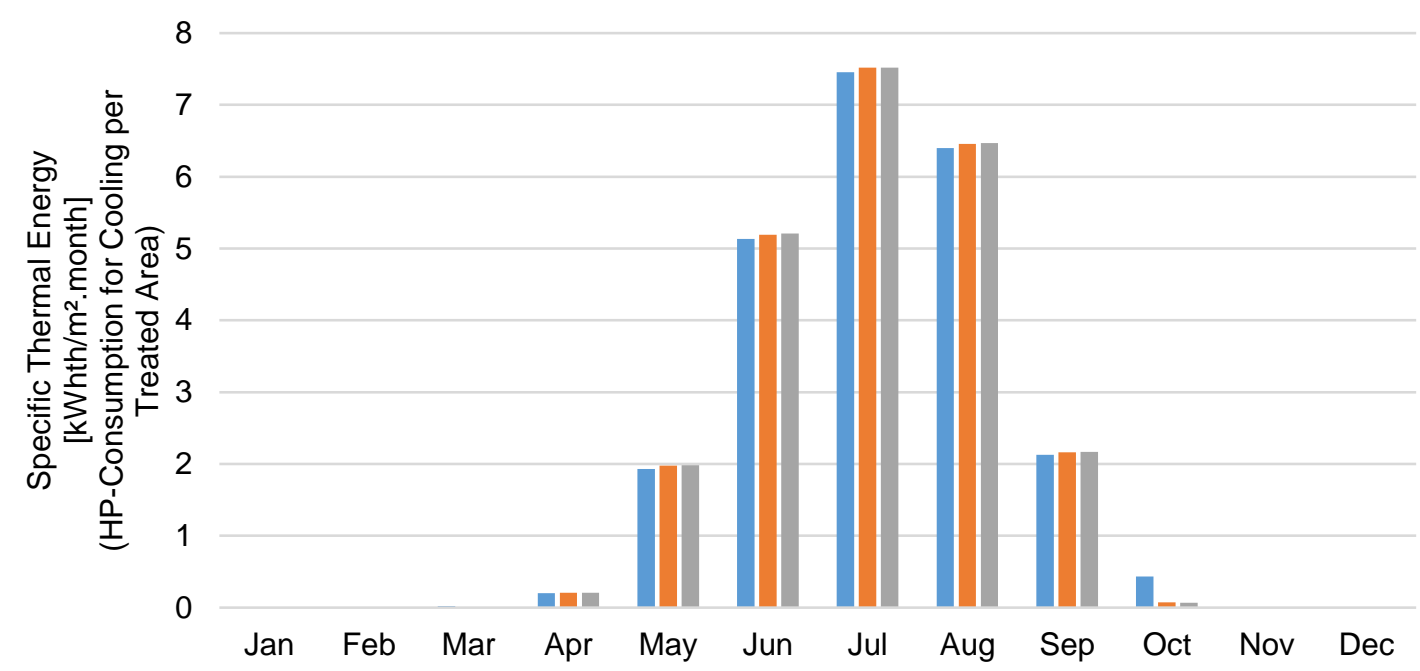

a) STOCKHOLM

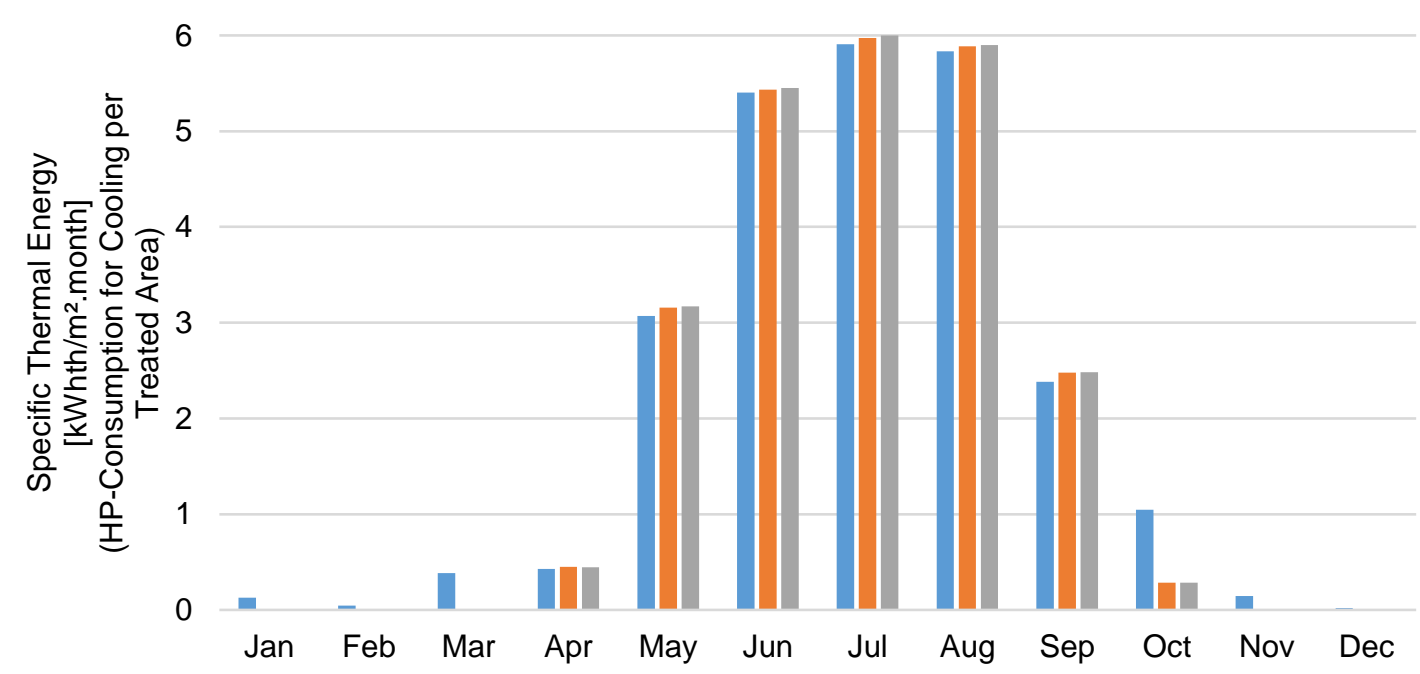

b) STUTTGART

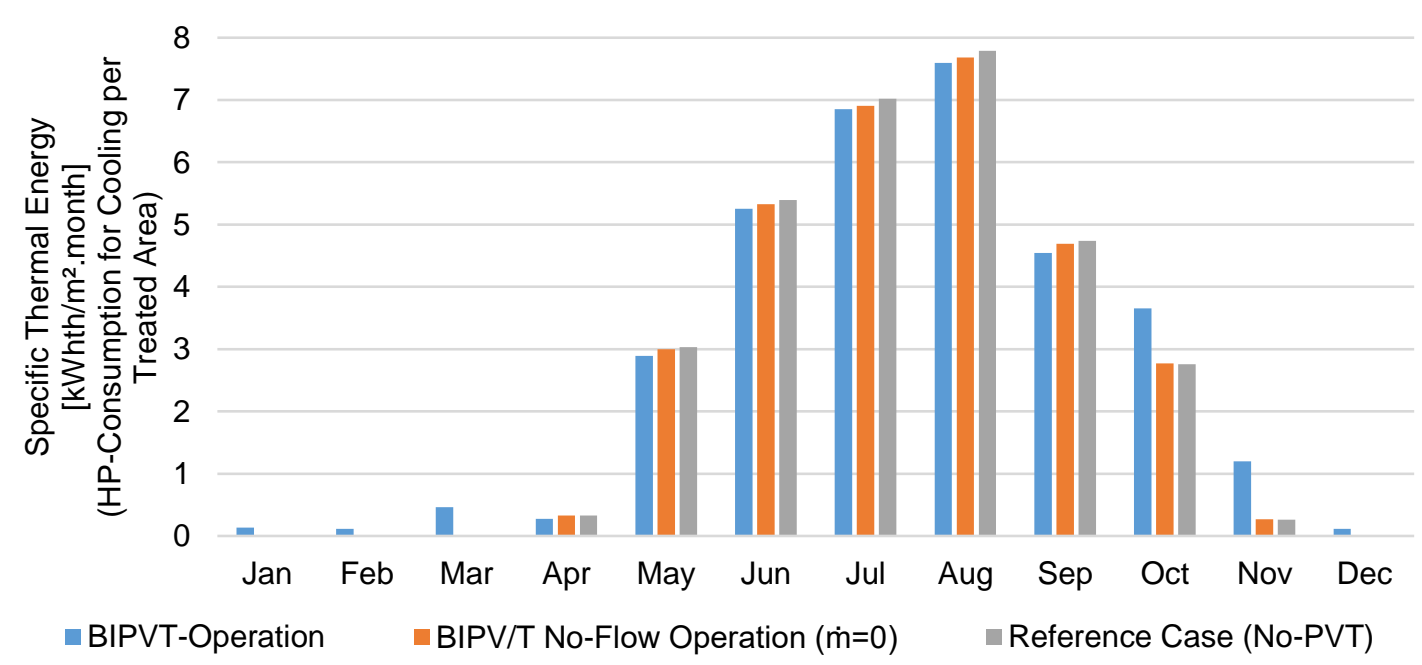

c) ROME

Figure 2-56: The monthly cooling demand of the thermal zone (supplied by the HP) in the three simulation cases of the $\mathrm{BIPV} / \mathrm{T}$ concept in the three cities under study 


\section{Conclusion of the BIPV/T Concept}

From the thermal perspective, it can be concluded that integrating a PV-Layer to the building envelope as configured in this case-study is beneficial all over the year. In case (2), the transmission losses are reduced in winter while increased in summer. Such a behaviour matches well the thermal energy demand of the building, which eventually helps the yearly energy consumption. However, implementing a mechanical (fan) system to the BIPV/T system (case 1) should be carefully considered. It is unconditionally beneficial in summer (even more beneficial than case (2) thanks to the cooling effect). However, to be beneficial in winter, the preheated air should be re-used within the building's ventilation system. Nevertheless, the control strategy has to be more sophisticated than the one presented here in this study in order to avoid any overheating which may lead to an undesired cooling demand during winter time as can be noticed in Figure 2-56. On the other hand, and from the electrical perspective, cooling down the PV-Panels is beneficial in general. In case (1), the PV-Temperatures were less, the PV-Efficiency were improved, and hence the electrical power was higher. Such a benefit was at highest levels in moderate climates, represented by Stuttgart. The annual increase in the PV-Power generation was $2.31 \%$, compared to $1.74 \%$ in Stockholm and $1.62 \%$ in Rome. However, it was not possible to benchmark the results of the BIPV/T cases (case 1 and 2) to the reference case (case 3). Comparing the electrical power produced by a BIPV/T model in TRNSYS to that produced by only a PV model is an inaccurate method and should not be done. 


\title{
2.2.4 Integration of a solar thermal collectors in curtain walls in tertiary office building: simulation-based evaluation of the energy performance
}

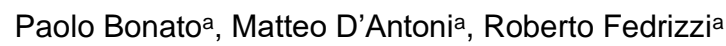 \\ aEURAC research, Institute for renewable energy, Via A.Volta 13/A, 39100 Bolzano, Italy
}

In the here presented concept, a solar thermal collector is integrated into the lower opaque part of a façade module for tertiary office building. The glazed collector enables to harvest the solar heat, which can be either directly distributed to the interior thanks to a radiant panel installed in the interior of the façade or can be convoyed to a central water storage. The radiant panel can be used as emission terminal also during the cooling season. Figure 2-57 shows a simplified layout of the hydraulic system.

The use of a centralized water storage enables to deliver the solar heat to an interconnection point where it can be exploited to satisfy different heat loads: it can be used to satisfy the space heating demand of office spaces and pre-heat the DHW. Back-up heaters are used to complement the solar heat production. A unique HC loop connects all the emission terminals in the office spaces and a single solar loop connects all solar facades in the same floor.

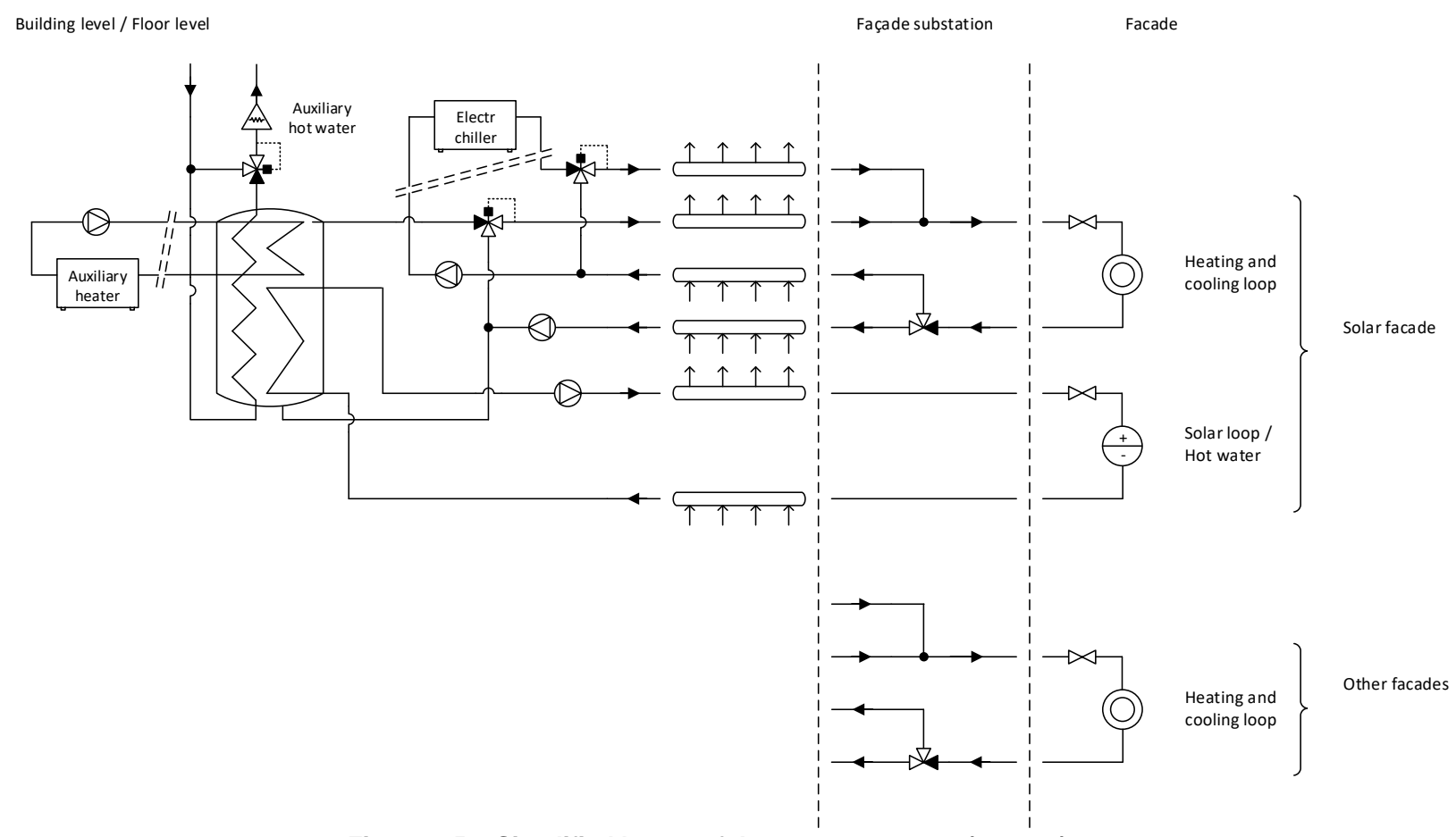

Figure 2-57: Simplified layout of the energy concept (system)

\section{Reference building floor and office spaces}

The energy performances of the proposed concept are assessed with dynamic simulations. As the energy concept is integrated into the floor energy generation/consumption dynamic, it is not sufficient to model and simulate a single office space, but a whole floor is considered for these simulations. The analyzed office floor has the following characteristics:

- $\quad$ The floor has a rectangular plant and it is composed by 32 office cells disposed along the building perimeter. The aspect ratio of the building footprint is 3:1 and the gross floor area is $972 \mathrm{~m} 2$.

- The solar thermal façade modules replace the traditional ones in all offices facing a single orientation, whereas a traditional façade design is considered for the remaining orientations;

- Four different cases are analysed to understand the potential of the solution in a variety of configuration. Different building orientations and active façade ratios $\left(f_{\text {sol }}\right.$, ratio between number of active façade modules and total number of façade modules) are considered:

- Case 1 (P1): the main orientation of the building is North-South, and the South-façade integrates 36 solar modules in 12 office cells. $f_{\text {sol }}$ is equal to $37.5 \%$

- Case 2 (P2): the main orientation of the building isEast-West, and the West-façade integrates 36 solar modules in 12 office cells. $f_{\text {sol }}$ is equal to $37.5 \%$ 
- Case 3 (P3): the main orientation of the building is East-West and the South-façade integrates 12 solar modules in 4 office cells. $f_{\text {sol }}$ is equal to $12.5 \%$

- Case 4 (P4): the main orientation of the building is North-South and the West-façade integrates 12 solar modules in 4 office cells. $f_{\text {sol }}$ is equal to $12.5 \%$

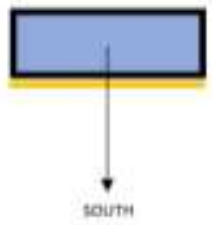

Case 1

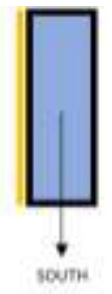

Case 2

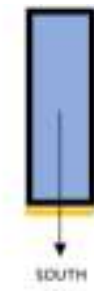

Case 3

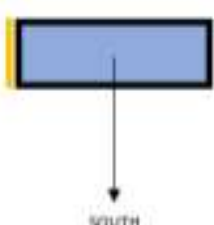

Case 4

Figure 2-58: analysed cases

A series of simplifications were made to reduce the simulation effort in terms of computation time and modelling work:

- $\quad$ Common areas, WC, transit areas and technical spaces are not included in the floor model. They do not represent a load for the heating/cooling systems and do not exchange heat with the internal walls of the offices;

- Corner offices are not considered.

Boundary conditions such as infiltration, ventilation, temperature set-points and the control strategy of the shadings are identical in all offices, disregarding the orientation of the facade. Such conditions are described in Deliverable DC.1. It is assumed that the heat transfer across internal walls/floors/ceiling is negligible. It follows that the thermal behavior of the office rooms facing the same orientation is identical and it is possible to simulate only one office room per orientation, significantly reducing the computation time.

In addition to the conditions presented in Deliverable DC.1, the DHW load is also considered in the numerical model. The DHW withdrawal schedule is modelled distributing the total daily $\mathrm{DHW}$ load (4 L/day/person at $\left.60^{\circ} \mathrm{C}\right)$ among the occupation hours following the hourly occupancy profile. The DHW load is reduced by a contemporaneity factor equal to 0.8 [2] and is modulated throughout the day according to the occupancy level. The temperature of the tap water is $15^{\circ} \mathrm{C}$ and is pre-heated in the centralized tank. A three-way valve prevents the $\mathrm{DHW}$ to reach temperatures higher than $60^{\circ} \mathrm{C}$ at the mixing point. In case the pre-heating is not sufficient, the water flow is further heated up by an electric heater to the target temperature of $60^{\circ} \mathrm{C}$.

\section{Centralized storage, generation and distribution system}

The hot water storage is cylindrical with a fixed aspect ratio $d: h$ that is $1: 2$. Its capacity has been defined as:

$$
V_{\text {tank }}=r \cdot S_{\text {coll }}
$$

where $S_{\text {coll }}$ is the total surface of the solar thermal collector and $r$ is equal to 40 liters $/ \mathrm{m}^{2}$ or and 70 liters $/ \mathrm{m}^{2}$ depending on the scenario. It is assumed that a single hot water storage is used for each floor. Such storage is connected to both the emission terminals and to the solar facades on the same floor.

It is assumed that the space heating power is produced by a boiler (seasonal efficiency $=85 \%$ ) and that the space cooling power is produced by a compression chiller (SEER $=3.5$ ). An electric resistance works as back-up for the DHW preparation. It is assumed that the efficiency of the distribution system is equal to $90 \%$.

The warm/cold water mass flows required to satisfy the thermal demand of all offices is calculated assuming a parallel hydraulic connections. The same principle applies to the active solar technology.

The solar façade modules integrate a $1.8 \mathrm{~m}^{2}$ aperture area glazed solar thermal collector each and an equally sized radiant panel on the inner side. The performance of the components is calibrated to the performance of real products. 


\section{Simulation setup and Key performance indicators}

As already mentioned, a total of four different building positions (P1, P2, P3 and P4), two $r$ rates (40 L/m² and 70 $\mathrm{L} / \mathrm{m}^{2}$ ), three climates (Rome, Stuttgart and Stockholm) is considered for a total of 24 numerical simulations. A comparison is carried out with a reference case where no active solar technology is applied. In this case, two building positions and three climates are considered, for a total of 6 reference scenarios.

The performances of the energy system are compared in terms of useful energy demand, solar yield, solar fraction, thermal comfort and yearly final energy demand with respect to the reference case. The yearly total useful energy demand is the energy needed at floor level for space heating (QHEAT), space cooling (QcooL) and DHW preparation (QDHW). It is expressed in kWh per square meter of gross floor area. The solar yield (SY) is defined as the total of the solar energy annually harvested per square meter of solar thermal collector. The solar fraction is the fraction of thermal load that can be covered with solar energy or, in other words, the amount of heat provided by the solar technology divided by the total energy required. In addition to the overall solar fraction (SFTOT), separate yearly solar fractions for $\mathrm{DHW}\left(\mathrm{SF}_{\mathrm{DHW}}\right)$ and space heating $\left(\mathrm{SF}_{\mathrm{SH}}\right)$ are calculated. The yearly final energy demand of the floor is evaluated considering the energy intake (gas $Q_{\text {gas }}$ or electricity $\mathrm{W}_{\mathrm{el}}$ ) of the back-up systems. It is expressed in $\mathrm{kWh}$ per square meter of gross floor area.

\section{Results}

Comparing the results provided below, it is possible to see that the useful energy demand does not significantly differ from the reference case, meaning that the presence of the insulation layer and a small air cavity on the back of the panel limits the thermal interaction between solar collector and thermal zone.

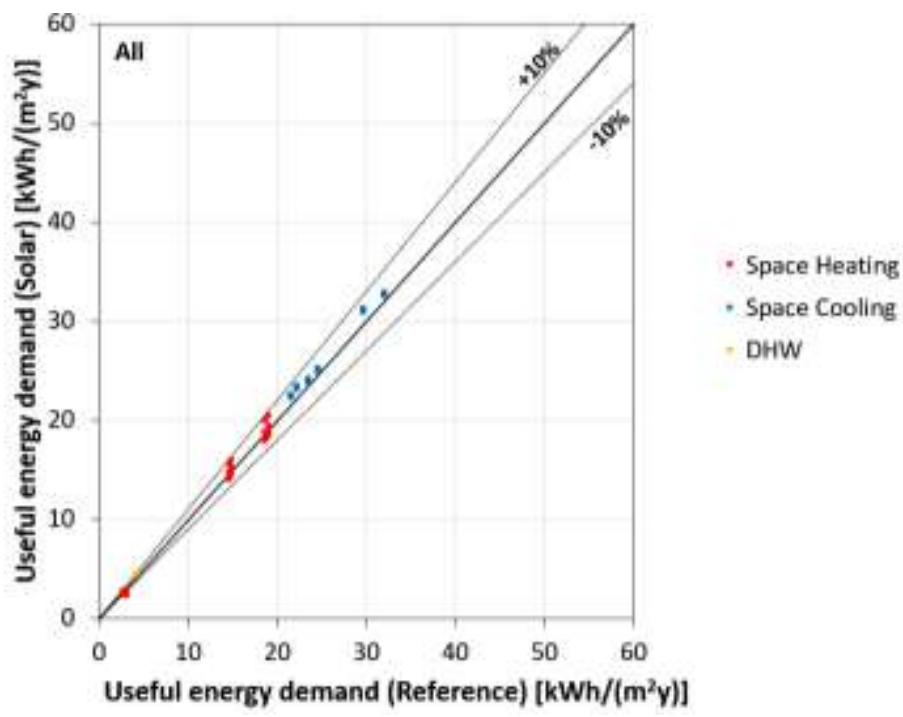

Figure 2-59: Useful energy demand for different active façade ratios divided into space heating/cooling and DHW

In the graphs shown below Figure 2-60, the energy climates for each climate are described by a quadrangle, where the top-right corner is represented by case $\mathrm{P} 1$, the bottom-right corner by case $\mathrm{P} 2$, the top-left corner by position $\mathrm{P} 3$ and the bottom-left corner by position P4. 


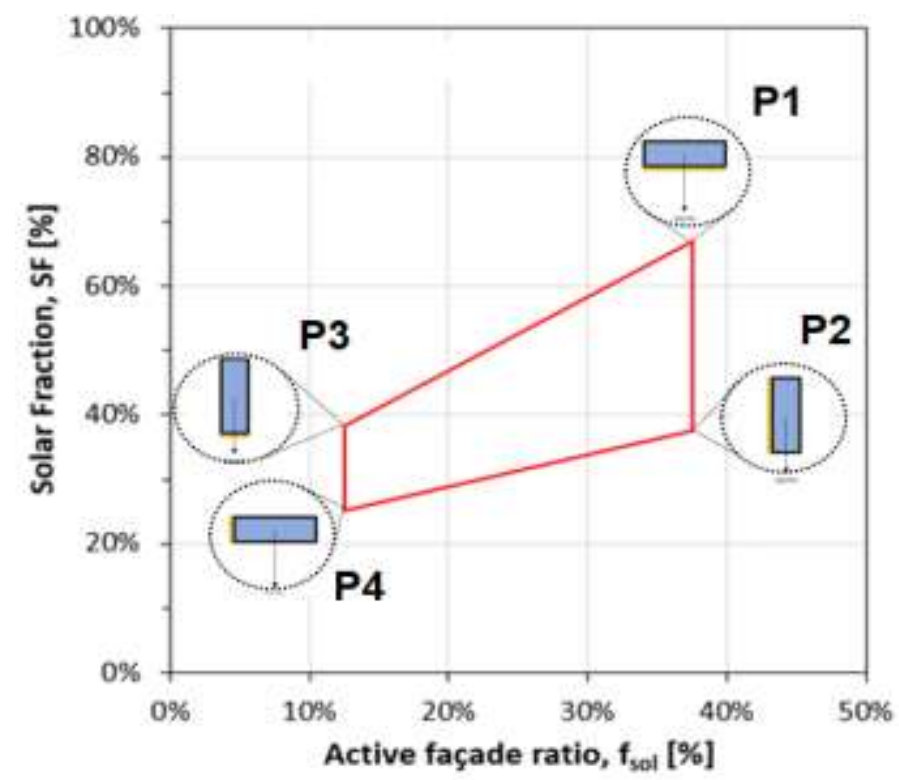

Figure 2-60: Solar fraction against active façade ratio described by a quadrangle, where the top-right corner is represented by case P1, the bottom-right corner by case P2, the top-left corner by position P3 and the bottom-left corner by position P4

Concerning the solar performances, the solar yield is shown in Figure 2-61. The solar yield is higher in Rome and lower Stuttgart and Stockholm. The solution where the solar collector area is exploited at best is P3. This can be easily explained considering that the solar radiation in winter -when the space heating demand is higher- on South facades is higher than for all the other orientations. West-, East- and North- orientations represent indeed suboptimal solutions for the installation of solar technologies in this context. The solar yield is also higher for solutions where a smaller active façade ratio is used, as a smaller solar collectors' area is exploited much intensively than a large collector field. The solar yield reached with unglazed collectors is between $63 \%$ and $41 \%$ lower than for glazed collectors, depending on the scenario. The improvement in terms of solar yield obtained with the use of a larger water storage is only between $13 \%$ and $6 \%$.
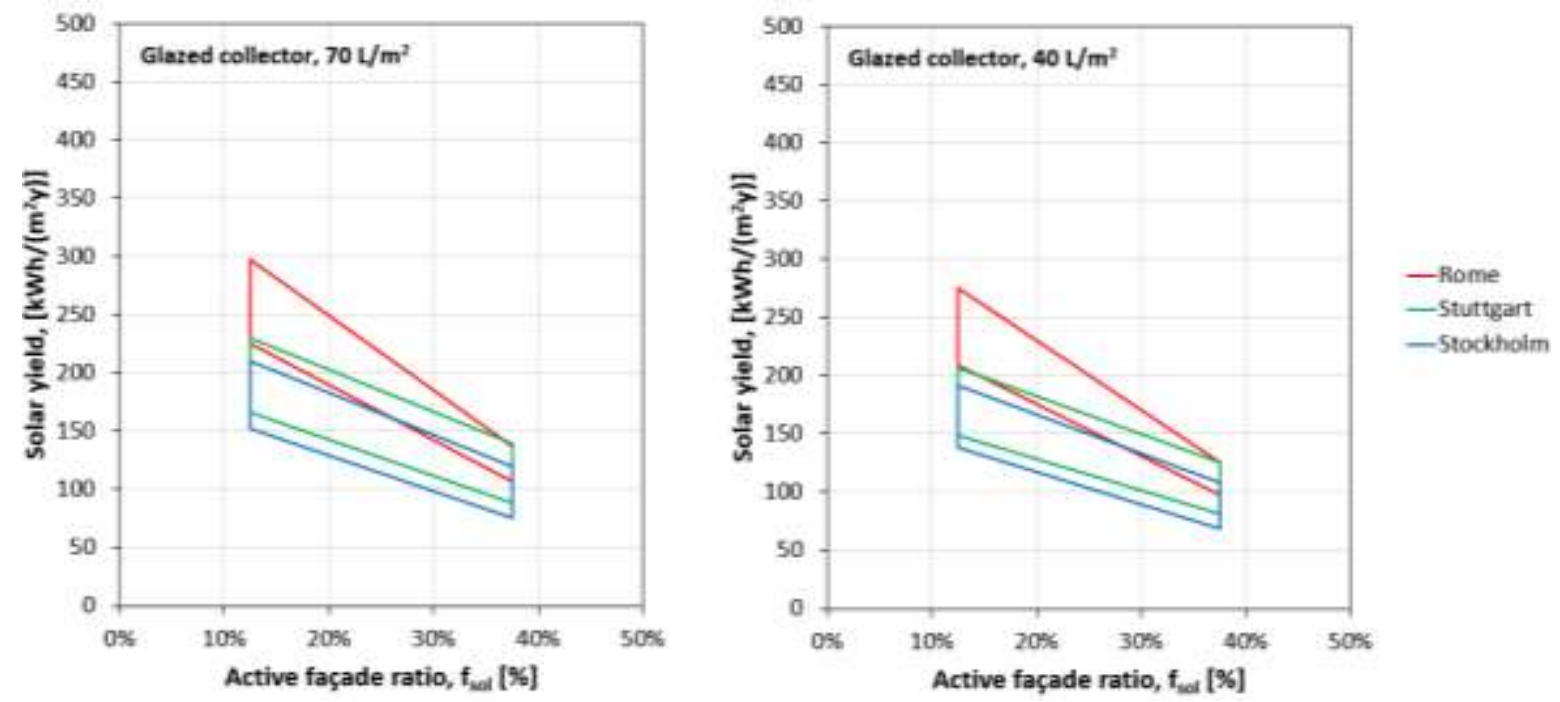

Figure 2-61: Solar yield for different active façade ratios in three locations (Rome, Stuttgart and Stockholm)

The overall solar fraction determined for different scenarios is shown in Figure 2-62. As it can be seen, the trends already discussed above can be found here with the difference that façades with higher $f_{\text {sol }}$ guarantee higher $S F$. The overall energy deliveries are higher for larger solar collector's areas even though the solar yield is lower. 

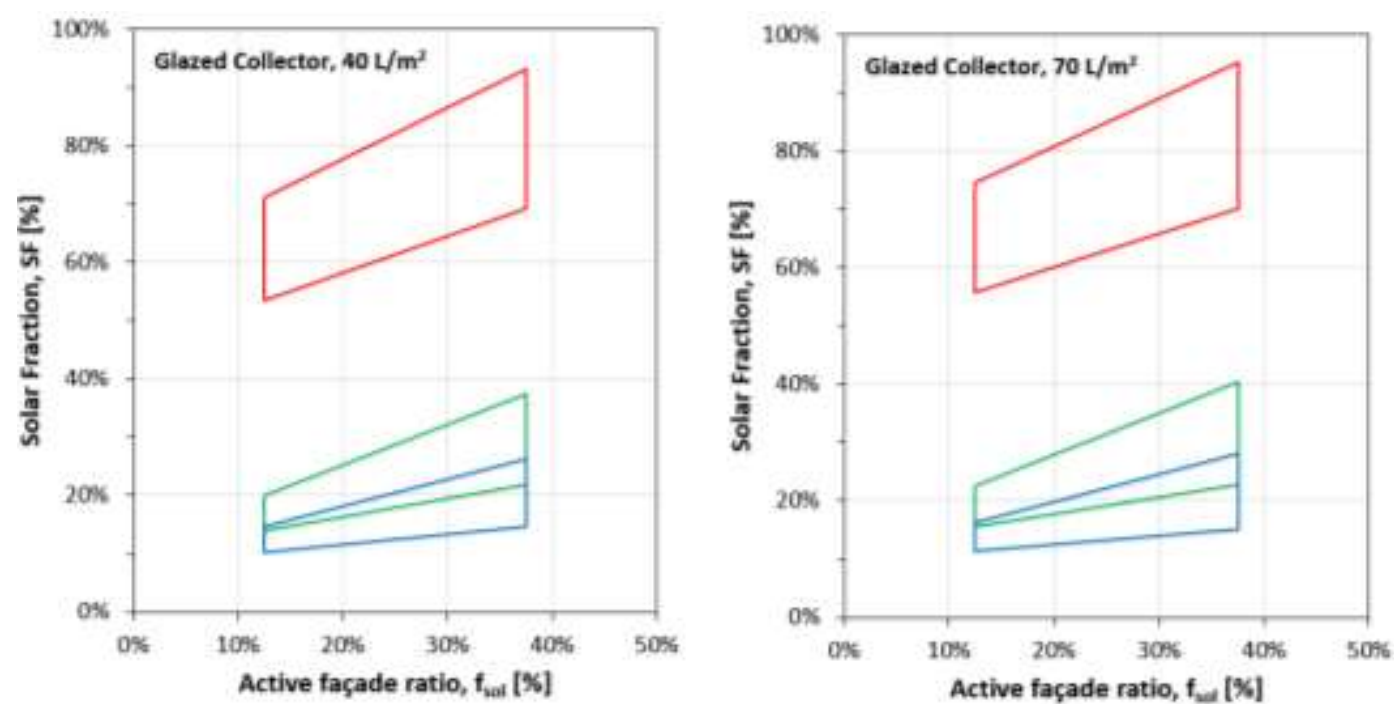

Figure 2-62: Solar fraction for different active façade ratios in three locations (Rome, Stuttgart and Stockholm)

The final energy consumption for space heating and DHW preparation is evaluated in all cases and the comparison with the reference scenarios is reported in Figure 2-63. It can be seen that the electricity consumption is basically unvaried, whereas a notable reduction of the gas consumption is achieved (up to $67 \%$ in Rome, $29 \%$ in Stuttgart and $20 \%$ in Stockholm). The highest reduction in gas consumption is achieved always in the case of 12 Southfacing offices and larger tanks. Overall, the use of larger water storages reduces only minimally the gas consumption (up to $14 \%$ in Rome, $2 \%$ in Stuttgart and $1 \%$ in Stockholm).

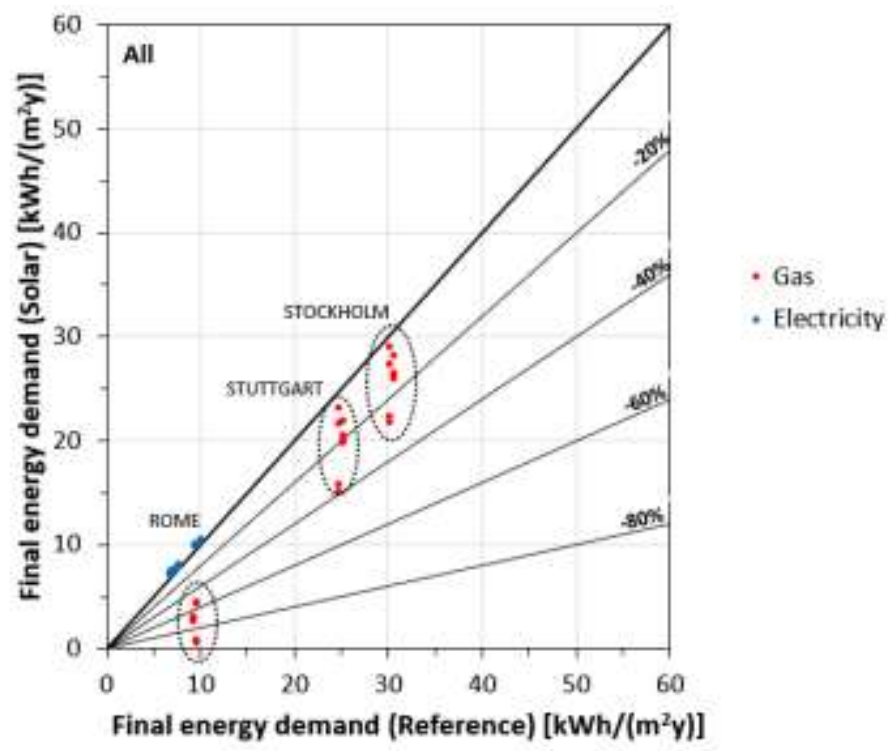

Figure 2-63: Final energy demand for different active façade ratios in three locations (Rome, Stuttgart and Stockholm) 
Table 2-18: Summary of the results (i.e. Solar index and final energy) for the different climates and different considered cases (P1, P2, P3, P4) considering different storage sizes

SOLAR INDEXES

\begin{tabular}{|c|c|c|c|c|c|c|c|c|c|}
\hline \multirow[b]{2}{*}{ Climate } & \multirow[b]{2}{*}{$\begin{array}{l}\text { V/S } \\
{\left[\mathrm{l} / \mathrm{m}^{2}\right]}\end{array}$} & \multirow[b]{2}{*}{$\begin{array}{c}\text { Position } \\
{[-]}\end{array}$} & \multirow[b]{2}{*}{$\begin{array}{c}\mathbf{f}_{\text {sol }} \\
{\left[\mathrm{m}^{2} / \mathrm{m}^{2}\right]}\end{array}$} & \multirow[b]{2}{*}{$\begin{array}{c}\text { Solar yield } \\
{\left[\mathrm{kWh} / \mathrm{m}^{2} / \mathrm{coll}\right]}\end{array}$} & \multirow[b]{2}{*}{$\begin{array}{c}\text { Solar fraction } \\
{[\%]}\end{array}$} & \multicolumn{2}{|c|}{ with solar facade } & \multicolumn{2}{|c|}{ without solar facade } \\
\hline & & & & & & $\begin{array}{c}\text { GAS } \\
{\left[\mathrm{kWh} / \mathrm{m}^{2} / \mathrm{y}\right]}\end{array}$ & $\begin{array}{c}\mathbf{W}_{\mathrm{EL}} \\
{\left[\mathrm{kWh} / \mathrm{m}^{2} / \mathrm{y}\right]}\end{array}$ & $\begin{array}{c}\text { GAS } \\
{\left[\mathrm{kWh} / \mathrm{m}^{2} / \mathrm{y}\right]}\end{array}$ & $\begin{array}{c}\mathbf{W}_{\mathrm{EL}} \\
{\left[\mathrm{kWh} / \mathrm{m}^{2} / \mathrm{y}\right]}\end{array}$ \\
\hline Rome & 40 & $\mathrm{P} 1$ & $38 \%$ & 126 & $93 \%$ & 0.70 & 9.91 & 9.73 & 9.47 \\
\hline Rome & 40 & $\mathrm{P} 2$ & $38 \%$ & 98 & $69 \%$ & 2.97 & 10.43 & 9.40 & 10.20 \\
\hline Rome & 40 & $\mathrm{P} 4$ & $13 \%$ & 209 & $54 \%$ & 4.45 & 9.81 & 9.73 & 9.47 \\
\hline Rome & 40 & P3 & $13 \%$ & 275 & $71 \%$ & 2.87 & 10.35 & 9.40 & 10.20 \\
\hline Rome & 70 & P1 & $38 \%$ & 137 & $95 \%$ & 0.50 & 9.90 & 9.73 & 9.47 \\
\hline Rome & 70 & $\mathrm{P} 2$ & $38 \%$ & 107 & $70 \%$ & 2.91 & 10.43 & 9.40 & 10.20 \\
\hline Rome & 70 & P4 & $13 \%$ & 225 & $56 \%$ & 4.20 & 9.81 & 9.73 & 9.47 \\
\hline Rome & 70 & P3 & $13 \%$ & 297 & $75 \%$ & 2.50 & 10.35 & 9.40 & 10.20 \\
\hline Stuttgart & 40 & P1 & $38 \%$ & 125 & $37 \%$ & 15.71 & 7.42 & 24.85 & 7.09 \\
\hline Stuttgart & 40 & P2 & $38 \%$ & 81 & $22 \%$ & 20.00 & 7.98 & 25.29 & 7.81 \\
\hline Stuttgart & 40 & $\mathrm{P} 4$ & $13 \%$ & 149 & $14 \%$ & 23.01 & 7.33 & 24.85 & 7.09 \\
\hline Stuttgart & 40 & P3 & $13 \%$ & 207 & $20 \%$ & 21.76 & 7.91 & 25.29 & 7.81 \\
\hline Stuttgart & 70 & P1 & $38 \%$ & 139 & $40 \%$ & 14.94 & 7.43 & 24.85 & 7.09 \\
\hline Stuttgart & 70 & P2 & $38 \%$ & 88 & $23 \%$ & 19.71 & 7.98 & 25.29 & 7.81 \\
\hline Stuttgart & 70 & $\mathrm{P} 4$ & $13 \%$ & 166 & $16 \%$ & 21.58 & 7.33 & 24.85 & 7.09 \\
\hline Stuttgart & 70 & P3 & $13 \%$ & 230 & $22 \%$ & 20.42 & 7.91 & 25.29 & 7.81 \\
\hline Stockholm & 40 & P1 & $38 \%$ & 108 & $26 \%$ & 22.19 & 7.16 & 30.19 & 6.86 \\
\hline Stockholm & 40 & $\mathrm{P} 2$ & $38 \%$ & 69 & $15 \%$ & 26.14 & 7.63 & 30.69 & 7.47 \\
\hline Stockholm & 40 & P4 & $13 \%$ & 138 & $10 \%$ & 28.99 & 7.05 & 30.19 & 6.86 \\
\hline Stockholm & 40 & P3 & $13 \%$ & 191 & $15 \%$ & 28.16 & 7.56 & 30.69 & 7.47 \\
\hline Stockholm & 70 & P1 & $38 \%$ & 119 & $28 \%$ & 21.64 & 7.15 & 30.19 & 6.86 \\
\hline Stockholm & 70 & $\mathrm{P} 2$ & $38 \%$ & 75 & $15 \%$ & 25.81 & 7.62 & 30.69 & 7.47 \\
\hline Stockholm & 70 & $\mathrm{P} 4$ & $13 \%$ & 152 & $11 \%$ & 27.24 & 7.05 & 30.19 & 6.86 \\
\hline Stockholm & 70 & P3 & $13 \%$ & 210 & $16 \%$ & 26.47 & 7.56 & 30.69 & 7.47 \\
\hline
\end{tabular}




\title{
2.2.5 Solar thermal venetian blind as synergetic and adaptive sun protection device in double skin façades ${ }^{6}$
}

\author{
Simon Frederik Haeringer a, Bruno Bueno a \\ ${ }^{a}$ Fraunhofer Institute for Solar Energy Systems ISE, Freiburg, Germany
}

Solar thermal venetian blinds (STVB) offer a novel solution to reduce the energy demand of buildings with highly transparent façades. They can provide solar control functions like adaptive glare protection, control of solar heat gains and daylight. At the same time the STVB functions as solar thermal collector and can be used to preheat domestic hot water or as a source for heat pumps. STVB can be integrated into glass facades such as double skin and closed cavity façades and prevent overheating of the cavity by extracting excess heat.

A test sample of a double skin façade element with integrated STVB was manufactured at Fraunhofer ISE. By employing heat pipes and a switchable thermal coupling for heat transfer from each slat to the header tube, all thermal connections within the STVB are dry connections. Outdoor calorimetric measurements of the façade element were conducted to evaluate solar thermal performance and solar heat gain control. Based on the measurement data a simulation model is currently being calibrated and validated.

\section{Working principle}

The technological approach for solar thermal venetian blinds that is investigated within the presented work uses heat pipes to transfer the heat from the slat to the header tube (see Figure 2-64). Heat pipes are closed pipes which facilitate highly efficient heat transfer via evaporation and condensation of a heat transfer fluid. From the heat pipe condensator the heat is transferred to the header tube at the side of the façade element via a dry connection. This so-called switchable thermal coupling allows transferring the heat via a mechanical contact of touching metal surfaces. Via a mechanism the contact can be opened and the slats can be moved as in conventional venetian blinds (tilting, and lifting and lowering) [22].

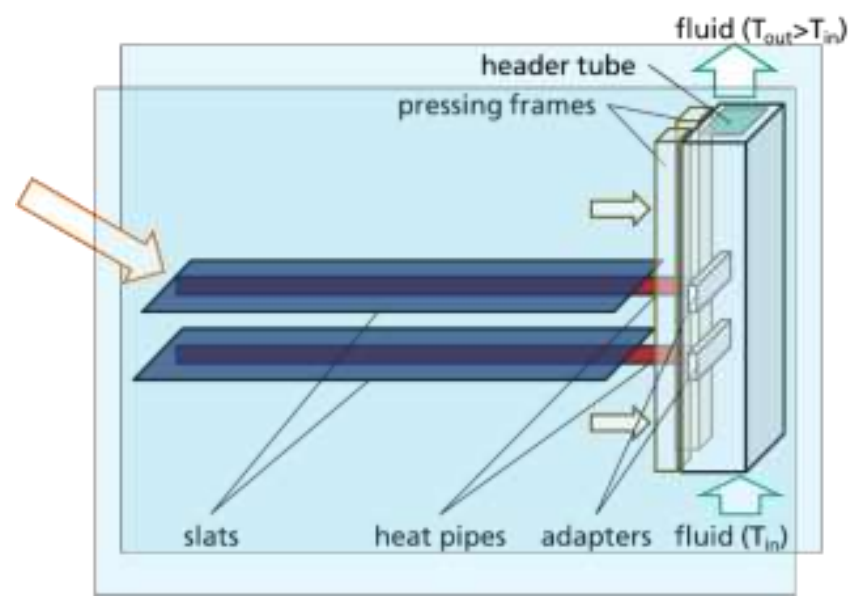

Figure 2-64: Working principle of solar thermal venetian blind with heat pipes and switchable thermal coupling. (C) Fraunhofer ISE

\section{Test sample and measurements}

A test sample of a real-size double skin façade element with integrated solar thermal venetian blind as shown in Figure 2-65 was developed by Fraunhofer ISE in collaboration with Priedemann Façade-Lab and manufactured at Fraunhofer ISE. The façade element has an exterior $8 \mathrm{~mm}$ single pane thermally strengthened low-iron glazing of $3.6 \mathrm{~m} \times 1.4 \mathrm{~m}$ and an interior double insulating glazing unit with low-e coating Iplus Top 1,1 by Interpane of size $2.6 \mathrm{~m} \times 1.1 \mathrm{~m}$. The remaining area of the back surface is covered by plain steel sheets. For the measurement at

\footnotetext{
${ }^{6}$ Parts of this contribution have been published in conference papers before ([23], [22] and [24]). Quotationmarks are avoided for readability. This concept was also presented in report DA.1+2.
} 
Fraunhofer ISE'S OFREE test facility the back surface has to be flat, therefore the surfaces of glazing and steel sheets are in one plane. The cavity between the exterior and interior glazing is $31 \mathrm{~cm}$ in depth and the slats, header tube and mechanism of the solar thermal venetian blind are placed in between.

The top surface of each slat is an absorber sheet (copper with spectrally selective coating) as used in conventional solar thermal collectors. A mesh heat pipe of $8 \mathrm{~mm}$ diameter is laser-welded to the back surface of said absorber sheet as visible in Figure 2-65. The heat pipe condensator is fitted with a triangular adapter which transfers the heat to the header tube. The header tube has an inlet and an outlet pipe which are connected to the thermostat cycle of the test facility which controls collector fluid inlet temperature and mass flow.
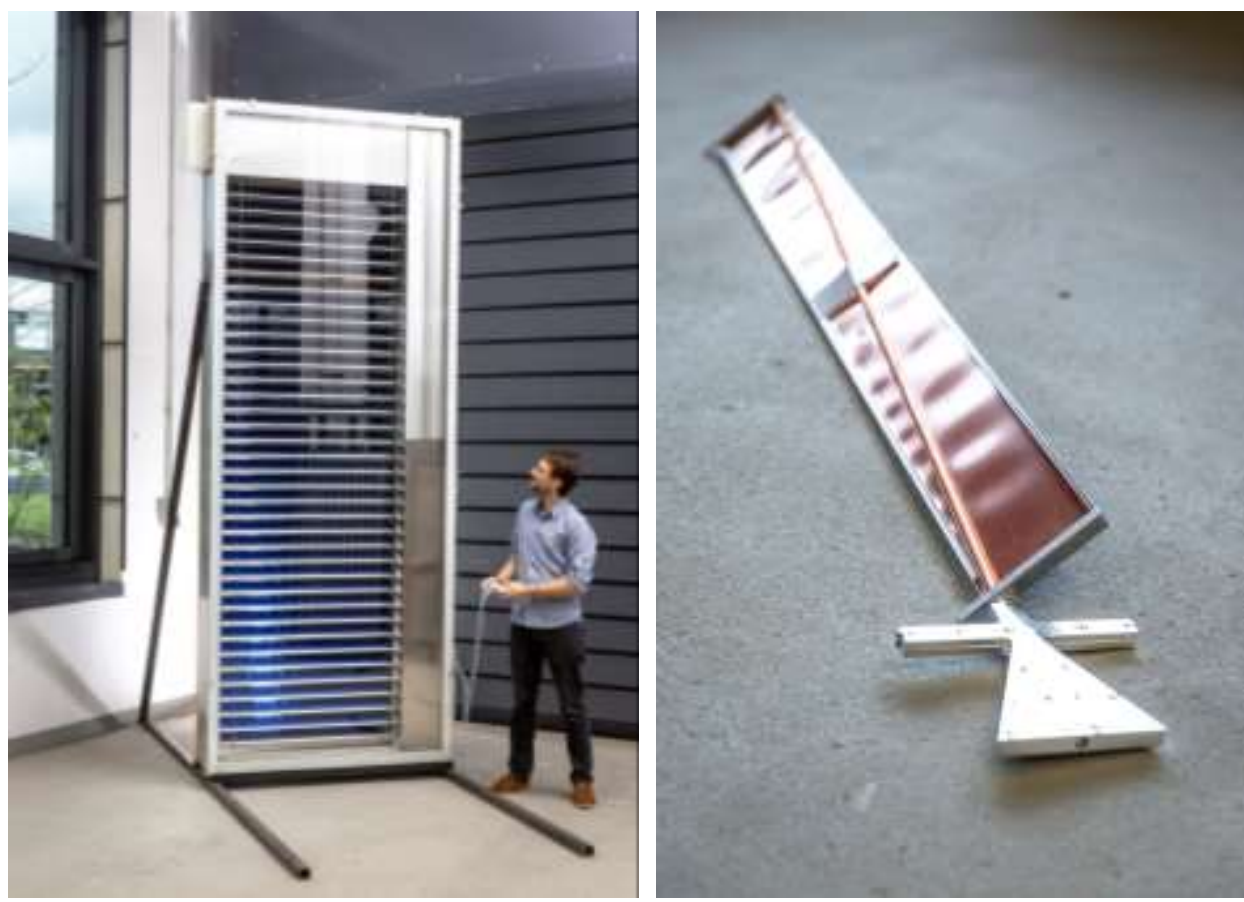

Figure 2-65: Left: Test sample of double skin facade element $(3.6 \mathrm{~m} \times 1.4 \mathrm{~m})$ with integrated solar thermal venetian blind seen from the exterior side. Right: Back surface of a slat with diagonally mounted heat pipe and triangular adapter in the foreground (back cover sheet removed). () Fraunhofer ISE

The solar thermal efficiency $\eta$ was evaluated for quasi-stationary conditions for different operation conditions and shown as efficiency curve in Figure 2-66. The center-of-glazing solar heat gain coefficient SHGC for closed and lowered slats are on the order of $8-12 \%$ depending on solar thermal operation [22]. 


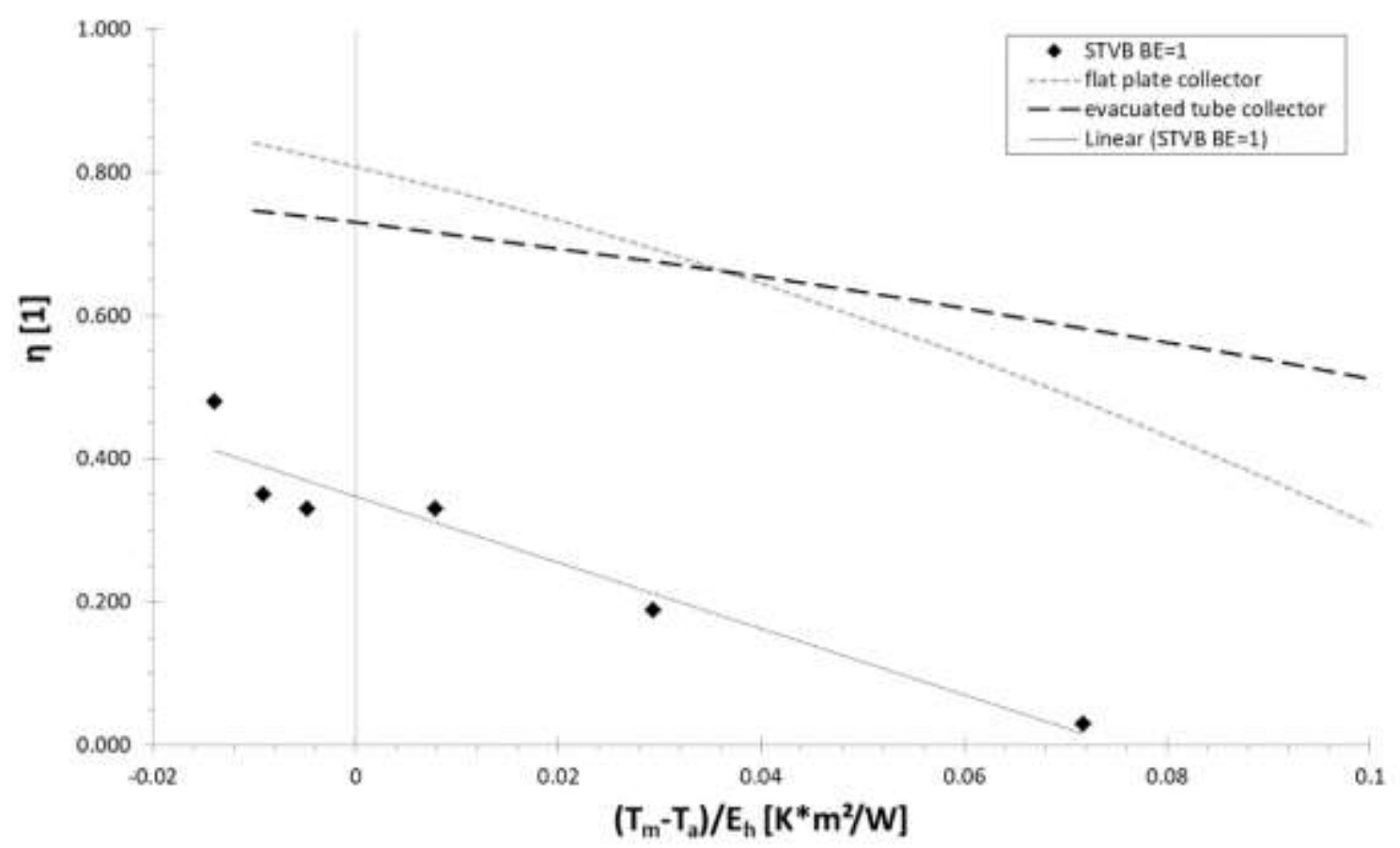

Figure 2-66: Measured efficiency $\eta$ of STVB test sample as function of mean fluid temperature $T_{m}$, ambient temperature $T_{a}$ and irradiance $E_{h}$ for $B E=1$ and $\beta=82^{\circ}$ compared to commercially available flat plate [25] and evacuated tube collectors [26] at a comparable incidence angle of $40^{\circ}$ and for interior room temperature $T_{i n t} \approx T_{a}$. () Fraunhofer ISE

\section{Application cases}

STVB have the potential to integrate solar thermal functionality into transparent façade areas and to improve thermal comfort in the building interior. STVB are particularly interesting to be used in double-skin façades (DSF) and façades with box-type windows. Closed-cavity façades (CCF) as a subcategory of DSF are promising, as they provide a clean environment to the STVB and no soiling of the slats will occur. The overheating problem present in CCF could be reduced by using STVB. An ideal application of STVB would be a building with large transparent building envelope areas, significant demand for domestic hot water in which external blinds are not desired or feasible.

A promising application case of a STVB with focus of lowering the $g$-value is an office high-rise building with solar dehumidification. To prove the potential of the STVB the simulation studies will compare a building with STVB with reference cases. Examples for reference cases include the same building with conventional blinds in the glazing cavity with or without improved solar control glazing or with less transparent areas in building envelope [23].

The application of a STVB with focus of high solar thermal performance would be promising for example in a highrise building which is partly used as hotel. Reference cases for simulation studies aiming to prove the potential of this STVB could include the same building with conventional blind in the glazing cavity, or with conventional solar thermal collectors on opaque building envelope areas, or with stationary semi-transparent solar thermal collectors on opaque building envelope areas [23].

\section{Simulation Work Flow}

The simulation model is based on a model for transparent solar thermal collector (TSTC) developed by [27] written in $\mathrm{C} / \mathrm{C}++$ which can be used in TRNSYS for building simulations. The thermal node network used for the STVB is shown in Figure 2-67. Most parameters are estimated from physical properties of the components. Unknown properties like the heat transfer across the thermal contact of the switchable thermal coupling $h_{19}$ are calibrated using the measurement data. The calibrated model is then compared to another set of measurement data for validation. 


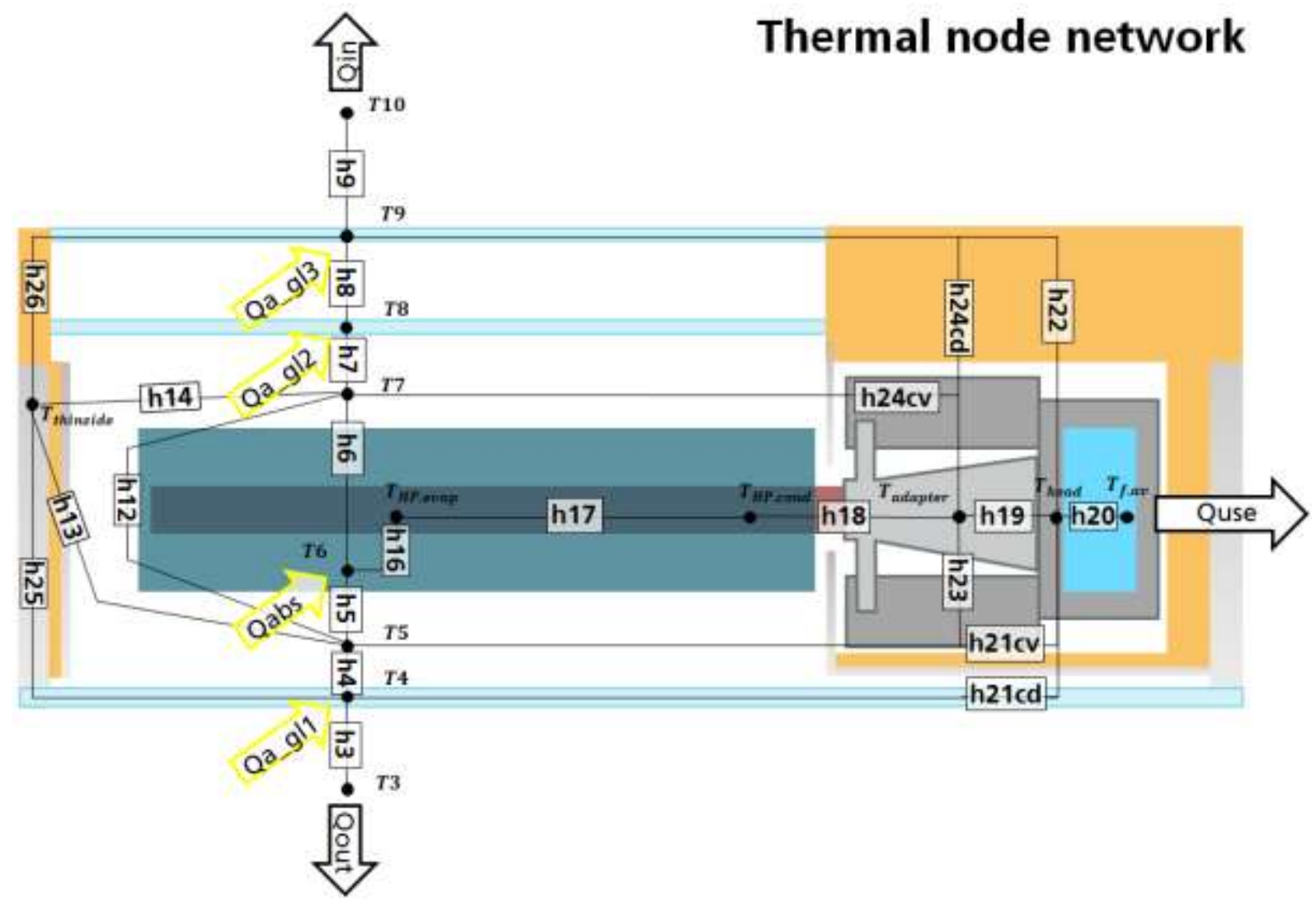

Figure 2-67: Thermal node network of the STVB superposed on a schematic drawing of a horizontal cross section of a STVB façade element. () Fraunhofer ISE. 


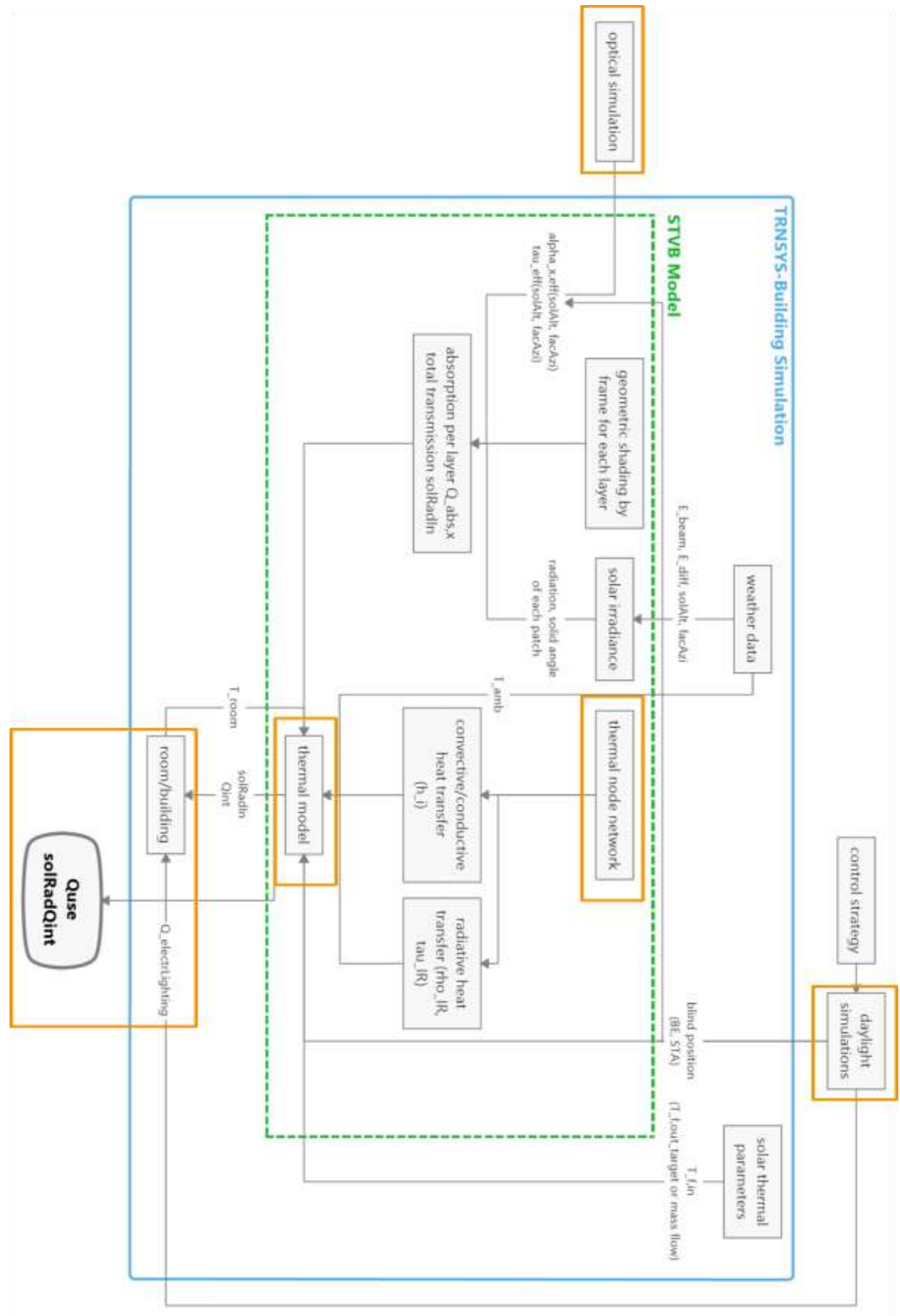

Figure 2-68: Simulation work flow with relevant inputs and intermediate outputs exchanged between different simulation steps. (C) Fraunhofer ISE. 
The yearly building energy simulations include several simulation steps including optical simulations, daylight simulations and finally building performance simulations in TRNSYS as schematically shown in Figure 2-68. The optical properties - effective absorptance of each layer and effective transmittance of the element - are calculated by the Klems matrix formalism [28] implemented in the FENER tool [29], [30]. FENER is then used for the daylighting simulations of the STVB. FENER is a building simulation engine based on the three-phase method [31] and a detailed energy balance of one room. It calculates simultaneously the heating and cooling energy demand of the room, thermal comfort metrics, daylighting metrics and daylight glare indexes. The simulation engine has been specifically designed for the evaluation and design of complex fenestration systems and their control. The tool provides significant flexibility and accuracy in the definition of fenestration systems and is very powerful testing innovative control strategies for them [32].

The optical properties and results of the daylight simulations - blind position and artificial lighting demand - are used as inputs for the TRNSYS simulations, which carries out the yearly building energy simulations based on the thermal model.

The room is a shoebox model with $4 \times 3 \mathrm{~m}^{2}$ façade and $5 \mathrm{~m}$ depth. The STVB façade simulated for the case study contains three STVB elements of $1 \times 2.5 \mathrm{~m}^{2}$ resulting in $25 \%$ opaque wall area. As reference model a conventional grey venetian blind is modeled with the STVB model. The blinds are controlled with a cut-off control and retracted below a threshold irradiance on the façade of $150 \mathrm{~W} / \mathrm{m}^{2}$. An office is considered as building type. The building usage is modeled according to standard (DIN V 18599-10 [33]). The solar thermal system is not modeled explicitly (i.e. the analysis is made based on the solar thermal energy yield from the STVB). Different solar thermal operation modes are modeled by using different fluid inlet temperatures and in most cases matched flow control with a fixed target fluid outlet temperature (Table 2-19). Operation at low temperature (const15) aims primarily at lowering the SHGC value and not at supplying solar thermal heat.

Table 2-19: Solar thermal operation modes considered in the analysis

\begin{tabular}{|c|c|c|}
\hline solar thermal control & const15 & 30 to 40 \\
\hline mass flow & constant & matched \\
\hline $\min$ mass flow [kg/s] & 0.054 & 0.002 \\
\hline max mass flow $[\mathrm{kg} / \mathrm{s}]$ & 0.054 & 0.06 \\
\hline $\mathrm{T} \_\mathrm{f}$,in $\left[{ }^{\circ} \mathrm{C}\right]$ & 15 & 30 \\
\hline $\mathrm{T}_{-} \mathrm{f}, \mathrm{out}\left[{ }^{\circ} \mathrm{C}\right]$ & 15.5 & 40 \\
\hline $\begin{array}{l}\text { Potential use of solar } \\
\text { heat }\end{array}$ & $\begin{array}{l}\text { DHW preheating / combination with heat } \\
\text { pump }\end{array}$ & $\begin{array}{l}\text { TABS, radiant heating, supply air heating, } \\
\text { source for heat pump }\end{array}$ \\
\hline Buidling type & Office & Office \\
\hline
\end{tabular}

\section{Preliminary simulation results}

The presented preliminary results are based on a first calibration and validation of the simulation model as presented in a master thesis [34]. In this case study results of an office in Frankfurt are presented for the measured test sample (STVB_01) and for an improved version (STVB_17) in comparison to a venetian blind as reference (Ref1). Monthly solar thermal yield Quse and monthly cooling demand are presented in Figure 2-69. It can be seen that the cooling demand in these simulations is significantly reduced by the STVB. The difference of Quse between different STVB types and solar thermal operation modes is much larger than the difference of cooling load reduction. The primary energy savings are shown in Figure 2-70. Improving the current test sample will yield significantly higher solar thermal yields, cooling load reduction and primary energy savings. 


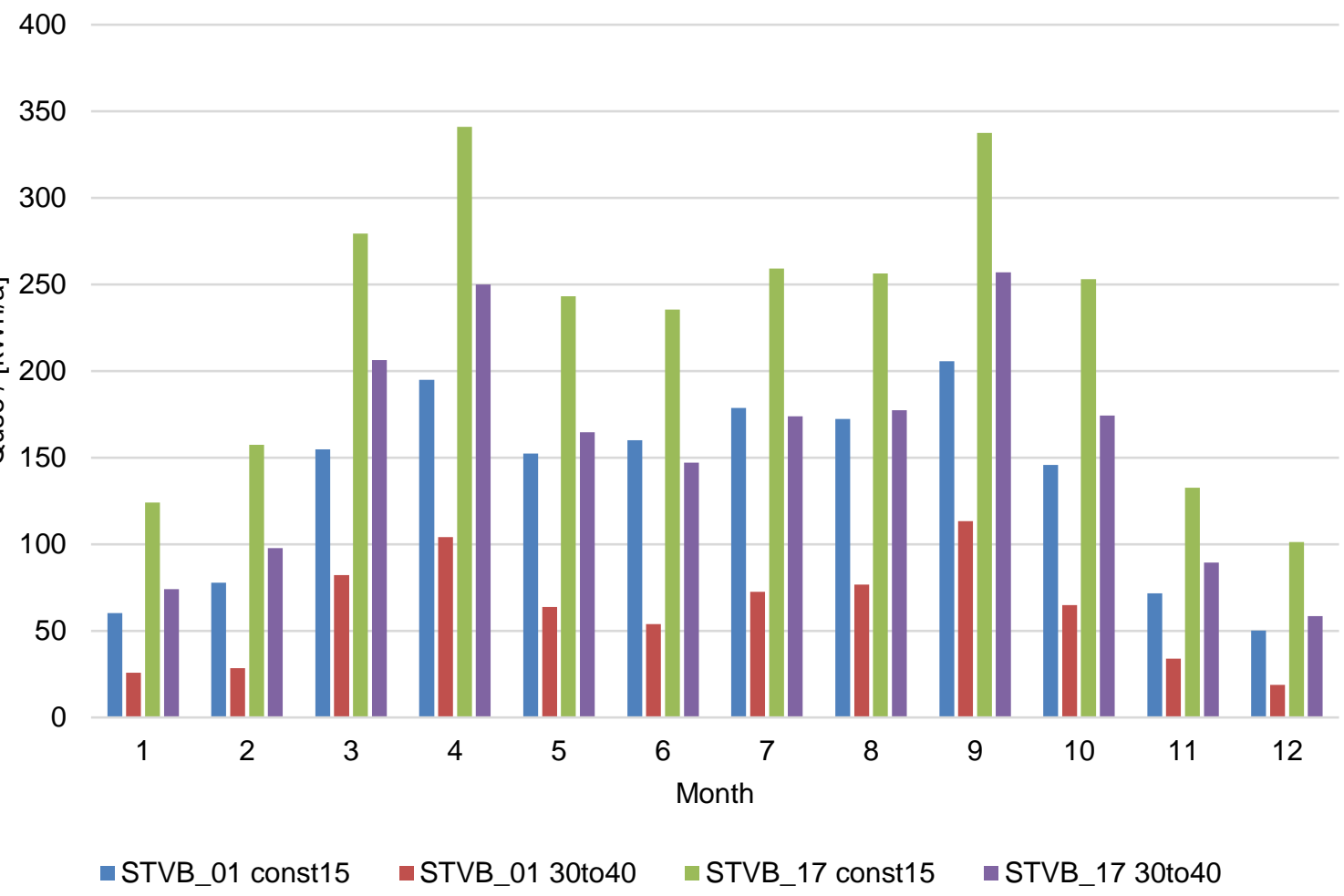

(a)

300

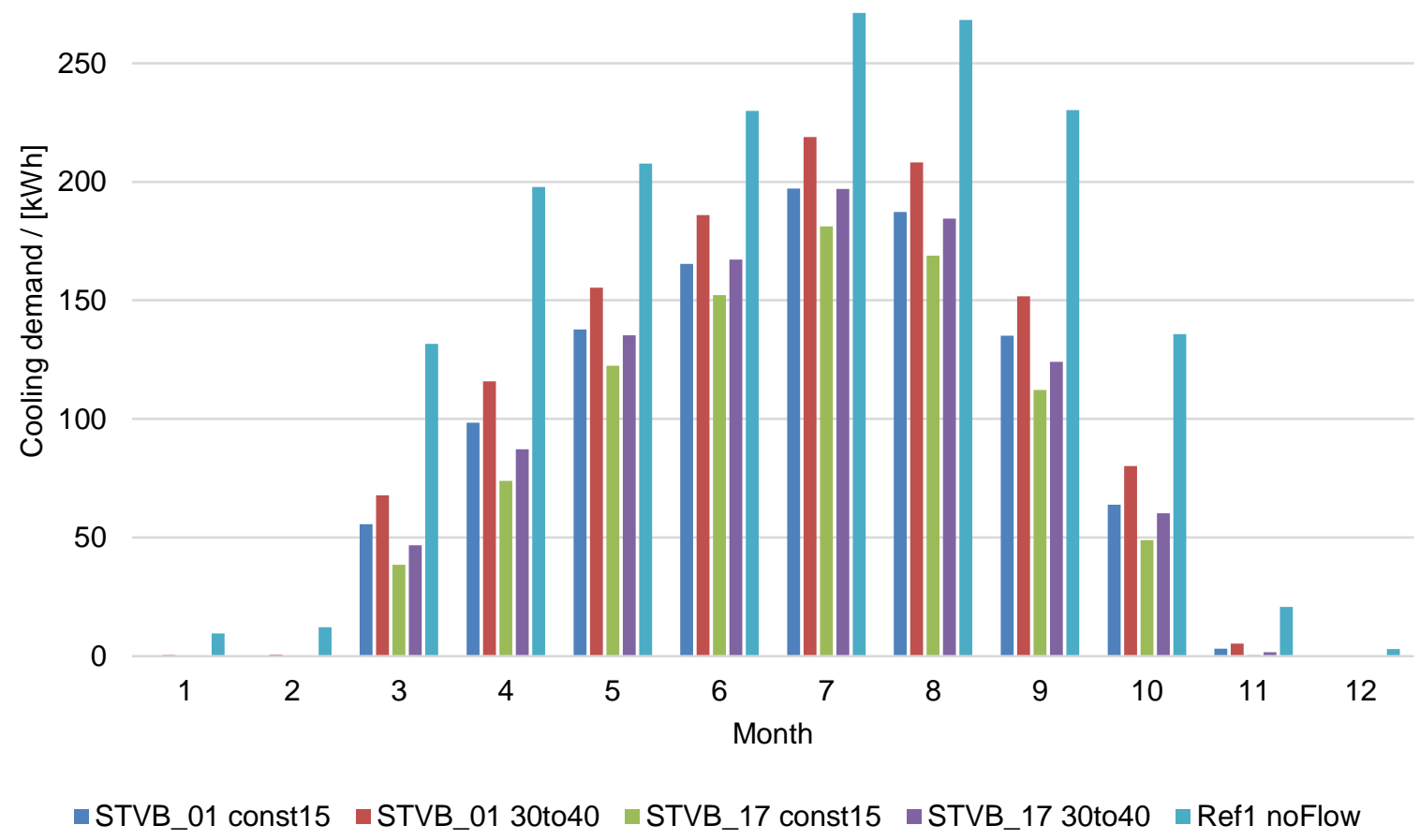

(b)

Figure 2-69: Preliminary monthly simulation results for an office room with STVB in Frankfurt, south oriented facade. (a) Monthly solar thermal yield Quse. (b) Monthly cooling energy demand of the room. Three different configurations are compared: STVB_01 - measured test sample, STVB_17 - STVB with technical improvements and Ref1 conventional venetian blinds. Different solar thermal operation modes are considered: const15 - Inlet temperature $15^{\circ} \mathrm{C}$ and fixed mass flow $0.054 \mathrm{~kg} / \mathrm{s}$. 30to40 - Inlet temperature $30^{\circ} \mathrm{C}$ and matched flow control with a fixed target fluid outlet temperature $40^{\circ} \mathrm{C}$. The STVB area is $7.5 \mathrm{~m}^{2}$ and the floor area is $20 \mathrm{~m}^{2}$. 


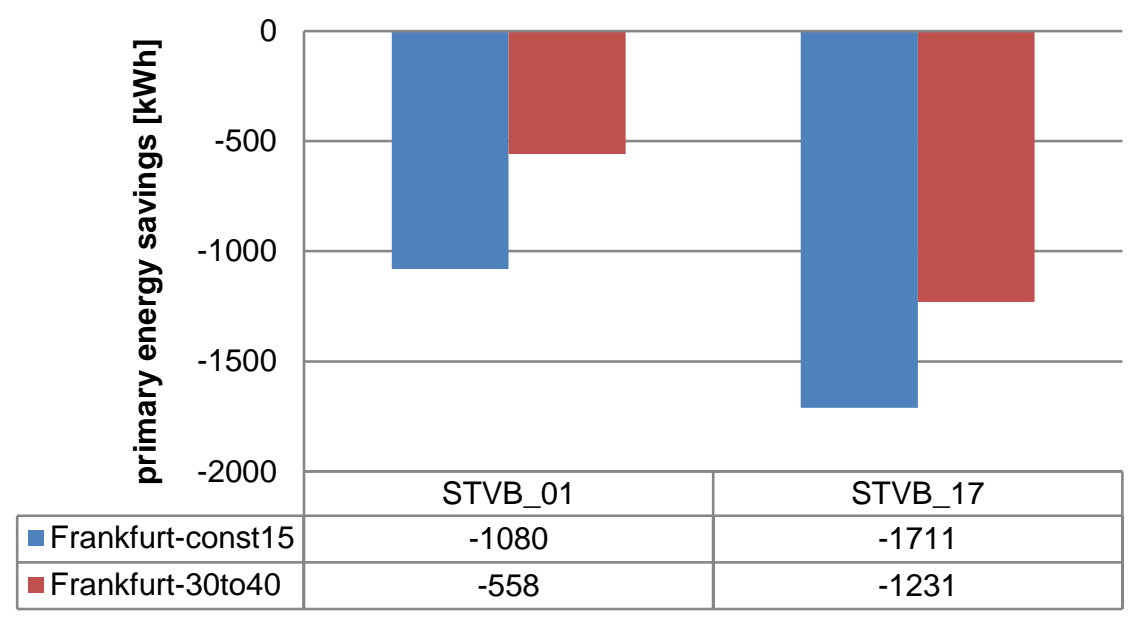

Figure 2-70: Primary energy savings of office room equipped with STVB compared to conventional venetian blind (preliminary results). Two different configurations are compared: STVB_01 - measured test sample and STVB_17 STVB with technical improvements. Different solar thermal operation modes are considered: const15 - Inlet temperature $15^{\circ} \mathrm{C}$ and fixed mass flow $0.054 \mathrm{~kg} / \mathrm{s}$. 30to 30 - Inlet temperature $30^{\circ} \mathrm{C}$ and matched flow control with a fixed target fluid outlet temperature $40^{\circ} \mathrm{C}$. The STVB area is $7.5 \mathrm{~m}^{2}$ and the floor area is $20 \mathrm{~m}^{2}$. 


\title{
2.2.6 Kindow sun tracking vertical blinds
}

\author{
Samuel de Vriesa, Roel Loonena \\ aEindhoven University of Technology, Eindhoven (The Netherlands)
}

\section{Goal of this case study}

Different façade solutions each come with different investments, operational costs and benefits. In designing facades and selecting glazing and solar shading systems, the competing performance aspects of visual comfort, daylighting performance, thermal comfort, costs and energy performance will therefore need to be balanced. This task is complicated by the fact that the effects of glazing and shading solutions on building energy performance are increasingly being determined by interactions between the thermal and the visual domain. The traditional approach in the building industry has been to treat these two physical domains as separate design and engineering problems but with the advent of daylight dimming, high reflectance metal coatings and advanced solar shading controls, these domains are becoming increasingly interlinked.

The goal of this case study is to illustrate how simulations can be used to find balanced trade-off solutions considering the multitude of conflicting performance aspects in the selection of solar shading and glazing technologies. Additionally, this case study will explore how the design space for such solutions can evolve as a result of changes in the technical and economic context. In this study, the performance of the Kindow sun tracking vertical blind system (DA.1+2 page 67) will be assessed in relation to other conventional solutions for controlling the admission of solar heat gains and daylight.

\section{Approach}

In this study, two conventional control approaches (both titled baseline) for roller blinds will be compared to three different versions of the Kindow sun tracking blinds strategy (Table 2-20). For both the baseline and the Kindow control strategy multiple variations to the main control approach will be evaluated. These variations relate to different control settings which can be chosen to admit more or less daylight.

The baseline strategies fully raise or lower the roller blind in response to a sensor threshold. Here two alternatives are used which either prioritise visual comfort (vertical indoor illuminance sensor [ $\left.E_{v}\right]$ and a 6400 lux threshold) or the admission of daylight (vertical exterior irradiance sensor [ $\left.\mathrm{I}_{\mathrm{g} ; \mathrm{v}}\right]$ and a $200 \mathrm{~W} / \mathrm{m}^{2}$ threshold).

The Kindow blind system is developed by the company Kindow B.V. in the Netherlands. The Kindow system (Figure 2-71) utilises vertical blinds made out of a fabric with a high solar reflectance metal coating on one side. The blinds are operated in relation to the position of the sun and indoor daylight conditions. Under bright sky conditions the blinds track the sun to prevent occupants from perceiving glare from direct sunlight whilst admitting daylight and views to the outdoors. Under overcast conditions, or when the sun is not in view of the façade, the system fully opens.

Three variations to the Kindow strategy will be evaluated:

- The first variation, titled Low+High, employs the most closed form of sun tracking which prioritises visual comfort over daylighting performance;

- $\quad$ The second variation, titled Low+Mid+High, prioritises the admission of daylight and tracks the sun in a way which allows for a greater visibility of the sky;

- The third strategy is identical to the second one with the exception that this strategy employs a slightly wider slat such that the edges of the blind overlap in a fully closed position. The overlapping blinds help prevent visual disturbance from direct sunlight being visible during small dangling movements of the blinds. In this alternative a full rotation of the blinds is not possible because the width of the slats is larger than their individual spacing. In this strategy both sides of the blind have to therefore be used in order to track the sun and the metallised side is facing the sun only during the morning.

The admission of solar radiation depends on interactions between the glazing and solar shading system. Important factors are the position of the solar shading system, its solar reflectance and transmittance, the type of glass coating that is used and its position inside the glazing system. In this study, three alternatives will be assessed (Table 2-21): high solar gain glazing (low reflectance low-E coating in position 2) in combination with a metallised interior shading system, solar control glazing (high reflectance low-E coating in position 2) in combination with a metallised interior shading system, and high solar gain glazing (low reflectance low-E coating in position 3 ) in combination with a nonmetallised exterior shading system. All shading fabrics have an identical visual and solar transmittance. The three 
alternatives each offer a distinct set of visual and thermal properties and have different investment and maintenance costs associated to them.
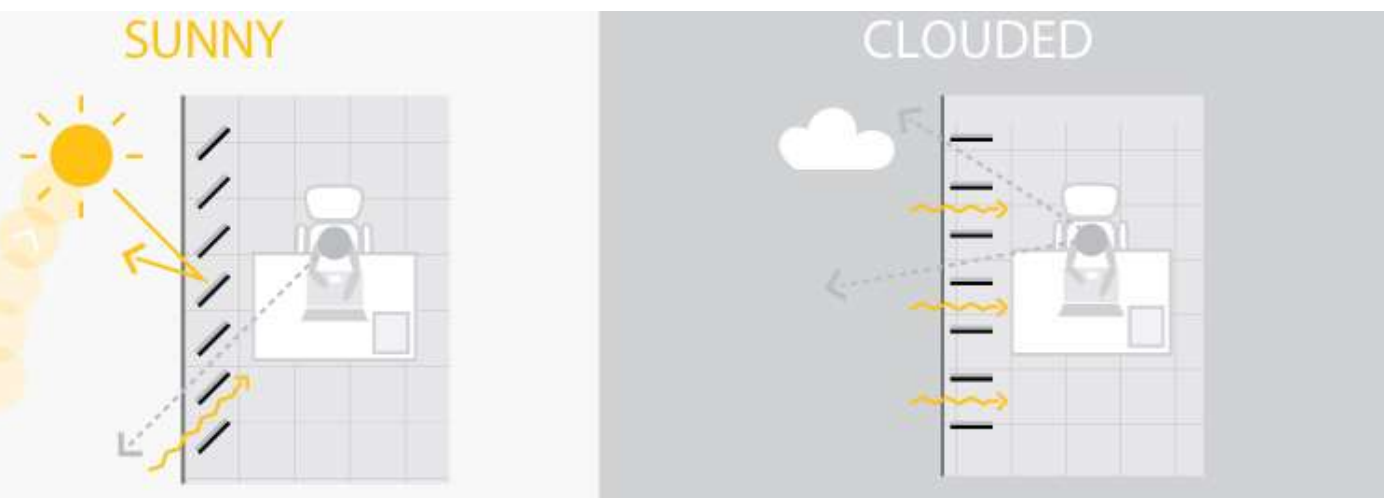

Figure 2-71 The Kindow sun tracking vertical blinds system

The reference office that is used in this case study largely follows the description given in DC.1. Table 2-20 and Table 2-21 give an overview of the assumptions in this case study that differ from the general description of the reference office building reported in the report DC.1.

Table 2-20: Solar shading control strategies and assumptions

Shading strategy

Conventional roller blind (BL: Baseline)

Kindow sun tracking vertical blinds (Kindow verticals)

\section{Control approach}

Conventional: Down if $\mathrm{I}_{\mathrm{g} ; \mathrm{v}}>200 \mathrm{~W} / \mathrm{m}^{2}$ else up Conventional: Down if $E_{v}>6400$ lux else up

Most closed sun tracking (Low+High), always reflecting

Most closed and more open sun tracking (Low+Mid+High), always reflecting

Most closed and more open sun tracking (Low+Mid+High), reflect in morning

\begin{tabular}{|c|c|}
\hline Window to wall ratio & $80 \%$, South facing window \\
\hline Climate & Amsterdam, the Netherlands (IWEC database) \\
\hline Daylight dimming & None or linear dimming (500 lux target work plane $E_{h}$ ) using two lighting zones \\
\hline HVAC conventional & $\begin{array}{l}\text { Gas furnace and low efficiency air-source compression cooling. } \eta_{\text {cool,deliv }}=0.7 \text { (air system } \\
\text { eff. cooling), } \mathrm{COP}_{\text {cool }}=3, \eta_{\mathrm{h}}=0.85 \text { (heating system eff.) }\end{array}$ \\
\hline HVAC all-electric & Air source heat pump for heating and cooling as described in appendix 0 \\
\hline Primary energy ratios (PER) & $\begin{array}{l}E U_{\text {total }} 2.5_{\text {constant, }}, 10-10-10_{\text {non-ren.,varying monthly, }} 10-30-30_{\text {non-ren.,varying monthly }} \text { (see Appendix A. } 1 \text { in } \\
\text { report DC. } 1 \text { ) }\end{array}$ \\
\hline
\end{tabular}




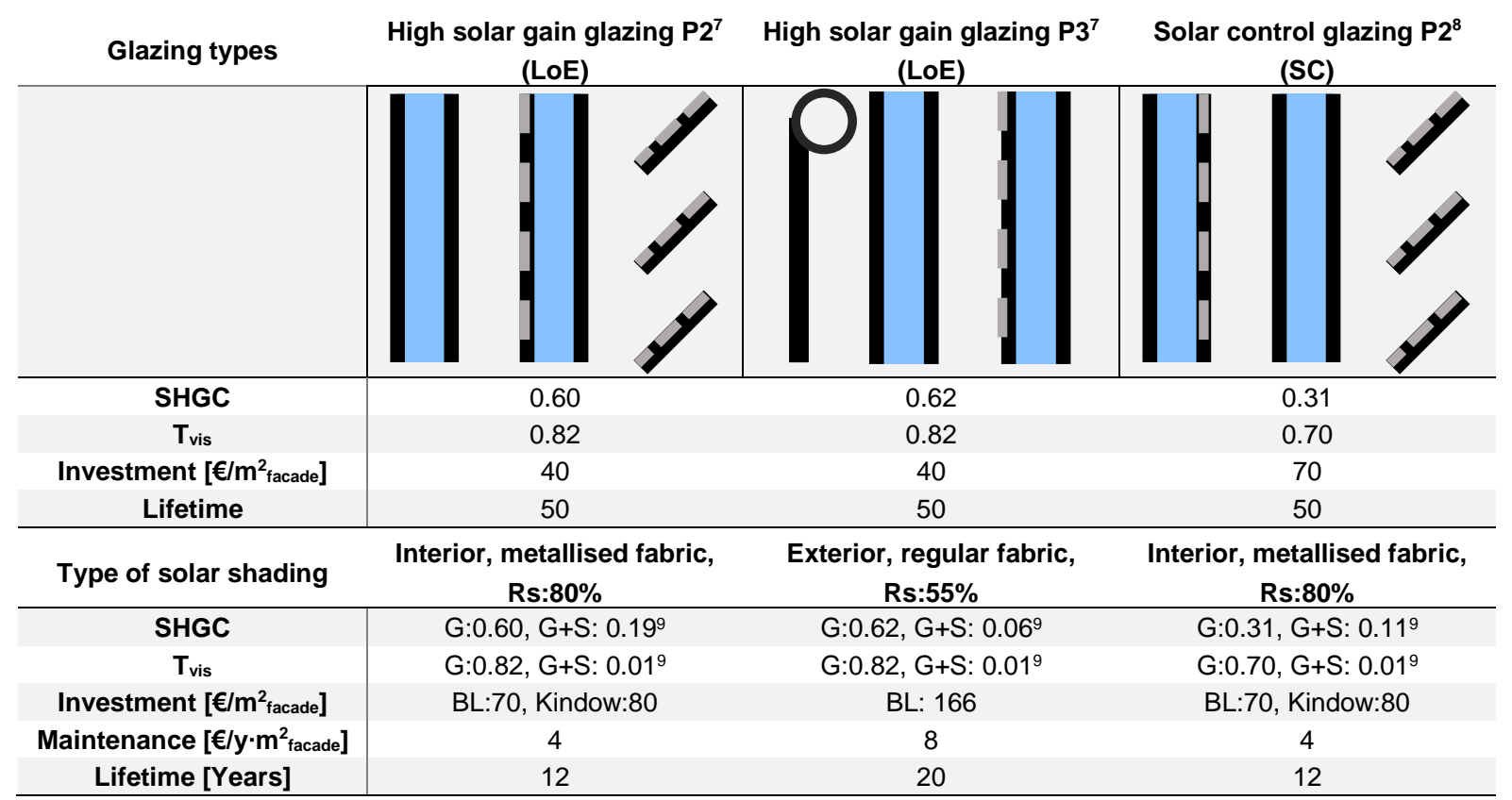

Table 2-22: Shading / fenestration technology design space

Glazing + shading

\begin{tabular}{l}
\hline \\
Low-E P2, Internal fabric \\
SC P2, Internal fabric \\
Low-E P3, External fabric \\
Low-E P3, External fabric
\end{tabular}

Shading control

\begin{tabular}{cc}
\multicolumn{2}{c}{ Kindow verticals } \\
Low, High, & Low, Mid, High, \\
Reflect always & Reflect always
\end{tabular}

Low, Mid, High, Baseline: Ig;v > 200 Baseline: Ev > $\begin{array}{lll}\text { Reflect in } & \mathrm{W} / \mathrm{m} 2 & 6400 \text { lux }\end{array}$

morning

\begin{tabular}{|c|c|c|c|c|c|c|c|c|}
\hline S.1 & $\mathrm{DD}^{10}$ & S.2 & $\mathrm{DD}^{10}$ & $\begin{array}{l}\text { S.3 } \\
\text { ookmark not defined. }\end{array}$ & S. 4 & $\mathrm{DD}^{10}$ & S.5 & $\mathrm{DD}^{10}$ \\
\hline \multirow[t]{3}{*}{ H.1 } & $\mathrm{DD}^{10}$ & $\mathrm{H} .2$ & $\mathrm{DD}^{10}$ & $\mathrm{H} .3 \quad \mathrm{DD}^{10}$ & H.4 & $\mathrm{DD}^{10}$ & H.5 & $\mathrm{DD}^{10}$ \\
\hline & & & & & P.4 & $\mathrm{DD}^{10}$ & P.5 & $\mathrm{DD}^{10}$ \\
\hline & & & & & C. 4 & no-DD & C.5 & $0-D^{11}$ \\
\hline
\end{tabular}

Table 2-22 gives an overview of the full design space of glazing, shading and control alternatives that is evaluated in this study. Two additional alternatives are included which do not include daylight dimming of artificial lighting. These alternatives are otherwise identical to the conventionally controlled alternatives with external shading. The two alternatives without daylight dimming are most similar to the DC. 1 description and they are included to assess what performance gains can be attributed to the daylight dimming system alone.

For assessing visual (dis)comfort, DGPs (DC.1 5.4 and DC.2 2.1.2), and the fraction of occupied time with at least disturbing glare (DGPs $\geq 0.4$ ) will be used. Here a distinction is made between two viewing directions: one where the occupants are facing the window at 45 degrees and one where the occupants are facing a side-wall. For each viewing direction, two seating positions are used; one facing east and one facing west. At each time step, the maximum DGPs value of both positions is used. Daylighting performance is operationalised using sDA $3001 \times / 50 \%$ (DC. 1 5.4). Energy performance is assessed using the primary energy consumption for heating, cooling, lighting, ventilation and equipment. The effects of two different HVAC concepts and three different primary energy ratio (PER) scenarios are evaluated (Table 2-20). The economic costs and benefits over the entire lifetime of the different solutions is evaluated using total annual costs as an indicator. In this approach the investment costs of technologies with different lifespans are computed into Equivalent Annual Costs using an assumed annual interest rate according to the method presented in DC. 1 chapter 5.5 and summed with operational energy and maintenance costs. In this study, the costs for glazing, shading, daylight dimming and cooling and ventilation systems are included (Table

\footnotetext{
${ }^{7}$ Coating in position 3 (outside of inner glass pane)

${ }^{8}$ Coating in position 2 (inside of outer glass pane)

${ }^{9} \mathrm{G}$ : Glazing only, G+S: Glazing with fully closed shading

${ }^{10} \mathrm{DD}$ : With daylighting dimming of artificial lighting

${ }^{11}$ no-DD: Without daylighting dimming of artificial lighting
} 
2-23). The sizing dependent costs of cooling and ventilation are estimated for each alternative using a load duration curve and 125 allowed temperature exceedance hours as a criterion. The uncertainty related to assumptions regarding costs, lifespan, interest rates, and energy prices is evaluated by varying the assumptions using ranges taken from 2.2.2 which are shown in Table 2-23. For assessing the aforementioned performance indicators the cosimulation model, discussed in chapter 2.1.4.2, is used [11].

Table 2-23: Other costs and parameters for economic performance assessment

\begin{tabular}{l|ll|ll} 
& \multicolumn{3}{l}{ Lifetime: } \\
\hline Daylight dimming system (TL-5 not included) & 12 & $€ / \mathrm{m}^{2}$ floor & 20 & years \\
Variable sizing dependant costs of cooling and ventilation: & 518 & $€ / \mathrm{kW}$ & 30 & years \\
Revenue per employee (3 in room) & 50000 & $€ /$ year & & \\
\hline
\end{tabular}

\begin{tabular}{|c|c|c|c|c|}
\hline & Min: & Median: & Max: & \\
\hline Assumed productivity increase from Kindow & $0 \%$ & & $1 \%$ & \\
\hline Uncertainty ranges for life time, investment and maintenance costs & $90 \%$ & $100 \%$ & $110 \%$ & \\
\hline Annual interest rates & $2 \%$ & $3 \%$ & $4 \%$ & \\
\hline Average electricity price over period & & & 0.23412 & $€ / \mathrm{kWh}$ \\
\hline Average gas price over period & & & 0.5805 & $€ / \mathrm{nm}^{3}$ \\
\hline Uncertainty ranges for energy costs & $80 \%$ & $100 \%$ & $120 \%$ & \\
\hline
\end{tabular}

\section{Results}

Figure 2-72 shows the daylighting and glare performance of the investigated solar shading and glazing solutions. Using this graph the following can be concluded:

- $\quad$ Conventionally controlled alternatives (numbers 4 and 5) lead to poor daylighting performance $(0-24 \%$ sDA300lx $/ 50 \%$ ) whilst the Kindow strategies offer a very desirable daylighting performance $(74-99 \%$ sDA300lx/50\%) which comes close to the daylighting performance without any shading system (100\%, yellow markers).

- The Kindow strategies (numbers 1-3) are each designed to prevent 'disturbing' glare at all times in the most critical viewing angle, where the occupants are facing the wall. For this viewing direction, the Kindow strategies perform significantly better than the baseline $200 \mathrm{~W} / \mathrm{m}^{2}$ strategy $(5-8 \%$ less DGPs 0.4 exceedance).

- $\quad$ For the viewing direction facing the window, the Kindow strategies perform better to slightly worse as the baseline $200 \mathrm{~W} / \mathrm{m}^{2}$ strategy (number 4), depending on which Kindow alternative is chosen. Although the control threshold can be chosen more stringently in the conventional strategies, such that glare is always prevented (number 5: baseline 6400lx), doing so would have a severe negative impact on daylighting performance $(0 \%$ sDA300Ix/50\%).

- The trade-off between prohibiting visual discomfort and maximizing the admission of daylight is more desirable for Kindow than it is for the conventional approaches.

- Choosing for solar controlled glazing (hexagrams) can improve visual comfort (0-6\% decrease in DGPs0.4 exceedance) and have a negative effect on daylighting performance (5\% decrease in sDA300Ix/50\%). These effects are, however, very small in comparison to the effects that can be achieved by choosing a particular shading control strategy. 


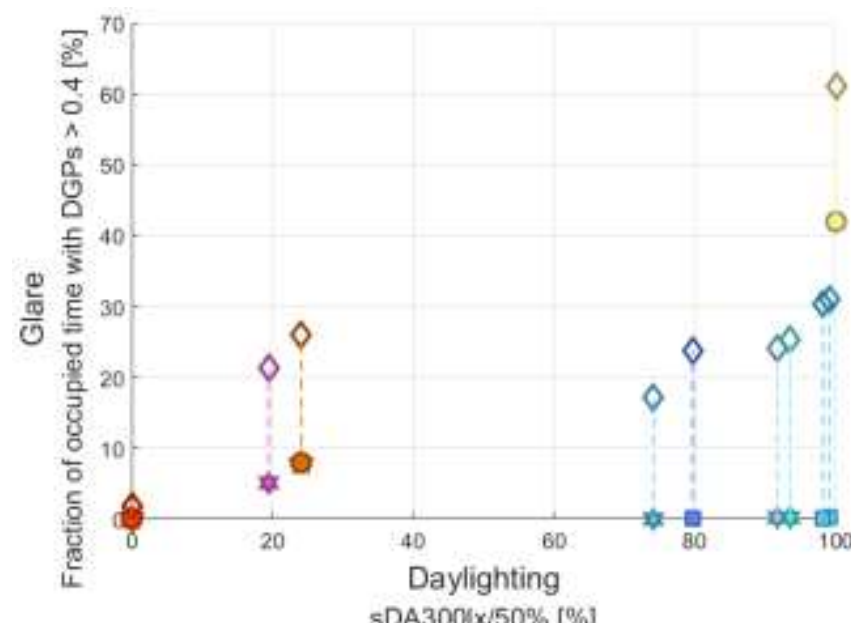

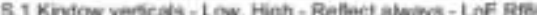

S. 2 Kindow varscals - Low, Mid, High - Reflect always - LoE RRo

a S.J Kindow werbeals - Low, Mid. High - Reflect only in inoming - LoE Rtso

a S.4 Baselire - UpDown Igve > 200 Wim2 - LOE RroC

5.5 Baseine - UpDown Evi $>6400$ lux - LoE Rleo

C.6 Baseine - Always down - LoE Rea

- C.7 Baseine - Always up - LOE RSBo

* H.t Kindow verticab - Low, High - Reflect atways - SC Rego

- H.2 Kindow verticals - Low. Mid, High - Reflect ahways - SC Ribo

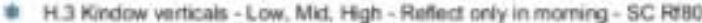

- H.4 Easeline - UphiDown lgve > 200 Wim2 - SC Rac

- H.5 Easeline - Upidown Evis 6400 lux - SC Raso

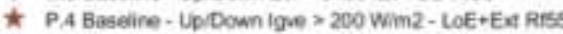

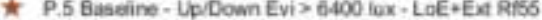

- C.4 Baseine - UpiDown lgve $>200$ WIm2 - LoE+Est Pf55 - No dimming

- C.5 Baseline - LipiDown Evis $>5400$ kix - LoE+Ext Rt5s - No dimming

DGPs 0.4 exceedance for view directions:

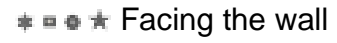

- Facing the window at 45 degrees

Figure 2-72: Daylighting and glare performance of different shading strategies and glazing systems. Glare is expressed as the fraction of occupied hours with DGPs $>0.4$ for two viewing directions

In Figure 2-73, the energy performance and costs associated with each glazing and solar shading alternative are explored in relation to different scenarios for the primary energy ratio of electricity and in combination with two HVAC concepts. In each individual graph, primary energy consumption and total costs are expressed as a difference between each alternative and a common baseline. Here, the alternative with daylight dimming, an external shading device, and the baseline ${ }_{6400 l u x}$ control approach (prioritises visual comfort) is chosen as the common baseline (orange pentagram) and is plotted at the origins of each axis. In these graphs, positive values for $\triangle P E$ and $\triangle$ Total annual costs indicate that the alternative in question offers a reduction in primary energy consumption and total annual costs, respectively. The vertical dashed lines in this graph represent the spread in total costs as a result of variations in underlying assumptions regarding investment costs, lifespan, interest rates and energy prices. The marker in this graph is placed at the median of all $\Delta$ Total annual costs outcomes. It should be noted that the plotted spread gives the degree of uncertainty in the difference between a particular solution and the common baseline. This spread given for a particular alternative is therefore indicative of the uncertainty in the predicted costs of both that alternative as well as that of the baseline.

Figure 2-73 A shows the results for a conventional low-efficiency HVAC system and assuming the EU-2.5 total primary energy ratio. These assumptions are in line with current building codes and the electrical primary energy ratios in the Netherlands in the past decade. By comparing the conventionally controlled approaches (numbers 4 and 5 ) in combination with different glazing/shading configurations (S: squares, $\mathrm{H}$ : hexagrams, $\mathrm{P}$ : pentagrams), the following can be observed:

- $\quad$ Metallised indoor solar shading $(\mathrm{S}$ and $\mathrm{H})$ is more beneficial in terms of total costs. This difference in costs can be primarily attributed to the lower maintenance costs of indoor solutions but their lower initial investment costs also contribute strongly.

- $\quad$ The energy performance of the high solar gain $(\mathrm{S})$, solar control $(\mathrm{H})$, and exterior shaded glazing $(\mathrm{P})$ shows that reducing solar heat gain appears to improve overall energy performance.

- Using solar controlled glazing with a metallised indoor shading fabric $(\mathrm{H})$ gives the most beneficial trade-off between total costs and primary energy consumption. This solution offers a lower energy consumption for similar total costs as using high solar gain glazing (S) with indoor shading. Compared to the external shading device alternative $(P)$, the solar control glazing solution has a slightly higher primary energy consumption but it is significantly less expensive.

- Implementing a daylight dimming device (pentagrams $P$ in relation to circles $C$ ) significantly improves energy performance. The effects on primary energy consumption are of the same order of magnitude as the choices made concerning the glazing/shading configuration.

- Implementing a daylight dimming device has a positive effect on total costs. This effect is much smaller, however, than the difference between indoor and outdoor shading. 

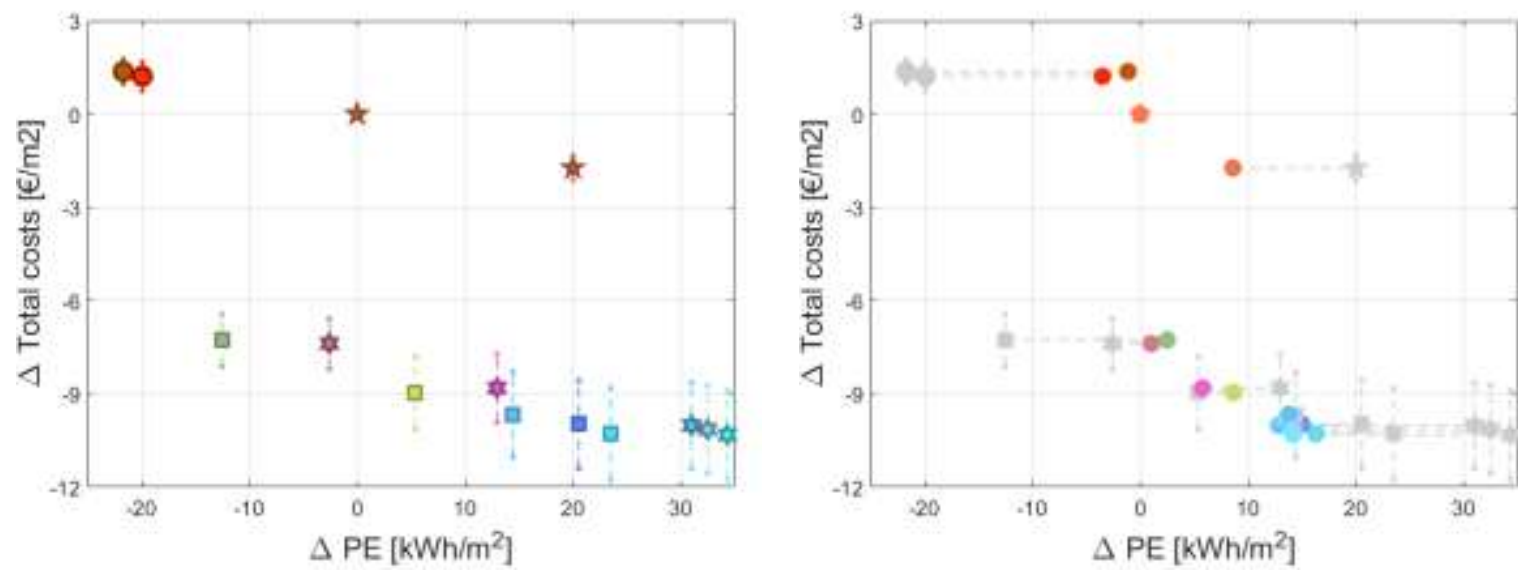

C. All-electric HVAC concept, PER: EU-2.5

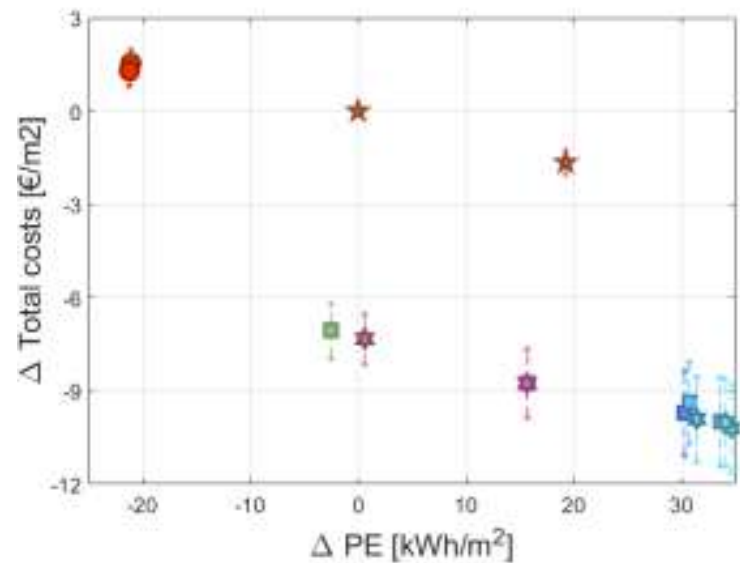

D. All-electric HVAC concept, PER: 10-30-30

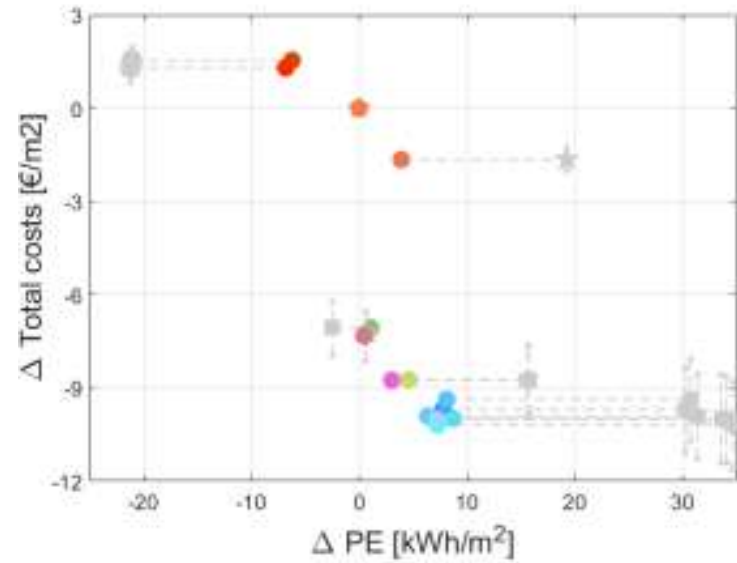

E. All-electric HVAC concept, PER: 10-30-30,

$1 \%$ productivity gains for Kindow concepts

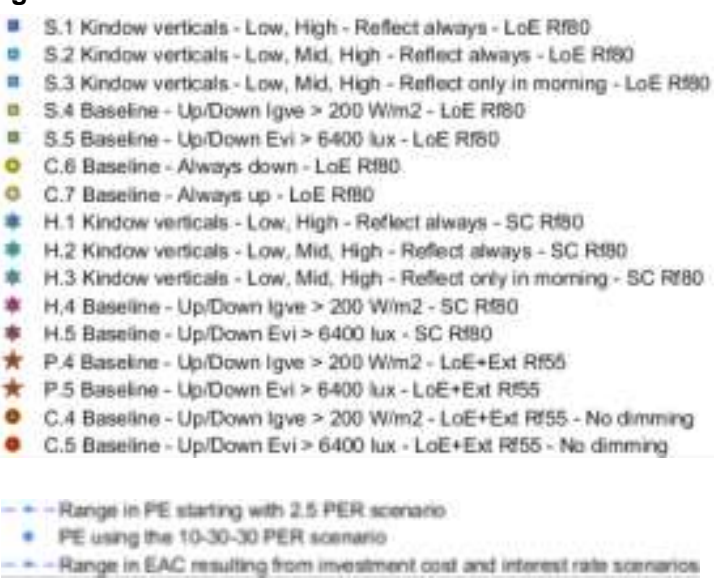

a S.1 Kindow verticals - Low, High - Refect alwaya - LoE Rroo

S.2 Kindow verticals - Low, Mid, Hgh - Reflect always - LoE Rte0

S.3 Kindow verticals - Low, Md. High - Reflect only in morning - LoE Rsép

S. B Baseine - UaDown lgve $>200$ Wim2 - toE RR8

S.5 Easeine - Lorown Evi $>6400$ UX - LCE RFo

C.6 Baseline - Aways down - LoE PREO

C.7 Baseaine - Aiways w - LoE RRe

H.1 Kindow verticals - Low High - Refloct always - SC Riso

H. 2 Kindow versicels - Low, Mid High - Refect atways - SC Rigo

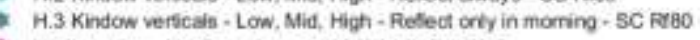

H,4 Baseane - Up/Down lgve > 200 Wim2 - 5 C RKO

H.5 Baspaine - Up/Down Evi > 6400 lux * SC Prag

P. Aaseine - Up/Down Igve > 200 Wim2 - LoE - Ext ReSS

P 5 Baseine - LaDown Exi > 6400 ux - LOE+Ext Ress

C.A Baseäne - Up,Down lgve > 200 Wim2 - LoE +Ext Pr55 - No dimmro

- C.5 Baseine - Up/Down Evi $>6400$ lux - LoE + Ext F\&55 - No dimming

- Mange in PE statrog with 2.5 PER sceraco

PE usang the to $30-30$ PER scenario

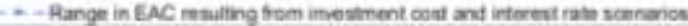

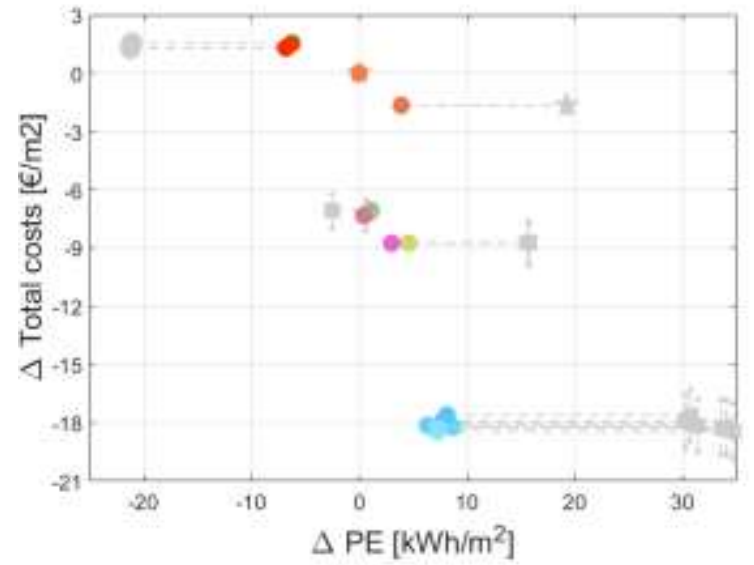

Figure 2-73: Difference in primary energy consumption $(\Delta \mathrm{PE})$ and total annual costs $(\Delta$ Total costs) of different shading strategies and glazing systems compared to the outdoor roller blind baseline.

From a comparison of the Kindow control concepts with the alternative approaches the following can be concluded:

- Kindow (S and $\mathrm{H}$ numbers 1-3) offers significant reductions in terms of primary energy consumption for similar costs as the other indoor solution solutions ( $\mathrm{S}$ and $\mathrm{H}$ numbers 4-5).

- Kindow with high solar gain glazing (S.1-3) leads to similar energy performance as conventionally controlled exterior solar shading (P.4-5) but does so at much lower total annual costs.

- Using a Kindow solar shading system together with solar control glazing (H.1-3) gives offers the most optimal overall performance. 
Figure 2-73 C shows the same comparison as in Figure 2-73 A, but now for the all-electric HVAC concept. Compared to the conventional HVAC concept the following aspects change in the all-electric concept:

- Increased heating and cooling efficiency reduce the overall primary energy consumption for all alternatives. For most alternatives, however, the differences with the common baseline $(\triangle \mathrm{PE})$ remain largely unchanged.

- The energy performance of the high solar gain glazing alternatives $(\mathrm{S})$ improves relative to the solar control glazing $(\mathrm{H})$ and exterior shading alternatives $(\mathrm{P})$.

- This can be explained by the higher efficiency of cooling equipment which reduces the impact that undesired solar gains have on overall energy performance. The electrification of heating, in combination with a high PER, increases the relative importance of heating and desired solar gains in the heating season.

The graphs $\mathbf{B}$ and $\mathbf{D}$ in Figure 2-73 show the same evaluations as in $\mathbf{A}$ and $\mathbf{C}$ but now assuming the 10-30-30 primary energy ratio scenario. In these graphs the following can be observed:

- The differences in primary energy consumption become smaller in absolute terms.

- $\quad$ Alternatives which reduce solar heat gains no longer offer superior energy performance. The low primary energy ratios associated to the abundance of renewable electricity during the summer months reduce the importance of cooling.

- The choice in glazing/shading configuration hardly affects energy performance. Daylight dimming and the solar shading control strategy do still affect energy performance significantly. The hierarchy of solutions in terms of energy performance shown in graphs $\mathbf{C}$ and $\mathbf{D}$ reflects the daylighting performance of the different alternatives.

\section{Discussion and conclusion}

Some aspects of this case-study require elaboration and place some limitations on the interpretation of its conclusions. This study focussed on a south facing perimeter office in the Dutch context.

The way in which total costs are operationalised in this study allows for a comparison of solar shading and glazing solutions on the basis building related costs but it omits the operational benefits that improved visual comfort and exposure to daylight and views could have on the well-being and productivity of office workers. Although there is sufficient research indicating that such benefits exists, it is difficult to translate these findings into quantifiable improvements from specific daylighting technologies ( [35], [36], [37], [38], [39]). Considering that, for a typical office building, building related costs constitute only $10 \%$ of the total operating expenses and salary and employee related costs can be as high as $80 \%$ ( [37], [40]), it is likely that potential productivity improvements will have a very strong effect on total costs. Figure 2-73 E illustrates the extent to which potential productivity gains might influence the total costs presented in this study. Here the assumption is made that the improved visual comfort and daylighting performance would lead to an increase in productivity of $1 \%$ compared to the conventional shading control alternatives

This assumption can be considered as a conservative estimate in comparison to what is reported in the aforementioned literature. The graph shows that, even with a conservative estimate, the effects of including productivity gains in the total cost are as large as the difference between the best and the worst conventionally controlled alternatives.

From this study, the following can be concluded:

- The Kindow solar shading concept offers superior daylighting, visual comfort and energy performance compared to conventional automated solar shading solutions. This conclusion is robust with respect to different assumptions regarding PER scenarios, HVAC concepts and glazing systems.

- The presence of a daylight dimming system is an essential condition for the Kindow system to offer improvements in energy performance over conventional automated control approaches.

- With regards to building related costs, the Kindow system performs similar to other indoor solar shading solutions. 
- More efficient cooling systems and improvements in the PER of electricity will decrease the relative importance of energy performance in relation to other performance aspects in the selection of glazing and solar shading systems.

- If daylight dimming systems and more efficient cooling systems become more ubiquitous, and the presence of renewable electricity from PV gives rise to favourable PER in the summer months, reducing solar heat gains will become less important in the selection of glazing and the control of solar shading systems. Effective daylighting becomes the most defining aspect in improving energy performance.

- For daylighting technologies, the financial benefits of an improved visual environment are likely to be large in comparison to differences in terms of other operational costs. Although more research is needed in order to quantify these financial benefits, there is sufficient evidence to weigh potential improvements in the visual environment strongly in relation to energy performance and building related costs. 


\title{
2.2.7 Impact of Integral Day- and Artificial Lighting Solutions on Energy Demand and User Comfort
}

\author{
Martin Hauera, David Geisler-Morodera

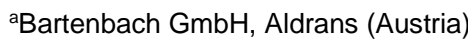

As an extension to the baseline evaluation (chapter 2.1.2), further investigations have been made in evaluating the energy saving potential by introducing:

- Efficient artificial lighting systems and controls;

- Daylight redirecting façade systems including efficient controls.

The investigated case studies compare the stepwise improvements in those aspects, starting from the baseline results (Reference case). The evaluation has been conducted for the three locations Rome, Stuttgart and Stockholm. For evaluating the end energy demand, a coefficient of performance (COP) of 2.5 for heating and an energy efficiency ratio (EER) of 3.0 for cooling is assumed.

Table 2-24: Description of the investigated case studies

\begin{tabular}{l|ll} 
Investigated case & \multicolumn{2}{l}{ Settings } \\
\hline Reference case: & $\bullet$ & Artificial light constantly on during occupancy \\
Baseline model (DC.1 section 3.3) & $\bullet$ & Glazed façade + solar protection with exterior screen \\
Case 1: & $\bullet$ & Light with on/off control based on daylight availability \\
+ daylight depending artificial lighting control & - & Glazed façade + solar protection with exterior screen \\
Case 2: & $\bullet$ & Light with on/off control based on daylight availability \\
+ daylight redirection system & - & Glazed façade + shading VB (FB2) and specular VB (FB3) \\
Case 3: & $\bullet$ & Light with dimming control based on daylight \\
+ combining lighting control \& daylight utilization & - & Glazed façade + shading VB (FB2) and specular VB (FB3) \\
\hline
\end{tabular}

The façade configuration for the reference case and case 1 represents a standard system with a 3-pane insulation glazing unit and an exterior screen with a visual transmittance of $30 \%$. By exceeding $120 \mathrm{~W} / \mathrm{m}^{2}$ of incident direct beam radiation on the south façade, the window changes in shading state as shown in Figure 2-74
only Glazing
(basic state)

\section{Glazing + external screen (shading state)}

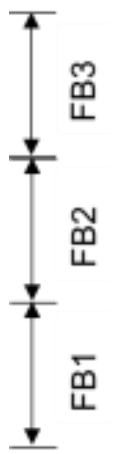

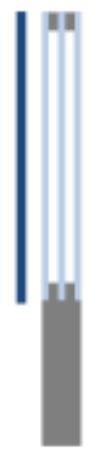

Figure 2-74: Facade configuration for the reference case and case 1

The façade configuration for case 2 and case 3 (Figure 2-75) consists of two individual facade parts, including a convex shading blind with diffuse surface finish (FB2) and a concave daylight redirecting blind with a strong specular reflection characteristic (FB3). Two façade settings are included: a winter state, which accounts for glare control $\left(\max .3000 \mathrm{~cd} / \mathrm{m}^{2}\right.$ on the inner façade) and a summer state, which considers glare and solar control (max. $\left.10 \mathrm{~W} / \mathrm{m}^{2}\right)$. Therefore, in winter state both transparent façade parts $(F B 2+3)$ are controlled in cut-off position as an ideal compromise in blocking direct sun penetration and using solar gains via diffuse radiation contribution. In contrast, in summer state FB3 is controlled at fixed $0^{\circ}$ slat angle to enhance daylight utilization, FB2 at fixed $45^{\circ}$ slat angle to avoid glare and overheating. The unshaded situation is represented in both cases again by a 3-pane insulation glazing unit. 


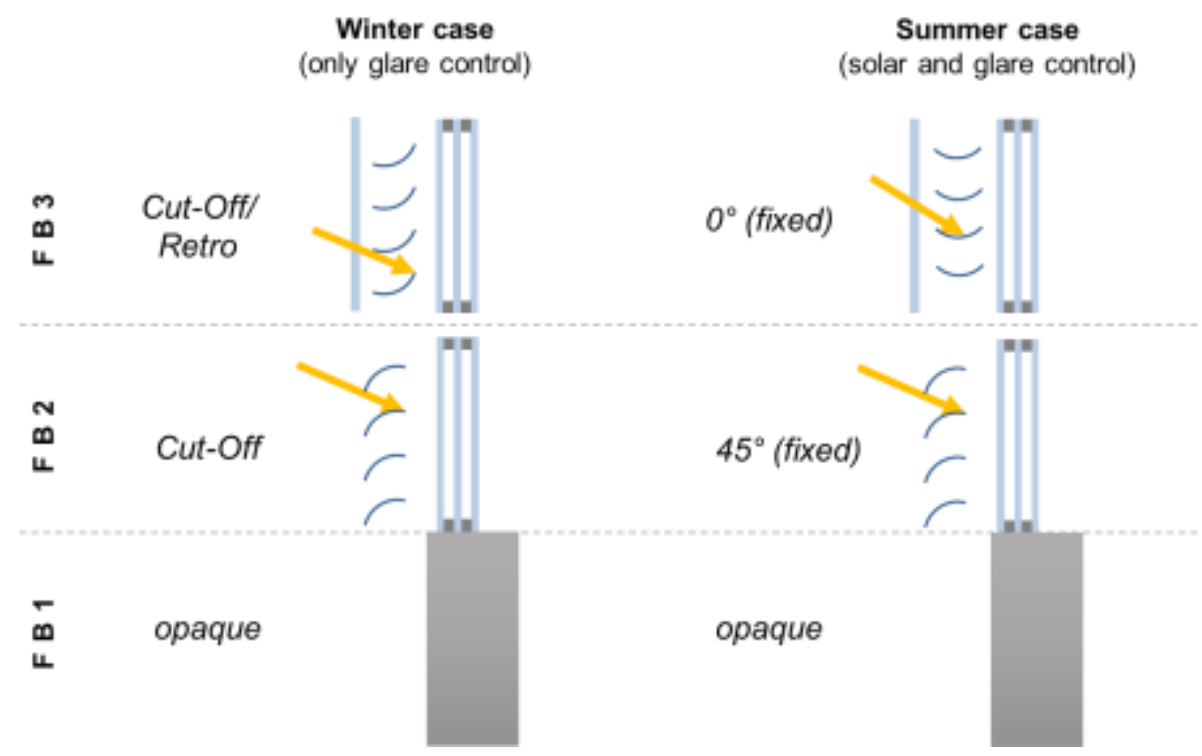

Figure 2-75: Facade configuration for case 2 and case 3

Results Rome:

Table 2-25: Monthly case studies results from DALEC simulations for the location of Rome

\begin{tabular}{l|ccc|ccc|ccc|ccc|}
\multicolumn{10}{c|}{ Month } & \multicolumn{10}{c|}{ Reference Case } & \multicolumn{3}{c|}{ Case 1 } & \multicolumn{1}{c|}{ Case 2 } & \multicolumn{3}{c|}{ Case 3 } \\
\cline { 2 - 14 } & HT & CO & LI & HT & CO & LI & HT & CO & LI & HT & CO & LI \\
\hline Jan & 1.77 & -0.33 & 2.76 & 1.42 & -0.10 & 2.13 & 1.56 & -0.03 & 2.27 & 1.92 & -0.01 & 0.98 \\
Feb & 1.54 & -0.47 & 2.40 & 1.38 & -0.16 & 1.78 & 1.43 & -0.12 & 1.75 & 1.80 & -0.03 & 0.71 \\
Mar & 0.47 & -0.86 & 2.64 & 0.24 & -0.40 & 1.91 & 0.25 & -0.37 & 1.53 & 0.45 & -0.07 & 0.53 \\
Apr & 0.21 & -1.40 & 2.52 & 0.16 & -0.70 & 1.69 & 0.15 & -0.72 & 1.50 & 0.35 & -0.10 & 0.47 \\
May & 0.01 & -3.50 & 2.76 & 0.01 & -2.27 & 1.86 & 0.01 & -2.38 & 1.85 & 0.05 & -0.79 & 0.53 \\
Jun & 0.00 & -5.16 & 2.52 & 0.00 & -3.95 & 1.76 & 0.00 & -4.05 & 1.75 & 0.00 & -2.36 & 0.43 \\
Jul & 0.00 & -6.66 & 2.64 & 0.00 & -5.60 & 1.68 & 0.00 & -5.75 & 1.66 & 0.00 & -3.86 & 0.43 \\
Aug & 0.00 & -7.57 & 2.76 & 0.00 & -6.44 & 1.76 & 0.00 & -6.55 & 1.68 & 0.00 & -4.31 & 0.56 \\
Sep & 0.00 & -4.68 & 2.40 & 0.00 & -3.70 & 1.54 & 0.00 & -3.68 & 1.44 & 0.00 & -1.60 & 0.71 \\
Oct & 0.06 & -3.61 & 2.76 & 0.03 & -2.64 & 2.03 & 0.03 & -2.51 & 1.96 & 0.07 & -0.81 & 1.21 \\
Nov & 0.48 & -1.38 & 2.64 & 0.39 & -1.08 & 1.97 & 0.43 & -0.89 & 2.10 & 0.53 & -0.61 & 0.86 \\
Dec & 1.36 & -0.30 & 2.52 & 1.20 & -0.22 & 2.00 & 1.31 & -0.16 & 2.16 & 1.60 & -0.08 & 0.93 \\
\hline Total & $\mathbf{5 . 9 0}$ & $\mathbf{- 3 5 . 9 4}$ & $\mathbf{3 1 . 2 9}$ & $\mathbf{4 . 8 3}$ & $\mathbf{- 2 7 . 2 5}$ & $\mathbf{2 2 . 1 0}$ & $\mathbf{5 . 1 7}$ & $\mathbf{- 2 7 . 2 1}$ & $\mathbf{2 1 . 6 6}$ & $\mathbf{6 . 7 8}$ & $\mathbf{- 1 4 . 6 5}$ & $\mathbf{8 . 3 6}$ \\
\hline
\end{tabular}

In Rome the solar gains dominate the influence on the overall energy balance. Therefore, by changing the façade system from a diffuse screen (case 1) towards a shading/daylighting blind system (case 2) shows a high potential in reducing the cooling load. At the same time, the application of a daylighting system reaches only minor improvements in reduction of artificial lighting power. This is mainly due to the low room depth (Figure 2-76).

Instead, an artificial lighting system with a daylight-based control saves up to $30 \%$ in energy demand for artificial lighting compared to the reference case (light always on during occupancy). By implementing a dimming function to complement the missing daylighting part to $500 \mathrm{~lx}$ via artificial lighting, another significant amount of $13 \mathrm{kWh} / \mathrm{m}^{2}$ can be saved, which leads to an overall reduction of the artificial light energy demand of $73 \%$ compared to the reference case scenario (Figure 2-77).

Changes in the heating demand are neglectable compared to the cooling demand. Nevertheless, it tends to increase slightly with the number of cases, mainly due to a reduced solar entry through the façade by a stricter glare control as well as reduced artificial lighting gains. The continuous daylight autonomy shows no influence in the façade-near area MA1 (redirecting effect is not present), but slight improvements for the façade-far area MA2 for case 2. Although the potential for daylighting in this particular case is limited, it might be promising for rooms with deep floor plans. The glare evaluation shows significant exceeding's by using the solar control, which is not applicable. Case 1 and 2 shows a sufficient daylight utilization while avoiding glare - and therefore an optimal control. 


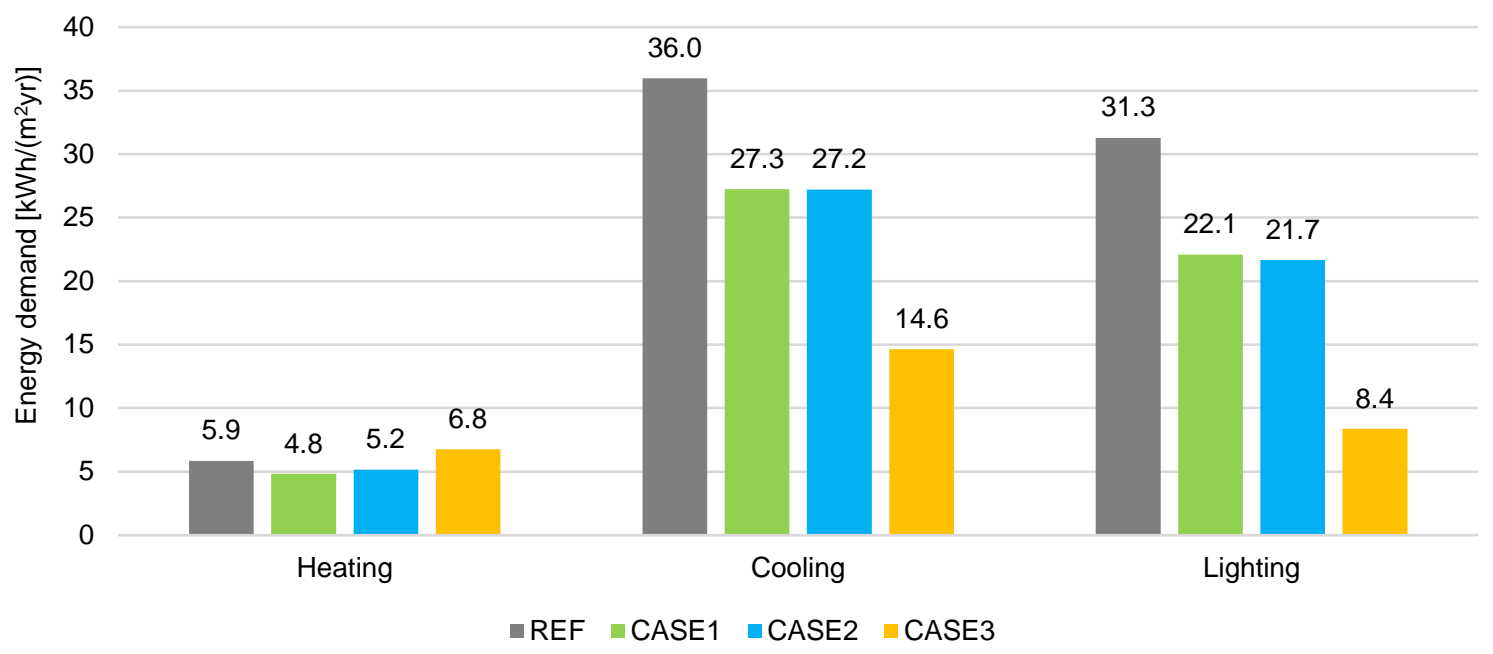

Figure 2-76: Energy balance for space heating and cooling demand and lighting in Rome

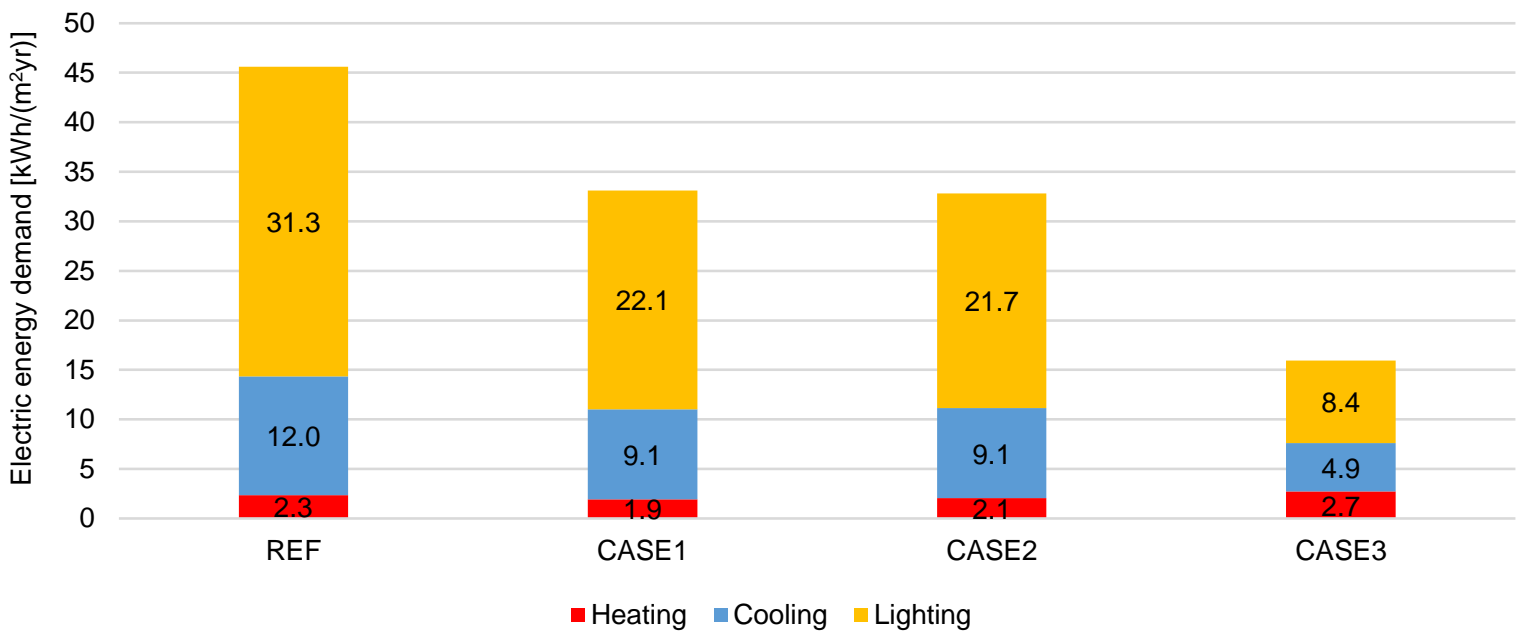

Figure 2-77: Electric energy demand for heating, cooling and lighting in Rome 


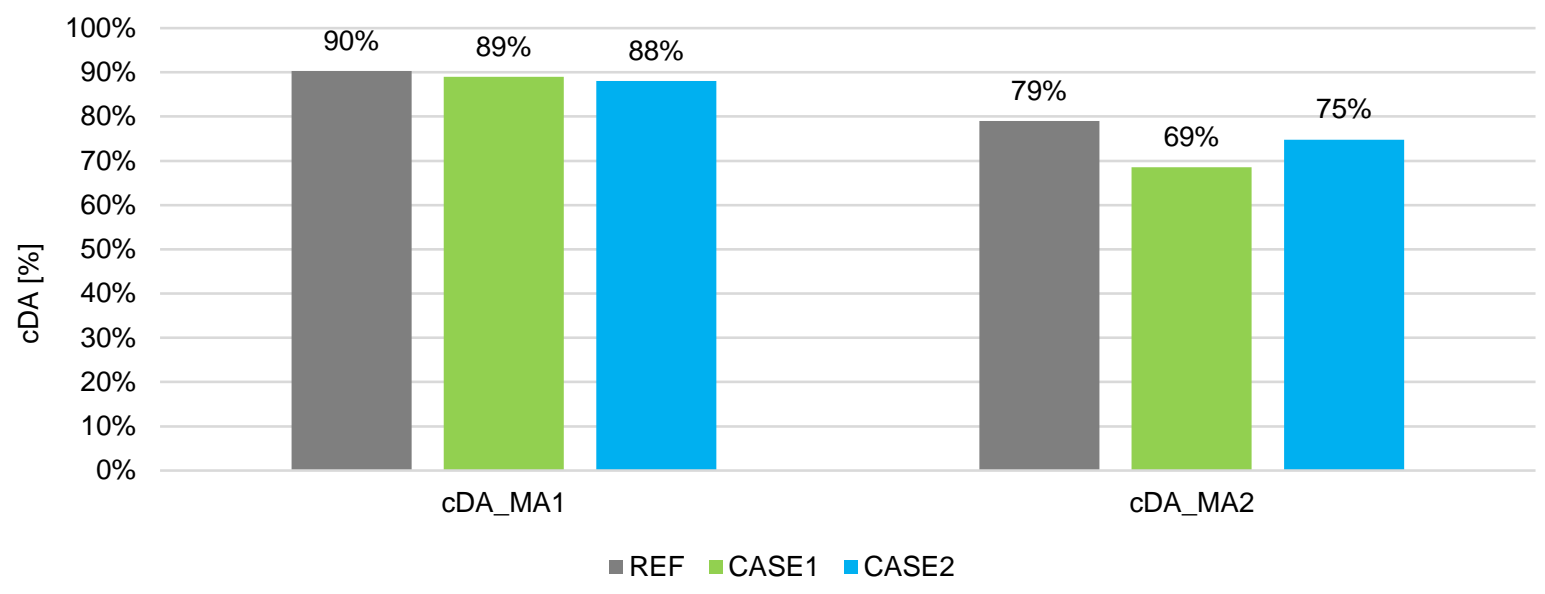

Figure 2-78: Comparison of continuous daylight autonomy results between Reference case (baseline), case 1 (diffuse shading screen) and case 2 (daylight redirecting system) in Rome. The results for case 3 are equal to case 2 (only differs in artificial lighting).

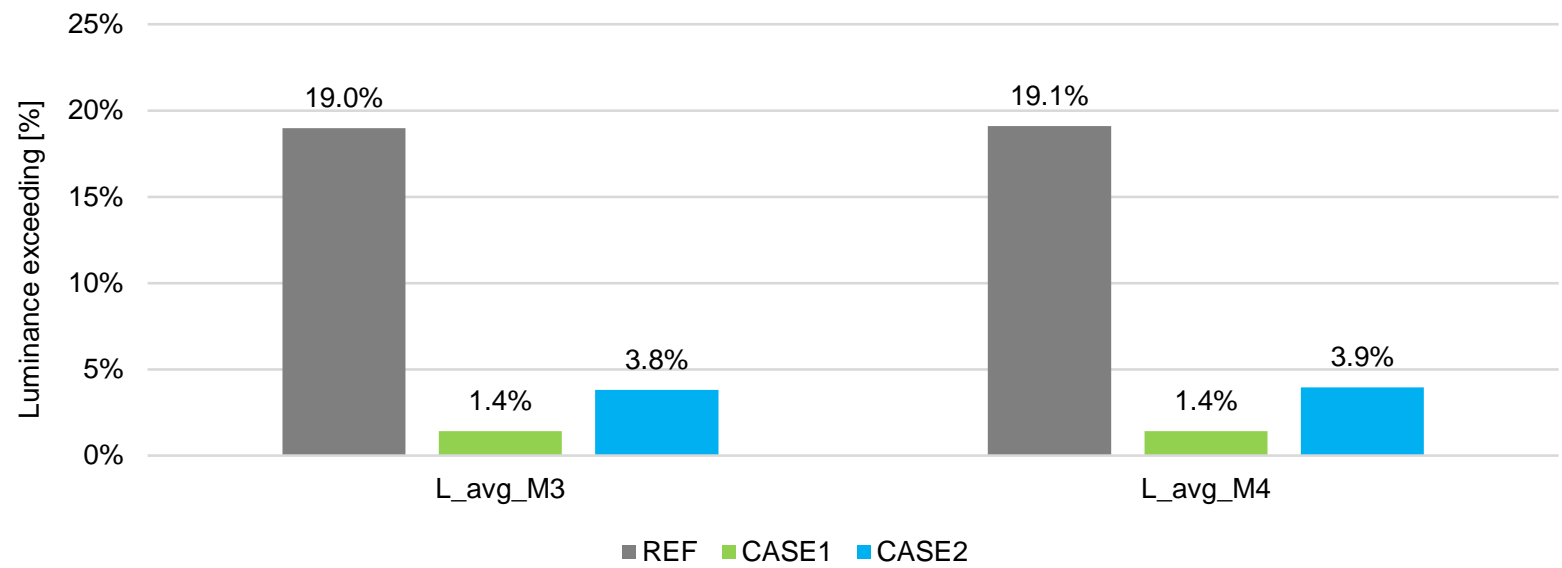

Figure 2-79: Comparison of exceeding luminance between Reference case (baseline), case 1 (diffuse shading screen) and case 2 (daylight redirecting system) in Rome. The results for case 3 are equal to case 2 (only differs in artificial lighting).

\section{Results Stuttgart:}

Table 2-26: Monthly case studies results from DALEC simulations for the location of Stuttgart

\begin{tabular}{|c|c|c|c|c|c|c|c|c|c|c|c|c|}
\hline \multirow{3}{*}{ Month } & \multicolumn{12}{|c|}{ Monthly useful energy demand $\left[\mathrm{kWh} /\left(\mathrm{m}^{2} \mathrm{mo}\right)\right]$} \\
\hline & \multicolumn{3}{|c|}{ Reference Case } & \multicolumn{3}{|c|}{ Case 1} & \multicolumn{3}{|c|}{ Case 2} & \multicolumn{3}{|c|}{ Case 3} \\
\hline & HT & $\mathrm{CO}$ & LI & HT & $\mathrm{CO}$ & LI & HT & $\mathrm{CO}$ & LI & HT & $\mathrm{CO}$ & LI \\
\hline Jan & 4.71 & -0.16 & 2.76 & 4.64 & -0.15 & 2.37 & 4.69 & -0.12 & 2.51 & 5.21 & -0.19 & 1.22 \\
\hline Feb & 3.11 & -0.13 & 2.40 & 2.87 & -0.34 & 2.01 & 2.88 & -0.36 & 2.01 & 3.38 & -0.35 & 0.93 \\
\hline Mar & 1.89 & -0.58 & 2.64 & 1.99 & -0.51 & 1.97 & 1.86 & -0.77 & 1.81 & 2.26 & -0.58 & 0.74 \\
\hline Apr & 0.52 & -1.52 & 2.52 & 0.65 & -0.61 & 1.85 & 0.48 & -0.89 & 1.73 & 1.16 & -0.15 & 0.59 \\
\hline May & 0.06 & -4.28 & 2.76 & 0.08 & -1.89 & 2.02 & 0.06 & -2.54 & 1.99 & 0.17 & -0.69 & 0.58 \\
\hline Jun & 0.00 & -5.54 & 2.52 & 0.00 & -3.31 & 1.86 & 0.00 & -3.95 & 1.86 & 0.00 & -2.07 & 0.48 \\
\hline Jul & 0.00 & -5.83 & 2.64 & 0.00 & -3.98 & 1.86 & 0.00 & -4.69 & 1.81 & 0.00 & -2.41 & 0.52 \\
\hline Aug & 0.01 & -6.08 & 2.76 & 0.02 & -4.15 & 1.82 & 0.02 & -4.96 & 1.73 & 0.02 & -2.33 & 0.62 \\
\hline Sep & 0.03 & -2.78 & 2.40 & 0.04 & -1.79 & 1.79 & 0.02 & -2.35 & 1.77 & 0.19 & -0.42 & 0.79 \\
\hline Oct & 0.61 & -1.15 & 2.76 & 0.74 & -0.47 & 2.23 & 0.63 & -0.67 & 2.23 & 1.52 & -0.13 & 1.35 \\
\hline Nov & 2.53 & -0.31 & 2.64 & 2.46 & -0.28 & 2.20 & 2.47 & -0.27 & 2.33 & 2.91 & -0.33 & 1.13 \\
\hline Dec & 4.72 & -0.02 & 2.52 & 4.35 & -0.18 & 2.27 & 4.42 & -0.18 & 2.36 & 4.86 & -0.19 & 1.26 \\
\hline Total & 18.19 & -28.38 & 31.29 & 17.83 & -17.68 & 24.25 & 17.53 & -21.77 & 24.1 & 21.68 & -9.85 & 10.21 \\
\hline
\end{tabular}


In Stuttgart, similar as in Rome, the application of a daylighting system reaches only minor improvements in reduction of artificial lighting power. The main reduction in artificial light gain is reached in combining a daylighting system with a dimmable artificial lighting system. Operating the redirecting façade part (FA3) in constant $0^{\circ}$ slat position increases the cooling demand clearly $\left(+5 \mathrm{kWh} / \mathrm{m}^{2} \mathrm{a}\right)$, in contrast it shows clear benefits in daylight utilization for façade-far areas. Means, it is always a balancing in both aspects.

Including all improvements, the cooling load can be reduced by $65 \%$ according to the reference case and the lighting energy demand by $68 \%$ compared to the reference situation.

Due to the insulation quality and the thermal boundary situations, the heating demand is generally low and shows only minor influence by the different strategies. A slightly increased heating demand is clearly due to reduced artificial light gains.

Similar trends also for the continuous daylight autonomy. The overall level on daylight availability is lower compared to Rome, the façade-far area reaches still satisfying daylight utilization. Glare issues are significant only by using a solar-based control (reference case), but show satisfying results by including an illuminance-based blind control.

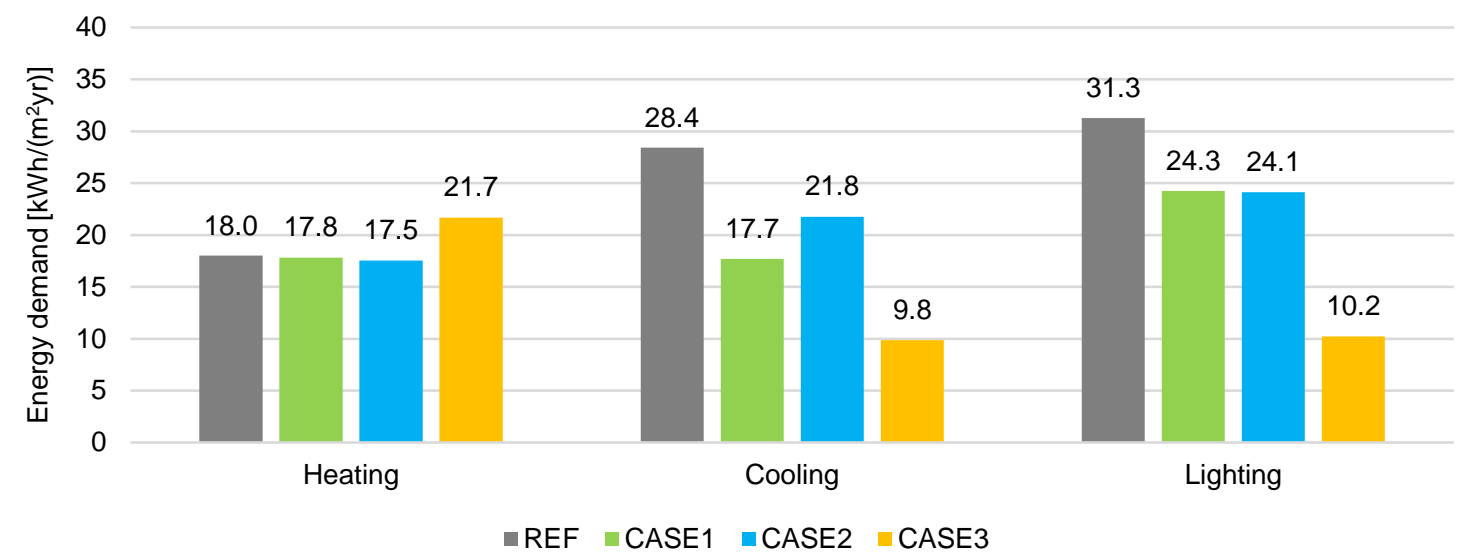

Figure 2-80: Energy balance for space heating and cooling demand and lighting in Stuttgart

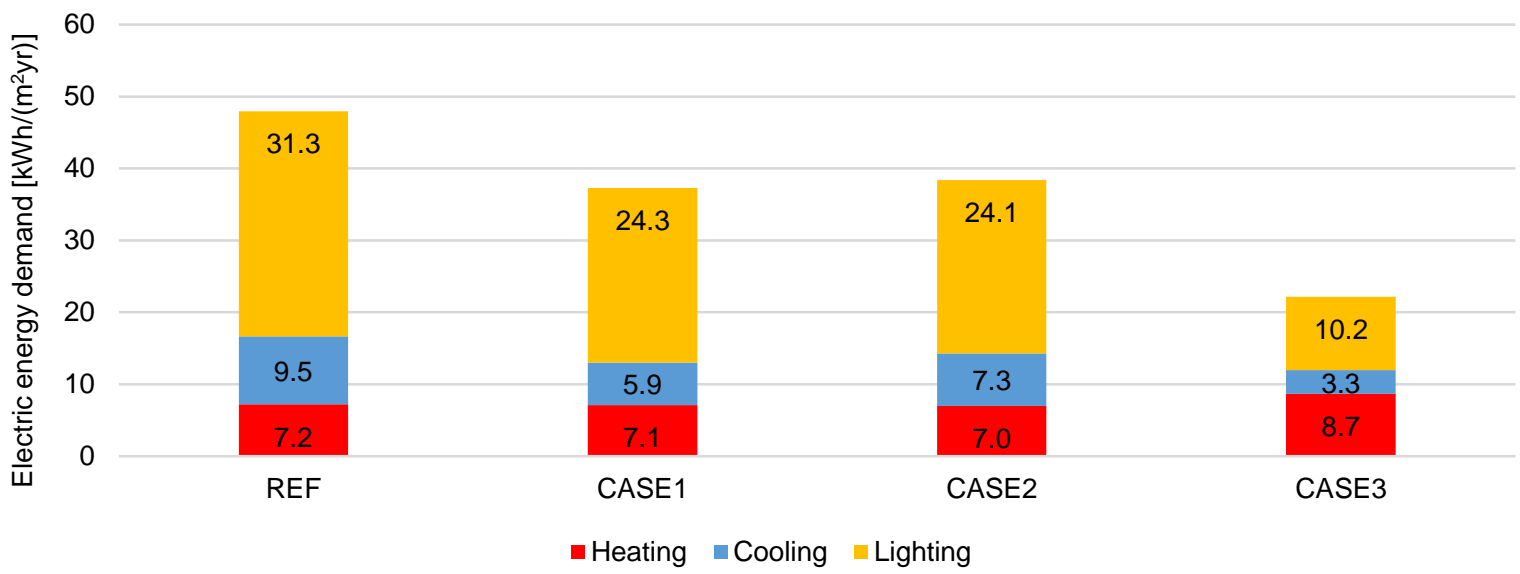

Figure 2-81: Electric energy demand for heating, cooling and lighting in Stuttgart 


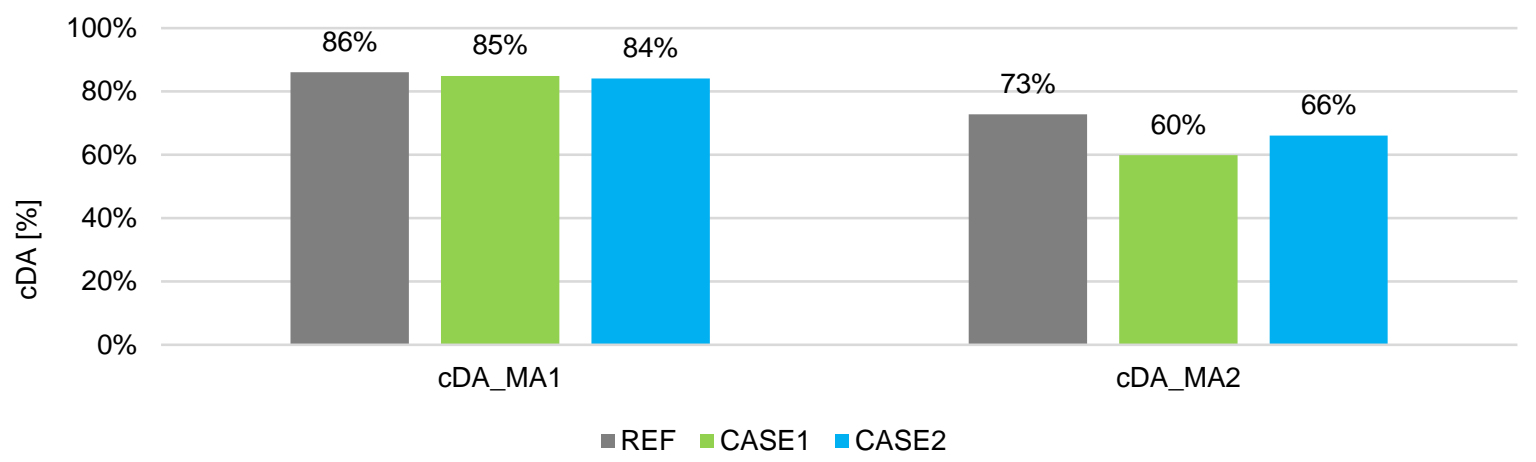

Figure 2-82: Comparison of continuous daylight autonomy results between Reference case (baseline), case 1 (diffuse shading screen) and case 2 (daylight redirecting system) in Stuttgart. The results for case 3 are equal to case 2 (only differs in artificial lighting).

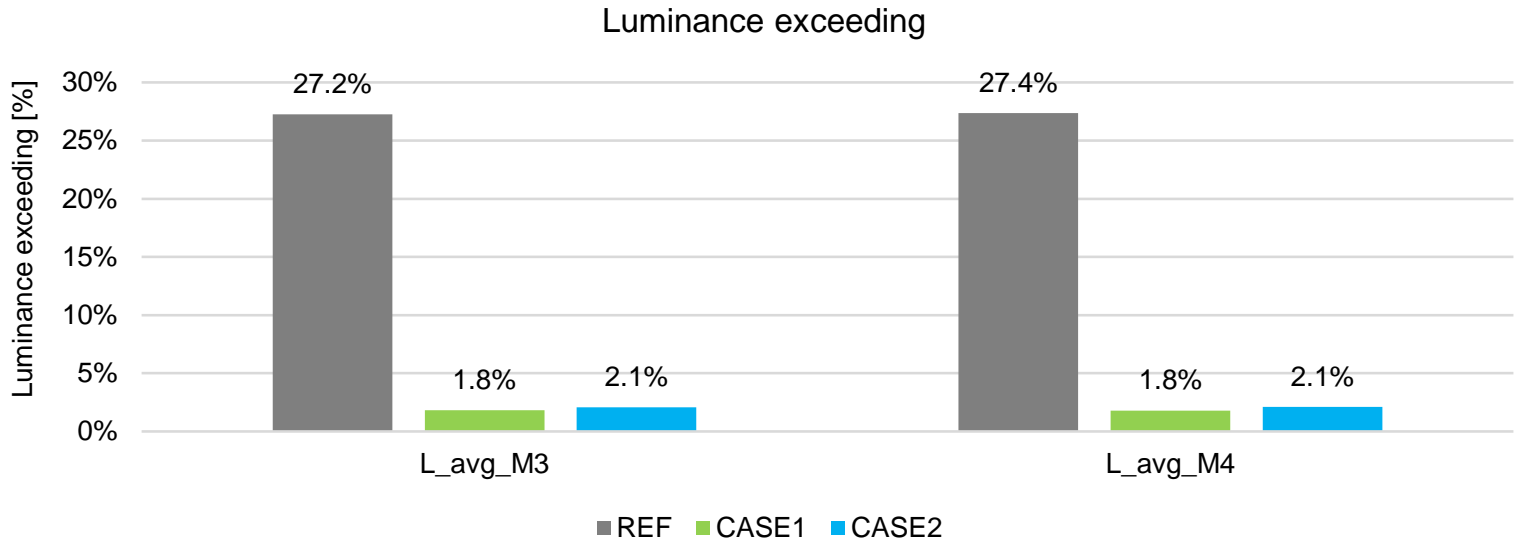

Figure 2-83: Comparison of exceeding luminance between Reference case (baseline), case 1 (diffuse shading screen) and case 2 (daylight redirecting system) in Stuttgart. The results for case 3 are equal to case 2 (only differs in artificial lighting).

\section{Results Stockholm:}

Table 2-27: Monthly case study results from DALEC simulations for the location of Stockholm

\begin{tabular}{|c|c|c|c|c|c|c|c|c|c|c|c|c|}
\hline \multirow{3}{*}{ Month } & \multicolumn{12}{|c|}{ Monthly useful energy demand $\left[\mathrm{kWh} /\left(\mathrm{m}^{2} \mathrm{mo}\right)\right]$} \\
\hline & \multicolumn{3}{|c|}{ Reference Case } & \multicolumn{3}{|c|}{ Case 1} & \multicolumn{3}{|c|}{ Case 2} & \multicolumn{3}{|c|}{ Case 3} \\
\hline & HT & CO & LI & HT & $\mathrm{CO}$ & LI & HT & $\mathrm{CO}$ & LI & HT & $\mathrm{CO}$ & LI \\
\hline Jan & 4.29 & 0.00 & 2.76 & 4.06 & -0.00 & 2.57 & 4.16 & -0.00 & 2.57 & 5.44 & -0.00 & 1.98 \\
\hline Feb & 3.26 & -0.04 & 2.40 & 2.77 & -0.11 & 2.15 & 3.10 & -0.03 & 2.08 & 4.95 & -0.00 & 1.54 \\
\hline Mar & 1.68 & -0.22 & 2.64 & 1.34 & -0.25 & 2.01 & 1.57 & -0.19 & 1.95 & 3.52 & -0.00 & 1.40 \\
\hline Apr & 0.43 & -1.56 & 2.52 & 0.46 & -1.36 & 1.80 & 0.38 & -1.33 & 1.73 & 1.12 & -0.03 & 0.90 \\
\hline May & 0.02 & -3.73 & 2.76 & 0.03 & -1.86 & 1.84 & 0.00 & -3.12 & 1.72 & 0.09 & -0.45 & 0.67 \\
\hline Jun & 0.00 & -5.34 & 2.52 & 0.00 & -3.38 & 1.79 & 0.00 & -4.50 & 1.65 & 0.00 & -1.83 & 0.54 \\
\hline Jul & 0.00 & -7.30 & 2.64 & 0.00 & -5.06 & 1.81 & 0.00 & -6.45 & 1.74 & 0.00 & -3.22 & 0.59 \\
\hline Aug & 0.00 & -6.44 & 2.76 & 0.00 & -4.31 & 1.92 & 0.00 & -5.48 & 1.81 & 0.00 & -2.40 & 0.76 \\
\hline Sep & 0.00 & -2.83 & 2.40 & 0.00 & -1.69 & 1.75 & 0.00 & -2.59 & 1.72 & 0.10 & -0.31 & 1.07 \\
\hline Oct & 0.73 & -0.74 & 2.76 & 0.84 & -0.33 & 2.26 & 0.71 & -0.65 & 2.17 & 1.54 & -0.00 & 1.62 \\
\hline Nov & 2.40 & 0.00 & 2.64 & 2.12 & -0.05 & 2.50 & 2.22 & -0.01 & 2.47 & 3.38 & -0.00 & 1.75 \\
\hline Dec & 4.07 & 0.00 & 2.52 & 3.72 & -0.02 & 2.44 & 3.87 & -0.00 & 2.45 & 5.01 & -0.00 & 1.80 \\
\hline Total & 16.87 & -28.20 & 31.29 & 15.34 & -18.42 & 24.84 & 16.03 & -24.34 & 24.1 & 25.16 & -8.24 & 14.60 \\
\hline
\end{tabular}


In Stockholm, heating as well as cooling shows a significant sensibility on the different cases. The resulting end energy demand for Case 2 with daylight redirection shows already slightly higher values compared to Case 1 using the diffuse screen.

Including all improvements, the heating demand is increases by $33 \%$, while the cooling demand decreases significantly by $70 \%$. The artificial light demand can be reduced by $55 \%$, which shows clearly an improvement in the overall end energy demand.

For the continuous daylight autonomy, the daylight system shows improvements in the façade-far area. While for Rome and Stuttgart the "Cut-off" control strategy for the daylight-redirecting part in winter gives the best results for daylight utilization, in Stockholm the "Retro" control strategy for this particular façade parts gives optimum results.

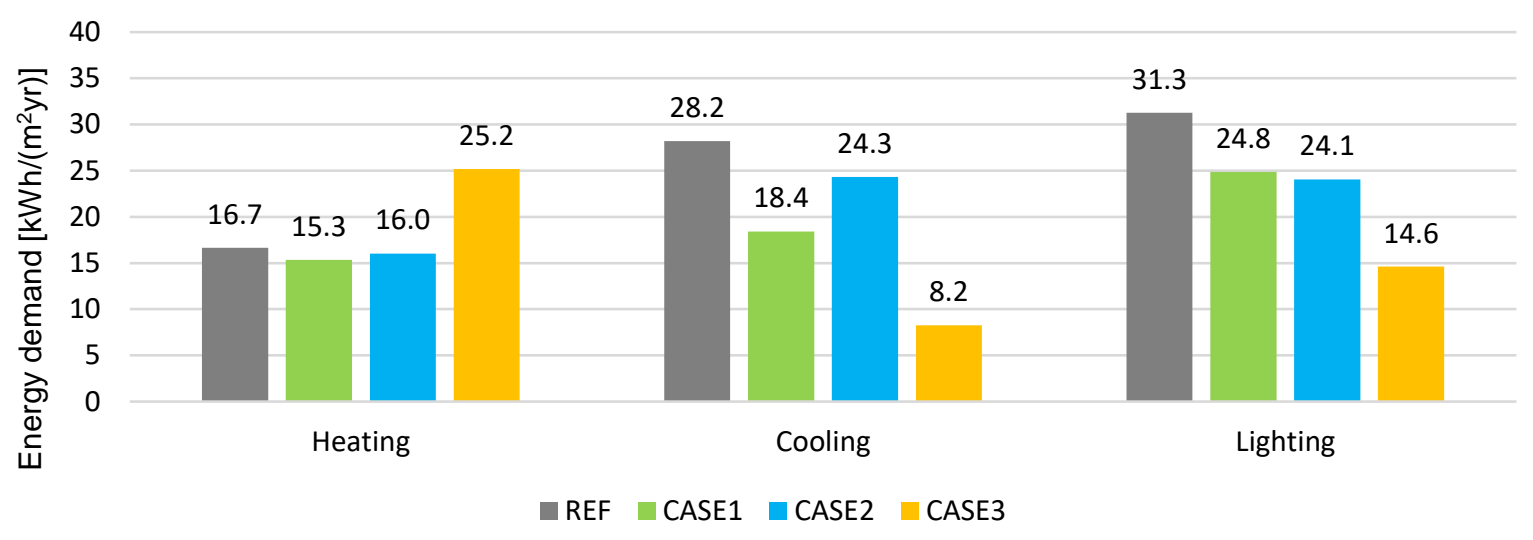

Figure 2-84 Energy balance for space heating and cooling demand and lighting in Stockholm

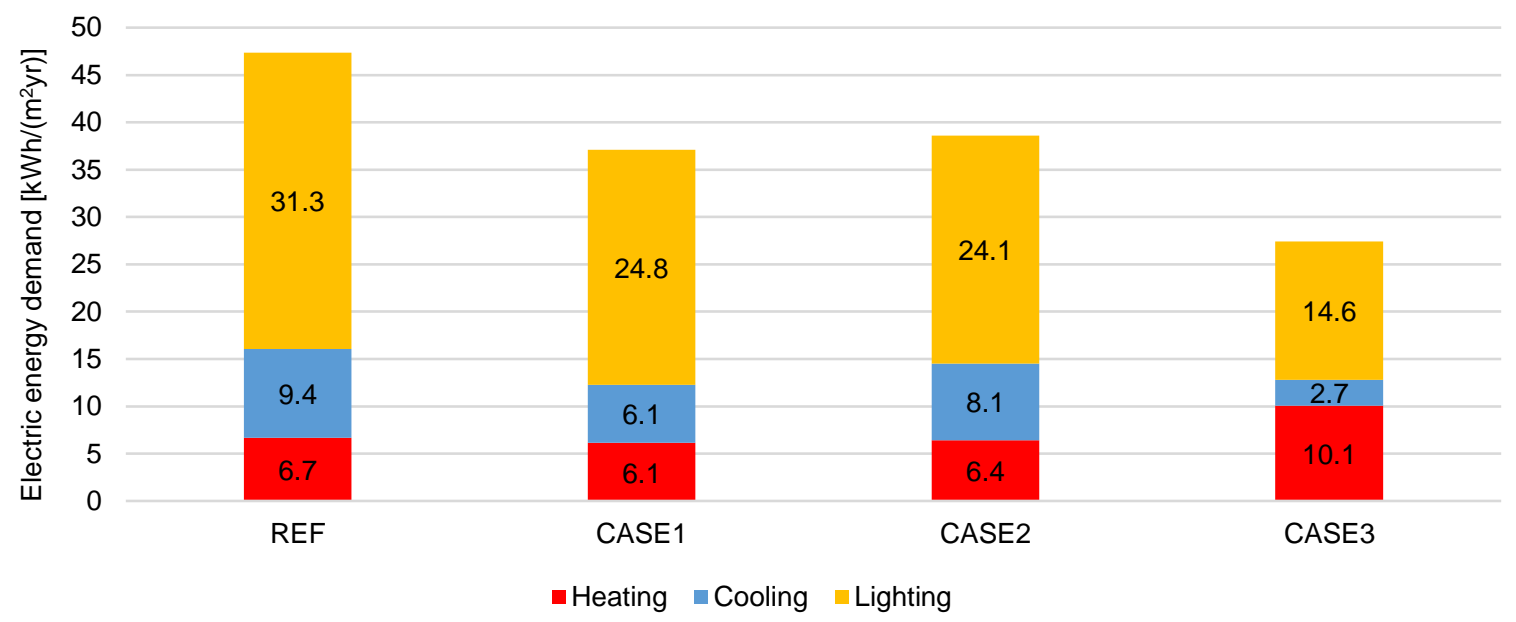

Figure 2-85: Electric energy demand for heating, cooling and lighting in Stockholm 


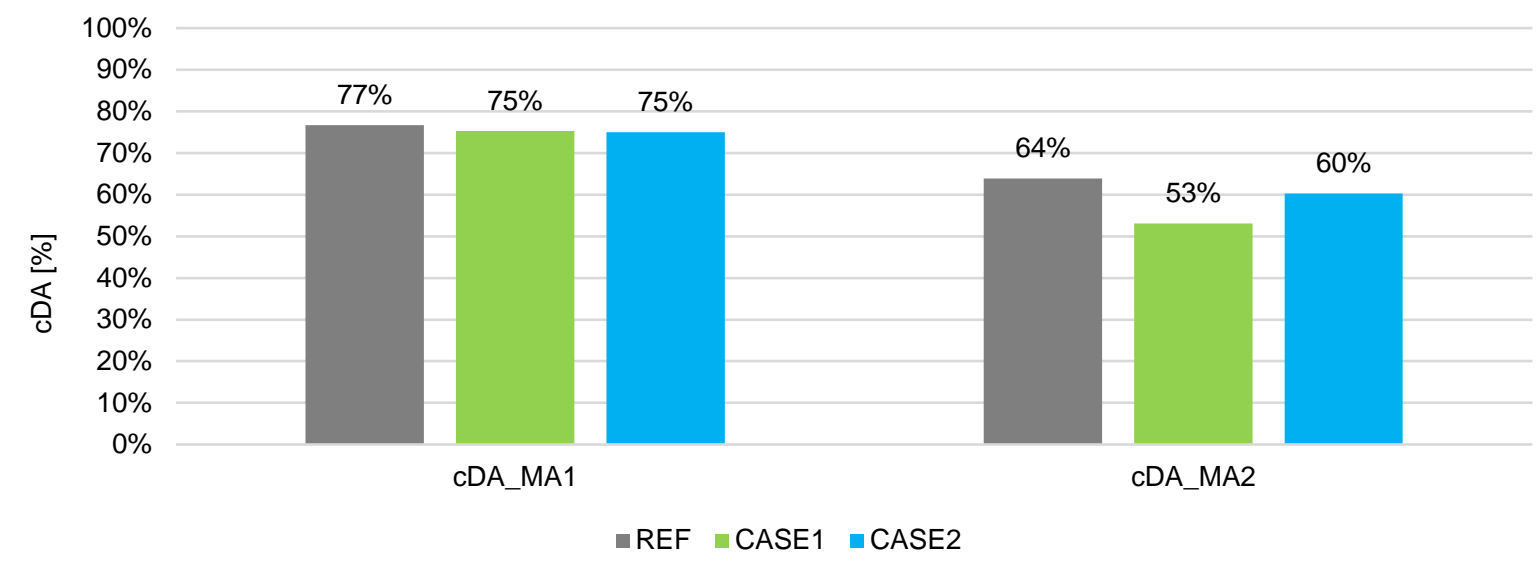

Figure 2-86: Comparison of continuous daylight autonomy results between Reference case (baseline), case 1 (diffuse shading screen) and case 2 (daylight redirecting system) in Stockholm The results for case 3 are equal to case 2 (only differs in artificial lighting).

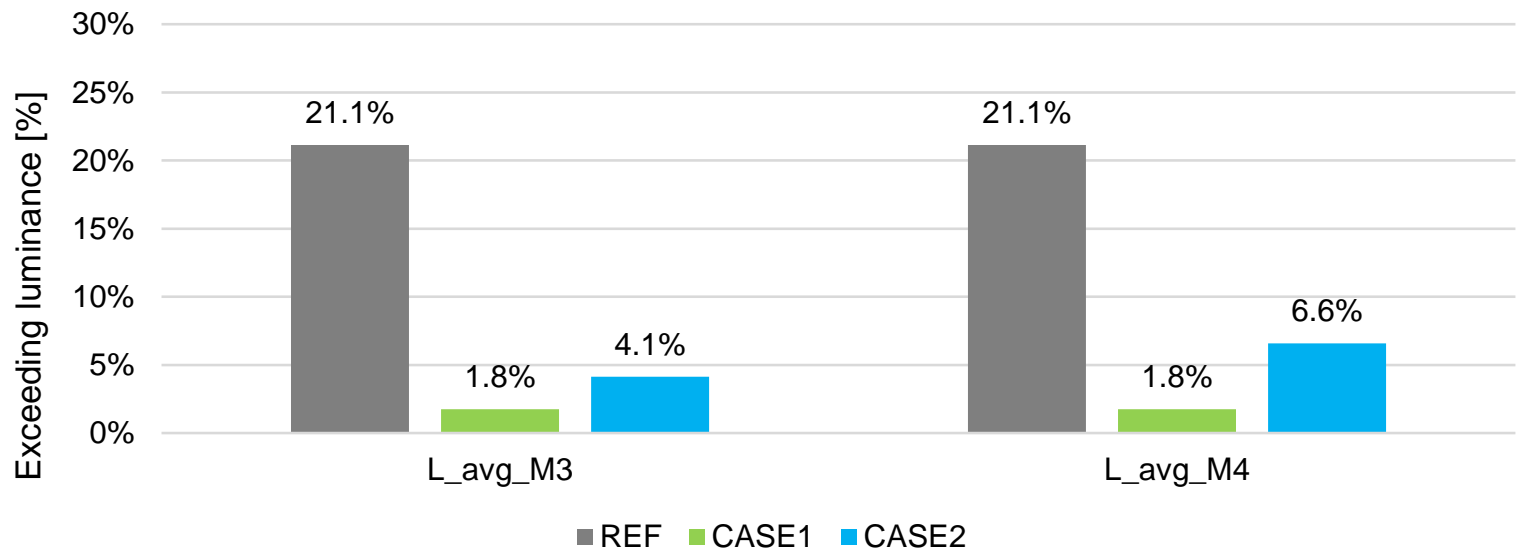

Figure 2-87: Comparison of exceeding luminance between Reference case (baseline), case 1 (diffuse shading screen) and case 2 (daylight redirecting system) in Stockholm The results for case 3 are equal to case 2 (only differs in artificial lighting).

\section{Conclusion:}

The investigated cases show a significant influence of improved lighting control strategies considering the natural daylight availability as well as the visual comfort by using a proper blind control strategy, taking glare issues into account. (REF vs. Case 1 and 2). Furthermore, the low glare effects for the shading screen with glare control are due to the assumption of an ideal diffusing system. This should be considered when comparing Case 1 and 2 in terms of glare. Daylight redirecting systems show benefits in all climates especially for daylighting in the façade-far area as well as for uniformity in the illuminance distribution. Nevertheless, it is always a balancing between solar entries (increasing cooling loads) and daylight availability (increased daylight autonomies). 


\section{Part B: Residential Building}

In this section different "Solar Envelope" solutions for residential buildings, with focus on Multi Family Houses (MFH), are investigated and evaluated by comparing building and system simulation results against a reference HVAC technology for the same building.

Different HVAC technologies need to be integrated in the building models:

- Heat Recovery and ventilation distribution;

- $\quad$ Energy (heat/cold/electricity) generation and distribution.

Detailed technical/economic analysis are carried out in order to assess the impact of the integration of the solar envelope components for different buildings in different climates.

Models for these technologies shall allow to develop and optimize control strategies for coupled control of indoor air quality, thermal and visual comfort (lighting) considering optimal energy performance.

This report has the goal to describe the reference building and HVAC system.

The buildings under consideration are a multi-story residential building. In order to investigate decentral (i.e. flatwise) façade integrated solar technologies, it is useful to simulate a flat in detail instead of the entire building. Hence, the building simulation model considers one of several flats of the building (with $\mathrm{n}_{\text {flats }}$ number of flats).

There are two possibilities for the definition of one flat:

1) a real flat that is either the ground floor flat, the attic flat or one of the central flats such that:

$$
Q_{H D \text {,building }}=n_{\text {ground floor flats }} \cdot Q_{H D, \text { ground floor flats }}+n_{\text {central flats }} \cdot Q_{H D, \text { central flats }}+n_{\text {attic flats }} \cdot Q_{H D, \text { attic flats }} \text { Eq. 3-1 }
$$

2) a virtual average flat with a heating/cooling demand such that:

$$
Q_{H D \text {,building }}=n_{\text {flats }} \cdot Q_{H D, f l a t}
$$

The traffic area (staircase, cellar) is assumed as unheated space but must be considered in the calculation of the treated area and the volume. In both cases appropriate boundary conditions need to be considered for the cellar or ground temperature, the staircase, adjacent flats and buildings (if applicable).

The simulation results presented in Part B.1 are performed using the first approach. A study following the second approach is described in Part B.2.

\subsection{Renovation case study of a multi-family house (project SaLüH!)}

Ochs Fabiana, Calabrese Tonia, Bertagnolli Felix, Siegele Dietmara, Dermentzis Georgiosa, Venus David, Venturi Elisa ${ }^{a}$

aUniversity of Innsbruck, Technikerstraße 13, Innsbruck 6020, Austria

\section{Simulation Platform}

The simulation platform used in part B.1 is CARNOT, a toolbox extension for MATLAB/SIMULINK. University of Innsbruck developed a modified version of CARNOT toolbox (called carnotUIBK) with which an object of the building is created in MATLAB reading the information from an Excel file. This version of the CARNOT toolbox gives the possibility to change most relevant parameters (e.g., HVAC system, controls, door opening model, etc.) easily in MATLAB/Excel.

\section{Location and climate data}

The climate data of Innsbruck (Austria) was chosen as reference climate. Figure 3-1 shows the monthly average ambient and ground temperature and the monthly horizontal global irradiation (see Table A. 6 in the Appendix for details). A monthly average development is implemented for the ground temperature, coming from PHPP. 


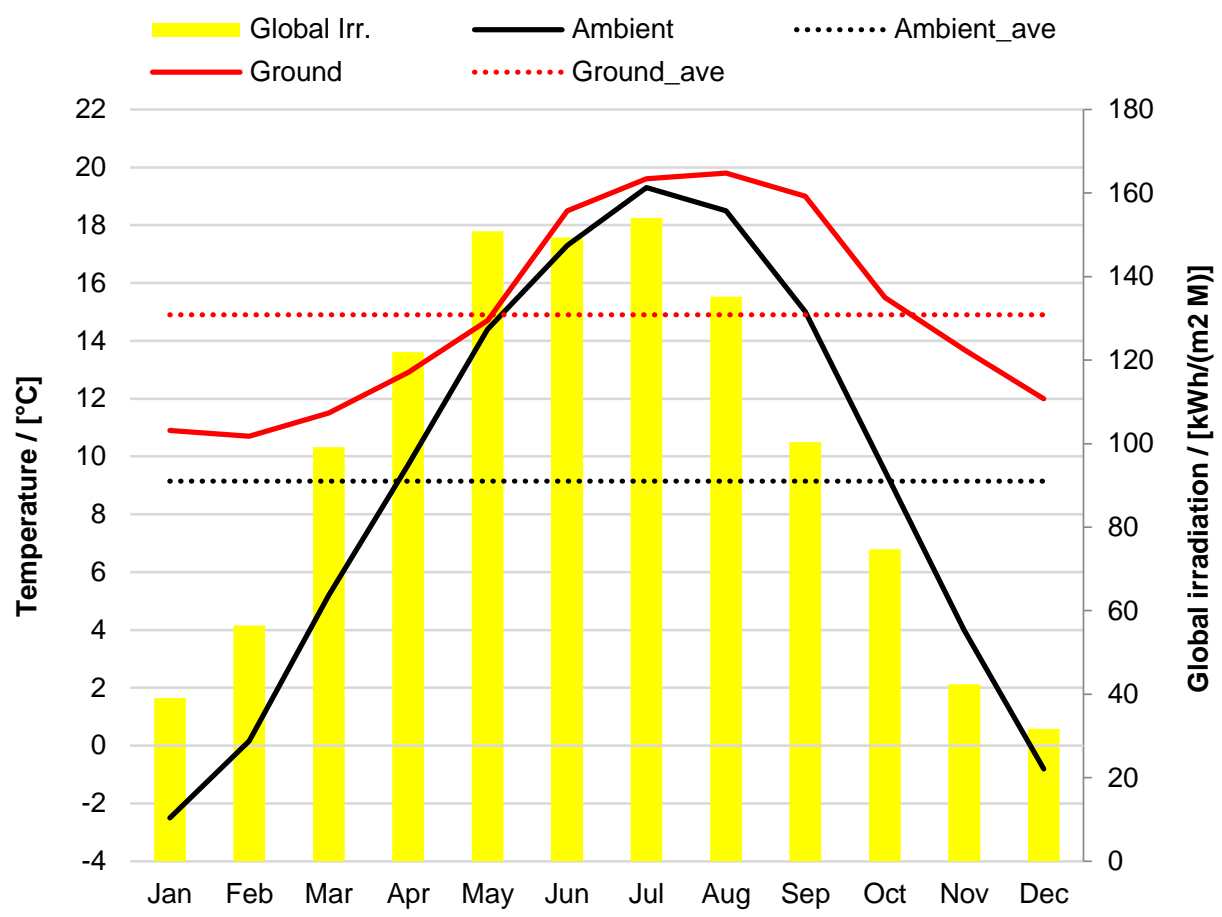

Figure 3-1: Monthly average ambient $\left(T=9.1^{\circ} \mathrm{C}\right)$ and ground $\left(\mathrm{T}=14.9^{\circ} \mathrm{C}\right)$ temperature (left axis) and monthly horizontal irradiation (Irr. $=1155 \mathrm{kWh} /\left(\mathrm{m}^{2} \mathrm{a}\right)$ (right axis)

The main characteristics of Innsbruck climate are presented in Table 3-1.

Table 3-1. Yearly climatic parameters of Innsbruck (N 4716 E 1123 Elevation 754 m)

\begin{tabular}{|c|c|c|c|c|c|c|c|c|}
\hline Location & $\begin{array}{c}\mathrm{I}_{\mathrm{g}, \mathrm{h}} \\
{\left[\mathrm{kWh} /\left(\mathrm{m}^{2} \mathrm{a}\right)\right]}\end{array}$ & $\begin{array}{c}\mathrm{I}_{b, \mathrm{~h}} \\
{\left[\mathrm{kWh} /\left(\mathrm{m}^{2} \mathrm{a}\right)\right]}\end{array}$ & $\begin{array}{c}\boldsymbol{\vartheta}_{\mathrm{amb}, \min } \\
{\left[{ }^{\circ} \mathbf{C}\right]}\end{array}$ & $\begin{array}{c}\vartheta_{a m b, \max } \\
{\left[{ }^{\circ} \mathrm{C}\right]}\end{array}$ & $\begin{array}{c}\text { Winter } \\
\text { period } \\
\text { [h] }\end{array}$ & $\begin{array}{l}\text { HDD } \\
{[\mathrm{Kd}]}\end{array}$ & $\begin{array}{c}\text { Summer } \\
\text { period } \\
\text { [h] }\end{array}$ & $\begin{array}{l}\text { CDD } \\
\text { [Kd] }\end{array}$ \\
\hline Innsbruck & 1148 & 1022 & -14.6 & 33.1 & 5188 & 3533 & 1627 & - \\
\hline
\end{tabular}




\subsubsection{Reference building description}

\section{Building model approaches}

The building under consideration is a multi-story residential building. The simulated flat that is either the ground floor flat, the attic flat or one of the central flats must fulfill the requirements of Eq. 3-1.

A preliminary PHPP calculation shows the difference of the heating demand (HD) and of the heating load $(H L)$ for the three different flat types (Table 3-2).

Table 3-2. Heating demand (HD) and heating load (HL) calculated by PHPP for the three different flats

\begin{tabular}{c|ccc} 
& ATTIC & CENTRAL & GROUND FLOOR \\
\hline HD $\left[\mathbf{k W h} /\left(\mathbf{m}^{2} \mathbf{a}\right)\right]$ & $29^{12}$ & $17.3^{12}$ & $38.1^{12}$ \\
$\mathrm{HL}\left[\mathbf{W} / \mathbf{m}^{2}\right]$ & 21 & 16.8 & 20.6 \\
\hline
\end{tabular}

\subsubsection{Multi-story residential building and reference flat}

The building under consideration is a typical multi-story building (Figure 3-2). It consists of five stories and two symmetrical flats for each story. The staircase and the basement are not heated. The basement consists in five rooms: staircase, two rooms on the North-East side and two further rooms on the South-West side. All the central flats oriented on the North-East (or the three central flats on the South-West side, respectively) are defined in the same way and are assumed to behave identical for the same boundary conditions. The reference flat considered here, is the flat of the first floor oriented to the Northeast side.
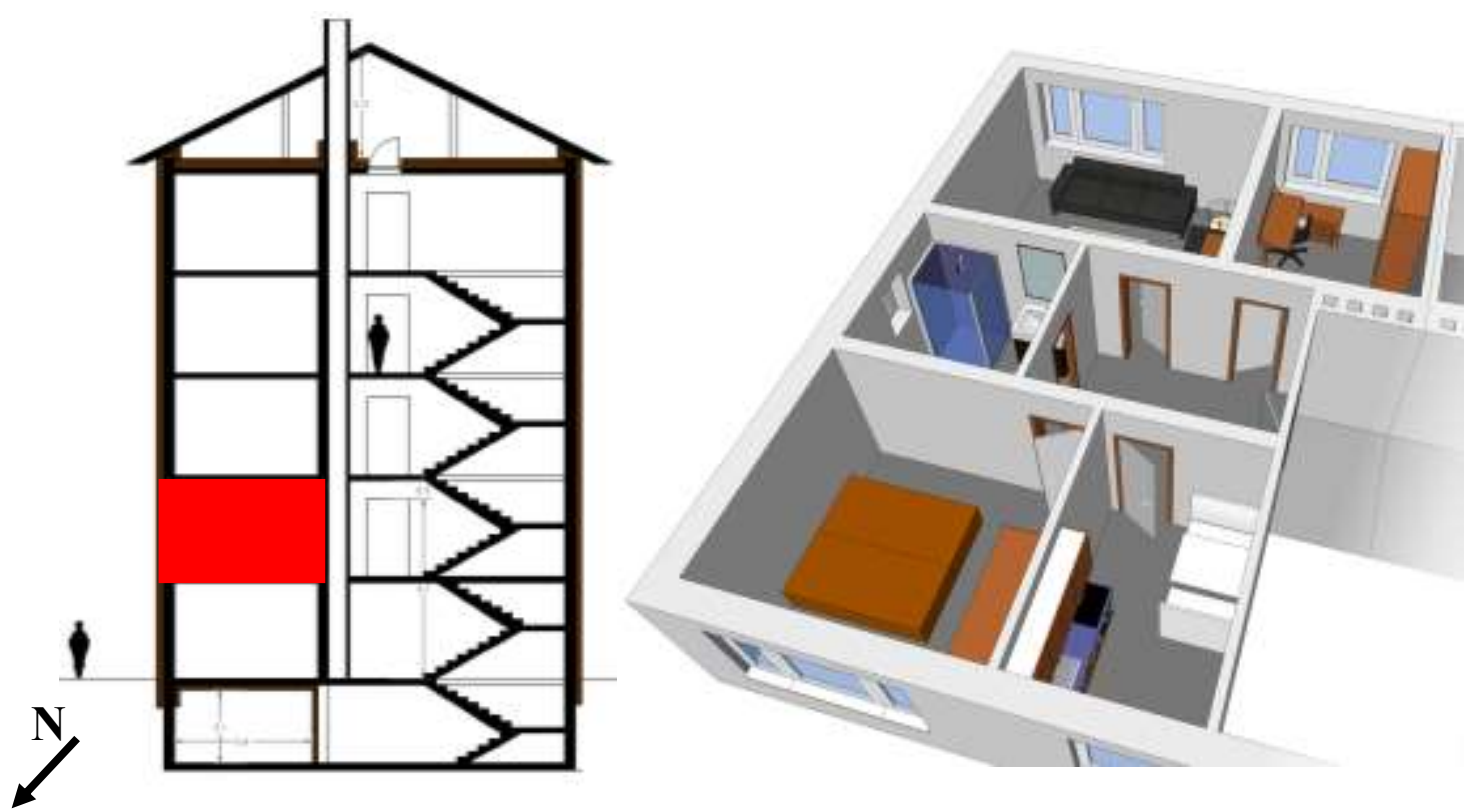

Figure 3-2: Side view of the multi-storey building (left) and 3D view of the flat (right). The flat under investigation is the flat of the first floor (highlighted in red) oriented to Northeast side (1F_E)

\section{Geometry: Floor plan and Zoning}

The reference flat is shown in Figure 3-3. The heated area is $70.8 \mathrm{~m}^{2}$. The walls and window constructions are reported in section 3.1.1.5. Unlike what Figure 3-3 shows, a window is present also in the bathroom (see Table 3-15). A balanced ventilation unit for the flat is considered: the air is supplied in the child room, sleeping room and living room, while is extracted from the kitchen and the bathroom (see section 3.1.1.3 for details about the ventilation system). Table 3-3 shows the surface and the extract/supply air system for each room.

\footnotetext{
12 The heating demand presented here does not consider the energy demand of the additional electric heater placed in the bathroom which will be included later from chapter 3.1.2
} 
Table 3-3. Surface of each room of the flat (total area of $70.8 \mathrm{~m}^{2}$ ). The mechanical ventilation system supplies fresh air to the SL, $\mathrm{CH}$ and $\mathrm{LI}$ and extracts exhaust air from BA and $\mathrm{KI}$.

\begin{tabular}{c|cc} 
Zone & Area $\left[\mathrm{m}^{2}\right]$ & Extract / supply air room \\
\hline Kitchen (KIKI) & 8.4 & Extract \\
Sleeping room (SLSL) & 14.3 & Supply \\
Corridor (COCO) & 9.8 & $/$ \\
Bathroom (BABA) & 7.5 & Extract \\
Child room (CHCH) & 12 & Supply \\
Living room (LILI) & 18.8 & Supply \\
\hline
\end{tabular}

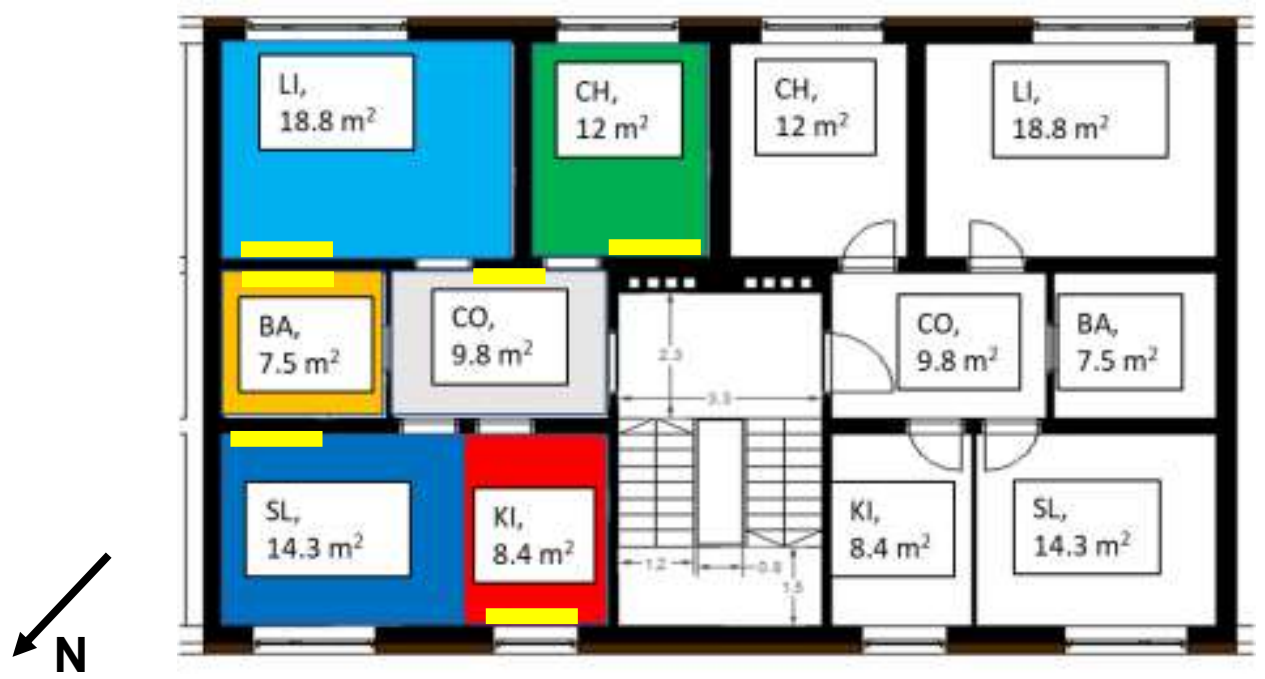

Figure 3-3: Reference flat. Two symmetrical flats were assumed for each storey of the building. The electric radiators of the reference heating system (see section 3.1.1.6) are highlighted

Through the simulation platform carnotUIBK, two different variants of "zoning" of the building are defined:

- Variant "10 thermal zones" (building);

- Variant "6 thermal zones" (flat).

In the variant "10 thermal zones", the whole building is simulated, but just one flat consists in 6 thermal zones and can be simulated in detail. The zoning is the following: flat under consideration (zones 1:6), basement (zone 7), staircase (zone 8), flats located under the flat under consideration and adjacent flat (zone 9), flats located above the flat under consideration (zone 10). In this variant ambient and ground represent the boundary conditions of the simulation.

In the variant "6 thermal zones", a single flat is simulated. The flat under consideration consists in six thermal zones (kitchen, sleeping room, corridor, bathroom, child room and living room), while the other flats (below, above and adjacent the flat simulated), basement, staircase and ambient are boundary conditions of the flat.

\subsubsection{Internal gains}

\section{Occupancy}

The reference flat is conceived to be occupied by 3 persons (ca. $23 \mathrm{~m}^{2} /$ person). The reference building is a residential building. It is assumed that the daily schedule of the occupation profile is valid also during the weekend. The daily schedule is shown in Figure 3-4. For detailed information on the occupation profile Table A. 7 and Table A. 8 in the Appendix.

Figure 3-5 shows the daily schedule of the activity profile considered in the reference building. The level of activity is assumed to be the same for all the zones; low level of activity (i.e. no physical work (0) or relaxed work (1)) is 
considered. According to this activity profile, a sensible internal gain of $60 \mathrm{~W} /$ person (divided into convective (35 W) and radiative $(25 \mathrm{~W})$ ) is considered.

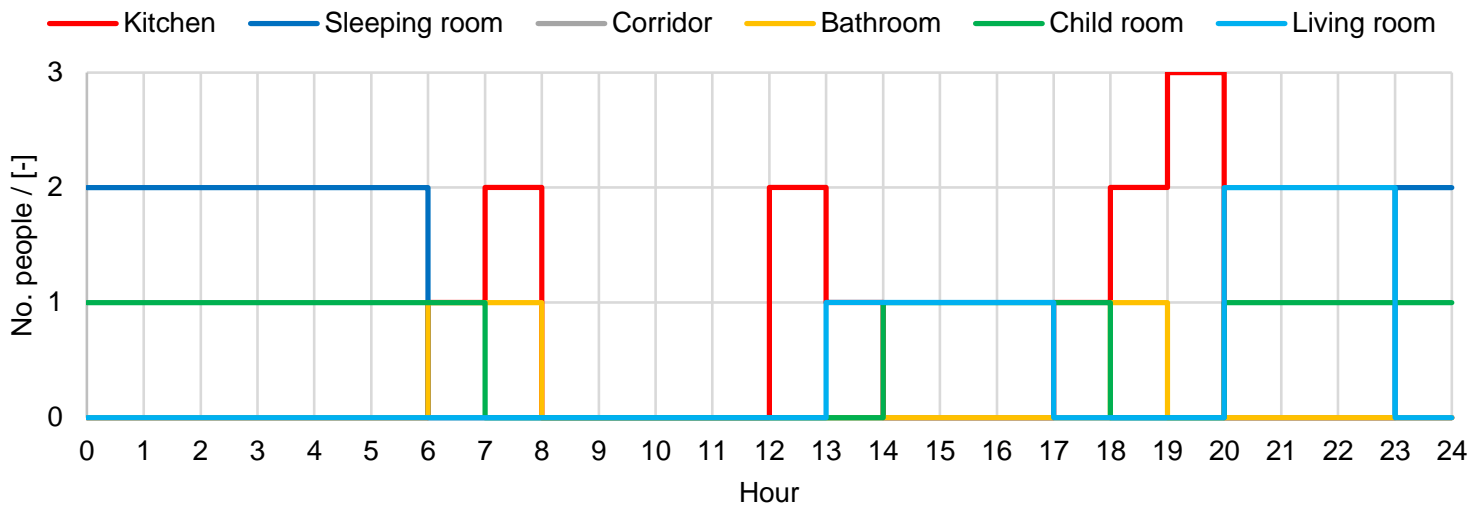

Figure 3-4: Daily schedule of the occupational profile for each room

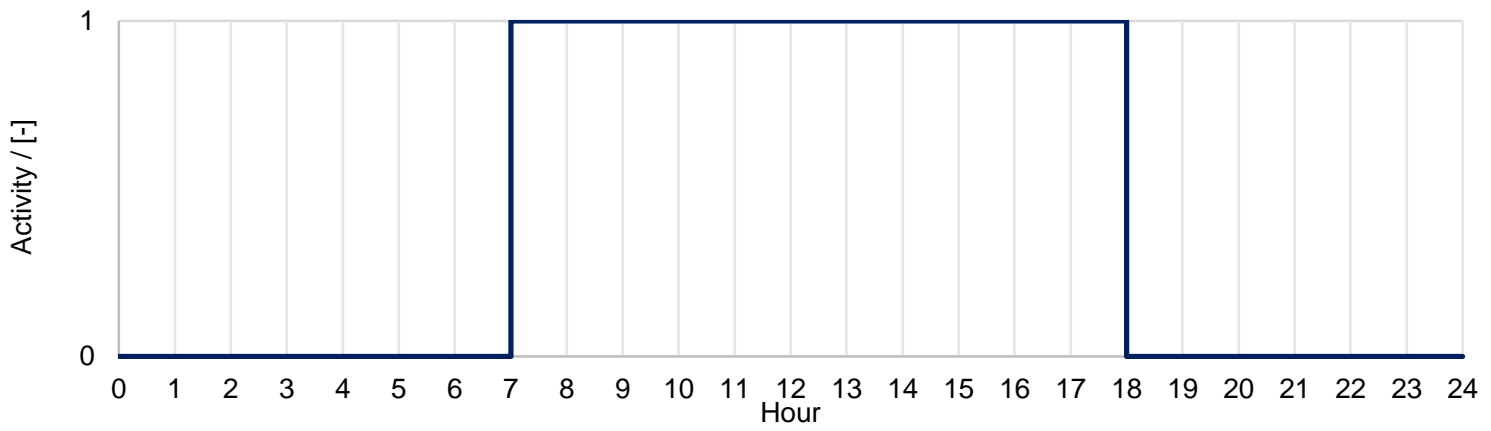

Figure 3-5: Daily schedule of the level of activity

The latent internal gains and the $\mathrm{CO}_{2}$ emissions are considered as function of the operative temperature of the zone and of the activity level, respectively (see Figure 3-6 and Table 3-4, respectively). In the Appendix, the values of the latent internal gains are shown in detail (Table A. 8).

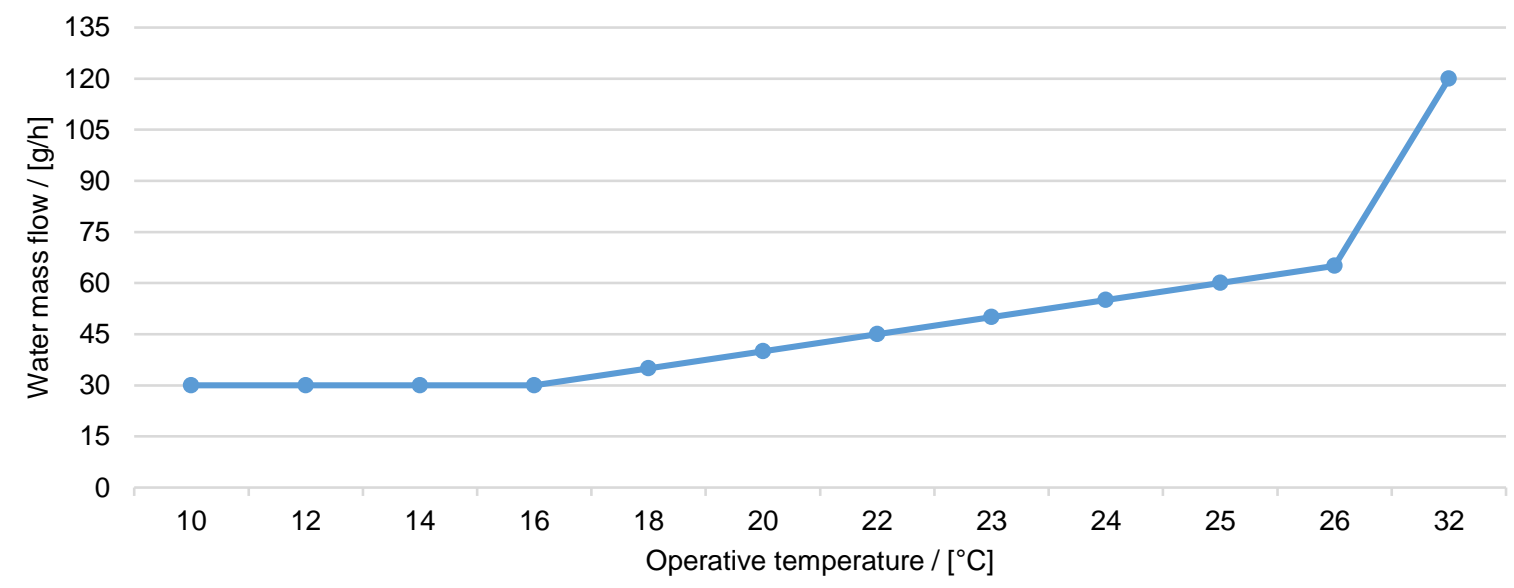

Figure 3-6: Latent internal gain [g/h] produced by 1 person depending on the operative temperature of the zone for level of activity $0-1$ 
Table 3-4. $\mathrm{CO}_{2}[\mathrm{~g} / \mathrm{h}]$ emitted by 1 person depending on the activity level

\begin{tabular}{c|cccc}
\multicolumn{5}{c}{ Activity level } \\
\hline $\mathbf{0}$ & 1 & 2 & 3 & 4 \\
$\mathbf{2 0 . 4 1 2}$ & 25.488 & 40.788 & 73.116 & 118.98 \\
\hline
\end{tabular}

Additional water vapour sources are considered (see Figure 3-7) in order to consider humidity peaks in the bathroom and in the kitchen (shower, cooking, etc.).

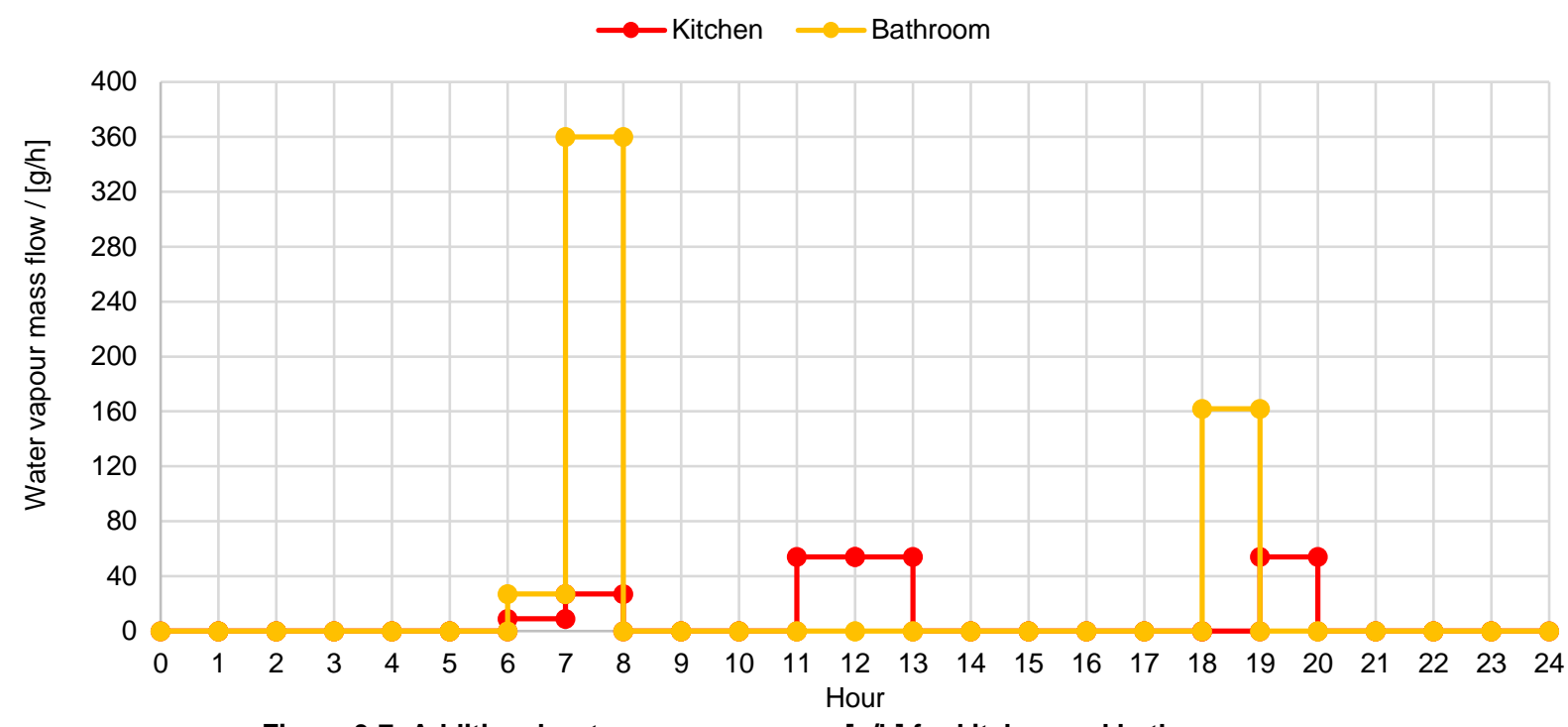

Figure 3-7: Additional water vapour sources $[\mathrm{g} / \mathrm{h}]$ for kitchen and bathroom

In zone 9 (flats located below the flat under consideration and flat of the first floor on the west side) and zone 10 (flats located above the flat under consideration) for sake of simplicity a constant internal gain of $2.1 \mathrm{~W} / \mathrm{m}^{2}$ is considered (with a convective part of $50 \%$ ), while no internal gains are considered in staircase and basement.

\section{Appliances and Lighting}

Figure 3-8 shows the internal gains due to the appliances for each zone. Appliances gain profile is the same in the child room and sleeping room, while no appliances are considered in the corridor and in the bathroom.

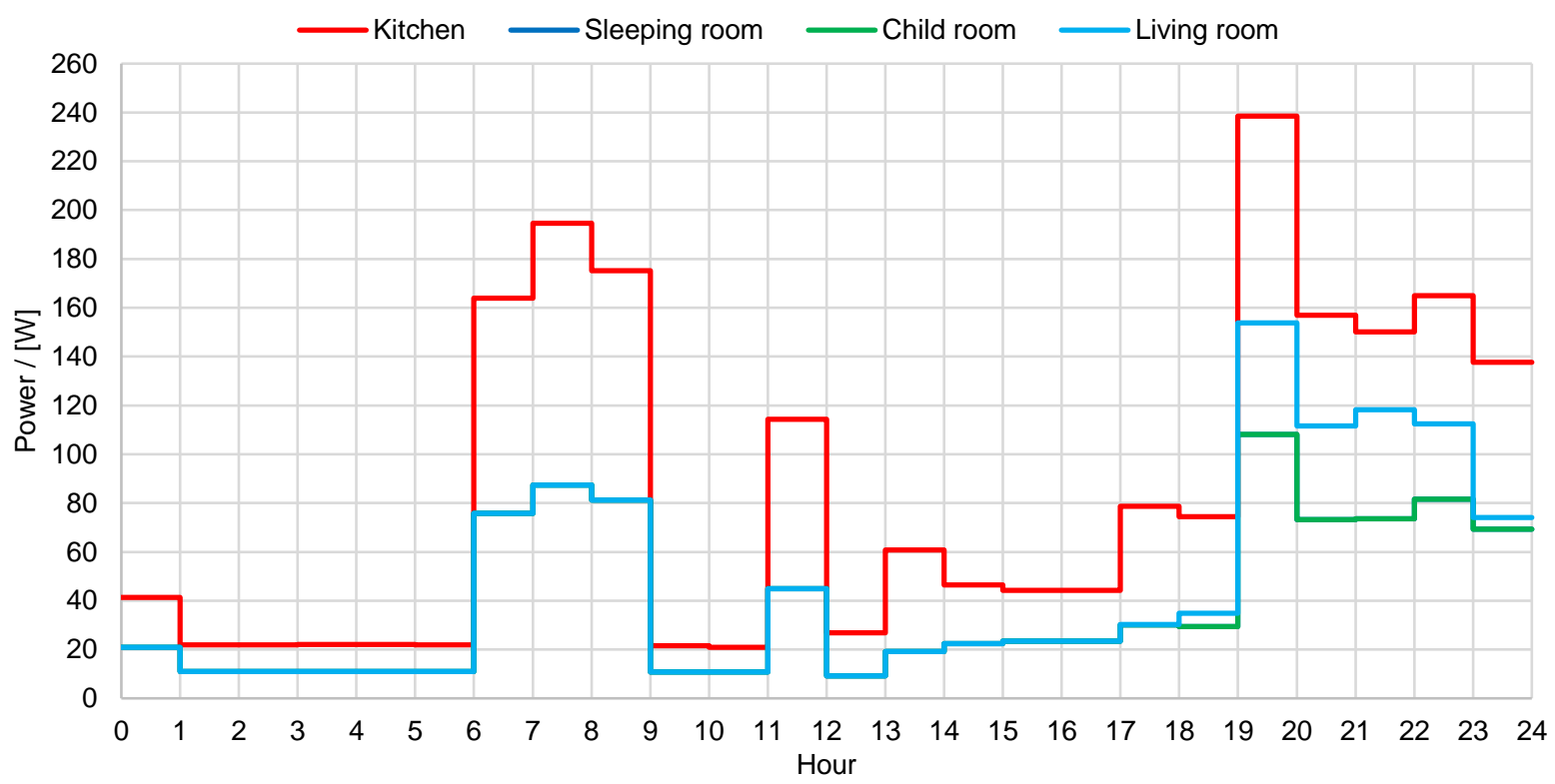

Figure 3-8: Daily schedule of gains for appliances [W] for each zone 


\subsubsection{Ventilation and infiltration}

An air change rate of $0.07[1 / \mathrm{h}]$ due to infiltration through the façade is assumed (corresponding to a blower door test result of $n 50=1[1 / \mathrm{h}]$ and considering a wind protection coefficient of 0.07$)$. This value is considered constant throughout the year.

A total volume flow of fresh air of $100 \mathrm{~m}^{3} / \mathrm{h}$ is supplied to the flat (i.e. $33 \mathrm{~m}^{3} / \mathrm{h} /$ person) through a balanced mechanical ventilation unit with a specific fan power of $0.45 \mathrm{~W} / \mathrm{m}^{3} / \mathrm{h}$. The fresh air is supplied to the sleeping room $\left(40 \mathrm{~m}^{3} / \mathrm{h}\right)$, child room $\left(20 \mathrm{~m}^{3} / \mathrm{h}\right)$ and living room $\left(40 \mathrm{~m}^{3} / \mathrm{h}\right)$ and is extracted from the kitchen $\left(60 \mathrm{~m}^{3} / \mathrm{h}\right)$ and bathroom $\left(40 \mathrm{~m}^{3} / \mathrm{h}\right)$. A heat recovery unit with a sensible effectiveness of 0.87 is considered. The heat recovery unit is by-passed when the operative temperature of the corridor is higher than $24.5^{\circ} \mathrm{C}$, the external air temperature is lower than the operative temperature of the corridor (with a hysteresis of $0.5 \mathrm{~K}$ ) and the daily average ambient temperature is higher than $15^{\circ} \mathrm{C}$. No ventilation through windows is considered during the winter.

In addition to the mechanical ventilation unit, air exchange between two adjacent zones through the opening of the doors was modelled in MATLAB/SIMULINK, based on an empirical model developed by [41].

In the reference building the door of the sleeping room (SL), bathroom (BA) and child room (CH) are always closed, while the door of the kitchen $(\mathrm{KI})$ and of the living room (LI) are open.

Opening of the windows in summer period is considered for each room. The free cooling strategy is activated when the operative temperature of the room is higher than $24.5^{\circ} \mathrm{C}$ and when external air temperature is lower than the operative temperature of the room (with hysteresis of $0.5 \mathrm{~K}$ ). The free driven window ventilation is based on the model developed by [42], considering a maximum angle of opening of window of $10^{\circ}$.

\subsubsection{Shadings}

The solar shading consists in generic external movable shading blinds that can block $70 \%$ of the solar radiation. The shading device is activated for all windows during the summer time (between the $1^{\text {st }}$ of June and the $1^{\text {st }}$ of September) independently of the solar radiation and indoor temperature.

No additional shadings (i.e. other buildings, trees, reveals, etc.) of the building are considered.

\subsubsection{Building assemblies}

\section{Opaque structures}

The wall constructions of the opaque structures are listed in the following Tables (from Table 3-5 to Table 3-13). The emissivity factor is 0.94 for all the walls; the absorption factor is 0 and 0.65 for internal walls and external walls, respectively. The $U$-values shown in the tables consider the standard convective heat transfer coefficients (1/Rsi, $1 / \mathrm{Rse})$; the external $\left(\mathrm{h}_{\mathrm{e}}\left[\mathrm{W} /\left(\mathrm{m}^{2} \mathrm{~K}\right)\right]\right)$ and internal $\left(\mathrm{h}_{\mathrm{i}}\left[\mathrm{W} /\left(\mathrm{m}^{2} \mathrm{~K}\right)\right]\right)$ convective heat transfer coefficient are variable and are implemented with the following two equations

$$
\begin{gathered}
h_{e}=4 \cdot w+4 \\
h_{i}=1.6 \cdot\left|T_{r}-T_{c}\right|^{0.3}
\end{gathered}
$$

Where:

- $\quad \mathrm{T}_{\mathrm{r}}$ and $\mathrm{T}_{\mathrm{c}}$ are the radiative and convective temperature of the zone, respectively $\left[{ }^{\circ} \mathrm{C}\right]$;

- $\quad w$ is the wind speed $[\mathrm{m} / \mathrm{s}]$.

Table 3-7 and Table 3-8 show the construction of internal walls of the apartment. All the internal walls are implemented with the wall constructions shown in Table 3-7 except the wall between corridor and bathroom, between corridor and staircase, between kitchen and staircase and between kitchen and sleeping room in which the thickness of brick is $15 \mathrm{~cm}$ (see Table 3-8).

All doors (also the external door between the corridor and the staircase) are modelled for sake of simplicity with the same constructions shown in Table 3-8.

The basement of the building consists in five rooms. All the external and internal walls of the basement are not insulated (see Table 3-13), while the walls between the basement staircase and the others four rooms are insulated (see Table 3-12) 
Table 3-5. Construction of internal floor/ceiling

\begin{tabular}{l|ccccc} 
Material & $\begin{array}{c}\mathbf{s} \\
{[\mathbf{m}]}\end{array}$ & $\begin{array}{c}\boldsymbol{\lambda} \\
{[\mathbf{W} /(\mathbf{m} \mathbf{K})]}\end{array}$ & $\begin{array}{c}\mathbf{r} \\
{\left[\mathbf{k g} / \mathbf{m}^{3}\right]}\end{array}$ & $\begin{array}{c}\mathbf{c}_{\mathbf{p}} \\
{[\mathbf{J} /(\mathbf{k g ~ K})]}\end{array}$ & $\begin{array}{c}\mathbf{u}-\mathbf{v a l u u} \mathbf{e}^{\mathbf{1 3}} \\
{\left[\mathbf{W} /\left(\mathbf{m}^{2} \mathbf{K}\right)\right]}\end{array}$ \\
\hline Pavement & 0.02 & 0.13 & 1797 & 1000 & \\
Sand pipes & 0.04 & 0.6 & 1568 & 1000 & 1.61 \\
Slab & 0.2 & 1.6 & 2400 & 1100 & \\
Inside plaster & 0.015 & 1 & 1400 & 900 & \\
\hline
\end{tabular}

Table 3-6. Construction of external walls

\begin{tabular}{l|ccccc}
\multicolumn{1}{l}{ Material } & $\begin{array}{c}\mathbf{s} \\
{[\mathbf{m}]}\end{array}$ & $\begin{array}{c}\boldsymbol{\lambda} \\
{[\mathbf{W} /(\mathbf{m} \mathbf{K})]}\end{array}$ & $\begin{array}{c}\mathbf{r} \\
{\left[\mathbf{k g} / \mathbf{m}^{3}\right]}\end{array}$ & $\begin{array}{c}\mathbf{c}_{\mathbf{p}} \\
{[\mathbf{J} /(\mathbf{k g ~ K})]}\end{array}$ & $\begin{array}{c}\mathbf{u}-\mathbf{v a l u e} \mathbf{1}^{\mathbf{1 4}} \\
{\left[\mathbf{W} /\left(\mathbf{m}^{2} \mathbf{K}\right)\right]}\end{array}$ \\
\hline Inside plaster & 0.01 & 1 & 1400 & 900 & \\
Brick & 0.3 & 0.7 & 1400 & 900 & 0.14 \\
Insulation & 0.2 & 0.031 & 30 & 802.6 & \\
Outside plaster & 0.015 & 1 & 1800 & 1100 & \\
\hline
\end{tabular}

Table 3-7. Construction of internal walls (brick thickness of $30 \mathrm{~cm}$ )

\begin{tabular}{l|ccccc}
\multicolumn{1}{c}{ Material } & $\begin{array}{c}\mathbf{s} \\
{[\mathbf{m}]}\end{array}$ & $\begin{array}{c}\boldsymbol{\lambda} \\
{[\mathbf{W} /(\mathbf{m ~ K})]}\end{array}$ & $\begin{array}{c}\mathbf{r} \\
{\left[\mathbf{k g} / \mathbf{m}^{3}\right]}\end{array}$ & $\begin{array}{c}\mathbf{c}_{\mathbf{p}} \\
{[\mathbf{J} /(\mathbf{k g ~ K})]}\end{array}$ & $\begin{array}{c}\mathbf{u}-\mathbf{v a l u e} \mathbf{1}^{13} \\
{\left[\mathbf{W} /\left(\mathbf{m}^{2} \mathbf{K}\right)\right]}\end{array}$ \\
\hline Inside plaster & 0.01 & 1 & 1400 & 900 & \\
Brick & 0.3 & 0.7 & 1400 & 900 & 1.41 \\
Inside plaster & 0.01 & 1 & 1400 & 900 & \\
\hline
\end{tabular}

Table 3-8. Construction of internal walls (brick thickness of $15 \mathrm{~cm}$ )

\begin{tabular}{l|ccccc} 
Material & $\begin{array}{c}\mathbf{s} \\
{[\mathbf{m}]}\end{array}$ & $\begin{array}{c}\boldsymbol{\lambda} \\
{[\mathbf{W} /(\mathbf{m} \mathbf{K})]}\end{array}$ & $\begin{array}{c}\mathbf{r} \\
{\left[\mathbf{k g} / \mathbf{m}^{3}\right]}\end{array}$ & $\begin{array}{c}\mathbf{c}_{\mathbf{p}} \\
{[\mathbf{J} /(\mathbf{k g ~ K})]}\end{array}$ & $\begin{array}{c}\mathbf{u - v a l u e} \mathbf{1}^{\mathbf{3}} \\
{\left[\mathbf{W} /\left(\mathbf{m}^{2} \mathbf{K}\right)\right]}\end{array}$ \\
\hline Inside plaster & 0.01 & 1 & 1400 & 900 & \\
Brick & 0.15 & 0.7 & 1400 & 900 & 2.02 \\
Inside plaster & 0.01 & 1 & 1400 & 900 & \\
\hline
\end{tabular}

Table 3-9. Construction of roof

\begin{tabular}{cccccc} 
Material & $\begin{array}{c}\mathbf{s} \\
{[\mathbf{m}]}\end{array}$ & $\begin{array}{c}\mathbf{\lambda} \\
{[\mathbf{W} /(\mathbf{m} \mathbf{K})]}\end{array}$ & $\begin{array}{c}\mathbf{r} \\
{\left[\mathbf{k g} / \mathbf{m}^{3}\right]}\end{array}$ & $\begin{array}{c}\mathbf{c}_{\mathbf{p}} \\
{[\mathbf{J} /(\mathbf{k g ~ K})]}\end{array}$ & $\begin{array}{c}\mathbf{u}-\mathbf{v a l u e}^{14} \\
{\left[\mathbf{W} /\left(\mathbf{m}^{\mathbf{2}} \mathbf{K}\right)\right]}\end{array}$ \\
\hline Inside plaster & 0.015 & 1 & 1400 & 900 & \\
Concrete & 0.17 & 2.3 & 2400 & 1100 & 0.13 \\
Cellulose insul. & 0.3 & 0.04 & 55 & 2544 & \\
\hline
\end{tabular}

Table 3-10. Construction of basement floor

\begin{tabular}{c|ccccc} 
Material & $\begin{array}{c}\mathbf{s} \\
{[\mathbf{m}]}\end{array}$ & $\begin{array}{c}\boldsymbol{\lambda} \\
{[\mathbf{W} /(\mathbf{m K})]}\end{array}$ & $\begin{array}{c}\mathbf{r} \\
{\left[\mathbf{k g} / \mathbf{m}^{3}\right]}\end{array}$ & $\begin{array}{c}\mathbf{c}_{\mathrm{p}} \\
{[\mathbf{J} /(\mathbf{k g ~ K})]}\end{array}$ & $\begin{array}{c}\mathbf{u}-\mathbf{v a l u e}^{13} \\
{\left[\mathbf{W} /\left(\mathbf{m}^{2} \mathbf{K}\right)\right]}\end{array}$ \\
\hline Slab & 0.2 & 1.6 & 2400 & 1100 & 3.92 \\
\hline
\end{tabular}

Table 3-11. Construction of basement ceiling

\begin{tabular}{c|ccccc} 
Material & $\begin{array}{c}\mathbf{s} \\
{[\mathbf{m}]}\end{array}$ & $\begin{array}{c}\boldsymbol{\lambda} \\
{[\mathbf{W} /(\mathbf{m} \mathbf{K})]}\end{array}$ & $\begin{array}{c}\mathbf{r} \\
{\left[\mathbf{k g} / \mathbf{m}^{3}\right]}\end{array}$ & $\begin{array}{c}\mathbf{c}_{\mathbf{p}} \\
{[\mathbf{J} /(\mathbf{k g ~ K})]}\end{array}$ & $\begin{array}{c}\mathbf{u}-\mathbf{v a l u e}^{\mathbf{3}} \\
{\left[\mathbf{W} /\left(\mathbf{m}^{2} \mathbf{K}\right)\right]}\end{array}$ \\
\hline Pavement & 0.02 & 0.13 & 1797 & 1000 & \\
Sand pipes & 0.04 & 0.6 & 1568 & 1000 & 0.34 \\
Concrete & 0.2 & 2.3 & 2400 & 1100 & \\
Teklatan insul. & 0.1 & 0.04 & 185 & 840 & \\
\hline
\end{tabular}

\footnotetext{
13 standard Rsi $\left(0.13\left[\mathrm{~m}^{2} \mathrm{~K} / \mathrm{W}\right]\right)$ value is used

${ }^{14}$ standard Rsi $\left(0.13\left[\mathrm{~m}^{2} \mathrm{~K} / \mathrm{W}\right]\right)$ and Rse $\left(0.04\left[\mathrm{~m}^{2} \mathrm{~K} / \mathrm{W}\right]\right)$ values are used
} 
Table 3-12. Construction of basement wall

\begin{tabular}{l|ccccc} 
Material & $\begin{array}{c}\mathbf{s} \\
{[\mathbf{m}]}\end{array}$ & $\begin{array}{c}\boldsymbol{\lambda} \\
{[\mathbf{W} /(\mathbf{m} \mathbf{K})]}\end{array}$ & $\begin{array}{c}\mathbf{r} \\
{\left[\mathbf{k g} / \mathbf{m}^{3}\right]}\end{array}$ & $\begin{array}{c}\mathbf{c}_{\mathbf{p}} \\
{[\mathbf{J} /(\mathbf{k g ~ K})]}\end{array}$ & $\begin{array}{c}\mathbf{u}-\mathbf{v a l u} \mathbf{u}^{\mathbf{1 3}} \\
{\left[\mathbf{W} /\left(\mathbf{m}^{2} \mathbf{K}\right)\right]}\end{array}$ \\
\hline Inside plaster & 0.015 & 1 & 1400 & 900 & \\
Concrete & 0.25 & 2.3 & 2400 & 1100 & 0.36 \\
Mineral wool & 0.1 & 0.04 & 30 & 840 & \\
Inside plaster & 0.015 & 1 & 1400 & 900 & \\
\hline
\end{tabular}

Table 3-13. Construction of basement wall (without insulation)

\begin{tabular}{|c|c|c|c|c|c|}
\hline Material & $\begin{array}{c}\mathbf{s} \\
{[\mathrm{m}]}\end{array}$ & $\stackrel{\lambda}{\lambda \mathrm{W} /(\mathbf{m} \mathrm{K})]}$ & $\begin{array}{c}\mathbf{r} \\
{\left[\mathrm{kg} / \mathrm{m}^{3}\right]}\end{array}$ & $\begin{array}{c}c_{p} \\
{[J /(k g ~ K)]}\end{array}$ & $\begin{array}{c}\text { u-value }{ }^{13} \\
{\left[W /\left(m^{2} K\right)\right]}\end{array}$ \\
\hline Inside plaster & 0.015 & 1 & 1400 & 900 & \multirow{3}{*}{3.44} \\
\hline Concrete & 0.3 & 2.3 & 2400 & 1100 & \\
\hline Inside plaster & 0.015 & 1 & 1400 & 900 & \\
\hline
\end{tabular}

For evaluating thermal comfort (and ensuring moisture protection), the moisture balance needs to be considered. In such a case the moisture buffer capacity of surrounding walls, floors and ceilings as well as of the furniture needs to be considered in order to avoid unrealistic moisture peaks.

The simulation platform carnotUIBK allows to choose three different models of constructions: "UA", "RC" or "Hygrothermal". If "Hygrothermal" wall model is specified, the moisture within the building envelope and the exchange of humidity between the walls and the ambient can be considered. In case the moisture balance is considered, moisture buffer of walls and furniture needs to be accounted for.

\section{Transparent structures}

Table 3-14 and Table 3-15 show the most relevant characteristics of the windows of the apartment. Each room of the apartment has a window (except the corridor) with identical thermal properties (see Table 3-14), but with different dimensions and frame ratio (see Table 3-15). Each pane has a thickness of $4 \mathrm{~mm}$ and in the $U$-value the thermal bridges due to glass-frame connection and installation are considered. The $g$-value of the windows is calculated in CARNOT/Matlab as a function of the incidence angle of the solar radiation [43].

Table 3-14. General thermal characteristics of the windows

\begin{tabular}{l|c}
\hline Uglass $\left[\mathrm{W} /\left(\mathrm{m}^{2} \mathrm{~K}\right)\right]$ & 0.53 \\
Uframe $\left[\mathrm{W} /\left(\mathrm{m}^{2} \mathrm{~K}\right)\right]$ & 0.79 \\
G-value [-] & 0.53 \\
Number panes & 3 \\
Emission [-] & 0.94 \\
Absorption [-] & 0.65 \\
\hline
\end{tabular}

Table 3-15. Physical characteristics and U-value for the windows of the different zones

\begin{tabular}{|c|c|c|c|c|}
\hline Zone & $\begin{array}{l}\text { Width } \\
\text { [m] }\end{array}$ & $\begin{array}{c}\text { Height } \\
{[\mathrm{m}]}\end{array}$ & $\begin{array}{c}\text { Frame ratio } \\
{[-]}\end{array}$ & $\begin{array}{l}\text { U-value } \\
{\left[\mathrm{W} /\left(\mathrm{m}^{2} \mathrm{~K}\right)\right]}\end{array}$ \\
\hline Kitchen & 1.34 & 1.40 & 0.32 & 0.76 \\
\hline Sleeping room & 2.52 & 1.40 & 0.41 & 0.78 \\
\hline Bathroom & 0.60 & 0.90 & 0.56 & 0.92 \\
\hline Child room & 1.89 & 1.40 & 0.38 & 0.78 \\
\hline Living room & 2.52 & 1.40 & 0.41 & 0.78 \\
\hline
\end{tabular}

\subsubsection{Reference heating system}

The flat " $1 F \_E$ " (flat of the first floor oriented to the Northeast) is simulated (variant " 6 thermal zones"). The staircase and the basement are not heated, while the flats below/above the flat under study and the flat "1F_W" (flat adjacent to the flat " $1 \mathrm{~F} \mathrm{E}$ ") are boundary conditions of the simulation, considering a set point temperature of $20^{\circ} \mathrm{C}$.

The reference heating system of the flat under investigation consists of 6 electric radiators (one for each room of the flat, see Figure 3-3) to keep the operative room temperature in each room constant (set point of $21^{\circ} \mathrm{C}$ ). Each 
electric radiator (maximum power of $1000 \mathrm{~W}$ ) is controlled using a PI controller. The thermal power of the electric radiator has a convective part of $40 \%$.

Active cooling of the flat was not considered in the simulation.

\subsubsection{Hot water demand}

The different domestic hot water profiles considered in this study are described in section 1143.1.2.2 (see Table 3-18).

\subsubsection{Simulation results}

\subsubsection{Energy demand, thermal comfort and indoor air quality - Reference heating system}

The heating demand of the flat (in this case equal to the total electricity demand of the electric radiators) is $26.8 \mathrm{kWh} /\left(\mathrm{m}^{2} \mathrm{y}\right)$. A maximum daily heating load (for each day the average heating load of the flat was calculated and, then, the maximum value was considered) for the flat of $11.6 \mathrm{~W} / \mathrm{m}^{2}$ was calculated. Table 3-16 shows the relevant results for each zone of the flat under investigation.

The heating season (see Figure 3-9) takes 8 months (i.e. Oct-May). During the summer season, passive cooling through the opening of the windows, while the solar gains are strongly reduced because of the activation of the shading system (see 3.1.1.4 for details). The value of heating demand is higher compared to the value obtained with the PHPP (see Table 3-2) because of the different assumption (set point temperature, supply air flow rate, etc.). Figure 3-9 shows, for each month, the energy balance of the flat. In the months of June, July and August the solar gains are lower because of the activation of shading (see section 3.1.1.4 for details), while ventilation losses through windows are present during the summer because of the opening of the window (see section 3.1.1.3 for details of the window opening controls).

Table 3-16. Heating demand, maximum daily heating power and maximum daily heating load for each zone of the flat

\begin{tabular}{|c|c|c|c|c|}
\hline Zone & $\begin{array}{l}\text { Area } \\
{\left[\mathrm{m}^{2}\right]}\end{array}$ & $\begin{array}{l}\text { Heating demand } \\
{\left[\mathrm{kWh} /\left(\mathrm{m}^{2} \mathrm{y}\right)\right]^{15}}\end{array}$ & $\begin{array}{c}\text { Maximum daily } \\
\text { heating power } \\
{[\mathrm{W}]}\end{array}$ & $\begin{array}{c}\text { Maximum daily } \\
\text { heating load } \\
{\left[\mathrm{W} / \mathrm{m}^{2}\right]^{15}}\end{array}$ \\
\hline Kitchen & 8.4 & 3.1 & 99.1 & 1.4 \\
\hline Sleeping room & 14.3 & 5.8 & 205.3 & 2.9 \\
\hline Corridor & 9.8 & 4.7 & 113.3 & 1.6 \\
\hline Bathroom & 7.5 & 4.1 & 85 & 1.2 \\
\hline Child room & 12 & 2.7 & 113.3 & 1.6 \\
\hline Living room & 18.8 & 6.4 & 219.5 & 3.1 \\
\hline
\end{tabular}

\footnotetext{
15 referred to the total area of the flat $\left(70.8 \mathrm{~m}^{2}\right)$
} 


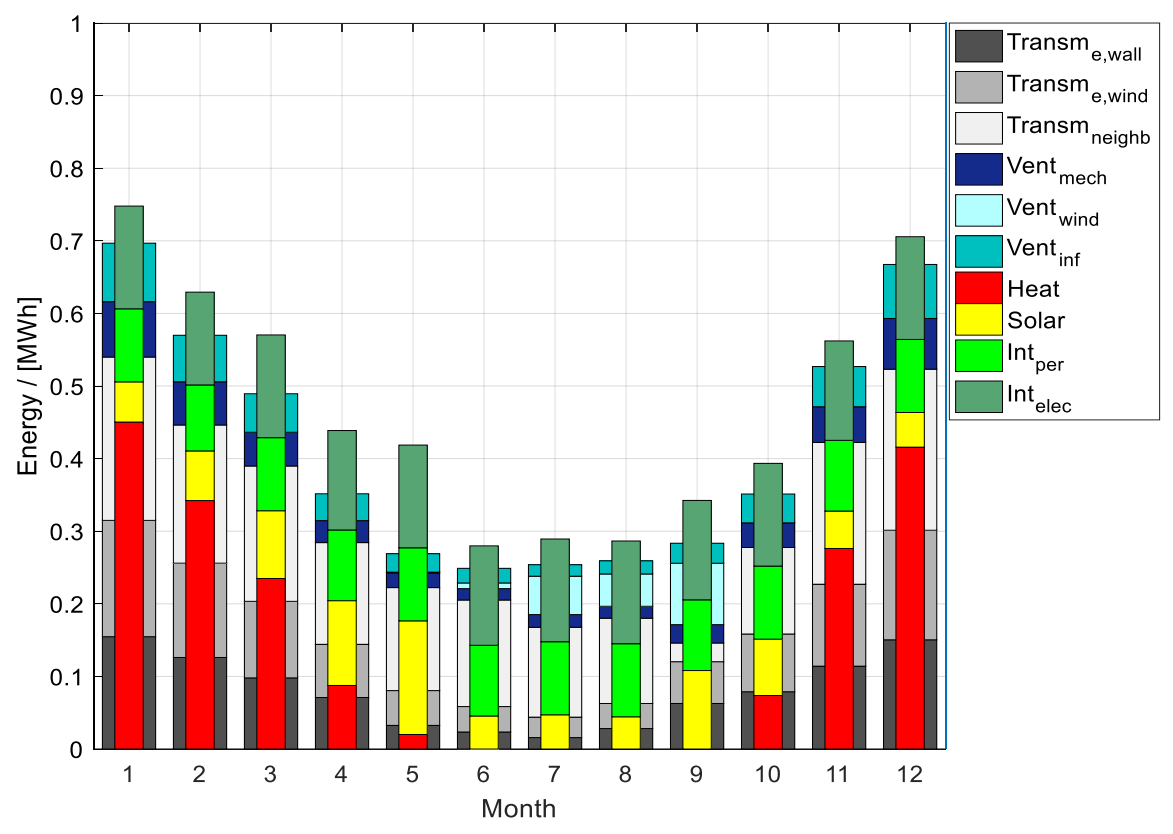

Figure 3-9: Monthly energy balance of the flat

Figure 3-10 shows the operative temperature development during the year for each zone of the flat. No cooling power is required (temperature never reach the value of $26^{\circ} \mathrm{C}$ in all rooms) because shading system and opening of the windows can ensure a good thermal comfort during the summer time.

The thermal comfort and the indoor air quality in the apartment have been analysed and the results are shown in Figure 3-11. The indoor air quality is acceptable and, in each room, $\mathrm{CO}_{2}$ concentration is always below $1100 \mathrm{ppm}$. The comfort conditions are satisfied, except some hours during the summer season where high temperatures and relative humidity occurs. Because of the additional water vapour sources (see Figure 3-7), the bathroom presents higher values of relative humidity during the whole year compared to the other rooms.

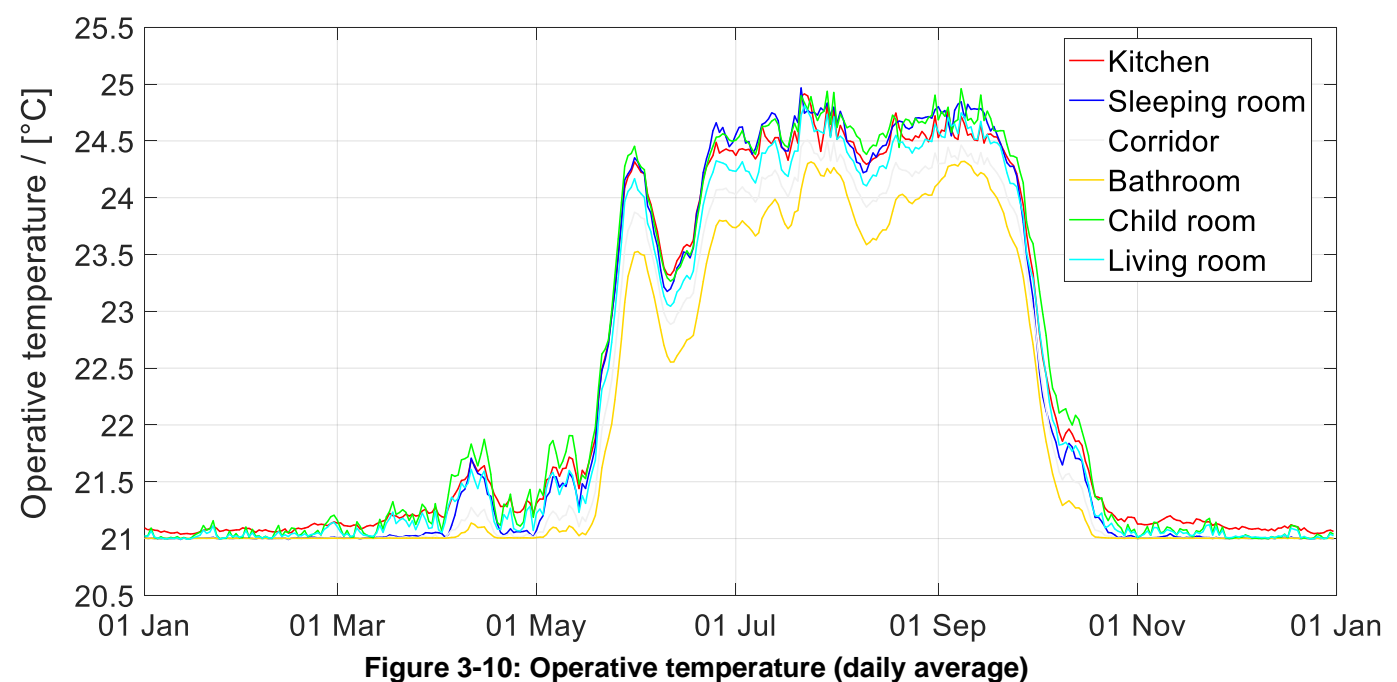



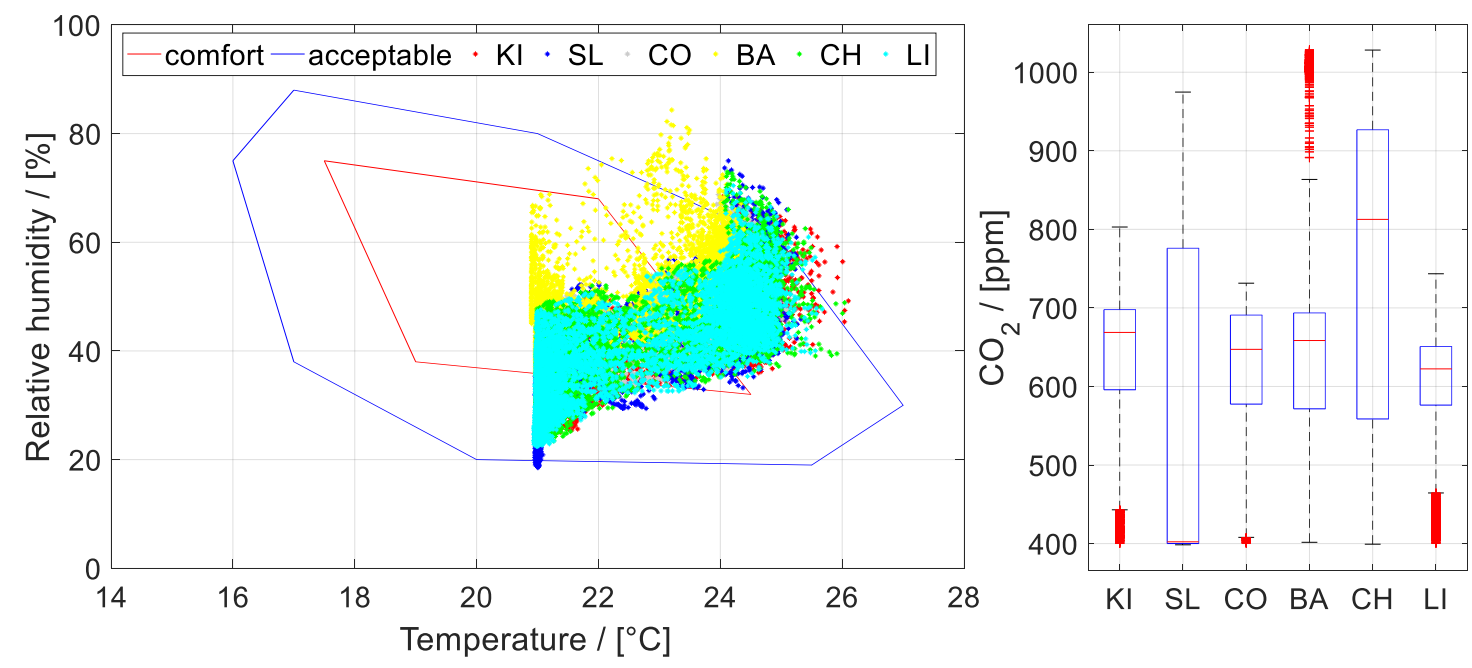

Figure 3-11: Relative humidity vs. temperature for each room of the flat (left) and $\mathrm{CO} 2$ concentration (right) - A constant $\mathrm{CO}_{2}$ concentration of $400 \mathrm{ppm}$ was considered for the ambient air

\subsubsection{Self-consumption of PV electricity for a flat of the MFH - Simulation study for different PV sizes and electricity requests}

\section{PV field sizes}

Figure 3-12 shows the MFH and the area (highlighted in yellow) assumed available for the installation of a PV system. The roof and the façade oriented to South-East were assumed available for the installation of the PV field. Three different PV sizes configurations were simulated: a PV field installed only on the roof, only on the façade or a PV installed on the roof and on the façade. In order to find the PV area available for a single flat of the MFH (Table 3-17), the total PV area was correspondingly divided by 10.
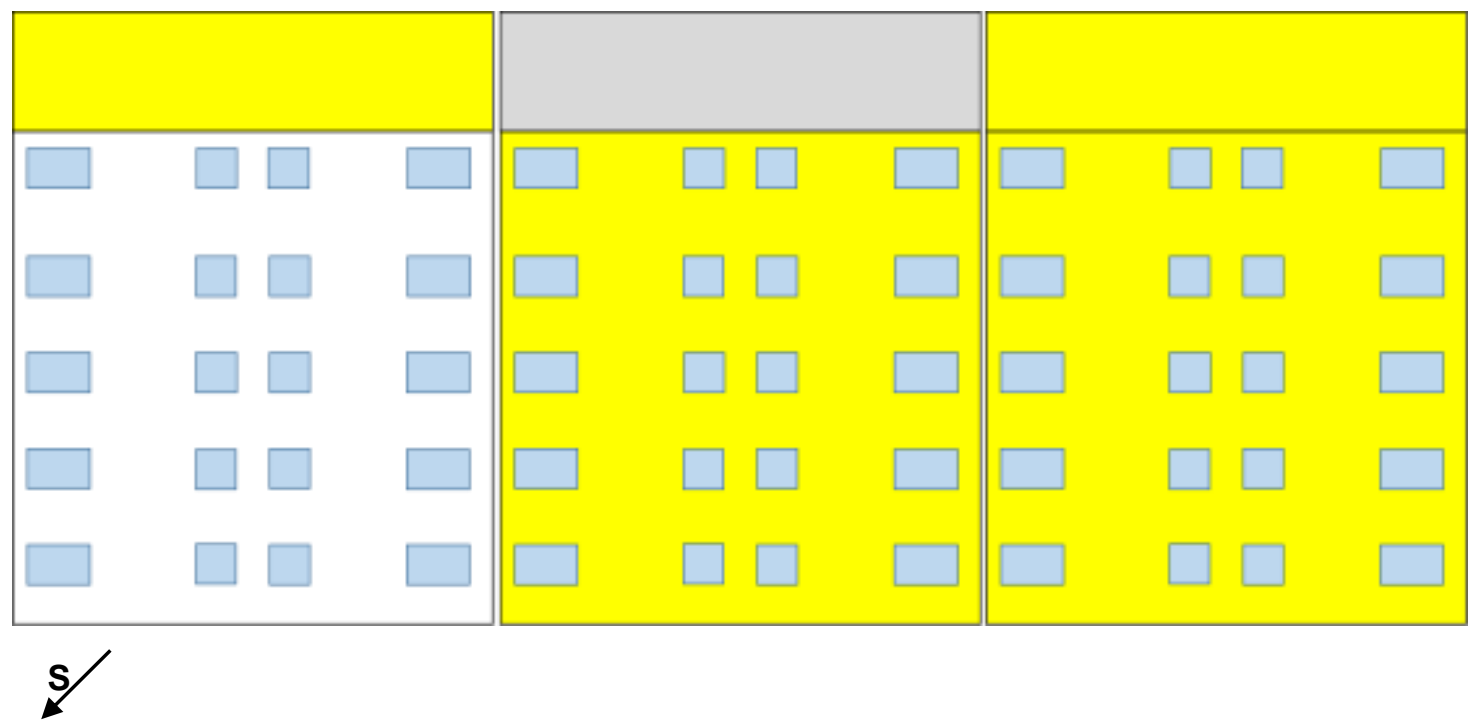

Figure 3-12: View of the MFH with the area (highlighted in yellow) assumed available for the installation of the PV system.

Table 3-17. Data of PV fields considered in the simulation study (PV size and peak power are referred to a single flat)

\begin{tabular}{l|ccc} 
Zone & roof & facade & roof \& facade \\
\hline Slope & $30^{\circ}$ & $90^{\circ}$ & $30^{\circ}$ (roof) \& $90^{\circ}$ (facade) \\
PV size $\left[\mathrm{m}^{2}\right]$ & 8.2 & 11.6 & 19.8 \\
Peak power $\left[\mathrm{W}_{\mathrm{p}}\right]$ & 1250 & 1750 & 3000 \\
\hline
\end{tabular}




\section{Electricity demand}

The electric power demand of the flat of the first floor oriented to North-East for appliances, heating, ventilation and DHW preparation was considered in this study.

Figure 3-8 shows the hourly profiles of the internal gains due to appliances for the different rooms of the flat. A factor of $1 / 0.7$ was assumed to derive the electric power profile of the appliances from the internal gains. An annual electricity demand of $2650 \mathrm{kWh} / \mathrm{a}$ for appliances was calculated.

A balanced ventilation system with a constant airflow rate of $120 \mathrm{~m}^{3} / \mathrm{h}$ was assumed. Specific Fan Power (SFP) of $0.45 \mathrm{Wh} / \mathrm{m}^{3}$ for both fans (i.e. supply and extract airflow rate) was assumed to consider the electric power supply of the ventilation system (electricity demand of $946 \mathrm{kWh} / \mathrm{a}$ ).

The flat under study with a heating demand (HD) of $33.4 \mathrm{kWh} /\left(\mathrm{m}^{2} \mathrm{a}\right)$ was heated during the winter with a supply airexhaust air heat pump (with post-heater) and an additional electric radiator placed in the bathroom for comfort reasons (see Figure 3-13 and Figure 3-14 for details). A total electricity demand of $1292 \mathrm{kWh} / \mathrm{a}$ for heating was calculated.
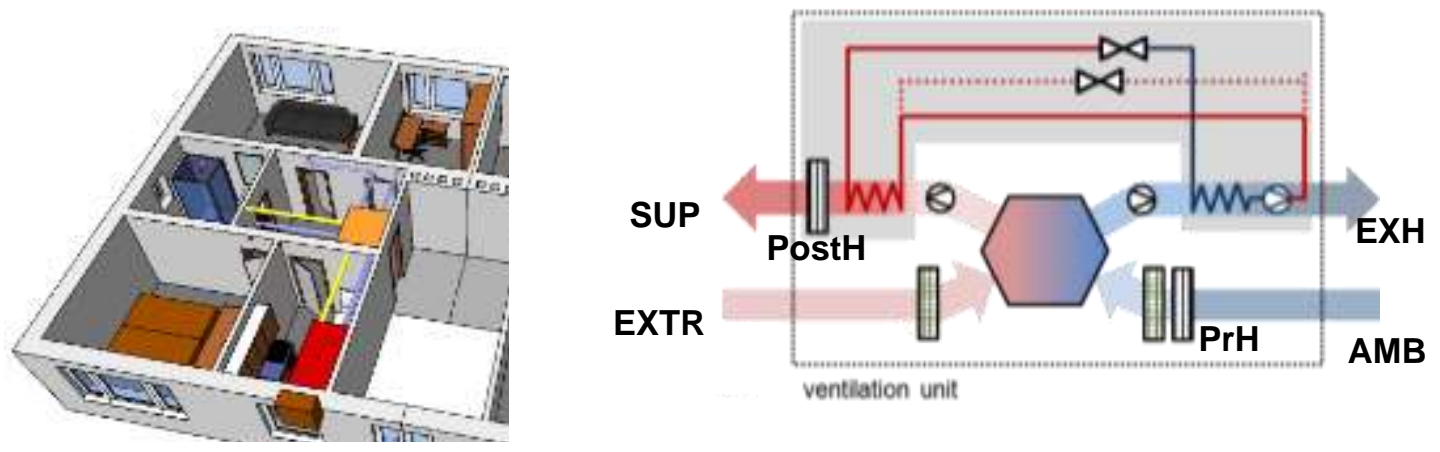

Figure 3-13: 3D view of the flat with the supply air - exhaust air heat pump system (left) and scheme of the heat pump in combination with HRV (right). "PostH" and "PrH" represent the post-heater and the pre-heater, respectively

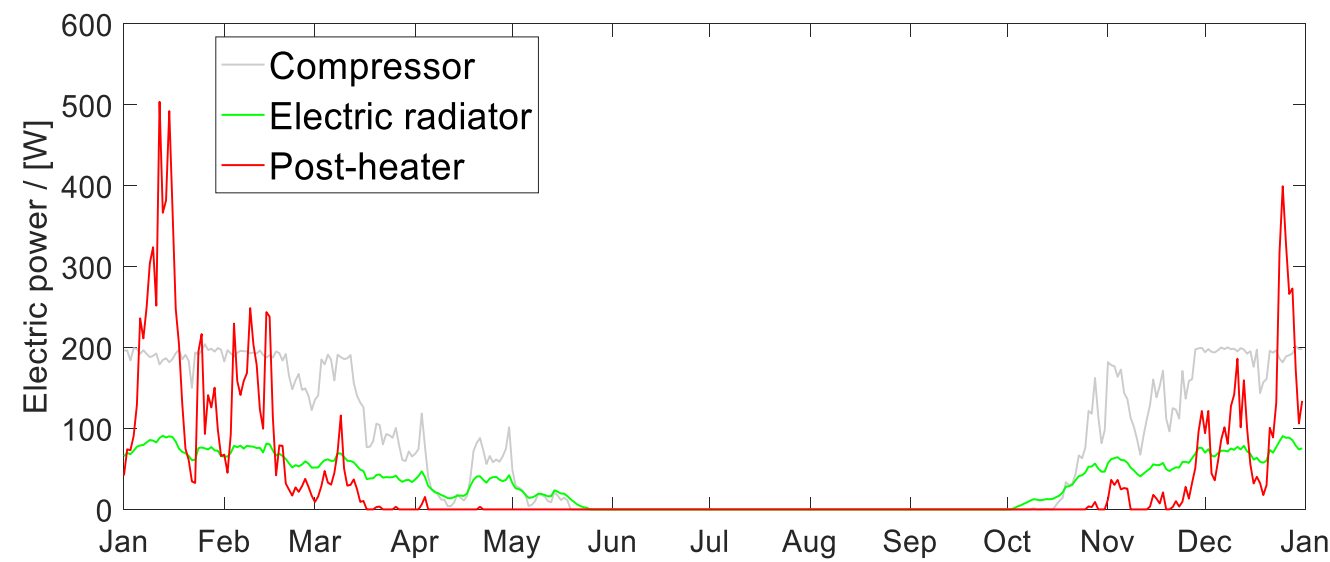

Figure 3-14: Daily average values of the electric power demand of the heating system (i.e. supply air - exhaust air heat pump in combination with MVHR) considered in the simulation study (Wel $=1292 \mathrm{kWh} / \mathrm{a}$ ).

Three different profiles for domestic hot water (DHW) energy demand (see Table 3-18) were considered in this study. $\mathrm{DHW}(3)$ is a variation of $\mathrm{DHW}(2)$ assuming a preparation with air-to-water heat pump instead of direct electric heating. 
Table 3-18. Details of the three DHW profiles analysed in the simulation study

\begin{tabular}{c|cccc} 
Case & Electric & Profile & $\begin{array}{c}\text { Energy } \\
{[\mathbf{k W h} / \mathbf{a}]}\end{array}$ & $\begin{array}{c}\text { Electricity } \\
{[\mathbf{k W h} / \mathbf{a}]}\end{array}$ \\
\hline DHW(1) & Electric & Flat & 2190 & 2190 \\
DHW(2) & Electric & Hourly & 2404 & 2404 \\
DHW(3) & Heat pump & Hourly & 2404 & 906 \\
\hline
\end{tabular}

\section{Simulation study}

Figure 3-15 shows the simplified scheme of the modelled system. Three different PV field configurations (Table 3-17) and three electric demands for DHW preparation (see DHW(1), DHW(2) and DHW(3) in Table 3-18) were considered. The assumption is that the electricity of the PV field first covers the appliances electricity demand and only the remaining PV electricity is available to cover the electric power demand of the HVAC system (i.e. ventilation, heating and DHW preparation). The rest of PV electricity is injected to the grid. In the model, the balance between the PV production and the electric demand is done each 10 minutes and then the values are integrated to calculate the PV self-consumed and the amount of electricity that is covered by the grid. In the following sections "Demand(1)", "Demand(2)" and "Demand(3)" indicate the total electric demand if DHW(1), DHW(2) and DHW(3) are considered, respectively.

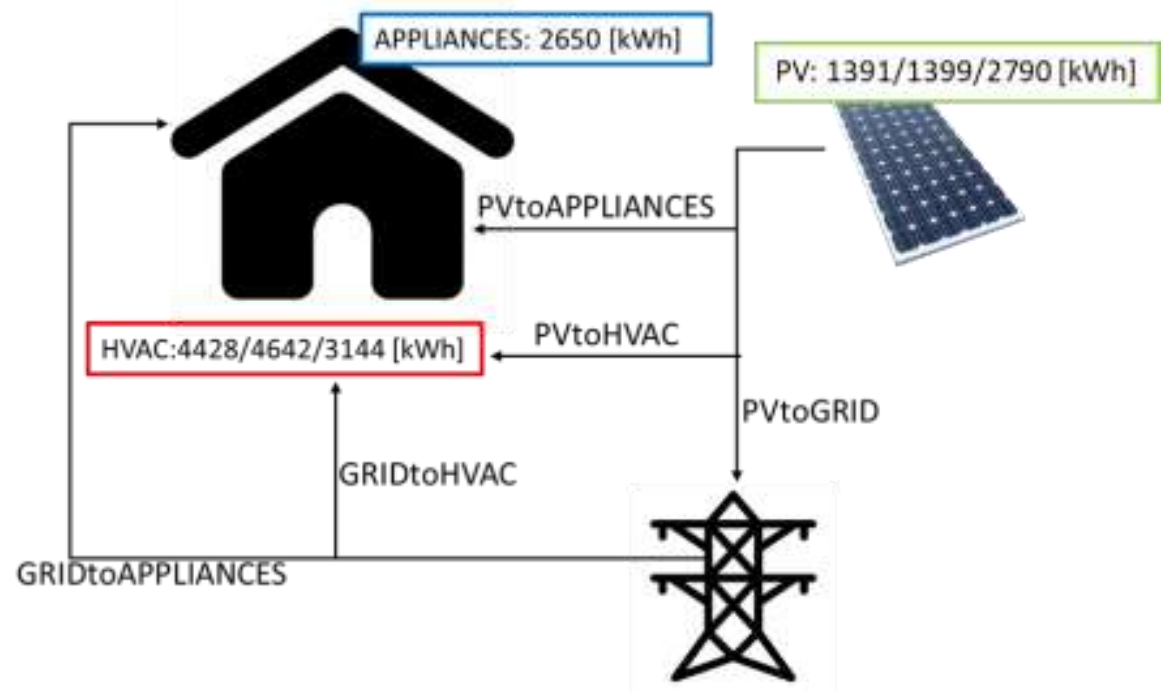

Figure 3-15: Simplified scheme of the simulated PV system with PV energy production and electricity demand (i.e. HVAC system and appliances). Three different PV sizes (see Table 3-17) and three electricity demands depending on the DHW profile (see Table 3-16) were considered. REMARK: "HVAC" indicates the sum of ventilation, heating (with HP) and DHW preparation.

\section{Results and discussion}

Figure 3-16 shows the annual purchased electricity depending on the PV area for the three investigated electricity requests (i.e. Demand(1), Demand(2) and Demand(3)). The installation of a PV system on the roof can reduce the purchased electricity of $-17 \%$ in case of Demand(1) compared to the case in which PV in not installed. Even if the $\mathrm{PV}$ area is bigger on the façade of the flat $\left(11.6 \mathrm{~m}^{2}\right)$ compared to the PV area on the roof $\left(8.2 \mathrm{~m}^{2}\right)$, the PV production (see Figure 3-15) and the purchased electricity are almost the same (with a difference below $2 \%$ ) for the two cases (i.e. "PV on roof" and "PV on façade") for the three electric demand investigated. The same reduction of the purchased electricity (compared to the case without PV) can be obtained through the installation of a PV field on the roof or on the façade, but the economic comparison between the two solutions of energy renovation should consider the higher investment costs in case of PV installed on the façade (due to the bigger PV area for each flat). Furthermore, a reduced yield for PV on the façade should be expected because of shading in many locations.

For all the three investigated electricity demand profiles, the purchased electricity decreases in case PV is installed also on the façade and this reduction is of $-10 \%$ in case Demand(3) is considered. This reduction is limited by the fact that only the $30 \%$ of the PV produced by the PV on the façade is self-consumed, while the rest ( $969 \mathrm{kWh})$ is fed to the grid (see Figure 3-17). 


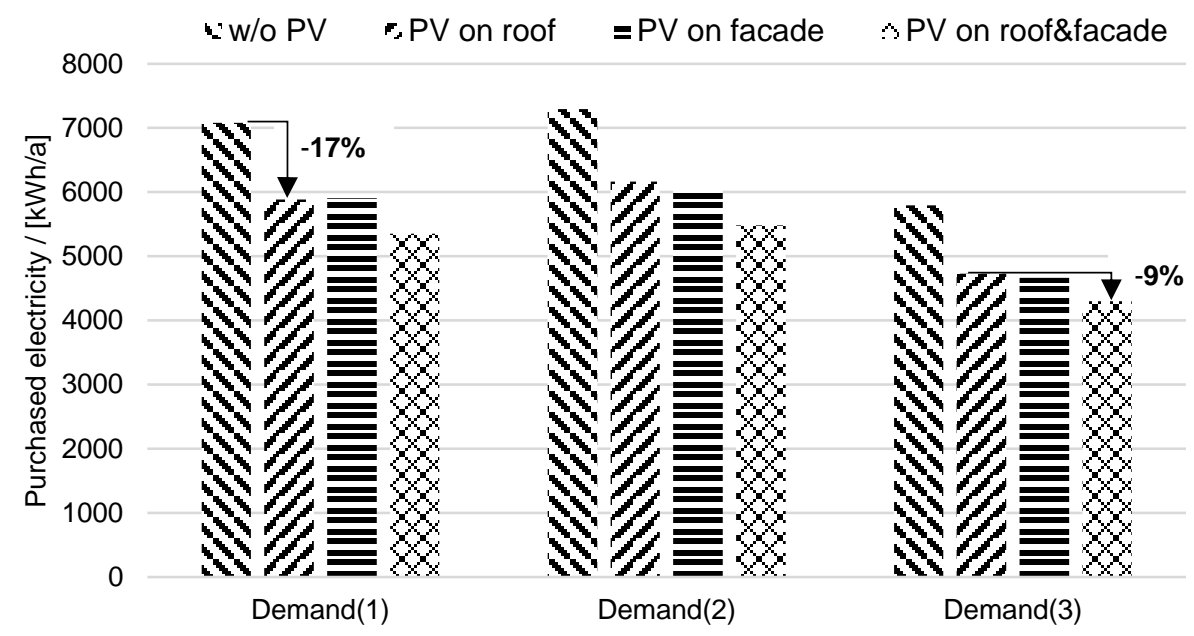

Figure 3-16: Annual purchased electricity depending on the PV sizes for the three different electricity demands ("w/o PV" indicates the case in which PV is not installed

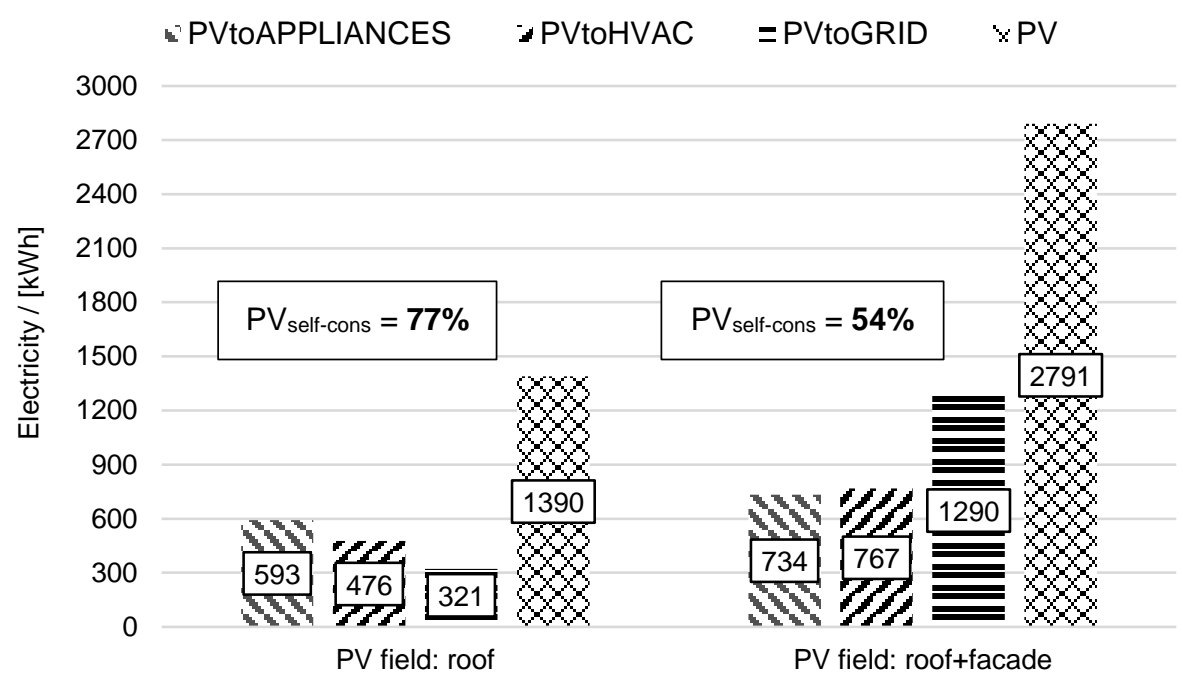

Figure 3-17: Use of PV electricity for two PV sizes in case Demand(3) is considered - w/o electric storage of PV electricity

A big percentage of the additional PV electricity produced by the PV on the façade (i.e. $69 \%, 969 \mathrm{kWh}$ ) is fed to the grid and cannot be self-consumed. These results suggested an additional simulation study in which a daily electric storage of the PV electricity is assumed. The results are presented in Figure 3-18 and show that a daily storage can reduce significantly the PV fed to the grid (compared to the case w/o storage) of $-89 \%$ in case PV is installed on the roof and façade. In case a daily storage is assumed, the level of PV self-consumed is kept high (95\%) even in case of PV installed on roof and façade. 


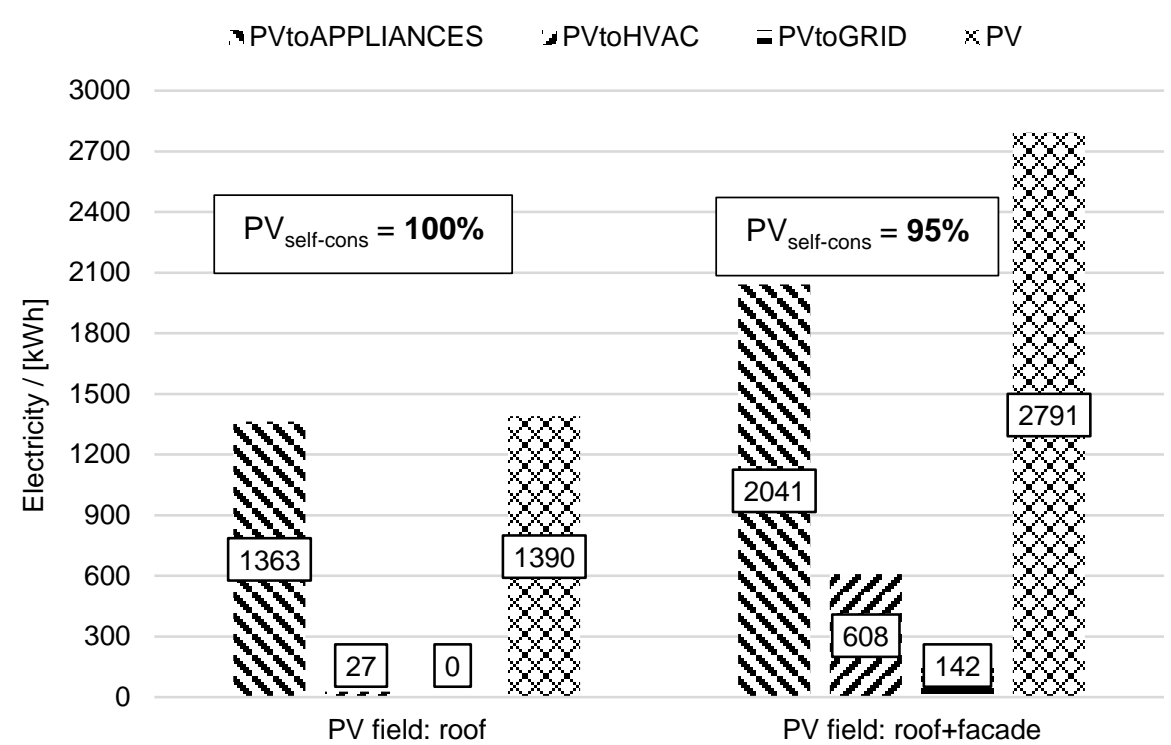

Figure 3-18: Use of PV electricity for two PV sizes in case Demand(3) is considered. Daily storage of PV electricity is assumed

The installation of a PV system on the roof (and the façade) of the building can reduce the (non-renewable) primary energy (PE) consumption of the flat.

Two scenarios for monthly $f_{P E}$ are considered in this study, depending on the different scenarios of the share of renewable energy in the energy mix $\left(10 \%\right.$ hydro, $10 \%$ wind and $10 \% \mathrm{PV}$ for $\mathrm{f}_{\mathrm{PE} 1}$ and $10 \%$ hydro, $30 \%$ wind and $30 \% \mathrm{PV}$ for $\left.\mathrm{f}_{\mathrm{PE} 2}\right)$. The average annual value is 1.64 and 0.77 for $\mathrm{f}_{\mathrm{PE} 1}$ and $\mathrm{f}_{\mathrm{PE} 2}$, respectively.

Table 3-19 shows the annual PE demand depending on $\mathrm{f}_{\mathrm{PE}}$ and on PV size in case Demand(3) is considered. A reduction of the annual PE demand of $-17 \%$ and $-24 \%$ (for $f_{P E 1}$ ) and of $-13 \%$ and $-20 \%$ (for $f_{P E 2}$ ) can be obtained in case PV is installed on the roof only or also on the façade. If the PV field is installed on the roof and on the façade, a reduction of annual PE demand of $8 \%$ (compared to the case of PV on the roof only) can be obtained. This is because a large percentage $(70 \%)$ of the additional PV electricity produced by the PV field of the façade is fed to the grid (especially during the summer season) and cannot be self-consumed (see Figure 3-17). In case PV is installed on the roof and on the façade, the saving of PE is higher in case of annual $f_{P E}$ compared to the case in which monthly $f_{P E}$ values are considered $\left(-26 \%\right.$ instead of $-24 \%$ in case of $f_{P E 1}$ and $-26 \%$ instead of $-20 \%$ in case of fPE2).

The self-consumption can be increased in case electric storage of PV electricity is considered (see Figure 3-18). Table 3-20 shows the potential of further reduction of PE demand in case an electric storage is considered (i.e. daily storage). The importance of a storage is relevant in the case in which PV is installed on the roof and façade, where the PE demand could be decreased by $46 \%$. A daily electric storage (in case of PV installed on the roof) could lead the PE to a value of $7226 \mathrm{kWh} / \mathrm{a}$ (in case of $f_{P E}=1.64$ ), almost equal to the PE in case of PV installed on the roof and façade without storage $(7059 \mathrm{kWh} / \mathrm{a})$.

Table 3-19. Annual PE demand and relative deviation of PE (respect to the case w/o PV) depending on the PV field and fPE - Demand(3) is considered

\begin{tabular}{|c|c|c|c|c|c|}
\hline & \multicolumn{3}{|c|}{ PE [kWh/a] } & \multicolumn{2}{|c|}{$\Delta \mathrm{PE}$} \\
\hline & w/o PV & PV on roof & $\begin{array}{c}\text { PV on } \\
\text { roof\&façade }\end{array}$ & $\begin{array}{l}\triangle \mathrm{PE} \\
\text { (roof) }\end{array}$ & $\begin{array}{c}\Delta \mathrm{PE} \\
\text { (roof\&façade) }\end{array}$ \\
\hline Monthly $f_{P E 1}$ & 9945 & 8266 & 7541 & $-17 \%$ & $-24 \%$ \\
\hline Monthly $\mathbf{f}_{\mathrm{PE} 2}$ & 5314 & 4628 & 4257 & $-13 \%$ & $-20 \%$ \\
\hline Annual $f_{P E 1}=1.64$ & 9507 & 7762 & 7059 & $-18 \%$ & $-26 \%$ \\
\hline Annual $f_{\mathrm{PE} 2}=0.77$ & 4432 & 3619 & 3291 & $-18 \%$ & $-26 \%$ \\
\hline
\end{tabular}


Table 3-20. Annual PE demand and relative deviation of PE (with respect to the case without PV) depending on the PV field, electric storage and fPE - Demand(3) is considered

\begin{tabular}{|c|c|c|c|c|c|c|c|c|c|}
\hline & \multicolumn{5}{|c|}{ PE [kWh/a] } & \multicolumn{4}{|c|}{$\Delta \mathrm{PE}[\%]$} \\
\hline & \multicolumn{3}{|c|}{ No storage } & \multicolumn{2}{|c|}{ Daily storage } & \multicolumn{2}{|c|}{ No storage } & \multicolumn{2}{|c|}{ Daily storage } \\
\hline & $\begin{array}{l}\text { w/o } \\
\text { PV }\end{array}$ & $\begin{array}{l}\mathrm{PV} \text { on } \\
\text { roof }\end{array}$ & $\begin{array}{l}\mathrm{PV} \text { on } \\
\text { roof\& } \\
\text { façade }\end{array}$ & $\begin{array}{l}\text { PV on } \\
\text { roof }\end{array}$ & $\begin{array}{l}\text { PV on } \\
\text { roof\& } \\
\text { façade }\end{array}$ & $\underset{\text { (roof) }}{\Delta \mathrm{PE}}$ & $\begin{array}{c}\Delta P E \\
\text { (roof\& } \\
\text { façade) }\end{array}$ & $\underset{\text { (roof) }}{\Delta \mathrm{PE}}$ & $\begin{array}{c}\triangle \mathrm{PE} \\
\text { (roof\& } \\
\text { façade) }\end{array}$ \\
\hline$f_{P E 1}=1.64$ & 9507 & 7762 & 7059 & 7226 & 5162 & $-18 \%$ & $-26 \%$ & $-24 \%$ & $-46 \%$ \\
\hline$f_{P E 2}=0.77$ & 4432 & 3619 & 3291 & 3369 & 2407 & $-18 \%$ & $-26 \%$ & $-24 \%$ & $-46 \%$ \\
\hline
\end{tabular}

\subsubsection{Economic evaluation}

In this chapter the cost analysis is carried out. The same cases of the simulation analysis are considered. Moreover, cases with electric radiators as space heating system are evaluated. Table 3-21 shows the cases taken into account in the economic analysis.

Table 3-21: Considered cases in the economic analysis

\begin{tabular}{c|ccc} 
Case & Space heating & DHW & PV \\
\hline REF & Electric & Electric & No \\
A & Electric & A/W HP & No \\
B & A/A HP & Electric & No \\
C & A/A HP & Electric & Roof \\
D & A/A HP & Electric & Façade \\
E & A/A HP & Electric & Roof + Façade \\
F & A/A HP & A/W HP & No \\
G & A/A HP & A/W HP & Roof \\
H & A/A HP & A/W HP & Façade \\
I & A/A HP & A/W HP & Roof + Façade \\
\hline
\end{tabular}

The economic analysis is based on the Equivalent Annual Cost (EAC), considering a period of 20 years and a real interest rate of $3 \%$. The electricity price is assumed to be $0.2 € / \mathrm{kWh}$ and an energy price escalation rate of $2 \%$ is considered.

The space heating demand is equal to $33.4 \mathrm{kWh} /\left(\mathrm{m}^{2} \mathrm{a}\right)$ and only the hourly profiles for the $\mathrm{DHW}$ are considered ( $2404 \mathrm{kWh} / \mathrm{a}$ in case of electric boilers and $906 \mathrm{kWh} / \mathrm{a}$ in case of air/water HP).

Figure 3-19 shows the results assuming the total European primary energy conversion factor (2.5). All the cases lead to a primary energy saving. A quite wide range (from $37.9 \mathrm{kWh} /\left(\mathrm{m}^{2} \mathrm{a}\right)$ to $143.5 \mathrm{kWh} /\left(\mathrm{m}^{2} \mathrm{a}\right)$ ) is achieved depending on the system. The two cases with PV panels on the roof and on the facade are the only ones that don't allow cost savings during the 20 years period. Cases assuming HP are always convenient compared to the reference (all electric case). With the same system, the PV adoption only on the roof is the most convenient case, even if the PV area is smaller than the PV area on the façade. PV only on the façade leads to PE savings, but to a higher cost during the 20-years period. This is explained by the fact that the specific auto-consumption of PV production (referred to the PV area) is higher for the PV installed on the roof. According to the results, the optimum case for PE and costs is case G: heat pump for both heating and DHW and PV installation on the roof. 


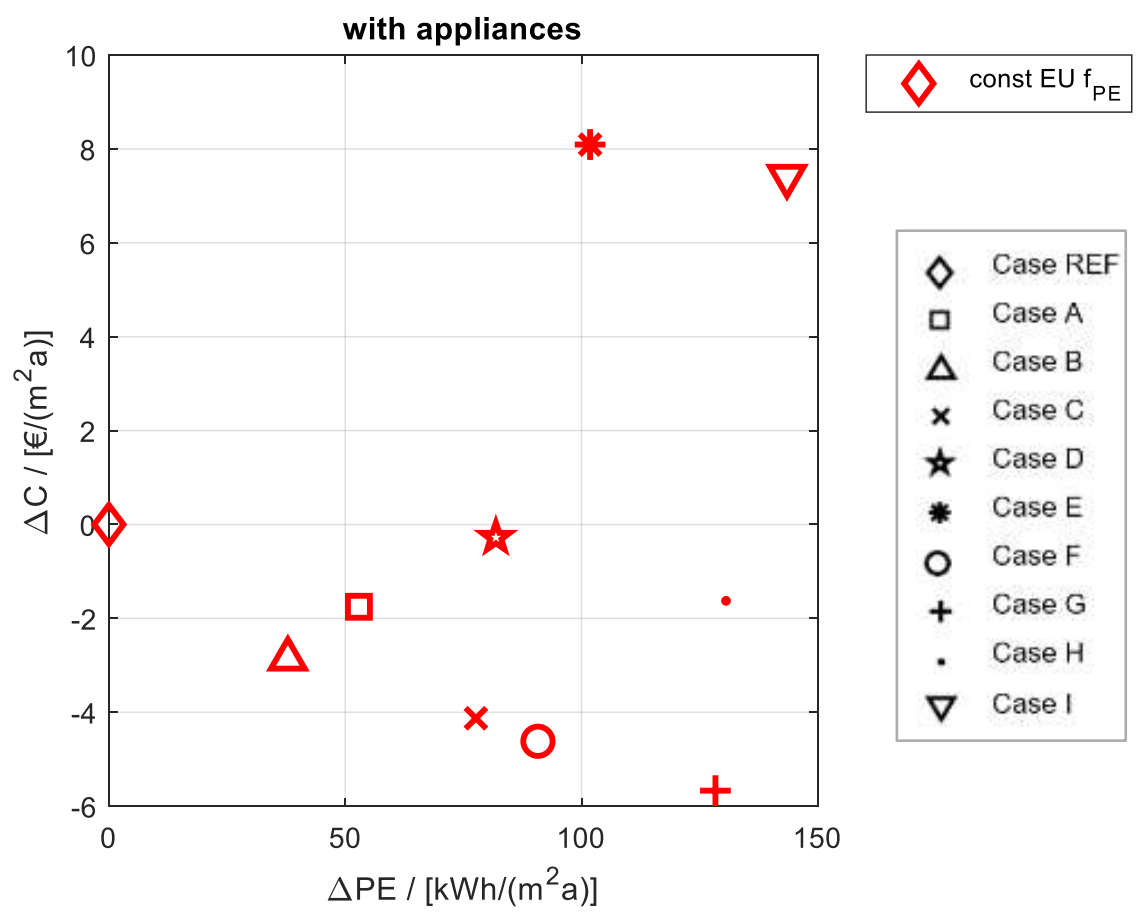

Figure 3-19: Comparison of the primary energy savings and additional costs for the analysed cases (including household electricity)

Four different primary energy factors are considered in order to evaluate the primary energy reduction. $f_{P E 1}$ and $f_{P E 2}$ are the same considered in the simulation results, but only annual values are considered (which are respectively 1.64 and 0.77 ). Moreover, the Austrian value referred to the total primary energy (1.91, according to OIB 2015 [44]) and the European value (2.5) are considered. Figure 3-20 shows the results regarding primary energy savings and the additional costs for the analysed cases. Lower primary energy savings are verified when the considered primary energy factor is different than the European one. 


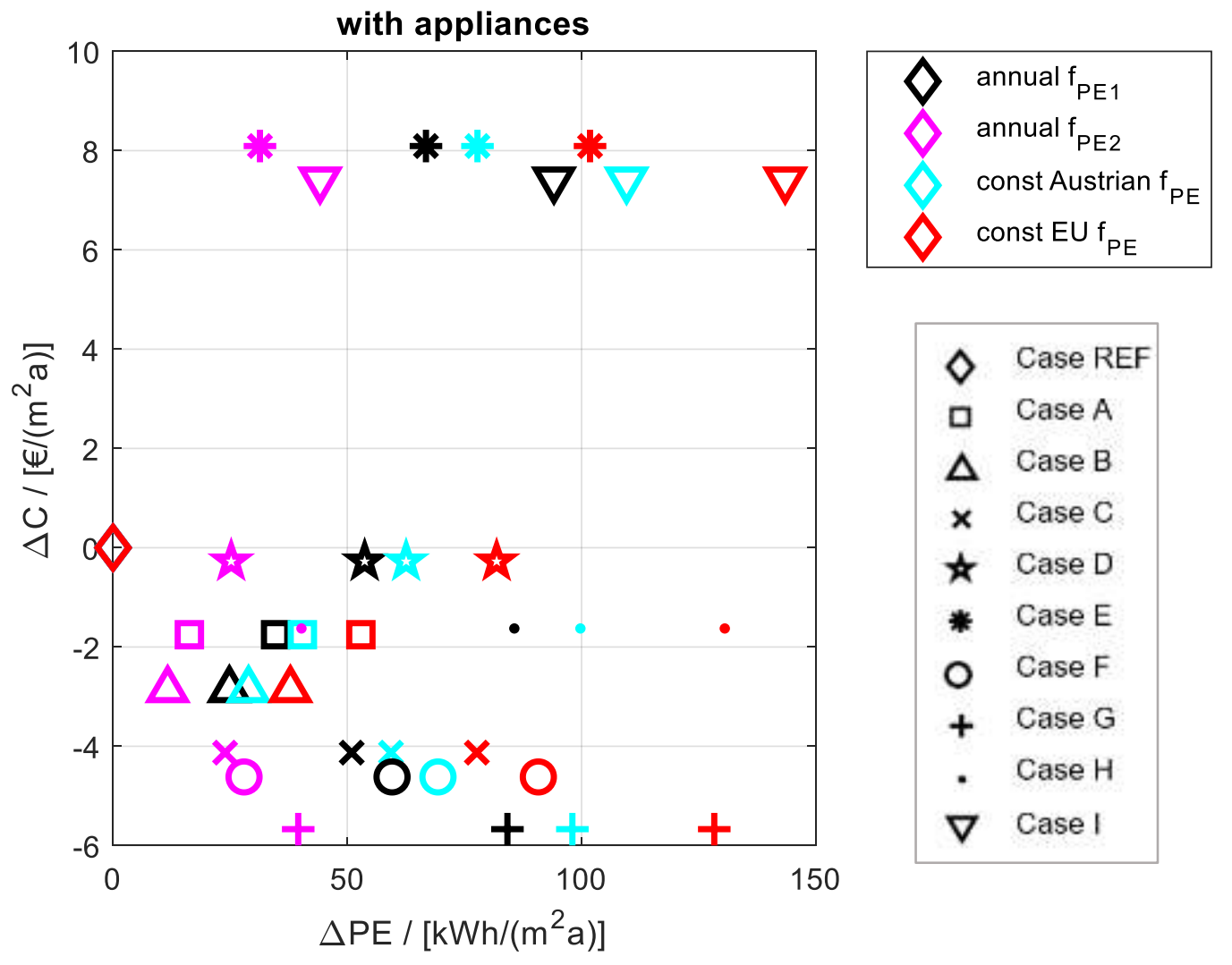

Figure 3-20: Comparison of the primary energy savings and additional costs for the analysed cases (including household electricity) with different primary energy conversion factor

Table 3-22 show the detailed values regarding the primary energy saving and the additional costs, compared to the reference case (electric space heating and DHW production without PV system).

Table 3-22: Primary energy savings and additional costs for the analysed cases (including household electricity)

\begin{tabular}{|c|c|c|c|c|c|c|c|c|c|c|}
\hline & & A & B & C & D & E & $\mathbf{F}$ & G & H & $\mathbf{I}$ \\
\hline \multirow{4}{*}{ Primary energy savings $\left[\mathrm{kWh} /\left(\mathrm{m}^{2} \mathrm{a}\right)\right]$} & $f_{\mathrm{PE} 1}$ & 34.7 & 24.8 & 50.9 & 53.7 & 66.8 & 59.5 & 84.2 & 85.7 & 94.1 \\
\hline & $\mathbf{f}_{\mathrm{PE} 2}$ & 16.3 & 11.7 & 23.9 & 25.2 & 31.4 & 28.0 & 39.5 & 40.2 & 44.2 \\
\hline & $f_{P E, A T}$ & 40.4 & 28.9 & 59.3 & 62.6 & 77.8 & 69.4 & 98.0 & 99.8 & 109.6 \\
\hline & $f_{P E, E U}$ & 52.9 & 37.9 & 77.7 & 81.9 & 101.8 & 90.8 & 128.3 & 130.6 & 143.5 \\
\hline Additional cost $\left[€ /\left(m^{2} a\right)\right]$ & & -1.8 & -2.9 & -4.1 & -0.3 & 8.1 & -4.6 & -5.7 & -1.6 & 7.4 \\
\hline
\end{tabular}




\subsection{HVACviaFacade}

\section{Venus Davida, Dagmar Jähniga, Fabian Ochs ${ }^{b}$}

aAEE - Institute for Sustainable Technologies, Feldgasse 19, Gleisdorf A-8200, Austria

bUniversity of Innsbruck, Technikerstraße 13, Innsbruck 6020, Austria

\section{Simulation Platform}

In this report, the simulation platform TRNSYS in version 17.02.0004 was used to simulate the building and the HVAC system.

\section{Location and climate data}

The climate data of Graz (Austria) was chosen as the reference climate. Figure 3-21 and Figure 3-22 show the average ambient temperature and the monthly horizontal global irradiation. Detailed values can be found in Table A. 9 in the Appendix.

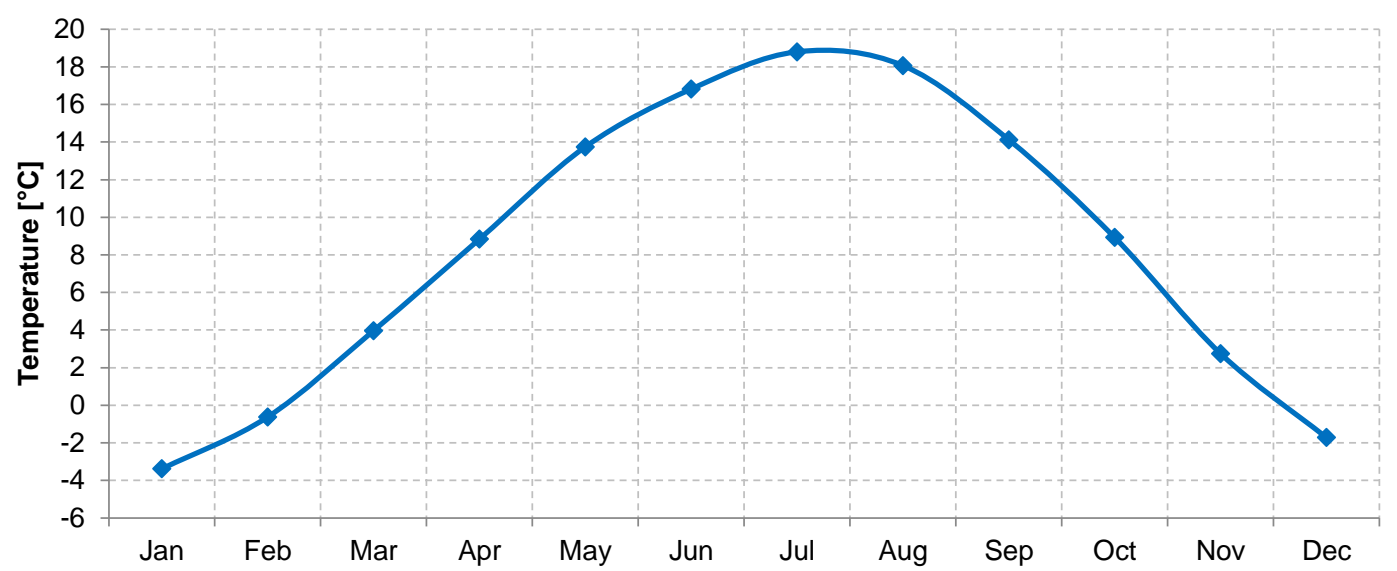

Figure 3-21: Monthly average ambient temperature

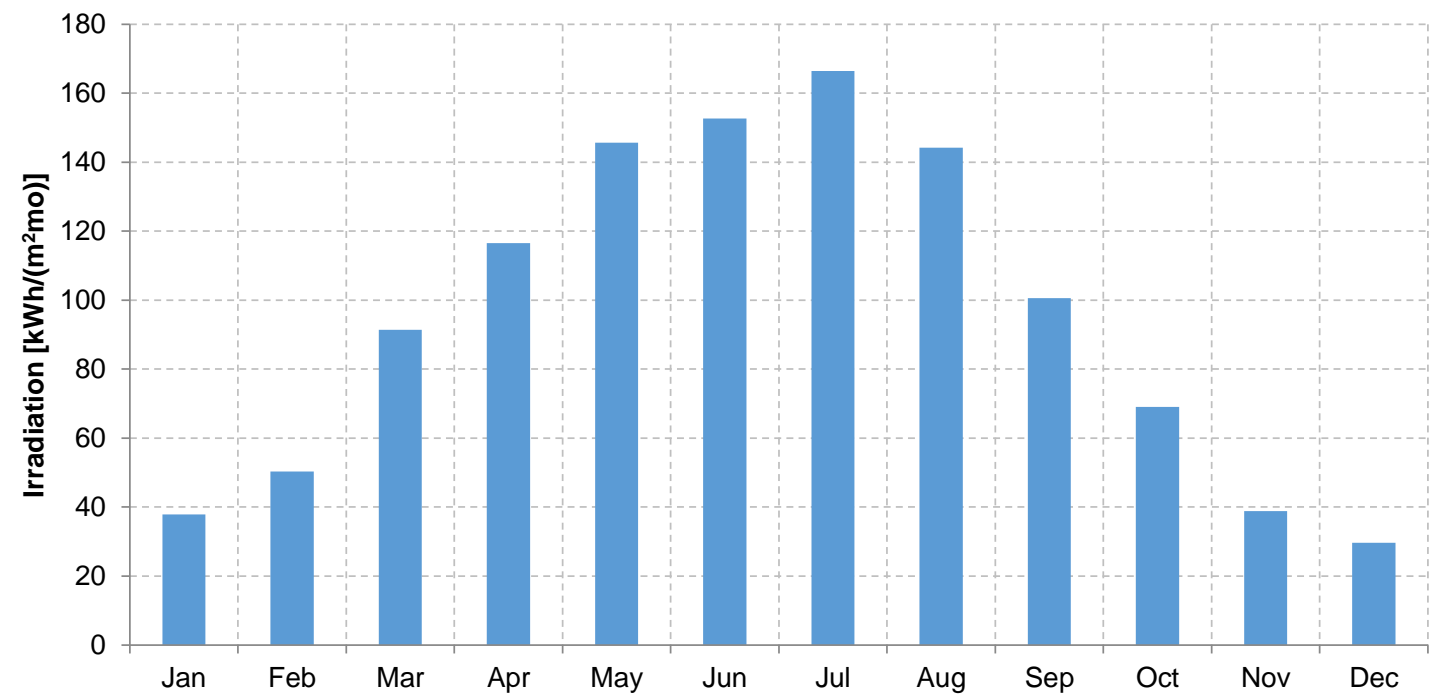

Figure 3-22: Monthly global horizontal irradiation 


\subsubsection{Reference building description}

\subsubsection{Multi-storey residential building}

A typical multi-story reference building (developed and investigated in the FFG project HVACviaFACADE - see Figure 3-23) is taken as an example. In order to investigate decentral (i.e. flat-wise) façade integrated solar technologies, it is useful to simulate a flat in detail instead of the entire building. Hence, the building simulation model considers one of several flats of the building.

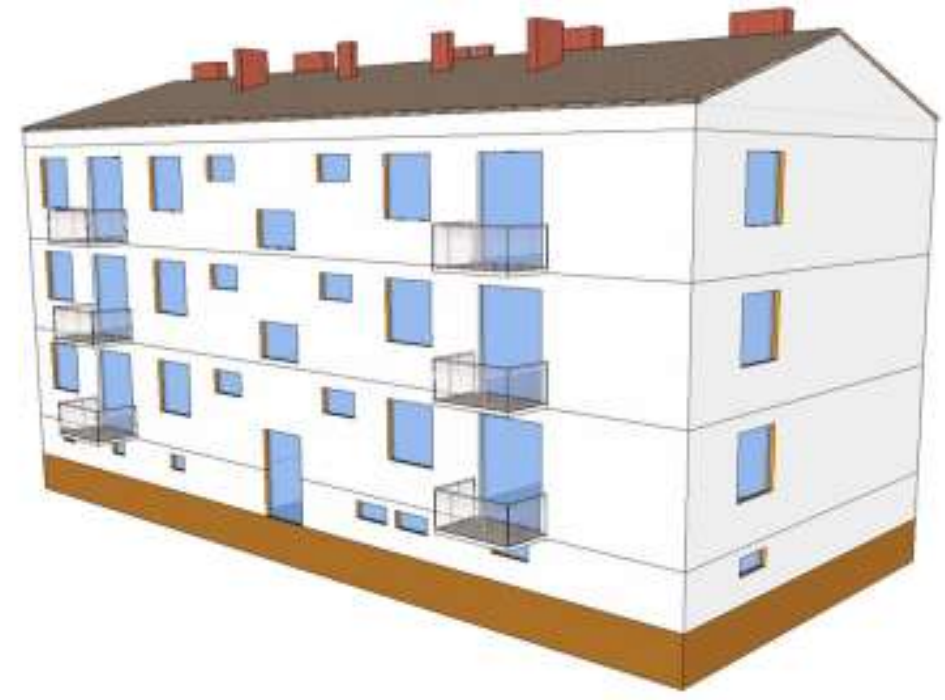

Figure 3-23. Side view of the multi-storey building

\section{Geometry and floor plan}

The floor plan of one storey of the multi-family building is shown in Figure 3-24. On each storey four flats are located: two smaller ones (flat type B) with a useful area of about $40 \mathrm{~m}^{2}$ and two larger ones (flat type A) with a useful area of about $60 \mathrm{~m}^{2}$. The staircase is located in the centre of the multi-family building.

The smaller flats have windows only to the west side, the larger flats also have windows to the east side.

Based on the flats of type $A$ and $B$ an average flat was designed whose heating demand is one-twelfth of the heating demand of the entire building (see Eq. 3-2). To achieve this the surfaces of flat type A was modified. A detailed overview of the different surfaces of the individual thermal zones can be found in the appendix (see A. 4).

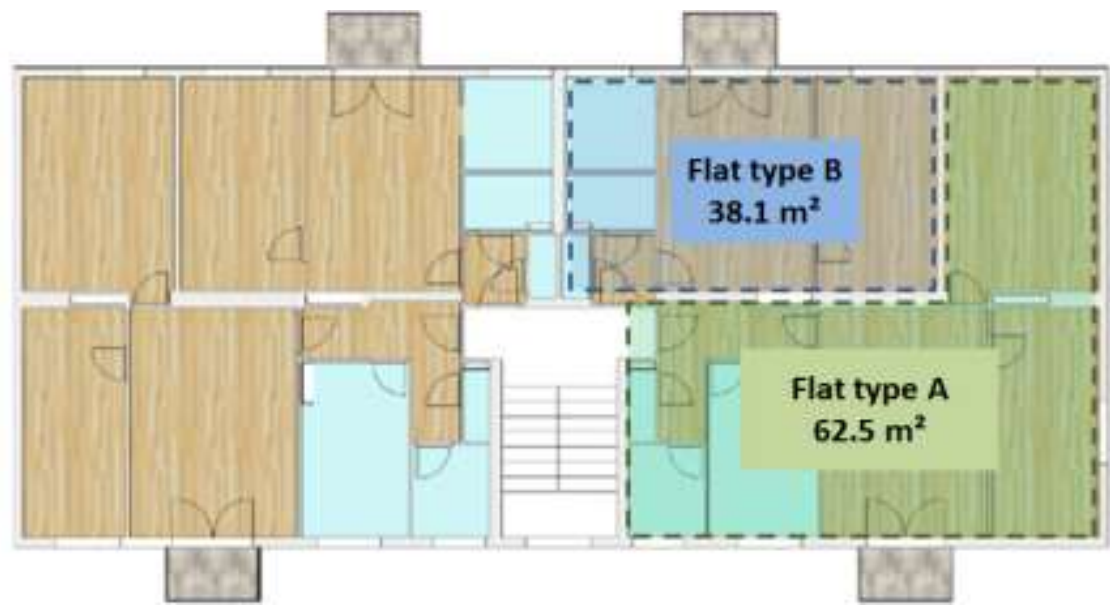

Figure 3-24. Floor plan

The average flat is assumed to be adjacent to other flats (no heat flow) and partly to the unheated staircase (see also Table A. 10 in the appendix). The room temperature of the unheated staircase was calculated in a previous 
simulation of the entire building and set as a boundary condition. The monthly average temperatures in the staircase are visible on an hourly basis in Figure 3-25 and in Table A. 11 in the appendix.

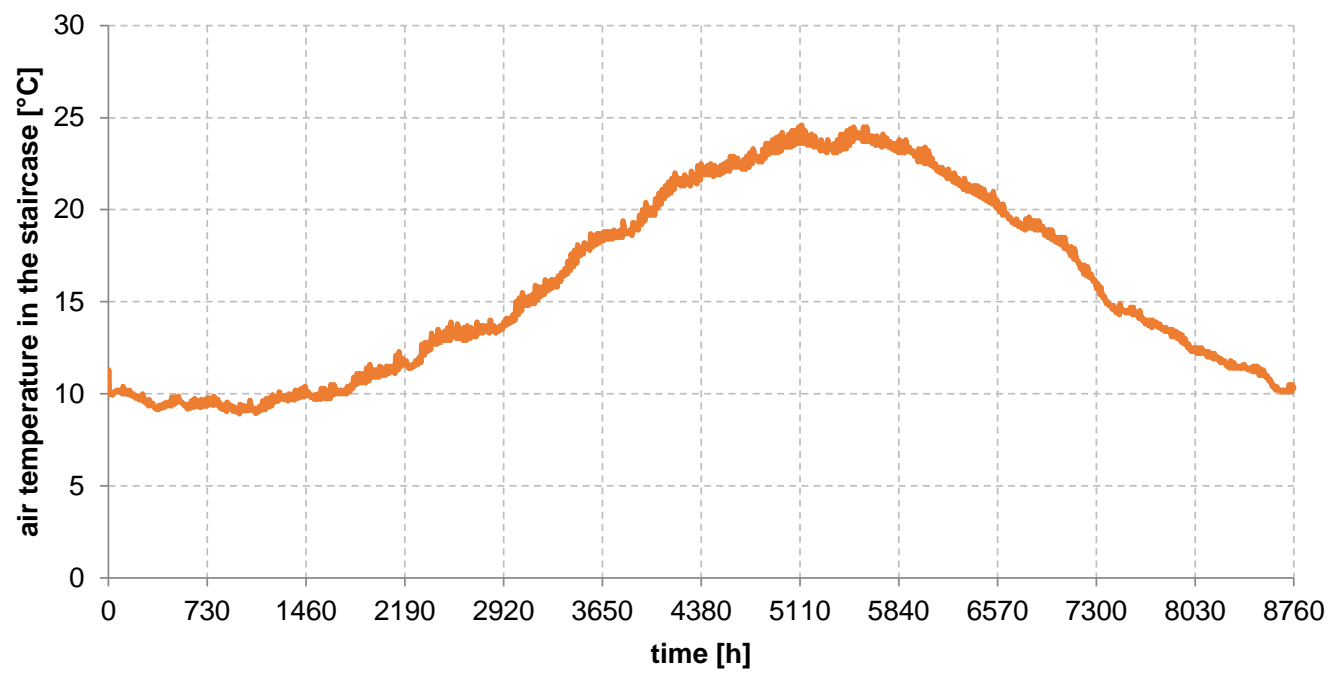

Figure 3-25: air temperatures in the staircase

\section{Zoning}

The flat was subdivided into four thermal zones. Figure 3-26 shows the thermal zones:

- $\quad$ Kitchen (1)

- Bathroom (2)

- $\quad$ Living room (3)

- $\quad$ Sleeping room (4)
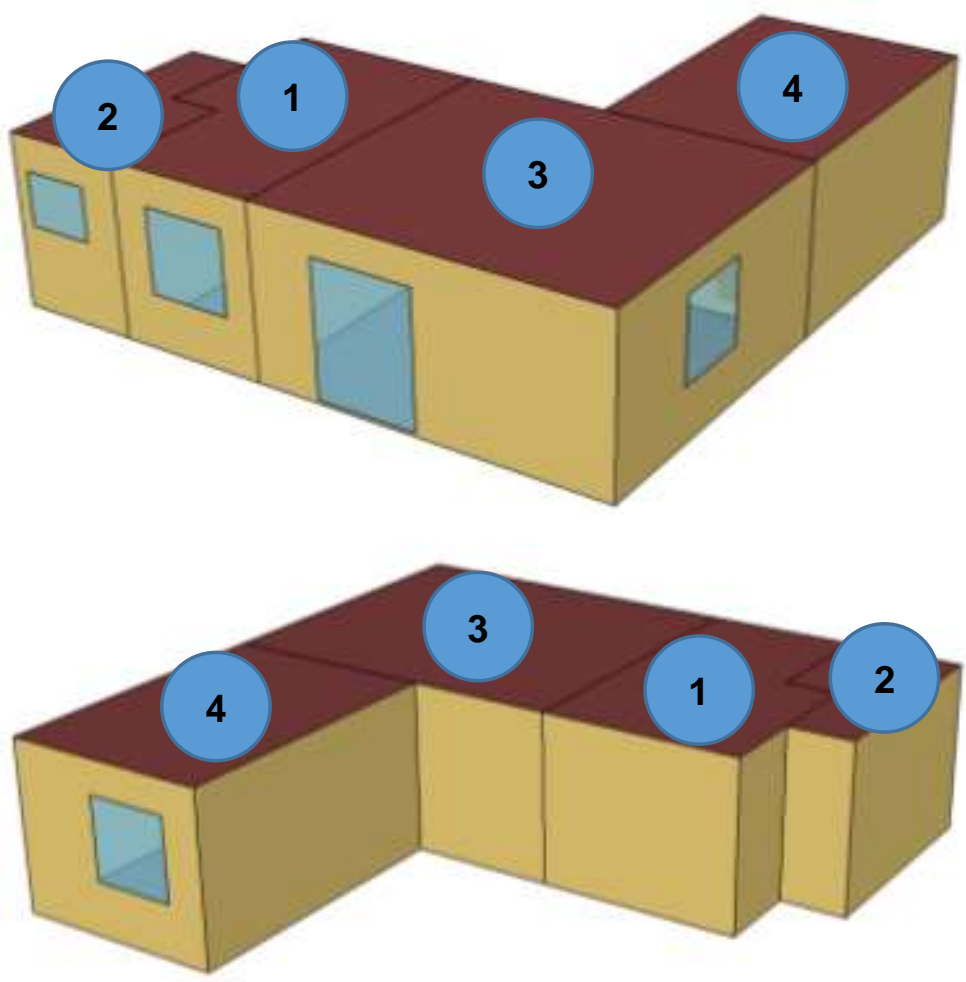

Figure 3-26: Google SketchUp model of the simulated flat including the four thermal zones (1=kitchen, 2=bathroom, $3=$ =living room, $4=$ sleeping room) 


\subsubsection{Internal gains}

\section{Occupancy rate}

The presence of the occupants in the flat was modelled according to the profile of Streicher et al. [45]. In this study, the presence of the occupants in residential buildings was ascertained by questionnaires. The occupancy was given in hourly values for every single day of the week. From the data provided in [45] average values for the hourly presence were calculated and used in this simulation study.

Figure 3-27 shows the presence of the occupants during one week for the four thermal zones. For the kitchen and the living room, the total appearance is presented. In the simulation, it was assumed that $50 \%$ of the people are in the kitchen and $50 \%$ in the living room.

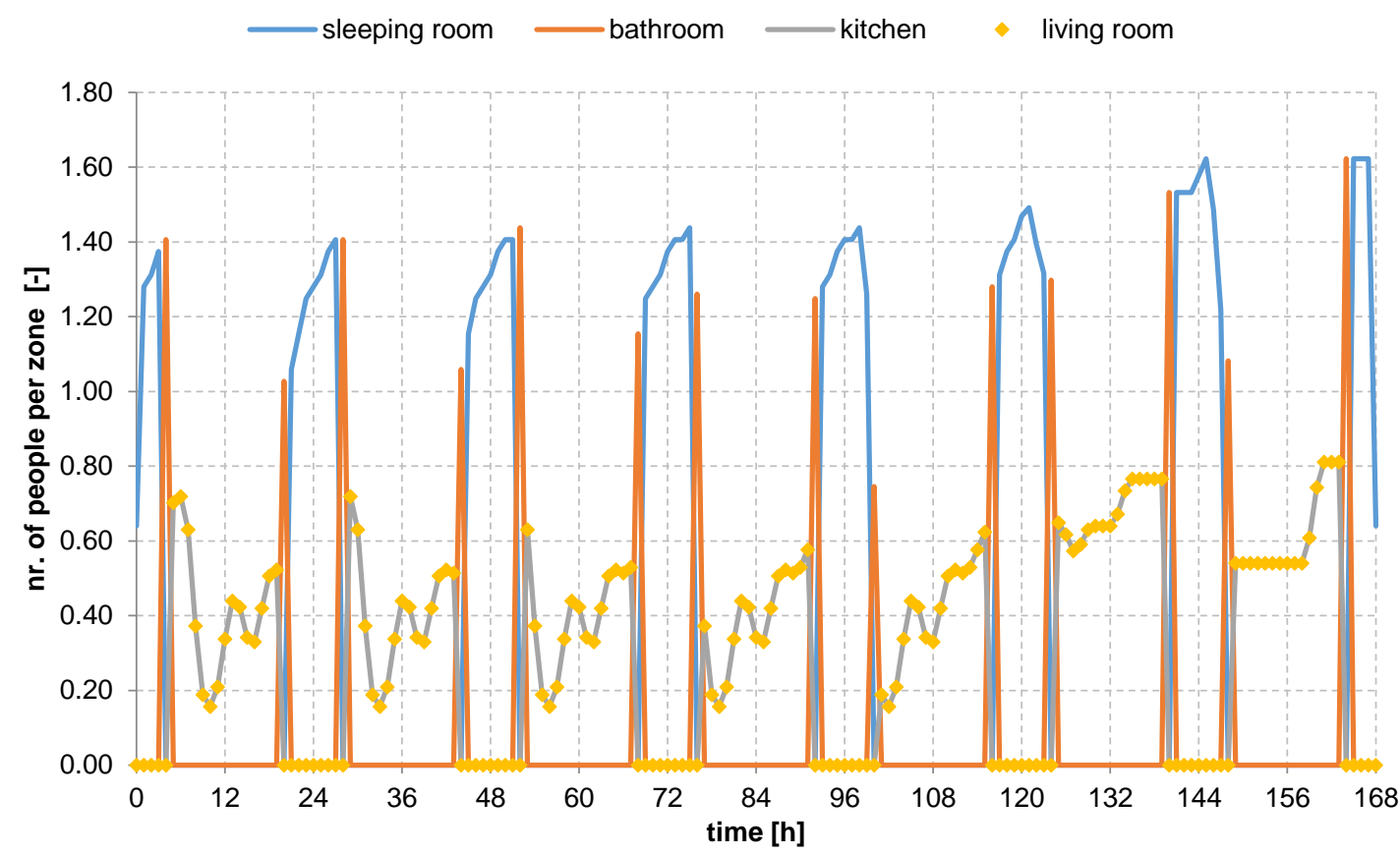

Figure 3-27. presence of occupants during one week in the four thermal zones; the occupancy in the kitchen and the living room was assumed to be identical, therefore also the graphs are identical

For the internal heat gains, as a result of the presence of the occupants, $90 \mathrm{~W}$ per person was assumed, according to the hourly presence as visible in Figure 3-27.

The internal gains are modelled as $66 \%$ radiative and $33 \%$ convective, with an additional moisture load of $0.08 \mathrm{~kg} / \mathrm{h}$.

\section{Appliances and Lighting}

For the appliances following gains were considered:

- $\quad$ bathroom: $4 \mathrm{~W}$ when people are present in the zone, $5 \mathrm{~W}$ permanent

- $\quad$ kitchen: $30 \mathrm{~W}$ when people are present, $15 \mathrm{~W}$ permanent

- $\quad$ living room: $50 \mathrm{~W}$ when people are present, $15 \mathrm{~W}$ permanent

- $\quad$ sleeping room: $10 \mathrm{~W}$ permanent

For the lighting following settings were used:

- bathroom: $5 \mathrm{~W} / \mathrm{m}^{2}$, controlled according to the level of daylight and the presence of people

- kitchen: $5 \mathrm{~W} / \mathrm{m}^{2}$, controlled according to the level of daylight and the presence of people

- living room: $5 \mathrm{~W} / \mathrm{m}^{2}$, controlled according to the level of daylight and the presence of people

- sleeping room: no lighting considered

For the controlling of the daylight, the TRNSYS default settings for daylight were used, which assume that the lights are turned on if the radiation on the horizontal is lower than $120 \mathrm{~W} / \mathrm{m}^{2}$ and turned off if the radiation is higher than $200 \mathrm{~W} / \mathrm{m}^{2}$. 


\subsubsection{Ventilation and infiltration}

For the ventilation of the flat, a mechanical ventilation system with heat recovery was considered. The fresh air supply is assumed with $30 \mathrm{~m}^{3} / \mathrm{h} /$ person. The sensible heat efficiency of the heat recovery unit is $65 \%$ (ÖNORM B 8110-6, 2010). No additional air change through the windows was assumed. Furthermore, also no air change representing the infiltration was included in the simulation model.

The electricity consumption of the fan is calculated with an SFP (specific fan power) of $0.34 \mathrm{~W} / \mathrm{m}^{3} / \mathrm{h}$.

No night cooling strategy for the summer period, as well as no bypass of the heat recovery in warm periods, were considered.

\subsubsection{Shadings}

The solar shading consists of generic external movable shading blinds that are able to block $70 \%$ of the solar radiation. The shading device is activated when the irradiation on the external façade (vertical plane) exceeds a threshold of $140 \mathrm{~W} / \mathrm{m}^{2}$, whereas is retracted when it is lower than $120 \mathrm{~W} / \mathrm{m}^{2}$. These limit values are TRNSYS default values.

No influence of the urban or environmental context in terms of unwanted shading on the active solar façade is considered.

\subsubsection{Building assemblies}

\section{Opaque structures}

Thermal and optical characteristics of opaque assemblies and building materials are listed from Table 3-23 to Table 3-25. As already mentioned, the reference flat is delimited by adiabatic surfaces (internal walls, floor and ceilings) that do not exchange heat with the adjacent zones, one internal wall adjacent to the unheated staircase and the external façade.

Table 3-23: Construction of internal walls.

\begin{tabular}{l|cccc}
\multicolumn{1}{c}{ Material } & $\mathbf{s}$ & $\boldsymbol{\lambda}$ & $\mathbf{\rho}$ & $\mathbf{c}_{\mathbf{p}}$ \\
{$[\mathbf{m}]$} & {$[\mathbf{W} / \mathbf{m K}]$} & $\begin{array}{c}\left.\mathbf{p} / \mathbf{m}^{3}\right] \\
{[\mathbf{k J} /(\mathbf{k g K})]}\end{array}$ \\
\hline Internal plaster & 0.015 & 0.800 & 1800 & 1.130 \\
Brick & 0.120 & 0.300 & 1000 & 0.936 \\
Internal plaster & 0.015 & 0.800 & 1800 & 1.130 \\
\hline
\end{tabular}

Table 3-24: Construction of floor/ceiling.

\begin{tabular}{l|cccc}
\multicolumn{1}{c}{ Material } & $\begin{array}{c}\mathbf{s} \\
{[\mathbf{m}]}\end{array}$ & $\begin{array}{c}\boldsymbol{\lambda} \\
{[\mathbf{W} / \mathbf{m K}]}\end{array}$ & $\begin{array}{c}\mathbf{\rho} \\
{\left[\mathbf{k g} / \mathbf{m}^{3}\right]}\end{array}$ & $\begin{array}{c}\mathbf{c}_{\mathbf{p}} \\
{[\mathbf{k J} /(\mathbf{k g K})]}\end{array}$ \\
\hline Screed & 0.060 & 1.400 & 2000 & 1.116 \\
Slag & 0.050 & 0.330 & 750 & 0.900 \\
Reinforced concrete & 0.140 & 2.300 & 2300 & 1.080 \\
Internal plaster & 0.015 & 0.800 & 1800 & 1.130 \\
\hline
\end{tabular}

Table 3-25: Construction of the external wall.

\begin{tabular}{l|cccc}
\multicolumn{1}{c}{ Material } & $\begin{array}{c}\mathbf{[ m}] \\
{[\mathbf{W} / \mathbf{m K}]}\end{array}$ & $\begin{array}{c}\boldsymbol{\rho} \\
{\left[\mathbf{k g} / \mathbf{m}^{3}\right]}\end{array}$ & $\begin{array}{c}\mathbf{C}_{\mathbf{p}} \\
{[\mathbf{k J} /(\mathbf{k g K})]}\end{array}$ \\
\hline Internal plaster & 0.015 & 0.800 & 1800 & 1.130 \\
Brick & 0.250 & 0.300 & 1000 & 0.936 \\
External plaster & 0.025 & 0.700 & 1400 & 1.000 \\
EPS & 0.250 & 0.031 & 17 & 1.400 \\
External plaster & 0.025 & 0.700 & 1400 & 1.000 \\
\hline
\end{tabular}




\section{Transparent structures}

Table 3-26 shows the thermal characteristics of the windows used in the simulation.

Table 3-26: Thermal and optical characteristics of transparent structures.

\begin{tabular}{c|ccc}
\multicolumn{1}{c}{ Description } & Assembly & $\begin{array}{c}\text { U-value } \\
{\left[\mathbf{W} /\left(\mathbf{m}^{2} \mathbf{K}\right)\right]}\end{array}$ & $\begin{array}{c}\text { g-value } \\
{[-]}\end{array}$ \\
\hline Double Glazing Filled With Argon & $4 / 16 / 4$ & 1.06 & 0.586 \\
\hline
\end{tabular}

\subsubsection{Hot water demand}

For the domestic hot water demand, the European tapping cycle $\mathrm{M}$ was adapted to 109 litres per day at $45^{\circ} \mathrm{C}$ (based on Fink and Riva [46]) with a temperature of cold tap water to be assumed constantly $12^{\circ} \mathrm{C}$. This profile was used for all days of the year. It is visible in Figure 3-28 and Table A. 13 in the appendix.

This tapping cycle, together with the assumptions made, result in a domestic hot water demand of $4.19 \mathrm{kWh} / \mathrm{d}$, which is a little bit lower than the European tapping cycle M, which assumes a daily hot water demand of $5.85 \mathrm{kWh} / \mathrm{d}$.

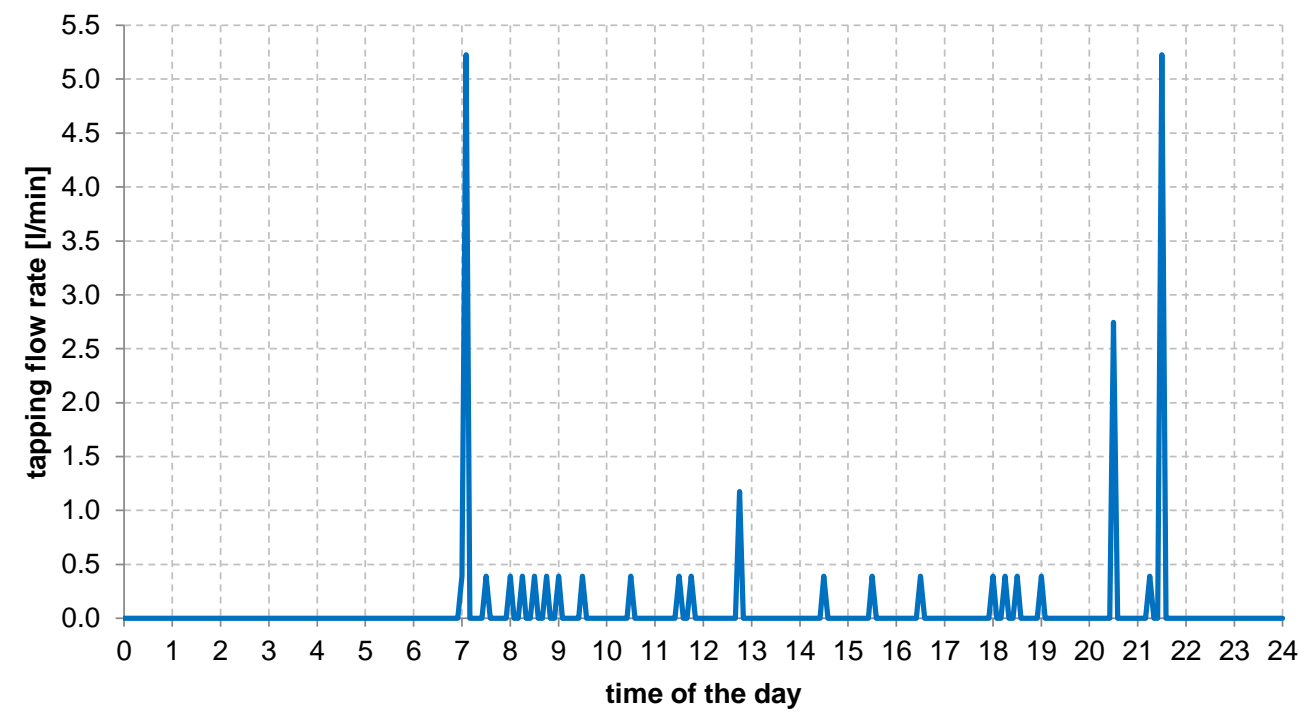

Figure 3-28: daily tap profile of the hot water system; 5 minutes interval

\subsubsection{Investigated energy supply systems}

\subsubsection{Reference system}

The reference heating system was modelled as an ideal direct electrical heating system including also an ideal control system following the room air temperature.

The setpoint for the room temperature is $20^{\circ} \mathrm{C}$ between 5 a.m. in the morning and midnight. Between midnight and 5 a.m., the setpoint is reduced to $17^{\circ} \mathrm{C}$.

For the domestic hot water generation, a 150-litre hot water tank is included, which is also heated directly by electricity (using an electric heating rod).

In the reference energy supply system no photovoltaic installation was considered. That means that the entire electricity for heating, domestic hot water and the household appliances has to be taken from the grid.

\subsubsection{Direct electric heating + PV on the façade (concept A)}

This concept is based on the reference system as described above. But in this variant, the building is equipped with about $176 \mathrm{~m}^{2} \mathrm{PV}$ modules, which are mounted on the south, east and west facades. Around $15 \mathrm{~m}^{2} \mathrm{PV}$ are allocated 
to each flat. This is the maximum possible amount of PV modules if all facades except the north façade are used (excluding window and door areas).

\subsubsection{Direct electric heating + PV on the façade and on the roof (concept B)}

This concept is also based on the reference system as described above. But in this variant, the building is equipped with about $419 \mathrm{~m}^{2}$ PV modules, which are situated on south, east and west facade as well as on the roof. Here, around $35 \mathrm{~m}^{2} \mathrm{PV}$ are allocated to each flat.

Following Figure 3-29 shows a schema of the energy supply concepts, using direct electric heating. The PV areas considered in concept A and B are summarized in Table 3-27.

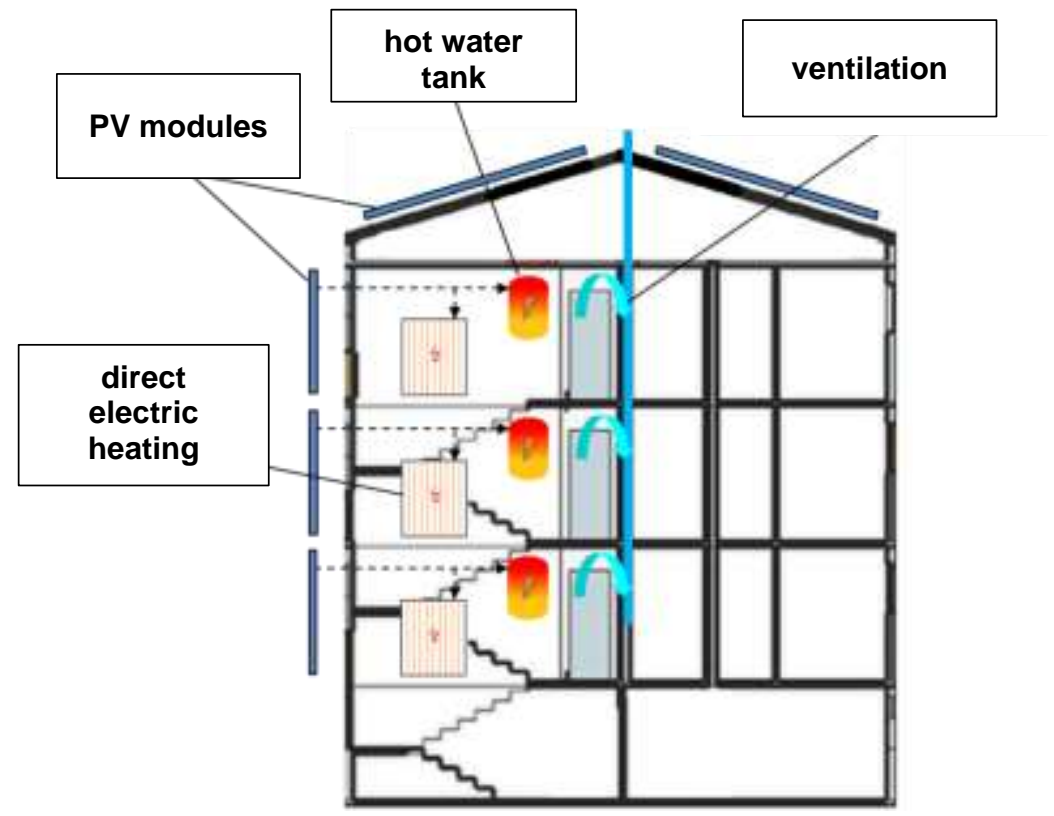

Figure 3-29: schema of the direct electric heating concepts

Table 3-27: summary of PV area in the two direct electric heating concepts

\begin{tabular}{l|cccc} 
& INCLINATION & CONCEPT A & CONCEPT B & \\
\hline South Façade & $90^{\circ}$ & 4.5 & 4.5 & $\mathrm{~m}^{2} / \mathrm{flat}$ \\
East Façade & $90^{\circ}$ & 4.5 & 9.0 & $\mathrm{~m}^{2} / \mathrm{flat}$ \\
West Façade & $90^{\circ}$ & 5.6 & 9.0 & $\mathrm{~m}^{2} / \mathrm{flat}$ \\
Roof East Oriented & $20^{\circ}$ & 0 & 5.6 & $\mathrm{~m}^{2} / \mathrm{flat}$ \\
Roof West Oriented & $20^{\circ}$ & 0 & 6.8 & $\mathrm{~m}^{2} / \mathrm{flat}$ \\
Total Per Flat & & $\mathbf{1 4 . 6}$ & $\mathbf{3 4 . 9}$ & $\mathrm{m}^{2}$ \\
Total At Building & & $\mathbf{1 7 5 . 5}$ & $\mathbf{4 1 8 . 5}$ & $\mathbf{m}^{2}$ \\
\hline
\end{tabular}

\subsubsection{Heat pump without PV (concept C)}

The second investigated energy supply system is based on decentralised air source heat pumps using ambient air for each apartment. This concept has the largest proportion of façade integration since small-scale heat pumps can also be integrated into the façade. Thanks to the decentralised systems, the pipe lengths for both heating and hot water preparation can be kept very short. A hydraulic separator is available for heating. The flow rates in the heat pumps and in the heating circuit can vary depending on the heating load.

The domestic hot water preparation is done, similar to the reference system, with the help of a 150-litre hot water tank, but in this concept heated by the heat pump. All other parameters, relevant for the simulation, were chosen similar/equal to the direct electrical heating concept.

In a first step, the heat pump heating concept was calculated without photovoltaic modules and therefore, similar to the reference system, the entire energy consumption has to be taken from the grid. 


\subsubsection{Heat pump + PV on the south façade (concept D)}

This concept is based on the previously described heat pump supply concept but also includes $68 \mathrm{~m}^{2}$ of photovoltaic modules, which are located on the south façade of the building. For each flat, this means that $5.6 \mathrm{~m}^{2} \mathrm{PV}$ are directly allocated to each flat.

\subsubsection{Heat pump + PV on the south, east and west facade (concept E)}

Concept $E$ is also based on the heat pump supply system and includes in total $176 \mathrm{~m}^{2} \mathrm{PV}$. The modules are located on the south, east and west façade of the building. Unlike in the energy supply concepts that are based on direct electric heating, no PV modules on the roof are necessary.

For each flat, that means, that $14.6 \mathrm{~m}^{2}$ of $\mathrm{PV}$ is directly allocated.

Figure 3-30 shows a schema of the heat pump supply system, Table 3-28 a summary of the PV areas.

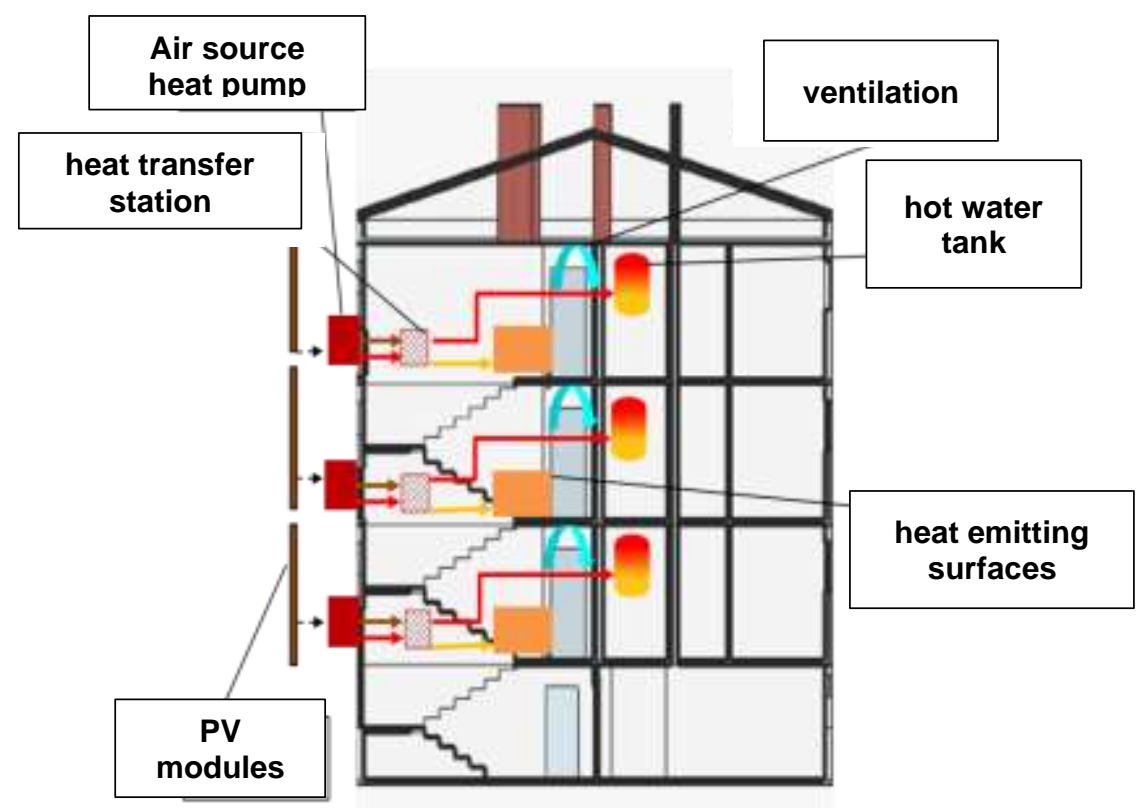

Figure 3-30: schema of the heat pump energy supply concepts

Table 3-28: summary of PV area at the heat pump energy supply systems

\begin{tabular}{l|ccccc} 
& INCLINATION & CONCEPT C & CONCEPT D & CONCEPT E & \\
\hline South Façade & $90^{\circ}$ & 0 & 5.6 & 4.5 & $\mathrm{~m}^{2} / \mathrm{flat}$ \\
East Façade & $90^{\circ}$ & 0 & 0 & 4.5 & $\mathrm{~m}^{2} / \mathrm{flat}$ \\
West Façade & $90^{\circ}$ & 0 & 0 & 5.6 & $\mathrm{~m}^{2} / \mathrm{flat}$ \\
Roof East Oriented & $20^{\circ}$ & 0 & 0 & 0 & $\mathrm{~m}^{2} / \mathrm{flat}$ \\
Roof West Oriented & $20^{\circ}$ & 0 & 0 & 0 & $\mathrm{~m}^{2} / \mathrm{flat}$ \\
Total Per Flat & & 0 & $\mathbf{5 . 6}$ & $\mathbf{1 4 . 6}$ & $\mathrm{m}^{2}$ \\
Total At Building & & $\mathbf{0}$ & $\mathbf{6 7 . 5}$ & $\mathbf{1 7 5 . 5}$ & $\mathbf{m}^{\mathbf{2}}$ \\
\hline
\end{tabular}

\subsubsection{Summary of PV areas}

Table 3-29 shows the summary of the PV areas of the different energy supply systems. The table also shows the labels for the different PV sizes, which were used in the report (“zero", "small”, medium”, "large). 
Table 3-29: overview of the PV sizes of all six investigated energy supply concepts

\begin{tabular}{|c|c|c|c|c|}
\hline & $\begin{array}{c}\text { CONCEPT } \\
\text { NAME }\end{array}$ & $\begin{array}{l}M^{2} \text { PV PER } \\
\text { FLAT }\end{array}$ & $\begin{array}{l}M^{2} \text { PV AT } \\
\text { BUILDING }\end{array}$ & $\begin{array}{c}\text { PV SIZE } \\
\text { NAME }\end{array}$ \\
\hline Reference System & reference & 0 & 0 & zero \\
\hline Direct Electric Heating + PV on the Façade & A & 14.6 & 175.5 & medium \\
\hline Direct Electric Heating + PV on the Façade and on the Roof & B & 34.9 & 418.5 & large \\
\hline Heat Pump Without PV & $\mathrm{C}$ & 0 & 0 & zero \\
\hline Heat Pump + PV on the South Façade & D & 5.6 & 67.5 & small \\
\hline Heat Pump + PV on the South, East And West Facade & E & 14.6 & 175.5 & medium \\
\hline
\end{tabular}




\subsubsection{Simulation models used}

\subsubsection{Photovoltaics}

As a simulation model for the photovoltaic surfaces both in the façade and on the roof, TRNSYS Type 94a was used in combination with Type 48a inverters. The following Table 3-30 and Table 3-31 show the parameters used. One module has $1.125 \mathrm{~m}^{2}$. Depending on the space available on the facades or on the roof, several of the modules were used in series or connected in parallel.

Table 3-30: parameters of TRNSYS Type 94a used in the simulations

\begin{tabular}{l|l} 
Parameters of type 94a & VALUES \\
\hline Module short-circuit current at reference conditions & $5.18 \mathrm{~A}$ \\
Module open-circuit voltage at reference conditions & $43,8 \mathrm{~V}$ \\
Reference temperature & $289 \mathrm{~K}$ \\
Reference insolation & $1000 \mathrm{~W} / \mathrm{m}^{2}$ \\
Module voltage at max power point and reference conditions & 36 \\
Module current at max power point and reference conditions & 4,58 \\
Temperature coefficient of isc at (ref. Cond) & $0.00518 \mathrm{~A} / \mathrm{K}$ \\
Temperature coefficient of voc (ref. Cond.) & $-0.16644 \mathrm{~V} / \mathrm{K}$ \\
Number of cells wired in series & 72 \\
Number of modules in series & 2 \\
Number of modules in parallel & 4 \\
Module temperature at noct & $320 \mathrm{~K}$ \\
Ambient temperature at noct & $293 \mathrm{~K}$ \\
Insolation at noct & $800 \mathrm{~W} / \mathrm{m}^{2}$ \\
Module area & $1.125 \mathrm{~m}{ }^{2}$ \\
Tau-alpha product for normal incidence & 0.95 \\
Semiconductor bandgap & $4,12 \mathrm{eV}$ \\
Slope of iv curve at isc & 0 \\
Module series resistance & infinite \\
\hline
\end{tabular}

An efficiency can be entered in the inverter model. This means that the inverter has a certain loss. Inputs are the power generated by the PV modules and the current load. The inverter model then calculates the portion of the load that is covered by the PV modules at the time and the excess load that must then be covered by the grid. This calculation was performed for each time step. No battery storage for the current was taken into account.

Table 3-31: parameters of TRNSYS Type 48a used in the simulations

\begin{tabular}{c|c} 
Parameter of type 48a & VALUE \\
\hline Efficiency & 0.9 \\
\hline
\end{tabular}

\subsubsection{Heat pump}

For the heat pump concepts, a speed-controlled heat pump should be used to make the best possible use of the available PV electricity. For this reason the heat pump type 977 (author: M. Haller, Institut für Solartechnik SPF) was used. This is a characteristic curve model with a biquadratic polynomial for COP and condenser power. For this purpose six parameters must be entered in each case. Unlike other characteristic curve models, the reference temperature for condenser and evaporator is not the inlet temperature (evaporator) and the outlet temperature (condenser), but the average temperature in the respective heat exchanger. Depending on the mass flows used, this can make a considerable difference.

There are two additional inputs (frCond and frCOP) to calculate the performance values at partial load operation. The COP and condenser capacities are then multiplied by these. 
Table 3-32: parameters of TRNSYS Type 94a used in the simulations

Parameters of type 977

ABBREVIATION

VALUES

1st to 6th coefficient for bi-quadratic polynomial function for the condenser power

$c 1-c 6$

$\mathrm{kW}$

1st to 6th coefficient for bi-quadratic polynomial function for

the cop

Start time constant

Stop time constant

Temperature of ambient air (inlet) below which defrosting takes place

Efficiency of defrosting

Electricity consumption of ventilator

Electricity consumption of controller

Minimum temperature for evaporator inlet

Maximum temperature for evaporator inlet

Minimum temperature for condenser outlet

Maximum temperature for condenser outlet

Specific heat of the evaporator heat source

Specific heat of the condenser heat sink

Number of hours heat pump stays on error (compressor and ventilator off)

Heat loss and startup calculation mode

Thermal capacity of the heat pump

Ua-value for thermal losses of the heat pump

$\operatorname{cop} 1-\operatorname{cop} 6$

$\tau_{\text {start }}$

$\tau_{\text {stop }}$

$t_{\text {evap }, \text { ice }}$

$72 \mathrm{~s}$

$\eta_{\text {defrost }}$

$P_{\text {el,vent }}$

$P_{e l, c t r}$

$-1^{\circ} \mathrm{C}$

0,7

evap,min

$t_{\text {evap, } \max }$

evap, $\max$

$36^{\circ} \mathrm{C}$

$t_{\text {cond,min }}$

$12^{\circ} \mathrm{C}$

$t_{\text {cond, } \max }$

$90^{\circ} \mathrm{C}$

$c p_{\text {eva }}$

$1.006 \mathrm{~kJ} / \mathrm{kgK}$

$c p_{\text {cond }}$

$4.187 \mathrm{~kJ} / \mathrm{kgK}$

$\tau_{\text {error }}$

$0 \mathrm{~h}$

$M o_{\text {loss }}$

$C_{\text {therm }}$

0 (no losses)

$U A_{\text {los }}$

$83 \mathrm{~kJ} / \mathrm{K}$

$0.01 \mathrm{~W} / \mathrm{K}$
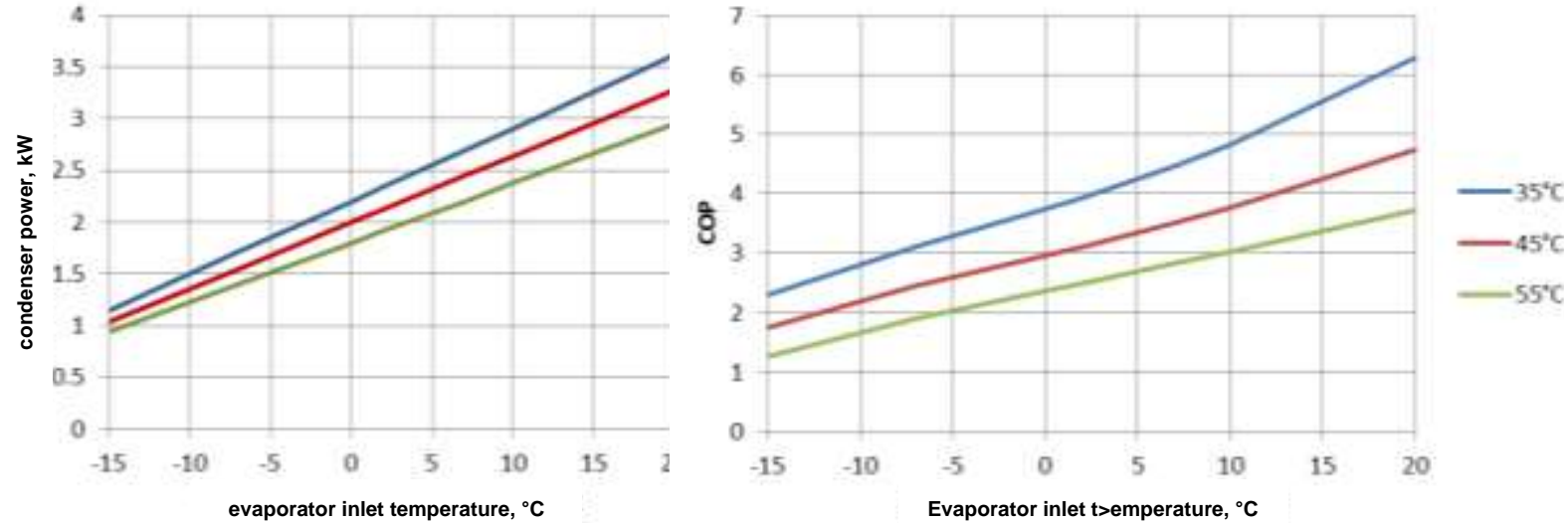

Figure 3-31: Characteristic diagrams (full load) of the heat pump used with $2 \mathrm{~kW}$ at $0^{\circ} \mathrm{C}$ evaporator inlet temperature and $45^{\circ} \mathrm{C}$ condenser outlet temperature 


\subsubsection{Economic evaluation}

In addition to the energetic evaluation of the concepts, also an economic evaluation of the different variants was performed. Life cycle costs (LCC) and their analysis (life cycle cost analysis, LCC analysis) are of essential importance for investments such as the refurbishment of buildings. By comparing the life cycle costs of different refurbishment variants, the most economical variant over the entire life cycle can be determined. The life cycle costs of a building include all payment flows that occur over the life cycle of the building. The considered building life cycle ranges from the construction phase to an operation period of 20 years. (The phase of demolition and object disposal was not considered in this analysis.)

For the evaluation of these phases and the comparison of the renovation variants, the net present value method was used. The following cost groups from ÖNORM B 1801-2 [47] were taken into account:

- Construction costs (related to the refurbishment);

- Property usage costs (operating and consumption-related costs, maintenance costs, replacement investments, dismantling and disposal costs for HVAC components).

For the economic evaluation, it was necessary to define the boundary conditions for the calculation. Table 3-33 shows an overview of the most important economic factors. The method for the economic evaluation is explained in report DC.1 chapter 5.5 .

Table 3-33: economic factors used in the LCC calculation

\begin{tabular}{l|l} 
Parameter & \multicolumn{1}{l}{ VALUE } \\
\hline Period under review & $20 \mathrm{a}$ \\
Real interest rate & $3.0 \% / \mathrm{a}$ \\
Electricity price & $0.20 \mathrm{EUR} / \mathrm{kWh}$ \\
Electricity price increase & $2.0 \% / \mathrm{a}$ \\
\hline
\end{tabular}

The Life Cycle Cost calculation was done with the tool "econ calc" which is available free of charge. It was developed by the Energieinstitut Vorarlberg and the Technical University of Graz in MS Excel format.

Figure 3-32 shows the total construction (investment) costs of the investigated variants. The analysis of the life cycle costs is addressed in chapter 3.2.5.5.

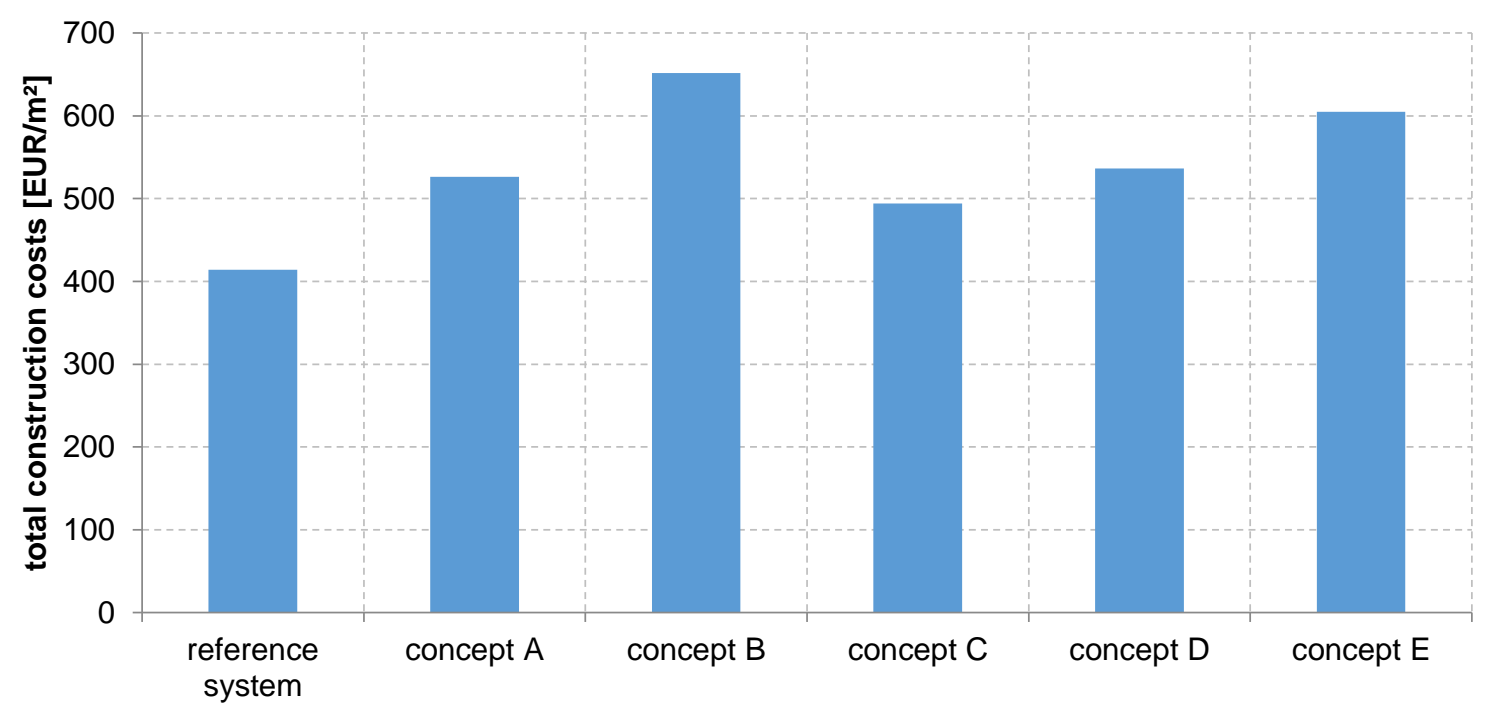

Figure 3-32: total construction costs of the investigated concepts in EUR per $\mathbf{m}^{2}$ 


\subsubsection{Results}

\subsubsection{Heating demand and heating load}

An annual heating demand of the entire flat of $14.5 \mathrm{kWh} / \mathrm{m}^{2} \mathrm{a}$ was calculated. Table 3-16 shows the relevant results for each zone of the flat under consideration.

Table 3-34: Heating demand, maximum daily heating power and maximum daily heating load for each zone of the flat

\begin{tabular}{c|cccc} 
Zone & $\begin{array}{c}\text { Area } \\
{\left[\mathbf{m}^{2}\right]}\end{array}$ & $\begin{array}{c}\text { Heating demand } \\
{\left[\mathrm{Kwh} / \mathbf{m}^{2} \mathbf{a}\right]}\end{array}$ & $\begin{array}{c}\text { Heating power } \\
{[\mathbf{W}]}\end{array}$ & $\begin{array}{c}\text { Heating load } \\
{\left[\mathbf{W} / \mathbf{m}^{\mathbf{2}}\right]}\end{array}$ \\
\hline Kitchen & 6.28 & 3.6 & 36 & 5.8 \\
Bathroom & 6.11 & 9.2 & 55 & 9.0 \\
Living room & 23.93 & 19.1 & 302 & 12.6 \\
Sleeping room & 18.56 & 14.2 & 160 & 8.6 \\
\hline
\end{tabular}

The daily average heating demand of the four thermal zones is visible in Figure 3-33.

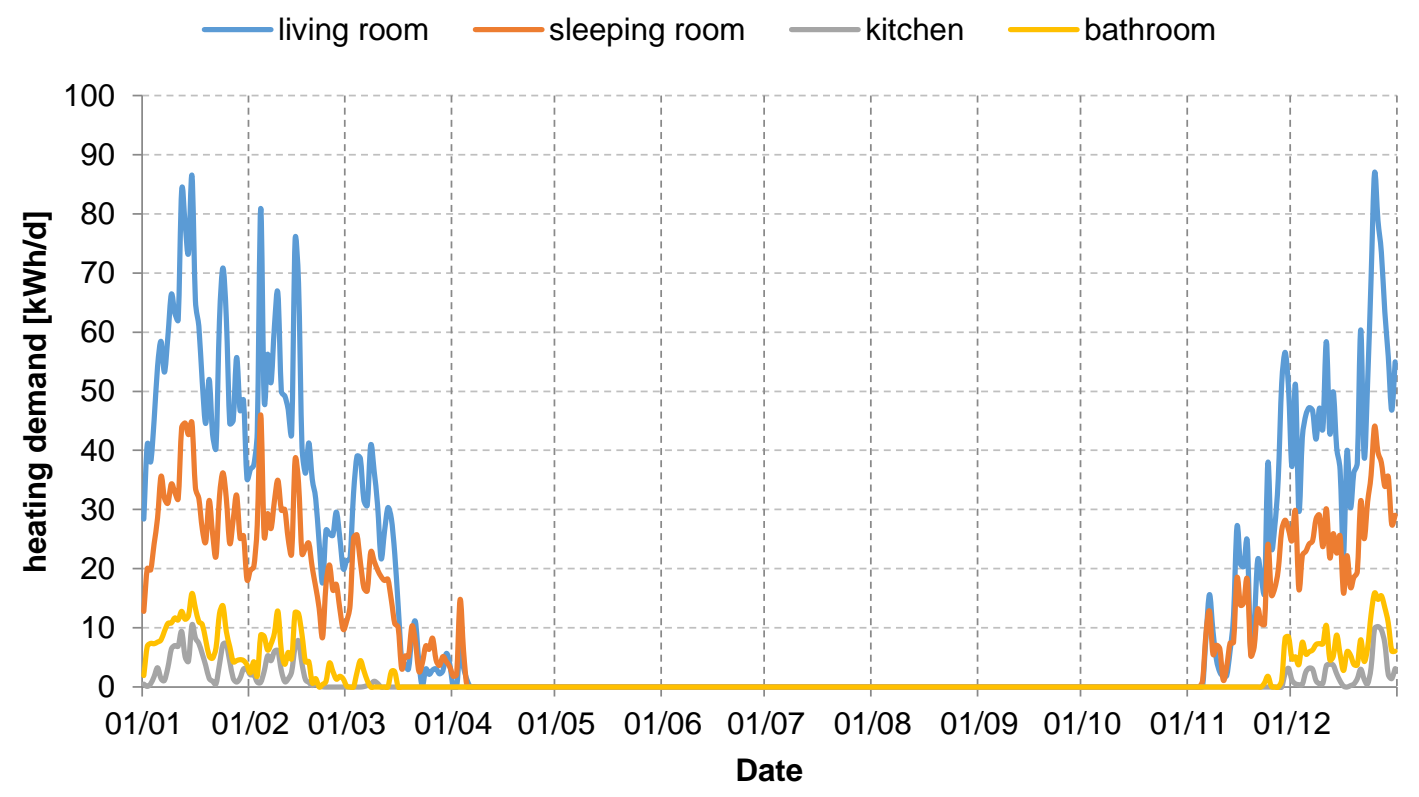

Figure 3-33: daily average heating demand of the four thermal zones 


\subsubsection{Indoor temperatures}

The operative room temperatures in the four thermal zones, during the heating season, are visible in Figure 3-34.

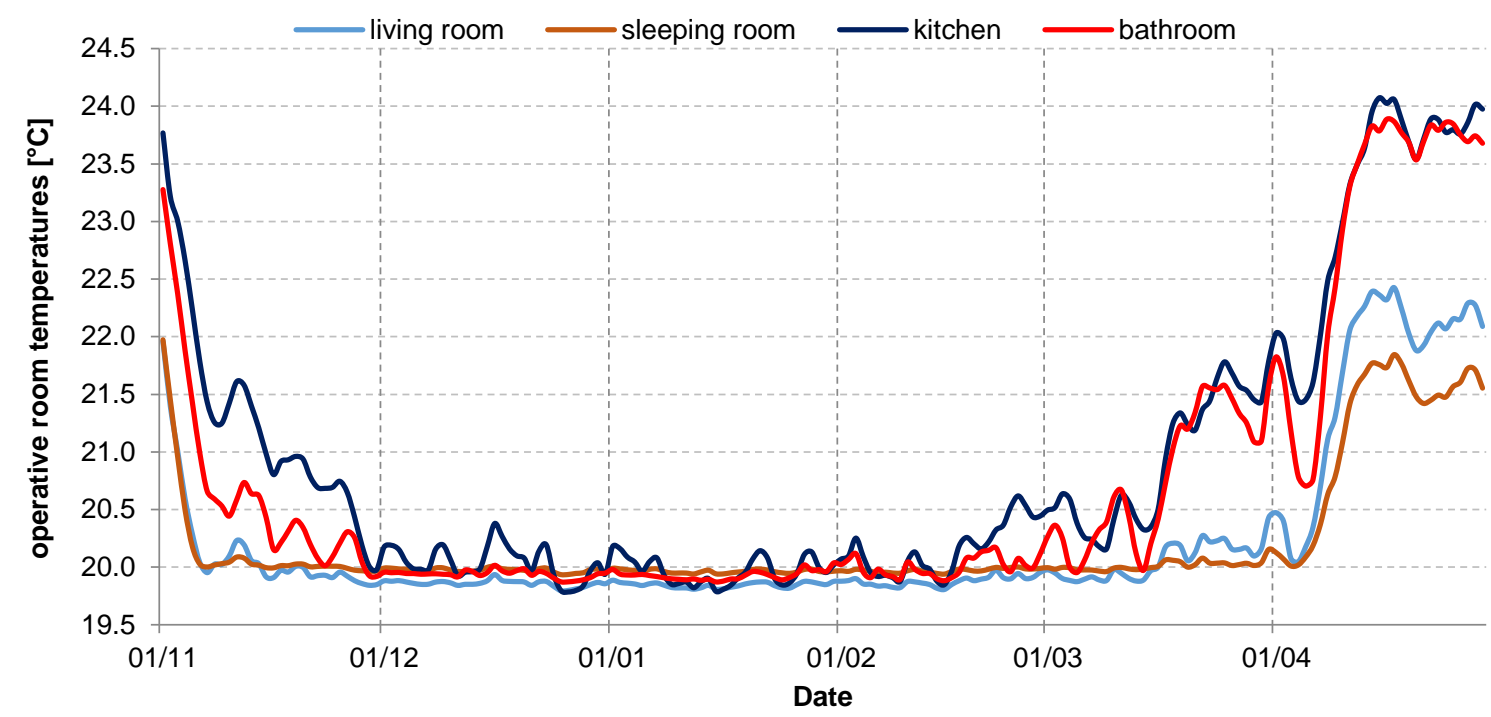

Figure 3-34: operative room temperatures during the heating season from November $1^{\text {st }}$ to $A$ pril $30^{\text {th }}$ (daily average)

\subsubsection{Electricity demand and PV production}

For all energy supply concepts described in chapter 3.2.2, the total electricity demand for heating, domestic hot water preparation and household electricity were determined. Also, the electricity production of the photovoltaic modules was simulated.

Figure 3-35 shows the simulation results for the different concepts excluding the electricity demand for household appliances. The results are plotted for one apartment and show, that the electricity demand of the direct electric heating systems ranges between 2800 and $3000 \mathrm{kWh} / \mathrm{a}$. By replacing the direct electric heating with a heat pump supply system, the electricity demand is reduced to 1300 to $1450 \mathrm{kWh} / \mathrm{a}$.

Without including the household appliances the photovoltaic system can produce $38 \%$ to $72 \%$ of the total electricity demand. Higher shares are achieved for the direct electric heating system, lower shares for the heat pump system (see also Figure 3-37). The reason for that is the higher electricity demand of the direct electric heating system, which in turn leads to an increase in the simultaneity of PV electricity production and electricity consumption in the flat. This also leads to a higher proportion of directly usable PV electricity.

In Figure 3-36 also the electricity demand for household appliances is included. The result is that the electricity demand increases to 3600 to $3900 \mathrm{kWh} / \mathrm{a}$ for the direct electric heating system and to 2200 to $2400 \mathrm{kWh} / \mathrm{a}$ for the heat pump system. The photovoltaic system can produce $35 \%$ to $65 \%$ of the total electricity demand on-site (see Figure 3-37). 


\section{without appliances}

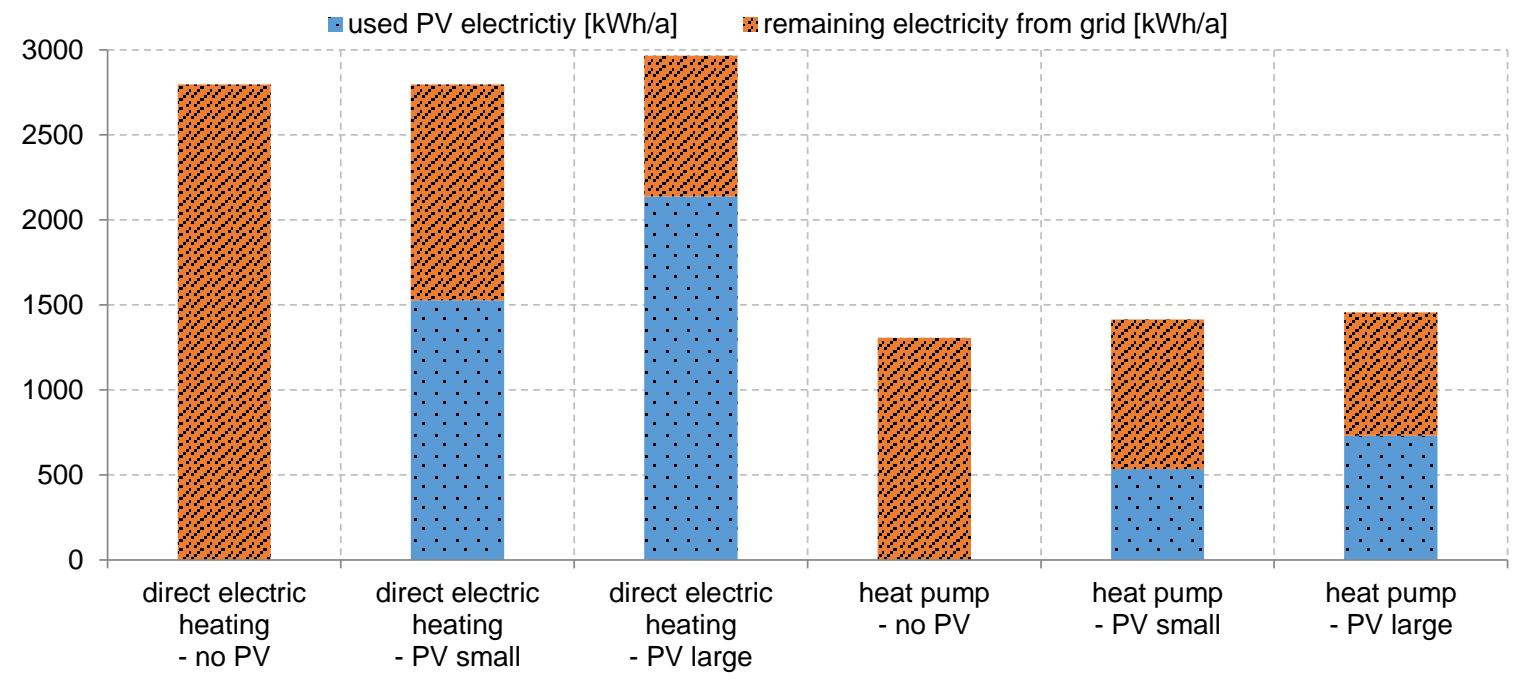

Figure 3-35: electricity demand of the different energy supply concepts, excluding the electricity demand for the household appliances

\section{with appliances}

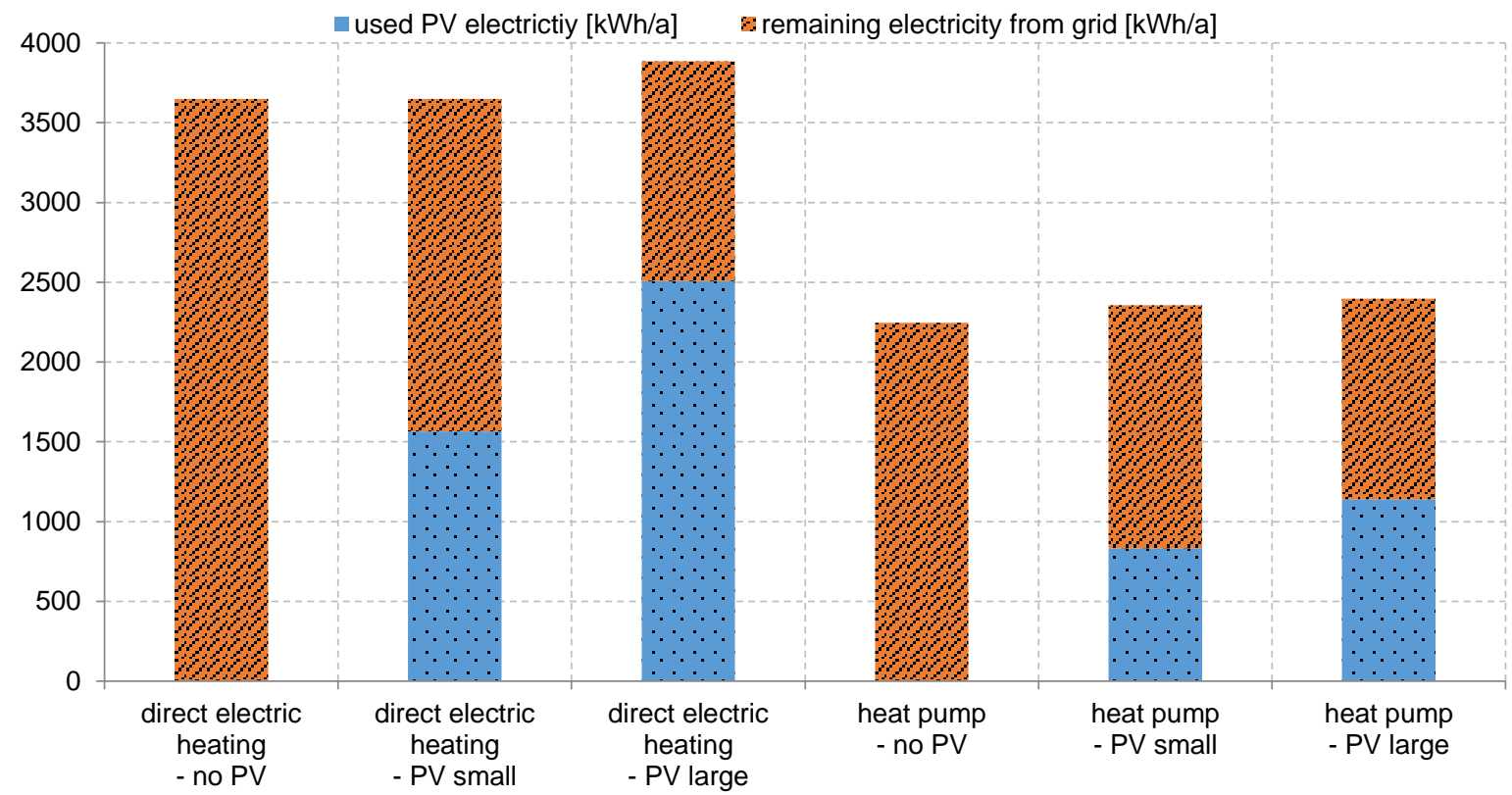

Figure 3-36: electricity demand of the different energy supply concepts, including also the electricity demand for the household appliances 


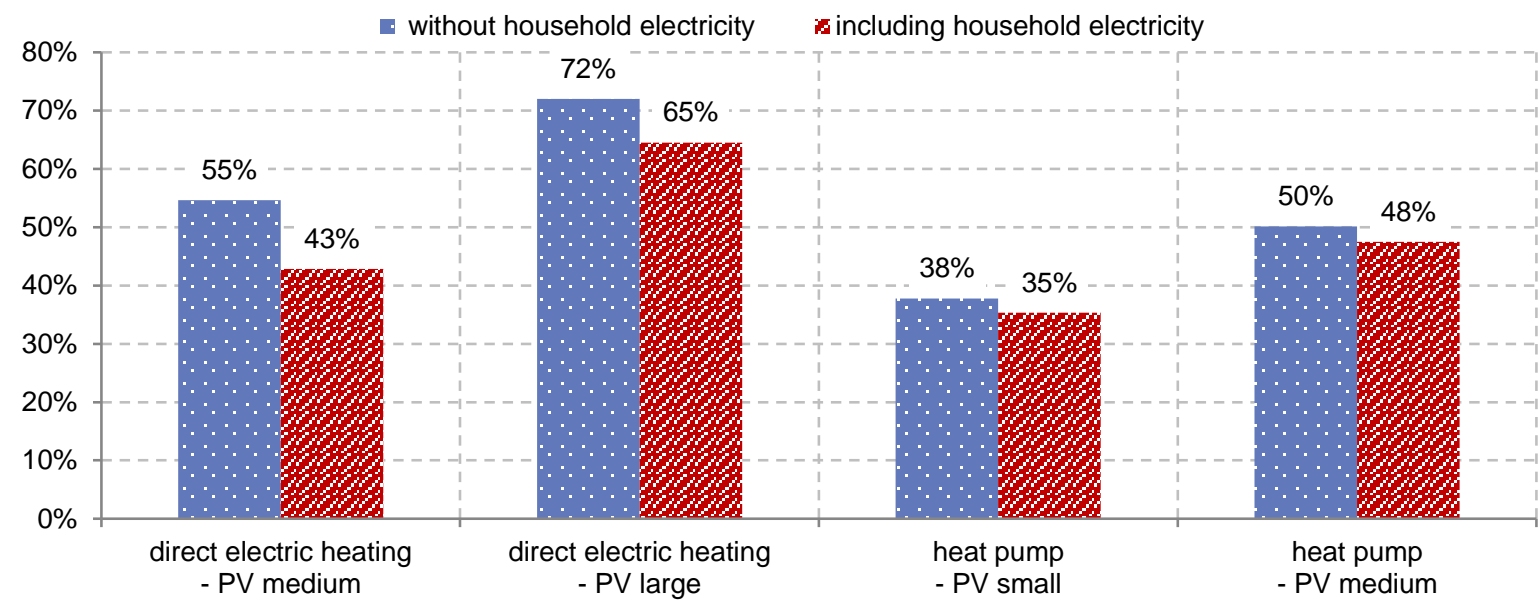

Figure 3-37: share of the total electricity consumption that can be covered by the photovoltaic system, with and without household electricity

\subsubsection{Primary energy demand}

For all investigated energy supply concepts also the primary energy demand was calculated. Therefore four different calculation methods were used (as described in report DC.1). Different monthly share of renewables (hydro, wind, PV, fossil) and corresponding PE non-ren. conversion factors, with (fPE1) a share of $10 \%$ hydro, $10 \%$ wind, $10 \%$ PV and $70 \%$ fossil, and (fPE2) a share of $10 \%$ hydro, $30 \%$ wind, $30 \%$ PV and $30 \%$ fossil in the electricity mix are considered (see chapter A.1 in report DC.1).

Summarized following Table 3-35 shows the primary energy consumption of the six energy supply concepts, excluding the electricity demand for the household appliances. The results are shown for the four different primary energy calculation methods. A monthly assessment with monthly variable factors was carried out twice (calculation methods $1+2$ ) and twice annual values were assumed (calculation methods $3+4$ ).

The results show, that depending on the evaluation method, the primary energy demand is halved within one concept. Comparing the different concepts, independent of the primary energy calculation method, the heat pump system in combination with a large PV achieves the lowest values (concept E).

Table 3-35: primary energy demand of the six different energy supply concepts, using four different primary energy calculation methods (without household electricity)

\begin{tabular}{ll|cccccc} 
& \multicolumn{2}{c}{ ANNUAL PRIMARY ENERGY DEMAND PER FLAT IN KWH } \\
& Calculation method & $\begin{array}{c}\text { Reference } \\
\text { system }\end{array}$ & Concept a & Concept b & Concept c & Concept d & Concept e \\
\hline $\mathbf{1}$ & Monthly factors (fPE1) & 4825 & 2445 & 1611 & 2313 & 1592 & 1319 \\
$\mathbf{2}$ & Monthly factors (fPE2) & 2650 & 1709 & 1148 & 1352 & 978 & 818 \\
$\mathbf{3}$ & Annual factor (fPE1) & 4575 & 2077 & 1358 & 2137 & 1440 & 1188 \\
$\mathbf{4}$ & Annual factor (fPE2) & 2140 & 971 & 635 & 999 & 673 & 556 \\
\hline
\end{tabular}

In Table 3-36 the calculated primary energy savings are shown. For each primary energy evaluation method, the different energy supply concepts were compared to the reference system. The results show, that reductions between $36 \%$ and $74 \%$ are possible. Higher savings are evident when the primary energy calculation is done with constant annual primary energy factors. 
Table 3-36: primary energy savings, compared to the reference system, for each of the four different primary energy calculation methods (without household electricity)

\begin{tabular}{ll|cccccc} 
Calculation method & $\begin{array}{c}\text { Reference } \\
\text { system }\end{array}$ & Concept a & Concept b & Concept c & Concept d & Concept e \\
\hline $\mathbf{1}$ & Monthly factors (fPE1) & $0 \%$ & $-49 \%$ & $-67 \%$ & $-52 \%$ & $-67 \%$ & $-73 \%$ \\
$\mathbf{2}$ & Monthly factors (fPE2) & $0 \%$ & $-36 \%$ & $-57 \%$ & $-49 \%$ & $-63 \%$ & $-69 \%$ \\
$\mathbf{3}$ & Annual factor (fPE1) & $0 \%$ & $-55 \%$ & $-70 \%$ & $-53 \%$ & $-69 \%$ & $-74 \%$ \\
$\mathbf{4}$ & Annual factor (fPE2) & $0 \%$ & $-55 \%$ & $-70 \%$ & $-53 \%$ & $-69 \%$ & $-74 \%$ \\
\hline
\end{tabular}

Figure 3-38 summarizes the main results of the previous two tables.

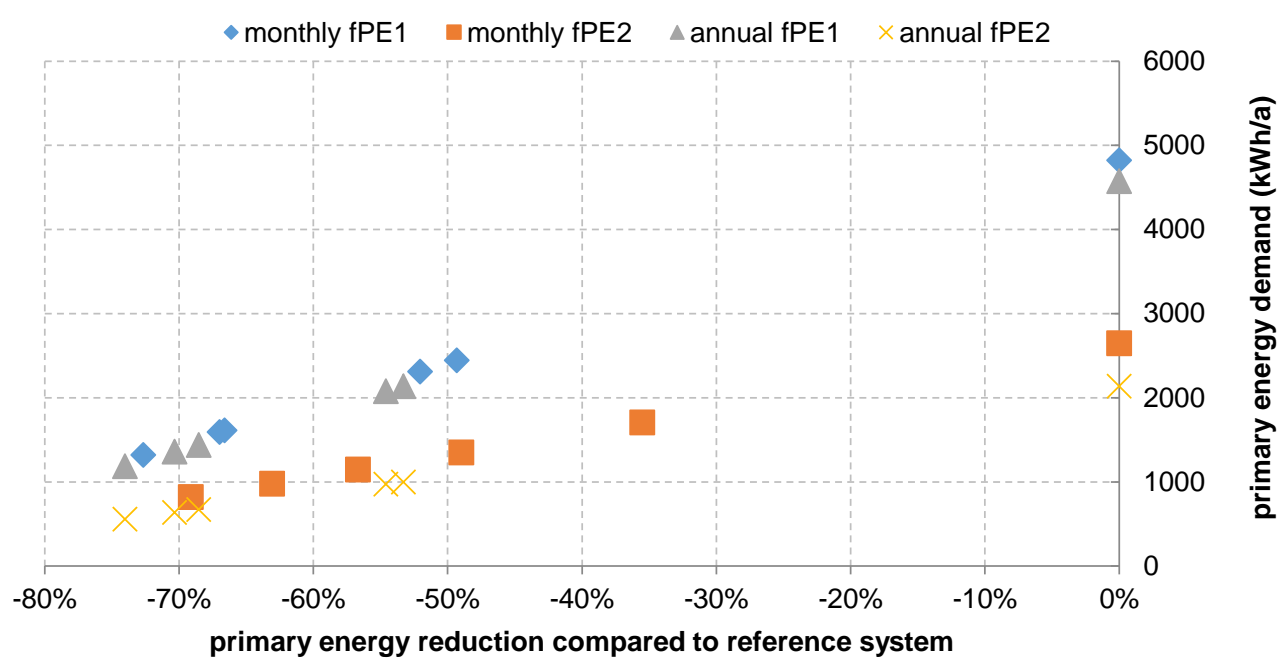

Figure 3-38: overview of the primary energy demand and the primary energy reductions of the investigated energy supply concepts and for the different primary energy evaluation methods (without household electricity)

The same investigations, as shown in the previous tables and figure, were done for the flat including also the household electricity. Again the primary energy demand for the different energy supply concepts and the different primary energy evaluation methods were determined. The results of the annual primary energy demand are shown in Table 3-37.

Table 3-38 shows the primary energy reductions of the different energy supply concepts, compared to the reference system.

Below that, Figure 3-39 shows the compilation of the results in one chart. 
Table 3-37: primary energy demand of the six different energy supply concepts, using four different primary energy calculation methods (including household electricity)

\begin{tabular}{llcccccc} 
& & \multicolumn{7}{c}{ Annual primary energy demand per flat in kWh } \\
& Calculation method & Reference system & Concept a & Concept b & Concept c & Concept d & Concept e \\
\hline $\mathbf{1}$ & Monthly factors (fPE1) & 6274 & 3848 & 2596 & 3887 & 2711 & 2255 \\
$\mathbf{2}$ & Monthly factors (fPE2) & 3407 & 2462 & 1738 & 2138 & 1598 & 1349 \\
$\mathbf{3}$ & Annual factor (fPE1) & 5969 & 3410 & 2255 & 3675 & 2492 & 2058 \\
$\mathbf{4}$ & Annual factor (fPE2) & 2792 & 1595 & 1055 & 1719 & 1165 & 963 \\
\hline
\end{tabular}

Table 3-38: primary energy savings, compared to the reference system, for each of the four different primary energy calculation methods (including household electricity)

Primary energy savings compared to reference system

\begin{tabular}{llcccccc} 
Calculation method & Reference system & Concept a & Concept b & Concept c & Concept d & Concept e \\
\hline $\mathbf{1}$ & Monthly factors (fPE1) & $0 \%$ & $-39 \%$ & $-59 \%$ & $-38 \%$ & $-57 \%$ & $-64 \%$ \\
$\mathbf{2}$ & Monthly factors (fPE2) & $0 \%$ & $-28 \%$ & $-49 \%$ & $-37 \%$ & $-53 \%$ & $-60 \%$ \\
\hline $\mathbf{3}$ & Annual factor (fPE1) & $0 \%$ & $-43 \%$ & $-62 \%$ & $-38 \%$ & $-58 \%$ & $-66 \%$ \\
$\mathbf{4}$ & Annual factor (fPE2) & $0 \%$ & $-43 \%$ & $-62 \%$ & $-38 \%$ & $-58 \%$ & $-66 \%$ \\
\hline
\end{tabular}

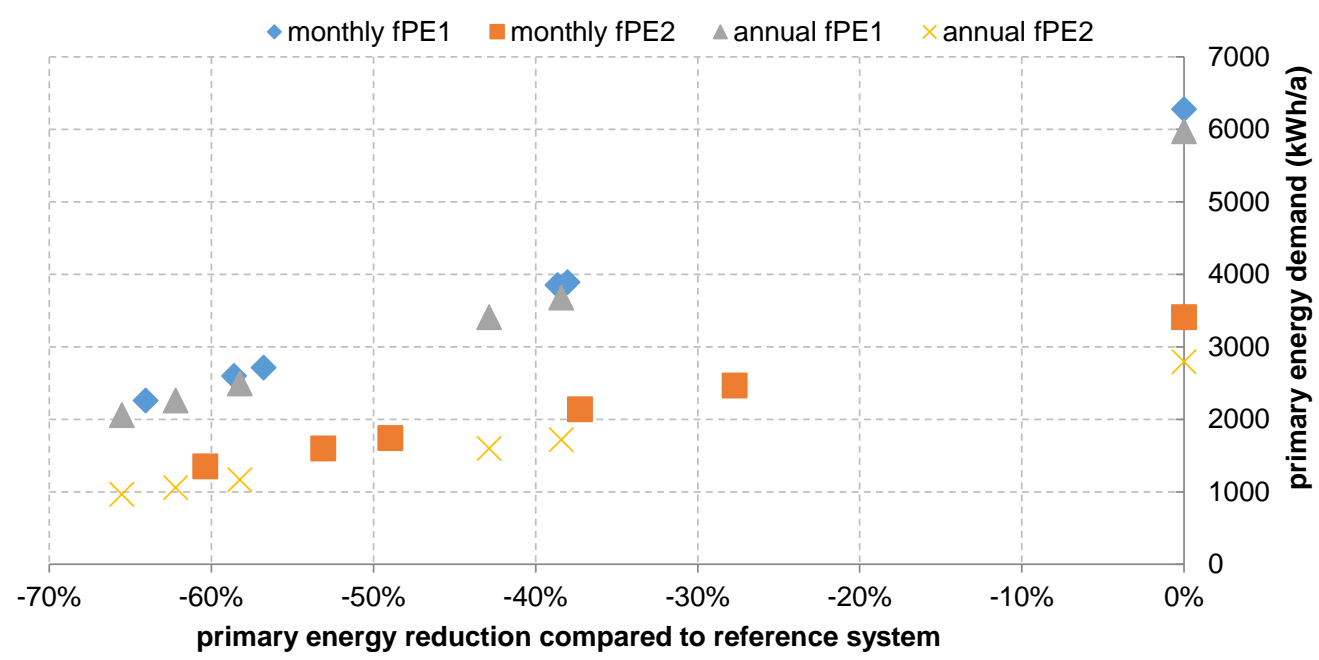

Figure 3-39: overview of the primary energy demand and the primary energy reductions of the investigated energy supply concepts and for the different primary energy evaluation methods (including household electricity) 


\subsubsection{Primary energy and cost savings}

The following figures and tables in this chapter show the results of the analysis of the life cycle costs and the primary energy demand of the investigated energy supply systems. The reference fPE is the European PE total conversion factor (2.5) while monthly and annual fPE1 and fPE2 are non-ren. PE conversion factors considering the monthly variation of the electricity mix (see previous chapter). Figure 3-40 shows the comparison of the additional life cycle costs and the primary energy reduction potentials of the six energy supply concepts. All results are compared to the reference scenario (direct electric heating without PV).

The analysis shows that the primary energy reductions potential ranges between 20 and $110 \mathrm{kWh} / \mathrm{m}^{2} \mathrm{a}$, depending on the used primary energy calculation method. The additional life cycle costs range between 1 and $8.5 \mathrm{EUR} / \mathrm{m}^{2} \mathrm{a}$. The highest primary energy reductions, but also highest costs, are achieved by those systems including a large PV system.

Regarding the primary energy savings, the analysis shows, that the decision of monthly or annual primary energy factors is used, is in this case quite small. More important is the conversion factor itself and the composition of the electricity grid (share of renewable energy), which is shown with the two different primary energy factors (fPE1 and fPE2). But it can be seen that for the scenario of using monthly primary energy factors (fPE2), a large PV system does not automatically lead to higher primary energy reductions. In fact, the two energy supply concepts with a large PV system achieve similar primary energy reductions than the heat pump system with a small PV installation. And this by achieving much lower additional costs.

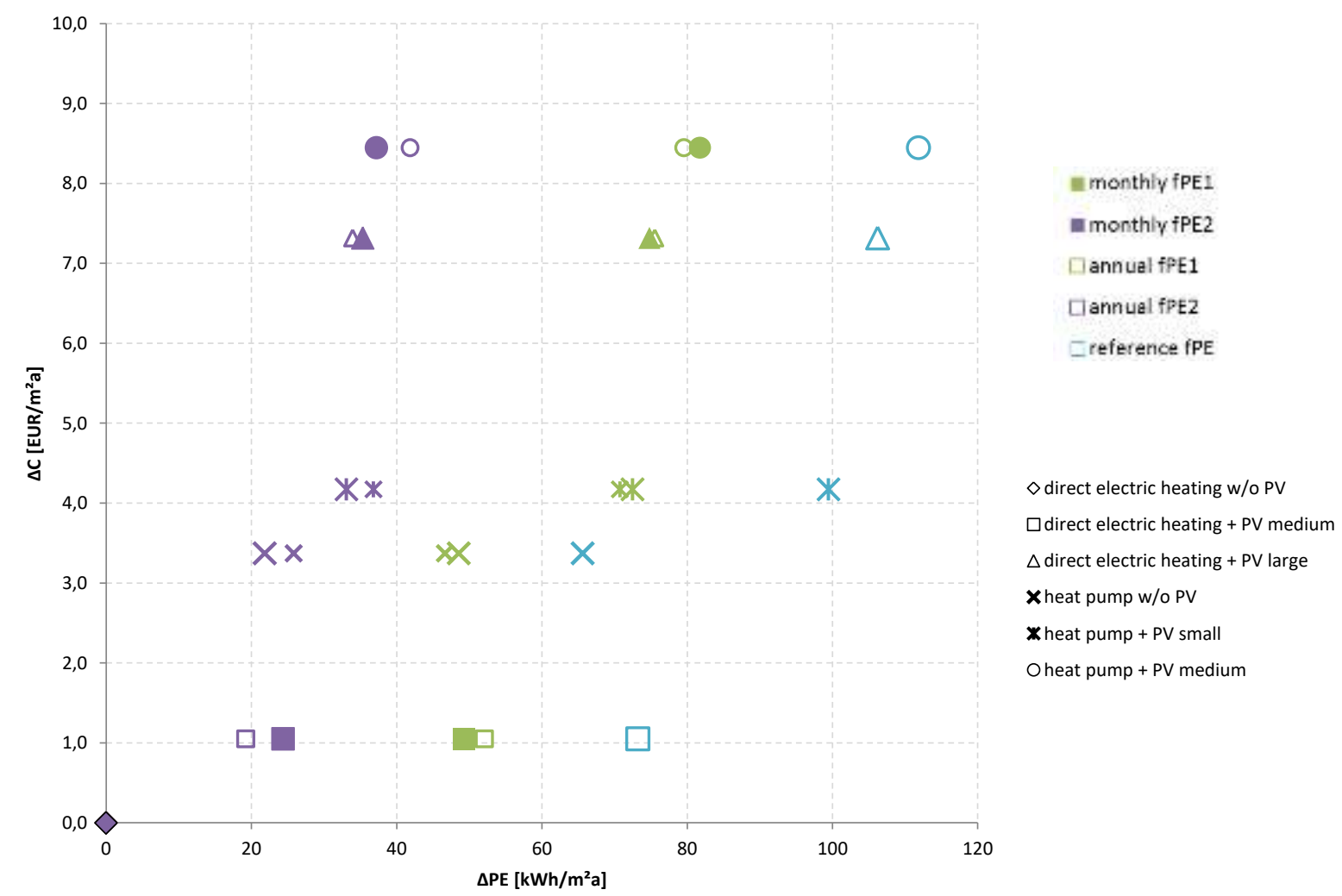

Figure 3-40: Comparison of the additional life cycle costs and the primary energy savings of the different concepts, including household electricity. The reductions are calculated based on the reference system. Additionally, the results of the different primary energy factors are also included.

Table 3-39 shows the calculation results of the reference energy supply system and the five other investigated energy supply concepts. For each concept, the primary energy reductions and the additional life cycle costs are shown. 
Table 3-39: Additional life cycle costs and primary energy savings of the different concepts compared to the reference system, including household electricity

\begin{tabular}{|c|c|c|c|c|c|c|}
\hline \multirow[b]{2}{*}{ Energy supply system } & \multicolumn{5}{|c|}{ Primary energy reductions $\left[\mathrm{kWh} / \mathrm{m}^{2} \mathrm{a}\right]$} & \multirow[b]{2}{*}{$\begin{array}{c}\text { Additional costs } \\
{\left[€ / \mathrm{m}^{2} \mathrm{a}\right]}\end{array}$} \\
\hline & $\begin{array}{c}\text { Monthly } \\
\text { fPE1 }\end{array}$ & $\begin{array}{c}\text { Monthly } \\
\text { fPE2 }\end{array}$ & $\begin{array}{c}\text { Annual } \\
\text { fPE1 }\end{array}$ & $\begin{array}{l}\text { Annual } \\
\text { fPE2 }\end{array}$ & $\begin{array}{l}\text { Ref } \\
\text { fPE }\end{array}$ & \\
\hline Direct electric heating w/o PV & 0.00 & 0.00 & 0.00 & 0.00 & 0.00 & 0.00 \\
\hline Direct electric heating + PV medium & 49.33 & 19.21 & 52.06 & 24.35 & 73.20 & 1.05 \\
\hline Direct electric heating + PV large & 74.80 & 33.93 & 75.54 & 35.33 & 106.21 & 7.32 \\
\hline Heat pump w/o PV & 48.54 & 25.81 & 46.65 & 21.82 & 65.60 & 3.37 \\
\hline Heat pump + PV small & 72.46 & 36.79 & 70.73 & 33.08 & 99.45 & 4.17 \\
\hline Heat pump + PV medium & 81.74 & 41.84 & 79.54 & 37.20 & 111.85 & 8.45 \\
\hline
\end{tabular}

Similar to the analysis before Figure 3-41 shows the comparison of the additional life cycle costs and the primary energy reductions of the six different energy supply concepts, including the five different primary energy calculation methods. In this figure, the household electricity is not considered in the calculations.

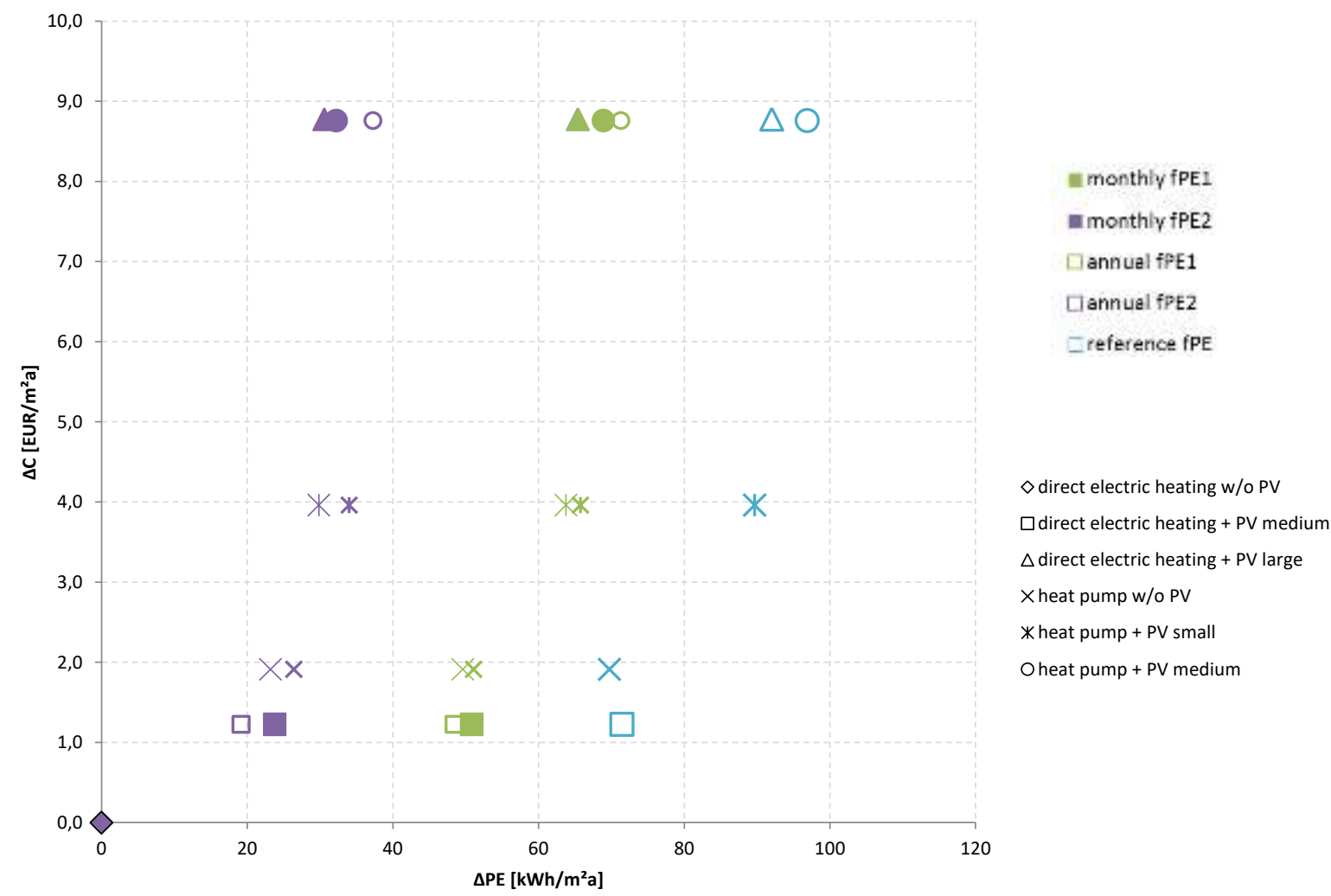

Figure 3-41: Comparison of the additional life cycle costs and the primary energy savings of the different concepts, without household electricity. The reductions are calculated based on the reference system. Additionally, the results of the different primary energy factors are also included.

Table 3-40 shows again the detailed results of each energy supply system.

Table 3-40: Additional life cycle costs and primary energy savings of the different concepts compared to the reference system, without household electricity

\begin{tabular}{|c|c|c|c|c|c|c|}
\hline \multirow[b]{2}{*}{ Energy supply system } & \multicolumn{5}{|c|}{ Primary energy reductions $\left[\mathrm{kWh} / \mathrm{m}^{2} \mathrm{a}\right]$} & \multirow[b]{2}{*}{$\begin{array}{c}\text { Additional } \\
\text { costs }\left[€ / \mathrm{m}^{2} \mathrm{a}\right]\end{array}$} \\
\hline & $\begin{array}{l}\text { Monthly } \\
\text { fPE1 }\end{array}$ & $\begin{array}{l}\text { Monthly } \\
\text { fPE2 }\end{array}$ & $\begin{array}{l}\text { Annual } \\
\text { fPE1 }\end{array}$ & $\begin{array}{l}\text { Annual } \\
\text { fPE2 }\end{array}$ & $\begin{array}{l}\text { Ref } \\
\text { fPE }\end{array}$ & \\
\hline Direct electric heating w/o PV & 0.00 & 0.00 & 0.00 & 0.00 & 0.00 & 0.00 \\
\hline Direct electric heating + PV medium & 48.39 & 19.14 & 50.81 & 23.76 & 71.45 & 1.23 \\
\hline Direct electric heating + PV large & 65.37 & 30.55 & 65.44 & 30.61 & 92.02 & 8.78 \\
\hline Heat pump w/o PV & 51.07 & 26.40 & 49.59 & 23.19 & 69.73 & 1.91 \\
\hline Heat pump + PV small & 65.74 & 34.00 & 63.76 & 29.82 & 89.66 & 3.96 \\
\hline Heat pump + PV medium & 71.30 & 37.26 & 68.89 & 32.22 & 96.87 & 8.76 \\
\hline
\end{tabular}




\title{
3.3 Variation of the envelope and HVAC quality and cost-optimality for a SFH
}

\author{
Fabian Ochs ${ }^{\mathrm{a}}$
}

aUniversity of Innsbruck, Technikerstraße 13, Innsbruck 6020, Austria

\subsubsection{Assumptions and simplifications}

A typical detached single family house (SFH) is used as a case study to investigate the cost-optimal configuration of envelope, HVAC technology and integration of renewables (PV) for different European climates. The SFH with 2 stories and $140 \mathrm{~m}^{2}$ of treated area is described in detail in IEA HPT Annex 49.
a) With and without mechanical ventilation with heat recovery (MVHR)
b) Heating and DHW preparation: Direct electric, A/W Heat Pump (A-HP), ground sourced heat pump (GW- $\mathrm{HP})$
c) With or without shower drain water recovery (SDWR)
d) With or without PV: $5 \mathrm{~kW}$ (30 $4 \mathrm{~m}^{2}$ on roof with $\left.32.5 \mathrm{~m}^{2}\right)+$ optionally 1 or $5 \mathrm{~kW}$ on south façade (with $51.7 \mathrm{~m}^{2}$ total opaque area with constant efficiency of $12.5 \%$ )

The analysis is done in 2 steps

1) Simple building, annual balance (PHPP), "EU reference" climate (Strasbourg STR) 3 Building Envelope qualities: Passive House (PH), low Energy House (LEH), Reference (Ref)

$$
\begin{aligned}
& \text { » } \mathrm{PH} \quad(\mathrm{MVHR}) \quad \mathrm{HD} 15 \mathrm{kWh} /\left(\mathrm{m}^{2} \mathrm{a}\right)+\mathrm{DHW} 15 \mathrm{kWh} /\left(\mathrm{m}^{2} \mathrm{a}\right) \\
& \text { " } P H “\left(\text { no MVHR) HD } 25 \mathrm{kWh} /\left(\mathrm{m}^{2} \mathrm{a}\right)+\mathrm{DHW} 15 \mathrm{kWh} /\left(\mathrm{m}^{2} \mathrm{a}\right)\right. \\
& \text { »LEH (no MVHR) HD } 50 \mathrm{kWh} /\left(\mathrm{m}^{2} \mathrm{a}\right)+\mathrm{DHW} 15 \mathrm{kWh} /\left(\mathrm{m}^{2} \mathrm{a}\right) \\
& \text { » REF (no MVHR) HD } 75 \mathrm{kWh} /\left(\mathrm{m}^{2} \mathrm{a}\right)+\mathrm{DHW} 15 \mathrm{kWh} /\left(\mathrm{m}^{2} \mathrm{a}\right)
\end{aligned}
$$

» $\operatorname{MVHR}\left(\eta T^{*}=0.6\right.$ remark: market available $\mathrm{MVH}$ have effectiveness ranging between 0.75 and 09 . The value of represents an effectiveness of 0.75 considering an infiltration rate corresponding to a n 50 -value of about $1 / \mathrm{h}$ )

» DE Heating (E-Boiler, E-Radiator) A/W-HP,W/W-HP

» $\mathrm{A}-\mathrm{HP} \mathrm{SPF}_{\mathrm{H}}=2.5, \mathrm{SPF}_{\mathrm{DHW}}=3.5$

» GW-HP SPFH $=3.5$, SPF $_{\text {DHW }}=2.75$

» DHW Losses: $5 \mathrm{kWh} /\left(\mathrm{m}^{2}\right.$ a) for $\mathrm{DE}, 10 \mathrm{kWh} /\left(\mathrm{m}^{2}\right.$ a) for HP

» Optional SDWR $\eta$ Teff $=0.5$ (with respect to DHW demand)

» Optional $5 \mathrm{~kW}$ PV roof $(\mathrm{R})$

» PV self -consumption $50 \%$ of DHW, Aux and Appliances

» $\quad f_{P E, e l, n o n-R E}=2.3\left(f_{P E, e l, t o t}=2.5\right)$

2) Simple building, dynamic simulation, monthly balance with different envelope qualities and in different climates

¿nvelope $\left(\mathrm{U}_{\mathrm{m}} /\left[\mathrm{W} /\left(\mathrm{m}^{2} \mathrm{~K}\right)\right]=[0.11,0.14,0.16,0.19,0.24,0.29,0.34,0.44,0.54]\right)$

» climates (Sto, Gda, Stu, Lon, Lyo, Str, IBK)

» $\operatorname{MVHR}\left(\eta T^{*}=0.6\right.$ remark: see above)

» DE heating and DHW-Boiler

» A-HP (heating, DHW, both)

» GW-HP (heating and DHW) 
» SDWR ( $\eta$ Teff $=0.45$ of useful DHW, ca. $30 \%$ of delivered DHW)

» $\quad \mathrm{PV} 5 \mathrm{~kW}$ PV roof $(\mathrm{R})+$ optionally $1 \mathrm{~kW}$ or $5 \mathrm{~kW}$ PV façade $(\mathrm{F})$

For each climate $9 \times 64=576$ dynamic building and HVAC simulations were performed and analysed.

\subsubsection{Techno-economic analysis}

The following simplified economic parameters were applied

¿ Economic Parameter (Annuity Method)

- Period of Consideration $\mathrm{N}=20$ yrs.

- Interest Rate (nominal) $i=3 \%$

Investment

- Envelope (Insulation)

$125 € / \mathrm{m}^{3}$

$\mathrm{L}=40$ yrs.

- $\quad$ Envelope (Window) $85 € / \mathrm{m}^{2}$

$\mathrm{L}=50 \mathrm{yrs}$.

- $\quad$ MVHR Invest

$3000 €$

$L=15$ yrs.

- MVHR Installation

$3000 €$

$\mathrm{L}=30 \mathrm{yrs}$.

- SDWR

$1200 €$

$L=15$. yrs.

- A-HP

$8000 €(3.5 \mathrm{~kW})$

$L=15$ yrs.

- $\mathrm{G}-\mathrm{HP}$

$+6000 €$

$\mathrm{L}=15 \mathrm{yrs}$. (ground source $30 \mathrm{yrs}$.)

- $\quad \mathrm{PV}(\mathrm{R})$

$1600 € / \mathrm{kW}_{\mathrm{p}}$

$L=15$ yrs.

- $\quad \mathrm{PV}(\mathrm{F})$

$3000 € / \mathrm{kW}_{\mathrm{p}}$

$\mathrm{L}=15 \mathrm{yrs}$.

» Operation

- $\quad$ Electricity

$\mathrm{Cel}_{\mathrm{el}}=0.25 € / \mathrm{kWh}$

- Maintenance/Repair

$5 \%$

\subsubsection{Solar potential (PV)}

The annual specific PV AC yield is shown in 
Table 3-41 for the SFH with the treated area of $A_{T}=140 \mathrm{~m}^{2}$ for three different cases:

- $\quad 5 \mathrm{~kW}_{\mathrm{p}}$ at $45^{\circ}$ slope towards south

- $\quad 5 \mathrm{~kW}_{\mathrm{p}}$ at $45^{\circ}$ slope towards south $+1 \mathrm{~kW}$ at south façade and

- $5 \mathrm{~kW}_{\mathrm{p}}$ at $45^{\circ}$ slope towards south $+5 \mathrm{~kW}_{\mathrm{p}}$ at south façade 
Table 3-41: Annual specific PV yield $(A C)$ in $\mathrm{kWh} /\left(\mathrm{m}^{2}\right.$ a) for the SFH $\left(A_{T}=140 \mathrm{~m}^{2}\right)\left(5 \mathrm{~kW}_{\mathrm{p}}\right.$ at $45^{\circ}$ slope towards south, 5 $\mathrm{kW}_{\mathrm{p}}$ at $45^{\circ}$ slope towards south $+1 \mathrm{~kW}_{\mathrm{p}}$ at south façade and $5 \mathrm{~kW}_{\mathrm{p}}$ at $45^{\circ}$ slope towards south, $+5 \mathrm{~kW}_{\mathrm{p}}$ at south façade) for several climates in Europe

\begin{tabular}{|c|c|c|c|c|c|c|}
\hline $\mathrm{Nr}$ & Climate & $\begin{array}{c}\text { Roof }\left(45^{\circ}\right. \\
\text { South) PV } \\
\text { yield / } \\
{\left[\mathrm{kWh} /\left(\mathrm{m}^{2} \mathrm{a}\right)\right]}\end{array}$ & $\begin{array}{c}\text { Façade (south) } \\
\text { PV yield / } \\
{\left[\mathrm{kWh} /\left(\mathrm{m}^{2} \mathrm{a}\right)\right]}\end{array}$ & $\begin{array}{c}5 \mathrm{kWp} \text { Roof PV } \\
\text { yield / } \\
{\left[\mathrm{kWh} /\left(\mathrm{m}^{2}{ }_{\mathrm{AT}} \mathrm{a}\right)\right]}\end{array}$ & $\begin{array}{c}5 \text { kWp Roof + } \\
1 \text { kWp Façade } \\
\text { (south) PV } \\
\text { yield / } \\
{\left[\mathrm{kWh} /\left(\mathrm{m}^{2}{ }_{\mathrm{AT}} \mathrm{a}\right)\right]}\end{array}$ & $\begin{array}{c}5 \mathrm{kWp} \text { Roof + } \\
5 \mathrm{kWp} \text { Façade } \\
\text { (south) PV } \\
\text { yield / } \\
{\left[\mathrm{kWh} /\left(\mathrm{m}^{2}{ }_{\mathrm{AT}} \mathrm{a}\right)\right]} \\
\end{array}$ \\
\hline 1 & Sto & 162.1 & 111.9 & 35.2 & 40.0 & 59.5 \\
\hline 2 & Gda & 168.1 & 110.5 & 36.5 & 41.2 & 59.5 \\
\hline 3 & Stu & 173.2 & 112.4 & 37.6 & 42.4 & 62.0 \\
\hline 4 & Lon & 160.7 & 105.0 & 34.9 & 39.4 & 57.7 \\
\hline 5 & IBK & 185.6 & 122.5 & 40.3 & 45.6 & 66.9 \\
\hline 6 & Str & 166.7 & 105.9 & 36.2 & 40.7 & 59.2 \\
\hline 7 & Lyo & 196.6 & 124.8 & 42.7 & 48.0 & 69.8 \\
\hline 8 & Mad & 251.9 & 124.8 & 54.7 & 61.5 & 89.0 \\
\hline 9 & Rom & 251.4 & 158.9 & 54.6 & 61.4 & 89.1 \\
\hline
\end{tabular}

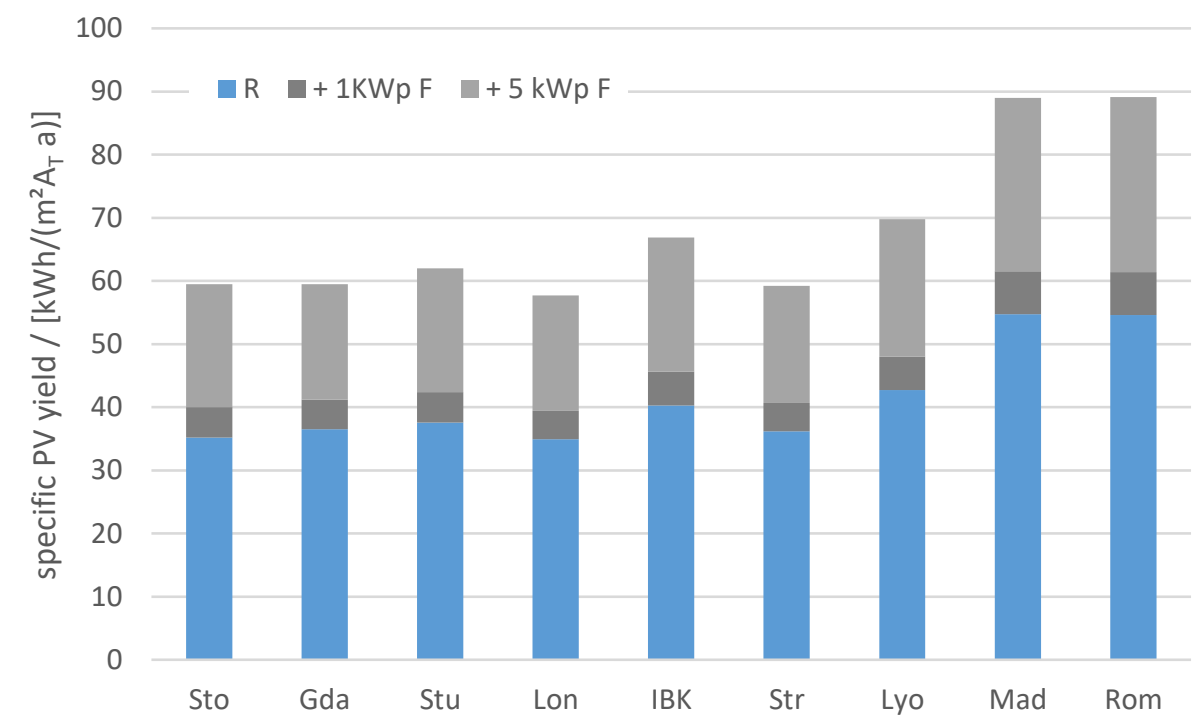

Figure 3-42: specific annual PV yield for a selection of European climates with $5 \mathrm{~kW}_{\mathrm{P}}$ on $45^{\circ}$ roof (R), with additional $1 \mathrm{~kW}_{\mathrm{p}}$ or $5 \mathrm{~kW}_{\mathrm{p}}$ on south façade (F)

The total annual PV yield can be significantly increased by using part the south façade in addition to the $5 \mathrm{kWp}$ on the roof. As can be seen in Figure 3-43 and Figure 3-44, the strong seasonal variation of the PV yield can be partly equalized in the southern warm and sunny climates while in particular in Stockholm the strong seasonal contribution of $\mathrm{PV}$ remains also when using $\mathrm{PV}$ in the façade (remark possible shading neighbour buildings or trees is not considered). 


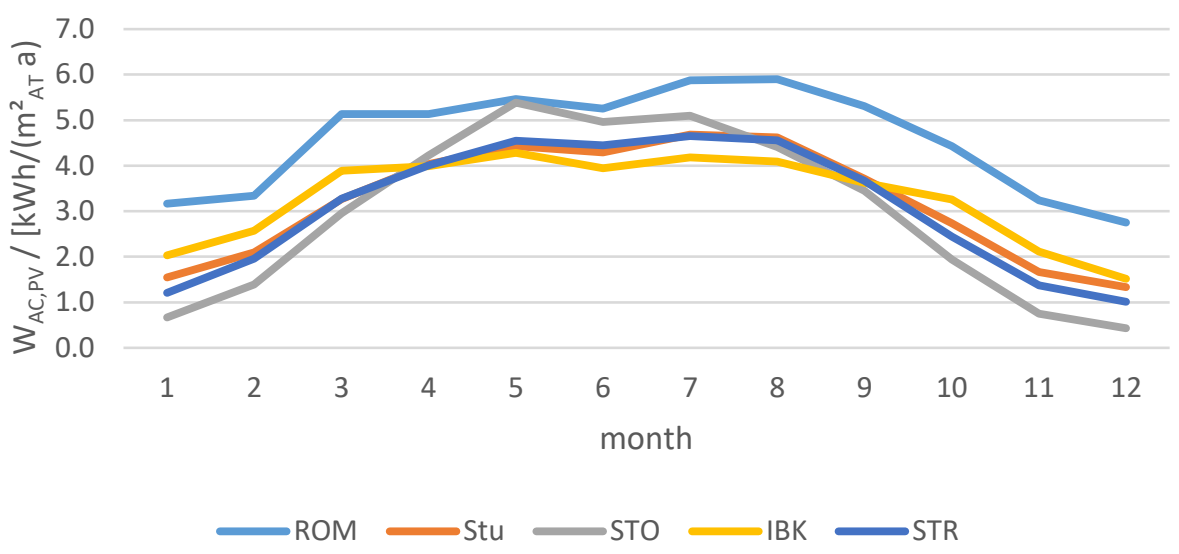

Figure 3-43: Monthly PV yield per $\mathrm{m}^{2}$ treated area $\left(140 \mathrm{~m}^{2}\right)$ for the case of $5 \mathrm{~kW}_{\text {peak }}$ on roof $\left(45^{\circ}\right.$, south) for Rome (It), Stuttgart (D), Stockholm (S), Innsbruck (At), Strasbourg (F)

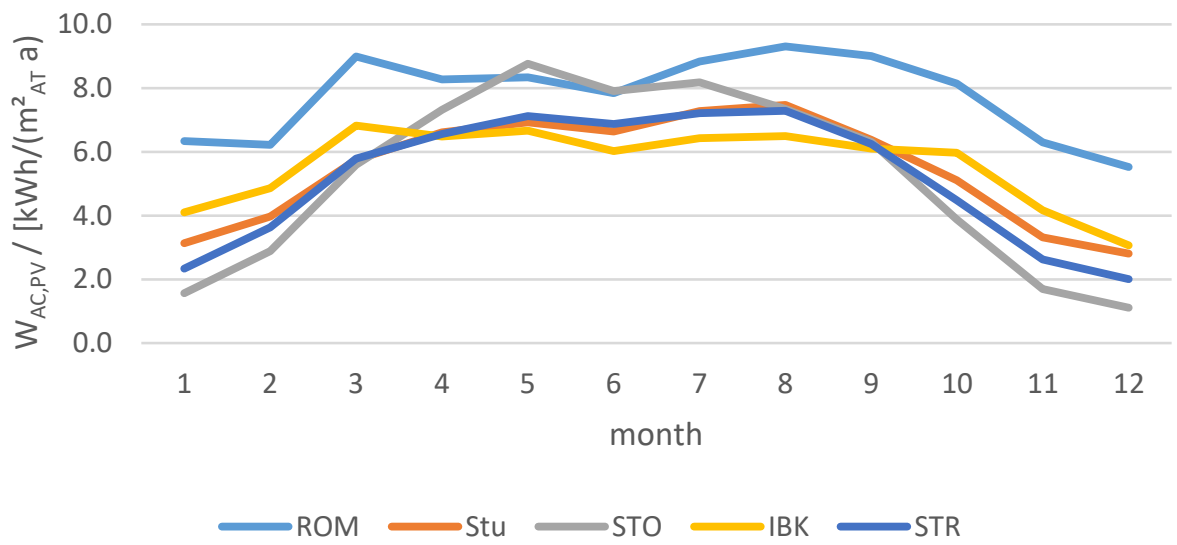

Figure 3-44: Monthly PV yield per $\mathrm{m}^{2}$ treated area $\left(140 \mathrm{~m}^{2}\right)$ for the case of $5 \mathrm{~kW}_{\text {peak }}$ on roof $\left(45^{\circ}\right.$, south) and $5 \mathrm{~kW}_{\text {peak }}$ on façade (south) for Rome (It), Stuttgart (D), Stockholm (S), Innsbruck (At), Strasbourg (F)

\subsubsection{Results}

\subsubsection{Reference climate (Strasbourg, PHPP)}

For the "Reference Climate" (Strasbourg), the monthly thermal energy and the monthly electric energy balance are shown for the SFH in Passive House Quality with A-HP and PV in Figure 3-45 and Figure 3-46, respectively. Figure 3-47 shows the monthly electric energy balance including PV production for or the case of the Passive House $(\mathrm{PH}$, $\mathrm{HD}=15 \mathrm{kWh} /(\mathrm{m} 2 \mathrm{a})$ ) and Figure 3-48 shows the corresponding monthly electric grid energy determined with different energy balance boundaries and time steps. 


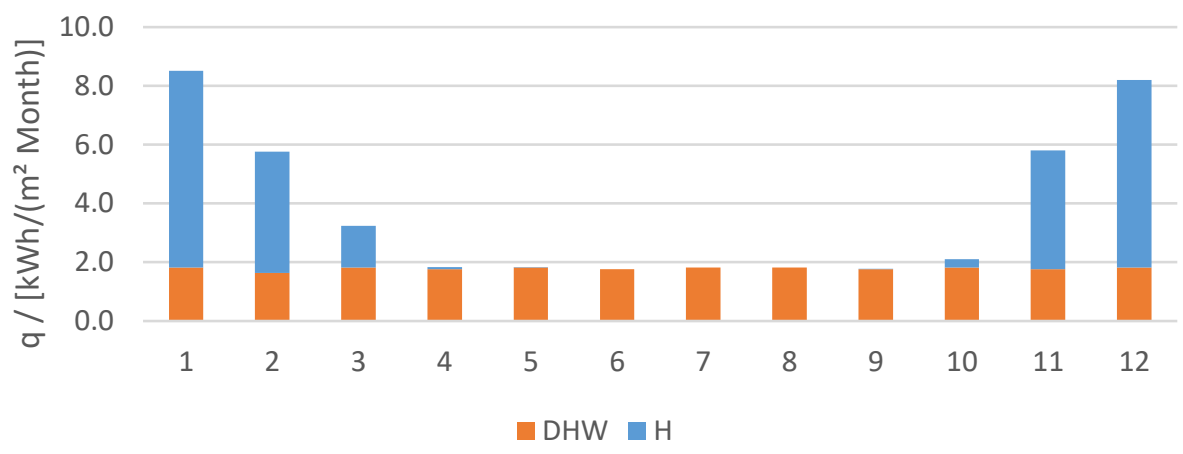

Figure 3-45: Monthly thermal energy balance for heating (HD = $23 \mathrm{kWh} / \mathrm{m}^{2}$ a)) and DHW $\left(21.4 \mathrm{kWh} / \mathrm{m}^{2}\right.$ a) including storage and distribution losses) climate Strasbourg

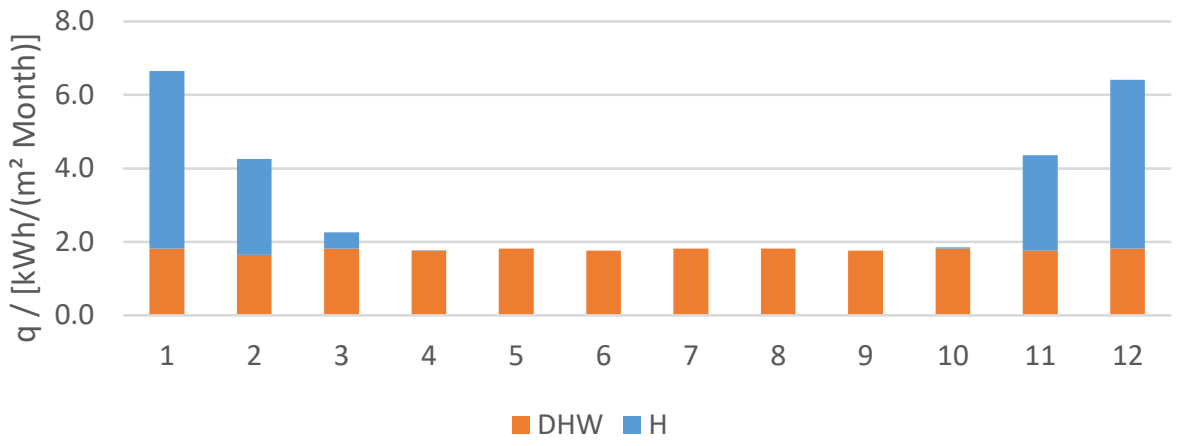

Figure 3-46: Monthly thermal energy balance for heating (HD = $15 \mathrm{kWh} / \mathrm{m}^{2}$ a)) and DHW $\left(21.4 \mathrm{kWh} / \mathrm{m}^{2}\right.$ a) including storage and distribution losses) climate Strasbourg - Passive House

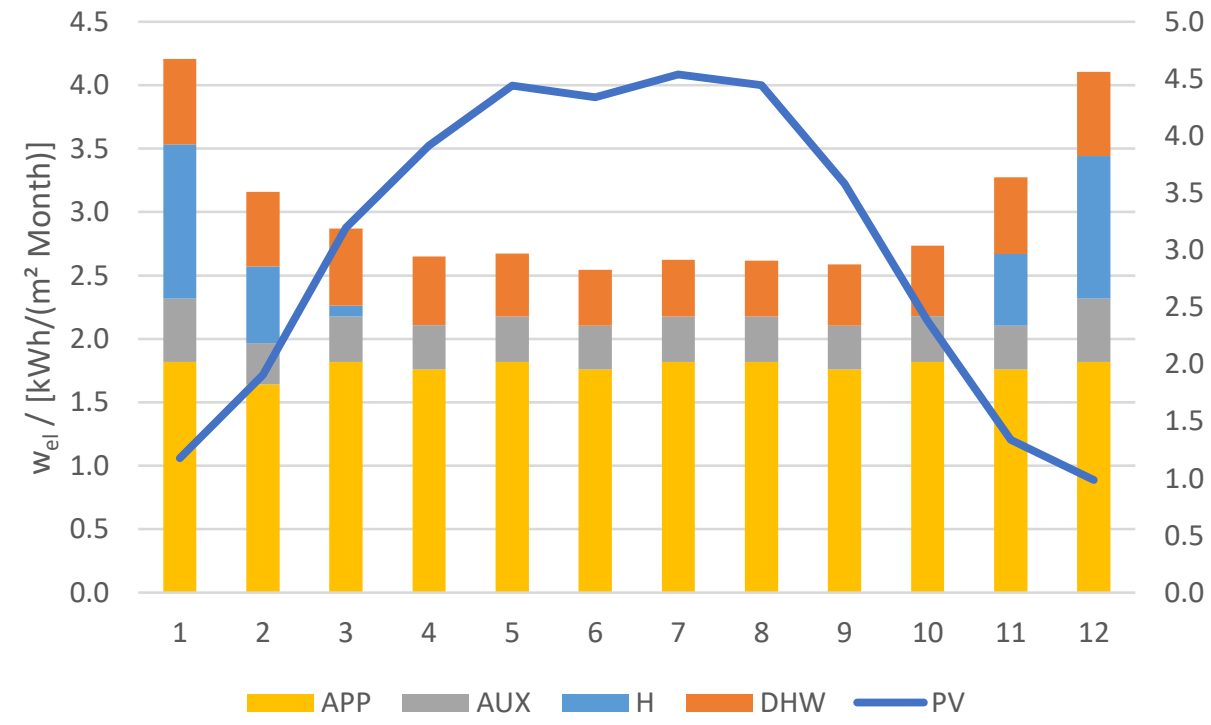

Figure 3-47: Monthly electric energy balance including PV production for or the $\mathrm{PH}(\mathrm{HD}=15 \mathrm{kWh} /(\mathrm{m} 2 \mathrm{a}))$ 


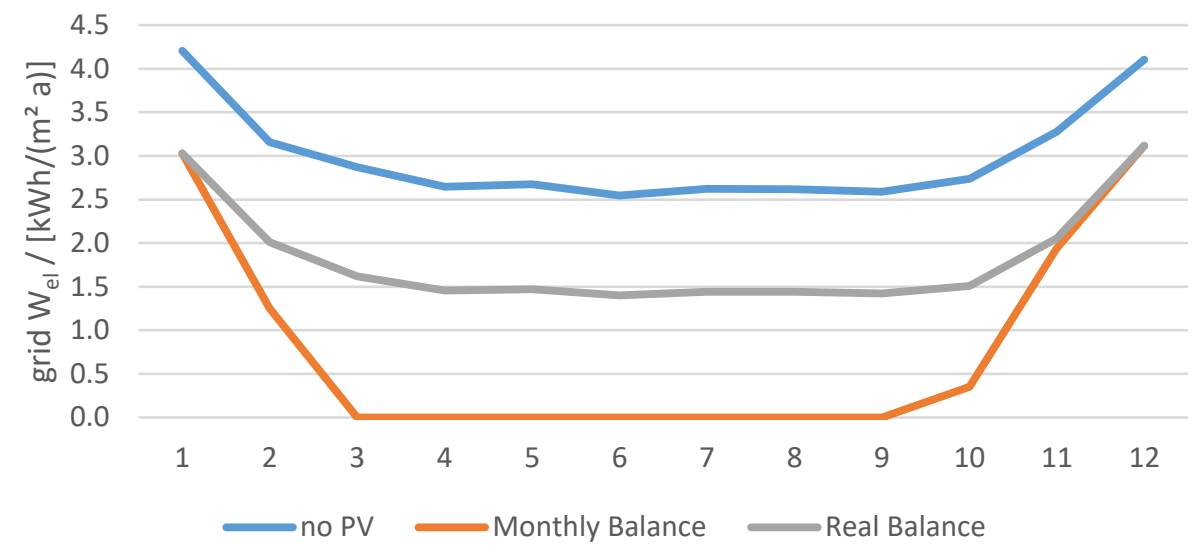

Figure 3-48: Monthly electric grid energy (for PH in Strasbourg) determined with different energy balance boundaries and time steps

With a net balance the $\mathrm{PH}$ in Strasbourg is a Net-Zero Energy Building (NZEB), with a real balance, it can be seen that the grid electricity is about $60 \%$ of the case without PV.

Table 3-42: Annual electric energy balance in $\mathrm{kWh} /\left(\mathrm{m}^{2} \mathrm{a}\right)$

\begin{tabular}{l|cc}
\multicolumn{1}{c}{} & $\mathrm{HD}=23 \mathrm{kWh} /\left(\mathrm{m}^{2} \mathrm{a}\right)$ & $\mathrm{HD}=15 \mathrm{kWh} /\left(\mathrm{m}^{2} \mathrm{a}\right)$ \\
\hline No PV & 38.5 & 36.0 \\
Net & 2.3 & -0.2 \\
Monthly Balance & 11.9 & 9.7 \\
Real Balance & 24.4 & 22.0 \\
\hline
\end{tabular}

It can be clearly seen that a net or monthly energy balance overestimates the PV own consumption. A simplified approach I used here on monthly basis. It is assumed that there is no PV contribution to heating and a max. of 45 $\%$ of DHW, aux and appliances can be covered by PV (without additional storage and dedicated control strategies).

$$
P V_{\text {own }, i}=\min \left(P V_{i} ; 0.45 \cdot\left(A P P_{i}+A U X_{i}+D H W_{i}\right)\right.
$$

This results in a SCF of $38.8 \%$ and a LCF of $39.1 \%$.

\section{PE evaluation}

In addition to the electric energy balance different methods/scenarios for the calculation of the primary energy can be applied (see also DC.1). The standard approach is using a constant (annual) primary conversion factor. In order to account for the use of the electricity over the course of the year thus for the variable electric energy mix, two different scenarios are applied referred to as scenario 10-10-10 and 10-30-30 (see DC.1 for a description).

Table 3-43 reports the annual specific non-RE PE demand calculated for the case without PV (no PV), the case with net PV balance (NET), with monthly balance (Month) and for the realistic own consumption (Real). For the latter in addition to the constant $\mathrm{PE}$ conversion factor of $\mathrm{f}_{\mathrm{PEnon}-\mathrm{RE}}=2.3$ the two scenarios with monthly PE conversion factors are applied. The choice of the balance and of the scenario does significantly influence the potential savings of applying PV. The range is from $100 \%$ savings (net balance) down to $13 \%$.

Table 3-44 reports for the three different approaches for the primary energy conversion factor the potential savings when improving the envelope quality from $\mathrm{HD}=23 \mathrm{kWh} /\left(\mathrm{m}^{2}\right.$ a) to $\mathrm{PH}$ quality (i.e. $\mathrm{HD}=15 \mathrm{kWh} /\left(\mathrm{m}^{2} \mathrm{a}\right)$. For a constant $\mathrm{PE}$ factor the savings are only $6 \%$ but increase if the scenario 10-30-30 with more seasonal variation of the PE conversion factor is used (as would be applicable in a future energy system with higher share of PV and wind). 
Table 3-43: Annual specific non-RE PE demand calculated for the two building standards (PH with $\mathrm{HD}=15 \mathrm{kWh} /\left(\mathrm{m}^{2}\right.$ a) and $\mathrm{HD}=23 \mathrm{kWh} /\left(\mathrm{m}^{2} \mathrm{a}\right)$ ) the case without PV (no PV), the case with net PV balance (NET), with monthly balance (Month) and for the realistic own consumption (Real); constant PE conversion factor of $f_{P E n o n-R E}=2.3$ and the two scenarios "10-10-10" and "10-30-30"

\begin{tabular}{|c|c|c|c|c|c|c|}
\hline & \multicolumn{3}{|c|}{$\mathrm{HD}=23 \mathrm{kWh} /\left(\mathrm{m}^{2} \mathrm{a}\right)$} & \multicolumn{3}{|c|}{$\mathrm{HD}=15 \mathrm{kWh} /\left(\mathrm{m}^{2} \mathrm{a}\right)$} \\
\hline & $\begin{array}{c}\mathrm{PE} / \\
{\left[\mathrm{kWh} /\left(\mathrm{m}^{2} \mathrm{a}\right)\right]}\end{array}$ & $\begin{array}{c}\Delta P E / \\
{\left[k W h /\left(m^{2} a\right)\right]}\end{array}$ & $\begin{array}{c}\Delta \mathrm{PE} / \mathrm{PE} / \\
{[-]}\end{array}$ & $\begin{array}{c}\mathrm{PE} / \\
{\left[\mathrm{kWh} /\left(\mathrm{m}^{2} \mathrm{a}\right)\right]}\end{array}$ & $\begin{array}{c}\Delta P E / \\
{\left[k W h /\left(m^{2} a\right)\right]}\end{array}$ & $\begin{array}{c}\Delta \mathrm{PE} / \mathrm{PE} / \\
{[-]}\end{array}$ \\
\hline No $P V f_{p e, n . R E}=2.3$ & 88.6 & - & - & 82.9 & - & - \\
\hline NET $f_{p e, n . R E}=2.3$ & 5.3 & 83.4 & 0.94 & -0.5 & 82.9 & 1.00 \\
\hline Month $f_{\text {pe,n.RE }}=2.3$ & 27.3 & 61.3 & 0.69 & 22.3 & 60.6 & 0.73 \\
\hline Real $f_{p e, n . R E}=2.3$ & 56.2 & 32.5 & 0.37 & 50.5 & 32.4 & 0.39 \\
\hline Real 10-10-10 & 42.5 & 23.1 & 0.35 & 37.7 & 23.1 & 0.28 \\
\hline Real 10-30-30 & 23.6 & 10.7 & 0.31 & 20.2 & 10.7 & 0.13 \\
\hline
\end{tabular}

Table 3-44: non-RE PE savings for the three different PE scenarios for an improvement of the building envelope from $\mathrm{HD}=23 \mathrm{kWh} /\left(\mathrm{m}^{2} \mathrm{a}\right)$ to $\mathrm{HD}=15 \mathrm{kWh} /\left(\mathrm{m}^{2} \mathrm{a}\right)$

\begin{tabular}{l|cc} 
& $\Delta \mathrm{PE} /$ & $\Delta \mathrm{PE} / \mathrm{PE} /$ \\
& {$\left[\mathrm{kWh} /\left(\mathrm{m}^{2} \mathrm{a}\right)\right]$} & {$[-]$} \\
\hline $\mathrm{f}_{\mathrm{pe}, \mathrm{n} \cdot \mathrm{RE}}=2.3$ & 5.7 & .06 \\
$10-10-10$ & 4.9 & .07 \\
$10-30-30$ & 3.5 & .10 \\
\hline
\end{tabular}

\section{Techno-economic analysis}

In the following all results apply for a constant primary energy factor of $f_{P E, n o n-R E}=2.3$. For the "Reference Climate" (Strasbourg), the capitalized life cycle costs (invest + maintenance + operation) are plotted vs. the non-RE primary energy (PE) in Figure 3-49. Figure 3-50 shows the additional capitalized life cycle costs (invest + maintenance + operation) $\Delta C$ vs. the non-RE primary energy savings $(\triangle P E)$ with respect to the reference (REF, $D E$ heating). The additional capitalized life cycle costs per saved kWh of non-RE PE $\Delta c / \Delta P E$ as a function of the non-RE primary energy savings $(\triangle P E)$ are displayed in Figure 3-51. In Figure 3-52, Figure 3-53 and Figure 3-54 the instead of the life cycle costs, the investment costs are shown. 


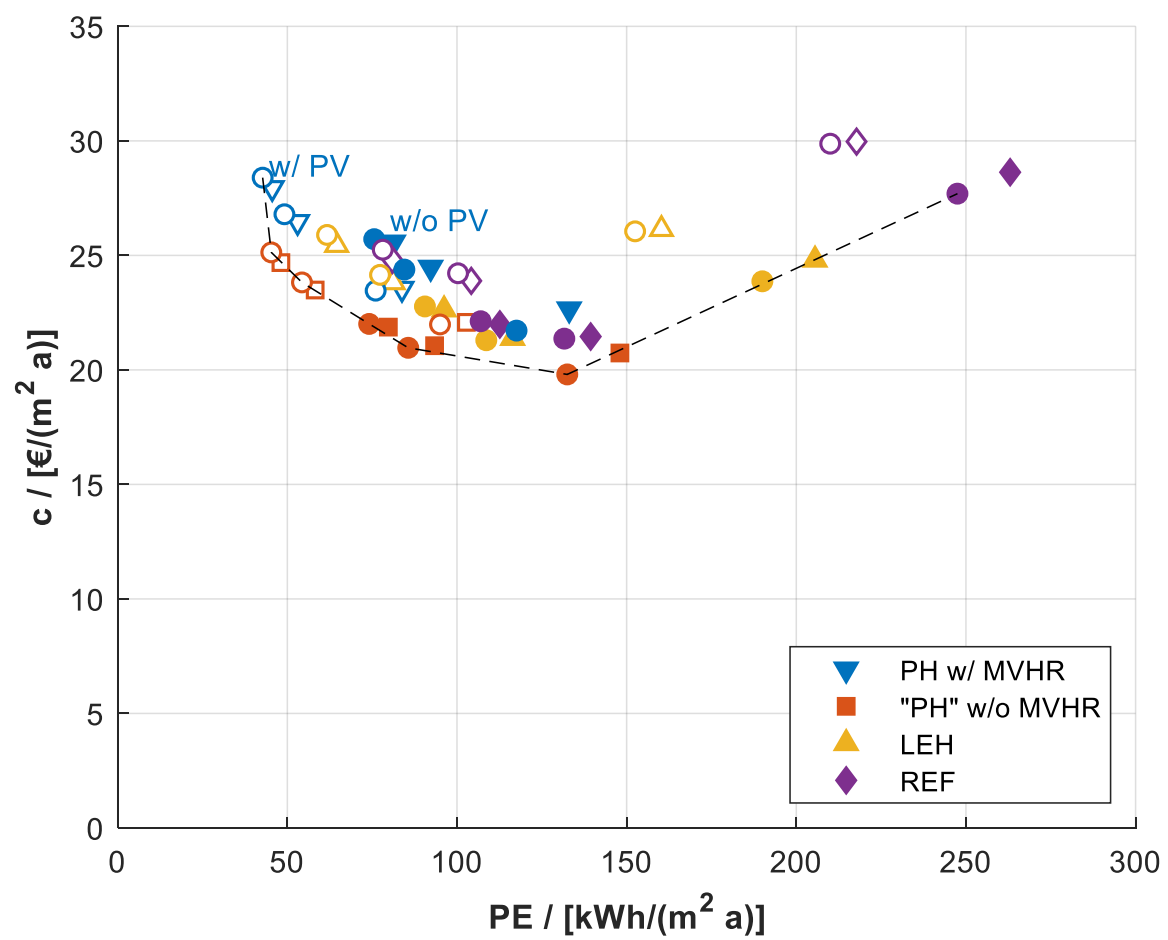

Figure 3-49: Capitalized life cycle costs (invest + maintenance + operation) vs. non-RE primary energy (PE); filled Marker without (w/o) PV, empty Marker with (w/) PV, circles show cases with shower drain water recovery, the dashed line indicates the minimum cost per PE

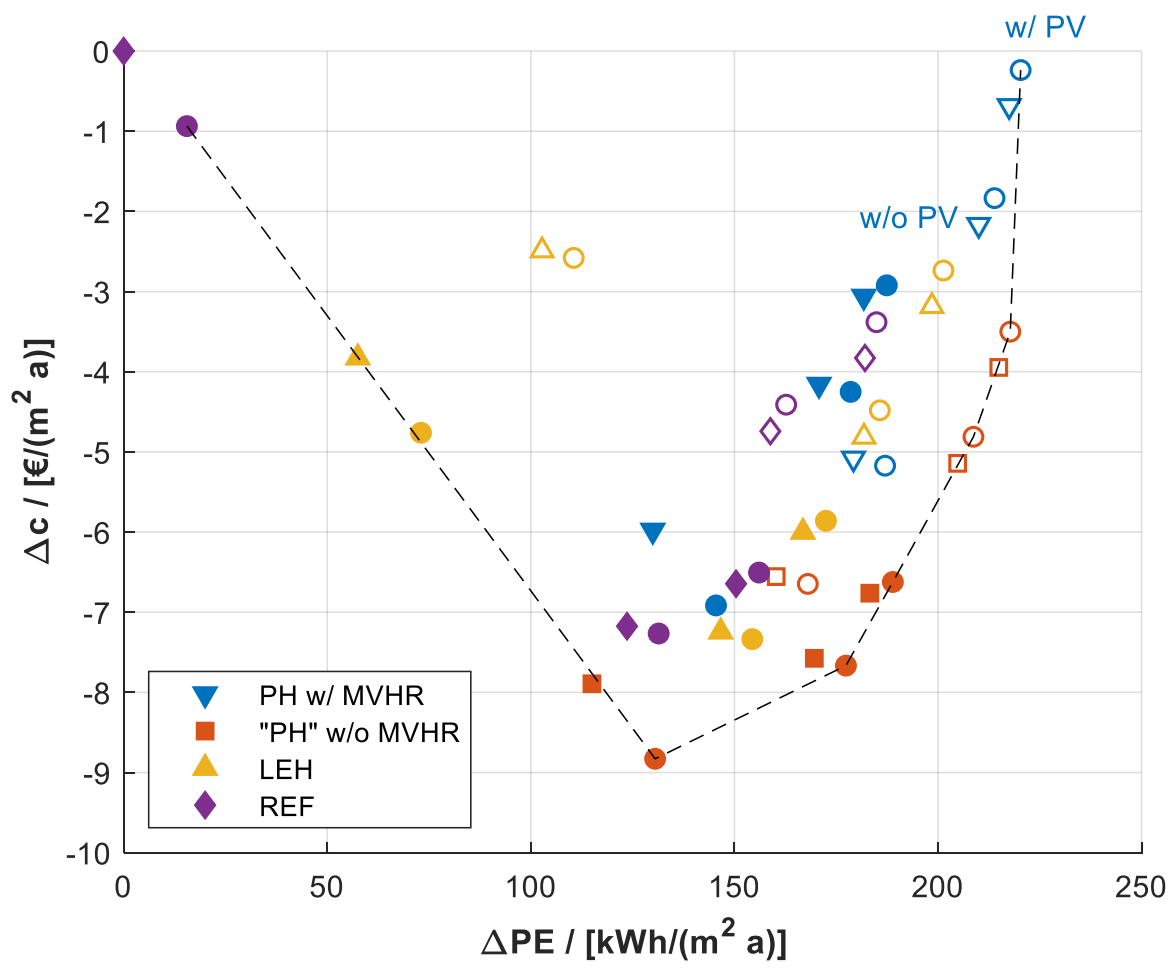

Figure 3-50: Additional capitalized life cycle costs (invest + maintenance + operation) $\Delta \mathrm{c}$ vs. non-RE primary energy savings $(\triangle \mathrm{PE})$ with respect to the reference (REF, DE heating); filled Marker without (w/o) PV, empty Marker with (w/)

PV, circles show cases with shower drain water recovery, the dashed line indicates the minimum cost per PE 


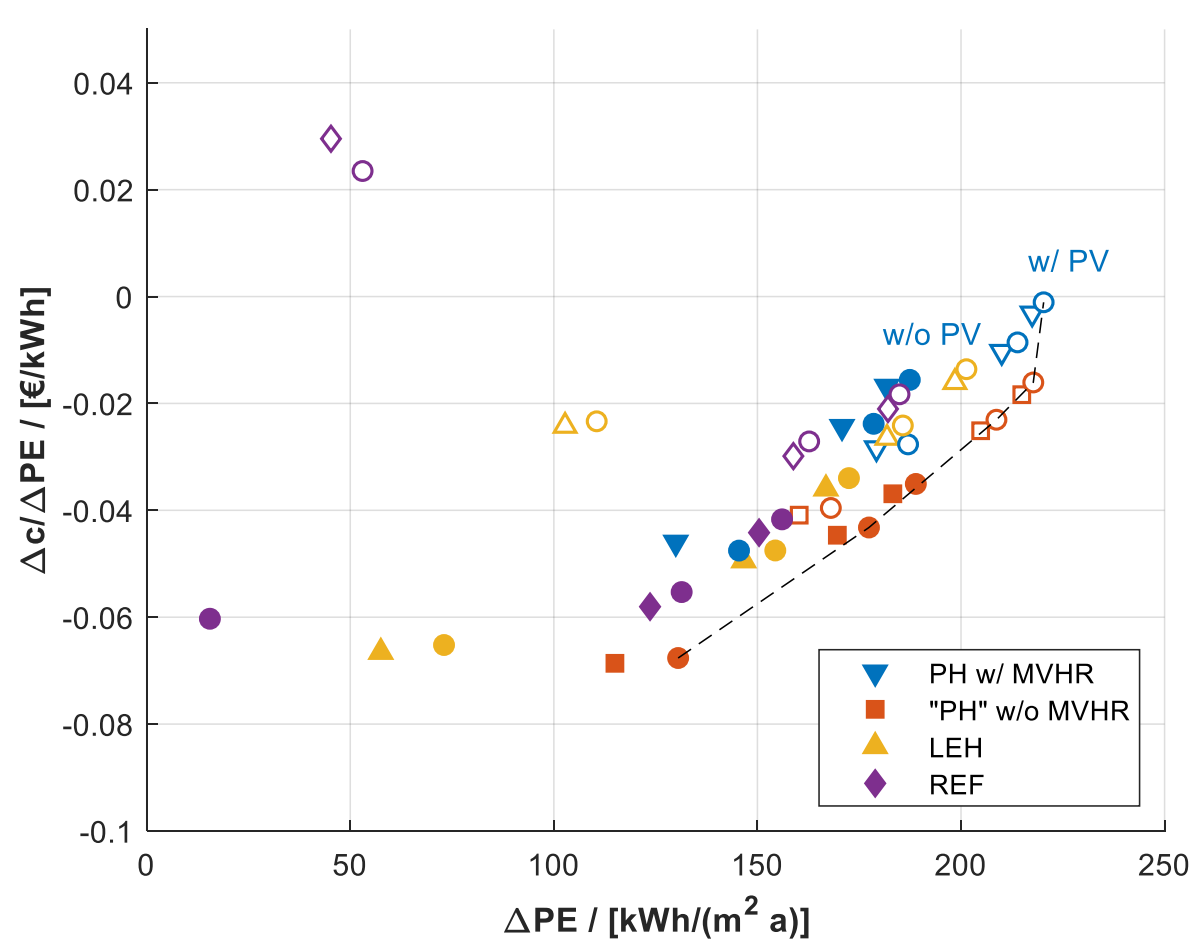

Figure 3-51: Additional capitalized life cycle costs per saved kWh of non-RE PE $\Delta \mathrm{c} / \Delta \mathrm{PE}$ vs. non-RE primary energy savings ( $\triangle \mathrm{PE}$ ); filled Marker without (w/o) PV, empty Marker with (w/) PV, circles show cases with shower drain water recovery, the dashed line indicates the minimum cost per PE

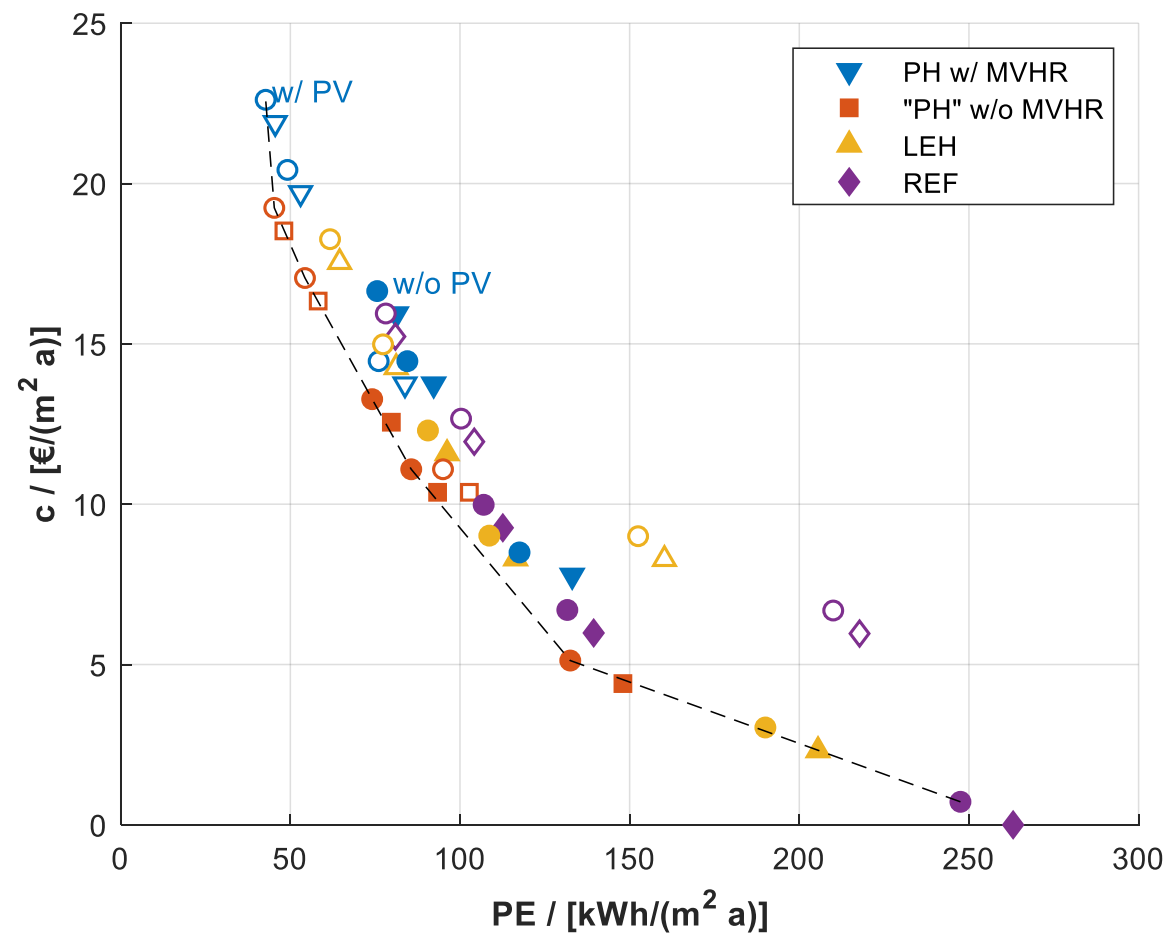

Figure 3-52: Capitalized investment costs vs. non-RE primary energy (PE); filled Marker without (w/o) PV, empty Marker with (w/) PV, circles show cases with shower drain water recovery, the dashed line indicates the minimum cost per PE 


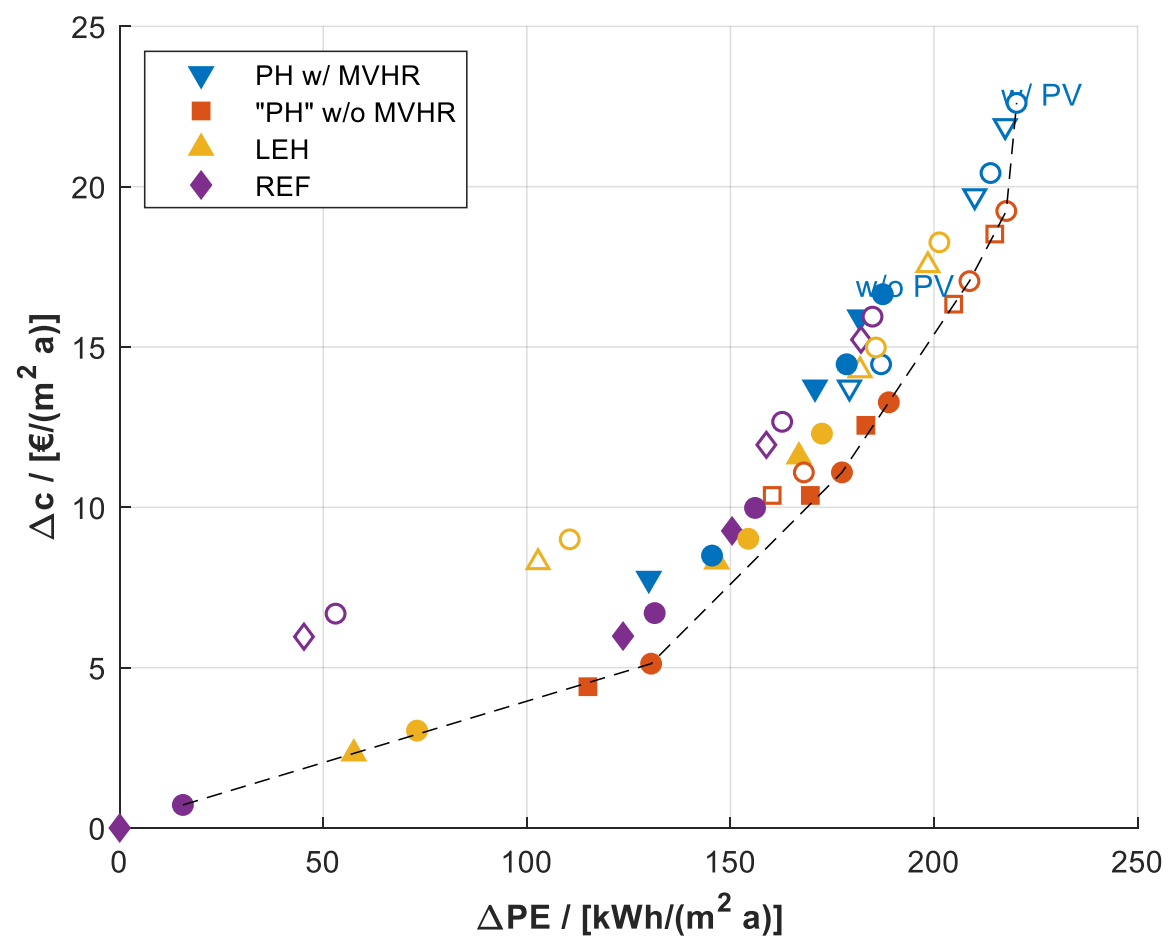

Figure 3-53: Additional capitalized investment costs $\Delta \mathrm{C}$ vs. non-RE primary energy savings ( $\triangle \mathrm{PE}$ ) with respect to the reference (REF, DE heating); filled Marker without (w/o) PV, empty Marker with (w/) PV, circles show cases with shower drain water recovery, the dashed line indicates the minimum cost per PE

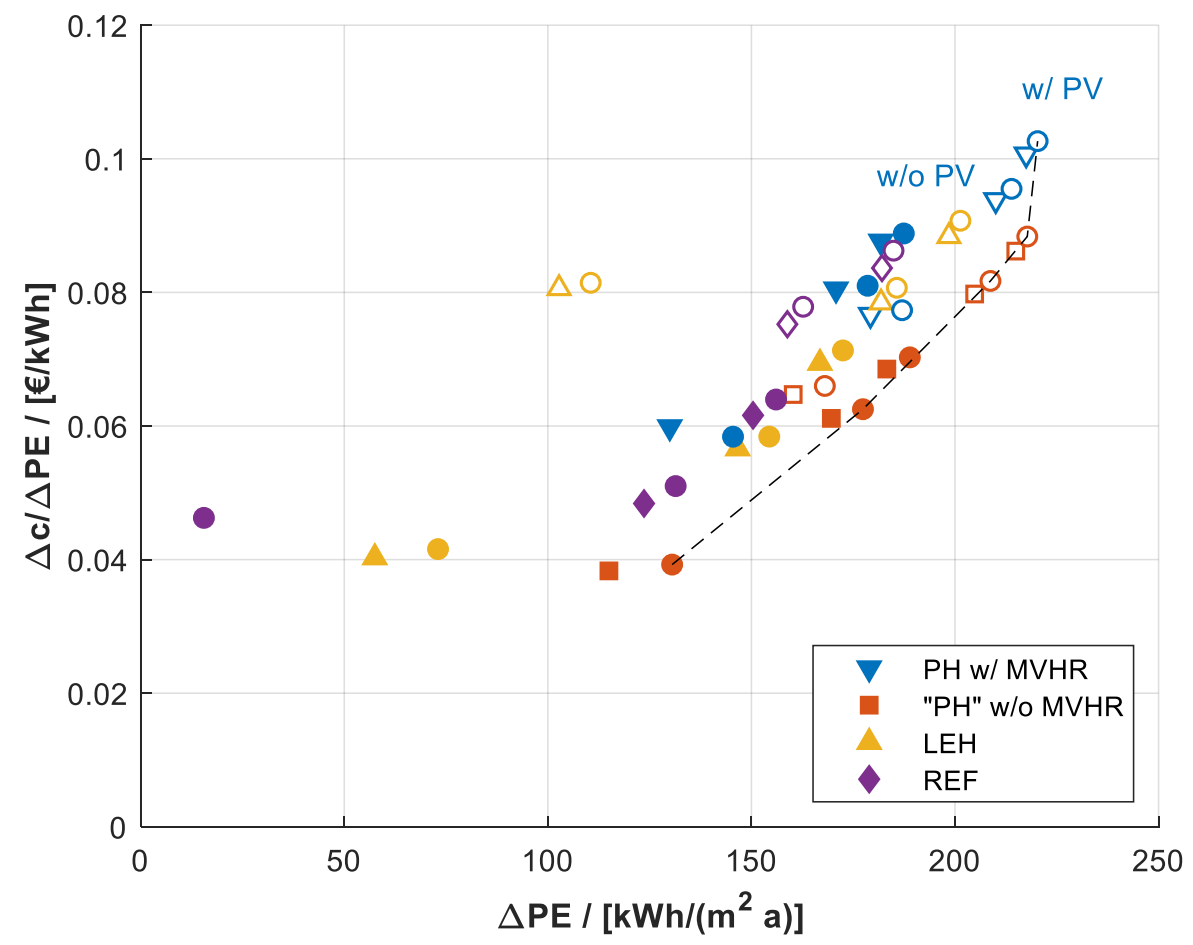

Figure 3-54: Additional capitalized investment per saved kWh of non-RE PE $\Delta \mathrm{c} / \Delta \mathrm{PE}$ vs. non-RE primary energy savings $(\Delta \mathrm{PE})$; filled Marker without (w/o) PV, empty Marker with (w/) PV, circles show cases with shower drain water recovery, the dashed line indicates the minimum cost per PE 
For the considered cases, the economic optimum (based on LCC) is at around $130 \mathrm{kWh} /\left(\mathrm{m}^{2} \mathrm{a}\right)$ at total capitalized costs of $20 € /\left(\mathrm{m}^{2} \mathrm{a}\right)$. The cost optimum is the Passive House envelope without MVHR, with DE heating and SDWR. With little extra costs by using a heat pump the primary energy could be significantly reduced to $75 \mathrm{kWh} /\left(\mathrm{m}^{2} \mathrm{a}\right)$. In case of an air-HP SDWR is again a good option from the economic point of view. When using GW-HP instead of air-HP even further savings can be obtained, while the benefit of SDWR reduces but also lays on the Pareto front. With DE heating and PV, similar PE savings could be achieved then with HP without PV, but the LCC are higher. With HP in combination with PV, the PE can be reduced to around $50 \mathrm{kWh} /\left(\mathrm{m}^{2}\right.$ a). All measures together allow to reduce $\mathrm{PE}$ to around $45 \mathrm{kWh} /\left(\mathrm{m}^{2} \mathrm{a}\right)$. Lower $\mathrm{PE}$ values are not possible without storage (or a net energy balance, see also below). The reduction from around $50 \mathrm{kWh} /\left(\mathrm{m}^{2} \mathrm{a}\right)$ to $45 \mathrm{kWh} /\left(\mathrm{m}^{2} \mathrm{a}\right)$ is associated with a high increase of LCC.

\subsubsection{Simulation results (Strasbourg)}

\section{Example - Daily Energy Balance}

The daily electric energy balance for the single-family house in PH standard with air-HP and PV (roof) is shown in Figure 3-55. The Daily electric energy, total consumption, PV generation and resulting grid load is shown in Figure 3-56. It is remarkable that even for a very good envelope quality, with MVHR and an air-HP, PV cannot significantly contribute to the electric energy demand in winter.

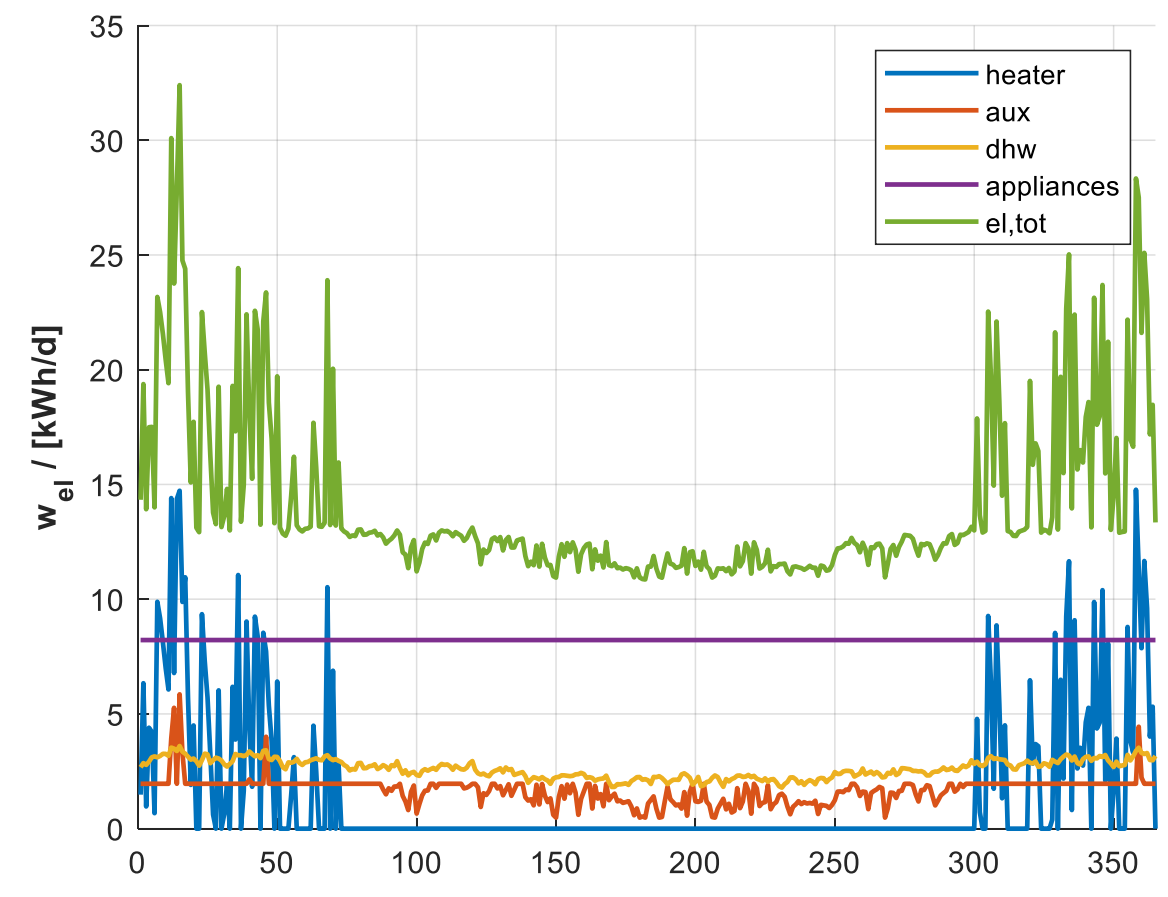

Figure 3-55: Daily electric energy balance for high performing and low performing building with and without PV (roof), remark: appliances are assumed to be constant throughout the year for sake of simplicity 


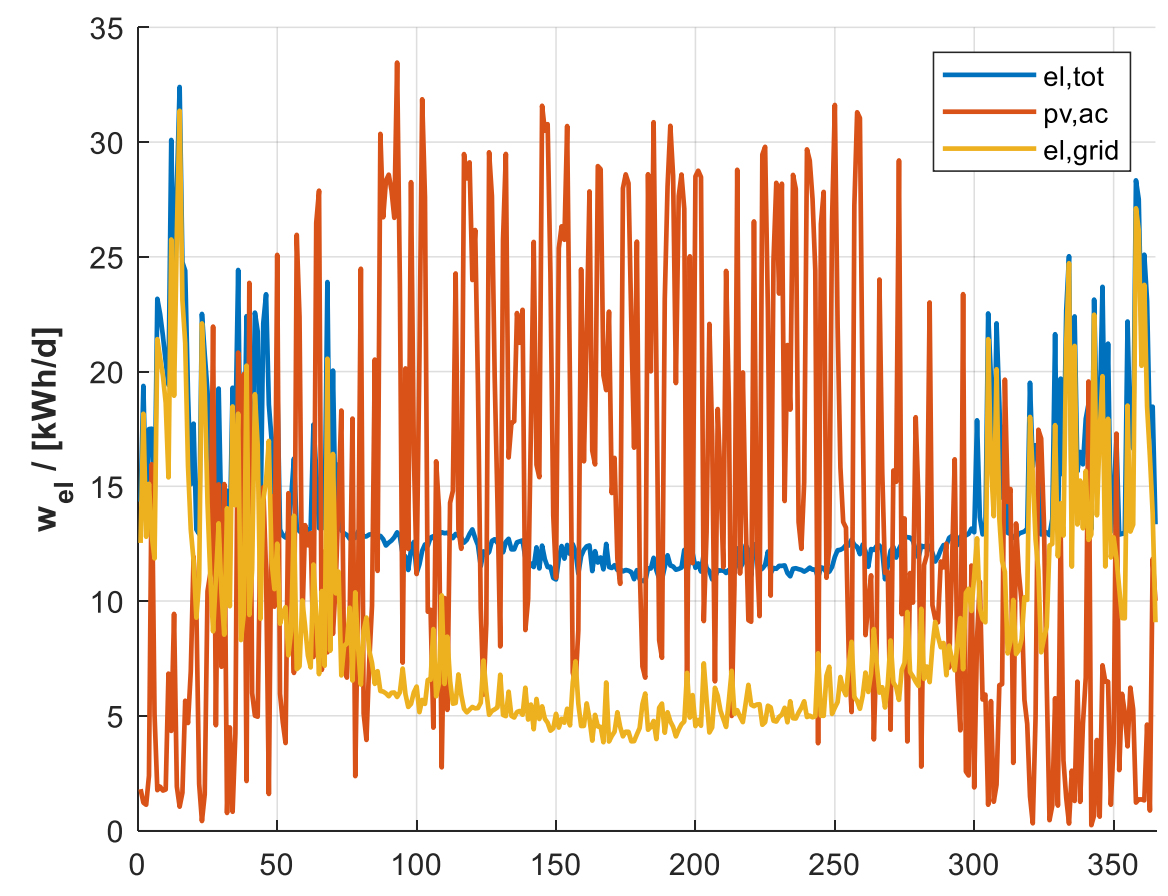

Figure 3-56: Daily electric energy, total consumption, PV generation and resulting grid load

\section{Techno-economic analysis for the climate of Strasbourg}

The results of 576 dynamic building and HVAC simulations are shown in the following figures for the climate of Strasbourg. The simulation results are comparable with the results of the simplified calculations (previous section), but more cases are investigated. The economic optimum is at approx. $94 \mathrm{kWh} /\left(\mathrm{m}^{2} \mathrm{a}\right)$ with LCC of ca. $18 € /\left(\mathrm{m}^{2} \mathrm{a}\right)$. For Strasbourg - under the given BC - the cost- optimal solution is with little extra costs $\left(20 € / \mathrm{m}^{2}\right.$ a) instead of 18 $€ /\left(\mathrm{m}^{2}\right.$ a) PE can be reduced to $75 \mathrm{kWh} /\left(\mathrm{m}^{2}\right.$ a) and for $22 € /\left(\mathrm{m}^{2}\right.$ a) even to $50 \mathrm{kWh} /\left(\mathrm{m}^{2} \mathrm{a}\right)$.

Figure 3-57 reveals that shower drain water recovery reduces the PE slightly (more obviously in case of DE than in case of HP) and is also economic in some cases. For lowest PE (below $50 \mathrm{kWh}\left(\mathrm{m}^{2}\right.$ a)) SDWR is required. The influence of MVHR on PE and LCC is shown in Figure 3-58. In most cases MHVR contributes significantly to PE reduction, however it is not economic. Only for very low PE demands (below $50 \mathrm{kWh} /\left(\mathrm{m}^{2}\right.$ a) some cases with $\mathrm{MVHR}$ are on the Pareto Front. It is important to remark that MVHR is strongly recommended in order to obtain high indoor air quality and good level of indoor air quality.

Figure 3-59 shows all 576 cases and distinguishes between different options of PV (i.e. without PV, $5 \mathrm{~kW}$ on roof, $5 \mathrm{~kW}_{\mathrm{p}}$ on roof + small façade system $\left(1 \mathrm{~kW}_{\mathrm{p}}\right)$ and $5 \mathrm{~kW}_{\mathrm{p}}$ on roof + large façade system $\left(5 \mathrm{~kW}_{\mathrm{p}}\right)$ ). Only for poor energy performing solutions (poor envelope, no MVHR, DE heating) additional PV on the façade contributes to significant savings. For better performing solutions (with PE below $100 \mathrm{kWh} /\left(\mathrm{m}^{2} \mathrm{a}\right)$ ) additional PV has a negligible contribution. The situation is different when a net balance is considered (see Figure 3-60), i.e. the total PV production is accounted for. It is noteworthy to mention that a net balance means that the grid serves as a seasonal storage and/or that sold excess PV electricity (in summer) has the same price than the costs for grid electricity (in winter). 


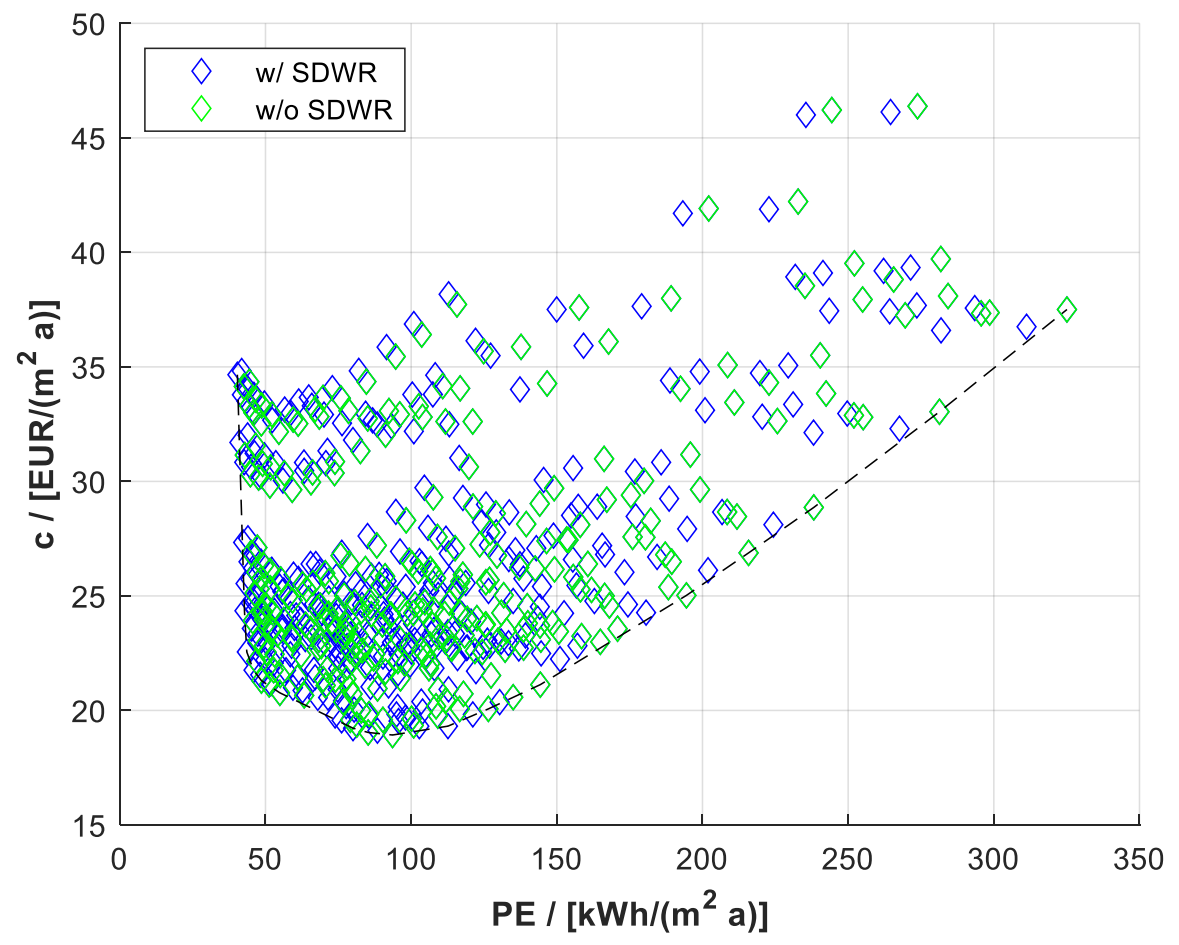

Figure 3-57: Capitalized life cycle costs (invest + maintenance + operation) vs. non-RE primary energy (PE) for all envelope qualities, and combinations of HVAC systems (MVHR, HP) and different use of PV; blue Markers indicate the use of SDWR, the dashed line indicates the minimum cost per PE

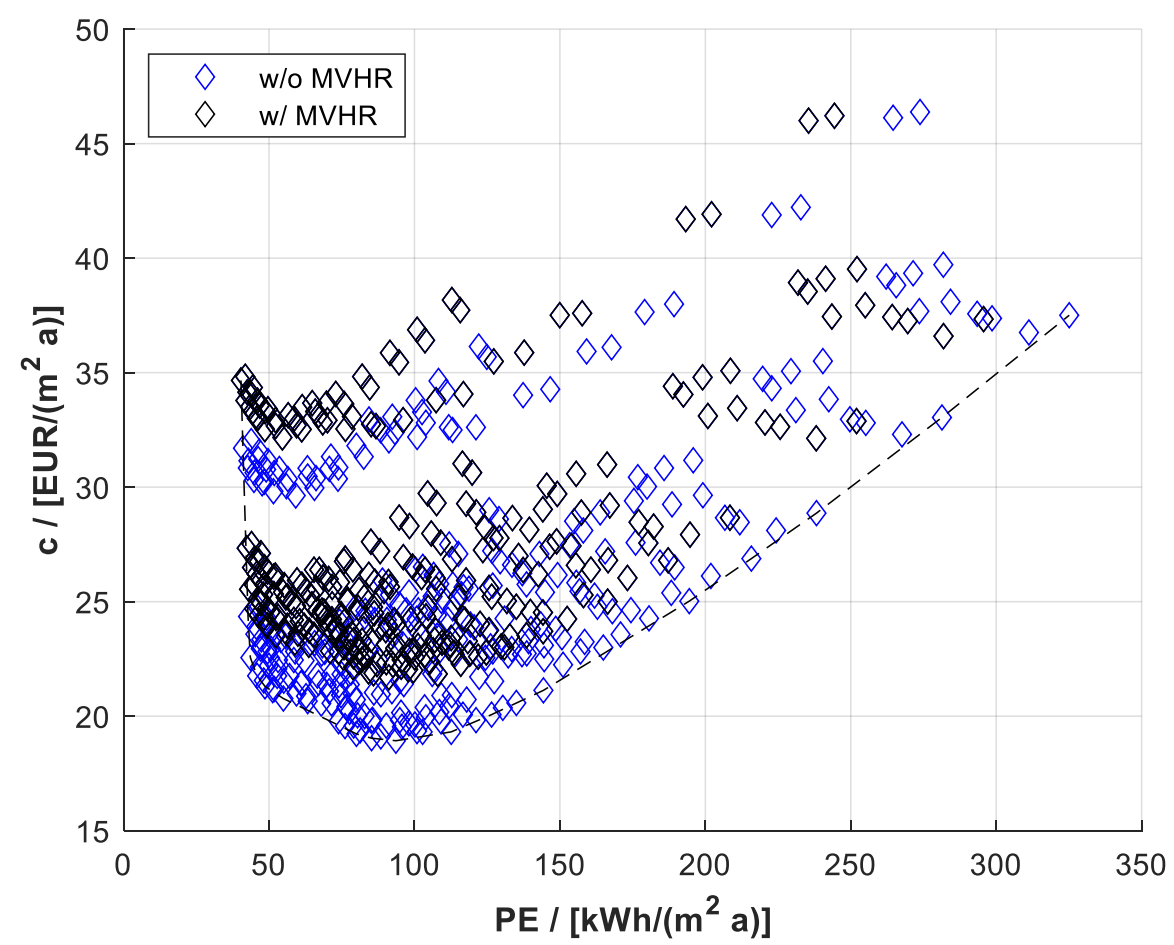

Figure 3-58: Capitalized life cycle costs (invest + maintenance + operation) vs. non-RE primary energy (PE) for all envelope qualities, and combinations of HVAC systems (MVHR, HP) and different use of PV; black Markers indicate the use of MVHR, the dashed line indicates the minimum cost per PE 


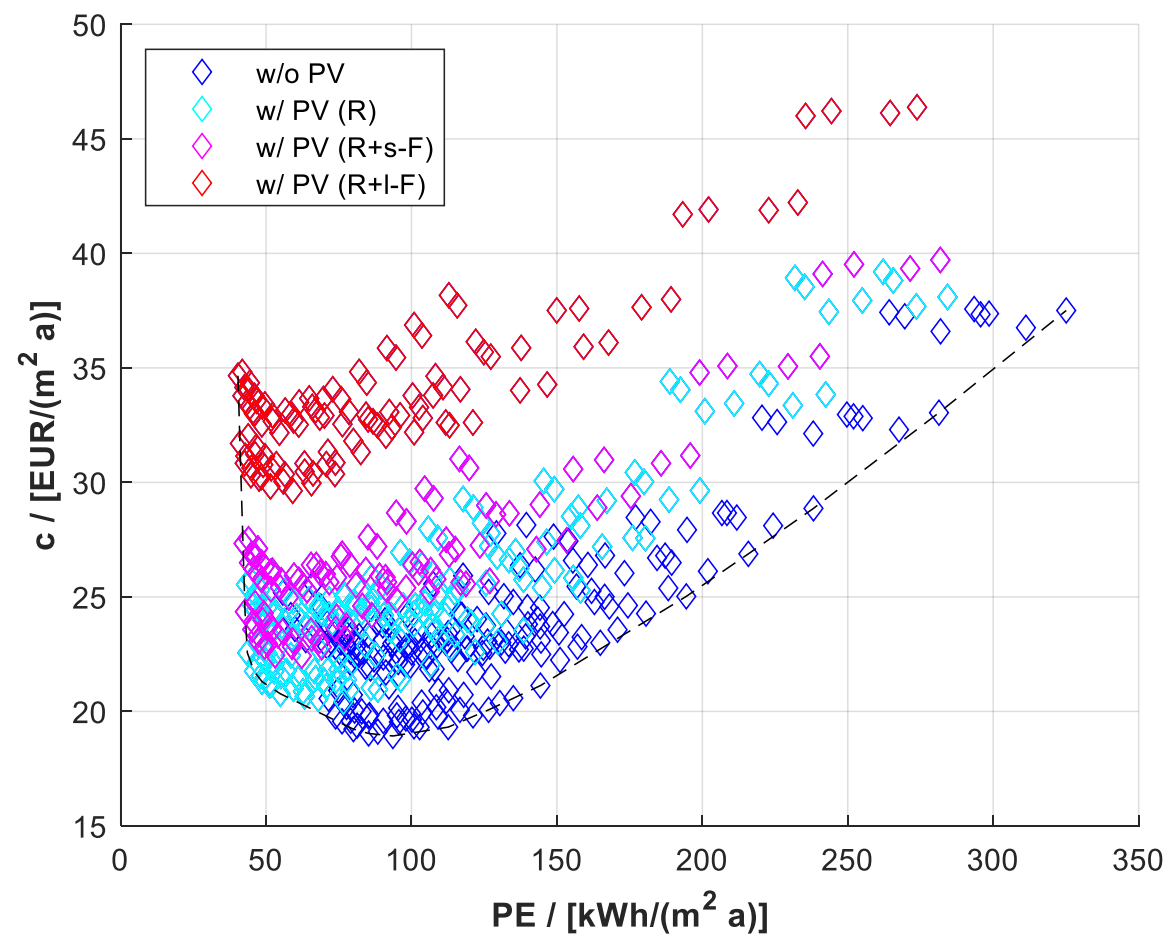

Figure 3-59: Capitalized life cycle costs (invest + maintenance + operation) vs. non-RE primary energy (PE) for all envelope qualities, and combinations of HVAC systems (MVHR, SDWR, HP); the colours indicate different use of PV blue no PV, cyan PV on roof, magenta PV on roof $+1 \mathrm{~kW}_{\mathrm{p}}$ on façade and red each $5 \mathrm{~kW}_{\mathrm{p}}$ on roof and façade; the dashed line indicates the minimum cost per PE

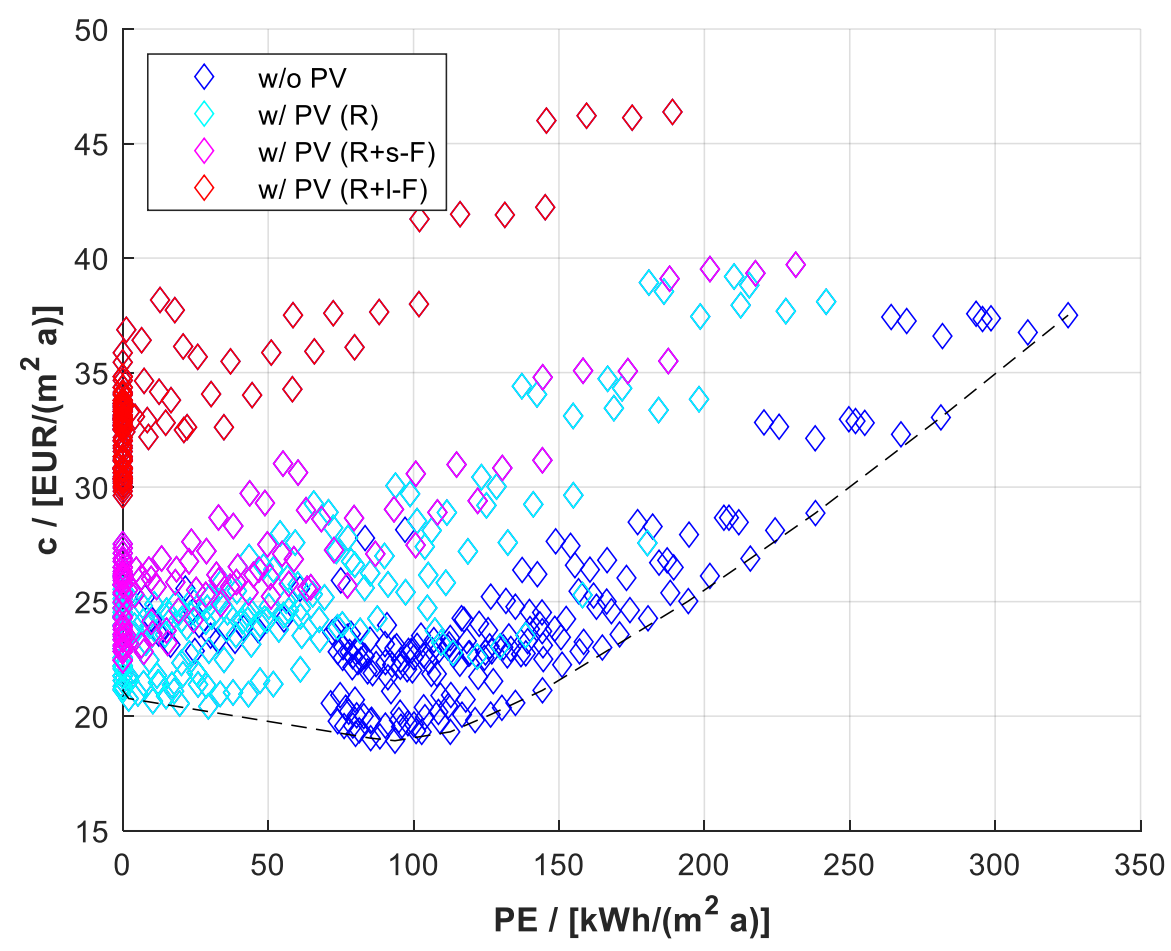

Figure 3-60: Capitalized life cycle costs (invest + maintenance + operation) vs. NET BALANCED non-RE primary energy (PE) for all envelope qualities, and combinations of HVAC systems (MVHR, SDWR, HP); the colours indicate different use of PV blue no PV, cyan PV on roof, magenta PV on roof $+1 \mathrm{kWp}$ on façade and red each $5 \mathrm{kWp}$ on roof and façade; the dashed line indicates the minimum cost per PE 


\subsubsection{Simulation results (Europe)}

The 576 cases were simulated in several European climates (see 
Table 3-41). It is important to note that active cooling is not considered in this section (therefore the trends for the warmer climates, i.e. Madrid and Rome might be associated with some uncertainties, see also sub-section 3, below). Some selected results are presented in the following figures (Figure 3-61 to Figure 3-64). Then, for better readability, only the curves with optimal costs per PE are compared in Figure 3-65, Figure 3-66 and Figure 3-67. There is a clear trend that when moving from cold to warm via moderate to cold climates, the primary energy demand reduces and also the LCC. In all cases the cost-optimum is relative flat and in a range between $60 \mathrm{kWh} /\left(\mathrm{m}^{2}\right.$ a) and $110 \mathrm{kWh} /\left(\mathrm{m}^{2} \mathrm{a}\right)$ and there is no clear trend for the cost-optimal PE with respect to the climate. However, a clear trend is visible if the cost difference are plotted vs. the saved PE with respect to the reference (i.e. DE heating, no MVHR, no PV), see Figure 3-66. From Figure 3-67 we can see that for all climates there is a range of PE savings, which feature low slope of the cost per saved kWh of PE and at a certain limit there is a strong increase in the slope of the curve (costs per saved kWh). In warm climates possible savings are small related to cold climates, but this mainly because the level of PE as already comparably low also for moderate building quality and without use of MVHR and heat pump.

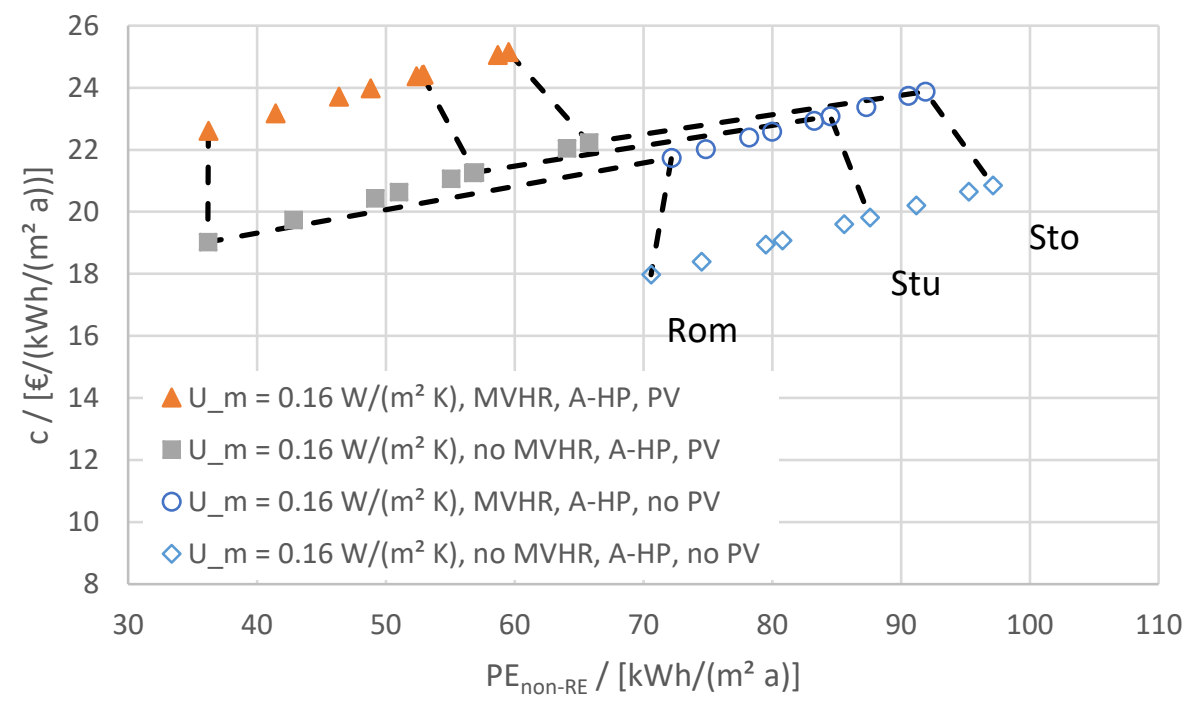

Figure 3-61: Specific LCC vs. non-RE PE for all climates, a good envelope quality $\left(U_{m}=0.16 \mathrm{~W} /\left(\mathrm{m}^{2} \mathrm{~K}\right)\right)$ and air-HP as well as with different options of HVAC (i.e. MHVR) and RE (i.e. PV)

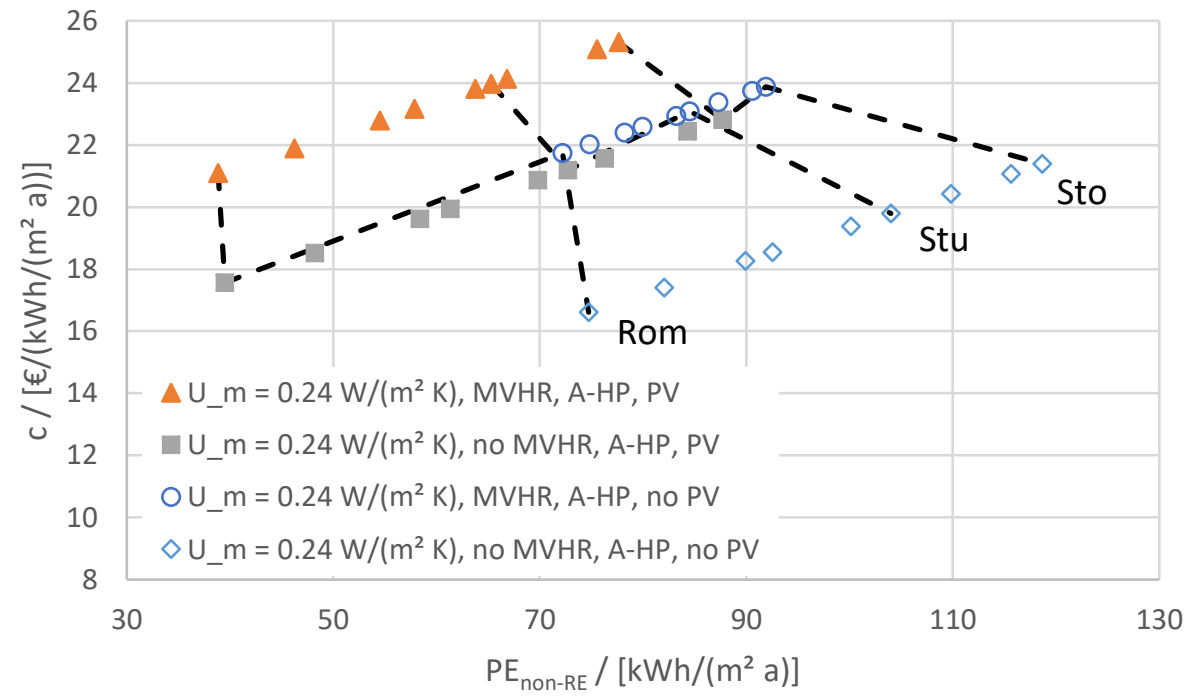

Figure 3-62: Specific LCC vs. non-RE PE for all climates, a medium envelope quality $\left(U_{m}=0.24 \mathrm{~W} /\left(\mathrm{m}^{2} \mathrm{~K}\right)\right)$ and air-HP as well as with different options of HVAC (i.e. MHVR) and RE (i.e. PV) 


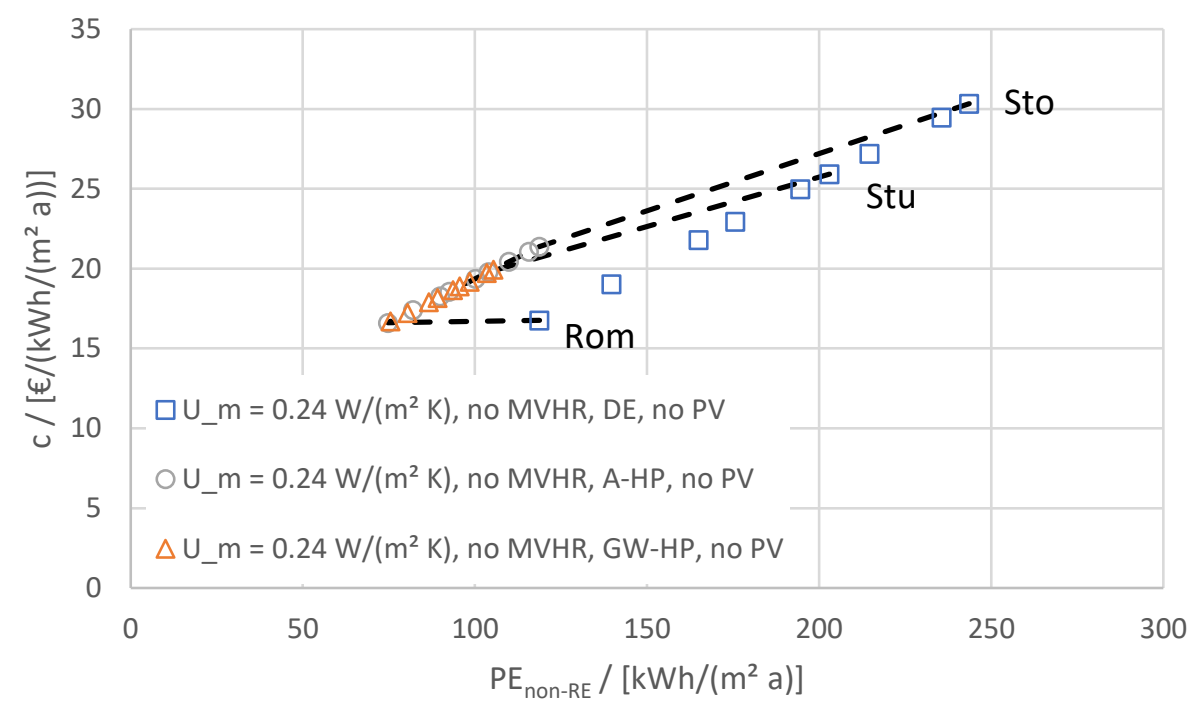

Figure 3-63: Specific LCC vs. non-RE PE for all climates, a medium envelope quality $\left(U_{m}=0.24 \mathrm{~W} /\left(\mathrm{m}^{2} \mathrm{~K}\right)\right)$, no $\mathrm{MVHR}$ and different options of HVAC (i.e. DE heating, air-HP, GW-HP) without PV

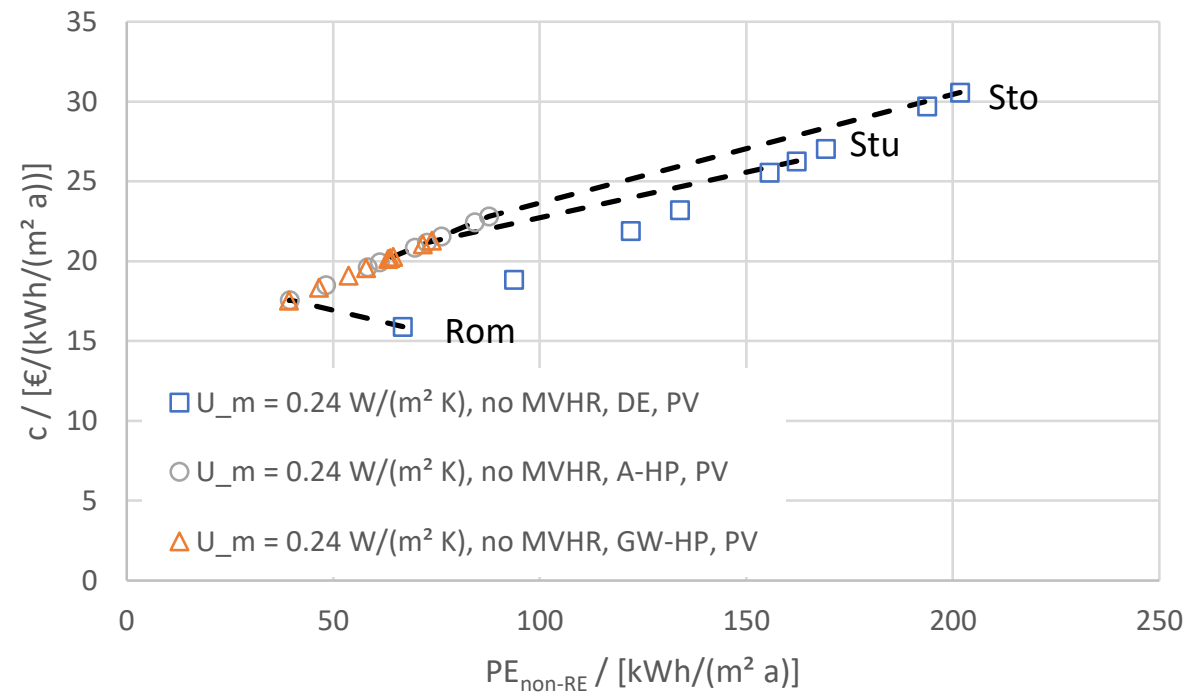

Figure 3-64: Specific LCC vs. non-RE PE for all climates, a medium envelope quality $\left(U_{m}=0.24 \mathrm{~W} /\left(m^{2} K\right)\right)$, no MVHR and different options of HVAC (i.e. DE heating, air-HP, GW-HP) with PV 


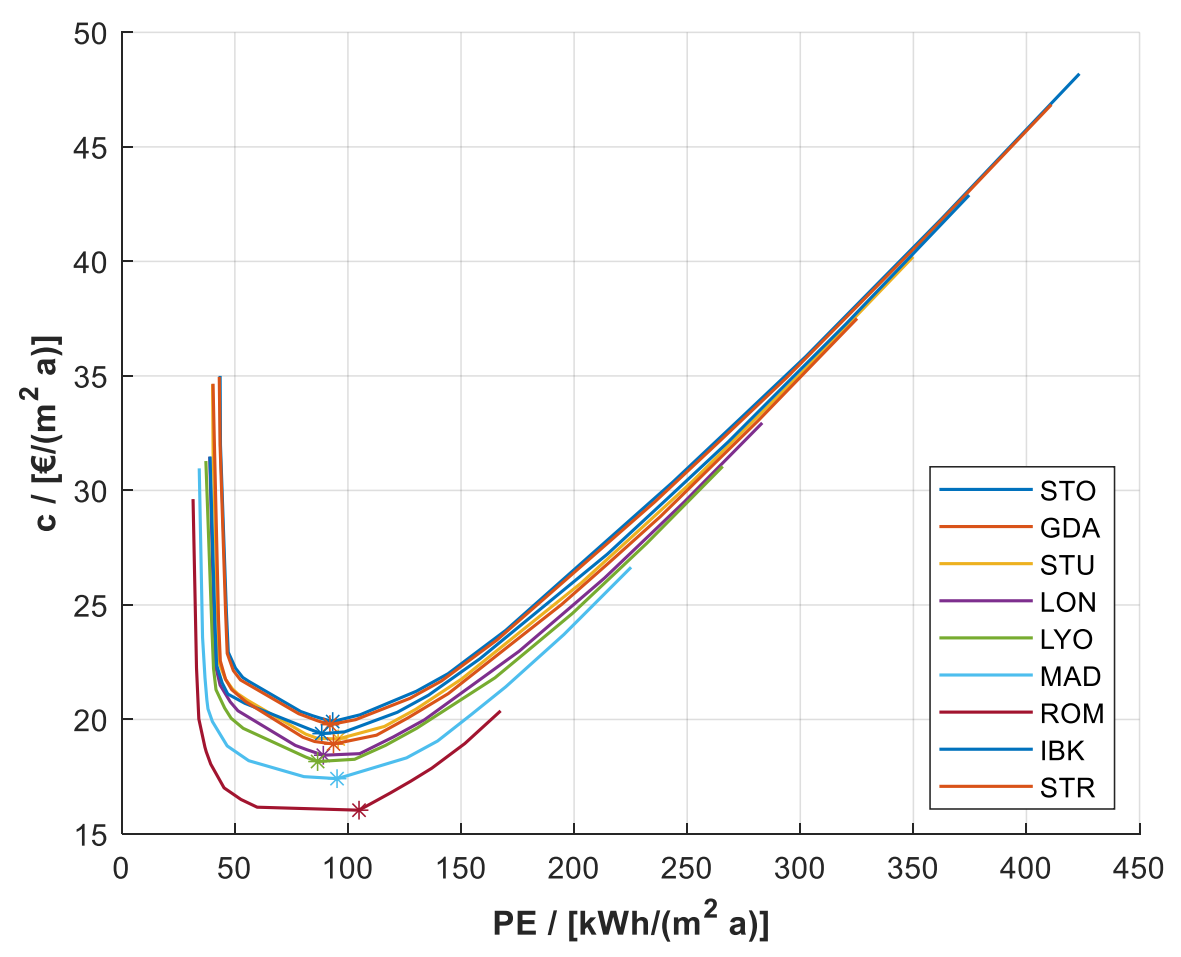

Figure 3-65: Curve with lowest cost per PE for 9 different European climates

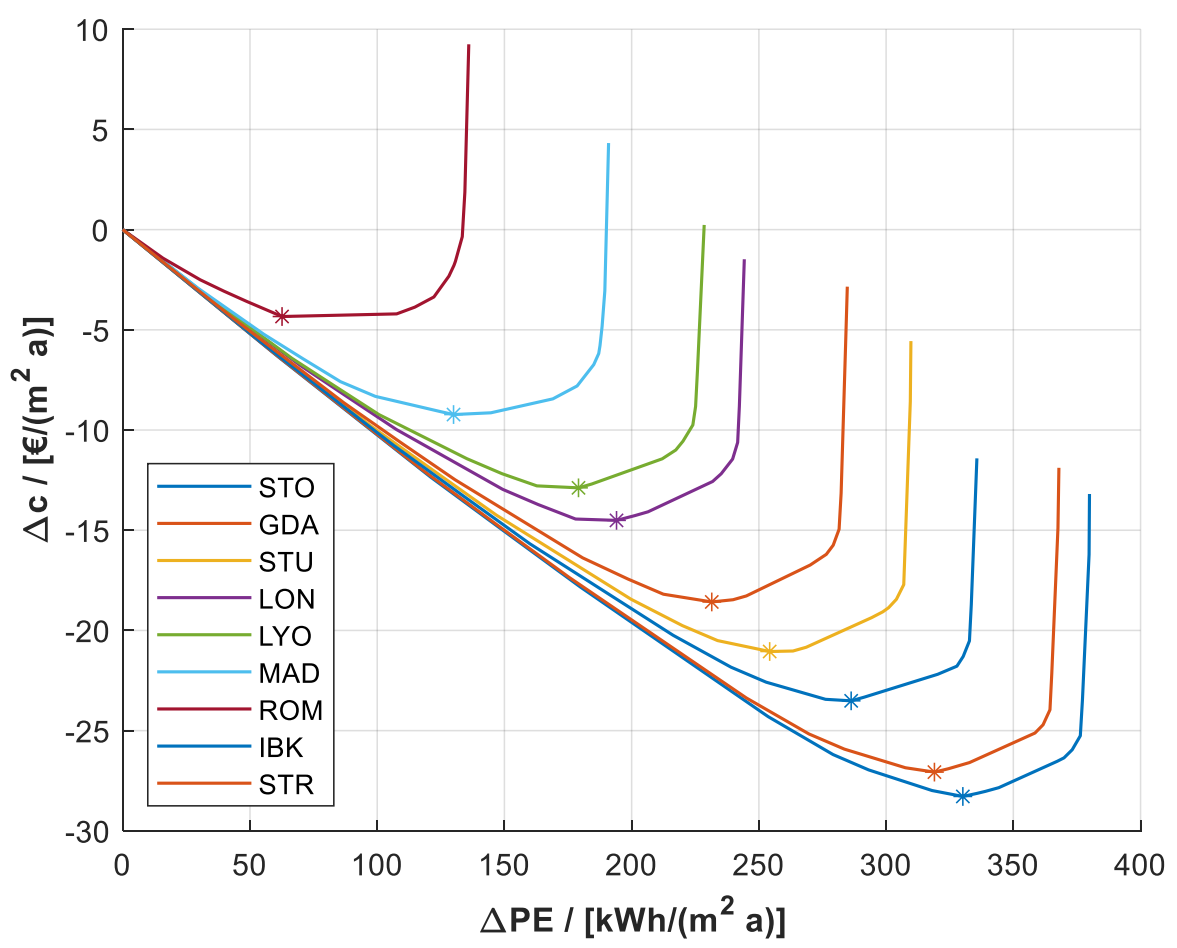

Figure 3-66: Curve with lowest cost difference per saved PE for 9 different European climates 


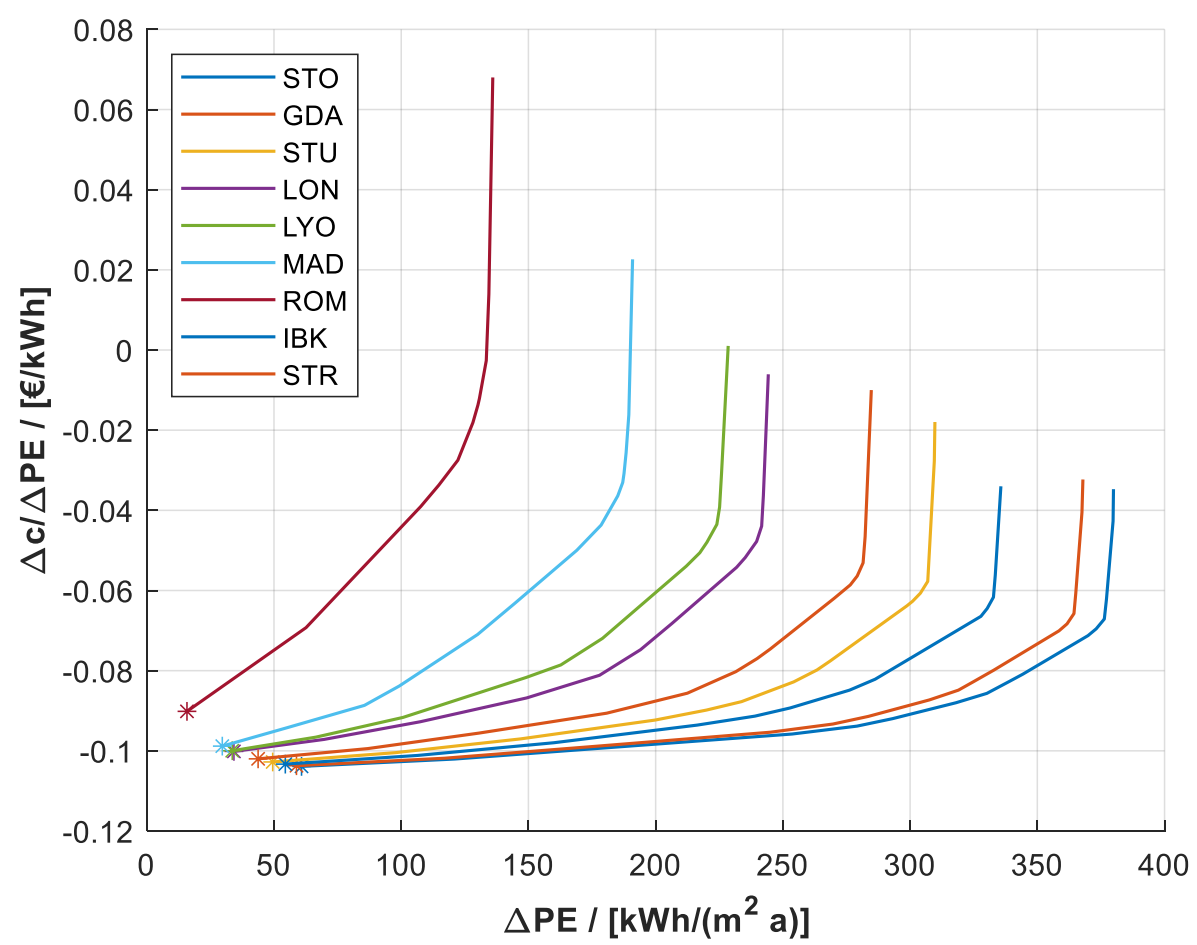

Figure 3-67: Curve with lowest cost per saved kWh per saved PE for 9 different European climates

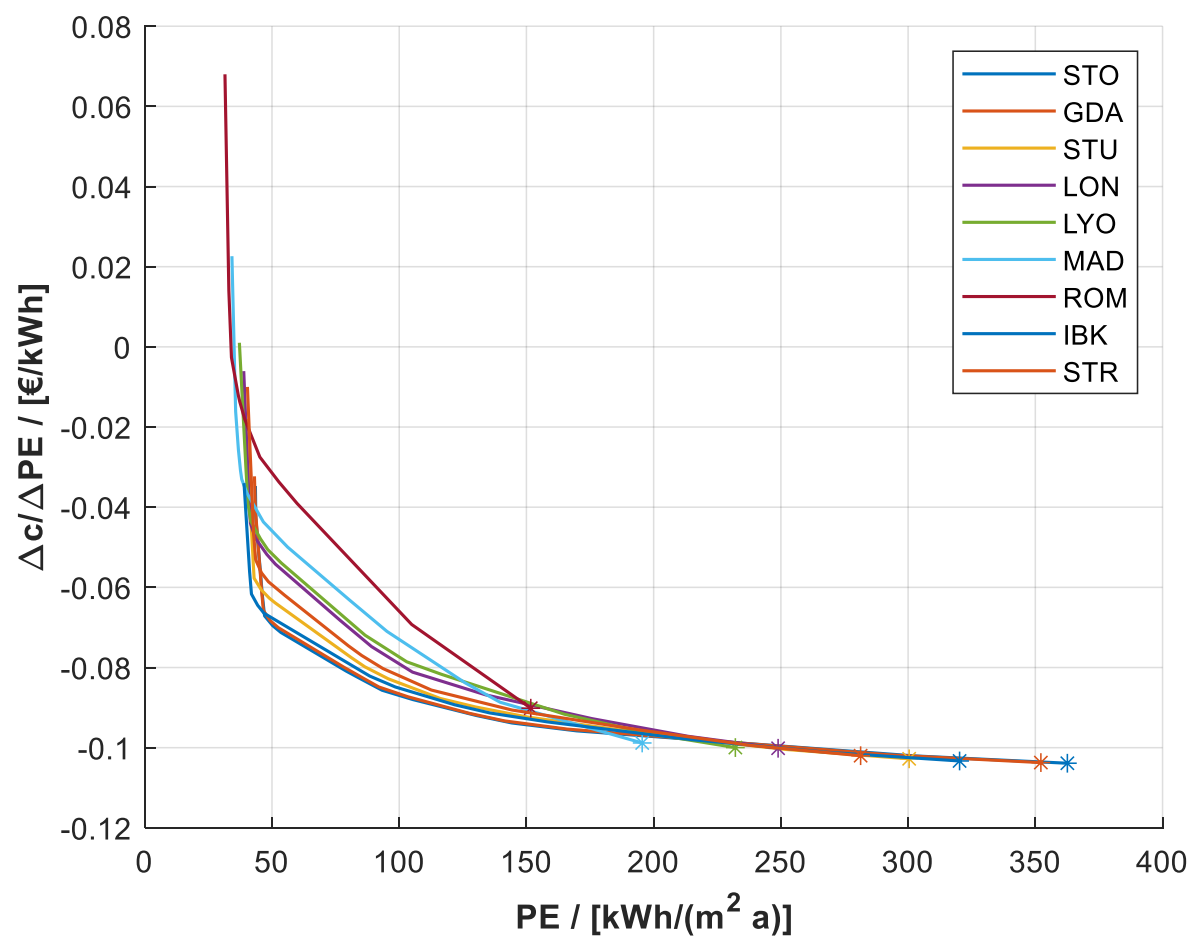

Figure 3-68: Curve with lowest cost per saved kWh as a function of PE for 9 different European climates 


\subsubsection{Simulation results with cooling (Rome)}

The previous cases were simulated without cooling, which might lead to misleading trends for the warm climates, therefore, in this section, for a selection of cases (DE Heating, with and without A-HP for DHW with and without MVHR, with and without PV) is simulated in the climate of Rome. The investment cost for the cooling equipment is assumed to be $6000 €$ with a service life of $15 \mathrm{yrs}$. For sake of simplicity the EER is assumed to be constant at 3 . A set point of $25^{\circ} \mathrm{C}$ is controlled with a hysteresis controller $( \pm 0.5 \mathrm{~K})$

If cooling is considered a relative small increase of the primary energy demand can be recognised: in the range of $5 \mathrm{kWh} /\left(\mathrm{m}^{2} \mathrm{a}\right)$ without $\mathrm{PV}$ and $2 \mathrm{kWh} /\left(\mathrm{m}^{2} \mathrm{a}\right)$ with $\mathrm{PV}$. The general trend remains the same, but the minimum LCC are significantly higher, i.e. approx. $20 € /\left(\mathrm{m}^{2} \mathrm{a}\right)$ instead of $16 € /\left(\mathrm{m}^{2} \mathrm{a}\right)$. In both cases $(\mathrm{w} / \mathrm{and} \mathrm{w} / \mathrm{o}$ cooling) the costoptimum is at a level of PE of around 67 to $71 \mathrm{kWh} /\left(\mathrm{m}^{2} \mathrm{a}\right)$ and is a medium quality envelope with $\mathrm{PV}$ on the roof. Façade integrated PV is again not economically feasible but is required if PE should be reduced to very low levels, i.e. to around $34 \mathrm{kWh} /\left(\mathrm{m}^{2} \mathrm{a}\right)$, see also Table 3-45.

Table 3-45: max, min and cost-optimal non-RE PE in $\mathrm{kWh} /\left(\mathrm{m}^{2}\right.$ a) for Rome, with and without cooling

\begin{tabular}{l|lll} 
& min & Cost-optimal & Max \\
\hline Without cooling & 34.2 & 66.8 at $16.2 € /\left(\mathrm{m}^{2} \mathrm{a}\right)$ & 167.5 \\
With cooling & 34.4 & 71.1 at $20.4 € /\left(\mathrm{m}^{2} \mathrm{a}\right)$ & 172.9 \\
\hline
\end{tabular}

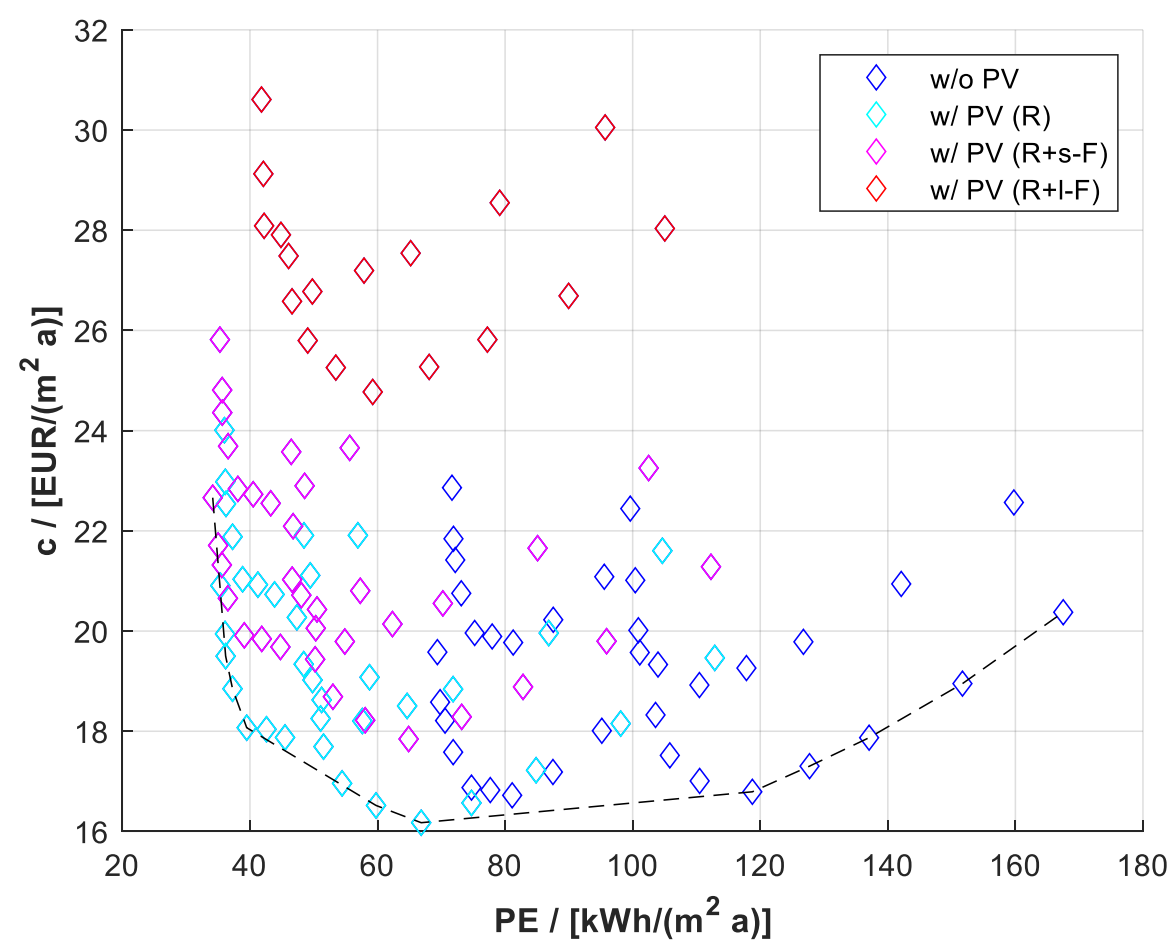

Figure 3-69: LCC vs. PE for selected cases in the climate of Rome without PV, with $5 \mathrm{kWp} \mathrm{PV}$ on roof (R) and with additional $1 \mathrm{kWp}$ or $5 \mathrm{kWp}$ on the façade without cooling 


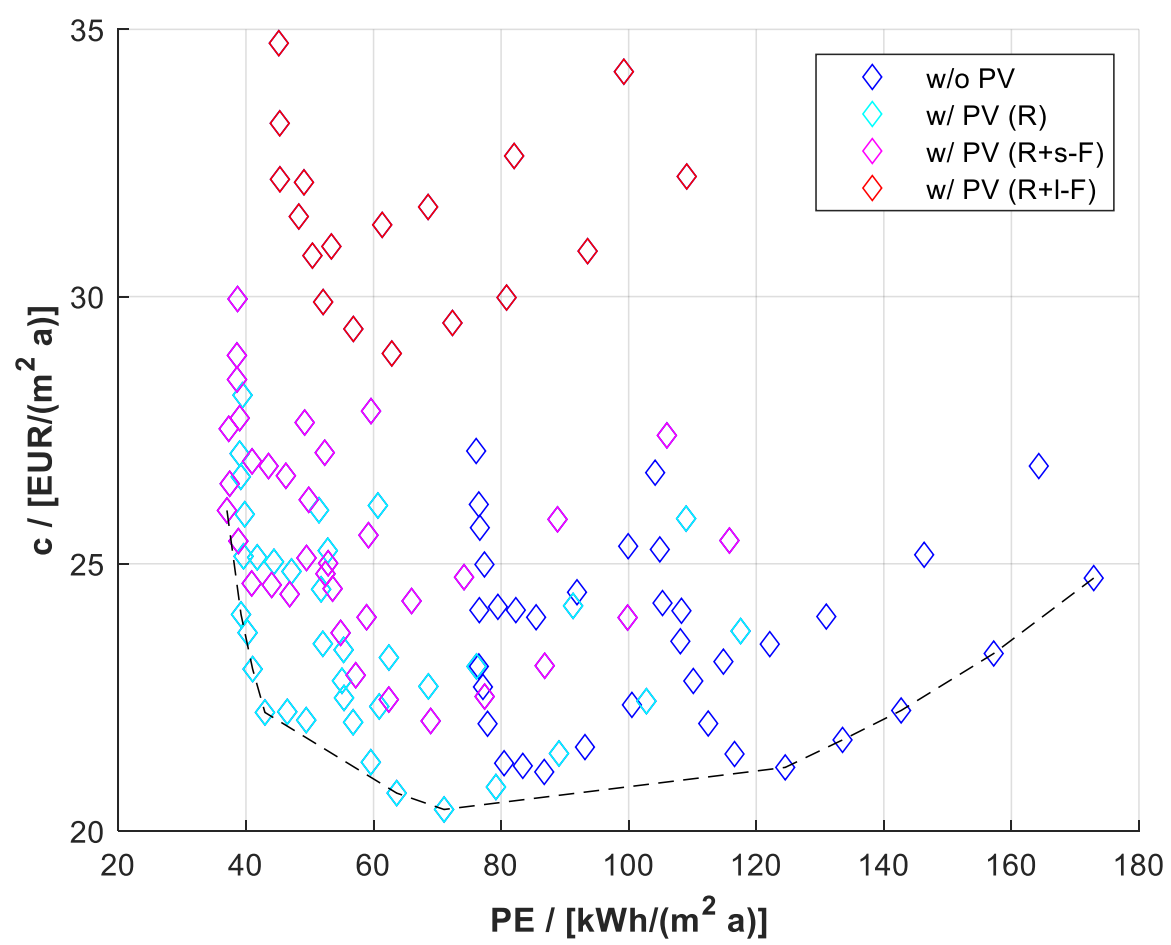

Figure 3-70: LCC vs. PE for selected cases in the climate of Rome without PV, with $5 \mathrm{~kW}_{\mathrm{p}} \mathrm{PV}$ on roof $(\mathrm{R})$ and with additional $1 \mathrm{~kW}_{\mathrm{p}}$ or $5 \mathrm{~kW}_{\mathrm{p}}$ on the façade with cooling

\subsubsection{Discussion}

The most-cost-effective building standard in the reference climate (Strasbourg) is under the given assumptions in the range of the Passive House envelope; MVHR is not economic. This leads to a heating demand in the range of $25 \mathrm{kWh} /\left(\mathrm{m}^{2} \mathrm{a}\right)$. However, it is important to note that in order to obtain the same indoor air quality with extract air ventilation, situations with discomfort (cold air) cannot be avoided and hence, MVHR is strongly recommended.

The investment costs per saved $\mathrm{kWh}$ of non-RE primary energy double from $0.04 € / \mathrm{kWh}$ non-RE PE when the non-RE PE savings increase along the Pareto front from ca. $130 \mathrm{kWh} /\left(\mathrm{m}^{2}\right.$ a) to $210 \mathrm{kWh} /\left(\mathrm{m}^{2}\right.$ a). For even higher savings the cost curve becomes steeper. Non-RE PE below $40 \mathrm{kWh} /\left(\mathrm{m}^{2}\right.$ a) is not achievable also in Rome. In Stockholm the minimum is around $48 \mathrm{kWh} /\left(\mathrm{m}^{2} \mathrm{a}\right)$.

Application of SDWR is economic in some cases, but it does not only significant contribution to PE savings in case of DE DHW preparation. In case of air-HP and in particular in case of GW-HP there is only a small benefit.

On a net energy balance, application of PV allows to reduce the PE to zero in many cases. Net balance physically means, that the electric grid is serving as a (seasonal!) storage and economically it means that PV surplus electricity that is sold to the grid has the same price than the costs of electricity purchased from the grid.

On European level, it can be seen that it is easier to reach low levels of PE in moderate to warm climates, however, the cost of reducing PE is lower in cold climates unless very high PE savings should be achieved. In this case in all climates the slope is very steep.

\subsubsection{Conclusions}

The cost-optimal combination of envelope (wall, window), HVAC (MVHR, heat pump) and renewables (PV) depends on the climate. In all cases the minimum of annual capitalized cost (investment, maintenance and operation) vs. PE (or cost difference vs. primary energy savings is relative flat and a range of combinations delivers similar results. It has to be considered, that there is a relative high uncertainty and potentially a large variation with respect to the cost assumptions and furthermore also a significant influence with respect to the user. However, with the aim to compare for a set of given boundary conditions the influence of the climate on the cost-optimal solution, it can be clearly shown that there is a mathematical minimum at a PE of $90 \mathrm{kWh} /\left(\mathrm{m}^{2}\right.$ a) for cold climates and around 60 
$\mathrm{kWh} /\left(\mathrm{m}^{2} \mathrm{a}\right)$ for more moderate climates) and that with little extra costs additional PE savings of about $50 \mathrm{kWh} /\left(\mathrm{m}^{2} \mathrm{a}\right)$ could be achieved. Integration of RE (here PV) in the building roof is required in order to obtain high primary energy savings. However, under the current boundary conditions, in particular façade integrated PV in residential buildings seems not to be economically feasible.

Heat recovery can also significantly reduce the primary energy demand. Yet, MVHR is not economic under the given boundary conditions, but is recommended anyway because of comfort and air quality constraints. Shower drain water recovery is economic for some of the investigated cases, however, the potential savings are relative low when combined with a heat pump (water heater). Only with direct electric water heating it delivers significant primary energy savings but then on a relative high level of PE.

If only the investment costs are considered, (which is in many cases the relevant criterion for a decision), the solutions with high PE savings clearly require also higher investment, which an investor would try to avoid. Incentives are required to foster the implementation of low LCC solutions. 
[1] M. Magni, F. Ochs, P. Bonato, M. D'Antoni, D. Geisler-Moroder, S. de Vries, R. Loonen, A. Maccarini, A. Afshari und T. Calabrese, „Comparison of Simulation Results for an Office Building Between Different BES Tools - The Challenge of Getting Rid of Modeller Influence and Identifying Reasons for Deviations, “ in Bilding Simulation Conference, Rome, 2019.

[2] SIA 2024:2015, Raumnutzungsdaten für di Energie- und Gebäudetechnik, Zurich, Switzerland.

[3] Bartenbach and University of Innsbruck, "DALEC," [Online]. Available: http://dalec.uibk.ac.at/\#room. [Accessed 0702 2020].

[4] D. B. Crawley, L. K. Lawrie, C. O. Pedersen and F. C. Winkelmann, "EnergyPlus: Energy Simulation Program," ASHRAE Journal, vol. 42, pp. 49-56, 2000.

[5] S. Klein, W. Beckman, J. Mitchell, J. Duffie, N. Duffie, T. Freeman und et al., „TRNSYS 17, TRaNsient SYstem Simulation program., “ University of Wisconsin, Madison, WI, USA, 1979.

[6] D. Siegele, E. Leonardi and F. Ochs, "A new MATLAB Simulink Toolbox for Dynamic Building Simulaiton with BIM and Hardware in the Loop compatibility," in Building Simulation, Rome, 2019.

[7] J. P. Campana und G. L. Morini, „BESTEST and EN ISO 52016 Benchmarking of ALMABuild, a New Open-Source Simulink Tool for Dynamic Energy Modelling of Buildings, “ Energies, Bd. 2938, pp. 12-15, 2019.

[8] M. Werner, "DALEC - Day- and Artificial Light with Energy Calculation," [Online]. Available: https://www.uibk.ac.at/bauphysik/forschung/projects/dalec/index.html.en. [Accessed 2812 2018].

[9] M. Wetter, W. Zuo und S. Nouidui, „Modeling of Heat Transfer in Rooms in the Modelica "Buildings" Library," in Proceedings of Building Simulation, Sydney, 2011.

[10] W. Feist, “PHPP - Passive House Planning Package,” [Online]. Available: https://passivehouse.com/04_phpp/04_phpp.htm. [Accessed 1601 2019].

[11] S. de Vries, R. Loonen und J. L. Hensen, ,Sensor selection and control strategy development support for automated solar shading systems using building performance simulation, " in Building Simulation, Rome, 2019.

[12] CEN, CEN - EN 14501: Blinds and shutters - Thermal and visual comfort - Performance characteristics and classification, 2005.

[13] F. Ochs und G. Dermentzis, „Evaluation of Efficiency and Renewable Energy Measures Considering the Future Energy Mix, “ in 7th International Building Physics Conference, Syracuse, NY,USA, 2018.

[14] M. Gustafsson, C. Dipasquale, S. Poppi, A. Bellini, R. Fedrizzi, C. Bales, F. Ochs, M. Sié und S. Holmberg, „Economic and environmental analysis of energy renovation packagesfor European office buildings," Energy and Buildings, Bd. 148, pp. 155-165, 2017.

[15] F. Ascione, N. Bianco, G. Maria Mauro und G. Peter Vanoli, „A new comprehensive framework for the multi-objective optimization of building energy design: Harlequin,“ Applied Energy, Bd. 241, pp. 331-361, 2019.

[16] European Parliament, Council of the European Union, Directive 2006/32/EC of the European Parliament and of the Council on energy end-use efficiency and energy services and repealing Council Directive 93/76/EEC, 2006.

[17] HFT-Stuttgart, "CIGS-Fassade Project," 2004 2019. [Online]. Available: https://www.hftstuttgart.de/forschung/projekte/aktuell/cigs-fassade. [Accessed 2204 2020].

[18] J. Tardif, J. Tamasauskas, V. Delisle and M. Kegel, "Performance of Air Based BIPV/T Heat Management Strategies in a Canadian Home," Procedia Environ. Sci., vol. 38, p. 140-147, 2017.

[19] M. Farshchimonfared, J. Bilbao and A. Sproul, "Channel depth, air mass fl ow rate and air distribution duct diameter optimization of photovoltaic thermal ( PV / T ) air collectors linked to residential buildings," Renew. Energy, vol. 76, p. 27-35, 2015.

[20] Y. Cengel and R. Turner, Fundamentals of thermal-fluid sciences, 2nd ed., New: McGraw-Hill, 2004.

[21] TRNSYS Manual “TESSLibs 17”, Electrical Library Mathematical Reference, Type567, vol. 03.

[22] S. F. Haeringer, P.-R. Denz, T. E. Kuhn und C. Maurer, ,Solar thermal venetian blind as synergetic and adaptive sun protection device in double skin façades - Characterization via calorimetric measurements, “ 
in 14th Conference on Advanced Building Skins. Conference on Advanced Building Skins, Bern, Switzerland, 2019.

[23] DIN CERTCO , "Summary of EN 12975 Test Results, annex to Solar KEYMARK Certificate.," Licence number: 011-7S1404 F, 2015. [Online]. Available: https://www.dincertco.tuv.com/registrations/60072471?locale=en. [Accessed 1206 2019].

[24] Viessmann Werke GmbH \& Co. KG, Data sheet: Vitosol 200-TM.

[25] S. F. Haeringer, I. Abderrahman, P. Vongsingha, K. T. E. Kuhn, P.-R. Denz und C. Maurer, ,Solar Thermal Venetian Blinds - Transparency, User Comfort and Solar Energy in one!, "in Passive Low Energy Architecture (PLEA) (Hg.): Proceedings of 33rd PLEA International Conference - Design to Thrive, 2017.

[26] C. Maurer, „Theoretical and experimental analysis and optimization of semi-transparent solar thermal façade collectors. Dissertation," Freiburg, 2012.

[27] J. H. Klems, A New Method for Predicting the Solar Heat Gain of Complex Fenestration Systems I. Overview and Derivation of the Matrix Layer Calculation, ASHRAE Transactions 100 Part 1, 1994.

[28] B. Bueno, J. M. Cejudo-Lopez und T. E. Kuhn, ,A general method to evaluate the thermal impact of complex fenestration systems in building zones," Energy and Buildings, Bd. 155, p. 43-53, 2017.

[29] B. Bueno, J. Wienold, A. Katsifaraki und T. E. Kuhn, „Fener: A Radiance-based modelling approach to assess the thermal and daylighting performance of complex fenestration systems in office spaces, "Energy and Buildings, Bd. 94, pp. 10-20, 2015.

[30] G. Ward, R. Mistrick, G. S. Lee, A. McNeil und J. Jonsson, „Simulating the Daylight Performance of Complex Fenestration Systems Using Bidirectional Scattering Distribution Functions within Radiance,“ LEUKOS 7, p. 241-261, 2011.

[31] A. Katsifaraki, B. Bueno and T. E. Kuhn, "A daylight optimized simulation-based shading controller for venetian blinds," Building and Environment, vol. 126, p. 207-220, 2017.

[32] DIN V 18599-10, Energetische Bewertung von Gebäuden - Berechnung des Nutz-, End- und Primärenergiebedarfs für Heizung, Kühlung, Lüftung, Trinkwarmwasser und Beleuchtung - Teil 10: Nutzungsrandbedingungen, Klimadaten, 2018.

[33] J. Bierbaum, Solar thermal venetian blinds - modelling and simulation of the energy performance, Freiburg, Albert-Ludwig-University: Master Thesis, 2019.

[34] L. Edwards und P. Torcellini, „Literature review of the effects of natural light on building occupants, “ National Renewable Energy Lab., Golden, CO.(US), 2002.

[35] L. Heschong, „Windows and offices: A study of office worker performance and the indoor environment,“ California Energy Commission, pp. 1-5, 2003.

[36] P. Wargocki, O. Seppänen, J. Andersson, A. Boerstra, D. Clements-Croome, K. Fitzner und S. Hanssen, Indoor climate and productivity in offices, Rotterdam: REHVA / ISSO, 2007.

[37] M. Boubekri, I. N. Cheung, K. J. Ivy N, . C.-H. Wang und P. C. Zee, „Impact of windows and daylight exposure on overall health and sleep quality of office workers: a case-control pilot study," Journal of clinical sleep medicine: JCSM: official publication of the American Academy of Sleep Medicine, Bd. 10, Nr. 6, p. 603, 2014.

[38] M. Knoop, O. Stefani, B. Bueno, B. Matusiak, R. Hobday, A. Wirz-Justice, K. Martiny, T. Kantermann, M. Aarts und N. Zemmouri, „Daylight: What makes the difference?, Lighting Research \& Technology, 2019.

[39] W. Beck, D. Dolmans, G. Dutoo, A. Hall und O. Seppänen, Solar Shading. REHVA Guidebook 12 , Forssa, Finland, 2010.

[40] G. Rojas, M. Spörk-Dür, D. Venus, A. Greml, L. Krissmer und R. Pfluger, „Lüften und Heizen in Passivhäusern in Österreich. Variantenvergleich auf Basis von Behaglichkeit und Nachhaltigkeit.," BMVIT, 2015.

[41] A. Weber, „Modell für natürliche Lüftung durch Kippfenster,“ EMPA Dübendorf.

[42] J. A. Duffie und W. A. Beckman, Solar Engineering of Thermal Processes, Wiley, 1991.

[43] OIB-Richtlinien 2015, OIB-Richtlinie 6: Energieeinsparung und Wärmeschutz, Österreichisches Institut für Bautechnik, 2015.

[44] W. Streicher, „Benutzerfreundliche Heizungssysteme für Niedrigenergie- und Passivhäuser,“ 2004.

[45] C. Fink und R. Riva, Solarunterstützte Wärmenetze im Geschoßwohnbau: Ein Planungshandbuch mit ganzheitlichem ansatz., Gleisdorf: AEE GmbH, 2004. 
[46] ÖNORM B 1801-2: 201104 01, Bauprojekt- und Objektmanagement - Teil 2: Objekt-Folgekosten, Austrian Standards, 2011.

[47] R. Aa van der, NEN 7120+ C2: Energieprestatie van gebouwen-Bepalingsmethode, Delft: Stichting Nederlands Normalisatie-instituut (NEN/CEN), 2012.

[48] S. F. Haeringer, P.-R. Denz, P. Vongsingha, A. Delgado und C. Maurer, „Arkol - Development and Testing of Solar Thermal Venetian Blinds,“ in Powerskin Conference. Proceedings, München, 2019. 


\section{A. 1 Monthly simulation results of TRNSYS}

Table A. 1: Monthly energy balance for the reference office zone in Stockholm.

\begin{tabular}{c|ccccccc}
\multirow{2}{*}{ Month } & \multicolumn{7}{|c}{ Specific energy balance $\left.\left[\mathbf{k W h} / \mathbf{m}^{2} \mathbf{y}\right)\right]$} \\
& $\mathbf{Q}_{\text {HEAT }}$ & $\mathbf{Q}_{\text {COOL }}$ & $\mathbf{Q}_{\text {INF }}$ & $\mathbf{Q}_{\text {VENT }}$ & $\mathbf{Q}_{\text {TRANS }}$ & $\mathbf{Q}_{\text {GINT }}$ & $\mathbf{Q}_{\text {SOL }}$ \\
\hline January & 4.9 & 0.0 & -2.5 & -2.2 & -7.2 & 5.0 & 2.1 \\
February & 3.7 & 0.0 & -2.3 & -2.0 & -7.0 & 4.3 & 3.3 \\
March & 1.6 & 0.0 & -2.3 & -2.4 & -7.1 & 4.8 & 5.5 \\
April & 0.0 & 0.3 & -1.8 & -3.5 & -5.5 & 4.6 & 6.5 \\
May & 0.0 & 2.2 & -1.4 & -3.7 & -5.0 & 5.0 & 7.4 \\
June & 0.0 & 5.5 & -1.0 & -2.3 & -3.2 & 4.6 & 7.5 \\
July & 0.0 & 7.9 & -0.7 & -1.4 & -2.3 & 4.8 & 7.5 \\
August & 0.0 & 6.8 & -0.8 & -1.9 & -2.5 & 5.0 & 7.1 \\
September & 0.0 & 2.3 & -1.3 & -3.2 & -3.4 & 4.4 & 5.9 \\
October & 0.3 & 0.1 & -1.7 & -3.2 & -4.2 & 5.0 & 3.9 \\
November & 2.6 & 0.0 & -1.9 & -1.9 & -5.2 & 4.8 & 1.7 \\
December & 4.8 & 0.0 & -2.3 & -1.9 & -6.4 & 4.6 & 1.4 \\
\hline Total & 17.8 & -25.1 & -20.2 & -29.6 & -59.0 & 56.5 & 59.6
\end{tabular}

Table A. 2: Monthly energy balance for the reference office zone in Stuttgart.

\begin{tabular}{|c|c|c|c|c|c|c|c|}
\hline \multirow{2}{*}{ Month } & \multicolumn{7}{|c|}{ Specific energy balance $\left[\mathrm{kWh} /\left(\mathrm{m}^{2} \mathrm{y}\right)\right]$} \\
\hline & Qheat & Qcool & $Q_{\text {INF }}$ & $Q_{\text {VENT }}$ & Qtrans & $Q_{\text {GINT }}$ & Qsol \\
\hline January & 4.2 & 0.0 & -2.3 & -2.3 & -7.6 & 5.0 & 3.1 \\
\hline February & 2.7 & 0.0 & -2.0 & -2.0 & -6.9 & 4.3 & 3.8 \\
\hline March & 1.3 & 0.0 & -1.9 & -2.6 & -6.3 & 4.8 & 4.8 \\
\hline April & 0.0 & -0.6 & -1.5 & -3.3 & -5.0 & 4.6 & 5.8 \\
\hline May & 0.0 & -3.5 & -1.1 & -2.9 & -4.6 & 5.0 & 7.3 \\
\hline June & 0.0 & -5.8 & -0.8 & -1.6 & -3.1 & 4.6 & 6.6 \\
\hline July & 0.0 & -6.3 & -0.7 & -1.4 & -2.6 & 4.8 & 6.2 \\
\hline August & 0.0 & -6.1 & -0.7 & -1.6 & -2.8 & 5.0 & 6.2 \\
\hline September & 0.0 & -2.7 & -1.1 & -2.7 & -3.4 & 4.4 & 5.5 \\
\hline October & 0.0 & -0.4 & -1.5 & -3.5 & -4.4 & 5.0 & 4.7 \\
\hline November & 1.5 & 0.0 & -1.8 & -2.2 & -5.3 & 4.8 & 3.0 \\
\hline December & 4.2 & 0.0 & -2.2 & -2.0 & -7.1 & 4.6 & 2.6 \\
\hline Total & 13.9 & -25.3 & -17.6 & -28.1 & -59.0 & 56.5 & 59.6 \\
\hline
\end{tabular}


Table A. 3: Monthly energy balance for the reference office zone in Rome.

\begin{tabular}{l|ccccccc}
\multirow{2}{*}{ Month } & \multicolumn{7}{|c}{ Specific energy balance $\left[\mathbf{k W h} /\left(\mathbf{m}^{2} \mathbf{y}\right)\right]$} \\
& $\mathbf{Q}_{\text {HEAT }}$ & $\mathbf{Q}_{\text {COOL }}$ & $\mathbf{Q}_{\text {INF }}$ & $\mathbf{Q}_{\text {VENT }}$ & $\mathbf{Q}_{\text {TRANS }}$ & $\mathbf{Q}_{\text {GINT }}$ & $\mathbf{Q}_{\text {SOL }}$ \\
\hline January & 1.5 & 0.0 & -1.6 & -2.1 & -5.2 & 5.0 & 2.5 \\
February & 0.9 & 0.0 & -1.4 & -1.8 & -4.5 & 4.3 & 2.5 \\
March & 0.2 & 0.0 & -1.3 & -2.4 & -4.2 & 4.8 & 3.0 \\
April & 0.0 & -0.4 & -1.1 & -2.3 & -3.6 & 4.6 & 2.8 \\
May & 0.0 & -3.2 & -0.7 & -1.4 & -2.6 & 5.0 & 2.9 \\
June & 0.0 & -5.5 & -0.3 & -0.4 & -1.1 & 4.6 & 2.8 \\
July & 0.0 & -7.1 & -0.1 & 0.1 & -0.3 & 4.8 & 2.5 \\
August & 0.0 & -7.8 & 0.0 & 0.2 & 0.1 & 5.0 & 2.7 \\
September & 0.0 & -4.9 & -0.5 & -0.7 & -1.2 & 4.4 & 2.9 \\
October & 0.0 & -3.0 & -0.8 & -1.9 & -2.3 & 5.0 & 3.0 \\
November & 0.0 & -0.3 & -1.2 & -2.7 & -3.2 & 4.8 & 2.6 \\
December & 0.6 & 0.0 & -1.4 & -1.9 & -4.3 & 4.6 & 2.5 \\
\hline Total & 3.3 & -32.1 & -10.4 & -17.4 & -32.4 & 56.5 & 32.6
\end{tabular}




\section{A. 2 PV, Inverter and HP map of performances}

In chapter 2.1.5 is presented a comparison between different dynamic simulation tools modelling also the photovoltaic panels (PV) with the inverter and heat pump (HP) together with the office cell. In this chapter the technical characteristics of PV, Inverter and HP used in the simulations are reported.

\section{Photovoltaic panel}

Table A. 1 reports the main characteristics of the PV panels.

Table A. 4: PV technical sheet (STC - Standard Test Conditions: Irradiation $1000 \mathrm{~W} / \mathrm{m}^{2}$ - Air mass AM 1.5 - Cell temperature $25^{\circ} \mathrm{C}$ )

\begin{tabular}{l|l}
\hline Efficiency & $17.7 \%$ \\
Nominal power (Pmax) & $140 \mathrm{Wp}$ \\
Voltage & $16.1 \mathrm{~V}$ \\
Current & $8.8 \mathrm{~A}$ \\
Open Circuit Voltage (Voc) & $19.9 \mathrm{~V}$ \\
Short Circuit Current (Isc) & $9.3 \mathrm{~A}$ \\
Maximum (DC) Voltage & $1000 \mathrm{~V}$ \\
Tolerance of (Pmax) & $\pm 3 \%$ \\
Temperature Coefficient: $\mathbf{\alpha ( I s c )}$ & $+0.0405 \% / \mathrm{K}$ \\
Temperature Coefficient: $\boldsymbol{\beta}($ Voc) & $-0.2943 \% / \mathrm{K}$ \\
Temperature Coefficient: $\mathbf{Y ( P m a x )}$ & $-0.3750 \% / \mathrm{K}$ \\
Dimension & $985 \times 875 \times 6.5 \mathrm{~mm}$ \\
Useful Area & $985 \times 825 \times 6.5 \mathrm{~mm}$ \\
\hline
\end{tabular}




\section{Inverter}

Figure A. 1 a reports the inverter efficiency as a function of the ratio between output and rated power of the inverter. Figure A. $\mathbf{1}$ b reports the main technical data of the inverter.

(a)

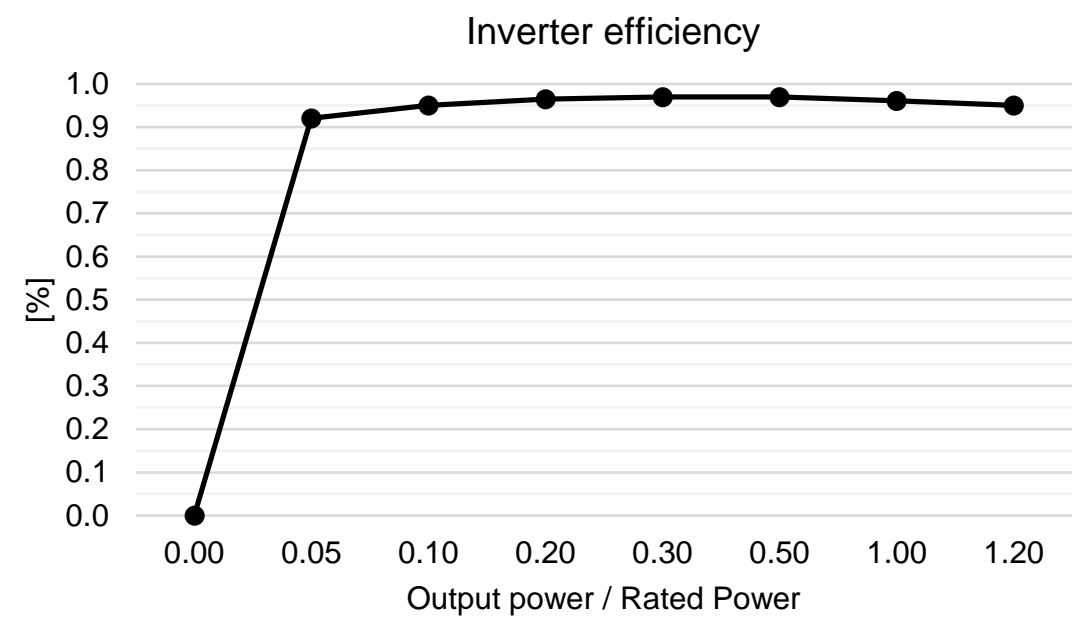

Technical data

Sunny Boy 3.0

Input (DC)

Max, generator power

Max, input voltage

MPP vollage ronge

Roted input vollage

Min, input voltage / initial input wollage

Mox. input current input $A$ / input $B$

Mex, input current per string input $A$ / input B

(b)

Number of independent MPP inputs / strings per MPP input

Outpul (AC)

Roted power (at $230 \mathrm{~V}, 50 \mathrm{~Hz}$ )

Max, apporent power $\mathrm{AC}$

Nominal $A C$ voltage / range

AC power frequency / range

Roled power frequency / rated grid volloge

Max, output current

Powner facter at roted power

Adjustable displocement power foctor

Feedin phases / connection phases

Efficiency

Mox, efficiency / European Elliciency

$5500 W_{p}$

$110 \mathrm{~V}$ to $500 \mathrm{~V}$

$3000 \mathrm{~W}$

$3000 \mathrm{VA}$

$16 \mathrm{~A}$

$97.0 \% / 96.4 \%$

Figure A. 1: (a) Inverter efficiency and (b) technical sheet 


\section{Heat Pump}

Two different HP type (i.e. Modulating and On/Off) have been modelled together with PV and Inverter in the Office cell. The main characteristics (i.e. heating and cooling power and air volume flows) are reported in Table A. 5 and the maps of performances in Figure A. 2, Figure A. 3 and Figure A. 4:

Table A. 5: Main characteristics of the modulating and On/Off heat pumps. The heating powers are specified for the external air temperature of $15^{\circ} \mathrm{C}$ and internal of $22^{\circ} \mathrm{C}$ while the cooling powers are specified for the external air temperature of $35^{\circ} \mathrm{C}$ and internal of $27^{\circ} \mathrm{C}$. For the modulating HP the performances are specified for the maximum $f_{\max }$ and minimum $f_{\min }$ frequency.

\begin{tabular}{|c|c|c|c|c|}
\hline & $\begin{array}{c}\text { Internal air } \\
\text { volume flow } \\
{\left[\mathrm{m}^{3} / \mathrm{h}\right]}\end{array}$ & $\begin{array}{c}\text { External air } \\
\text { volume flow } \\
{\left[\mathrm{m}^{3} / \mathrm{h}\right]}\end{array}$ & $\begin{array}{c}\text { Heating power } \\
\left(15^{\circ} \mathrm{C} / 22^{\circ} \mathrm{C}\right) \\
{[\mathrm{W}]}\end{array}$ & $\begin{array}{c}\text { Cooling power } \\
\left(35^{\circ} \mathrm{C} / 27^{\circ} \mathrm{C}\right) \\
{[\mathrm{W}]}\end{array}$ \\
\hline Modulating HP & 648 & 1872 & $\begin{array}{l}f_{\max }: 4006 \\
f_{\min }: 1006\end{array}$ & $\begin{array}{l}f_{\text {max }}: 2510 \\
f_{\text {min }}: 1248\end{array}$ \\
\hline On/Off HP low power & 187 & 1872 & 523 & 1250 \\
\hline On/Off HP high power & 648 & 1872 & 3923 & 2510 \\
\hline
\end{tabular}

Figure A. 2 a and $\mathbf{b}$ show respectively the Coefficient of Performances (COP) and energy efficiency ratio (EER) of the modulating HP for different room temperatures at the maximum and minimum HP frequency.

Figure A. 3 and Figure A. 4 a and b show respectively the COP and EER of the On/Off low power and high power HP for different room temperatures.

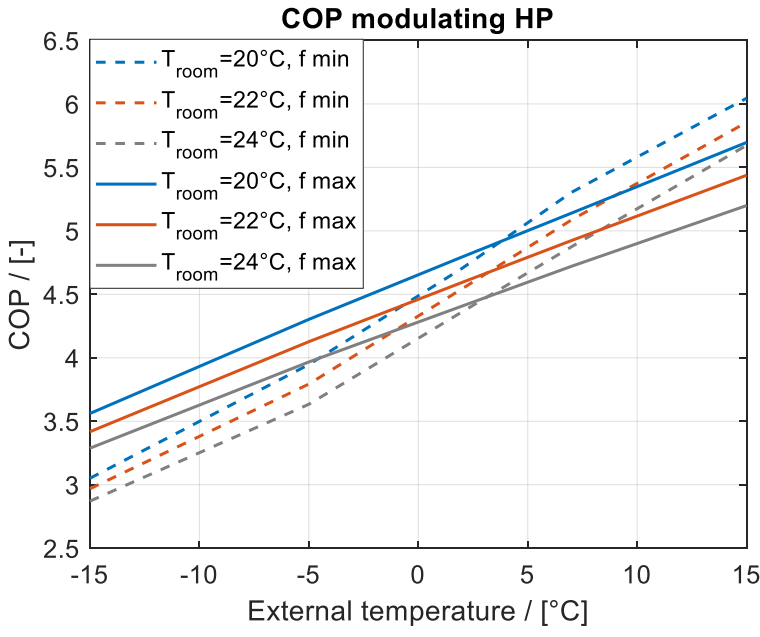

(a)

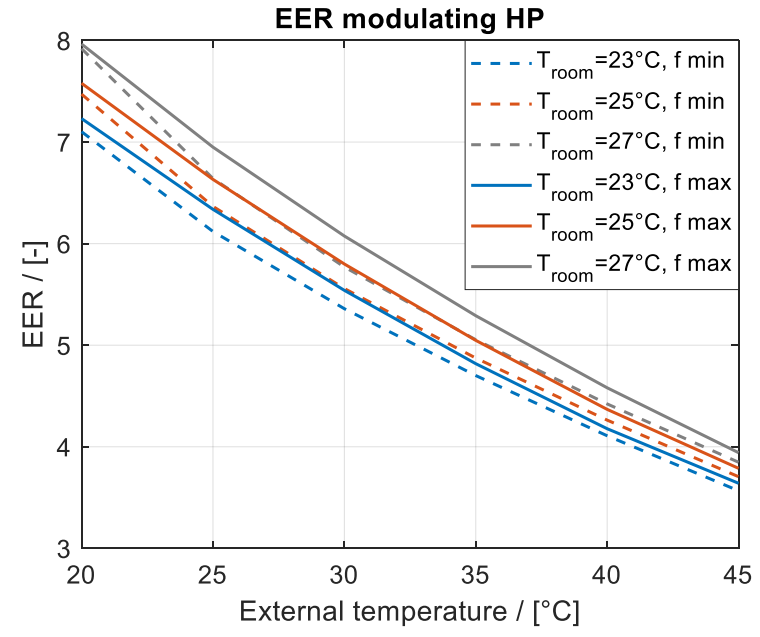

(b)

Figure A. 2: (a) COP and (b) EER of the modulating HP for different room temperatures at the maximum (continuous line) and minimum (dashed line) frequency 


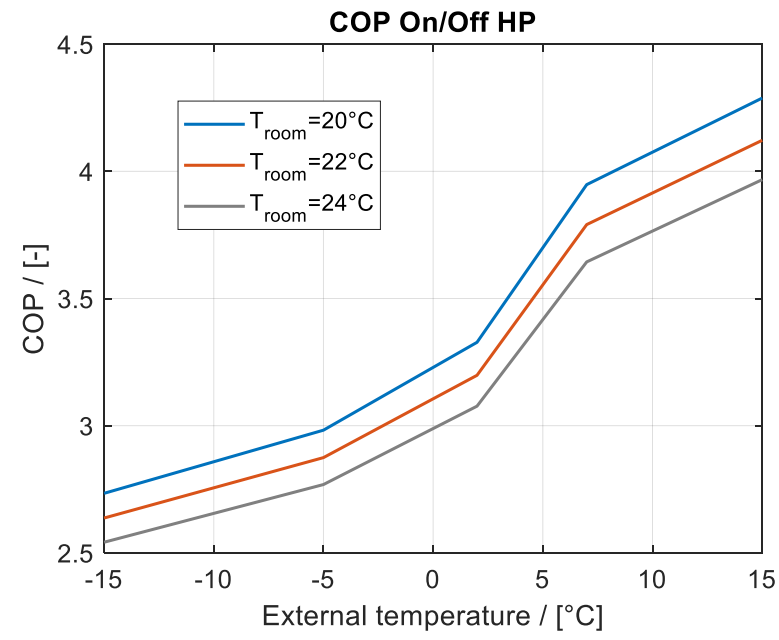

(a)

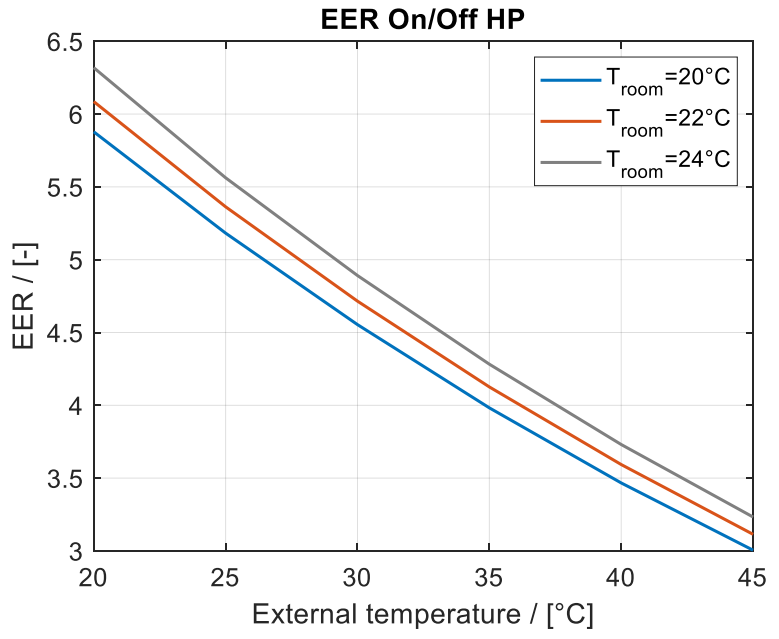

(b)

Figure A. 3: (a) COP and (b) EER of the On/Off HP low power for different room temperatures

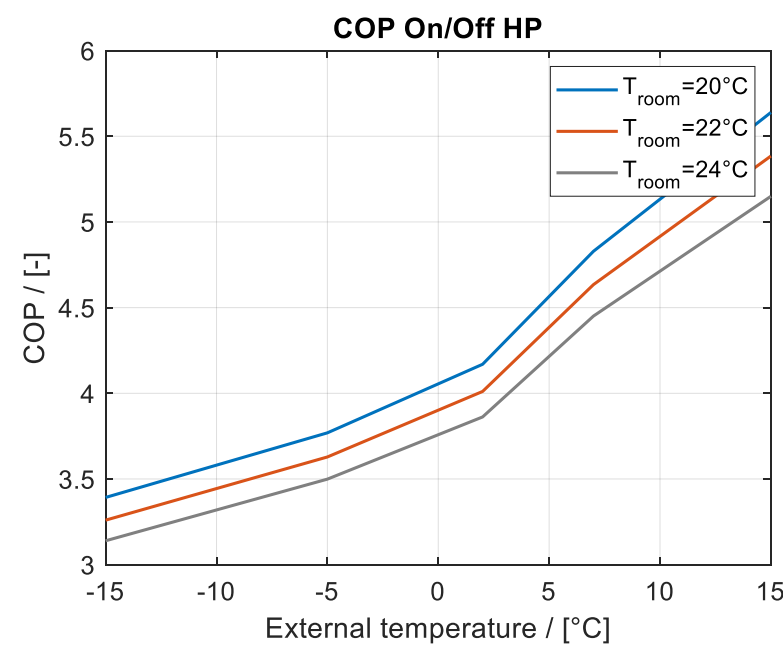

(a)

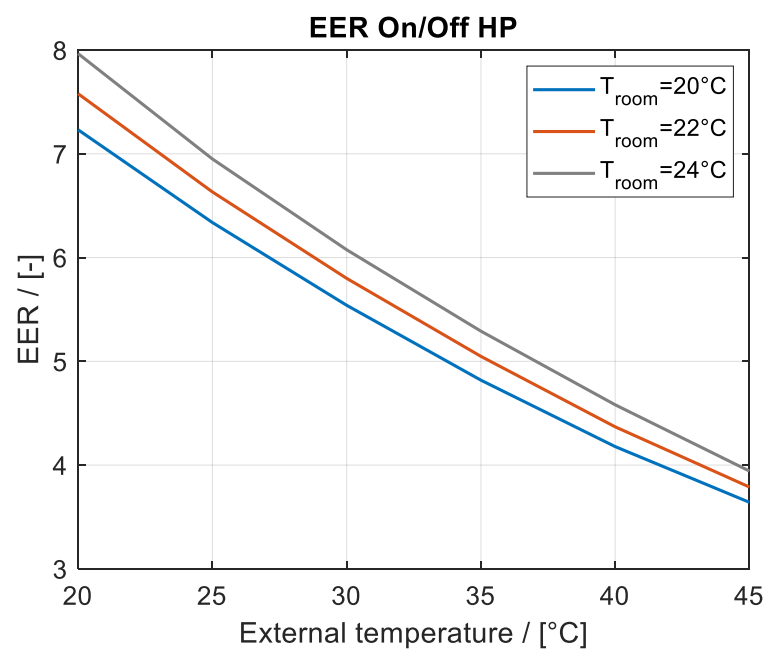

(b)

Figure A. 4: (a) COP and (b) EER of the On/Off HP High Power for different room temperatures 


\section{A. 3 Part B.1: internal gain profile and monthly weather data}

Table A. 6: Monthly average ambient temperature, monthly average ground temperature and monthly horizontal global irradiation

\begin{tabular}{|c|c|c|c|}
\hline Month & $\begin{array}{l}\text { Ambient temperature } \\
{\left[{ }^{\circ} \mathrm{C}\right]}\end{array}$ & $\begin{array}{c}\text { Ground temperature } \\
{\left[{ }^{\circ} \mathrm{C}\right]}\end{array}$ & $\begin{array}{l}\text { Monthly horizontal global irradiation } \\
\qquad\left[\mathrm{kWh} /\left(\mathrm{m}^{2} \mathrm{mo}\right)\right]\end{array}$ \\
\hline Jan & -2.5 & 10.9 & 39.1 \\
\hline Feb & 0.16 & 10.7 & 56.4 \\
\hline Mar & 5.2 & 11.5 & 99.2 \\
\hline Apr & 9.7 & 12.9 & 121.9 \\
\hline May & 14.4 & 14.7 & 150.8 \\
\hline Jun & 17.3 & 18.5 & 149.3 \\
\hline Jul & 19.3 & 19.6 & 154 \\
\hline Aug & 18.5 & 19.8 & 135.2 \\
\hline Sep & 15 & 19 & 100.4 \\
\hline Oct & 9.5 & 15.5 & 74.7 \\
\hline Nov & 4 & 13.7 & 42.4 \\
\hline Dec & -0.8 & 12 & 31.7 \\
\hline
\end{tabular}


Table A. 7: Daily schedule of the occupation profile for each zone

\begin{tabular}{c|cccccc} 
HOUR & Kitchen & Bedroom & Corridor & Bathroom & Child room & Living room \\
\hline $\mathbf{0 - 1}$ & 0 & 2 & 0 & 0 & 1 & 0 \\
$\mathbf{1 - 2}$ & 0 & 2 & 0 & 0 & 1 & 0 \\
$\mathbf{2 - 3}$ & 0 & 2 & 0 & 0 & 1 & 0 \\
$\mathbf{3}-4$ & 0 & 2 & 0 & 0 & 1 & 0 \\
$\mathbf{4 - 5}$ & 0 & 2 & 0 & 0 & 1 & 0 \\
$\mathbf{5 - 6}$ & 0 & 2 & 0 & 0 & 1 & 0 \\
$\mathbf{6 - 7}$ & 1 & 0 & 0 & 1 & 1 & 0 \\
$\mathbf{7 - 8}$ & 2 & 0 & 0 & 1 & 0 & 0 \\
$\mathbf{8 - 9}$ & 0 & 0 & 0 & 0 & 0 & 0 \\
$\mathbf{9 - 1 0}$ & 0 & 0 & 0 & 0 & 0 & 0 \\
$\mathbf{1 0 - 1 1}$ & 0 & 0 & 0 & 0 & 0 & 0 \\
$\mathbf{1 1 - 1 2}$ & 0 & 0 & 0 & 0 & 0 & 0 \\
$\mathbf{1 2 - 1 3}$ & 2 & 0 & 0 & 0 & 0 & 0 \\
$\mathbf{1 3 - 1 4}$ & 1 & 0 & 0 & 0 & 0 & 1 \\
$\mathbf{1 4 - 1 5}$ & 0 & 0 & 0 & 0 & 1 & 1 \\
$\mathbf{1 5 - 1 6}$ & 0 & 0 & 0 & 0 & 1 & 1 \\
$\mathbf{1 6 - 1 7}$ & 0 & 0 & 0 & 0 & 1 & 1 \\
$\mathbf{1 7 - 1 8}$ & 1 & 0 & 0 & 0 & 1 & 0 \\
$\mathbf{1 8 - 1 9}$ & 2 & 0 & 0 & 1 & 0 & 0 \\
$\mathbf{1 9 - 2 0}$ & 3 & 0 & 0 & 0 & 0 & 0 \\
$\mathbf{2 0 - 2 1}$ & 0 & 0 & 0 & 0 & 1 & 2 \\
$\mathbf{2 1 - 2 2}$ & 0 & 0 & 0 & 0 & 1 & 2 \\
$\mathbf{2 2 - 2 3}$ & 0 & 0 & 0 & 0 & 1 & 2 \\
$\mathbf{2 3 - 2 4}$ & 0 & 2 & 0 & 0 & 1 & 0 \\
\hline
\end{tabular}

Table A. 8: Latent internal gain emitted by 1 person for a level of activity $0-1$ depending on the operative temperature of the room

\begin{tabular}{c|c}
$\begin{array}{c}\mathbf{T}_{\text {op }} \text { room } \\
{\left[{ }^{\circ} \mathbf{C}\right]}\end{array}$ & $\begin{array}{c}\text { Water mass flow } \\
{[\mathbf{g} / \mathbf{h}]}\end{array}$ \\
\hline 10 & 30 \\
12 & 30 \\
14 & 30 \\
16 & 30 \\
18 & 35 \\
20 & 40 \\
22 & 45 \\
23 & 50 \\
24 & 55 \\
25 & 60 \\
26 & 65 \\
32 & 120 \\
\hline
\end{tabular}




\section{A. 4 Part B.2: internal gain profile, monthly weather data and surfaces included in the flat model}

Table A. 9: Monthly average ambient temperature and monthly horizontal global irradiation for the location Graz

\begin{tabular}{|c|cc} 
Month & $\begin{array}{c}\text { Ambient Temperature } \\
{\left[{ }^{\circ} \mathbf{C}\right]}\end{array}$ & $\begin{array}{c}\text { Monthly Horizontal } \\
\text { Global Irradiation } \\
{\left[\mathbf{k W h} /\left(\mathbf{m}^{\mathbf{2}} \mathbf{m o}\right)\right]}\end{array}$ \\
\hline JAN & -3.38 & 38 \\
FEB & -0.62 & 50 \\
MAR & 3.97 & 91 \\
APR & 8.84 & 117 \\
MAY & 13.75 & 146 \\
JUN & 16.82 & 153 \\
JUL & 18.80 & 166 \\
AUG & 18.07 & 144 \\
SEP & 14.12 & 101 \\
OCT & 8.92 & 69 \\
NOV & 2.75 & 39 \\
DEC & -1.72 & 30 \\
\hline
\end{tabular}

Table A. 10: overview of surfaces of the simulated flat

\begin{tabular}{|c|c|c|c|}
\hline Zone & Surface Type & Area $\left[\mathrm{m}^{2}\right]$ & Adjacent To \\
\hline Kitchen & external wall & 5.53 & external \\
\hline Kitchen & window & 1.26 & external \\
\hline Kitchen & internal wall & 6.52 & identical (no heat flux) \\
\hline Kitchen & ceiling/floor & 5.30 & identical (no heat flux) \\
\hline Kitchen & ceiling/floor & 5.30 & identical (no heat flux) \\
\hline Kitchen & internal wall & 6.52 & living room \\
\hline Kitchen & internal wall & 6.79 & bathroom \\
\hline Kitchen & ceiling/floor & 0.98 & unheated staircase \\
\hline Kitchen & ceiling/floor & 0.98 & identical (no heat flux) \\
\hline Kitchen & external wall & 1.50 & external \\
\hline bathroom & internal wall & 4.45 & living room \\
\hline bathroom & internal wall & 9.21 & identical (no heat flux) \\
\hline bathroom & internal wall & 4.52 & living room \\
\hline bathroom & internal wall & 6.79 & kitchen \\
\hline bathroom & internal wall & 2.34 & unheated staircase \\
\hline bathroom & ceiling/floor & 4.99 & identical (no heat flux) \\
\hline bathroom & internal wall & 4.68 & living room \\
\hline bathroom & ceiling/floor & 4.99 & identical (no heat flux) \\
\hline bathroom & ceiling/floor & 1.12 & identical (no heat flux) \\
\hline bathroom & ceiling/floor & 1.12 & identical (no heat flux) \\
\hline bathroom & external wall & 2.02 & external \\
\hline bathroom & window & 0.98 & external \\
\hline living room & internal wall & 4.52 & bathroom \\
\hline living room & internal wall & 15.72 & sleeping room \\
\hline living room & external wall & 5.91 & external \\
\hline living room & window & 3.83 & external \\
\hline living room & internal wall & 4.68 & bathroom \\
\hline
\end{tabular}




\begin{tabular}{|c|c|c|c|}
\hline Zone & Surface Type & Area $\left[\mathrm{m}^{2}\right]$ & Adjacent To \\
\hline living room & ceiling/floor & 20.83 & identical (no heat flux) \\
\hline living room & internal wall & 9.74 & identical (no heat flux) \\
\hline living room & internal wall & 4.45 & unheated staircase \\
\hline living room & internal wall & 4.45 & bathroom \\
\hline living room & ceiling/floor & 20.83 & identical (no heat flux) \\
\hline living room & internal wall & 6.52 & kitchen \\
\hline living room & ceiling/floor & 3.10 & identical (no heat flux) \\
\hline living room & external wall & 0.20 & external \\
\hline living room & window & 0.50 & external \\
\hline living room & ceiling/floor & 3.10 & identical (no heat flux) \\
\hline sleeping room & internal wall & 15.72 & living room \\
\hline sleeping room & external wall & 5.99 & external \\
\hline sleeping room & window & 1.96 & external \\
\hline sleeping room & internal wall & 15.72 & identical (no heat flux) \\
\hline sleeping room & ceiling/floor & 14.96 & identical (no heat flux) \\
\hline sleeping room & ceiling/floor & 14.96 & identical (no heat flux) \\
\hline sleeping room & internal wall & 7.95 & identical (no heat flux) \\
\hline sleeping room & ceiling/floor & 2.20 & unheated staircase \\
\hline sleeping room & ceiling/floor & 3.60 & identical (no heat flux) \\
\hline
\end{tabular}

Table A. 11: monthly average air temperature of the staircase

\begin{tabular}{c|c} 
Month & $\begin{array}{c}\text { Monthly Average Air } \\
\text { Temperature of the Staircase } \\
{\left[{ }^{\circ} \mathbf{C}\right]}\end{array}$ \\
\hline JAN & 9.65 \\
FEB & 9.48 \\
MAR & 10.58 \\
APR & 12.90 \\
MAY & 16.00 \\
JUN & 20.00 \\
JUL & 22.80 \\
AUG & 23.73 \\
SEP & 22.02 \\
OCT & 18.52 \\
NOV & 14.03 \\
DEC & 11.34 \\
\hline
\end{tabular}


Table A. 12: people occupancy of the four rooms; one week as reference for the entire year; hourly values

\begin{tabular}{|c|c|c|c|c|}
\hline Time [h] & Sleeping Room & Bathroom & Kitchen & Living Room \\
\hline 0 & 0.64 & 0.00 & 0.00 & 0.00 \\
\hline 1 & 1.28 & 0.00 & 0.00 & 0.00 \\
\hline 2 & 1.31 & 0.00 & 0.00 & 0.00 \\
\hline 3 & 1.37 & 0.00 & 0.00 & 0.00 \\
\hline 4 & 0.00 & 1.41 & 0.00 & 0.00 \\
\hline 5 & 0.00 & 0.00 & 0.70 & 0.70 \\
\hline 6 & 0.00 & 0.00 & 0.72 & 0.72 \\
\hline 7 & 0.00 & 0.00 & 0.63 & 0.63 \\
\hline 8 & 0.00 & 0.00 & 0.37 & 0.37 \\
\hline 9 & 0.00 & 0.00 & 0.19 & 0.19 \\
\hline 10 & 0.00 & 0.00 & 0.16 & 0.16 \\
\hline 11 & 0.00 & 0.00 & 0.21 & 0.21 \\
\hline 12 & 0.00 & 0.00 & 0.34 & 0.34 \\
\hline 13 & 0.00 & 0.00 & 0.44 & 0.44 \\
\hline 14 & 0.00 & 0.00 & 0.42 & 0.42 \\
\hline 15 & 0.00 & 0.00 & 0.34 & 0.34 \\
\hline 16 & 0.00 & 0.00 & 0.33 & 0.33 \\
\hline 17 & 0.00 & 0.00 & 0.42 & 0.42 \\
\hline 18 & 0.00 & 0.00 & 0.51 & 0.51 \\
\hline 19 & 0.00 & 0.00 & 0.52 & 0.52 \\
\hline 20 & 0.00 & 1.03 & 0.00 & 0.00 \\
\hline 21 & 1.06 & 0.00 & 0.00 & 0.00 \\
\hline 22 & 1.15 & 0.00 & 0.00 & 0.00 \\
\hline 23 & 1.25 & 0.00 & 0.00 & 0.00 \\
\hline 24 & 1.28 & 0.00 & 0.00 & 0.00 \\
\hline 25 & 1.31 & 0.00 & 0.00 & 0.00 \\
\hline 26 & 1.37 & 0.00 & 0.00 & 0.00 \\
\hline 27 & 1.41 & 0.00 & 0.00 & 0.00 \\
\hline 28 & 0.00 & 1.41 & 0.00 & 0.00 \\
\hline 29 & 0.00 & 0.00 & 0.72 & 0.72 \\
\hline 30 & 0.00 & 0.00 & 0.63 & 0.63 \\
\hline 31 & 0.00 & 0.00 & 0.37 & 0.37 \\
\hline 32 & 0.00 & 0.00 & 0.19 & 0.19 \\
\hline 33 & 0.00 & 0.00 & 0.16 & 0.16 \\
\hline 34 & 0.00 & 0.00 & 0.21 & 0.21 \\
\hline 35 & 0.00 & 0.00 & 0.34 & 0.34 \\
\hline 36 & 0.00 & 0.00 & 0.44 & 0.44 \\
\hline 37 & 0.00 & 0.00 & 0.42 & 0.42 \\
\hline 38 & 0.00 & 0.00 & 0.34 & 0.34 \\
\hline 39 & 0.00 & 0.00 & 0.33 & 0.33 \\
\hline 40 & 0.00 & 0.00 & 0.42 & 0.42 \\
\hline 41 & 0.00 & 0.00 & 0.51 & 0.51 \\
\hline 42 & 0.00 & 0.00 & 0.52 & 0.52 \\
\hline 43 & 0.00 & 0.00 & 0.51 & 0.51 \\
\hline 44 & 0.00 & 1.06 & 0.00 & 0.00 \\
\hline 45 & 1.15 & 0.00 & 0.00 & 0.00 \\
\hline 46 & 1.25 & 0.00 & 0.00 & 0.00 \\
\hline 47 & 1.28 & 0.00 & 0.00 & 0.00 \\
\hline 48 & 1.31 & 0.00 & 0.00 & 0.00 \\
\hline 49 & 1.37 & 0.00 & 0.00 & 0.00 \\
\hline 50 & 1.41 & 0.00 & 0.00 & 0.00 \\
\hline 51 & 1.41 & 0.00 & 0.00 & 0.00 \\
\hline 52 & 0.00 & 1.44 & 0.00 & 0.00 \\
\hline 53 & 0.00 & 0.00 & 0.63 & 0.63 \\
\hline 54 & 0.00 & 0.00 & 0.37 & 0.37 \\
\hline 55 & 0.00 & 0.00 & 0.19 & 0.19 \\
\hline 56 & 0.00 & 0.00 & 0.16 & 0.16 \\
\hline 57 & 0.00 & 0.00 & 0.21 & 0.21 \\
\hline 58 & 0.00 & 0.00 & 0.34 & 0.34 \\
\hline 59 & 0.00 & 0.00 & 0.44 & 0.44 \\
\hline 60 & 0.00 & 0.00 & 0.42 & 0.42 \\
\hline 61 & 0.00 & 0.00 & 0.34 & 0.34 \\
\hline 62 & 0.00 & 0.00 & 0.33 & 0.33 \\
\hline 63 & 0.00 & 0.00 & 0.42 & 0.42 \\
\hline 64 & 0.00 & 0.00 & 0.51 & 0.51 \\
\hline 65 & 0.00 & 0.00 & 0.52 & 0.52 \\
\hline 66 & 0.00 & 0.00 & 0.51 & 0.51 \\
\hline 67 & 0.00 & 0.00 & 0.53 & 0.53 \\
\hline 68 & 0.00 & 1.15 & 0.00 & 0.00 \\
\hline 69 & 1.25 & 0.00 & 0.00 & 0.00 \\
\hline 70 & 1.28 & 0.00 & 0.00 & 0.00 \\
\hline 71 & 1.31 & 0.00 & 0.00 & 0.00 \\
\hline 72 & 1.37 & 0.00 & 0.00 & 0.00 \\
\hline
\end{tabular}




\begin{tabular}{|c|c|c|c|c|}
\hline Time [h] & Sleeping Room & Bathroom & Kitchen & Living Room \\
\hline 73 & 1.41 & 0.00 & 0.00 & 0.00 \\
\hline 74 & 1.41 & 0.00 & 0.00 & 0.00 \\
\hline 75 & 1.44 & 0.00 & 0.00 & 0.00 \\
\hline 76 & 0.00 & 1.26 & 0.00 & 0.00 \\
\hline 77 & 0.00 & 0.00 & 0.37 & 0.37 \\
\hline 78 & 0.00 & 0.00 & 0.19 & 0.19 \\
\hline 79 & 0.00 & 0.00 & 0.16 & 0.16 \\
\hline 80 & 0.00 & 0.00 & 0.21 & 0.21 \\
\hline 81 & 0.00 & 0.00 & 0.34 & 0.34 \\
\hline 82 & 0.00 & 0.00 & 0.44 & 0.44 \\
\hline 83 & 0.00 & 0.00 & 0.42 & 0.42 \\
\hline 84 & 0.00 & 0.00 & 0.34 & 0.34 \\
\hline 85 & 0.00 & 0.00 & 0.33 & 0.33 \\
\hline 86 & 0.00 & 0.00 & 0.42 & 0.42 \\
\hline 87 & 0.00 & 0.00 & 0.51 & 0.51 \\
\hline 88 & 0.00 & 0.00 & 0.52 & 0.52 \\
\hline 89 & 0.00 & 0.00 & 0.51 & 0.51 \\
\hline 90 & 0.00 & 0.00 & 0.53 & 0.53 \\
\hline 91 & 0.00 & 0.00 & 0.58 & 0.58 \\
\hline 92 & 0.00 & 1.25 & 0.00 & 0.00 \\
\hline 93 & 1.28 & 0.00 & 0.00 & 0.00 \\
\hline 94 & 1.31 & 0.00 & 0.00 & 0.00 \\
\hline 95 & 1.37 & 0.00 & 0.00 & 0.00 \\
\hline 96 & 1.41 & 0.00 & 0.00 & 0.00 \\
\hline 97 & 1.41 & 0.00 & 0.00 & 0.00 \\
\hline 98 & 1.44 & 0.00 & 0.00 & 0.00 \\
\hline 99 & 1.26 & 0.00 & 0.00 & 0.00 \\
\hline 100 & 0.00 & 0.74 & 0.00 & 0.00 \\
\hline 101 & 0.00 & 0.00 & 0.19 & 0.19 \\
\hline 102 & 0.00 & 0.00 & 0.16 & 0.16 \\
\hline 103 & 0.00 & 0.00 & 0.21 & 0.21 \\
\hline 104 & 0.00 & 0.00 & 0.34 & 0.34 \\
\hline 105 & 0.00 & 0.00 & 0.44 & 0.44 \\
\hline 106 & 0.00 & 0.00 & 0.42 & 0.42 \\
\hline 107 & 0.00 & 0.00 & 0.34 & 0.34 \\
\hline 108 & 0.00 & 0.00 & 0.33 & 0.33 \\
\hline 109 & 0.00 & 0.00 & 0.42 & 0.42 \\
\hline 110 & 0.00 & 0.00 & 0.51 & 0.51 \\
\hline 111 & 0.00 & 0.00 & 0.52 & 0.52 \\
\hline 112 & 0.00 & 0.00 & 0.51 & 0.51 \\
\hline 113 & 0.00 & 0.00 & 0.53 & 0.53 \\
\hline 114 & 0.00 & 0.00 & 0.58 & 0.58 \\
\hline 115 & 0.00 & 0.00 & 0.62 & 0.62 \\
\hline 116 & 0.00 & 1.28 & 0.00 & 0.00 \\
\hline 117 & 1.31 & 0.00 & 0.00 & 0.00 \\
\hline 118 & 1.37 & 0.00 & 0.00 & 0.00 \\
\hline 119 & 1.41 & 0.00 & 0.00 & 0.00 \\
\hline 120 & 1.47 & 0.00 & 0.00 & 0.00 \\
\hline 121 & 1.49 & 0.00 & 0.00 & 0.00 \\
\hline 122 & 1.39 & 0.00 & 0.00 & 0.00 \\
\hline 123 & 1.32 & 0.00 & 0.00 & 0.00 \\
\hline 124 & 0.00 & 1.30 & 0.00 & 0.00 \\
\hline 125 & 0.00 & 0.00 & 0.65 & 0.65 \\
\hline 126 & 0.00 & 0.00 & 0.62 & 0.62 \\
\hline 127 & 0.00 & 0.00 & 0.57 & 0.57 \\
\hline 128 & 0.00 & 0.00 & 0.59 & 0.59 \\
\hline 129 & 0.00 & 0.00 & 0.63 & 0.63 \\
\hline 130 & 0.00 & 0.00 & 0.64 & 0.64 \\
\hline 131 & 0.00 & 0.00 & 0.64 & 0.64 \\
\hline 132 & 0.00 & 0.00 & 0.64 & 0.64 \\
\hline 133 & 0.00 & 0.00 & 0.67 & 0.67 \\
\hline 134 & 0.00 & 0.00 & 0.73 & 0.73 \\
\hline 135 & 0.00 & 0.00 & 0.77 & 0.77 \\
\hline 136 & 0.00 & 0.00 & 0.77 & 0.77 \\
\hline 137 & 0.00 & 0.00 & 0.77 & 0.77 \\
\hline 138 & 0.00 & 0.00 & 0.77 & 0.77 \\
\hline 139 & 0.00 & 0.00 & 0.77 & 0.77 \\
\hline 140 & 0.00 & 1.53 & 0.00 & 0.00 \\
\hline 141 & 1.53 & 0.00 & 0.00 & 0.00 \\
\hline 142 & 1.53 & 0.00 & 0.00 & 0.00 \\
\hline 143 & 1.53 & 0.00 & 0.00 & 0.00 \\
\hline 144 & 1.58 & 0.00 & 0.00 & 0.00 \\
\hline 145 & 1.62 & 0.00 & 0.00 & 0.00 \\
\hline 146 & 1.49 & 0.00 & 0.00 & 0.00 \\
\hline 147 & 1.22 & 0.00 & 0.00 & 0.00 \\
\hline
\end{tabular}




\begin{tabular}{|c|c|c|c|c|}
\hline Time [h] & Sleeping Room & Bathroom & Kitchen & Living Room \\
\hline 148 & 0.00 & 1.08 & 0.00 & 0.00 \\
\hline 149 & 0.00 & 0.00 & 0.54 & 0.54 \\
\hline 150 & 0.00 & 0.00 & 0.54 & 0.54 \\
\hline 151 & 0.00 & 0.00 & 0.54 & 0.54 \\
\hline 152 & 0.00 & 0.00 & 0.54 & 0.54 \\
\hline 153 & 0.00 & 0.00 & 0.54 & 0.54 \\
\hline 154 & 0.00 & 0.00 & 0.54 & 0.54 \\
\hline 155 & 0.00 & 0.00 & 0.54 & 0.54 \\
\hline 156 & 0.00 & 0.00 & 0.54 & 0.54 \\
\hline 157 & 0.00 & 0.00 & 0.54 & 0.54 \\
\hline 158 & 0.00 & 0.00 & 0.54 & 0.54 \\
\hline 159 & 0.00 & 0.00 & 0.61 & 0.61 \\
\hline 160 & 0.00 & 0.00 & 0.74 & 0.74 \\
\hline 161 & 0.00 & 0.00 & 0.81 & 0.81 \\
\hline 162 & 0.00 & 0.00 & 0.81 & 0.81 \\
\hline 163 & 0.00 & 0.00 & 0.81 & 0.81 \\
\hline 164 & 0.00 & 1.62 & 0.00 & 0.00 \\
\hline 165 & 1.62 & 0.00 & 0.00 & 0.00 \\
\hline 166 & 1.62 & 0.00 & 0.00 & 0.00 \\
\hline 167 & 1.62 & 0.00 & 0.00 & 0.00 \\
\hline 168 & 0.64 & 0.00 & 0.00 & 0.00 \\
\hline
\end{tabular}


Table A. 13: daily tap profile of the hot water system; 5 minutes interval

\begin{tabular}{|c|c|}
\hline HOUR & L/MIN \\
\hline 0 & 0 \\
\hline 0.0833 & 0 \\
\hline 0.1667 & 0 \\
\hline 0.25 & 0 \\
\hline 0.3333 & 0 \\
\hline 0.4167 & 0 \\
\hline 0.5 & 0 \\
\hline 0.5833 & 0 \\
\hline 0.6667 & 0 \\
\hline 0.75 & 0 \\
\hline 0.8333 & 0 \\
\hline 0.9167 & 0 \\
\hline 1 & 0 \\
\hline 1.0833 & 0 \\
\hline 1.1667 & 0 \\
\hline 1.25 & 0 \\
\hline 1.3333 & 0 \\
\hline 1.4167 & 0 \\
\hline 1.5 & 0 \\
\hline 1.5833 & 0 \\
\hline 1.6667 & 0 \\
\hline 1.75 & 0 \\
\hline 1.8333 & 0 \\
\hline 1.9167 & 0 \\
\hline 2 & 0 \\
\hline 2.0833 & 0 \\
\hline 2.1667 & 0 \\
\hline 2.25 & 0 \\
\hline 2.3333 & 0 \\
\hline 2.4167 & 0 \\
\hline 2.5 & 0 \\
\hline 2.5833 & 0 \\
\hline 2.6667 & 0 \\
\hline 2.75 & 0 \\
\hline 2.8333 & 0 \\
\hline 2.9167 & 0 \\
\hline 3 & 0 \\
\hline 3.0833 & 0 \\
\hline 3.1667 & 0 \\
\hline 3.25 & 0 \\
\hline 3.3333 & 0 \\
\hline 3.4167 & 0 \\
\hline 3.5 & 0 \\
\hline 3.5833 & 0 \\
\hline 3.6667 & 0 \\
\hline 3.75 & 0 \\
\hline 3.8333 & 0 \\
\hline 3.9167 & 0 \\
\hline 4 & 0 \\
\hline 4.0833 & 0 \\
\hline 4.1667 & 0 \\
\hline 4.25 & 0 \\
\hline 4.3333 & 0 \\
\hline 4.4167 & 0 \\
\hline 4.5 & 0 \\
\hline 4.5833 & 0 \\
\hline 4.6667 & 0 \\
\hline 4.75 & 0 \\
\hline 4.8333 & 0 \\
\hline 4.9167 & 0 \\
\hline 15 & 0 \\
\hline 15.0833 & 0 \\
\hline 15.1667 & 0 \\
\hline 15.25 & 0 \\
\hline 15.3333 & 0 \\
\hline 15.4167 & 0 \\
\hline 15.5 & 0.3919942 \\
\hline 15.5833 & 0 \\
\hline 15.6667 & 0 \\
\hline 15.75 & 0 \\
\hline 15.8333 & 0 \\
\hline 15.9167 & 0 \\
\hline 16 & 0 \\
\hline
\end{tabular}

\begin{tabular}{|c|c|}
\hline HOUR & L/MIN \\
\hline 5 & 0 \\
\hline 5.0833 & 0 \\
\hline 5.1667 & 0 \\
\hline 5.25 & 0 \\
\hline 5.3333 & 0 \\
\hline 5.4167 & 0 \\
\hline 5.5 & 0 \\
\hline 5.5833 & 0 \\
\hline 5.6667 & 0 \\
\hline 5.75 & 0 \\
\hline 5.8333 & 0 \\
\hline 5.9167 & 0 \\
\hline 6 & 0 \\
\hline 6.0833 & 0 \\
\hline 6.1667 & 0 \\
\hline 6.25 & 0 \\
\hline 6.3333 & 0 \\
\hline 6.4167 & 0 \\
\hline 6.5 & 0 \\
\hline 6.5833 & 0 \\
\hline 6.6667 & 0 \\
\hline 6.75 & 0 \\
\hline 6.8333 & 0 \\
\hline 6.9167 & 0 \\
\hline 7 & 0.3919942 \\
\hline 7.0833 & 5.22658923 \\
\hline 7.1667 & 0 \\
\hline 7.25 & 0 \\
\hline 7.3333 & 0 \\
\hline 7.4167 & 0 \\
\hline 7.5 & 0.3919942 \\
\hline 7.5833 & 0 \\
\hline 7.6667 & 0 \\
\hline 7.75 & 0 \\
\hline 7.8333 & 0 \\
\hline 7.9167 & 0 \\
\hline 8 & 0.3919942 \\
\hline 8.0833 & 0 \\
\hline 8.1667 & 0 \\
\hline 8.25 & 0.3919942 \\
\hline 8.3333 & 0 \\
\hline 8.4167 & 0 \\
\hline 8.5 & 0.3919942 \\
\hline 8.5833 & 0 \\
\hline 8.6667 & 0 \\
\hline 8.75 & 0.3919942 \\
\hline 8.8333 & 0 \\
\hline 8.9167 & 0 \\
\hline 9 & 0.3919942 \\
\hline 9.0833 & 0 \\
\hline 9.1667 & 0 \\
\hline 9.25 & 0 \\
\hline 9.3333 & 0 \\
\hline 9.4167 & 0 \\
\hline 9.5 & 0.3919942 \\
\hline 9.5833 & 0 \\
\hline 9.6667 & 0 \\
\hline 9.75 & 0 \\
\hline 9.8333 & 0 \\
\hline 9.9167 & 0 \\
\hline 20.1667 & 0 \\
\hline 20.25 & 0 \\
\hline 20.3333 & 0 \\
\hline 20.4167 & 0 \\
\hline 20.5 & 2.74395935 \\
\hline 20.5833 & 0 \\
\hline 20.6667 & 0 \\
\hline 20.75 & 0 \\
\hline 20.8333 & 0 \\
\hline 20.9167 & 0 \\
\hline 21 & 0 \\
\hline 21.0833 & 0 \\
\hline 21.1667 & 0 \\
\hline
\end{tabular}

\begin{tabular}{|c|c|}
\hline HOUR & L/MIN \\
\hline 10 & 0 \\
\hline 10.0833 & 0 \\
\hline 10.1667 & 0 \\
\hline 10.25 & 0 \\
\hline 10.3333 & 0 \\
\hline 10.4167 & 0 \\
\hline 10.5 & 0.3919942 \\
\hline 10.5833 & 0 \\
\hline 10.6667 & 0 \\
\hline 10.75 & 0 \\
\hline 10.8333 & 0 \\
\hline 10.9167 & 0 \\
\hline 11 & 0 \\
\hline 11.0833 & 0 \\
\hline 11.1667 & 0 \\
\hline 11.25 & 0 \\
\hline 11.3333 & 0 \\
\hline 11.4167 & 0 \\
\hline 11.5 & 0.3919942 \\
\hline 11.5833 & 0 \\
\hline 11.6667 & 0 \\
\hline 11.75 & 0.3919942 \\
\hline 11.8333 & 0 \\
\hline 11.9167 & 0 \\
\hline 12 & 0 \\
\hline 12.0833 & 0 \\
\hline 12.1667 & 0 \\
\hline 12.25 & 0 \\
\hline 12.3333 & 0 \\
\hline 12.4167 & 0 \\
\hline 12.5 & 0 \\
\hline 12.5833 & 0 \\
\hline 12.6667 & 0 \\
\hline 12.75 & 1.17598258 \\
\hline 12.8333 & 0 \\
\hline 12.9167 & 0 \\
\hline 13 & 0 \\
\hline 13.0833 & 0 \\
\hline 13.1667 & 0 \\
\hline 13.25 & 0 \\
\hline 13.3333 & 0 \\
\hline 13.4167 & 0 \\
\hline 13.5 & 0 \\
\hline 13.5833 & 0 \\
\hline 13.6667 & 0 \\
\hline 13.75 & 0 \\
\hline 13.8333 & 0 \\
\hline 13.9167 & 0 \\
\hline 14 & 0 \\
\hline 14.0833 & 0 \\
\hline 14.1667 & 0 \\
\hline 14.25 & 0 \\
\hline 14.3333 & 0 \\
\hline 14.4167 & 0 \\
\hline 14.5 & 0.3919942 \\
\hline 14.5833 & 0 \\
\hline 14.6667 & 0 \\
\hline 14.75 & 0 \\
\hline 14.8333 & 0 \\
\hline 14.9167 & 0 \\
\hline & \\
\hline & \\
\hline & \\
\hline & \\
\hline & \\
\hline & \\
\hline & \\
\hline & \\
\hline & \\
\hline & \\
\hline
\end{tabular}




\begin{tabular}{|c|c|c|c|c|c|}
\hline HOUR & L/MIN & HOUR & L/MIN & HOUR & L/MIN \\
\hline 16.0833 & 0 & 21.25 & 0.3919942 & & \\
\hline 16.1667 & 0 & 21.3333 & 0 & & \\
\hline 16.25 & 0 & 21.4167 & 0 & & \\
\hline 16.3333 & 0 & 21.5 & 5.22658923 & & \\
\hline 16.4167 & 0 & 21.5833 & 0 & & \\
\hline 16.5 & 0.3919942 & 21.6667 & 0 & & \\
\hline 16.5833 & 0 & 21.75 & 0 & & \\
\hline 16.6667 & 0 & 21.8333 & 0 & & \\
\hline 16.75 & 0 & 21.9167 & 0 & & \\
\hline 16.8333 & 0 & 22 & 0 & & \\
\hline 16.9167 & 0 & 22.0833 & 0 & & \\
\hline 17 & 0 & 22.1667 & 0 & & \\
\hline 17.0833 & 0 & 22.25 & 0 & & \\
\hline 17.1667 & 0 & 22.3333 & 0 & & \\
\hline 17.25 & 0 & 22.4167 & 0 & & \\
\hline 17.3333 & 0 & 22.5 & 0 & & \\
\hline 17.4167 & 0 & 22.5833 & 0 & & \\
\hline 17.5 & 0 & 22.6667 & 0 & & \\
\hline 17.5833 & 0 & 22.75 & 0 & & \\
\hline 17.6667 & 0 & 22.8333 & 0 & & \\
\hline 17.75 & 0 & 22.9167 & 0 & & \\
\hline 17.8333 & 0 & 23 & 0 & & \\
\hline 17.9167 & 0 & 23.0833 & 0 & & \\
\hline 18 & 0.3919942 & 23.1667 & 0 & & \\
\hline 18.0833 & 0 & 23.25 & 0 & & \\
\hline 18.1667 & 0 & 23.3333 & 0 & & \\
\hline 18.25 & 0.3919942 & 23.4167 & 0 & & \\
\hline 18.3333 & 0 & 23.5 & 0 & & \\
\hline 18.4167 & 0 & 23.5833 & 0 & & \\
\hline 18.5 & 0.3919942 & 23.6667 & 0 & & \\
\hline 18.5833 & 0 & 23.75 & 0 & & \\
\hline 18.6667 & 0 & 23.8333 & 0 & & \\
\hline 18.75 & 0 & 23.9167 & 0 & & \\
\hline 18.8333 & 0 & 24 & 0 & & \\
\hline 18.9167 & 0 & & & & \\
\hline 19 & 0.3919942 & & & & \\
\hline 19.0833 & 0 & & & & \\
\hline 19.1667 & 0 & & & & \\
\hline 19.25 & 0 & & & & \\
\hline 19.3333 & 0 & & & & \\
\hline 19.4167 & 0 & & & & \\
\hline 19.5 & 0 & & & & \\
\hline 19.5833 & 0 & & & & \\
\hline 19.6667 & 0 & & & & \\
\hline 19.75 & 0 & & & & \\
\hline 19.8333 & 0 & & & & \\
\hline 19.9167 & 0 & & & & \\
\hline 20 & 0 & & & & \\
\hline 20.0833 & 0 & & & & \\
\hline
\end{tabular}

